


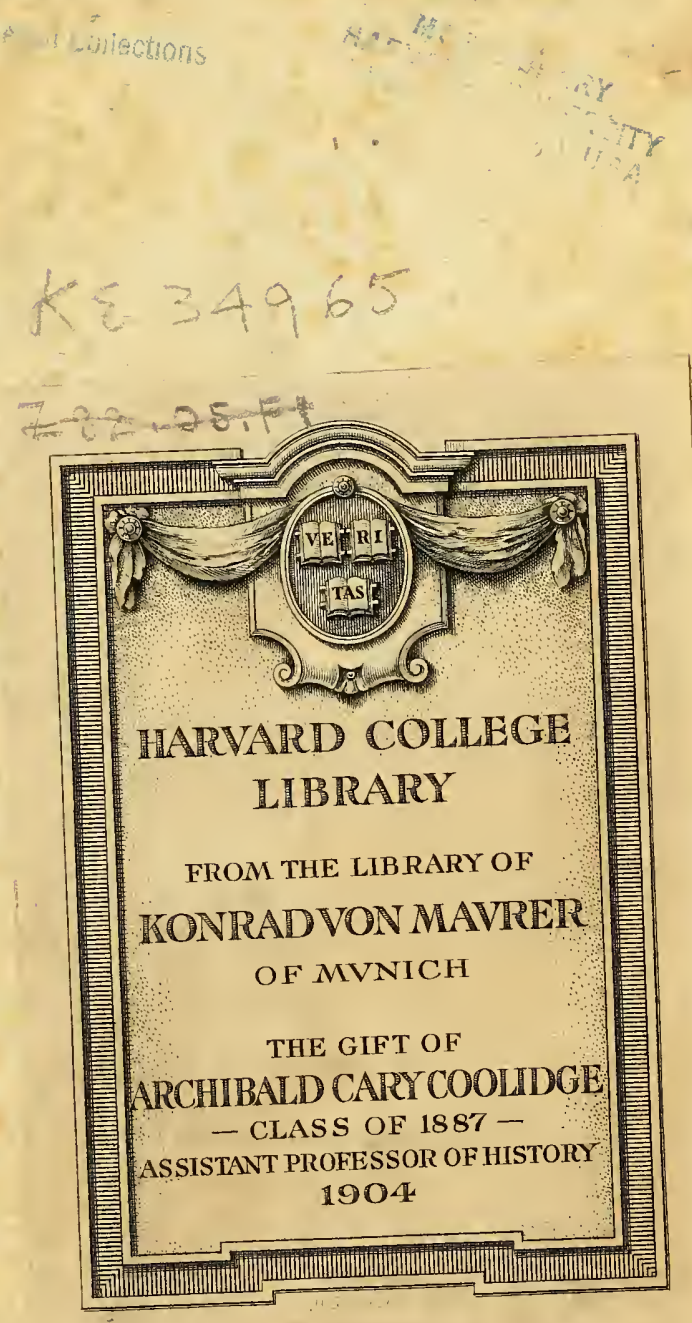






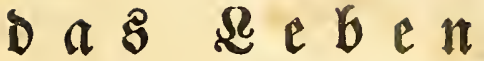

\author{
ber
}

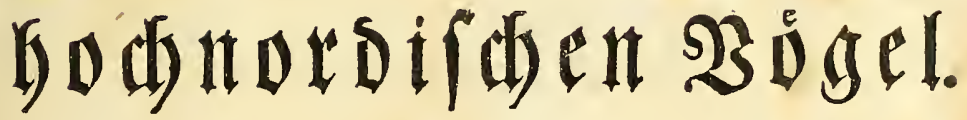

$\mathfrak{B} \bullet \mathfrak{n}$

$\mathfrak{F} \mathfrak{i} \mathfrak{e} b \mathfrak{r} \mathfrak{i} \mathfrak{d}) \mathfrak{F} \mathfrak{a} \mathfrak{b} \mathfrak{e}$

$$
\text { Erfte } \mathfrak{s} \text { Sheft. }
$$

$$
\text { Le } \mathfrak{i} \mathfrak{p} \mathfrak{i} \mathfrak{g}:
$$

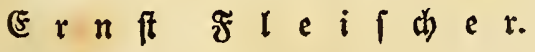

1825. 



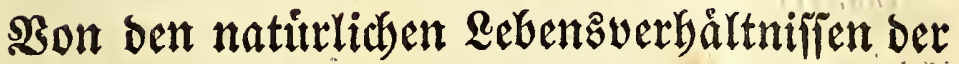 europái ja $\mathfrak{b}=$ borealen, injonderbeit ber

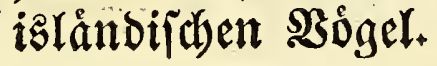

Bon ber geograplijeded 2 Cubbreitung und bem damit verbundenen $\mathfrak{S a n d e =}$ $\mathfrak{x} \mathfrak{n} \mathfrak{g} \mathfrak{v} \mathfrak{c} \mathfrak{c} \mathfrak{a} \mathfrak{a} \mathfrak{a} \mathfrak{i} \mathfrak{i}$.

\section{§. 1.}

Eime jebe Bogelart hat auf ber (Erbe unter bem Bufaumen= ftope einer gewiffer Ránge und Breite cinen Raum erbalten, inmerbalb weldem fie fid) nad beftimmten Raturgefersen aufhal= ten mus. Diejen Miaum fónnte man bez \$ogelz Bone nennen. Innerlyalb biejer 3one werben bie Inbividuen ber 2 lut augge= brütet, und bringen ba wenigftens bie erfte Bcit ihres sebens zu. Mand)e Bogelarten haben gemeinjofaftlid) bicjelbe Bone erbalten, uno jo ift umer Eroball in mebrece orinthologifdbe Bonen einzu= theilen. Die (Eintlyeilung bicjer Bonen ftimmt natürlicher 23 seije nicht úberein mit ber politifachen (Eintheilung ber Lånder, ba bas (Sintheilungsprincip fo jefre veridbieben ift. Das (El)arafteriftijhe námlich bey einem folthen Paume unjeres (Eroballs, weld)er fich als eine eigne \$ogelzone angejeben zut wetben eignet, ift, ba ex cine $2(n z a b l$ logelarten gemeinfdaftlid), feine eigenen Stant =

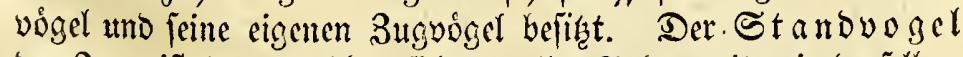
ber 3one ift Der, wetcher jid) zu allen Salyreszeiten in ber jelben auflaalt, uno $3 \mathfrak{u} g$ vogel ber, welcher inmerthalb ber Grenzen Deriflben ausgecbruttet wirb, nachlyer ba britet, aber Demnaidjt

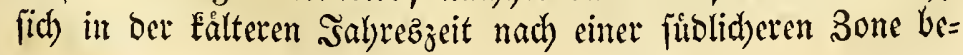


giebt. Wsirb dic Erfahrung auf biefe Regeln angewendet, fo

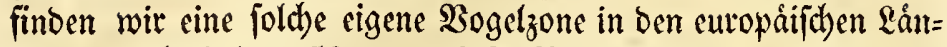

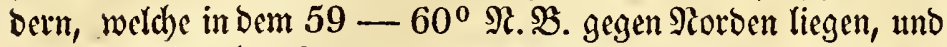

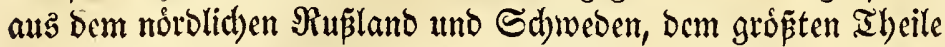

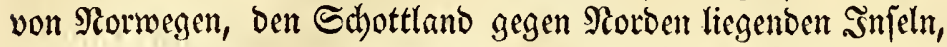
Ferroc, Şland und itberbaupt bem finnifhen Girónland nebjt

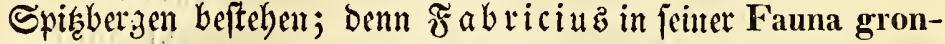

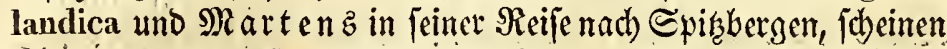

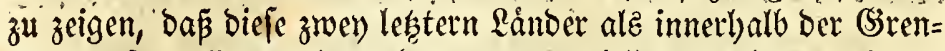
zen ber Bone liegeno betradtet werben múffen, weldhe wir bie ent= ropáij

Dieje 3one bat ihre eigenen Stanbodgel z. B. Fatco islandicus, Unia alle, Alca impennis, Monmon fratercula, Canbo graculus, Prfarinus arcticus milli, Colymbus glacialis, Avas spectabilis uno histrionica, Sula alba, Lanus eburneus, Lanus glaucus Brünnich tmo Lanos leucopterus mihi, Lestnis catarractes, Proceldania glacialis uno Proceltaria pelagica, mit melereen, welde alle inuerhalb bet

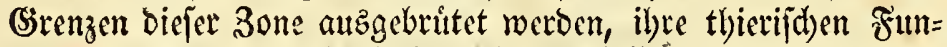
ctionen berribten uns fterben, mit 'Tußnabme ber einzelnen $\mathfrak{I n}=$ biviouen, weldye burd Maturbegebentheiten, ats Sturm, Nebel

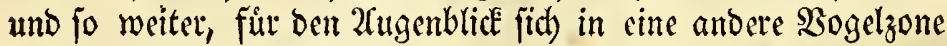
verimen, wo fie fid) nur jo lange aufbalten, biz die $\mathfrak{R}$ aturut=

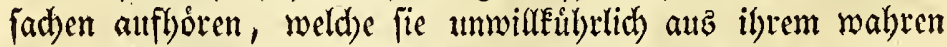
Baterlande wegriffer. Dep̄wegen fehen wir zumcilen im $\mathfrak{S}_{\mathbf{S i n}}=$

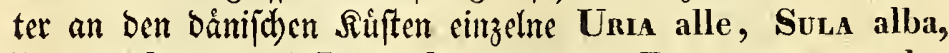
Larus glaucus und Lanus leucopterus, Procellamia pelagica uno megrere, meldhe übrigens Stanovógel ber nórblichern Bone fint.

Diefé 3one hat gleidufalls igre cigenen 3ttguogel, $\mathfrak{z}$. $\mathfrak{B}$. Embereza nivalis, 'Turnus iliacus', Calmors arenaria, Numenius phaeopus, 'Trenga islandica, Phalaropus platyrhinchus uno Phalaropus cinereus, Colvinbus rufogularis, Popiceps cormutus, Avas nigra, marila und mefrere nordi= ide Enten, Larus tridactylus, Lestris parasitica uno andere.

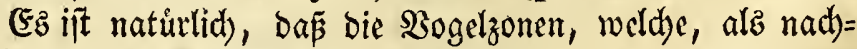
barliche 3onen, unnittelbar an einanderftopen, és jev num,

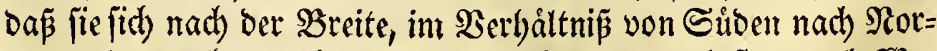

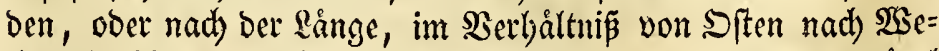
ften beribren, audd) verfdebicone 2frten 3ug = und Stanovigd

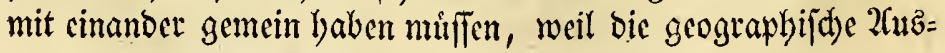


breitung jeber cinzelnen Bogelart fid) nidht allezeit auf eine Dogelzone bejd)rante und fo wirb zuweilen bie 3one einet cinzelnen Sogelart von weiterem $11 m$ fange, alz bie ormitlyo=

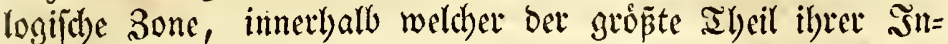
bivibuen fid) auflyalt. $\Im_{0}$ find Convus corax, Sxuvia troglodytes, Саnвo comoranus Standógel, fowohl ber ell=

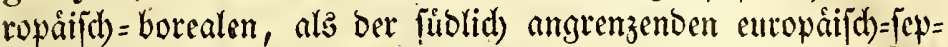
tentrionalen Bogelzone, in weldber bie bänij̄ben Injeln liegen, fo wic Monnon fratercula cin Stanovogel ift, fowobl jene: $\$ 30=$ gelzone, alz Der offtichern, in weldher Ramtid)atéa liegt.

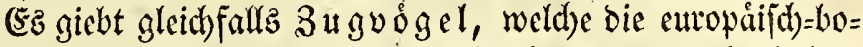
reale und jeptentrionale $\mathfrak{B o g e l} z$ one mit einander gemein baben, 3. $\mathfrak{B}$. Motacilla alba, Saxicola oenanthe, Axtuus pratensis, Chamanres hiaticula, Linosa melanura, 'Totanus calidris, Trenga alpina, Strerna arctica $\mathfrak{u} . \mathfrak{m}$.

Die 3ugvógel, weldbe Det curopäif h)=borealen Bogelzone eigen fint, mandern in ber Éâltern Sal)reszeit nad) ber benad)= barten füblidhern Bone, und verweilen entweder ba ben ganjen Ssinter lyindurd), ober paffiren nur butd) biejcl(be nad) nod) fúblid)er liegenden Sertern. "So balten fich Die meiften borealen (Sảnje und (Enten ben ganzen SSinter lyindurd) an ben bánifden Sifften auf, ba bingegen unter anderm Phalanopus cinereus und Lestris parasitiea gegen ben $\mathfrak{B i n t e r}$ yon ibrem nórblid)en Baterlande burd) bie feptentrionale $\mathfrak{B o g e l}$ one weiter gegen $\mathfrak{S}_{\mathfrak{u}}=$ Den ziel)en.

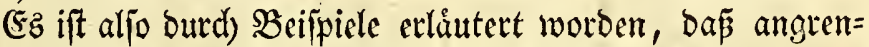
zende $B o g e l z o n e n$ zuweilen einzelne 2irten von Stand $=$ ober $31 \mathfrak{g}=$ vỏgeln, infonderbeit in ber Mấbe ber eigentlichen (Sirenzlinie, weld)e fie verbinbet, mit cinanber gemein baben konnen, obcr

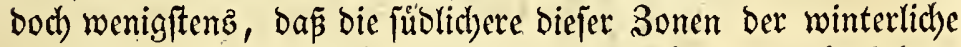

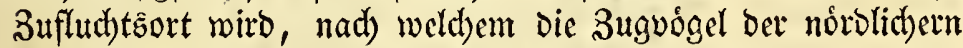
Sone fith wåbremb ber rauberen Sabreszeit hinbegeben. Som= men wir bingegen zu ben Bogelzonen, weld)e fith unter ben mebr oder am meiften bivergirenden Sraben ber Breite oder ber Långe, ober unter beiben gefammelt, entgegenfteben, fo borkt biefe (Ssemeinichaft nach und nach und zuleçt ganz auf, fo wie bieje gegenjeitige Mittbeilung ihrer Sogelarten; ganz verid)ie= bene Sogelarten, ja jogar Sogelformen, erjocinen in beiben, und nut einzelne Speciez der meiteften geographifd)en 2 utabrei= tung wetoen gemeinjd)aftlid) in beiben entoecft. Itm biejen

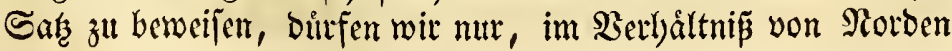


nad) Sůben, bie Sogetarten von Bironland und Sstand mit

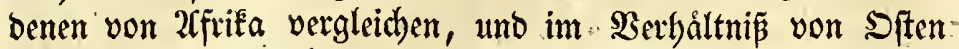

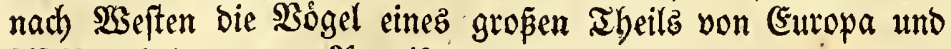

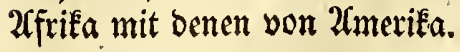

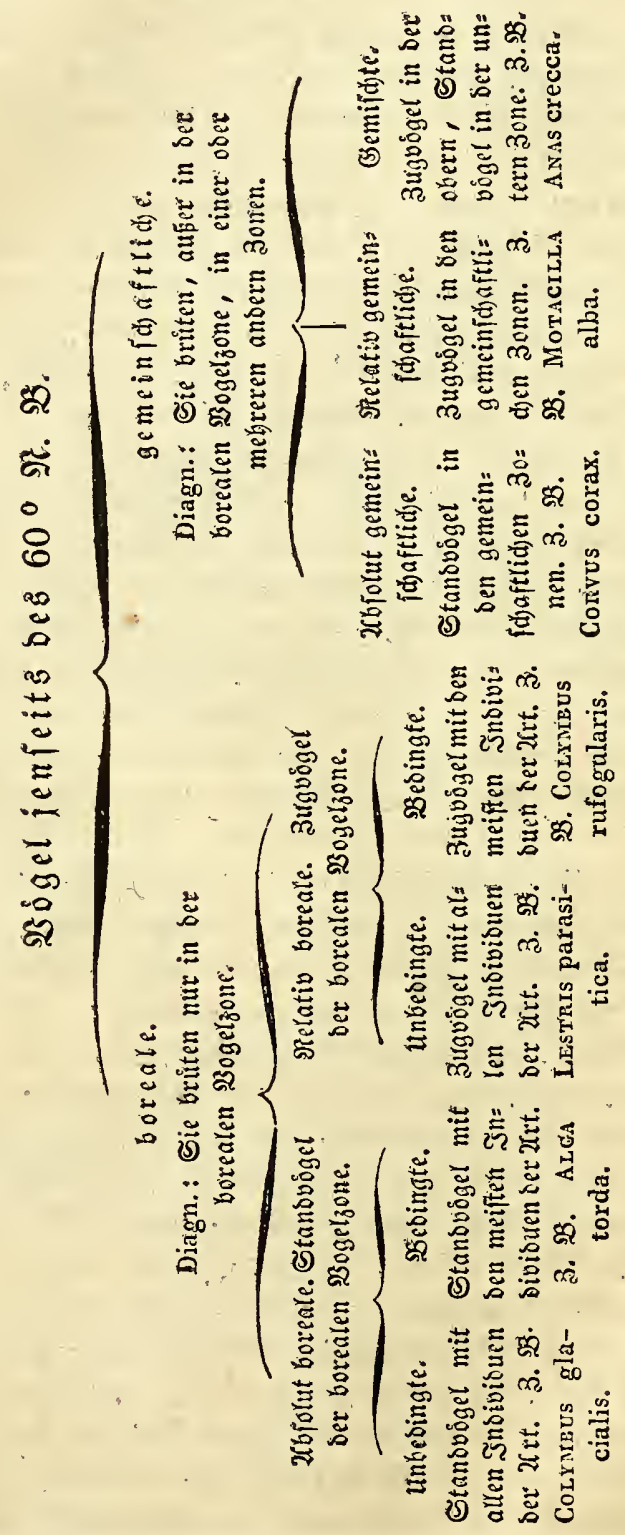




\section{§. 2.}

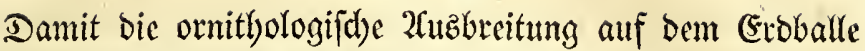

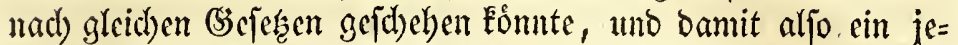
Der fît biefe SSejen bewolynbare \$la twerben, rutben bie erften Smbividuen jeder 3 sogelart, von $2 \mathfrak{n}=$

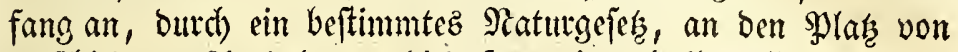

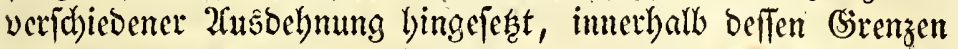

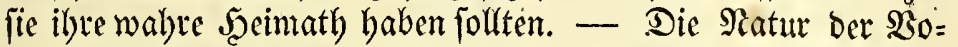

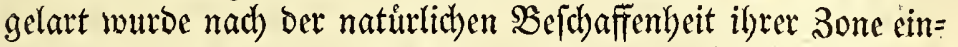

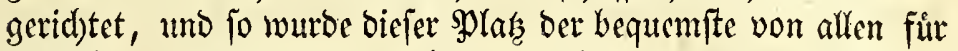
bie $\mathfrak{s o g} g e l$, ber $\mathfrak{g l a t}$, an weld)em fie fid) zut allen Sal)reszeiten in

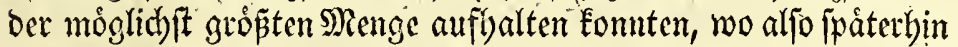
die Sogelart Standoogel mit ben meiften Sndivi= buen wurbs. Diejer anfängliche $\mathfrak{s l a t}$ feiner ornitbologifd)en

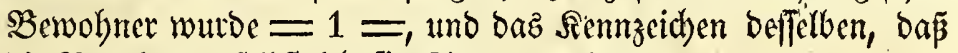
bie Bogetant bafelbft háffig Stanowogel wutrbe.

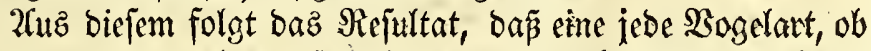
ibre Sndivibuen gleid) in um

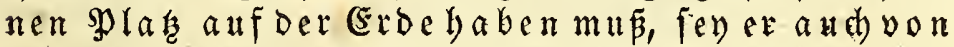

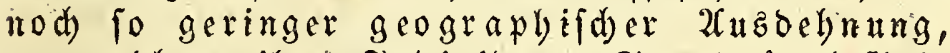
an weldem ihre sndiviouen Standvogel find.

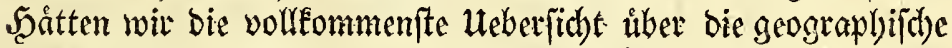

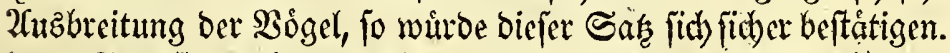

snderfen wuirbe biefer primitive befte splatg bods oft, bey ben zunelymenden Snbividuen der 2frt, bon zut geitinger

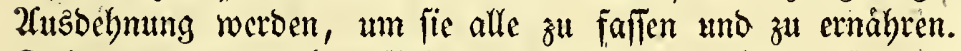
Daber wurben burd) bafjetbe Siaturgefes, welches biejen an=

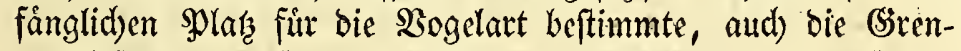

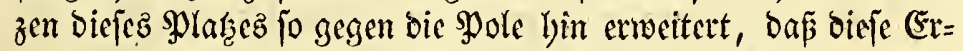
weiterung unter geniffen Bebingungen für bie Sndivibuen ber 2fit zum $\mathfrak{I}$ beil bewohnbar wutbe.

Die Matur ettl)êlte némlid) jeocm Indivibuum zwei un=

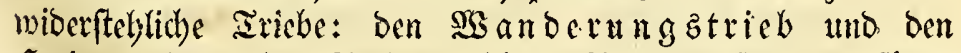
Seimwelytrieb. Solange fid) Der Bogel an feinent anfäing= lichen wal)en şlatze $=1=$ auffaalt, wo $\mathfrak{a r}$ Stanovogel ift, fithumnern bieje Iriebe; fie erwachen aber, wenn er auper ben Grenzen biefes splaţes unb in ber Erweitenung beflelben gegen bie \$ole bin tritt; weil eben biefe Iriebe bie gewiffen Bedingun=

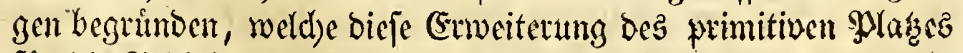
für bie Individuen ber 2 (rt bewoblubar mad)en. 


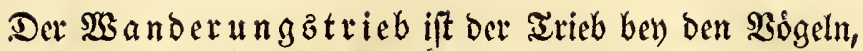
weldye innerhall ber Grenzen ber Errweiterung bez primitiven

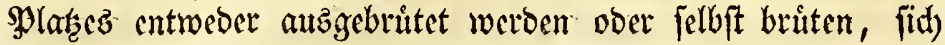

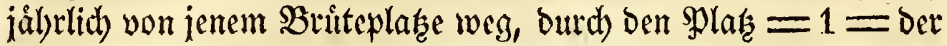
2Trt, nact) foldhen milbern (siegenden bin zu begeben, wo jie zu ber

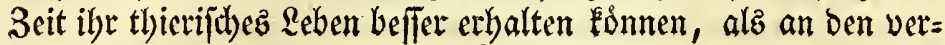
laffenen Sertern.

Der Soeimwehtrieb ift der Iriel bey benjelben $\mathfrak{B} \delta=$

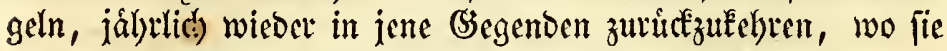
auşgebrütet fino, ober briteten, zu ber 3cit, ba bie $\mathfrak{M a t u r}$ es

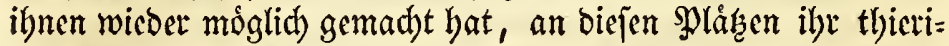

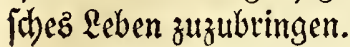

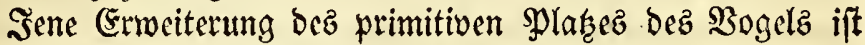
alío aud) $=\$ 9 l .1$ furt benfelben, aber mul bcoingt, ober $=$ bem - פol. 1 - x, weil bicje eben genannten Irtibe bazul bienen

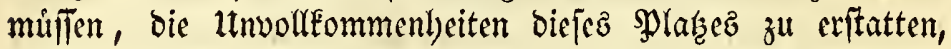
weldbe babutrd) entitanden, baß̃ ez cine minder bequeme (srwei=

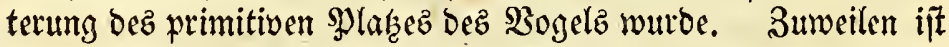

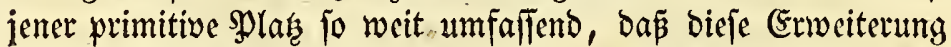

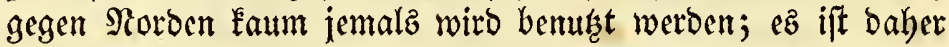
feine Folgerung, ba

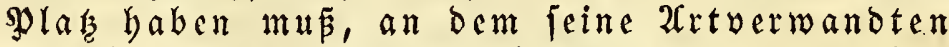

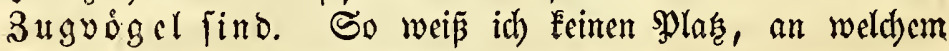
Convus corax ein 3uguggel jey.

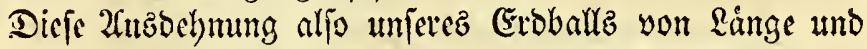
Brcite, in weld)er bie Inbivibuen einer gewiflen Sogetart, ent= weber mit ober obne 2 frwendung jener beiben Iriebe, ibr $\mathfrak{D a}=$ feun erbalten haven, bic erfte Periobe il) les \&ebenz zubringen,

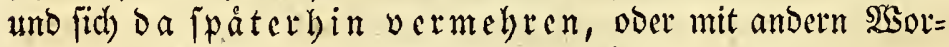
ten, ben \$la 3ug = ober Stanovugel gefunden wiro, Énnen lwir ridtig bie 3one ber Sogitart nennen: and wenn mebrere 30 gelatten sine Zone gemeinfldaftlid) $\mathfrak{h a b e n}$, fo billoen fie eine ornityolosi=

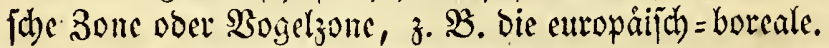

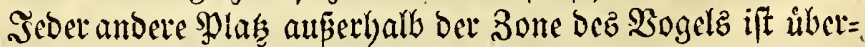
bautpt für benfelben als $=0=a$ mzujeryen, benn burdb ein unbe=

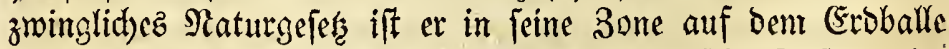
bingcicht und baran gebunden, ba erbjielt er fein Dafern, ba pflanzt er fid fort : und wirb er attd gezmungen, jál)rlid ein=

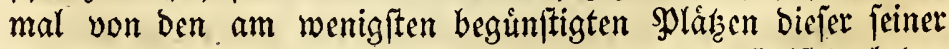
Bone nach) einem andern (Erbftrid) aubzumandern, fo ift bod ber 
Sheimwelytrieb mád)tig getulg, um ilgn wieber in feine vertaffene

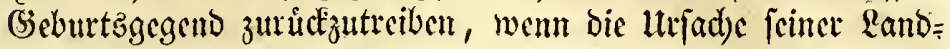

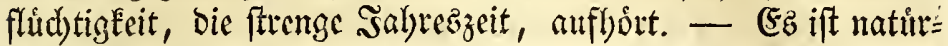
lich, baj ber 3 hguogel, wenn er wandert, burd ben wahren $\mathfrak{g l a}=1=$, wo feinc artucrwandten Stanovodgel find, nad) ciner fremben 30 ne ziebt, um ba ben $23 i n=$ ter zuzubringen. (Es mirtbe nánllid) wiberipred)end jenn, wemm Der $\mathfrak{B o g e l}$ nur nad) ben an meiften begimiftigten (Šegenden feiner Sone wanberte; benn fo wirten bie Srủnbe gehoben, warum

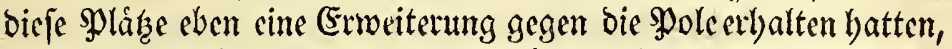

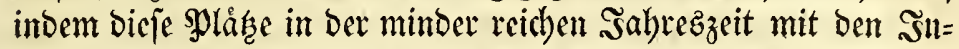
Divibuen ber 2 frt úberlaben werben; ber Sceimwehtrieb Eónnte, als eine Frolge beffen, baj̃ fie in ilyret eigenen 3one blicben, nidbt wirffam werben, und ber $\mathfrak{B}$ oget wủrbe alfo daz vertieren, waz ihn alz 3ugoogel daarafterifịt.

\section{§. 3.}

Wsem ber Sogel wandert, fo gefdielst folde e fet 3 von ben Polen gegen die Rinie, und nidet unge= $\mathfrak{k} \mathfrak{e} \mathfrak{b} \mathfrak{r t}$

Der Soget mandert allezeit gegen bie Wsinterjahyzeit auts;

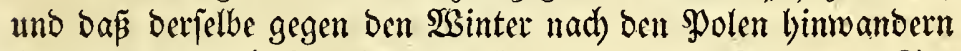
follte, wiberipridst fowohl ber Erfalsumg, alz ber $\Re$ atuer ber Sa= d)e. (G)lcidbfalls ift es nid)t butch bie (Frfalurung beftatigt, ba

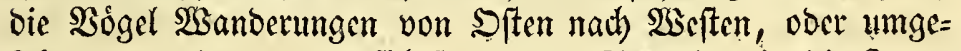
kebet, vornelymen, uno fid fo yon ber Seite har in bie Bonen

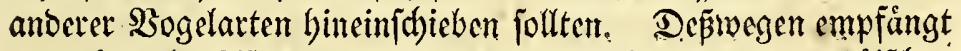

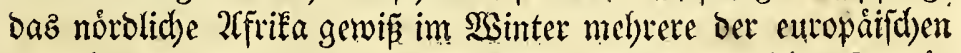
3utgoógel, ba hingegen bie eutopáifchen und afrifanifben 3ugvo:= gel in biefer unmilben salbreszeit nie nad) ben gegenibertiegenden

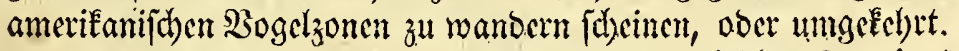

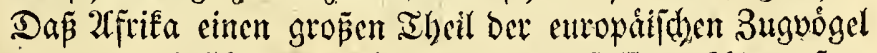

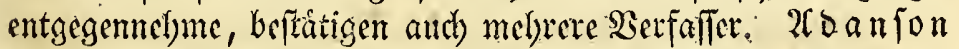
erzáblt in feimer Reife nad) Eenegal, baj bie Sd)walben zul ber. Beit nad) biefem Rande Famen, ba fie (suropa bertafien batten; Sruce be Rinnaino bezeugt baffelbe von 2lbefinniem, indem er bin=

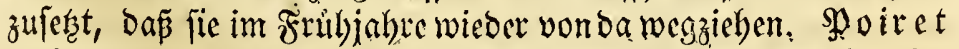

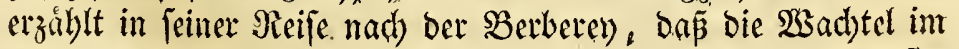
Detober und \$ovember babin Eomme, Sad Sgaffelquift $z$ Berid)t Eonmen Ribize nad) Egupten im September, und nad)

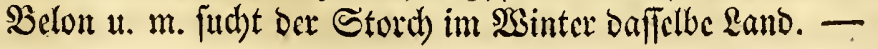


Dabingegen glaube id), als cine Folge ber vorftelention Regen, ba ́p kein 3 ugvogel von ben Molen gegen bie Rinie ziebe, um zubruten, uno báp alfo fein Sogel, ber

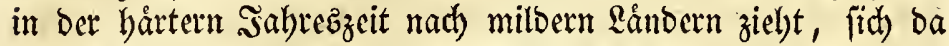
wieder mit bem Britten befafle. Denn ber Sott ibres Sommer= aufentbalts, wo fie felbft ausgebritet find, uno fpaterbin fectoft briteten, ift iffe wable Sceimatl), ift bic innen angewiejene Bone. Sie verlalfen biefe nur, wenn fie in einem 3uftande ber $\mathfrak{Q} a n d=$

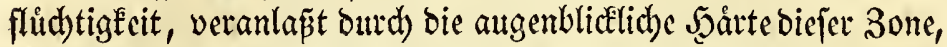
zum 2fuzwandern genótbigt werben, uno balten fid nur fo lange

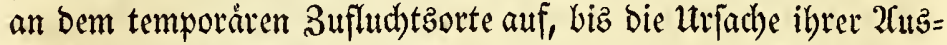

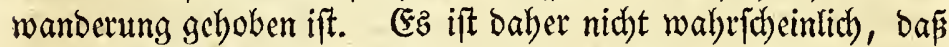

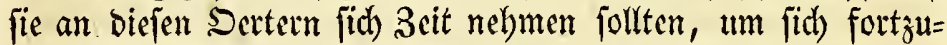
pflanżen. So jagt z. B. Koanfon von der Sdywalbe, Dá fie in Senegal nie sumge aubbrute. Bechltein bejweifelt

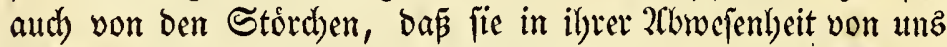

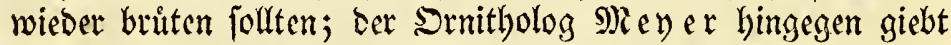

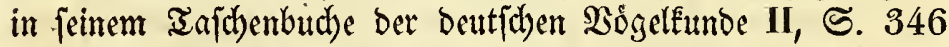
folgg: (Srinde bes Entgegengefergten an, ba er vermutthet, baß

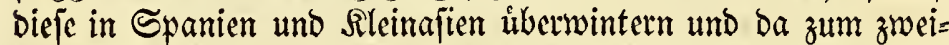
ten Male briter. Der Sornitholog $\mathfrak{B r e b m}$ beweift jebod) baz Gegentheil von $\mathfrak{R}$ eyerz angegebenen Gitunden in feinen Belttiágen z. Bogelfunde, III S. 119 zc.; er nimmt an; ba bie Stórdbe, bie von (Europa wegzieben, in ibrer 2 Cbwefent)eit nidbt wieber briten, uno fúlbrt unter melyeeren Berweifen ben

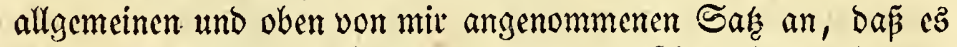

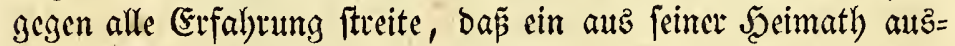
gewanderter 2 ogel zum zweiten Male britten follte, fowic er

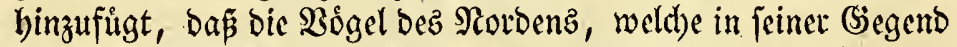
úberwintern, nie 2 (nftalten zu irgend einem $\Re e j$ fbaue madhen.

\section{§. 4.}

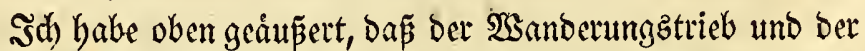

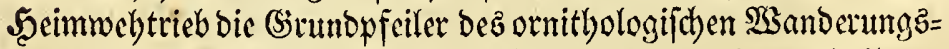
finftems find, bie artiebfebern, weldye ben Buguogel innerbalb bez

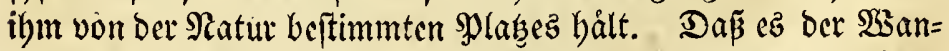
Derungstrieb jey, ber bie.3ugboggel auß ihren Sommeraufent=

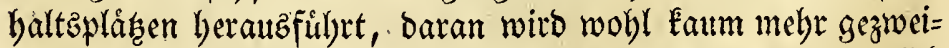

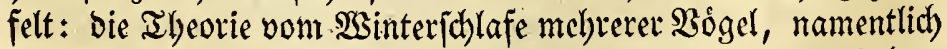

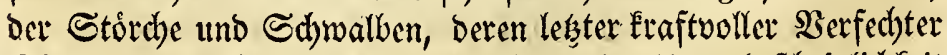

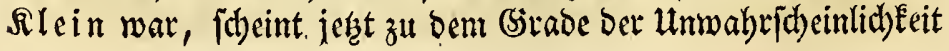




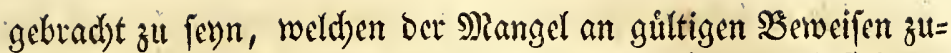
left elzeugen muste. Dalyingegen ift $\mathfrak{e}$ b nicht fo unbejtritten,

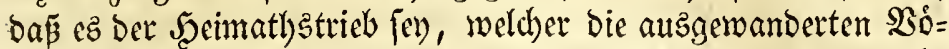

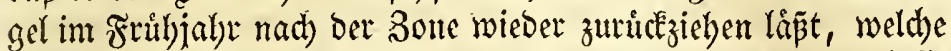
fie im vorbergehenden Şerbfte verlaffen batten, uno wojelbft fie entweber ausgebrutet wurben, ober felbit ibre sungen ausgebru= tet hatten. Dod reben widhtige (Srinde für biejen Seimmel)=

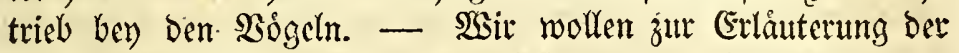
(ad)e aus der borealen Bogelzone Motacilla alba, Saxicola oenanthe und Artuus pratensis alz (Exempel wáljlen. Diefe find 3uguogel, fowobl in ber borealen, als in Der feptentrionalen Bogelzone. Sie fommen jályrlid) im Frübjabre nach Şzland und (Sironland, und verlafien bieje ijolirten \&ånder wieber nad) wenigen Monaten, wenn fie ilye. Jungen ausgebrutet lyaben.

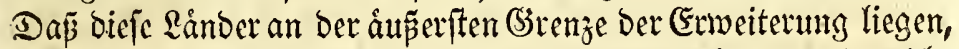
welche ibr wal)rer \$las =I eithielt, Daran Eonnen wir nidst

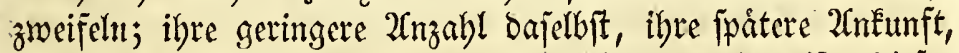

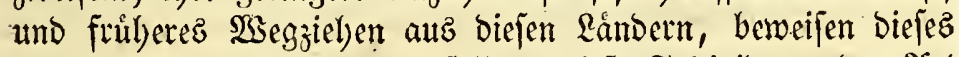

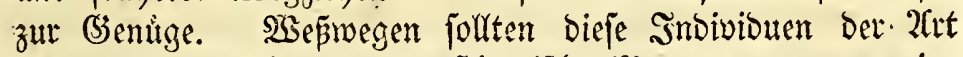
fid) liber fo weitlauftige und fturmifd)e Mere wagen, wo eine Menge yon ibnen cine Saute bet rajenden Elemente würoen?

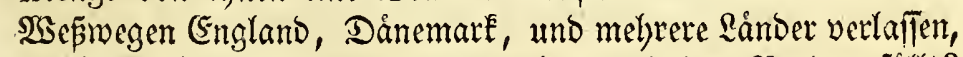
burd) weldye ibre $\mathfrak{B a n d e r u n g ~ n a c h ~ b e m ~ h o l y e n ~ S o r b e n ~ f a ́ l l t ? ~}$

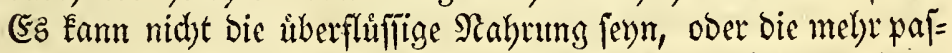
fenbe Iuftemperatur, welde bieje Indivibuen nad jenen bore= alen Rándern treibt; Denn es ift offenbar, dap dieje 2trten bie genennten Bebingungen in weit hod herem (Srabe in ben temperirten

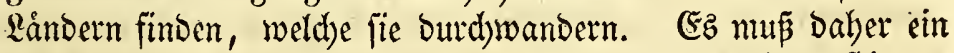
in fich jelbit gegrimbeter, von andern umgebenden (Segenftänden unabbångig wirfender Trieb jeyn, ber eben bieje Sndividuen, aller brobenden-(Siefabren ungead)tet, bie nórblict)ften $\mathfrak{a} \mathfrak{a} n=$ Der zu bevolkern zwingt, wo fie alz 3uguoggel fonnen gefunden

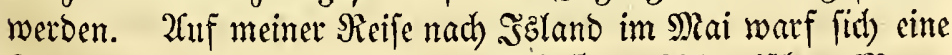
Saxicola oenanthe auf umer $\mathfrak{S} d$ if im 2 thantijhen Meere,

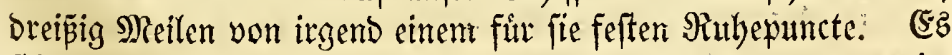
fturmte; inr ganzes 2(uz) eb)en zeugte von Ermattung; ber wit= Eende Seimwebtrieb aber ellaubte ibr keine Siube; ob fie gleid) ungeftoont auf bem ভdbiffe båtte ruben Eonnen, madte jie bod) beftändig Sogen gegen Norben, veridtwand in mebrexen Stun= ben, wutbe aber bann wicoer vom Stum auf jenes zutútége= worfen; endlich blieb bet Elcine $\mathfrak{S}_{\text {and }}$ erer ganz uno gar weg. - 
2uch bie (Erfabrung (prid)t Dafur, Daj ez Der Trieb nad) Dev vorigen Seimatl) fey, wo ber Sogel entweber felbft im Nefte lag, ober fein Seft batte, welder biefen die Sláł zum Som= metaufentbalt futben låpt, bie er anderz auz keinem andern (Srunbe alz die bequem/ten båtte wálblen fỏnnen. Mebrere $\mathfrak{A a}=$

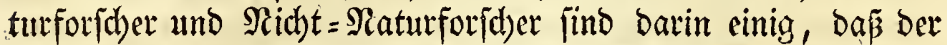
Stord) und bie Sdywalbe ibr voriges sleft fudben: man bat cz aber friber bey biefen Bogelarten bemerft, weil fie eine

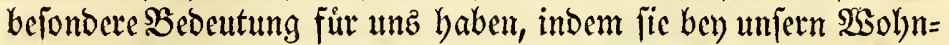

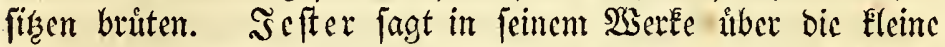

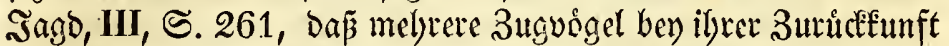
im Frúblinge jidch jebr gern zu ben Srintepláţen halten, an rol= dben fie im vorigen Sabre ibr Neft batten. Slaffen erzáblt in

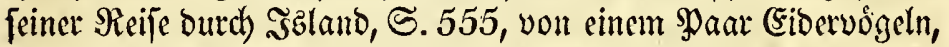

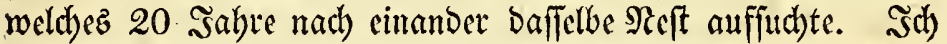

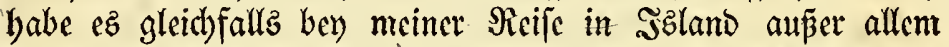

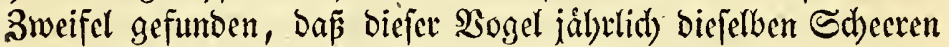

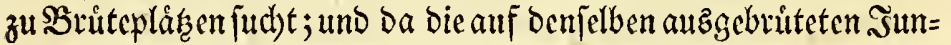
gen, wenn fie bruitfábig werben, auch bieje phląe zu Şrute= pláken wåblell, fo nimmt bie Babl biejer Bógel auf foldben Sd)ee=

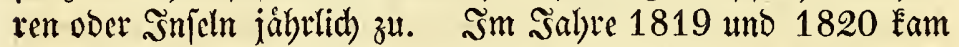

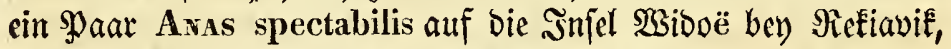
wo ez z wifoch ber Anas mollissima brutete. - $B e l)$ Dem

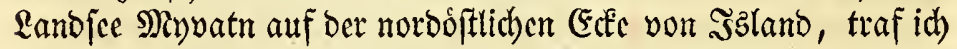

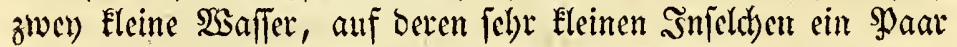

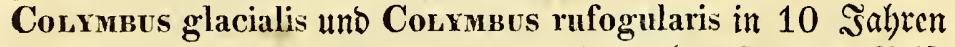
gebritet hatten. Siux an einem Srte fand id) auf meiner Reife ben Bruteplafs ber Uria alle, er war zwifd)en ben berunterge=

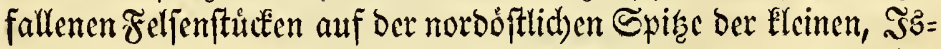
lano gegen Sorocn gelegenen, Injel (Sirimjö, wo ungefäbr 50 Spare, fo lange man fich eximnern fonnte, gcbrutet latten. Pufrinus arcticus mihi fand id) aud nirgendb, als alf bet gró $\beta=$

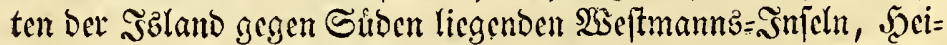

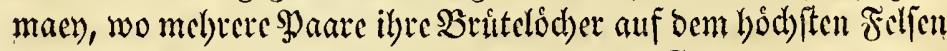
der Snjel gegraben lyatten. Einige Spaare des Caniso comoramus bruten jảbrlich in einer Slippe auf ber Eleinen Snjel Sitsoë in ber Saucht Scfjord, obgleid) Dicjer Bogel in einem Umfreije von mebreren Meilen nirgends einen Sruteplak hat. SFin Spaar Larus glaucus uno Larus marinus legt jebez $\mathfrak{S a b r}$ (Fier ait cinet Eleinen nadten Sdeete bev (Srimjoè. Phalanopus nefas ober platyrhinchus Temm. Fommen jåbrtid) zut cincm fleinen Teid) 


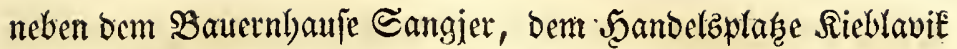
in Submeft, uno briten oa ibre (Eycr aub, ob id fie gleid) bey

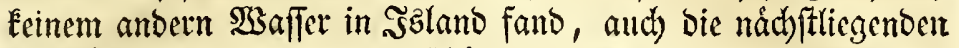
Ieide von bicjem flcinen fhoonen Sidwimmet nicht bewobnt werber. -

Unf berfelben ifolitten Rlippe am Strande, Roonbrangat

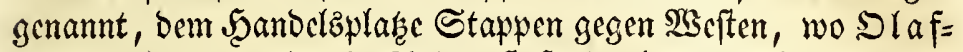
fen im sabre 1750 ein 2cblerneft fano, hatte noch im Sabre

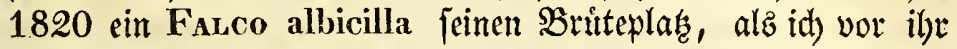

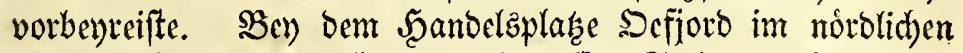
Şlano ift cin Kleiner Sararten, in beffen Steinzaun SaxicoLa oenanthe, nad) ber 2 fusfage bez (sigenthümerz, mebrere Jahre

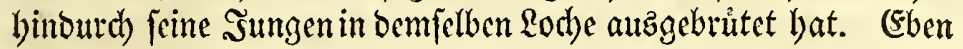
bas beridsteten mir bie (Einwohner auf bem \&ande an nelyeren Sorten von Motacila alba. Frrvgruha linaria fand id) mur

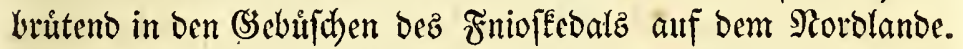

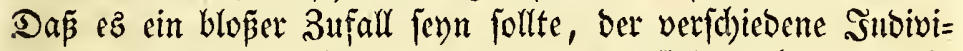

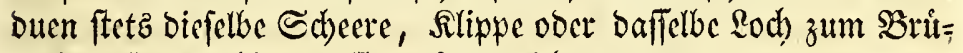

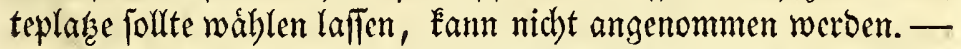

Heberlyaupt rebent bic in Şaland fogenannten 20 gelberge

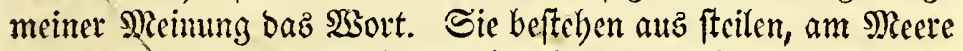

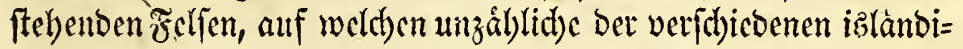

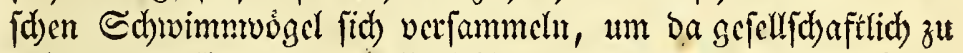
briten. (Es jint mut gevilfe Felien, bie fo von ben 2 sajpervoggeln bejudtet werben, ba man oft in ben naheliegenten Felfen, weld)e

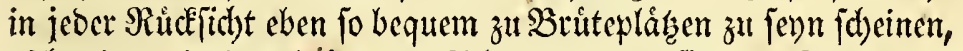
nidht einen einzigen brittenben Sdymimmyogel finbet. Die einmal

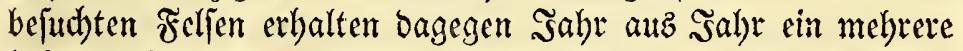

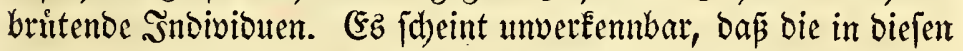

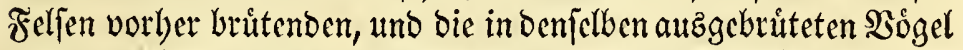
wieber nach cben biejen zutrúctemmen, wenr fie brúten wollen.

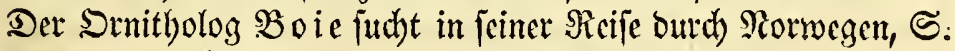

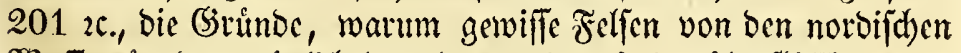

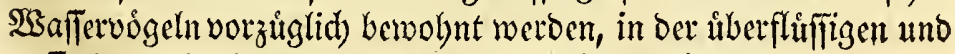
paffenderen Mabrung, bie fie bafclbit finden kónnen.

\section{§. 5.}

Den printitiven $\mathfrak{M l a f}$, no die erften snbivibuen ber Bogel= att bingejerst wurben, uno von wo aus ifre Bermelonung nad)= her burch bie ganze Bone ging, ben wabren $\mathfrak{p l a f}=1=$ an weld)em bic 2 Jogelart ibre Stanbudgel hat, E⿱ónnen wir mit bem 


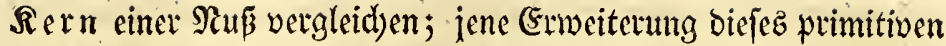
Slaféc gegen bie Sole, wo biefelbe Sogelant ibre 3łtgoógel

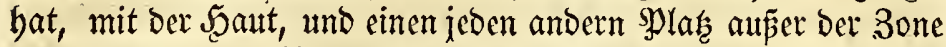

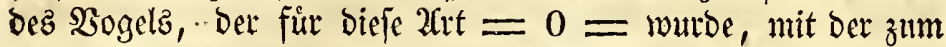
sftern unbraudbaren Sdyaale Des Sernz. Sm Mittelpuncte

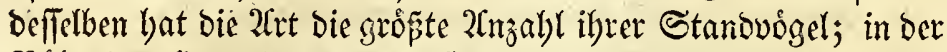

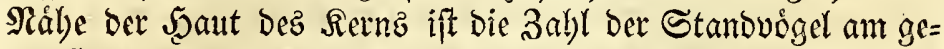
ringften. Șn ber Şaut, wo bie šndividuen ber 2trt 3ugvogel fino, werben biefe nad) uno nad) Feltner, je nåber fie ber Sdbarle fommen. Șn biejer Sdaale loórt bie $\mathfrak{B o g e l a r t}$ auf; fie ift auper ibrer Scimath, und nur Dann begeben fid) ibre sndividuen zu= weilen bal)in, wenn fie in ber \$eriode ibrer Landffitchtigfeit feines

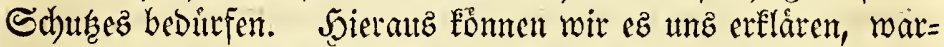

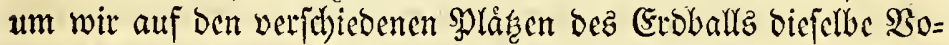
gelart als feltenen obei håufigen Standvogel, als feltenen ober

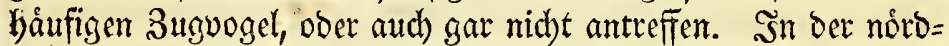

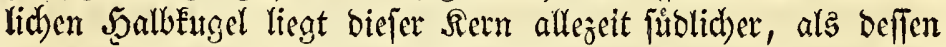

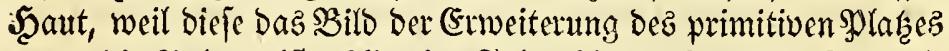

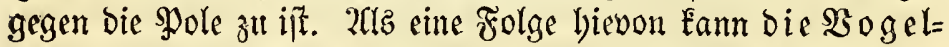
art, beren sndivibuen 3 uguogel in ber fublidern Bogelzone find, nidht alz ভtandoogel in ber nórb= lidern gefunden werben, wobl aber umgekebrt. Dod) findet man felten, bas cine Sogelart, Die Suguogel in einet norblichern Bogelzone ift, gleid) Stanboogel in ber fublid) benachbarten 3one witb, unt ift in jebem Falle ein $\mathfrak{B e}=$ weiz ber geringen geographijd)en 24ubreitung biejer 20 gelait. Dagegen ift eb cin 3eid)en einer weiten 2 uabreitung einer $\mathfrak{B} 0$

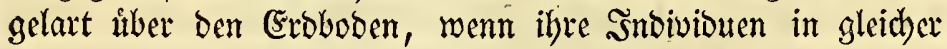
Menge burd) melbrete ornitbologifde 3onen gefunden wetben, ez fey num alz Bug= oder alz Stanovogel.

Einige Exempel zut Erlätetung, bergel)olt atb ber euro= páij (d)=borealen uno feptentrionalen \$ogelzone: Sruvia troglodytes ift fomobl Stanowogel in Şland, alz' in Dánemank. 'Die grópere Seltenl)cit berielben in J̈zland als in Dånemark zeigt, Daß fie auf jencr. Snjel weiter vom Mittelpuncte ilyrer 3one jeb, alb bey unz. Daffelbe gilt von ber Motacilua alba alz 3ıguo= gel. Numenius arquata uno Numenius phaeopus fino beibe boreale 3uguógel, jener aber an offlichern \$̧láţen, alz biefer; baber wiro er in siormegen unter ber Breite von Ssland gefun= ben, nidht aber auf Diefer Simfel, wo Numesius pliaeopus báufig ift.-Lurosa melanura ift Sttguogel fowoh)l in Saland, alz in 


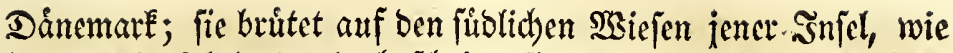
bey unz in Juttlano; Dod) fcheint fie melyr Der feptentrionalen,

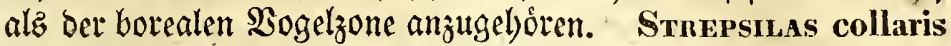
ift ein Suguogel forwolyl in J̦land, als in Dánemark aber

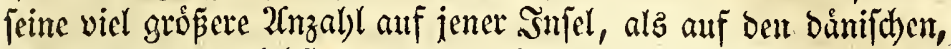

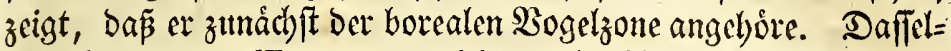
be gilt von bet 'Tringa maritima als Standoogel in beiben

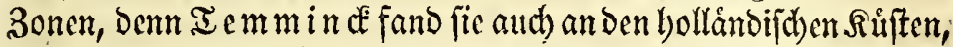
bod) bey weitem nidst in joldben Sdywårmen, wie in ben borealen Ránbern. Tnivga alpina ift 3uguogel in beiben 3onen, unb erge= Górt eben jo felyr jemer an, als biejer. 'Tringa pugnax if́t 3ngugogel in ber borealen 2 Bogelzone, wie in ber jeptentrionalen, aber mur in ben offtlid)en (Segenden jener 3one; baher wirb er, Şslano gegen= úber, båufig in Normegen gefunden, ba er bingegen weber nad) biefer Șnjel, nod) nad) ben Snjéln Faroë ober (Słrónland fommt. Scolopax gallinago ftelst in gleidhem Berbáltnifie zu

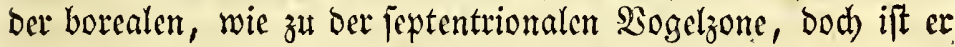
am feltenften in ben wefflid)ften uno norblid)en Gegenden jene: 3one. Sula alba ift Stanovogel in ber borealen Sogelzone; bie Menge aber beffelben in ben fitbmeftlichen Biegenden biefer

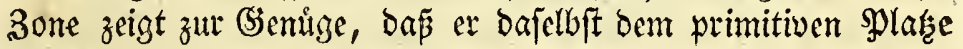

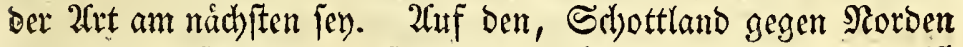
liegenden Smjeln, und auf ber Faloeị̂then Injel Mnggenaz, ift er båufig, auf bem jüblichen Fslande allgemein; bie Menge bef= felten nimmt fdon im norbliden Salande ab; auf Şrimjoë werben nar einige wenige \$aare gefumben; bev Dem nórolichern

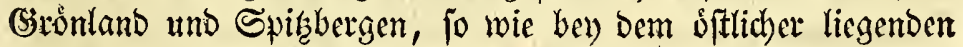
Rorwegen, ift er febr felten. Lanus eburneus uno Lanus leucopterus milki jino and Stanowogel in Det borealen $\mathfrak{B}$ ogel= zone, gebóren aber Den nơrolicb)ften nno weftlidbften (Segenden Derfertben an. Der erftere fómmt nie nath Sslant, febr felten

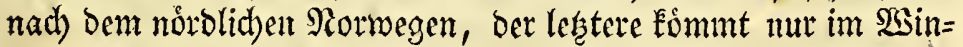

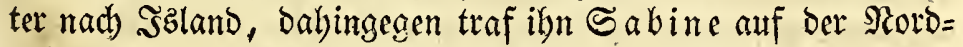
polerpebition, ber bem wefftichen (Sirónlano unter bem $70^{\circ}$, uno Ricutenant Scolból fpáterbin bey Der Rolonie (5̧otlyaab hauffig britend, fomie Mi artenz vor mebr alz 100 Sabren ben erftern bey) Epif́bergen. Lanus tridactylus, Lawes glaucus $\mathbf{B r}$. uno Lanus marinus, fino alle zum Ilyeil Stanbudgel ber bo= realen Bogelzune; ber Erfte aber gebt nơrblid)er, als ber 2tndere, utho biejer norblicher, ale ber Reste. Dr. Ma nd t fand oen (Er=

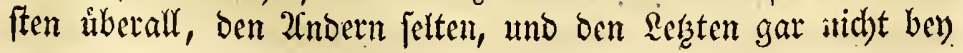


Spirbergen. Lanus tridactylus brîtet bảufiger auf (Şrimsoë,

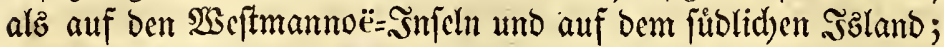
Lanus glancus und Lanus marinus bingegen båufiger an biejen Sertern, alz an jenen. (Ez ift merfwưtbig, baj Lanus argentatus Br., Lanus canus uno Lanus fuscus, welibe dod in Norwegen unter ber Sreite von ŞBland und (3ronland gefun= ben werben, fich nie an ben lef̧teren Sertern feben laffen. Da

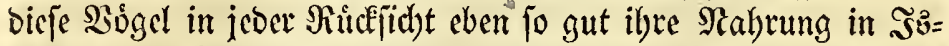
lanb finden Eonnen, to milffen wir annehmen, Dap ber weftlicblte (Grab ber Ránge von Norwegen bie Gienze ifrer geographi= fd)en 2(uabreitung im Berbáltnif́ von Siten nad) Şeften wurbe,

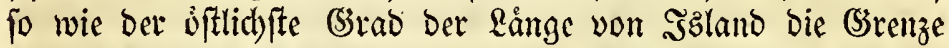

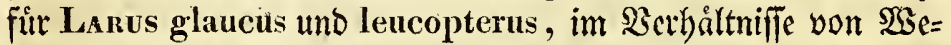
ften nad) Siten. Pnoceldanda glacialis ift Stanovogel in ber ganzen borealen Bogelzone, uno ift zu Shauje bis Spirbergen jenfcits bes $80^{\circ} \mathfrak{R}$. Br., wo bie ornitl)ologifd)e $\mathfrak{B s c l t}$ nod)

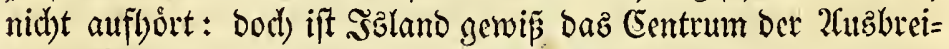
tung diejes 20 gels in ber nơrdlicben Şalbfugel. ProcednanIs pelagica bingegen gel)oint, alz Stanovogel ber borealen 3one, in ben jüblid) ften (šegenden beffelben zu Şauje. Er witb

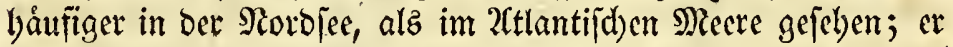
cridbeint unter bem $90^{\circ} \mathfrak{R}$. $\mathfrak{B}$., f(beint aber nidjt viel mebr

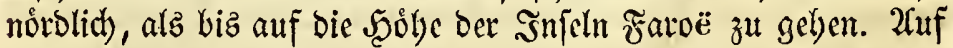

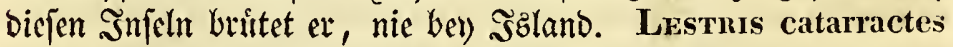
gel)ort alz Stanonogel in bie boreale 3one, mebr zu ben fiubli= d)en und weftlidben, alz zu Den nơrolid)en uno offtlid)en (Şegen=

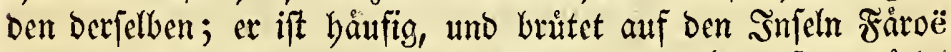

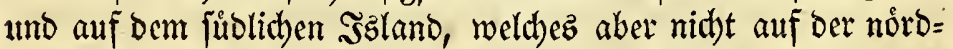

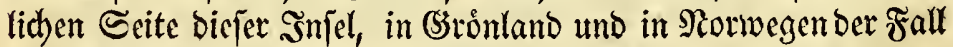
ift. Dab Anser-genus gebort mit finen 21rten uno Snoivibuen zum Iheil in berborealen Bogelzone als 3ugoogel zu Şaule, bod) hat Anser torquatus bajclbit eine nơrblichere Jecimath, alz Anser segetum, uno biefe eine noollid)ere, alz Arser albifrons. Die

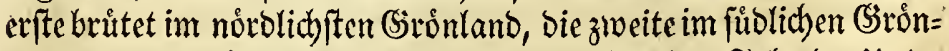

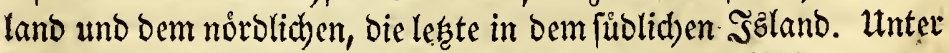
ben Enten geboirt Avas mollissima alz Gtanbuggelin ber ganzen borealen \$ogelzone zu Şaule, fo wic auth), objichon jeltener, in ber jeptentrionalen. Sie brưtet auf ben grónlánbifchen Sdee

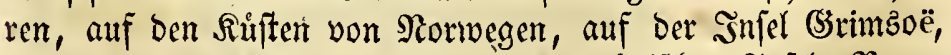

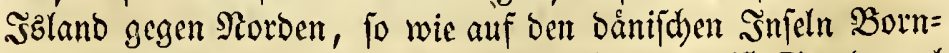
holm uno ๔amfoë. Aras spectabilis bingegen ift Stanboogd 
in ber borealen 3one allein, und gebort meiftens ben nơrolid)en und weftlidten Gergenden berfelben an. Sie ift häufig in Grón= lamb, felten in Şsland, Faroë unb Rormegen. Axas boschas ift eben fowohl båufig auf Faroë, in Jalano und Gitónland, als in Dánemark. Axas histrionica ift Stanovogel in ber bo=

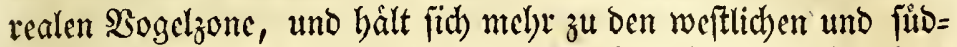

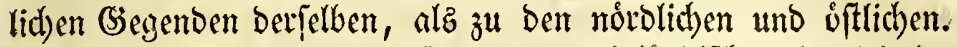
Die ůbrigen in meinem Prodromus ber išlánbijđ)en \$rnitl)olo=

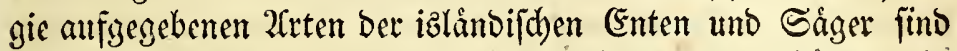

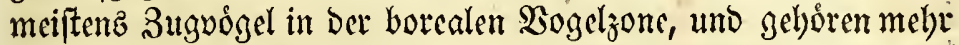
in bie fublichen und offtlichen, als nobrblichen uno weftlidyen (Ge=

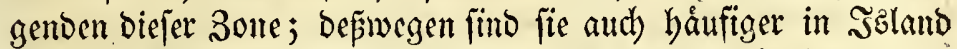
tmo Shorwegen, als in (Stionland, uno werden nad) $\mathfrak{R}$ arten nid)t in Spirgergen gefumben. (Es ift bemerkenşwerth), Dap Aras fusca und Aras fuligula nidyt in. Island gefunden wer=

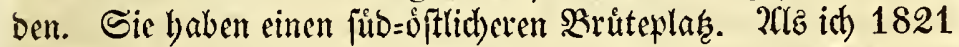

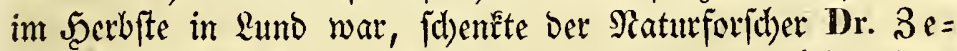
Derfite Dt, ber in bemjelbem Jabre von einer Reije nadb Lappland beimgetommen war, mir (Eyer biefer beiben Entenarten, weldbe

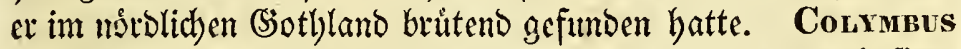
glacialis iff Stanboogel in ber borcalen Bogelzone unb băuffiger in bem jüblidben uno weftlid)en I Ibeile Derfetben, als in bem nórblidben und éftliden. Daffelbe gitt zum Iheil von ConmBus rufogularis als zugvogel. Conxmbus arcticus gebort in

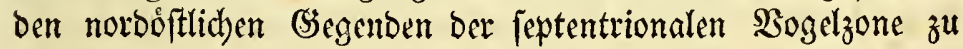
Şaule, wirb baher alz Sugvogel weder in Grionland, S̈land, Fåartoe, nod) Dånemark gefunden, wobl aber in bem nơroli= d)en Sdineden. Purfinus arcticus miki, ift Stanobogel in Der borealen Bogezone, getjort aber ben jübweftliden Besen= ben berjelben mebr an, als ben nórblichen. und ffftlichen; baher

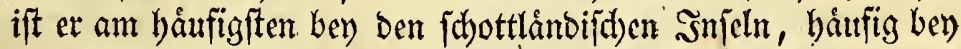

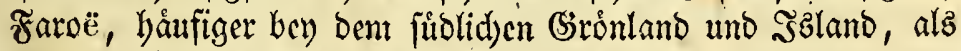

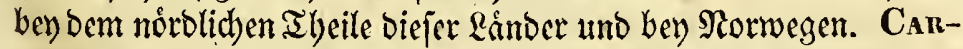
Bo graculus ift Stanovogel ber borealen Sogelzone, in ben fíblichern und offtlithern Ssegenden berjelben; båufiger bey $\mathfrak{F} \mathfrak{a}=$

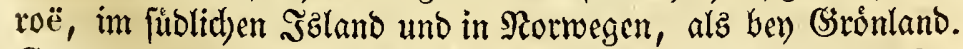
Carbo cormoranus ift Etanduggel in beiben angrenzenden $30=$

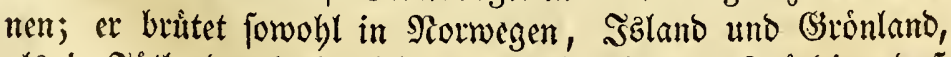

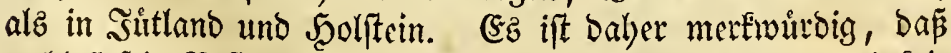

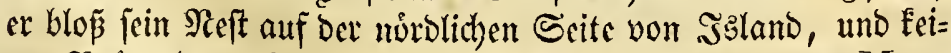

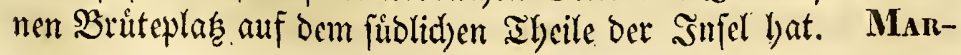


mos fratercula ift Stanoyogel ber, borealen Bogelzone, uno

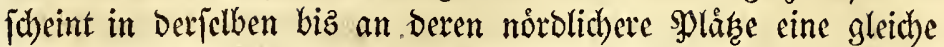
2hubbreitung ethalten zu haben; fogar bei Spisbergen bemette inn Dr. Alandt. Daffelbe gilt nid)t fo ganz von Alca torda; fie gebort mebr in bie fublid)eren (segenden ber borealen

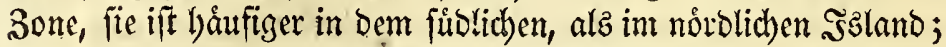
einige Paare traten aud jidon in bie Srenzen ber jeptentrio=

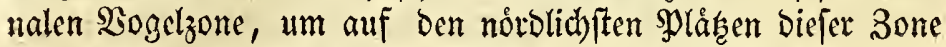
zu briten. Arca impenuis ift fider ein Stanoyogel ber borea= len $\mathfrak{B o g e l}$ gone, wird aber fiten angetroffen: Dod) ift es unleug=

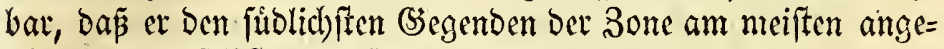

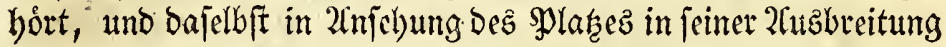
Bicles mit der Sula alba gemein hat. (Er mirb auf ben

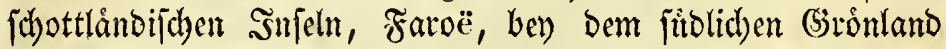
angetroffen, hatte vorlin Sritepläge auf ben Şmeld)en uno

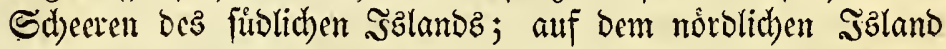
babe ith bingegen nie von ifjm reben gebort. Una alle and Unia Brünnichii jino Stanovo̊gel ber bovealen Bogelzone, uno geldoren meiftens den norblid)ften uno wefflid)en (segenden Der= jelben an. Sie find fel)r ljátufig bev (Sionlanto; Dr. Me a not traf bie eritere bâufiger bey Spisbergen, als bic lestere; fie bruten auf (strimpë, nơrblich von క̧sland, Unis alle hingegen nic auf

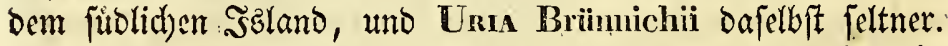
- Una grylle fdeint in der borealen 3one biz an bie nordlid)= ften (segenden berfelben gleid)formig vertbeilt, felbit bel) Spirs= bergen war fie båufiger, alz. Una Mandtii, weldye lef̧te nie in ben fûblicheren Gegenden ber botealen Sogelzone vorkommen foll. Sie wirb gleich båufig bey (sroinland, Szland, slorwegen, ben Faroijenen șmeln und Den (chottlándijeden İnjeln gefunden; mebrere \$aare traten aud) in bie norblid)iten shláge ber fep= tentrionalen, 3one ein, um zu bruten, zum Bebfpiel lángs ber vom Rattegat bejpulten fowmedifden Rujte, fo wie auf $\mathbf{B e i}=$ roë im Sorboft von Samioë. Una troile geboirt wobl aud) zum Theil als Standongel in ber borealen 3one zu Saule, aber

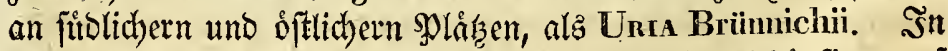
(Sroonlans fobcint fie nid)t vorzufonmen: fie ift viel baufiger auf:

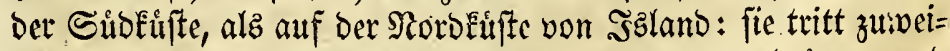
len inz Rattegat ein und in bic sftfee, um ba zu bruten, uno. ift im $\mathfrak{B i n t e r ~ e i n ~ b a ̊ u f i g e r ~ B o g e l ~ a n ~ u n i e m ~ \Re r i f t e n . ~ P h a l a - ~}$ nopos cinereus und PH. rufus find beibe 3ugvogel in ber bo=

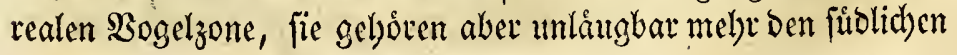


uno weftlidien, als ben norblichen und óftlidjen biegenden an. Die erften berfelben erfd deinen gemeiniglich im fübliden (Gron=

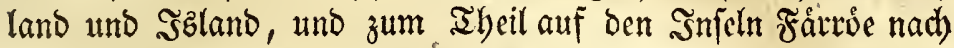

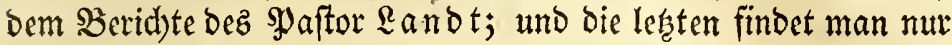

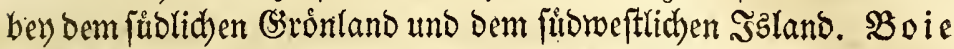
fand Eeine biejer zwei leften 2irten in Norwegen. -

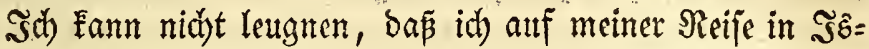
lano zrov Bogelarten fand, weld)e gegen bie oben angefübrte Regel, bap ein 3ugvogel in berfüblicheren 3one kein Standyogel in bet nórblidern fevn fonne, anftiểen, námlich. Rallus aquaticus und Hamatopus ostralegus, welde beibe Stand: vỏgel in Şzland und 3uguogel in Den Ránbern ber feptentrionalen Bone find; z. B. in Danemart. Dod fonnte bie Satur bes Rallus aquaticus bazu bentragen, biefen $\mathfrak{B S}_{\text {sideripruch }}$ in $2 \mathfrak{n}=$ febung feiner minter wiberiprechend zu madben. Sbjchon nåm=

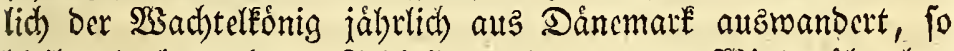
bleiben bod) mebrere Sndivibuen Den ganzen Sisinter über bey

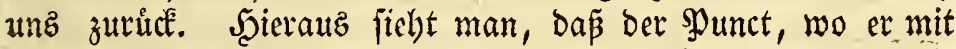
Der ganzen 2(rt Stanobogel ift, nid)t weit gegen Siben von Dánemark liege. Die crften Indivibuen biefez Sogelz, weldbe

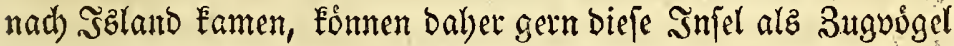
bejucht, eb aber wegen ilyter fulzen Flitgel und ber ijolitten $\mathfrak{l} \mathfrak{a}=$ geber Sัnjel nid)t ratbjam gefunden lyaben, diefelbe wicber zu ver=

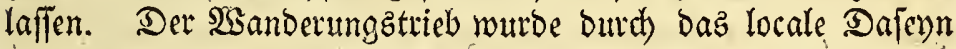

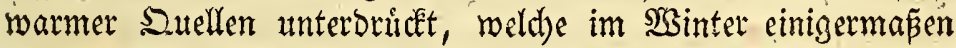

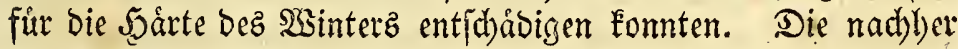
auf ber Šnjel auggebriteten Sutgen wurben zugleich burch ibre Riebe zut bem Strte, an bem fie auzgebritet rorben, an bieje gebunden, und fo murbe bieje Bogelart, gegen bie Regeln bex Natu, fo zu fagen, gezmungen sin Standoogel in Şland. Da= gegen ift eE eben fo gewi in gropen Sd)aaren auf Szland ủberwintert, ober gleid) auf

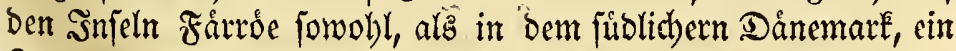
3ugbogel ift. Diefen Ssiberfpruch in Den Regeln bes Sande= rungsfyftems fann id) nid)t etelåren. Sod) mũ id bemerfen,

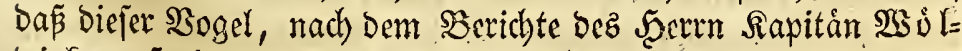

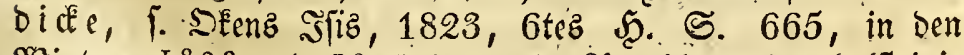

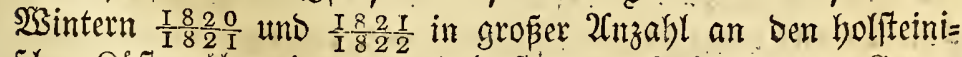

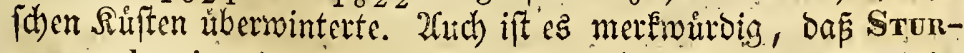

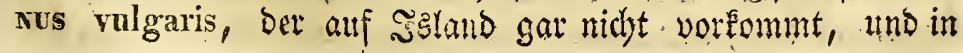




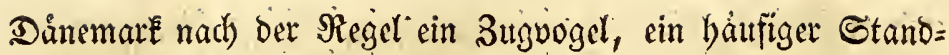
vogel auf den Faroë = Șijeln ift.

\section{§. 6.}

alz cine fernere Folge jenel entwickelten Regeln ergiebt (ich) aud bieje: je weiter ber $\mathfrak{s o g e l}$ fid won jenem uriprungliden plateentfernt, wo die sndiviouen feiner art Stanovogelfind; je weiter er als $3 \mathfrak{a t}=$ vogelgegen die norblide (s) renze der Ẽrweiterung biefez splatez, gegendie gyole hin austritt, befto

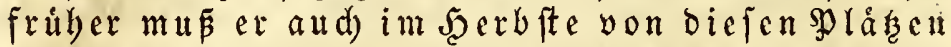
wegwanderu, und defto fpáter lommt er im $\mathfrak{F} \mathfrak{r} \mathfrak{h}=$ jabr in felbige zat $\mathfrak{r}$ dé.

Seine Reife ift långer, ba er gróp̧ere Strecken feiner Sone

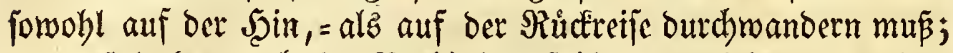
er mus baber audh im Nachjabre fruber wegzieben, um ben $\mathfrak{W}_{\mathrm{e}} \mathrm{g}$ u feinem Siele, bem $\mathfrak{B}$ interaufenthaltzorte, in paffen=

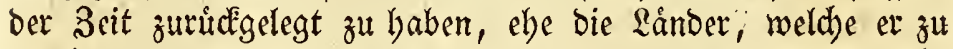
ourdwandern hat, auper Stand gefest worben find, bie burch= wandernoen $\mathfrak{B o g} g e l$ zu ernåbren. Ino da biefelben Inoivibuen

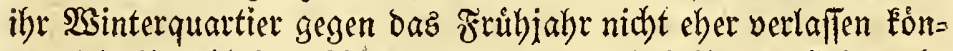
nen, alz igre úbrigen 2rtzerwanoten, weil theilz ber Seimmeb)= trieb fu berielben Seit bei ihnen allen erwadht, uno theils im entgegengejesten Falle biejelben Sierlyinderungen, wie auf oet Sinreife, ifnen begegnen wurben: fo folgt baraus, bas biefr, weldbe einen lángern $2 \mathfrak{s e g}$ nach therer Sommetlyeimatl) baben; und bod nicht eher, als ihre utbrigen Berwandten bie Rei je antreten, and) verbåltnifmåâtg fpåter bajelb/t antommen múfien. So

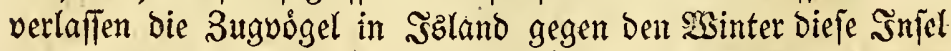
$8=14$ Iage frúber, alz ibre 2itţ̧verwandten. DánemarE, uno fommen aud Da im Fribjabre $8=14$ Tage pater an, als bie= fe bey uns antommen.

\section{§. $\boldsymbol{~ T . ~}$}

Esamulde oben gezeigt, Dapein Sogel ủberhaupt tein Stano=, vogel ciner norolichern 3one feun fann, wenn er 3ugwogel in einer fublidbern ift; Dagegen ift bas Entgegengefefte allezeit Der Far. Der 3 ugoogel in oer norolidern 3 one mu $\beta$ als Stanovogelinber fublichern irgendroo gef $u$ ben werden. Siele Exempel beftátigen dicjes. \$asenn ber. Bogel nut burd eine Sone Stanboogel, und foon itt ber ifr 
gegen Soroen liegenden 3one 3ugvogel ift, obne fich burdh meh)= rere Bomen aubzubreiten: 10 zettgt biejes von ber geringen geogra= whifchen 2ubbreitung biefes Bogelz. Es ift febr merfwurbig, bás die snoividuen ber jelben Bogelart zuweilen ineiner und berfelben ornitbologificengogelzone fowohl als 3 uguogel, alz Stanovogel vorkom= men. Diejer Sag loft fid) in zwey Unterabtheilungen auf, Daß́

a. bie Sogelart, welde ibrigens ein Standoogel ber Sone ift, einige Snoivibuen bat,

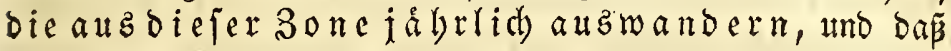

b. Die $\mathfrak{B}$ ogelart, weld e úbrigens ein. $3 \mathfrak{a}=$ vogel ber 30 neift, einige snoividuen bat, die als Standvigel zurudeleiben. -

Die Erfahrung beftátiget diefes, und die 2fuflojung liegt in bem oben angefúlyrten Saf̧e, Daß̧ bie 3one einer einzelnen Sogelart nicht allezeit mit Der ganzen ornitlologifhen Bone zulammentreffe, fondern offter eine weitere, zuweilen auth eine

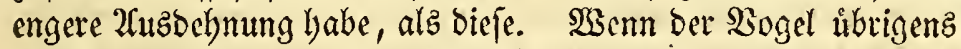
ein Stanowogel ber Bogelzone ift, aber bod einzelne Sndivi= buen wegzieben, fo witb baburch angezeigt, baj bie Sogelzone

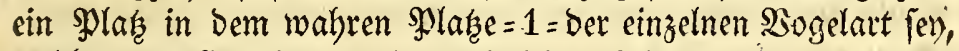

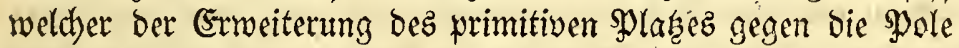
bin viel nåber liegt, als ben mittelpuncte beffelben, indem ber Wanberungstrieb fdon bey Eingelnen zu erwachen anfängt. - Der Şlás, wohin die Şálfte ber Sndividuen ber 2rut wandert; inbeffen bie andere Şålfte als Stanbogel zutrudeleibt, ift eben

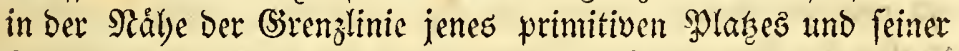

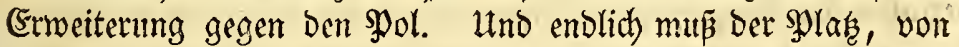
weldem bie meiften Sndividuen Der ?rt wegzielsen, indeffen ood einige zurudebleiben, ein Punct in ber Erweiterung Des primi=

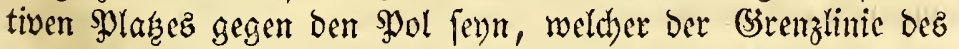
wabren Slakes= 1 = ganz nabe liegt, wo aljo ber $\mathfrak{B a}$ anderung

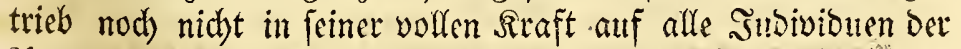

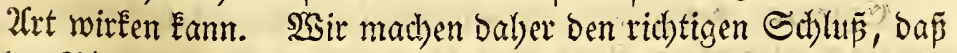
Der \$la weldem aber both einige ifyer Snbivibuen auswanbern, nicht weit von bem solage entfernt liege, wo die ganze Bogelart 3ugwogel jeyn wurbe, uno baf bingegen bei Wlá, an bem bie Sogelart uberbaupt cin Bugvogel ift, wo aber bod) eitzelne ib= rer Sndiviouen jåbrlich alz Gtanovogel zurudbleiben, nidjt weit 
von bem Solake entfernt liege, an Dem bie ganze Bogelant Stanbyogel fenn mưrbe.

Beyipiele. Sn Danemark find auper vielen andern Sruvia rubecula, S. modularis, Raluus aquaticus 3 ug= vógel, obgleich einzelne jąbrlid zuridelleiben. Convos cornix uno FrivgILla coelebs Standudgel dafelbft, obgleich cinzelne jábrlid) wegzieben. In Ş̧land find Emberrza nivalis, Frongruta linaria, Corunes rufogularis, Mengus, merganser tmo M. serrator, Arss glacialis, A. clangula, A. boschas, Lanus tridactylus, L. marinus 3uguogel, obgleid) melgrete ober wenigere berfelben bort jåbrlich ủberwintern. Dagegen fino Unia grylle, Unin troile, Alca torda, Anas mollis-

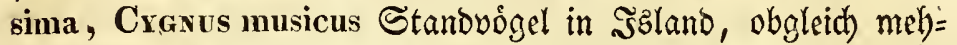
rere ober wenigete Sndivibuen jâbrlict) gegen ben Şinter von ba auswandern.

Shieber gebóren aud bie unregelmápigen 3 ìge, welde einige 2uten ber norbijden $\mathfrak{S a l d}=$ und Singuogel in geroillen sabren fdaarenweile gegen Suben vornebmen, ob fid gleid úbrigens nur einzelne berfelben im Şinter an biefen füblichen şläen fel)en lafien. Die ganze 2ret ift namlid Stanovogel in ber borealen Sogelzone. Die einzeluen Šndivibuen, weld)e jågrlid) in bie

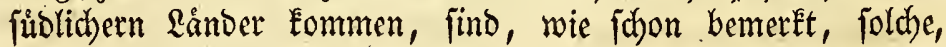

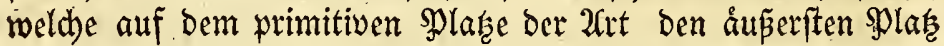
bid)t an ber Grenzlinie jemer Erweiterung gegen ben spol erbal= ten haben, an weldbem die 2rit Sugvogel feyn wuirbe. Sâenn nun in gewifien Sahren bie Bermebrung ber 2 rt fo anfebntid) geweên ift, Dap̃ fie nicht mit ber von ber probuction bes \$la

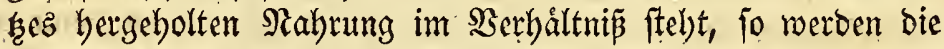

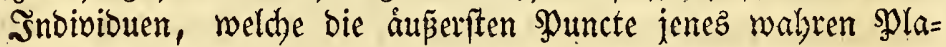

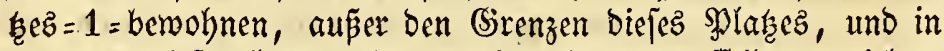
bie auper biejen Ërenzen liegende Errweiterung beffelben getrieben,

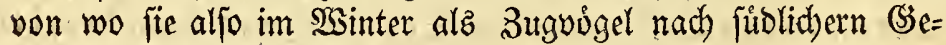
genden wandern mutjen. Şenn eben bieje Schaaren im Frút)=

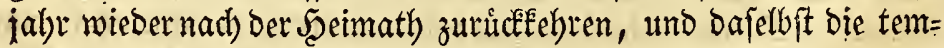
poráre $\mathfrak{U}$ rjache ihrer 2 tusmanderung gehoben finden, fo nefmen fie wieber ben alten $\$$ in $\mathfrak{B e f i}$, und wandern nid)t eber wieber aus biefer aus, bis biejelbe Utrjache fie aufz Neue bazu ziwingt. -

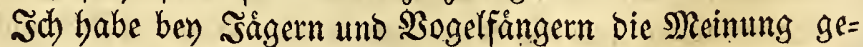
funben, baj biefe periobifche 2 uzwanderung allezeit nad) bem 
2cblaufe einerbeftimmten 2 (nzabl Sabre gejdeben follte, uno ba Ampelis garrula und Loxia curvirostra jedes ficbente Jabr

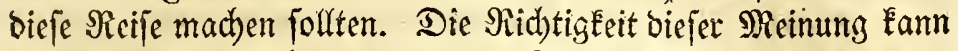
nid)t aus ber neutich vorgetragenen Entwidfehung lergeleitet mer= Den; meine (srfalyung bat fie aud) nid)t beftatigt.

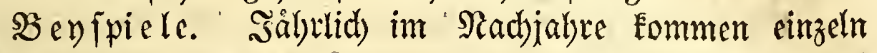
Anpelis garrula, Loxia curvirostra, febr felten Loxia enucleator, båufiger Frivgilua montifringilla uno Fr. flavirostris nad) Secland. Sm Sovember 1821 aber zeigten jid bie exften ba in grop̃er Nenge; die andern famen im December 1812 in groper Mienge nad) Diejer Sinfel; bie britten, von weldhen id). nur ein paar Benfpiele weip, bas fie borber in Secland find gefdoffen morden, zeigten fich ba in gropen Scaufen im Novem= ber und December 1817, und wurben uberall auf ber Snjel ge="

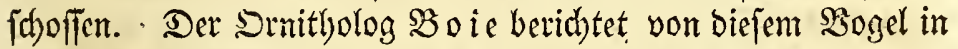

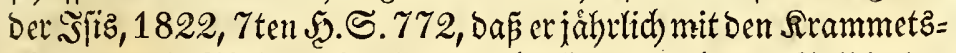
vogeln nad) Sittlano fomme; bod) ift Dies nicht ber Fall in ber (S)egend, wo id) wolne. Die vierte Eam im ssinter 1814=1815 in fo gropen Sibaacen nad) ber (Stegend um Sopenhagen, Dap fie beynah bie 3weige ber Báme bedecte, welche fïh unter Der Raft beugten. Die lesten biejer Beyjpiele zeigten jid bejon=

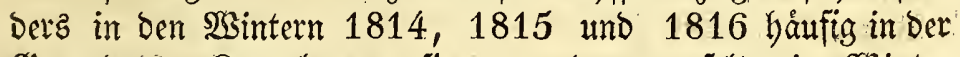
(Gegend von Ropenbagen; fie waren bagegen felten im SBinter $1813=14$, indeifen Fongilla linaria fid bamale in gropent Sdyaaten an benjelben Sertern befand, -

\section{§. 8.}

Esz ift zuwor bemerft worben, dap die borealen 3ugvógel ibre Secimath eber verlafien unb ipáter babin zurủckommen,

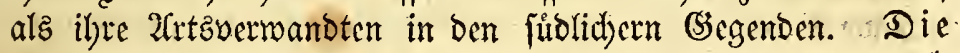
3uguogel aber berfelben Gegend wanbern aud nicht ftetz in jebem sabre andemjelben sage im Rachjabre aus, unblommen aud nid t an bemiel= ben Tage in ible Sommeraufenthaltzpláse zu= $\mathfrak{r}$ u ce: Denn obgleich oer Wbanderungstrieb fie jábulich zu ciner

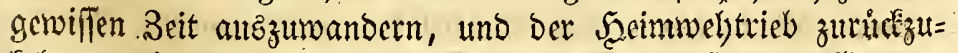
febren zwingt, fo ift bod biefe Beit butch feine fo enge (sirenzen

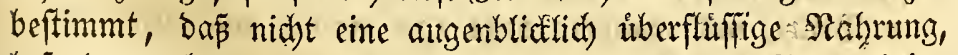
bejonders aber bie \&uftemperatur, fie bas eime Sabr einige Tage lánget zutudebleiben, ober einige Tage frubct antommen laffen follte, als in bem andern, wemnfie nur zut ber zur For'= 
pflanzung beftimmten Seit bey ibren Bruteplácen cintreffen. Sad) habe baher nie die Meinung (Giniger angenommen, bap bie 3uguogel jebez Salyr an bemielben Tage aufbredhen oder zurued = Fehren jollten, ba meine Erfalyrung biejer Theorie mebr wiber= fpricht, als fie beftåtigt.

Da $\mathfrak{E}$ vorzůglid) die enftemperatur i|t., die auf bie $\mathfrak{2} \mathfrak{n}=$ kunft ber veridhicbenen 3ugooget in einem Ranbe in ben ver=

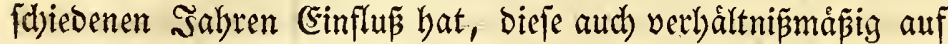
baz frubere ober fpátere (5rwachen ber im Sinterjh)lafe liegen= Den Thiere, und auf baj sluben ber Spllanzen wirkt; fo idbeint

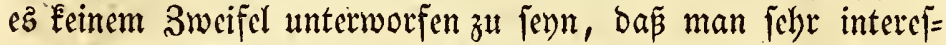

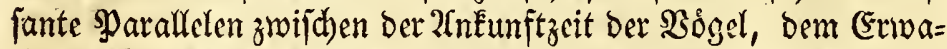
den ber im Winteridylafe liegenden Thiete und ber Bluttbezeit ber $\mathfrak{P}$ flanzen in ebendemielben $\mathfrak{a}$ ande zieben fonnte, wenn jorg= fáltige Beobad)tungen mebrere sabre hindurch baruber angeftellt

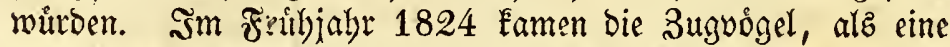

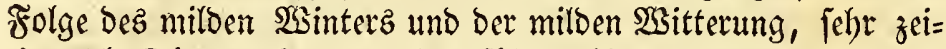
tig naid) Dånemark, uno obngefábr 8 biz 10 Tage frúlyer, als im Fritbjabr 1823, rold)eb auf einen ftrengen $\mathfrak{S}_{3}$ inter folgte. Sm erftbenannten Frubjabre fand ich auch bie Frubjabrpflanzen frủber blüben, âlz és bie in ben bånijhen Floren angegebene Blithezeit crmarten liế.

Sbgleid) bie Materialien nidht auz Der borealen Bogetzone bergebolt find, und alfo eigentlich nicht in bieje 2⿰亻blandlung

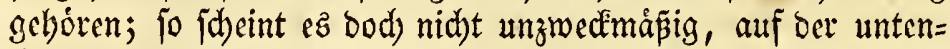
ftebenden Tabelle die Beobadtungen zu ordnen, weldse id in

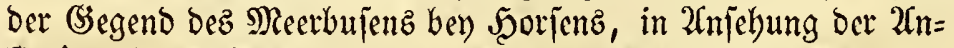

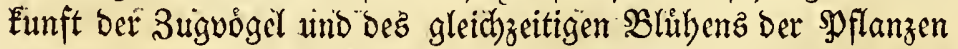
im Frůbjabre 1824 gemadyt babe, uno einzelne Bemerfungen

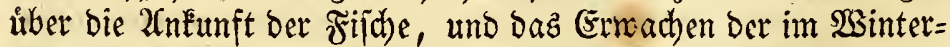

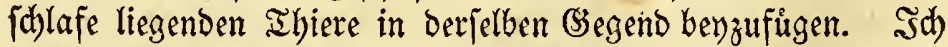
babe nut bic båufigen 3uguógel angefúbrt, weil man nur bey

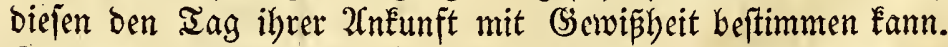
Die splanzen, weldhe idh an demjelben Iage, alš bie veridjie= benen 3uguogel antamen, blúbend fano, babe id) in ber $\Re u=$

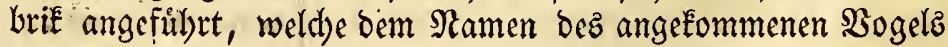
zur Seite fteht. 


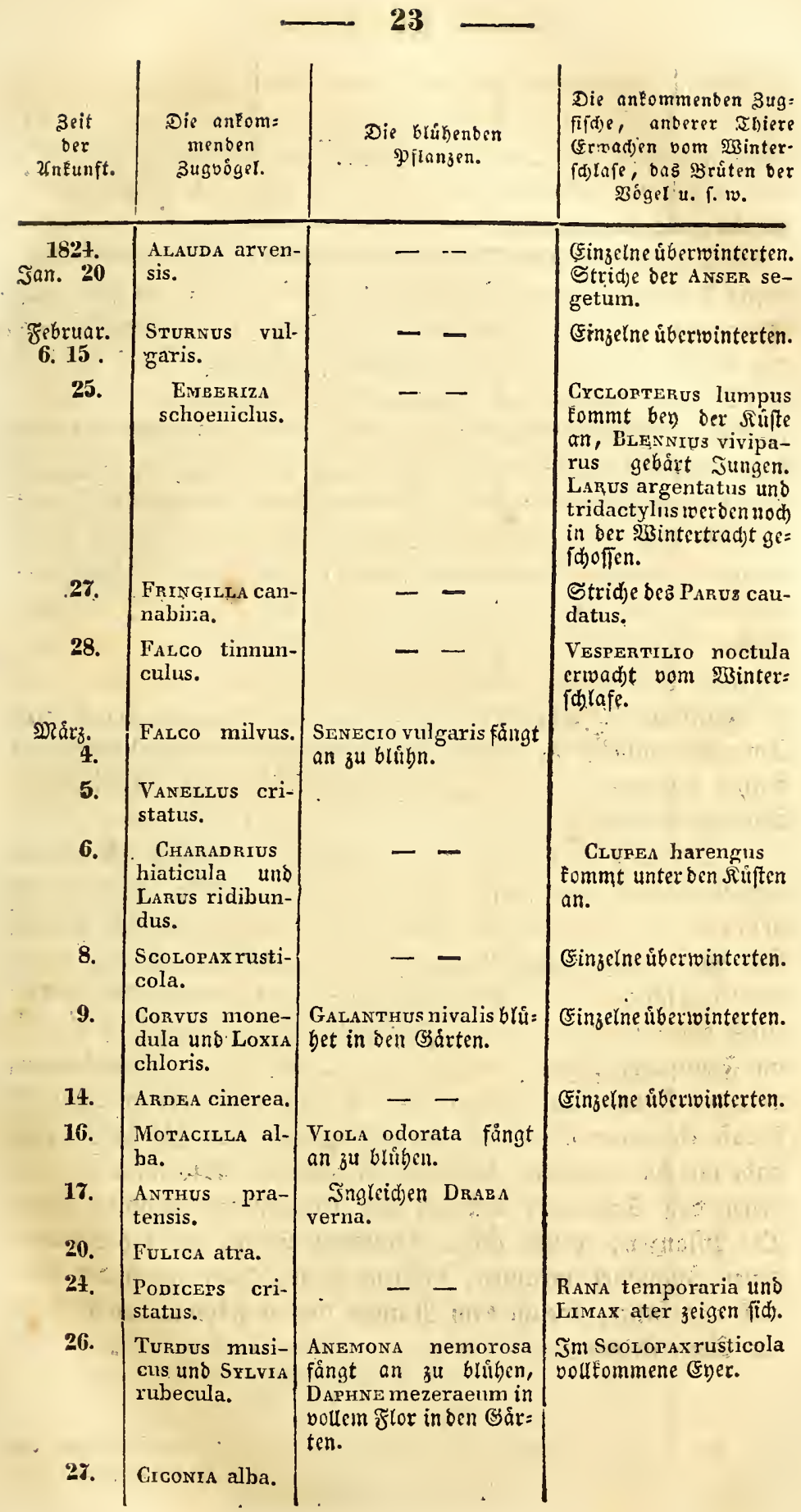




\begin{tabular}{|c|c|c|c|}
\hline $\begin{array}{l}\text { Seit bpr } \\
\text { Xntunft. }\end{array}$ & $\begin{array}{l}\text { Tie antommen = } \\
\text { bet âuguogel. }\end{array}$ & $\begin{array}{l}\text { Die Grifenben } \\
\text { פy flanjen. }\end{array}$ & 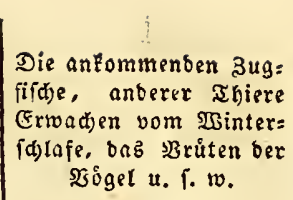 \\
\hline $\begin{array}{l}\text { Xpril. } \\
10 .\end{array}$ & $\begin{array}{l}\text { SAxicora oen- } \\
\text { anthe. }\end{array}$ & $\begin{array}{l}\text { Tussilago farfara und } \\
\text { PETAS1TES fangen an } \\
\text { zu blúgen. } \\
\text { Jm SSarten find Nar- } \\
\text { crssus pseudonarcis- } \\
\text { sus und Prunus arme- } \\
\text { niaca im flor. }\end{array}$ & 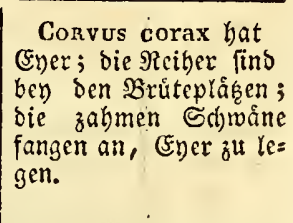 \\
\hline 20. & $\begin{array}{l}\text { Motacilla fla- } \\
\text { va. }\end{array}$ & 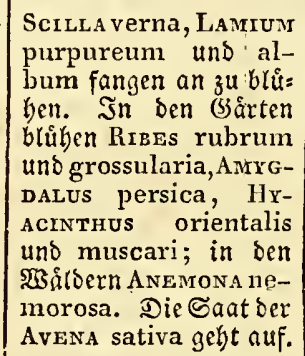 & 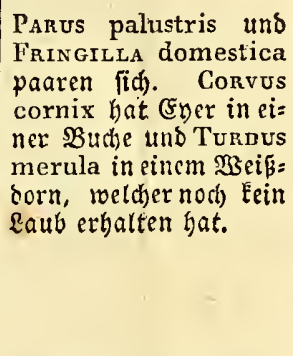 \\
\hline 22. & $\begin{array}{l}\text { STERNA arctića } \\
\text { und minuta. }\end{array}$ & 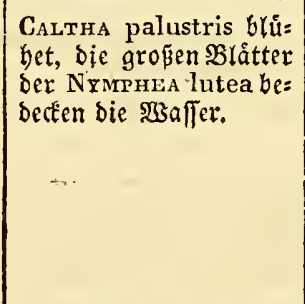 & 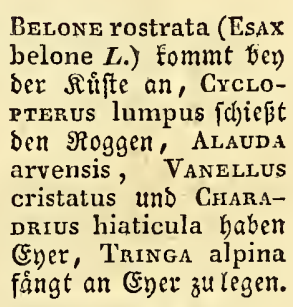 \\
\hline 23. & $\begin{array}{l}\text { Sruvia trochi- } \\
\text { lus. }\end{array}$ & $\begin{array}{l}\text { Orchis mascula in an= } \\
\text { fangendem, VIoLA } \\
\text { canina und Fragaria } \\
\text { vesca in vollem flor. }\end{array}$ & 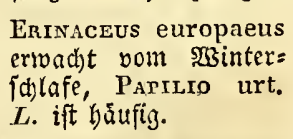 \\
\hline 24. & $\begin{array}{l}\text { HIRUNDo rusti- } \\
\text { ca. }\end{array}$ & 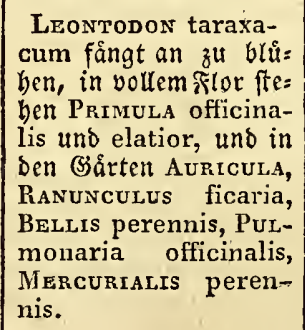 & $\begin{array}{l}\text { Dic lekten Anas marila } \\
\text { und glacialis find auf } \\
\text { ibrem 3uge nad) Porden, } \\
\text { Sturnus vulgaris bat } \\
\text { Eyer. }\end{array}$ \\
\hline 28. & $\begin{array}{l}\text { SrLvia phoeni- } \\
\text { curus, }\end{array}$ & $\begin{array}{l}\text { Carnamine pratensis } \\
\text { fangt an fut brufhen; } \\
\text { Fumaria officinalis im } \\
\text { flor. }\end{array}$ & $\begin{array}{l}\text { Columea oenas ferus } \\
\text { hat (Fyer. }\end{array}$ \\
\hline 29. & $\begin{array}{l}\text { Saxrcora rube- } \\
\text { tra. }\end{array}$ & $\begin{array}{l}\text { ORNITHOGaLLtU lute- } \\
\text { um, Alsine media und } \\
\text { HePATICa triloba blúben. }\end{array}$ & $\begin{array}{l}\text { CLuPEA harengus ver= } \\
\text { lápt die నúften.: }\end{array}$ \\
\hline
\end{tabular}




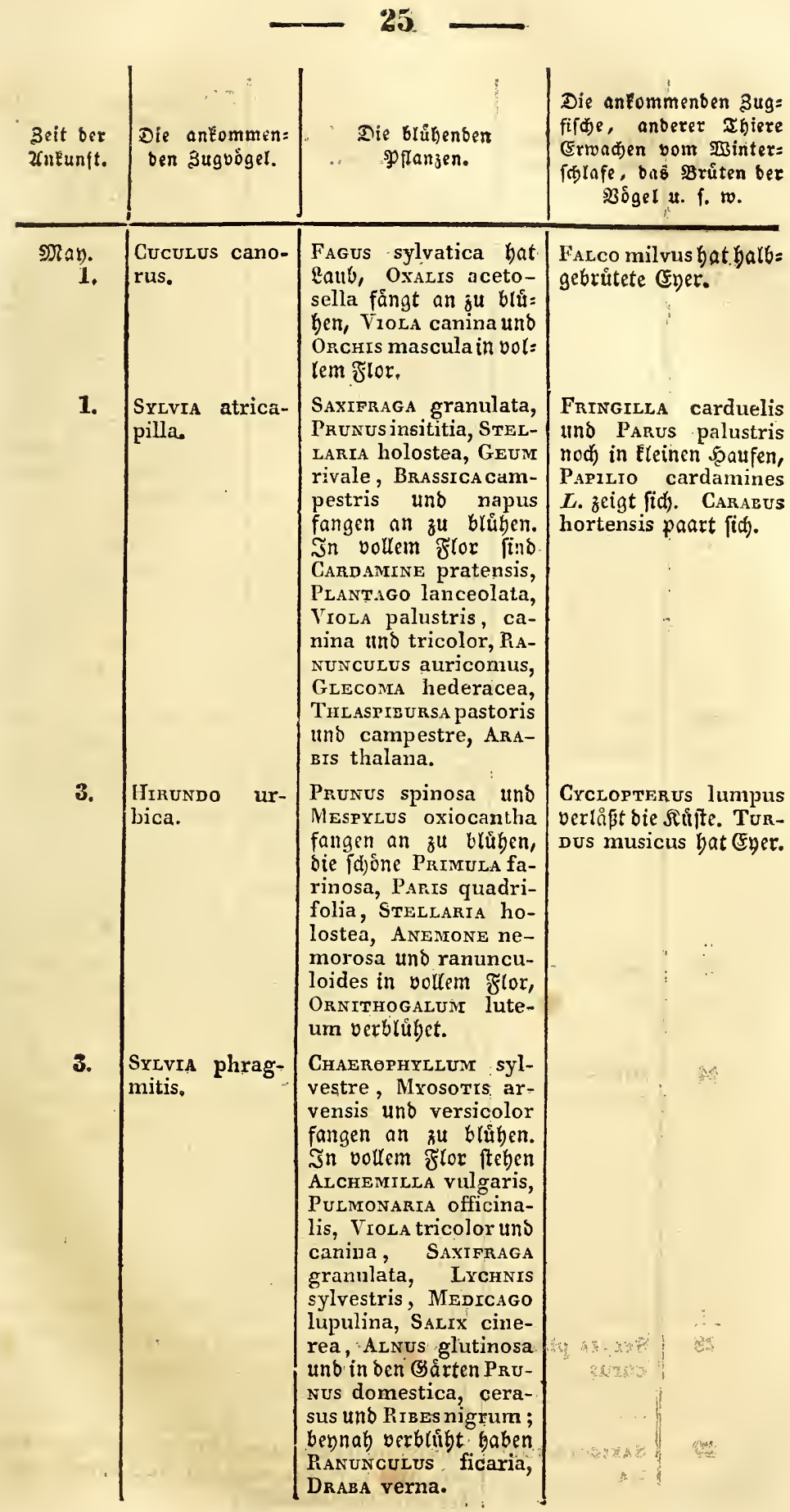




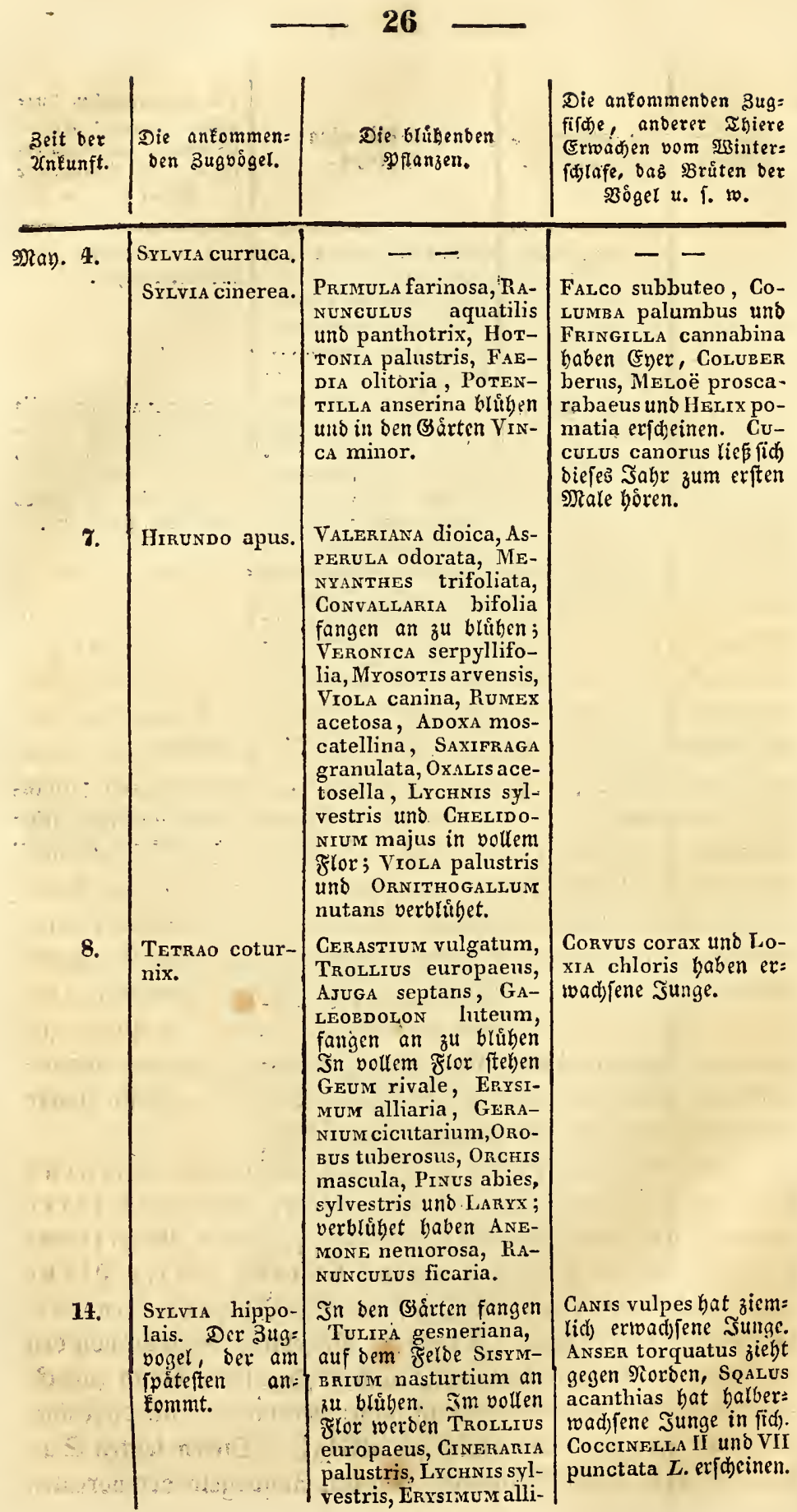




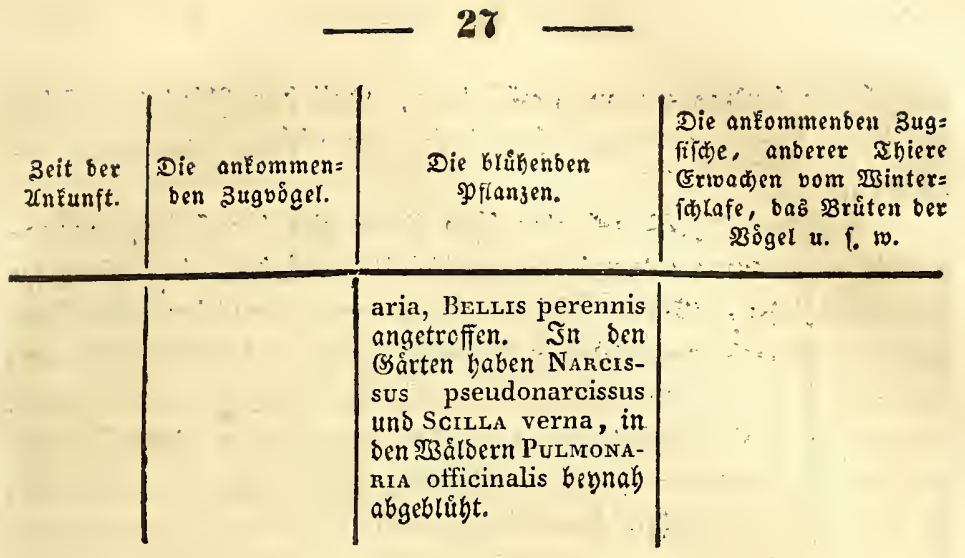

\section{§. 9.}

ud in einem and bempelben eande ift bas

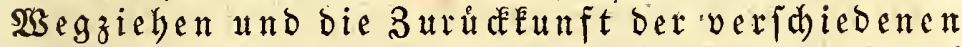
Arten ber 3 uguogel nad einer gemiffen 3 ugegel georonet, fo baj bie eine 2frt baffelbe entweder zeitiger, oder mit einer andern zugleid) verläpt, uno jith eben fo bafelbit mie=

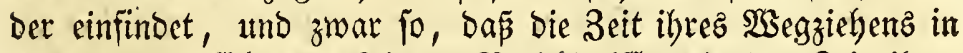
einem unter fid umgekebrten Berbåltniffe mit Der 3eit ilyrer

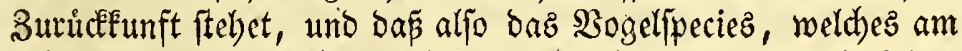
fpáteften wegwandert, auch am frübeften wieder zurủdffebrt.

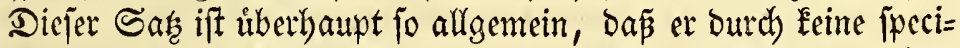
ellen Beyfpiele barf ertäutert werben. Eine jebe Bogelart nåm= lich erbielt ifren beftimmten primitiven \$laś, uno ihre ibr eigene \{uabreitung anf Dem Eroboden; je weiter nun bie Inoividuen ber

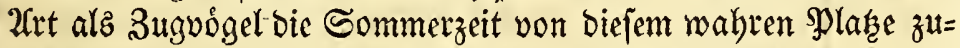
bringen, befto minder paifeno fur jie ift biejer Sommeraufent= baltzort, Defto elyer muifen fie ihn zu verlalien futchen, Defto fpáter Dabin zuricféegren, to wie auch umgefehrt.

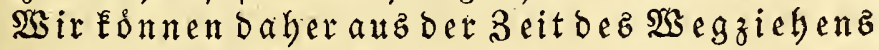
ber veridhiebenen $\mathfrak{B}$ ogelarten von, oder a a $z$ ihrer

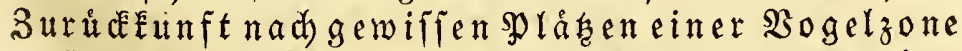
auf ben nảhern ober fernern 2 bftand biefer von bemprimitiven gla ce folder 3 aguógel in bie fer 30 ne falliepen. Denn bie Sogelart, bie fpát von ben

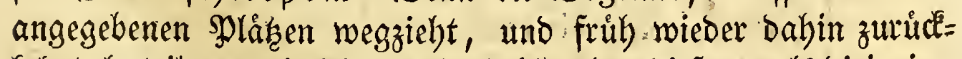

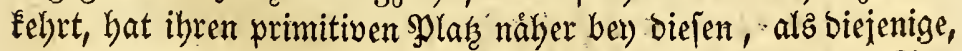

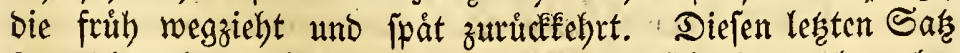

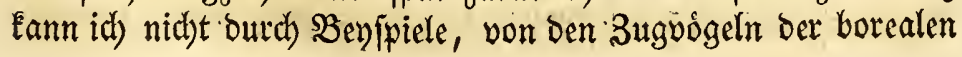


Bogelzone gergenommen, erláutern, weil ber \$ुlah ber Froe, mo bieje 3uguógel Standbơgel find, mir nidbt genau gemtg be= Eannt if́t.

Şättent alle Bogelarten ilgre Bone von bem jelben geogra= phijhen $\mathfrak{U}$ mfange angemiejen erhalten, fo wurben bieje Data zu

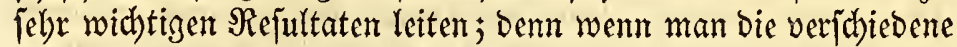

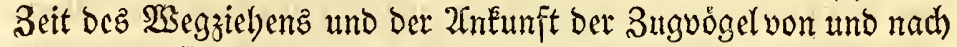
einem gewiffen Ranbe wúpte: fo wưrbe man in Den Stand gefeşt

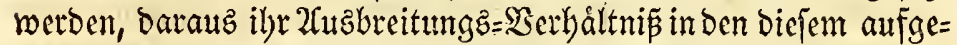
gebenen Rande gegen Norben liegenden (Segenden zu beftimmen; je fruber námlid ber $\mathfrak{B}$ ögel in bem aufgegebenen Lambe ankommen, und je fpåter er ez wieber ver=

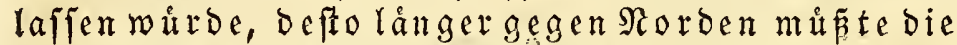
åuzerfte (Srenze feiner 3one fallen, und umgekehrt, befto weiter gegen ben Rorbpol múpte man aljo biefen Bogel an= treffen Konnen; fo wie man aud im Stande jeyn wutrbe, wenn

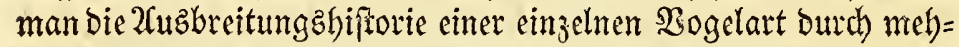

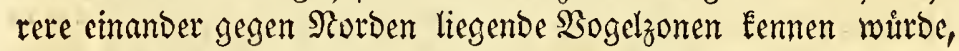

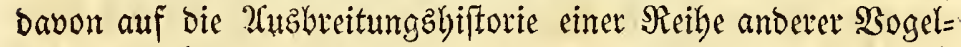

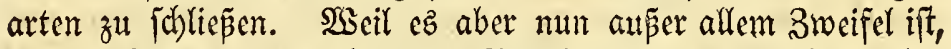

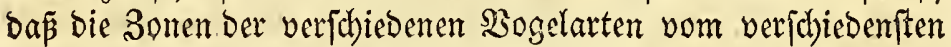

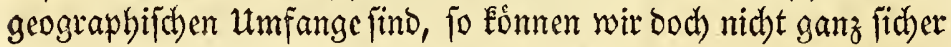

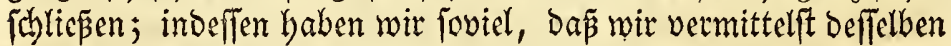
biöweilen zu ridbtigen Rejultaten geleitet werben Énnen.

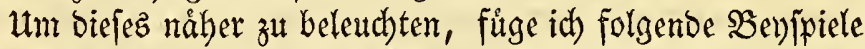

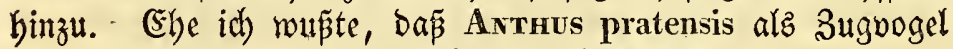

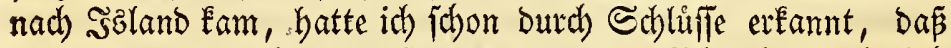

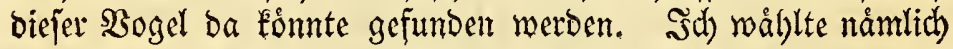

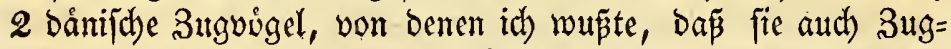
vỏget in šztand waren, námlidid Motacilda alba uno Saxicola oenanthe. Der (Erftere fonmt bey uns an bom 22ften

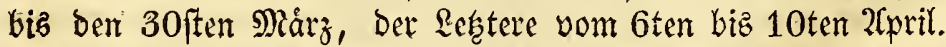
Da bieje beiben Singuoger jich als 3ugvógel in Saland einfin=

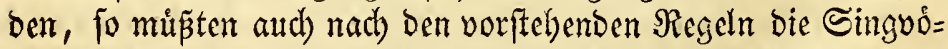

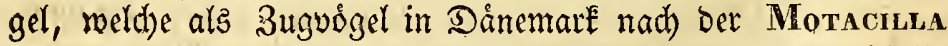
alba und yor der Saxicola oenanthe anformmen, gleidffalls

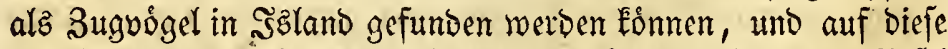
Sseife eben jomohl, als bie benamten 2rten bieje boreale জnjel zum Splate 1. $-x$ erbalten baben. Sndem idh nadboadte, fano idj, bap Sxivia rubecula, Accenton modularis und Turbus musicus fpåter, alz. Motacilda alba, und frủber, alz 
SAxrcola oenanthe in Dinemare antommen, naimlid yom 26ften Måz biz zum 4ten 2lpril. Dieje fonnte id) indeffen midyt

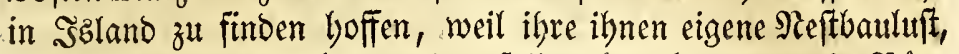
weld)e [pảterbin erflårt werben foll, námlich bey uno in Båu= men zu bauen, bajelbft nid)t befriebigt werben fonnte. Dagegen ift Antrus pratensis autch ein $\mathfrak{B o g e l}$, ber ben unz ankommt, ehe Saxicola oenanthe eriddeint, námlid) in ber britten 230 dhe

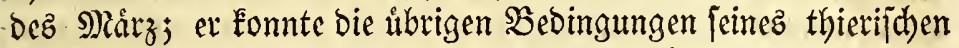

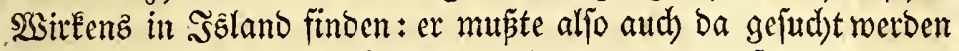
fónnen; uno als ich nad) Salano $\mathfrak{k} a m$, waro bieje (Evwartung erfưllt, inbem idj) in Arthus pratensis den angenelymften Sán= ger biejer ifolitten $\mathfrak{I}$ mjel fand.

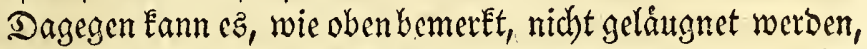

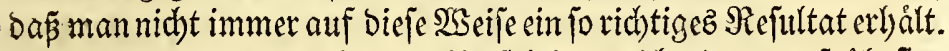
Demn Alaudn arvensis zum Seipiel, weldhe der am frủheften

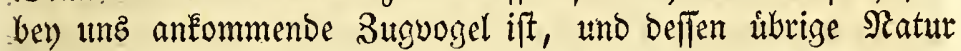

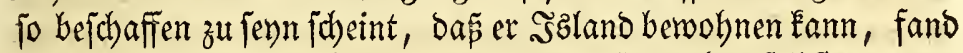

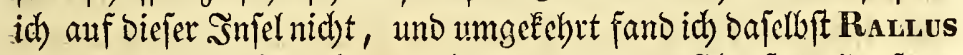
aquaticus, weldhen idc) ba nid)t ermartete. Ebenio. miberipre=

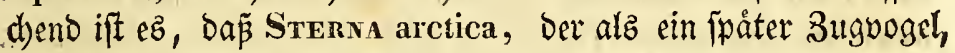

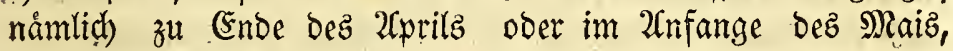
erft in Dånemark anfómmt, bod in gleid)er Menge jenjeitz bes Sুotarzirfets, wie bey unz gefunben wirb. - -

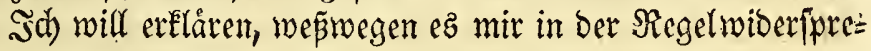
deno vorfommt, Dap Buguogel, weldbe fpát in einer Bone an= fommen, bod) bajelbft in Mienge und zuweilen allgemeiner, als bie in Derfellben 3one frủher anfommenden Bogelarten gefunden werben. Der Sogel ift als Bugyogel fofon außer Den Girenzent

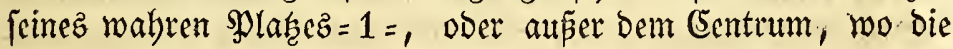

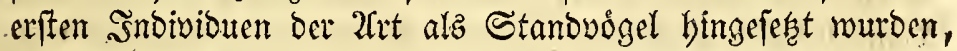
uno befindet fid) alfo in ben meniger begurnftigten (Segenben ber

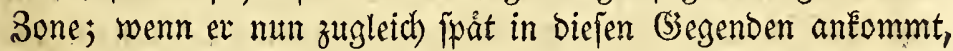
fo erbellt bierautz, bas er jegr weit yon feinem primitiven beften Mrage fen, uno weiter bavon ab, als bie Bugnobgel, welde frủber, als bieje 2frt an bemfelben şlase in ber 3one antommen. Da aber bie zut Berwobnumg minber bequemen spláf̧e nad) ei= nem richtigen $\mathfrak{S e r b a ̊ l t n i f f e ~ v o n ~ e i n e r ~ g e r i n g e r n ~} 2 \mathfrak{n} z$ ahl Inbivi=

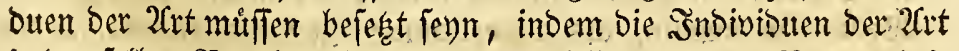

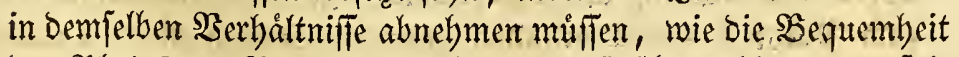
Des SPlaces zur Bewolynung abnimmt: fo fdheint bierauts zu fol=

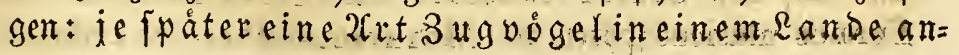


Eómmt, befto weniger sndiviouen mup fie aud ba= jelbit baben. Dodh fino ben biejer Siegel viele 2tusnabmen; eż ift unläugbar oft ber Fall, dẩ bie in ber borealen Sogelzone am frúbeften anfommenden 3uguogel aud bajelb fit mit einer gróseren Menge Inoivibuen gefunben werben, als bie jpåter añ= Eommenden.: Dấ aljo bie 3eit ber $2 \mathfrak{n} \mathfrak{k}$ unft im 2allgemeinen im birecten Berbáltniffe zu ber $2(\mathfrak{n} z a b)$ ber $2(n$ nfommenden fteht, bie beweifen zum Beifpiel verjofiedene 2frten Der Uria and Aras; bagegen finbet, wie gejagt, bas Entgegengefergte aud Statt. So find Sterna arctica und Phalaropus cinereus unter ben am jpåteften auf $\Im$ sland antommenden 3ugvoigeln, uno werben

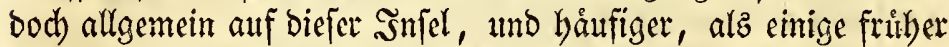
ankommende 3uguógel, z. B. Turnus iliacus, Saxicola oenanthe unb Lestris parasitica, ja jogar háufiger, alz gemiffe Standuogel dez 2 andez;; z. B. S. Lestris catarractes, angetroffen.

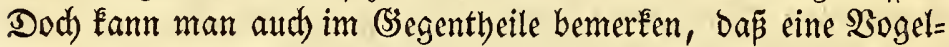
art an und für fid eine grósere Menge Sndiviouen, als eine an=

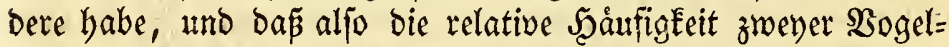

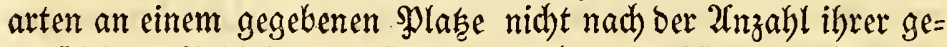
genjeitigen šnoivisuen, jonbern nad) ber abjolut exiftirenden

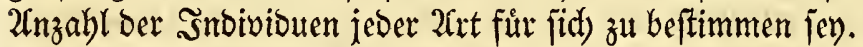

Fine Bogetart fann in einer 3one båufig, obne bod in berferben allgemein verbreitet fenn, und umgetefyrt. Die.2Afge= meinheit ibrer $\mathfrak{B e r b r e i t u n g ~ h a ̈ n g t ~ v o n ~ e i n e m ~ B e g r e n z u n g z ̌ v e r = ~}$

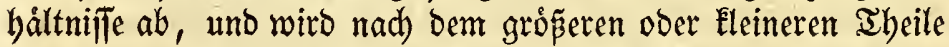
Der 3one, ber von ben sndividuen ber 2art befegst ift, beftimmt; bie Șånfigheit berielben bångt von einem Mengeverbåltniffe ab,

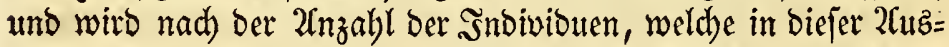
Debnumg leben, beftimmt. In ber borealen Bogelzone ift MarMos fratercula fowohl håafig, alz allgemein verbreitet, weil

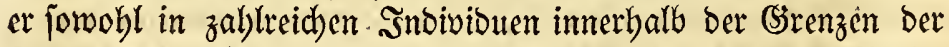
Sone, atz aud) unter ben meiften (šraben ber Rånge uno Breite gefunden wirb. Lestris catarractes ift in berferben hăufig, nidbt aber alfgemein verbreitet, weil er nut in Den füblichern und weftlid)ern (segenden, bann aber auth mit vieten Sndivibuten ba vorformmt; Alca impennis ift allgemein verbreitet, aber body jelten in ber Bone, weil er in ben meiften Molartándern, ůber= all aber mit jebr wenigen sndibibuten, angetroffen mirb; CaLIDris arenaria ift bajelbit Seibez jelten uno wenig verbreitet, ba er, foweit meine Erfabrung. reicht, in Eeinem andern europåa = 
folsen Syolartanoe, auper in SGland, gefunden worben ift; uno autd) ba nur in wenigen Indivibuen.

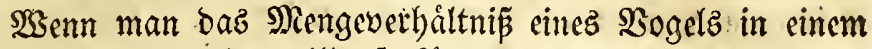
gewififen Lande angeben will, fo fơnnte nan Folgendes bemer=

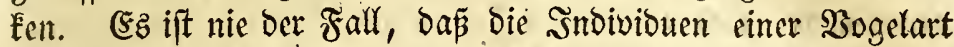
burth einganzes sand, obne Mruefefidyt auf bie Matur ber ver. jdjebenen Şegenben, gleid) vertbeilt gefunben werben follten,

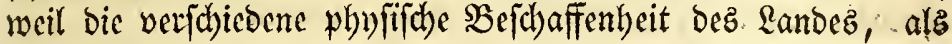

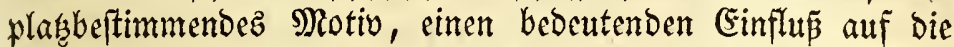

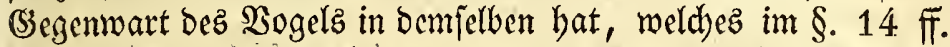
náber abgehandelt werben mirb. Main fann bie Bogelart mit Recht in einem gegebenen 2 ande all ge me $\mathrm{in}$ nennen, weldhe man mit (̧emwi man nad) jenen platgbeftimmenoen Motiven ihn zul futhen bered)=

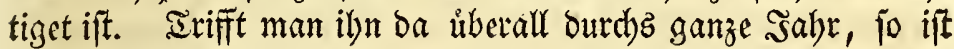
er allgemein als Standyogel; wirb er ba' nur im Sommer ge= funben, fo ift ex allgemein als suguogel. WSenn man an bies

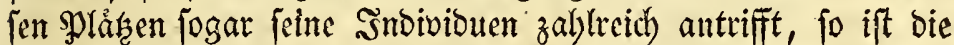

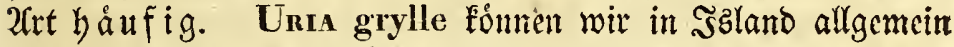
nemen, ob wir ibn gleid vergebens im. Snnern ber Sulfel fuchen wuirden; benn man kann allezeit gewiép jeiln, biefe Unia bey fteilen Meerufern anzutreffen, und mur in joldben Şegenden find wir auch beredhtigt, ihn zufolge feiner ihm eigenen Sieftult uno

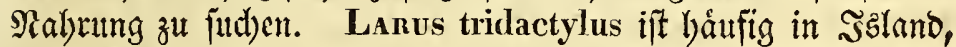

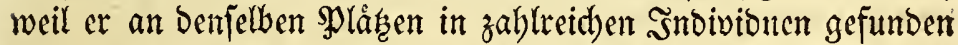

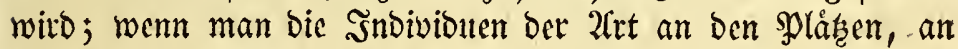
weld)en man fie ibuer Aatur narb zu futd)en bered)tigt iff, ófter nicht findet, als bas man fie ba-antrifft: fo benenne id) ihr $31 t=$ gegenfern im Rande burd): hin uno wieber; weldes mit. bem lateinifchen passim ủbereinftimmt. $\mathfrak{B}$ enn bie Indivibuen ber 2ret nur an ben wenigiten biejer sgláge gefunden werden, fo be= nene id) ben Bogel felten. In SElano fommt Tunnus iliacus bin uno mieber vor, Ratuss aquaticus aber ift bajelbft jel= ten. Sn Dånemark ift SIтta europaea allgemein, ob wir ify gleid) vergebens am Strande, auf $\mathfrak{B s i e j e n ~ u n d ~ S h e i b e n ~ j u c h e n ~}$

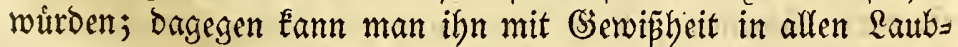
wăldern bez Ranbes finben, in welchen man audi) feitrer statur nach ilyn zu juthen beredtigt ift. Frengruma domestica ift fogar håufig in biefem Ranbe; Yunx torquilla fommet ljin uno mieber vor, und Sxlvia suecica ift ba felten.

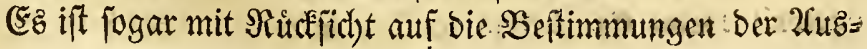


breitung Der Bogel úber ben (Eroboden nid)t unwidtig, bie Nengeverbăltniffe ber snbivibuen, welde jebe Mogelart an ver=

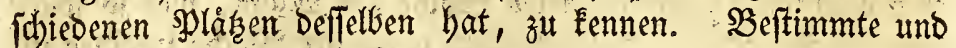

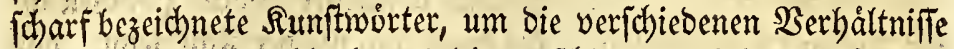
Der Renge, uno ủberbautpt bie verjdjiebenen sglaşerbåltniffe auszubriden, find eben fo unentbebrlid, als fie noch unter bie pia desiderata gehoren, ba ber geographifhe aheil ber \$rni= thologic nod nid)t fyftematifich georonet worben ift.

\section{§. 10.}

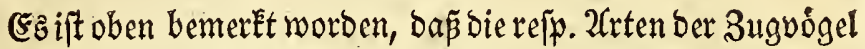

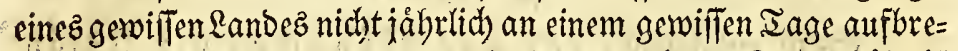
chen ober anfommen; be pewegen aber wiro bodb bas 3eituerbáltni Det SBanderungereihe, in weldher bie verichiebenen 2irten aus?

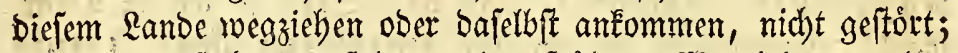

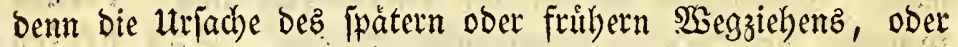
ber 2 TnEumft in ben veridhiebenen sabren, ift allgemein bey al= len feinen 3uguógeln, und wirft bal)er mit gleid)er Siraft auf bie verichiedenen 2 reten, fübrt aljo ben ihnen allen zu bemjelben Rejultate. Der widdtigfte (Stund, welcter ben Der einen 2 trt

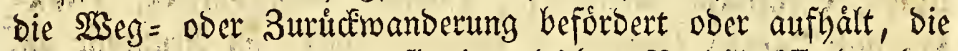
ssitterung námlich, wirb fie im gleichen Berbáltniffe bey ben iubrigen arten befórbern ober aufbalten. Daher gejdjiebt ç a ud nidbt, ba

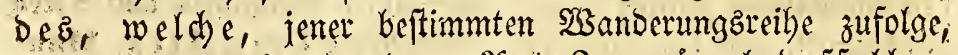
fruber, als eine andere 2 rt 3 ugoogel beflelben Eandes wegzieben ober ankommen foll, jemals fpáter yon ba wegzieben ober fruber baferbft an= fommen follte, als biefe, fo mie aud umgekefrt.

Beyipicle. Totanus calidris fommt in ber zweiten SSod)e bes 2(prils nad) Jälano, Chanadnus pluvialis in ber

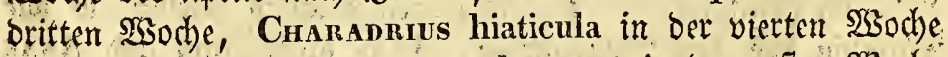

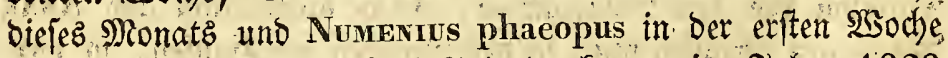
Des Mais. Die Zuguogel Jslands Eamen int Jabre 1820 einige, Iage fpáter an, als im sabre 1821, bod aber in glet= dem Derbáltnițe. Demn jo wie bie erften sndividuen bes ToTAxus calidirs im frubjabre 1820 nidjt eher, als in ben leeg=: ten Iagen ber zmeiten 250 dhe bes 2lprils ankamen, to Eamen. bie eriten snoivibuen bez Chananrius pluvialis aud nidte eher, als in Den lesten Iagen ber oritten sisod)e, bie bez CHa. hiati-

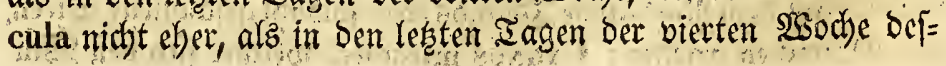


felben Monatz; bie bez Nux. phaeopus endlidj nidjt eber; als in ben lesten Iagen ber erften Kaodbe bez Manz; uno jo warb

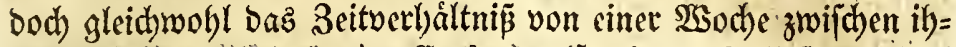

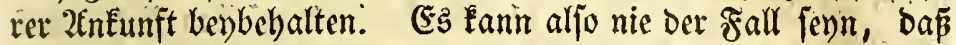

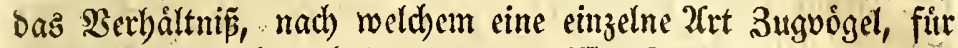
fich betrad)tet, jâllyrlich in cinem gewi ipen Lande antommt, je= mals mit bem Beitberbáltnifie, nad) weldbem bie ganze Reibe

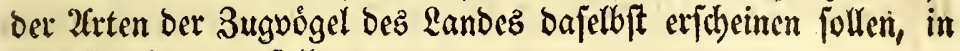
Eollifion fommen jollte.

\section{§. 11.}

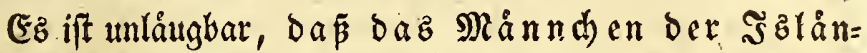
Difden Singuogel bajelbit im Frübjabre einige Tage eher ankommt, als die Sie, fo wie in Dáne= marke. Diefez babe id bey der. Motacilla alba, Anthus

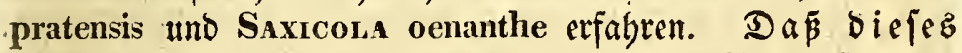
andererfeits aud ber Fall mit ben Sumpf = und Sd)wimmógeln salandz jeyn follte, baran zwei= fle id. Die J̈llandifhen 3uguỏgel ber (Befhled)ter Charadruus, Calidris, Numenius, Limosa, Strepsilas, Totasus uno Tringa fommen in Fleinen STaufen im Frübjabr an, von welden ich gleidh eben fo gut alte Sieen, alz alte Mainnd)en geid)oiten labe. Wsenn bic beiben 2frten Phataropus fidh an

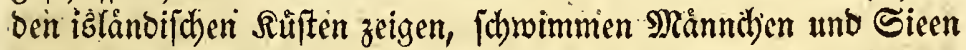
baufenweife zwijhen einander. Die 2frten Uria, Alca, Monmon, Carbo, Puffinus, Sula, Sterna, Larus, uno Procellanria, melde auf fteilen Meerfelfen britten, fommen im

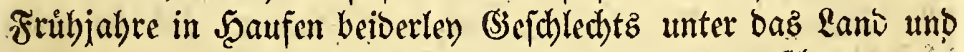

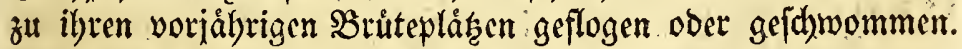

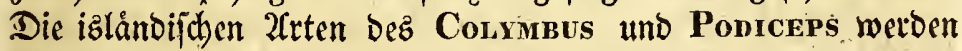
gleich im Frubjabre bey paaren in ben Butden gejeben, to wie fpảterhin bey Den Brưteplågren; Axas mollissima un Avas histrionica verlaffen fobon in ben Butchten bie Staufen, in wel= d)en fite im :Ssinter waren, und werben ba, elhe fie $z^{u}$ ibren Britepláken zieben, paarmeije berjammen gejeben. Die ben Mnvatn brütenden Enten uno Såger.fommen im fribjallere in gropen Scaufen bod in ber \&uft nach biejem Landjee geflogen, uno in biejen Saufen find eben fowohl Sicen, als Mändben; von den frủbeíten 3ugen ber Asser segetum und Arser leucopsis babe id) auf Dem Norblande Jzland seben fowohl gejhorfene Eieen,

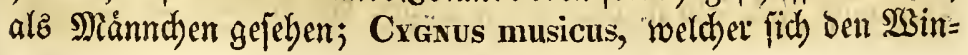


ter binbutth in Eleinen 5 aufen bey ben warmer 2 Eaffern und offe= nen Budten bes landes auflbalt, ziebt parmeife zu feinen Brú= tẹláąen auf den F゙elfen.

Die jungen $\mathfrak{B} \mathfrak{d} \mathfrak{g e l}$, melde in bempelben Salbre aus= gebrutet find, ziel)en feltener in (sefellid)aft ber $2 \mathfrak{C}=$ ten weg. Sie madien gern Şaufen fiul fich aus. (5ewodhn= lid) verlaffen diefe sungen ibre (s)eburtsgegenden fpater, und werben ba nod) langere 3cit, nadboem ibre (Eltern weggemandert fino, gefunden. Sie find nod) nie auper ibrer Seimath geweien; ber Sanderungetrieb war alfo bel) ilynen nod) nidbt wirffam. Sic zogern bal)er langer in ifren (Seburtb= gegenben, weil bey ibnen bie licbe zu ibler Seimath nod) unge= mijht ift. So babe id) auf neiner Sieife in Saland nod, am Ende Dez Decemberz junge 23ỏgel dez Ch. pluvialis, Totanus calidris uno Strepsilas collaris angetroffen. Suber jelben 3eit babe ich an Der Rirfte ben.jungen Monmon fratercula gejd)offen, uno ben jungen Ponicress cornutus gefehen. Die jungen Enten

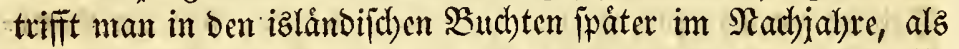
oie 2 tten an. Die junge Sterra arctica batte ben meiner $\mathfrak{A b}=$ reije von Şzland 2 utzgangz September biefe snjel nod) nidbt ver= laflen, obgleid) bie 2(lten fchon feit beynab cinem Monate weg waren.

\section{§. 12.}

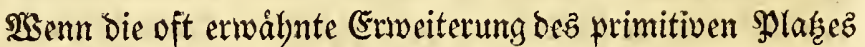

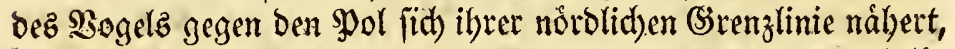

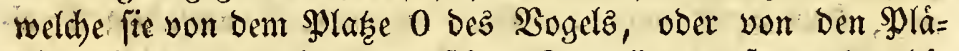
fen fijetbet, wolthe auper feiner 3one liegen: fo werben bie Iñivibuen bes Bogelz nad) und nad) faltener, bis fie gailz auffoiren. Sn. Dem $2 a n d e$, in weld)em, um bey Dem gemáblten

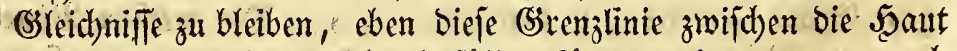

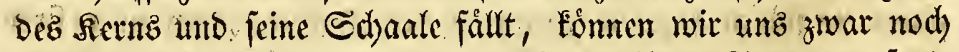

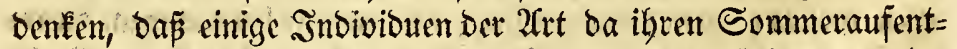
baltsort fudjen; , da aber bie (Sirenglinie bas 2uffornen ber be= grenzten Bone ift, fo minten fie bod) biefe (Sirenze ibrer. Sone wieber verlaffen, obne bajelbft ibre Fortpflanzung anz̧ufangen.

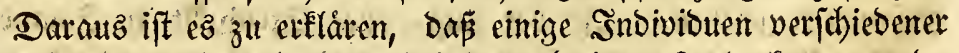

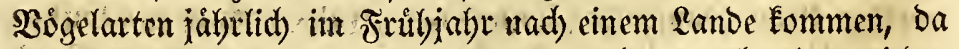
gleidfá Subereitungen zum Bruten mad)en; bod) aber wieber berjaninden, obne ez fu thun. Diefe sndibibuen Eonnen mid)t

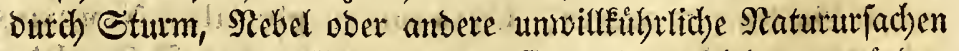
in bieje Gegenden gefübrt worben fenn, benn alsbann woinden 


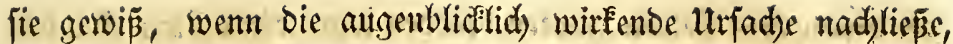
Dieje wieber verlafien, und am wenigiten bajelbft Bubereitumgen zum Sruiten mad)en. So gelyt bie (Stenzllinie bev 3one einiger

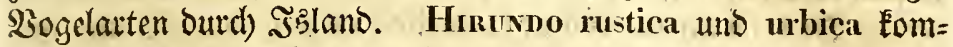
men jåhrlid in verichicbeme (siegenden ber Jamel, balten fid) paat= weife zu ben Şåufern, verid)minden aber wieber, obne cin Mieft gebauet zu haber. Vanelcus cristatus zeigt fich bajeben Som= mer, ziel)t aber wieber fort, obne ein $\mathfrak{A l e f t}_{\mathrm{t}} \mathrm{gel}$ )abt zu lyaben; we= nige \$aare ber Furica atra fommen jábrlid) nad) bem jitoliden

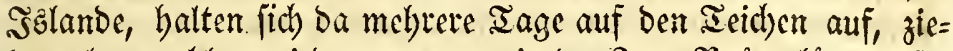
hen aber nachler wicber weg, um in ber Bone Britepläge zu fu= d)en, weldebe nidjt in ber Ssrenze berjelben liegen. Dieje Injel

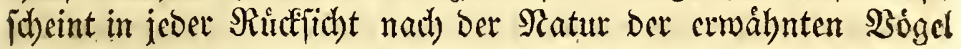
eben fo bequem, als Norwegen unter berjelben Breite, wo we= nigftens einige biejer 2lrten ben Sommer zubringen, und bod)

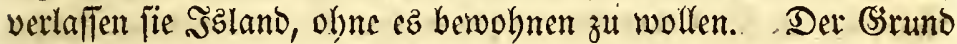
bingegen, warum Andes cinerea, weldhe fid) audd in gewifien Jabren im Sommer eingeln in Jaland zeigt, bieje Injel nicht zur 2 Sobnnung wåblt, muifen wir zum Ibeil aus einer ganz an= bern suefle berleiten, wovon. fpáterthin wirb gerebet werben.

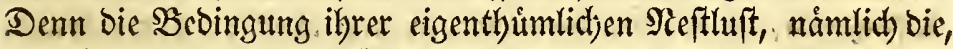

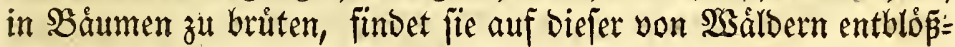
ten Şmfel niddt.

\section{§. 13.}

Sein Irieb madht ben Bogel ficheter unb vorifidtiger, als ber $\mathfrak{a s a n d e r u n g s t r i e b . ~ S o g a r ~ b i e ~}$ Bogelarten, weld)e, obme

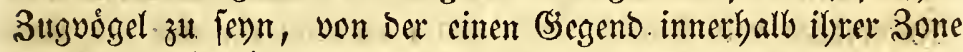
zur andern ftreichen, bel weld)en aljo biejer Irieb in jebr gerin=

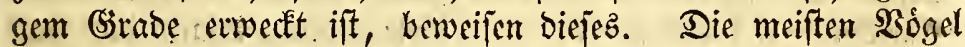
jammeln fich in Şaufen, wenn fie entweder wanbern ober ftrei= chen wollen; wenige halten fid familienneije bevjammen, bie.we= nigiten manbern einzeln. Dod glaube idh, baj biejez z. B. Det

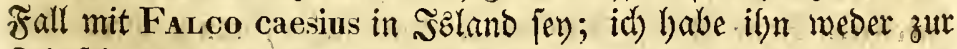

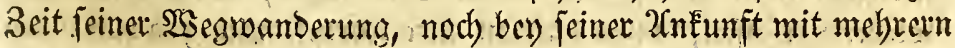

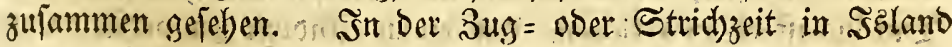

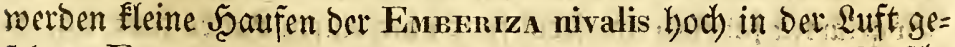

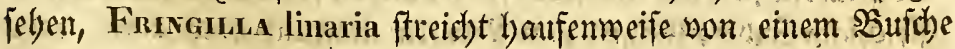

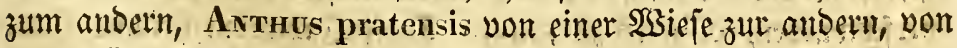
eimem Sarten zum amben, Charanries pluyialis, Nemenges phaeopus uno Limosa melanura, weldbe ben bem giefte fid ben 


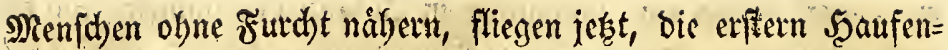
weife, bie beiben leģtern entweder einzelin ober wenige benfammen,

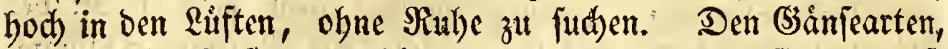
weldje beym Sefte eine foldese 3ahmbeit zeigen, baj fie um baf= Felbe herumlaufen, indefien man fie itgrer Ener beraubt, Eam

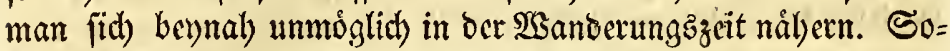

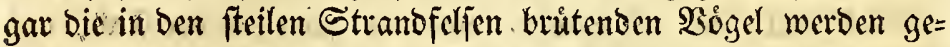
gen Den Winter vorfichtiger. Stur bas istandifhe Sduneebubn,

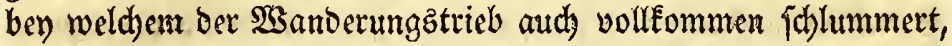
ift zu allen \$abreszeiten unoorfichtig und zahm.

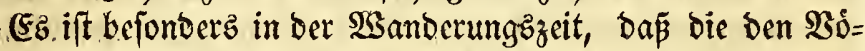

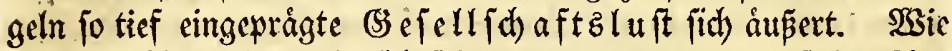

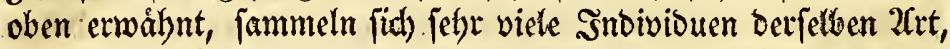
zuweilen aud) mefrerer 2 rten, um gemeinf(h)aftlid) ibre $2 \mathfrak{s a n =}$ Derungen vorzunebmen. (Eş ift bekannt, in weld)en ungeheuern Sdjaaren z. B. Chanadrius pluvialis, Tringa aỉpina, FrivGrila montifringilla, Eмвенuza nivalis uno methere reandern,

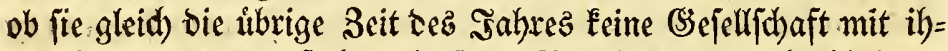

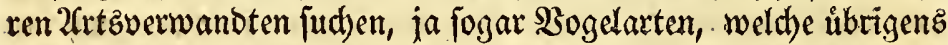
fidj einanber. zu nábern fid ficheuen, bereinigen fich in ber $.25 a n=$

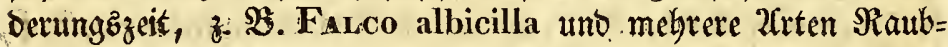

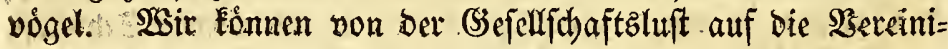

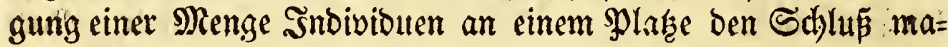
den, aber nidbt allezeit umgefehrt von ciner Sammlung sndivi=

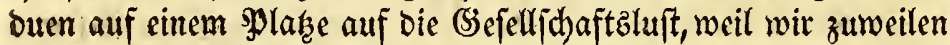

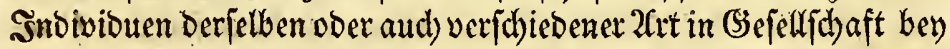

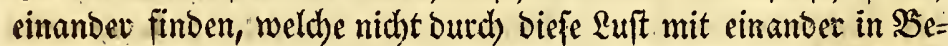

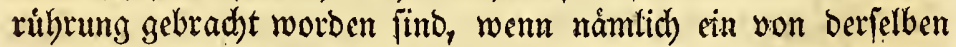
unabhängiger brittex: Ssegenftand jebes einzelne ber Indivibuen auf bemfelben :sounct gelodit hat; biefe werben baher nidgt aus

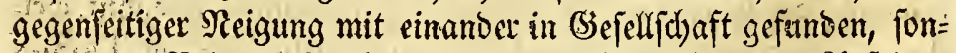
been aus Reigung zu jenem britten Bsegenftande. 2Guf bem

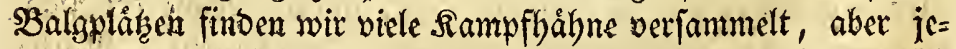
Der (Einzelne berfelben ziebt nach biejen \$olágen; tum fid sime fid)

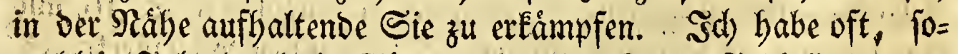
wohl in 'szland, als in Dảnemark, eine Menge Snotviouen von Convus corax mit eimander in (sefellyduaft angetroffen; id be=

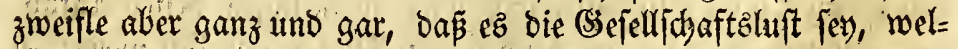

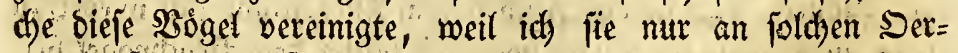

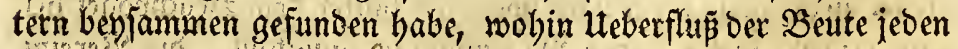

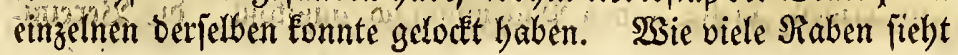




\section{- 3 r}

man nid)t bey ben Fif wetteiferno bie weggeworfenen Eingeweide, veer bie getroctineten Fif he wegnehmen. In Dảnemart fielt man fie oft ben

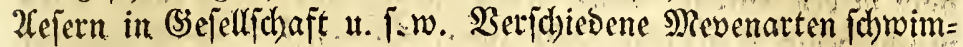
men in ber Sábe ber (Enten unb anderer Tautder, um an ibret aufgebolten Beute. Iheil zun nebmen. -

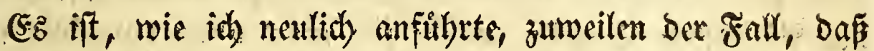

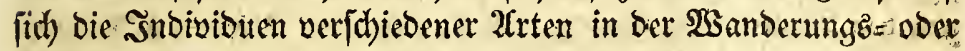
Strid)zeit in Scaufen vereinigen, $j a$, baj bie Inbivibuen ber cimen

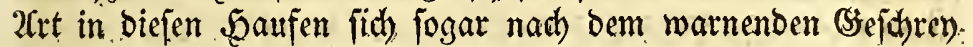

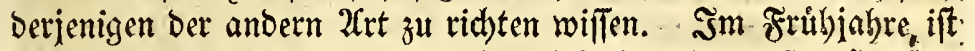

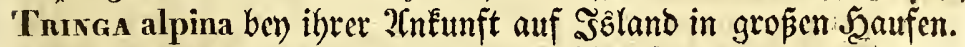
3wijthen biejen befinden fid autd getn einzetne Charaprivs hiaticula,Strnepsin as collaris,'Totavus calidris, oder, obgleidy feltener,

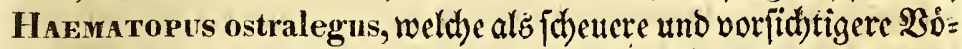
gel, alz die erfftbenannte Trixga, eher eine fid) nåbernoe (Sefahe

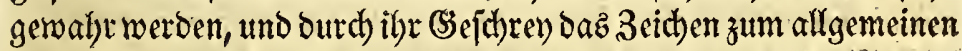

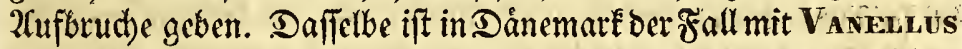
cristatıs, 'welcher fich vom Zfuguft biz zum Setober zwijd)en grope Jeaufen yon Chanadnus pluvialis mifatt, uno butch fein

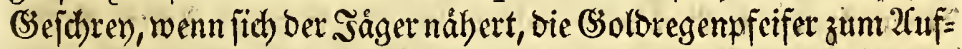

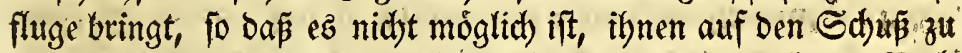

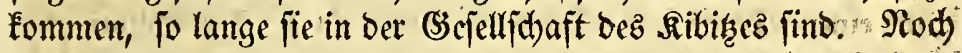
fpåter, im Sadjiahre, fiebt man biejen lestern unb ben Golbre: gempfeifer in (S)efellif aft mit Stunnus vilgaris auf ben Geldern, uno bejoribers im Fruibjabre ben lefgten, mit Jaatfen von Convus cornix vereinigt, bem $\$$ fluge folgen, fu weld)em Lanus canus jiid) żumeilen gefellt.

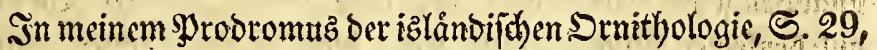

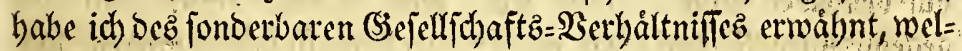
dees zwifden einem einzetnen Chanadrus pluvialis uno Tringa

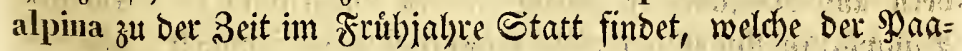
rungszeit bes 'Sradbogels unmittelbar vorlhergelt. Mohr

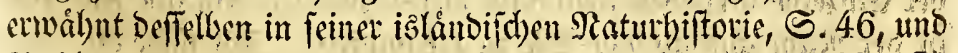

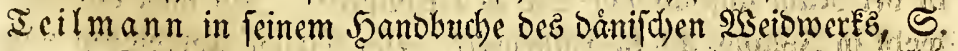

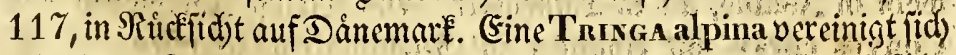
mit einem Cuar. pluvialis, uns wiro, jo zu fagen, beflen $2(n f i f)=$

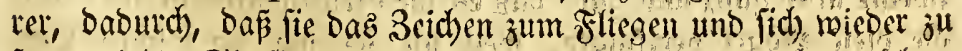
ferzen giebt. Sie fliegt bald vor, ball binter bem Brad)ooger her,

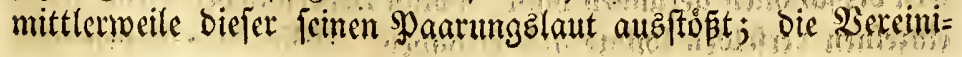


gung hoot aut, wenn ber Ģolbregenpfeifer feine Ģattin gefunben

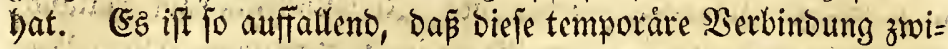
fiden diejen beiben Sogelarten ber Tringa alpina bey Sebermann

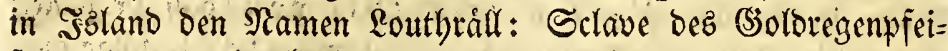
fert, zumege gebradth bat. -

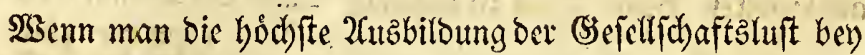
ben norbifachen Soigetn, weldye fich nidbt allsin temporár in ber 2Sanderung szeit, fonbern aud) in ben lubrigen Beiten bez Salbres,

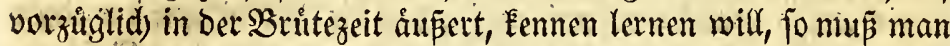

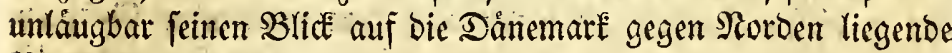
Siogelzone bimwenden.

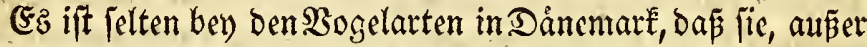

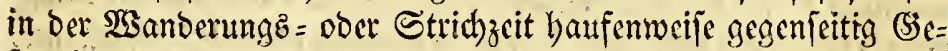

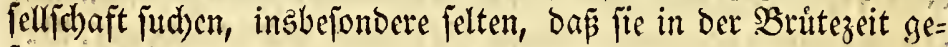

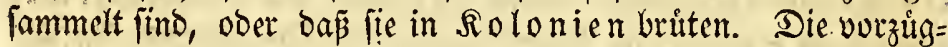

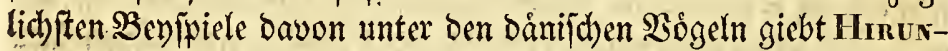

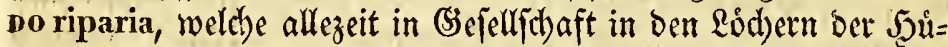
get brittet; Conves frugilegus und Arnea cinerea, von wel= den viele Snbivibuen auf Demfelben Baume ober auf bidht neben

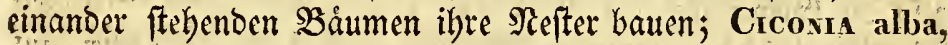

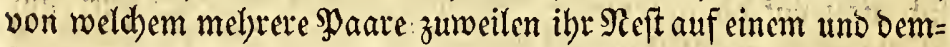
felben Dadbe lyaben; die 2frten der Stersa, inabefondere Stenra arctica und cantiaca, zum Iheil die bánifchen 2frtên bes Lanus, bejonbers argentatus uno ridibundus, welche fidt) cinzcine Flectem auf 2serbern und snjeftn wåblen, wo fie bid)t neben ein= anoer Eyer legen. Daß̃ es nidbt ein britter Şegenftand allein

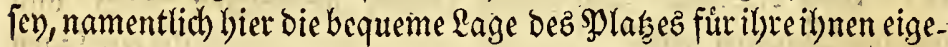

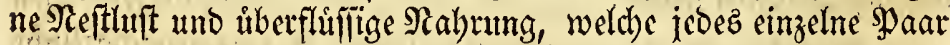
an benfertben \$lats gebract)t bat, fondern bie mirfliche \&ufft, in

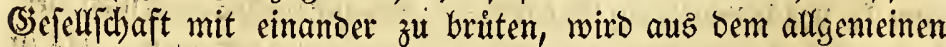
Interefle abgenommen, weldhes fo zu jagen jebes cinzelme Mit= gliés der Folonie fúr bie Sidjerbeit ber ganzen Jólonie hat, uno ause ber Unuthe, weldhe in Derfelben ent feht, wenn ein cinzelnes Intiviouum in Sefalbr fommt. Dagegen fenne idh atto eige= ner Erfabrung Ecine Bogelart in Dánemark, weldbe fid mit an= Dern, als ibren 2frtsuerwandten in Folonien fanmelt, $\mathfrak{t}$ m bruten. Es ift wobl eben to intereliant, alz auffalfeno, da

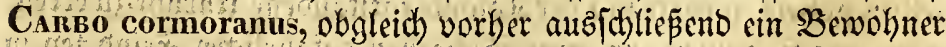
cimer fremben Sone, fich nun zugleid in ben létenten Decennien in

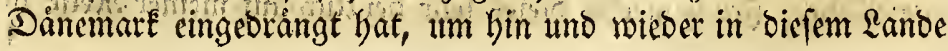




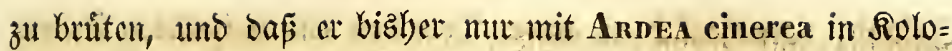
nien brùtend gefunben worben ift. In Miuffict) auf Laflano,

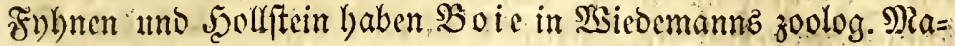
gazin, $\mathfrak{B}$. 1. Et. III. S: 150 , und $\mathfrak{B l}$ um enbad) in feiner Echifift de quormulam animantium coloniis, 1823 , idjon bie= fes bemerkt. 2(ber idh Eeme audh aus eigner (Erfabrung bieje Set=

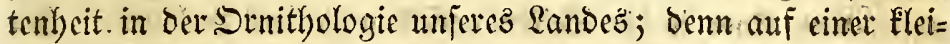
nen Snfel-2ibeloë, in bent See bey Ekanderborg; auf welchev eine

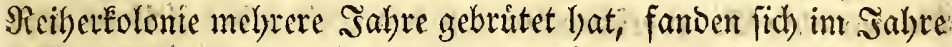

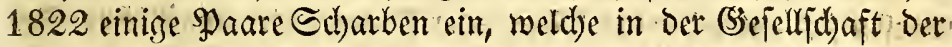
Rieiger briteten; im Sonmer 1823 waren fd)on mebr, als 100 \$aare diejez Canbo in ben Băumen auf biefer Smjel: Daffelbe ift ber Fall aut einter Eleinen mit SBåunten bewadjenen. Imiet in

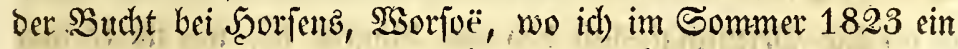
Paar Carbo cormorames zwijd)en einer nid)t unbebeutenden $\Re_{0}=$

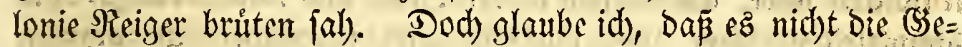
jelljdjaftsluft fen, weld)e bieje Ed)arben. fid Bruteplatąe in ber Rábe ber Reiger auffuchen láp̃ ; im (segentheile, bin ich virl cher Der Meinung, auf weld)e fich aud) Boic 1. c. Geztebt, bajp bie

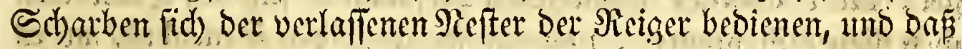
alfo bie (Semeinjd)aft biefer beiben Bogelarten in ber Britesent fid) nidgt auf bie gegenfeitige (Sejellfhaftzluft, jonbern eber auf bie ibnen eigene Rejthut gruinbet.

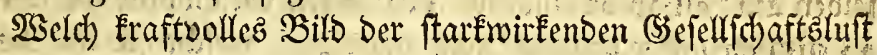
baben wit bingegen in ben brittenden $23 a$ fletwogeln bes boben

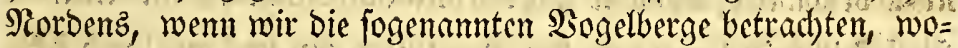
feibft in einem fortlaufenden fteilen Felfen am Meete fid viele

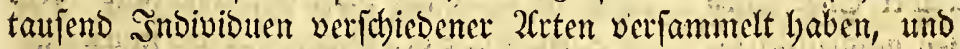

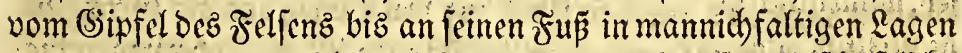
unter cinander vermijcht auf (Evern liegen. Der gemeinichaftlidse

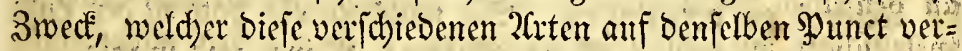
fanmelt bat, facheint fie in Sine Familie zu vereinigen. Es ift gleithfallz auffallend, wie gut biefe verfdicbenen 2 riten, weldhe

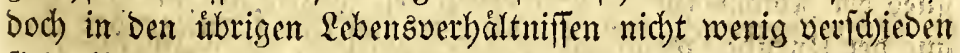

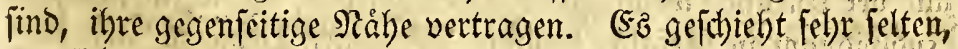

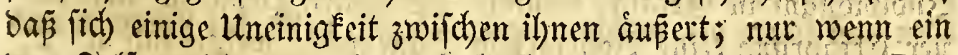
Dem Feljen nicht angehorender (Saft, 3 . B. Convis corax, LEstns catarractes ober parasitica, in raubgieriger 20 foicht fich bem= ferben nábert, giebt bie in Der Solonie entffanbene Unrithe zu erten=

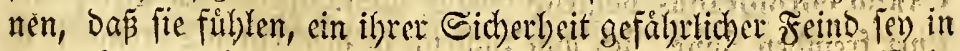

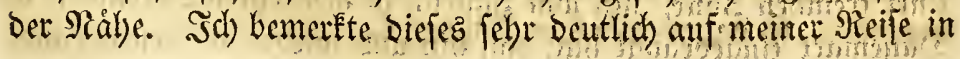


Şland, vornebmlith an einem Srte bey einem ijolirten Feljen;

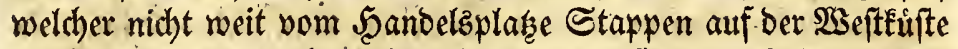
yon Şlano, Fenfrecht bidht am Strande ftebt. 2utf Dem (3ii= pfel biejer Sdjeete, weld)e \&oonorangar genannt wird, batte FaLco albicilla fein Neft; bod batte bieje gefábrlidbe গáabe eine Menge Una troile, Alca torda umb Lanus tridactylus nidbt abgebalten, Eyer in bie Seiten beflelben Felfens zu legen. Se=

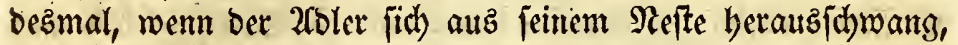

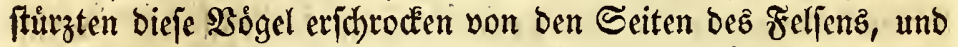
warfen fich entweber ins Reer, ober flogen unter ángftlid)em (Ses= faren umber. Da ber 2oler fid) oft von bem Felfen beraug= fdwang; to batten bieje Sdwimmoógel leidht einen iubigern Brưteplás finden Eónnen.

Die (Sejellfchaftzhuft bey ben $\mathfrak{B o g g e l n}$ ift, wie idh ez num entrwidelt babe, am meiften in ber Brit= uno $\mathfrak{s a n d e r u n g} g=$ ober Strichzeit wink fam, boch wirkt jie auch augenjebeinlid zuweilen

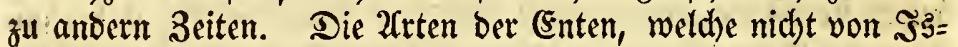

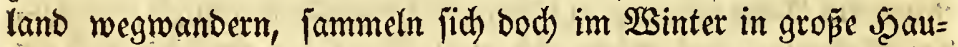
fen; bas islandijche Schnechuhn verjammelt fich bely Şunberten in berjelben Sabreszeit, unb baz jogar in ben (3egenben, no es

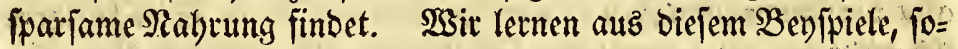
wie aus vielen anbern Erfabrungen berjelben 2Trt; bap bie (Sejeff= fidaftzluft im Eollijionsfalle ben biefen Geidbopfen bie Ruft an fiberflífigen $\mathfrak{R a b r u n g s m i t t e l n ~ b e z m i n g e , ~ w e l d b e ~ f i e ~ v i e l ~ l e i c h t e r ~}$ crbalten Eonnten, wenn jie fich, um biefe aufjujuchen, zerftreuten.-

Die Bógel wandern ber Regel nad) von uns meg, uno fel $)=$

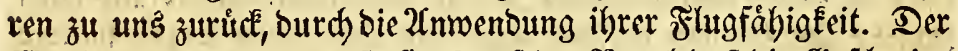

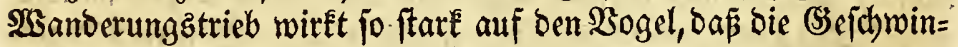
bigkeit.jeines Flugs mut allein im Stande ift, oie Foberungen bie= fes Triebez zu befriebigen. Sie wandern oft hoch in ber Luft

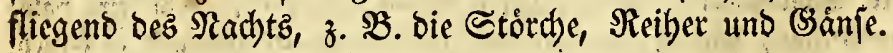

Als eine Folge biejer Regel nebme id) autb) nicht an, baß

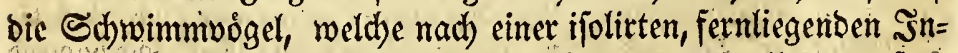

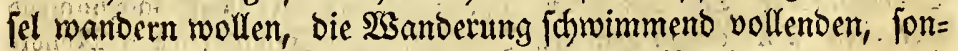
Dern bas fogar bie, weldhe ungern fliegen, z. B. bie \&ummen uno Steipfíne, fliegeno uber bas Meer zieben, uno erft, wenn fie fid) ibrex Sccimath auf einige Meilen genábert baben, fid inz Meer werfen uno bem Stranbe fdyimmeno nåbern. Der cinzige $\$$ Der borealen Bogelzone, weldber nicht fliegen Eann, námlid Alca impennis, ift baber auth Eein 3uguogel. 
Sch bin biefer Neinung, weil man fehr felten in ber 3 utg= zeit $\mathfrak{B o g e l}$ im offenen Meere viele Neilen vom Lande fiswimmen fieht, und bann nur foldhe, bie baz Meer nidht verlaffen wolken. (Es ftinmt audd nidbt mit ber $\mathfrak{Q} a n g$ ameeit ůberein, mit weld)er bie

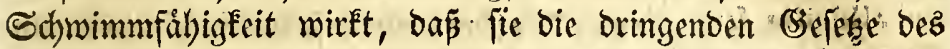

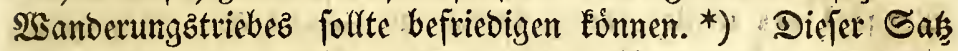

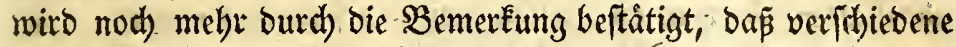
Sdhwimmbogel, von weldhen man' glaubte, bap fie felten unb

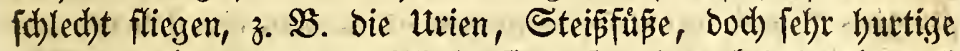
und ziemlidh auzhaltende Flieger find, fo wie aud) baburd, oa fo viele Eleine Singuogel im Stande find, uiber biefetben weiten Meere zu fliegen. Dagegen ift ez unlåugbar, bap̃ bie ziełbenden Schimimmbogel, weldhe im Stande find, fith nid)t allein bes (Ele= mentz ber suft zu bedienen, fondern audb bez \$leeres, um fich

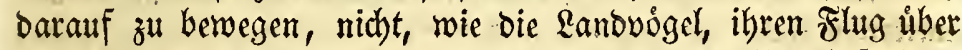
bas Meer umunterbrodyen beendigen, fondern zumeilen, bejonder's wenn fie ber Şunger zmingt, fid ins Meer werfen, uno bann

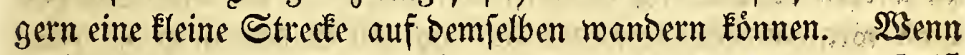
foldhe rondernde Sdimimmógel unter bas $2 a n d$ Eommen, fo if

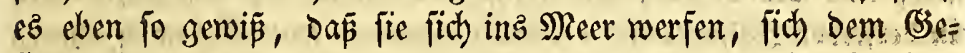

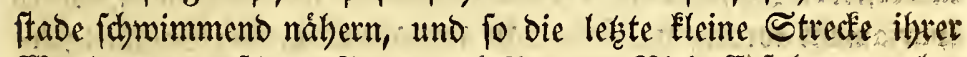
şanderung auf Dem Meere zurudelegen. Biele Erfahkungen be

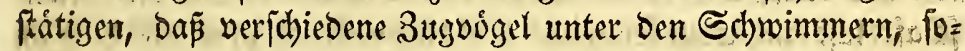
gardic Pralanópus-2frten, in ber $2 \mathfrak{s a n d e r u n g z z e i t ~ w e n i g e ~ M e i - ~}$

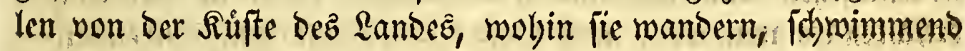

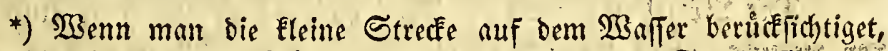

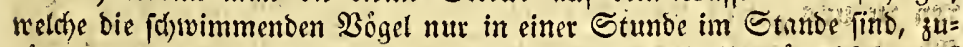

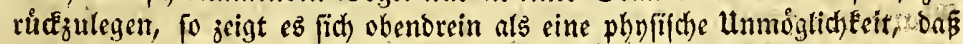

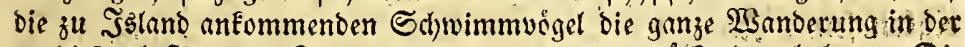

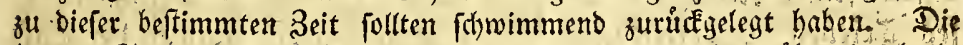

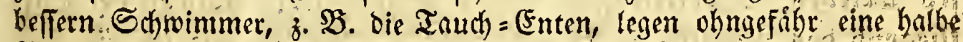

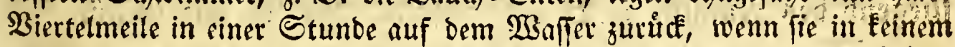
gereigten Zuftande find, bieß̄ macht 3 Meilen in-24 Etunden; vor Dine=

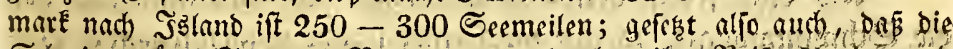

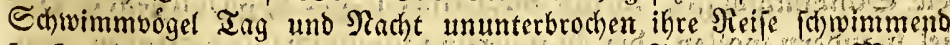

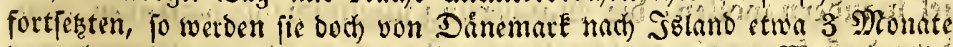

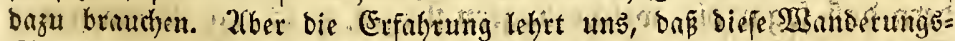

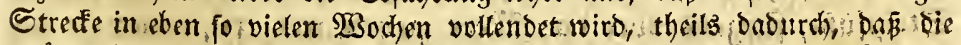

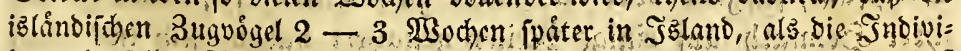

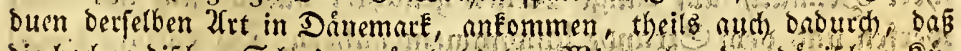

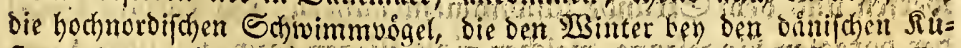

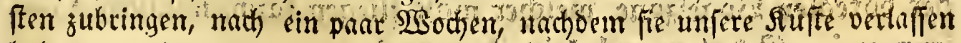

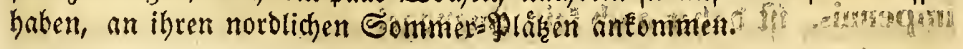


gefunden werben, und id) Eenne feinen nach Şland fommenden Sd)rimmvogel, der unter Der Kanderung unmittelbar nad ben Bruteplázen im Rande felbft flóge, obne baj er vorbel erif an bev Siufte fdowimment gefunden wirbe.

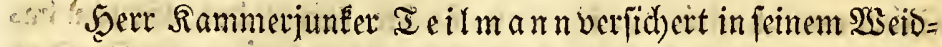
werte, $\subseteq .99$, den Şoloregenpfeifer, Thrva alpina und mebrete.

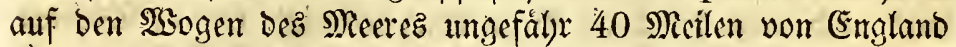

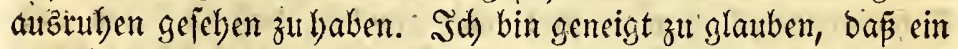
optifuber Betutg zu biejer Reuperung Des Berfafferz bie Meran= laffung gegeben babe, ba bieje $\mathfrak{B o g}$ el unter bem Friegen oft $\mathfrak{B D}=$

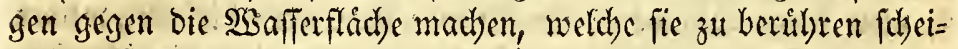

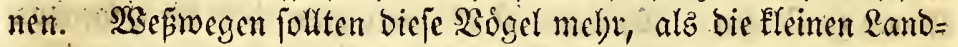

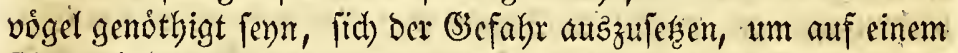
frumifoben Elemente, wo fie nidht zu Şaufe geboren; autszu= ruben?

2utd) Die ůber bem Rande wanbernoen Rogel vollenden

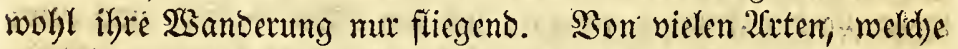
wit unter ber $\mathfrak{G}$ banderung bemerfen, wiflen wir biejez mit (Se $e=$

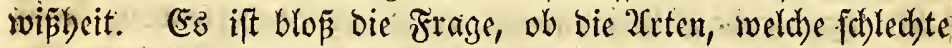
uno unwillige Flieget find, z. $\mathfrak{B}$. Galdrnola crex, RaLLus aquafieus, nidht randern, inbem fie mebr laufen, áls fliegen. Şr. $\$ 3 r e b m$ und mebrere Srnithologen nelymen biejez an. Sad wirbe jebod) geneigt fenn, bas Entgegengeferte zu glauben, benn

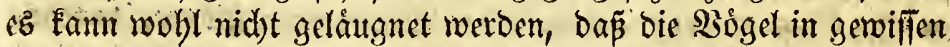
Ridhfungen wanbern: und biefe fonnen mut bann von oenjel ben genau befolgt werben, wenn fie aus ber \&uft bie (Gesenltán= be; het weldbe fie hinwandern, ůber fdauen fónnen; aud wirbe bie Natur vielet Siegenden bie laufend wandernden Bogel zwin= gen, bebeutende Itmwege zu machen, und baburd) bie SBande=

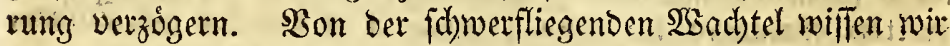

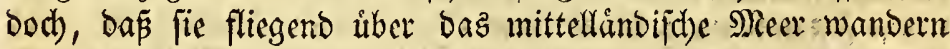
Eann. -

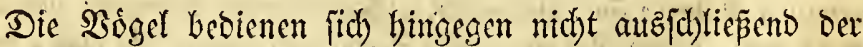
Flugfábigkeit, wenn fie als Strichvogel zum ltmberftreich)en $\mathbb{R}_{\text {uft }}$ befommen; bern ba bie umberftretbenden 2 sogel nicht an eimen gewiffen beitimmten $\mathfrak{H}$ lats bin zu fommen verlangen, auf weldbem fie fid zu einer gejeften Seit einfinden follen, fondern mur lin und wieber umbermandern, wo fie ibve Niabrung an reidblidften

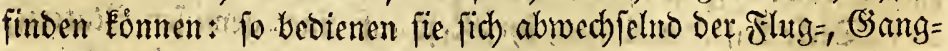

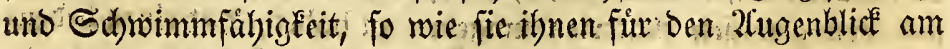
dienlidyften find, um ibren 3wede zu ereedden. So fiebt man bie 
umberftecichenden Singudgel, z. B. bie Panus - 2frten, Sruvia regulus uno.mehrere, von einer Stande ober von eincti Saume zum andern fliegen, bierauf auf bemfelben berauf unb binab: Lau=: fen, uno nadylyei ben Strich forteeren. Colymbus glacialis uno Aras histrionica ftreid)en ebenfalts im Madjiabre fdwwim=

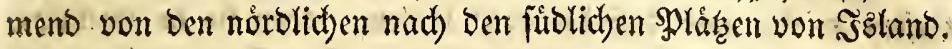

\section{\$. 11.}

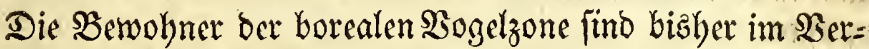

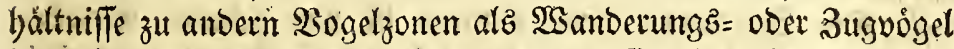
betrachtet worben, in ber Folge werben fie aber als $\mathfrak{B}$ ewobner ber borealen Bogelzone felbit, ohne Rilefficht auf die anberen $30=$ nen, bel)andelt werden.

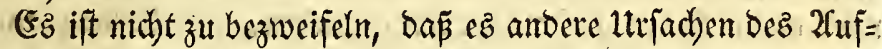

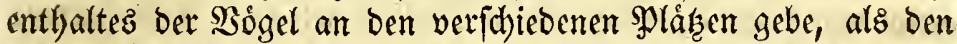

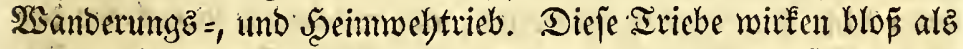
unwiberftebliche Naturgefese, wenn ber 20 gel atz feiner (Seburtszone berauz = und wieber in biefelbe zuturctgetrieben werben forf: Sie werben bagegen nidt in Bewegung gefert, follange der Bogel, obne bie (Sirenzen feiner Zone zu übertreten, als Stridjoggel in berjelben umlleriut. Die Mrfaden, weldye bie

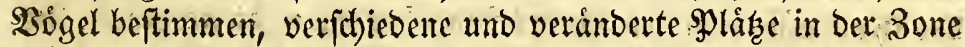

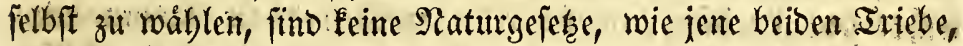

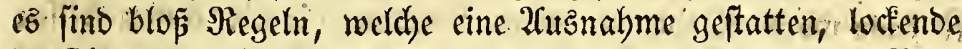

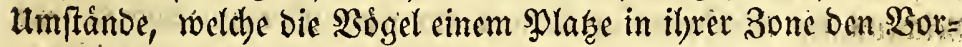

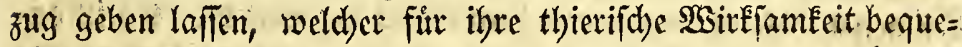
mer, als ein anberer zu jelnn id)eint. Dieje ltrjadyen, roeldhe bie

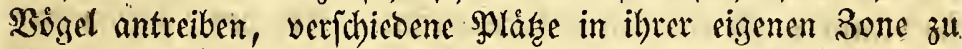

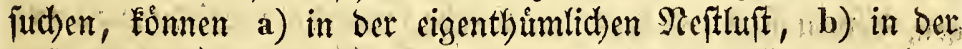

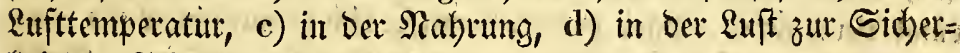
heit vor Feinben gegrumbet jeyn.

\section{§. 15.}

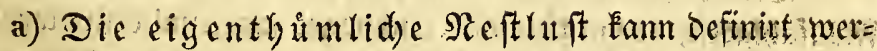

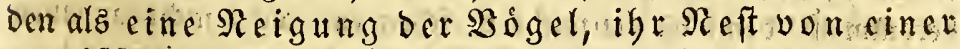
gewiffen Materie zubauen, jo wie ibre (sper auf einer gewiffen Materie unb unter ber umge= bung eincr gewiffen $\mathfrak{M}$ aterie auzzubriten.

Diefe Ruft ber 20 gel, ify Reft auf eimer gewiffen Materie,

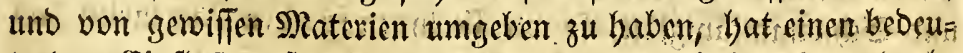
tenden Einflus auf bie Bertheilung in ibrer Sceimath, und ob: 


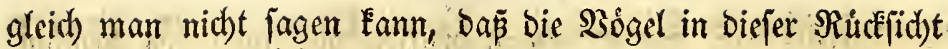
burd unbegninglide Saturgejege gebunden feren, weil nid)t fel=

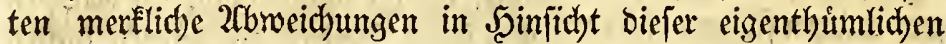

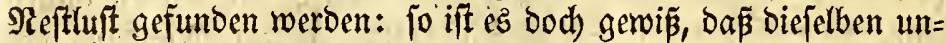

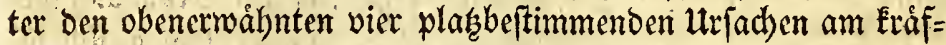

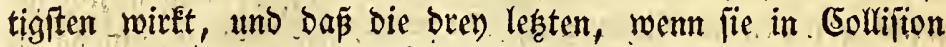
fommen follten, biejer weiden mújen. Der Saks wirb, wenn

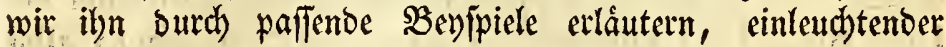
werben.

Die Srimath eines Sogels ift von feimem Srute=

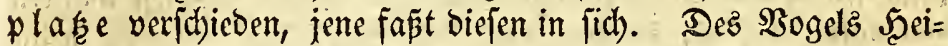

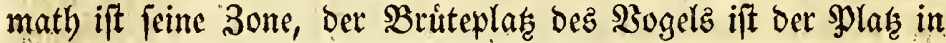
ber 3one, an weldbem er fein Meit hat. Radh feiner Seimath mirb er burd ben Sceimweltrtieb getrieben, zum Bruteplase zu=

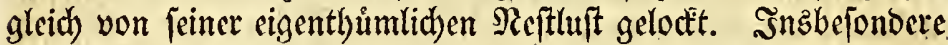
find ez bie umgebenden Raterien, auf weldhe Der Bogel ben ber

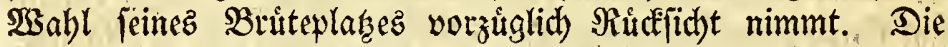
išlänififhen 2frten ber Sogelgattungen Uria, Arca, Mormon, Cambo, Puffinus, Sula, Sterna, Larus uno Procella-

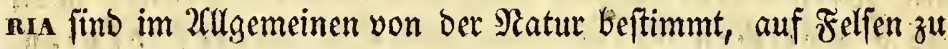

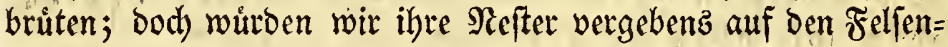
wånden im ' Snnern bes Randes fellbft fudden, nidjt einmal an ben fijobrciden Landfeen, wojelbift bie meiften biejer 2arten wenig=

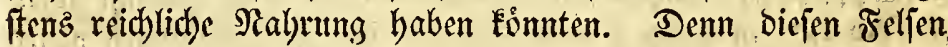
mangelt bie notljwendige $\mathfrak{u m g e b u n g}$ vom Reere, weld)es jene Zrten gemóhnlich ungern aus bem Ssefid)te berlieren. Es ift $b a=$ ber auf ben vom Meere befpurtten Felien, auf weldyen wir bie

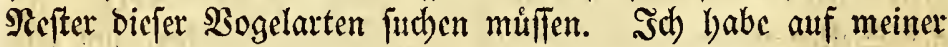

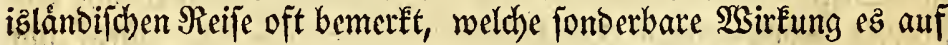

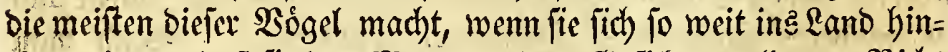

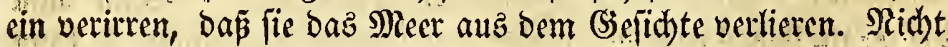
nur bie Eurzfluggelidten. Uris troile, Alca torda uno Monmos fratercula, jondern aud) bic außgezecidneten frlieget Suba alba umo Procellaria glacialis, vertieren augenblictlid) ocm (5) $\mathrm{c}=$

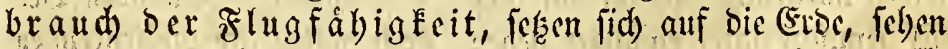
verwirtrt um fid her, uno laffen fid mit Sảnden greifort, Da fie

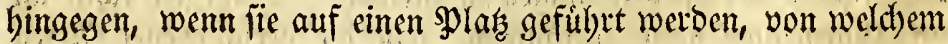
fie bas Meer , feben fónmen, fich auf cinmar wieber in bie Ruft erbeben, um zu Dem (Etemente bin zu fommen, von weld)em fic

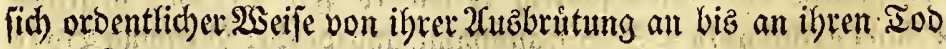
nic entfernen. 
Diefe Ruft, am Mecre zu brúten, hat uniter ben beñañn=

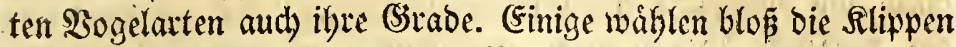
bez freien Meerez zur 2fnlegung ifres Neftez, Die andern fud)en

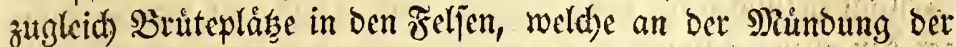
breiten Budgten gefumben werden, wieder andere wagen fith fo

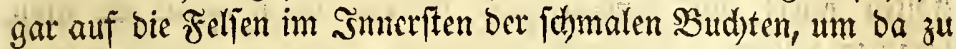
bruten. Ezz mútbe bal)er vergebens fenn, Den Bruteplatg ber Unia alle, Alca impennis, Puffinus arcticus, Suna alba

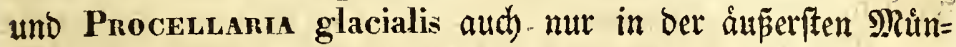

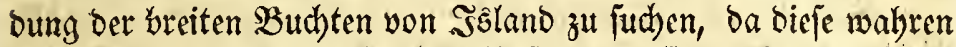

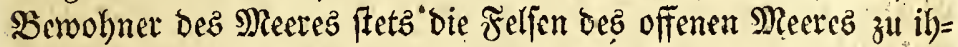
ten Sbrüteplásen wáblen, bejonders wenn jene ałz Sobeeren von bet sirite entfernt liegen. Una Brünichii, Una troile, ALca torda uno bie 2Urten ber Carso-(Sattung wagen fid) weiter in Die Reerbufen binein, um zut brüten; nod) weiter hincin geben Mormov fratercula, uno bie Laros-(S)attung, bis man cndlid) auf Usin grylle ftópt, weldye oft tief im snnerften. ber fdumal= ften Buthten ibre Eyer autbrutet. Diejenigen biefer Bogelar= ten, weldye tief in oen $B$ ud ten bruten, findet man aud zwifden jenen am offenen Meere bruten, aber, wie oben gejagt, nidjt umgeÉebrt.

Man nennt bie did)t am Sieftade ftehenden Felfen in Jatand Bogelberge, weld)e bod ridtiger Bogelferlen genant werben follten, auf weld)en eine unzáblige Menge sndivibuen vieler biefer \$ogetarten in Der Sommerzeit zum Bruiten jith verfam = meln. Die mertwuirbig|ten jold)er Bogelberge fimo in saltano

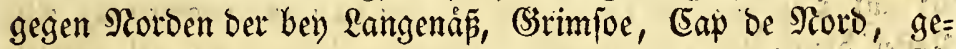
gen 2 seiften Leautraberg, Der ben Stappen, Shafinarberg uno (Et: boerne, gegen Süben Ebrnfemidfz, der şeftmanoe=smjeln uno Reiniżurg, außer vielen andern unbedeutenderen. Ssenm man Die locale Rage biejer Stranbfelien in Şlano unterfutht, fo Eann man, nadh bem zunor (sejagten, obngefáler beftimmen, weldye Bogelarten man auf jesem berfelben bruteno antreffen werbe.

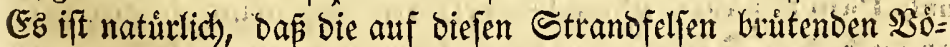
gel gemijat unter einander liegen, boch balten fich bie britemben

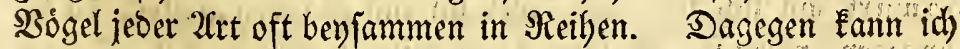

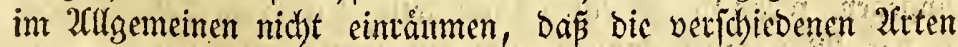

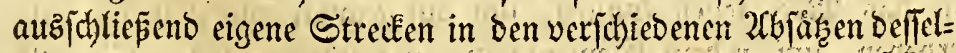

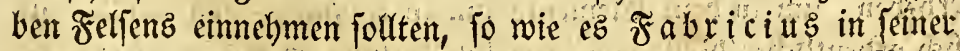

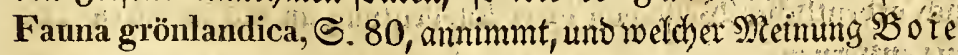

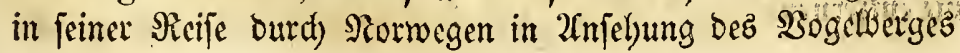




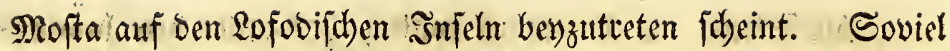
ift indeffen gewis, Das auf Den Bogelbergen, auf weld)en Unia alle und Lanus glaucus briten, biejer allezeit ben Şipfel bez Felfens cimnimmt, uno feine andern 2 Sogel úber fich butbet, jo wie jene ftetz ben Fũ beffellen, ober rid)tiger, bie vom. Felfen her= untergefallenen Felifenftucte bejest. Dodh lyabe id) nidbt felten Сanbo graculus, welcher oft bie obern Regionen dez Felfenz einnimmt, in ber Mitte beffelben zwifden \$caufen ber Uria troile uno Uria Brünnichii, Alca torda, Monmon fratercula und Procellaria glacialis auf Enetn liegend gefunden, welde fünf leẹten 2 rtten olyngefåly biejellen Bregenden bez Felfenb. zu Brutteplågen $\mathfrak{b} a b e n$, jo wie auth zumeilen Una grylle uno Lanus tridactylus, weldhe meiftens in Den untern $\Re$ egionen Des

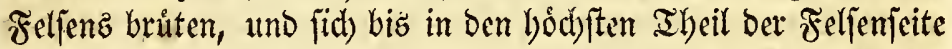
ergeben, um úber jeme Unia, Alca, Monmon und Procella-

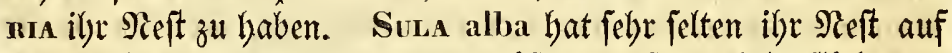

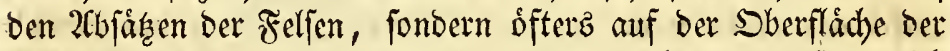
ifoliten, aus bem Meere hervorragenden Sdheeren, fo wie id audf) nie bie (Eyer des Puffixus arcticus, Stensa arctica Temm. uno Larus marinus auf Den $2(6)$ åa fondern ftets auf ilyer Sberflädbe gefunden habe. Bogel, Den Uria troile uno Unia Brïmichii, Mormos fratercula, Larus glaucus uno Proceldaria glacialis angehoreno, welde am

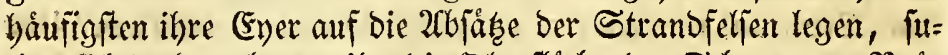
d)en fich bod aud zumeilen bic Sberflådbe ber Sideeren zu Bru= teplåţen aus.

\b ez gleidh jo ift entwiefelt worben, bap bie Neigung, bas

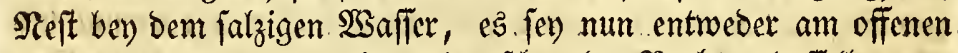
Meere ober in ben weiten ober fdi)malen Budhten beflelben, za

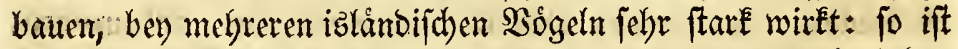
e's bod) andererfeitz eine Folge ber Natur Der eigenthumlidsen

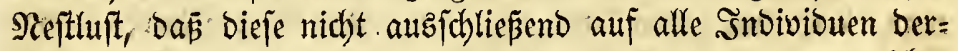
felben 2let witken fónne. So legt Carbo cormoranus, weldher in Şläbo nur. allein auf Den Felfen am Mieere brütet, feine Ener

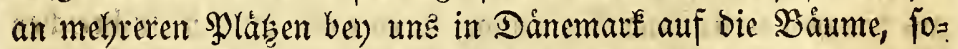

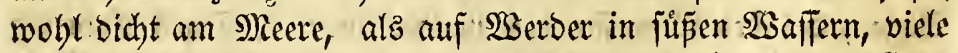
Meilen vom Strande: Stenira arctica legt nid)t mur igre (Ever auf dic Scheeren am Strande ben Szland, fondern brütet eben

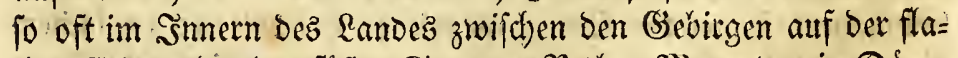
dhen Eroe neben Den füpen Seen, z. B. Gel Mlywatn; in Dáne=

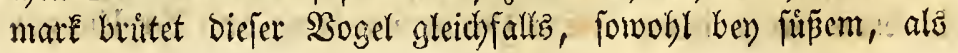




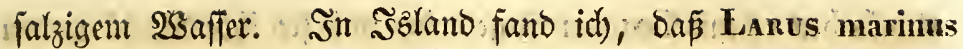

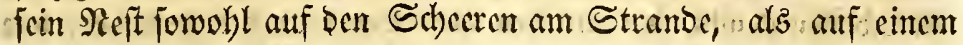
flachen $\mathfrak{S}_{3}$ erder in einem füpen See in. Suunbevatn Syffel hatte; bagegen ift ez mir nie gegluckt, zu bemerfen, wab Slaffen in

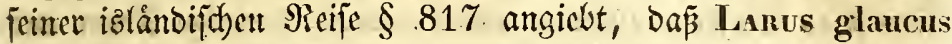
Brü̈michii einige Meilen vom Mecte ab nad) einem grofen Fellen ziel)e, um ba zu brúten. (Gs ift eine interefiante paralle $=$

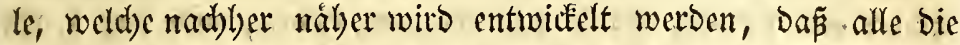
Schwimmvógel, welche atsichliepend am Meere. brüten, umein= gefd)rånt monogame fino.

\section{$\S 16$.}

So wic im vorhergehenden §. won Den Bogelarten.gehan= belt worben ift, weldhen, ber cigenthúmlichen $\Re$ efthuft wegen, im

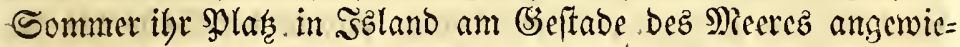
fen wurbe, fo gehen wir nun z̆u ben 2 Sogelarten liber, weldbe wir,

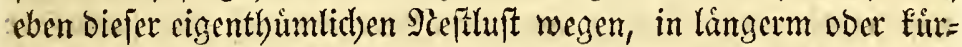

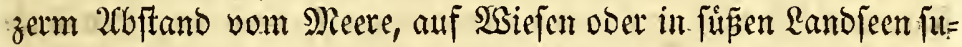
d)en múr|er.

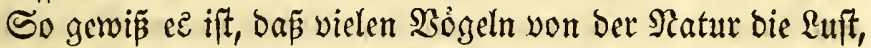

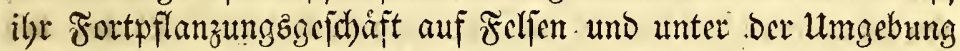
vom Meere zu vollenden, eingeprágt ift, cben fo ausgentad)t, ift

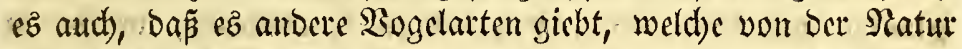
ibre Srritepláre an cbenen und niebrigen Srten unter ber $\mathfrak{U} m=$

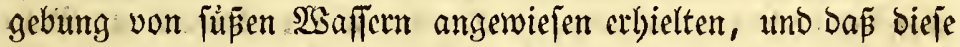

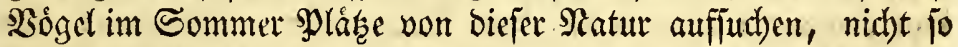

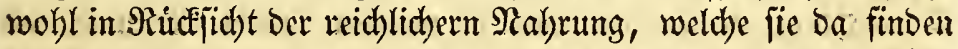
fónnen, als vielmelyr: gelocit burch bas in ber eigenthủmlichen

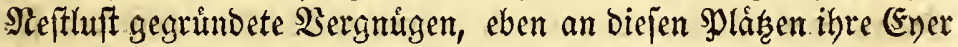
o $\mathfrak{u}$ bruten. Colrubus glacialis und Colymbes rufogularis, biefe gefrápigen Fifcher, weldhe ftets ben jûpen Seen, oft weit vom Meere brưten, wưrben gewi

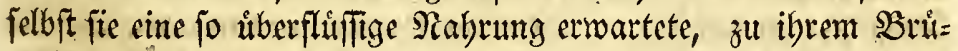
teplakge vorziefen, wenn nid)t eine anbere nod) ftärkere Reigung;

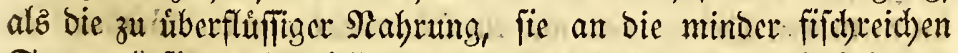

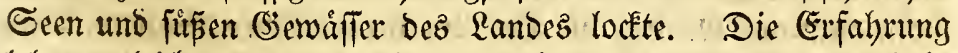

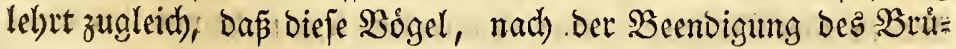

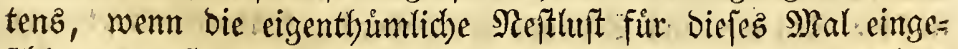

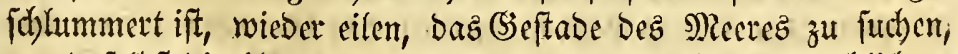

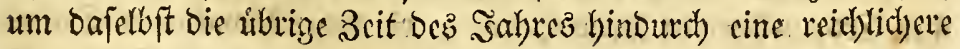
Rabrung zu geniepen. Die Poniceps-2irten mit Der Fulica 


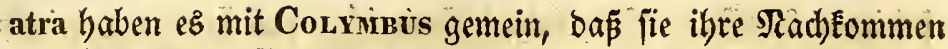

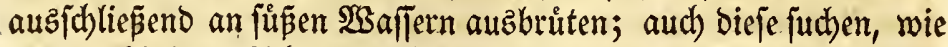

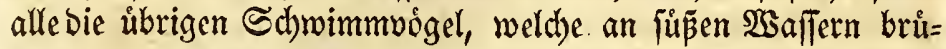
ten, baz Meer, wenn jie baż.Sruten beenoigt baben. 2alle iz= lánbijechen Ságer uno (Enten brüten, obgleid) einige 2(rten nid)t

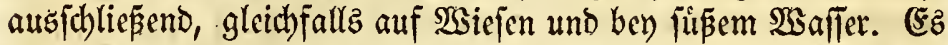
ift merfrouldoig, wie biefe $\Re e g e l$ in Der $\Re$ atur burch bie ganze $\Re e i=$

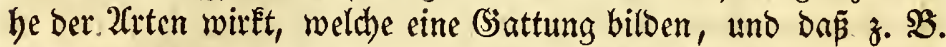
unter andern Avas glacialis und Aras histrionica, weld be bie ůbrige 3eit bez Sabres fich fo ungern vom Meere entfernen, Das: felbe bod, wenn fie brueten wollen, auŝfdliepend verlafien. 2(ud) (Sảnfe uno Sdbwanenarten entfernen fid) in ber Britezeit vom

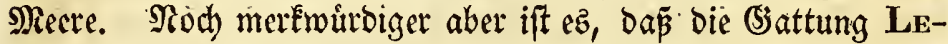
stris nidht zwijhen Larus und ben ubrigen Berwandten auf ben Stranbfelfen, fonbern ftets auf $\mathfrak{B i e f e n ~ u n d ~ i n ~ b e r ~ \Re a ́ b e ~ v o n ~ j u ̈ = ~}$

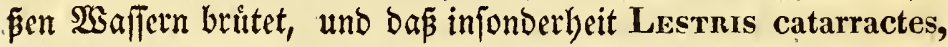
welder bie ubrige Beit fo ganz Dem Meere angebort, fo baj er

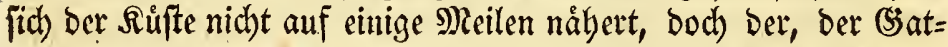

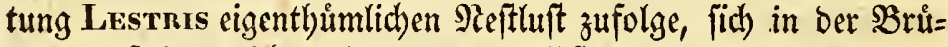
tezeit auf einen nidt unbedeutenden 26ffand vom Meere entfernt,

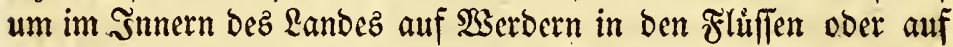
Sandebenen an füp̈en $\mathfrak{S a}$ alfern Eyer zu legen. Ez ift unleug= bar eine auffallende 2 usinabme, dap̃ die Raubmeben, weldbe in

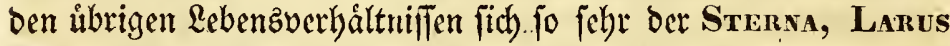
uno Procellaria nál)ern, bod) ohne 2(ünabme die unmittel=

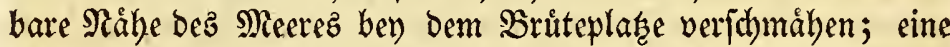
2fbweid)ung, welche boch babutch weniger in bie 2 ugen falleno wirb, weil man unter ber (S)attung Lanus uno. Stenva aud) einzelne Hebergangzarten findet, welde gleichfallz lieber bey fî:

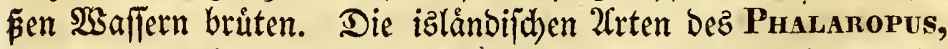
welde, obgleid wabre Sdbimmoigel, bod) auf ber (Sirenze ber

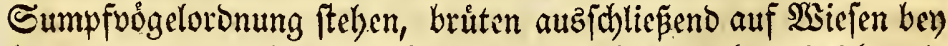
Lanbjeen uno Ieid)en. STh erinnere mich. Deutlich, wie id), als

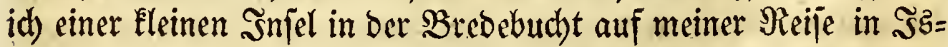
lano vorbenjegelte, beynah eine 2Uusnabme von Der $\Re e g e l$ zu finden befirchtete, daj die Phalanopus-3rten ftets ifre Eyer ben jữen $\mathfrak{B a}$ alfern legen. (Ein alter Phalanopus cinereus nåmlid) flog ångfflich bifht am Stranbe, unter bem Lautc; Dev zu

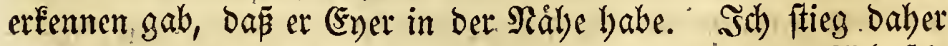
anż Ranb, um mich zu ủberzeugen, ob biejer $\mathfrak{B o g e l}$ wiuklid) jei= ne Eyer am Strande babe, fand aber zu meiner Befriedigung, 


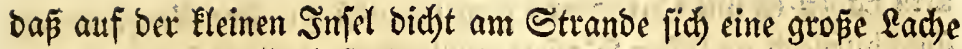
mit frijhem $23 a$ fifer befand, neben meldhe jeine Eyer gelegt ma=

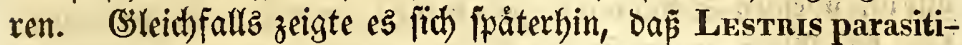
ca uno veridjiedene 2 rten (Enten auf mehreren Eleinen Jinjelden

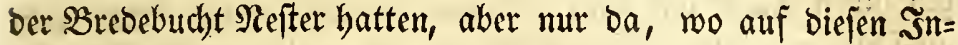

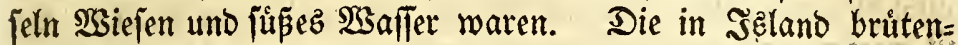
ben Sumpfoógel legen aud im (̧anzen genonmen Ener auf $23 i e=$ fen in långerer ober Elurzerer Entfernung vom Meere.

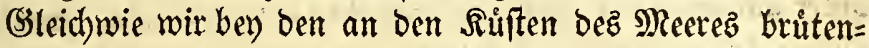

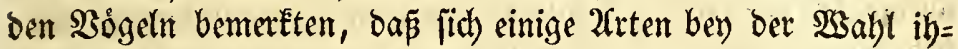
rer Bruitepláke mehr als andere von bem freien und offenen Meere entfernten, to finden wir audh bey benen im Innern bes

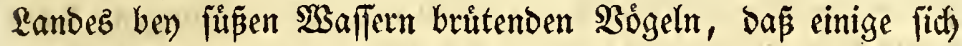

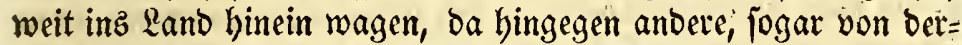

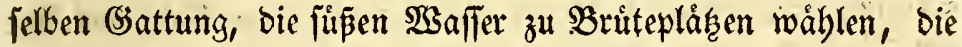
nidjt weit von ber Meereskei íte entfernt liegen.

So bålt fich Lrmosa melanura beftåndig auf 2 siejen in

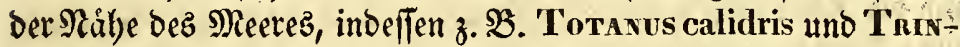

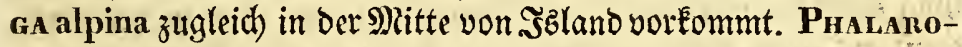
pos platyrhinchus Temm. wåhlt nur bic Ieidbe zu Brüteplá= fen, reldte ganz nabe am Strande liegen, Da bingegen Phalanopus cinereus fonohl bey folden Teidhen britet, als aud) bell

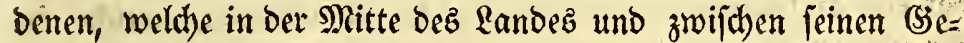
birgen liegen. Poniceps comutus wáblt, wie ber eriftgenannte

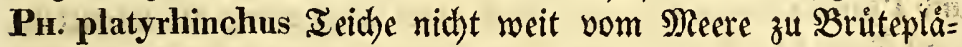
enen, indem bingegen Podiceps auritus Limn. oder areticus

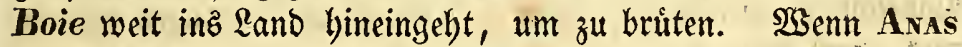

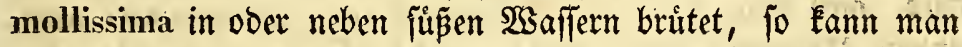

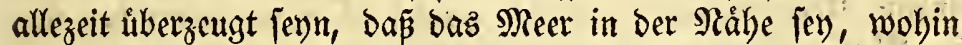

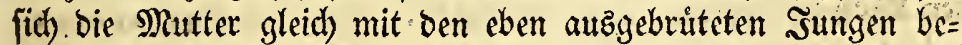

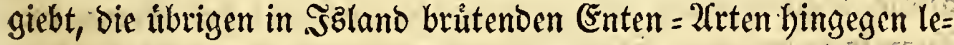
gen gróstentheils Eyer bey bem Ranbjee Mivatn, weldher meb= rere Meilen vom Strande entfernt liegt. (Enblid) Eann man auth bier binzufügen, Dap Lestris pomarina und parasitica eben=

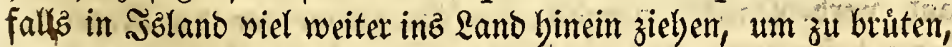
alb Lestris catarractes.

Im vorigen $\S$ warb abgebandelt, bas einzelne 2irten ber in

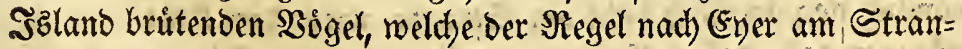
be legten, zugleich) alz eine 2fużnahme Indivibuen hatten; wel=

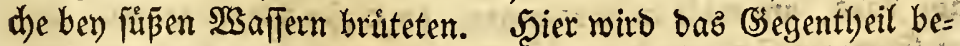

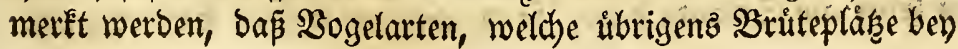




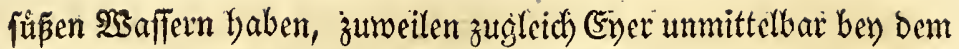
Meere legen, obgleid) biefer Falt weit feltner ift, als jener.

Inn İland finbet man die Eyer von HaEmatopus ostralegus und Chanannius hiaticula eben foroobl am Strande, alz

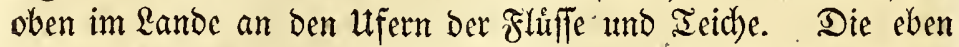
ausgebrutteten Iungen Der Trunga maritima fand idj auf einem fteinigten Felde nabe am Meere, entfernt von $23 i e j e$ und İeiden.

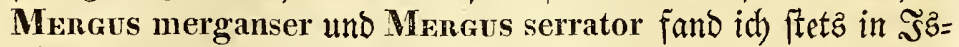

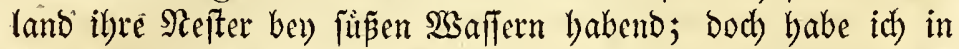
Seeland daz Meft bes erftern auf einem Baume nahe beym Mes'= re gefunben, fo wie er auth in Rapplano gemeiniglich auf $\mathfrak{B} \mathfrak{a} u=$ men brutet; ben lesertern fano ich bidst reben bem Strande auf

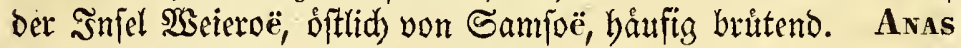
mollissima legt lyáufing Evyer auf Edbeeren im Miecre jelbft. EEben to traf id) einmal das $\mathfrak{R e f}$ ber Aras boschas auf einer fleinen Scheere am Strande meben Dem Scandelsplaşe Stappen.

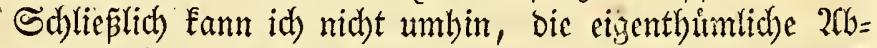
weichung verichiedener Entenarten und der mit il)nen berwand=

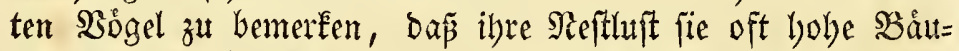

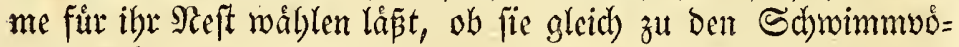

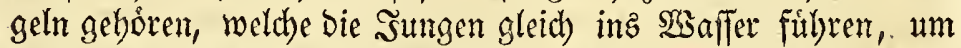

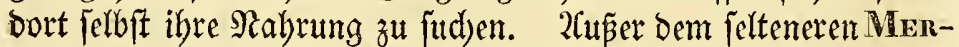
Gus merganser brittet Aras boschas bey unz båufig auf $\mathfrak{B} a \mathfrak{u}=$ men, ja fogar Axas tadoma, weldye fonft in Scoblen auf bet (Erbe baut; fliegt auf Der Injel (Endelabe im Sattegat auf in hob)= te Båame, um Ëner zut legen. Sielleidyt wirb biefelbe Sieigung in Bufunft bey mebreten (Entenarten entbeckt. (Ez ift baher nicht obne (šund, Dá bie jungen (Entd)en, wenn fie aus dem (En ge=

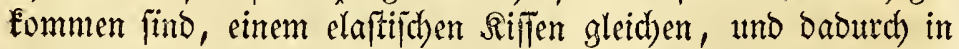
Den Stano gejef̧t fino, ben Stop za ertragen, weldien fie, in= bem fie ber Mutter folgen, Durd Den Siturz von Battme oder Der Slippe auf bie Eroe, oder inz Mcer erbalten; Denn mur auf

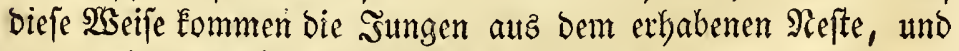

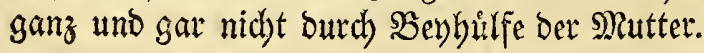

\section{§. 17.}

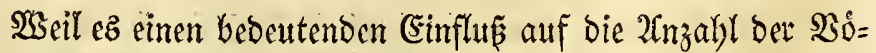
gel eines $\mathfrak{a} a n b e z$ bat, ob in bemfelben 2 satlder gefunden werben ober nidgt, fo baben wir bier einen we fentlid)en Şruno ber min=

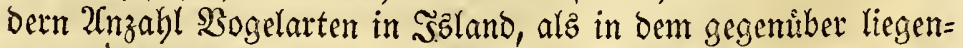

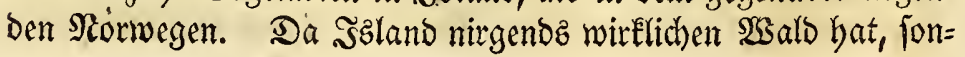




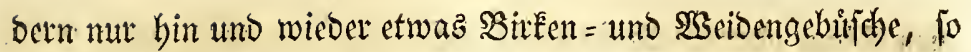

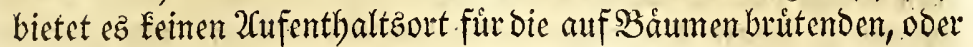

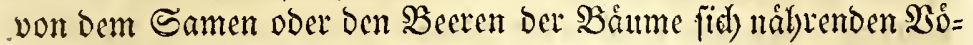
gel bar. (Ez ift ausgentad)t, Das 'Szlano innerl)alb ber (Sstenzen ber 3one liegt, welde fur mand)e ber $\mathfrak{B a l d}=$ und Singuogel

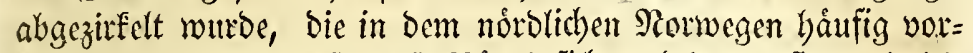

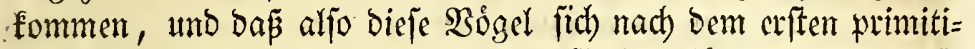
ven Naturgefese auf biefer Snjel auflbalten fonnen. Baeil fie

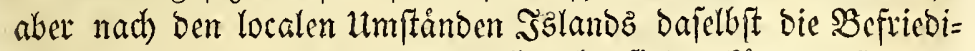
gung ifrer eigentlyumlid)en Reftuft nidst finden formen, fo wer:

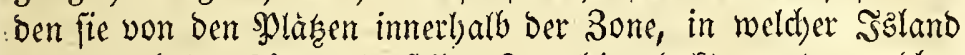
liegt, nach ben \&ången berjelben 3one bingelodet, tunter weld)en Normegen liegt, uno wojelbit jie dieje seigung befriebigen fon= nen. Man lafte einmal Wálbev in Şsland bervorwadjen, wie

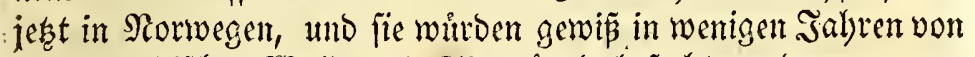

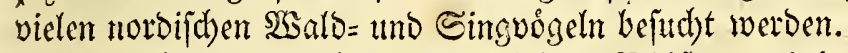

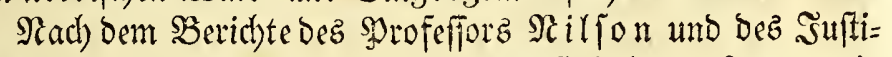
tiars Şo ie, weldye beide Rormegen bereift baben, fommen in biefem Rande vieie auf Båmen britende, oder von ben Frudden

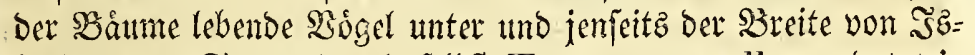
land vor. So werden dajelbft Tetrao urogallus und tetrix angegeben, fo mie Convus pica, Prcus viridis, Sturusus varius, Tundus pilaris, musicus, merula uno torquatus, Frivgula montifringilla, Limberiza citrinella, Parus major, ater und palustris, Avruus arboreus, Saxicona rubetra uno rubicula, Muscicapa atricapilla uno grisola; Sruva hortensis, hippolais, trochilus, rufa unb cyanecula, auper viclen an= Dern. Unter diefen genannten 2rten werben verfobiebene gefun= ben, welche fowobl auf şáumen niften, alz fid) von ben Fridch= ten Der Báume crnablen. Soldse werden baber in boppelter

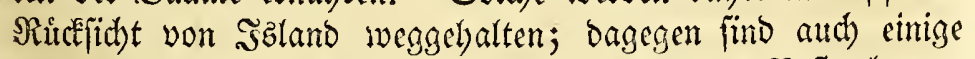
unter biefer 2fnzabl, welche mur allein auf Saamen Sefter bauten, ober unter ber Utmgebung Derfelben, obne zugleich vom Saamen ber şâme zu leben. Dieje 2 liten wurben baler bev Dem grab=

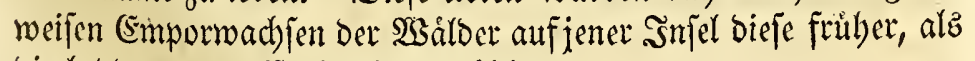

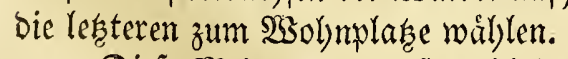

Diefe Meinung wito fowol)l buted) baz Factum beftatigt,

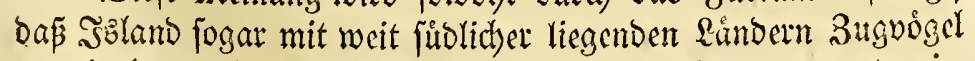
gemein bat, wie z. B. Motacmla alba uno Antrus pratensis,

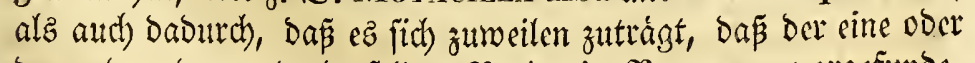
ber anbere der unter berfelben SBreite in Normegen vorgefunde= 
nen Sing = ober $\mathfrak{B a}$ aldoogel bie sinjel bejuchend angetroffen wirt, weldye er jebod ber angefubrten urjadien wegen bald wieber

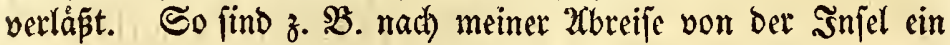
Tunnos pilaris und merula bajelbft gejthofien rorbent.

Dod muß es bier wieberhoit bemerft werben, dap audh unter ben eben genannten, in Norwegen bie Málder berwohnenden \$o̊geln walyridheinlid mebrete arten gefunden wetben, für beren geographijhe Berbreitung biefes Lano bie weftlichlte (Sirenze im Betbåltnilfe von Siten nath SEeften wurbe, to wie z. $\mathfrak{B}$. Dieje

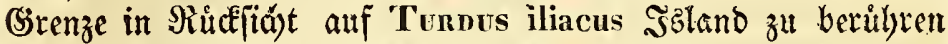
idheint. Soldye norwegifue Bogelarten werben naturtid erwei= fe in Eeinem Falle ŞBland in 3ukunft bewobnen, weil bieje șnjel

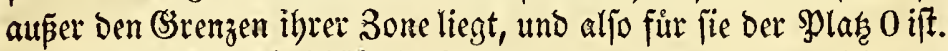

Die fleinen Ģebuifhe in Şకland bienen nur Tunbus iliacus,

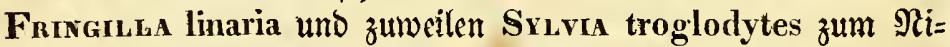
ften, injonterbeit mirb bas (sebbilfd) dez Fnioffedalz von ben beiben erften beroobnt. Falco albicilla, caesius uno Convus

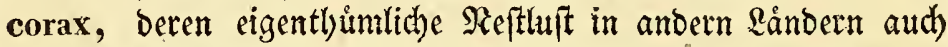

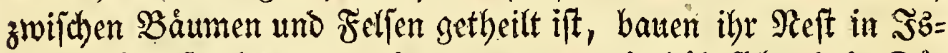
land auf biejen leftern. Avtrus pratensis bålt fid wie in $\mathfrak{D} a=$

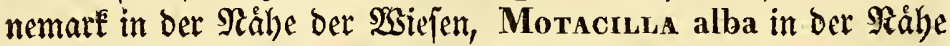

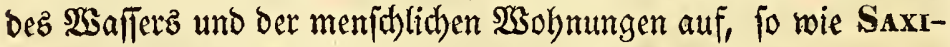
cous oenanthe fteinigte Ebenen und Seiben bewohnt.

\section{\$. 18.}

Der Bogel wohnt innerlyalb ber (Sirenge feinet 3one, die Satur aber ertbeilte gewifjen 2rten bie $\mathfrak{R}$ uft, fid) bie uber bie Sberflád) bez Meeres am meiften erbabenen Regionen zu 2Uufent= baltso̊rtern zu wåblen, andere blieben in ben niebrigern Negionen. Die.Berge lyaben baber nidt nur ibre eigene Flora, fie l)aben aud) zum Theil ibre eigene Fauna, und namentlich iljre eigene Drni= thologie. Die bie Berge bewolnenden Sógel fónnen paifend Berguỏgel genannt werben. Ez joheint minder ridhtig, bas Slafifen bie Sdymimmoogel, weld)e auf fteilen, am Meere fite= benden Feljen brüten, Berguogel nennt. Uria, Alca umo Monmon z. B. fino keine Berguogel, jie befteigen nie die Berge, weldbe bodh ftets in náberer ober weiterer (Entfernung vom Reere gefunden werden, im Gegentheil geboren bieje \$Bogel mehr, als alle andere, zut ben Berwohnern ber niebrigften (jegenden, ba fie nie bie Rerbindung mit bem Meere verlieren, und jith nur auf fteile (sieftabe empor begeben, um Eyer zu legen, bod obne da 
Die Meereßfläd) jeine Bedeutung fiut fie verlieren follte, indem fo zu fagen bas Meer baz Felb bleibt, auf weld)em fie ibren $\mathfrak{l} e=$ bensunterbalt juchen.

ZSenn úberhaupt ber Begriff Bergornitbologie in ber ftrengften Bebeutung genommen wirb, fo fann pon- Sçlant nicht gefagt werben, daz es eine eigene Bergornithologie habe,

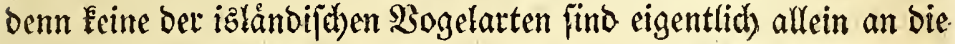
Berge gebunten, fo wie z. S. Der (Sreif an bie Schweizeralpen;

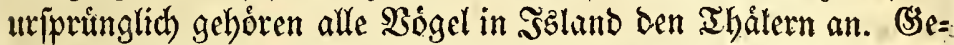
ben wir bingegen bem Begriffe Bergornithologie eine ausgebefn= tere Bebeutung, fo ba a auch bie zu ben Berguógeln gezáblt wer=

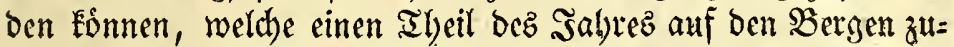
bringen, fo hat Jstant unlaugbar eine foldhe Srnitbologie.

Die Sduncelinie doer bie (Stenze bes ewigen Edhnees auf

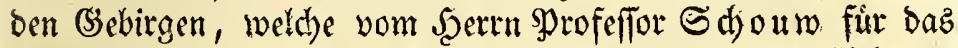

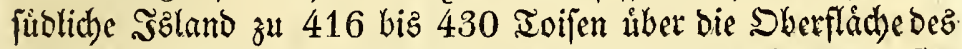

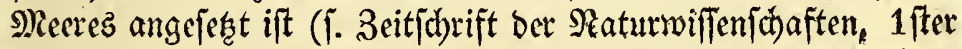
Sahrgang, 1ftes S5eft, S. 102), ift naturlicherweife bie norb=

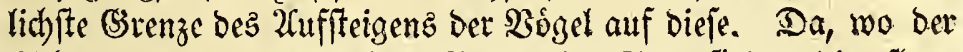
Schnee erwig liegt, kann keine Begetation Statt finden, bie pflan= zenfreflenden $\mathfrak{B o g} g e l$ finden ba Eeine $\Re a b r u n g$, uno ben ůbrigen

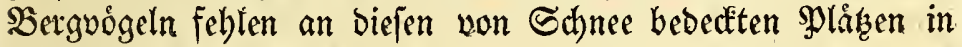
jebem Falle bequeme Britepląhe. Dagegen fino bie Regionen

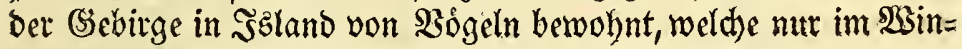
ter mit Sdunce bebeckt fino, ber jälurtid wieber johmilzt.

Der weientlichfte (S) sund, weldher bie temporåren Bergyoogel in Şstand bie Berge zu bejuchen lockt, ift bie eigenthumliche

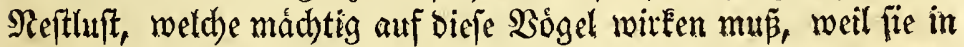
Der Brittezeit fich oft auf bie hótbften (Sebirge binauf begeben, uno bieje gleich wieber vertaffen, wenn ifre sungen erwachjen

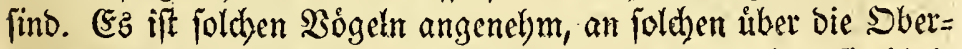

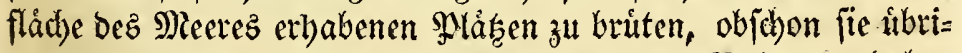
gens eine mehr paffende Rufttemperatur uno Nabrung Gaben Fönnten, wenn fie in ber Sommerzait in ben niedrigern Segenben blieben. So fliegen Colymbes glacialis, Arser segetum und

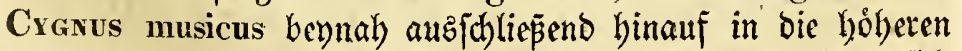
Şebirge, um ba ben Sommer zuzubringen, uno begeben fith gegen ben Şerbft mieder nach ben Thálern.

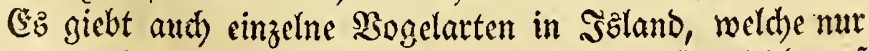
bie berge befteigen, um $\Re$ abrung zu futben, ob fie gleid) auf Den Ebenen uno in Den niebrigften ßregionen ber \$erge britten. 
Diefe Boget baten einen jenen entgegengeferten (S)ang auf ben Gsebirgen, Denn fie befteigen fie eben zu Der Zeit, Da jene SBerg= viggel, welche bicfelben erbabenen ßegionen nur allein um zu

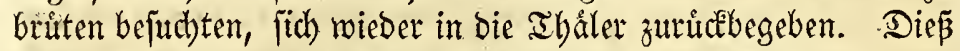
ift ber Fall mit bem islánbifden Sdaneelyubn und Enberiza nivalis; benn bicie- beiben bringen meiftenz den کommer auf mit Stauden berwadjenen und fteinbedectiten (Evbenen zu, wo fie brü= ten, fie fteigan hingegen mit bem Scerbfte mebr und melyr auf bie bojheren Berge, um jich da vom Saamen ber Bergpflanzen zu nåbren, weld)er um bie Beit reif ift, uno mut eine auperor= bentliche Menge Sdyne im SSinter, weldyer ibre Nabrung auf ben Gsebirgen bebectet, vermag biefe zwei 2Trten auf einige Beit

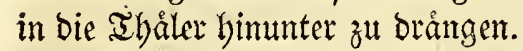

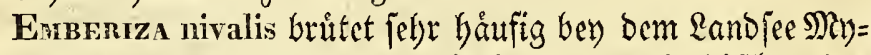
vatn und Tetrao islandorum biuffig in ben Gebuifchen bez Fnioffebals; bas Reft bes Refstern fand id) auth auf ben nie=

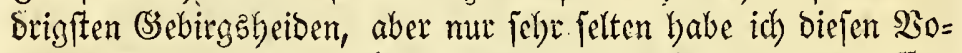
gel im Sommer in Den hoblern Regionen Der (Sebinge angetroffen; ba er bingegen in Sherbfte mit feinen erwadbjenen sumgen weit in bie Gebirge binauffiteigt, und da fo lange verbleibt, ale er ben Saamen ber auf Den hódjten (Jiebirgen wadh fenden Drxas octapetala, ober bie Rlugen ber auf ben jutbalpinifden Gegenden

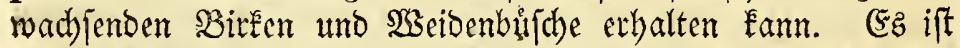

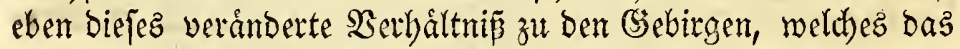

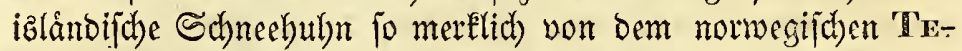
Tnao lagopus unterjheidet, mit welthem es ubrigens fo viel in

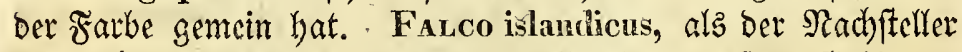

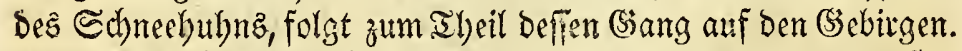

Die: $:$ soget, weldye im Sommer die niebern uno niedrigften

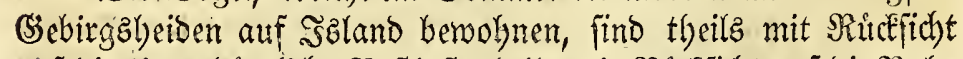

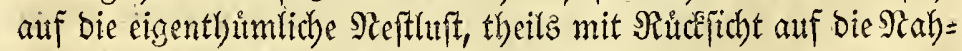

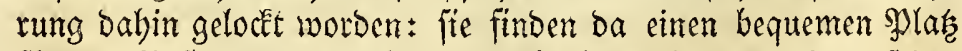

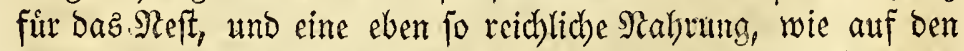
Ebenen, Denn bie Begetation ift auf biefen nicorigen Gebirgz=

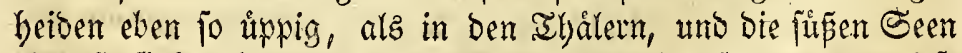

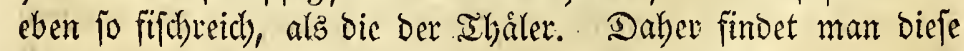
weniger erbabenen splähe Der (Sebirge ziemlid) berwolynt, bejon=

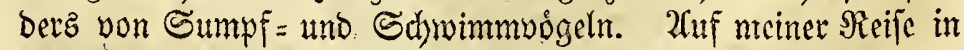

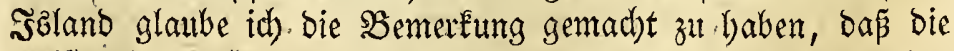
meiften Bergpflanzen, befonders yon Den niebern Gesenden ber (Sebirge, auth) zuweilen auf Den (Ébenen am Fupe Des serges an= 
getroffen werben, Da im Bsegentheil bie auf Den Esbenen zu Scaure

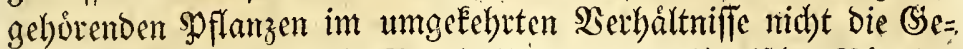

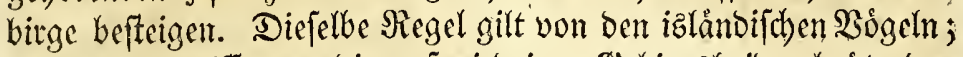
infonderbeit trifft man bie auf niedrigen Sebirgzbeiben brutenden siógel eben to haufig auf ben Ebenen bruttent an, ba im Begene.

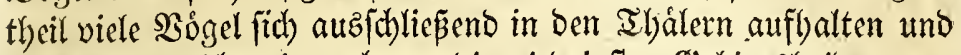
ba bríten, weld)e nie autch mut bie niebrigften (Sebirgsheiben zum, 2ưfenthaltzorte wåblen.

So findet man zumeilen baz $\mathfrak{A e f t}$ von Cranus musicus; Colyubus glacialis und rufogularis, famnt 'Tringa maritima,

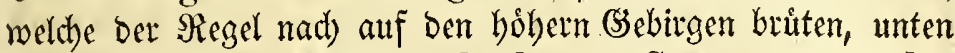
auf Den Ebenen. Tetrao islandorum, Saxicola oenanthe, Antrus pratensis, Chanadrus hiaticula und pluvialis, $\mathbf{N}_{\text {u- }}$ menus phaeopus, Totanus calidris, Tringa alpina, Scolopax gallinago, Poniceps areticus, Avas glacialis, marila und boschas, Stenna arctica, Lestris parasitica, mit mehreren,

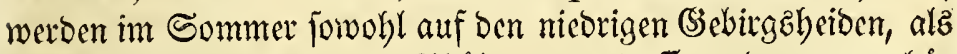

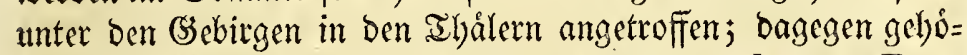
ren z. B. Hagmatopus ostralegus, Limosa melamura, Phacaropus platyrhinchus, alfe $\mathcal{Z} f \mathfrak{t e n}$ dez Uria, Alca, Mormon, Canbo, Puffinus und Sula, Poniceps cornutus, Avas mollissima, Arsen albifrons, fo wie Lestris catarractes, ganz Den Ebenen an, unb. fteigen nie auf bie Gsebirge linaur.

2uf meiner Sicife mangelten mir bie Snftruntente, um die

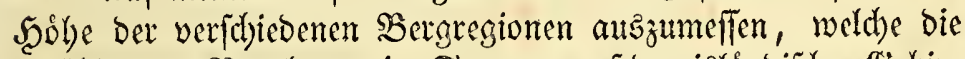

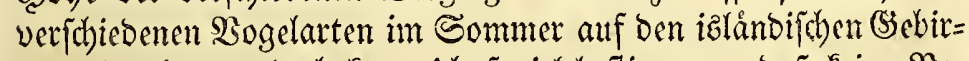
gen cinmel)men; Dod) fanm idh foviel beftimmen, baf feine $\Re e=$ gion irgenb einer Bogelart bis unmittelbar an bie wabre Edynee= linie fid eriftrectet, fo wie biefe im Monat 2ungult gefunden wirb.

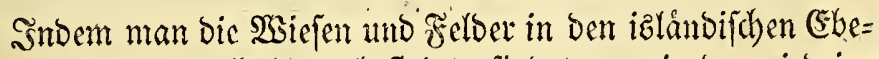
nen yertåpt uno bie (Sebtinge befteigt, findet man in ben micbrig=

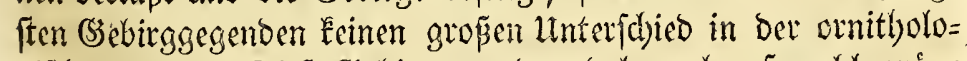

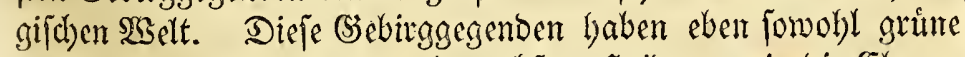
SBiefen und mit Sacibefraut bewadhjene Şeiben, wie die Ebenen felbit. Die Seeriddnepfe hoirt man ba mit ibrem vom ahale her befannten Summen, Der ઉjoldregenpfeifer, Der Bradjuogel, Der

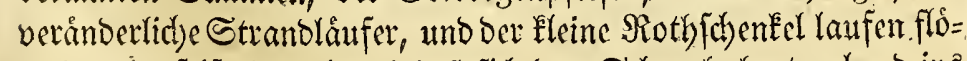
tend und pfeifend umber, indép fid) bas Sd)

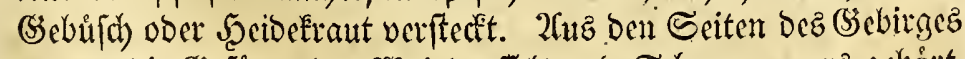

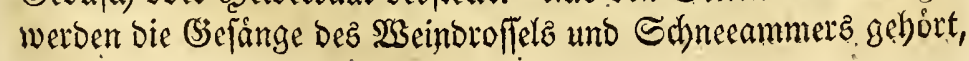


und ber $\mathfrak{S}$ siejen=Mieper to̊nt hod in ben Riften jeine Melobie. Sn einem nabeliegenden Teid)e fdhmimmen ber graue $2 \mathfrak{B a f f e r t r e f e r}$

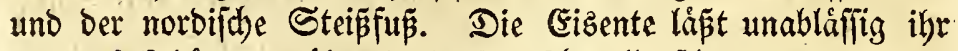

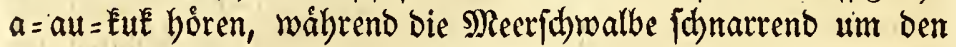

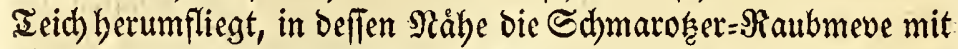
ifrem Nefte bejobiftiget ift. Wsenn man bober binaufifteigt, nimmt die Begetation ab, baz Graz wirb fparfamer, bie eigentli= d)en Bergpflanzen aber allgemeiner, bie von smjecten lebenden So̊gel verfahwinden ganz uno gar, nur cin einzelnez Sdhneebulgn

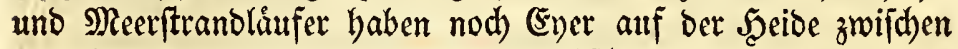
Dem Şeibekraute uno ben Rruickebeerbuifhen, uno in Den umber

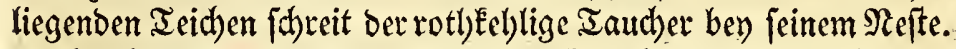

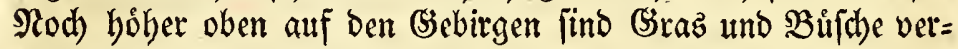

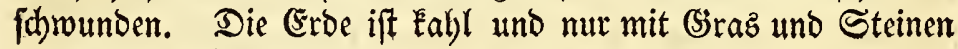
bedectt, zwifden weld)en cine sinzelne Bergpflanze, zur Druss

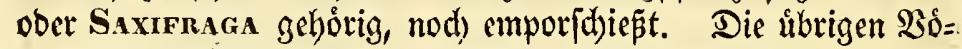
gel find verfichunden, uno bic Natur wåre, fo zu jagen, tobt, wenn nitht nod) Der (Eiztaudher fidh burd) jeine beulende Stimme

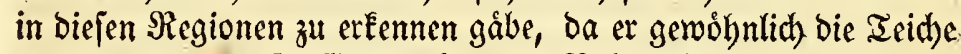

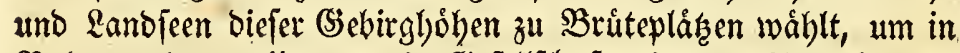

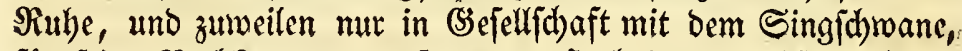

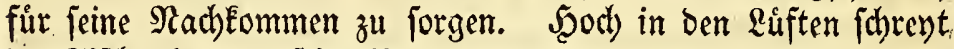
Der Fifhader, um jeine Beute unter Den $\mathfrak{a}$ adjanten biejer Berg=

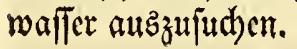

\section{§. 19.}

Zut Der eigenthumlid)en Reftuft entipringt bey ben monoga=

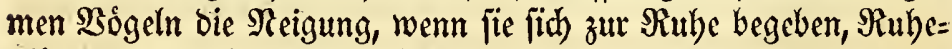

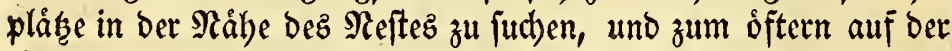
Materie, auf welder baz Mefit felbjt angelegt worden ift, inderfen Der (Satte brutet.

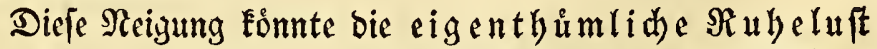
genannt werben, und hat aud) einigen (sinflus auf bie Beftim= mung bes 2 uffenthaltzortes bes Bogelz innerhalb feiner Bone.

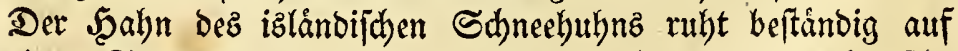

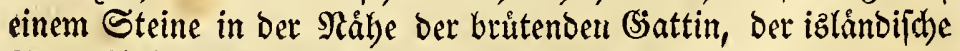

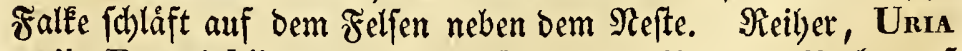
troile Brünnichii und ALCA torda werben Iag und $\mathfrak{R a d}$ t auf

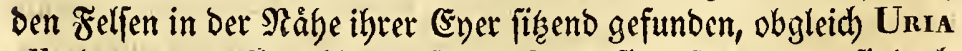
alle ben ganzen Tag iber auf Dem Meere find, jo Eommen fie bod) in ber Bruitezeit jeben 2Cbeno baufinmeife an ben Strand, und 


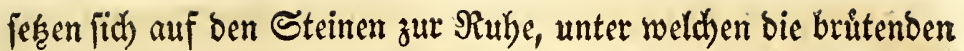
(Satten liegen. Dies ift auth ber Fall mit Mormon fratercula. Das Mändhen der Axas mollissima liegt rubig an ber Seite bez

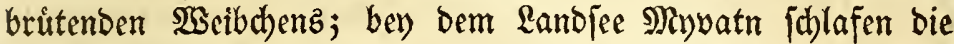
Måmeden ber bajelbft brůtenden Enten in ber Måbe ber Mefter

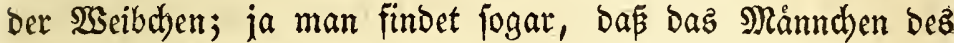
Singifhwans auf ben Gsebirgmalfern in bem gropen Nefte ne=

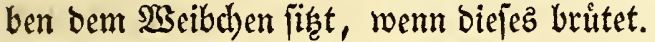

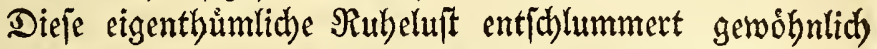

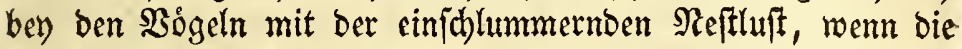

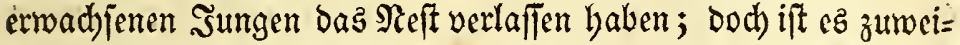

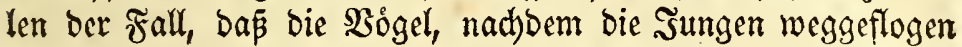

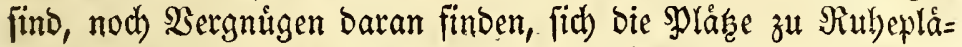
ken auszujuchen, wo baz Neft in Der Niále gemejen war, biz Der 2 Sanderung3trieb bie 3uguógel bieje Gegenden ganz und gar zu vertafien zwingt.

So foul ber 2roler beftåndig fein Neft berwohnen; ber Stord) uno bie Sdymalbe ruhen bey uns nodh gern auf bem Dade oder bem Balfen, auf welchem ihre Nefter angclegt waren:

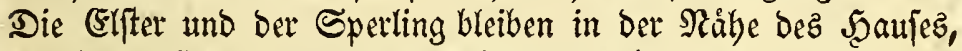

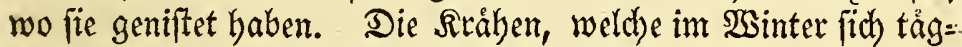

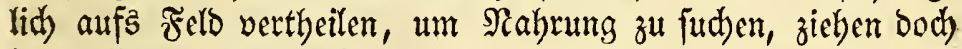

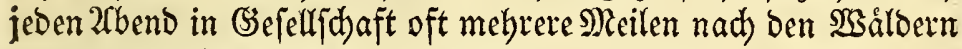
oder einzeln ftehenden hohen Båumen, um Dort zu ruben; wel=

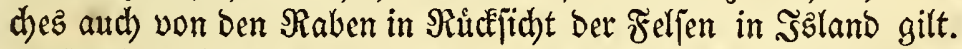
Dajelbft trifft man Motacilda alba und Saxicola oenanthe

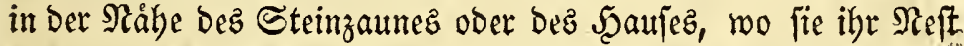
baben, biz fie megmandern; ber wei bejuchen zuweilen im ssinter bie Felfen, auf weldhen fie im vor= bergebenden Sommer wohnten; aber am meiften in bie 2 tugen

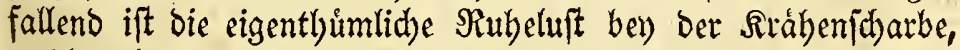

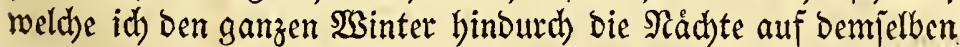
Felfen babe zubringen feben, auf welchem fie in ber Sruttezeit auf (Evern lag. (Es giebt jebod) aud Sogelarten, welde obne

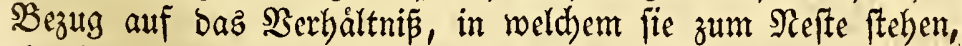

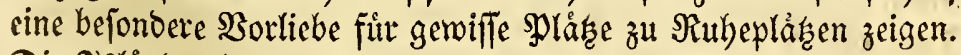
Die J̦zlånder benennen fogar hin und wieder Scheeren im Meere nach) der Carbo und Sula, weil fie, wenn fie fith in ber (Segend

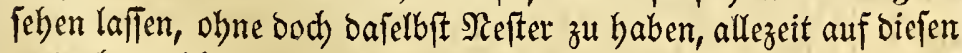
aušruben, bie umberliegenden Scheeren aber veridjmáhen. Das islånbifbe Sdjneebuhn hat gewiffe Steine, auf welden es jogat 
im Scerbfte und Sinter gern fist, und wo es felbft Sortath von Nabrungsmitteln einfammelt. Scolopax gallinago babe ich fowohl in şzland, als in Dánemark mebrere Tage nad) einander von bemfelben (5robaufen aufgejagt. STrix aluco und ficher= lich melirere (Ettemarten fohlafen gern in Demjelben sodbe in ber Mauer ober in holylen Båmen. Diejes ift aud ber Fall mit mebreren $\mathfrak{S a l d}=$ und Singoogeln. Avas mollissima judbt an benfalben Spláfen am Strande im Winter fein Sachtlager, und

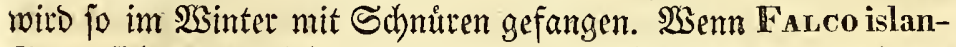
dicus fich im Seerbfte bey Den Şandeloplaten zeigt, to if bie. Flagftange fein gewóbnlidber $\Re$ itheplate, fo lange, biz Convus corax ibn ztt befebden anfångt.

\section{§. 20.}

b) Die auftemperatur ober bas Elimatifde

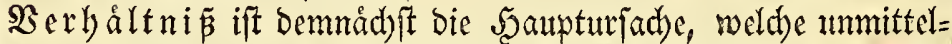

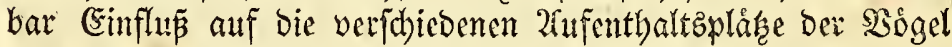

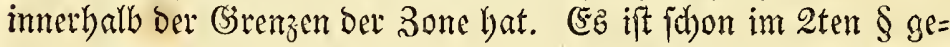

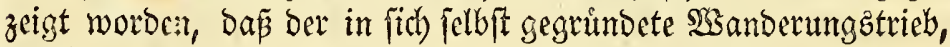
weldber eben zu ber .3eit bey ben 3ugvoggeln erwad)t, menn baz Slima minder paffend fur fie wito, bieje Bogel aub ibrer (Bse= burtzzone beraustrcibt. Es ift aljo nid)t bie ungüntige Derån= Derung Der \&ufttemperatur, weld)e bie Bogel unmittelbar aus ber einen 3one in bie andere treibt, ob man gleich annelymen

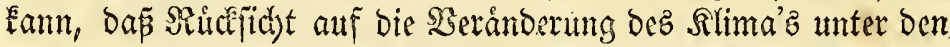
Mrotiven war, welcbe bie Natut beftimmte, ben $\mathfrak{S a n d e r u n g} 8=$ trieb bey Den Bógeln nieberzullegen.

Dagegen nimmt Der Bogel Rudefid)t auf bie Rufttempera=

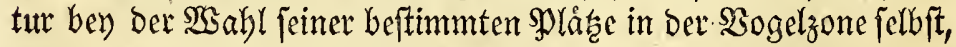
und auts biefem (Sefichtzmuncte betrad)tet ift die Rufttemperatur an und fitr jith eine wlabbeftimmende $\mathfrak{U}$ trad)e, nicht allein fir bie 3ttguogel, in ber 3eit, in weldyer fie fich in Der Bone auflyalten, fonoern vorziglici fir bic Gtanboogel Der 3one, melche naturli= d)er $23 e i j e$ Sommer und 2 Sinter innerbalb Der Srenzen Derjelben verbleiben.

Die $\mathfrak{B o g} g \mathfrak{l}$ lieben úberbaupt Sdulf, und wållen fid baber folde shláge, an melden fie ber. SGitking eines barten ßlima's, und infonoerbeit ber fdyarfen SSinde, am wenigften ausgefest find, wenn fie ubrigens Durd feine fráftiger witkende Urjachen ge= zwungen werben, folche unmilde \$láke zu berwolsnen; befonderz fitheuen fie folthe Srte bey ber $\mathfrak{B a b l}$ ibrer Brutepláce, wenn 


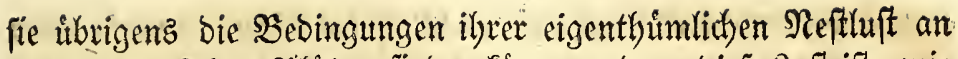

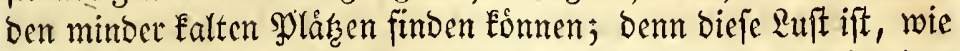
fdyon oben bemerft wurbe, Daz am meiften wirkende Motiv, ben

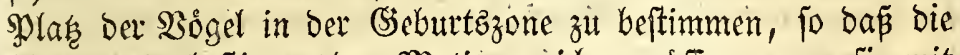
ábrigen plaşbeftimmenden Motive weichen múffen, wenn fie mit biefer in Sollifion kommen.

Diefe Sieftluft ift $\mathfrak{e}$ s, weldye z. $\mathfrak{B}$. Cranus musicus ando Colymbus glacialis antreibt, fich bem bårtern Silima ber Ģe= birge aubzule Sula, Procellania und mehreer in ben Strandfelfen britende Bögel geben, von berjelben angetrieben, den Brủteplácen auf ben Felfer am offenen Meere ben Sorzug, wo fie mebr ber Ein=

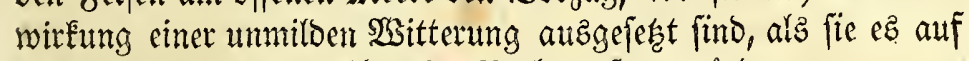
ben Feljen tief in Dest fdumalen $B$ utd)ten fenn wurben.

Es ift oft autfallend, Das man in einer Begend eine grope $\mathfrak{Z}_{\mathfrak{n} z a b l}$ Sógel findet, und bagegen in ber benachbarten feldr we=

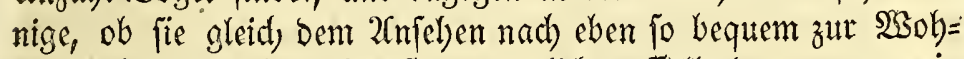
mung ift, als jerie. (Ez ift namentlid) auffiallend, warum ein Strandfelfen zum Britteplatse vieler Iaujende ber norbif hen

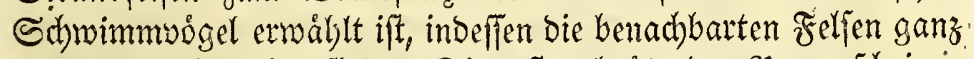
uno gar unbewolynt find. Die erften brittenden \$aare fdheinen eben fowohl biefen, als jemen, gewåhlt haben zu kỏmen; benn warum fie fpáterhin ben Brưteplats nidbt verånderten, uno we $\beta=$

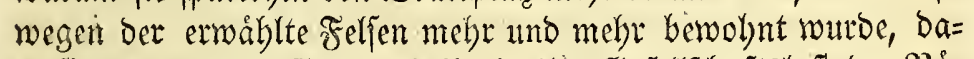

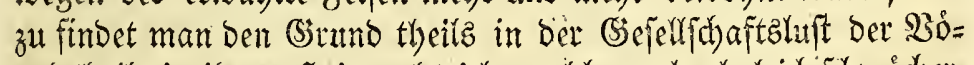

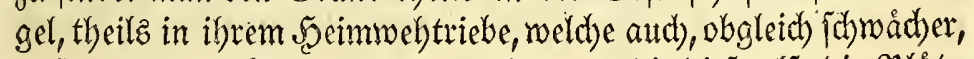

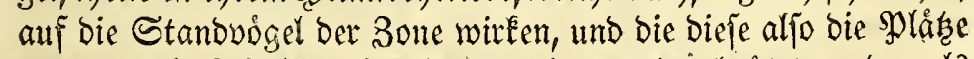
wieber futchen laffen, wo fie einmal entweder briteten ober als

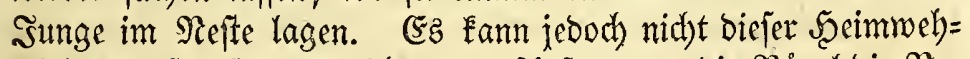

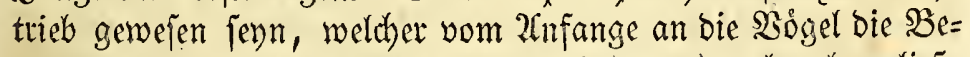

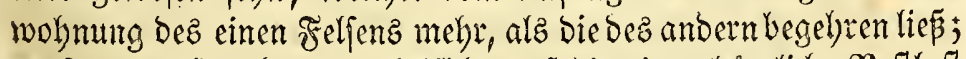

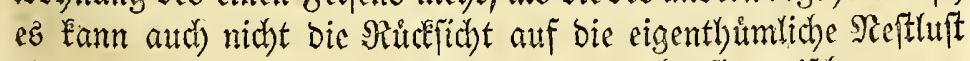
oder auf bie Sabutung gewejen fenn, welche fie zwifhen zwen

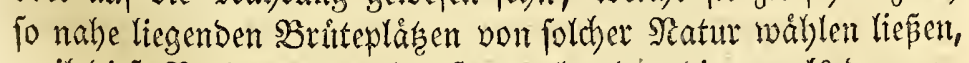
weil bieje sebingungen eben fo gut bey bem einen, als bem an= bern erbalten rerben fonnten; wir werben im Segentheil ben

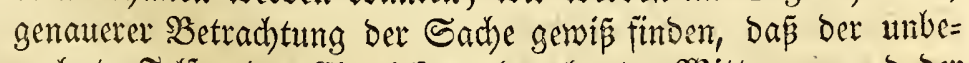
wohnte Felfen Der Eimwirking ber harten WSitterung und ber Stủme melst ausgejegt ift.

Die veriftiedenen Ritbtungen, in weldyen bie Rufttempera=

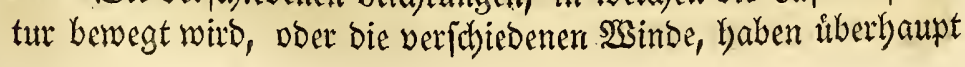




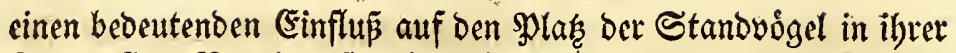

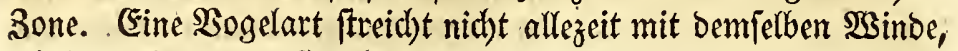
mit bem bie anbere ftreicht. Mit dem $\mathfrak{B s i n b e}$ weldher bie Enten

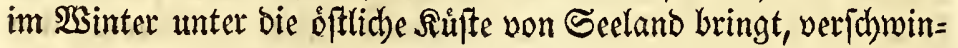
Den bie Meven, und umgeéehrt. Bey Dem Şandelsplate in

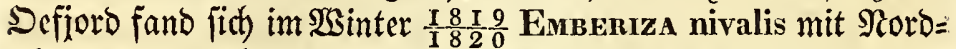
winde cin, verfdhwand aber mit Submino, da Frivgiula lina-

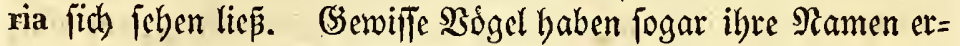

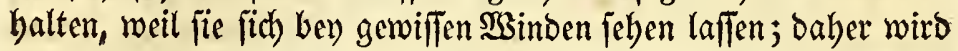

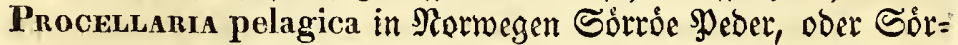

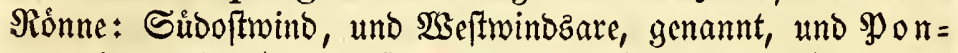

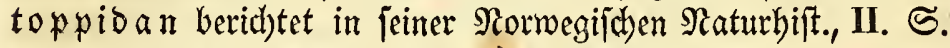
163, von einem Bogel, welcher ber Sibowinosvogel genannt wirb, weil er mar gefeben werbe, wenn ber Sübmino welken will. Weil bie meiften 2 Bogel fid) gern gegen ben sisind auz ber See erbeben, fo fanm man ibnen viel nảher auf ben Sdhus fegetn;

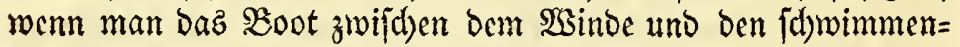

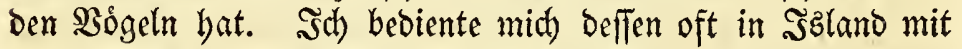
Bortheil auf meiner Secjago nad) Bogetn.

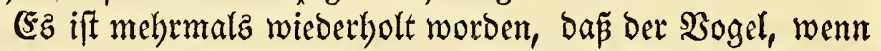

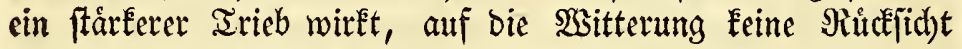

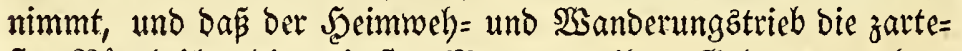
ften 2 Sogel ủber bie weiteften Meere auz ihrer Geburţzone her= $\mathfrak{a u g}=$ umb wieber in biejelbe zuritctzutreiben vermógen, inbem

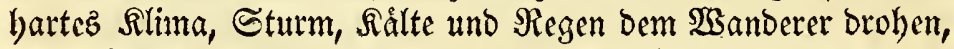

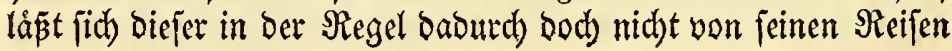
abbalten.

Die Stanowógel ber Zone find es infonberkeit, auf welde

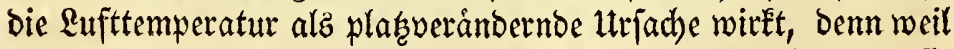

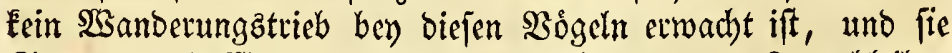
Sonmer und $23 i n t e r$ innerbalb ber Grenzen ber 3one bleiben múrfen, fo find jie genothigt, fiid ba nothwendig bie bequemften

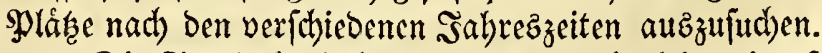

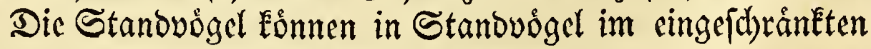
Berftande und in Stridboógel eingetlyeilt werben. -

Standoỏgel im eingefdranten Berftande

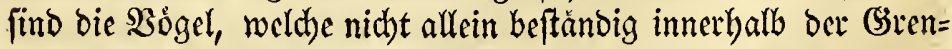
zen bez primitiven \$ląę, fondern aud), bejonderz wegen ber eigen=

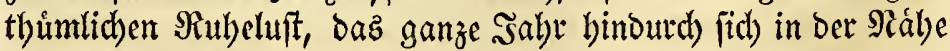

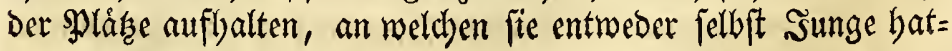
ten, ober sunge waren. 
Soldhe Stanbuogel im eingeifhránften Serftande bat I马: land nidht; nur zum I Iheil ift ez Der Fall mit Convus corax und Савво graculus; Dagegen bat Dånemark bieje 2fet Stanbodgel in Strix aluco uno passerina, Convus pica, Frivgilua domestica und mebreren.

Stridug gel find bie, meldhe wobl beftåndig innerlyalb

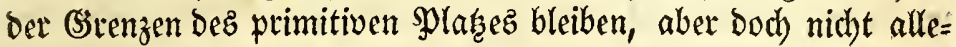

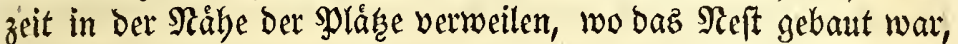
vidmebr frteidhen fie sffter haufenweife von bem einen \$olake zum andern, biz bie sigenthumliche Meftluft wieber erwadht, uno

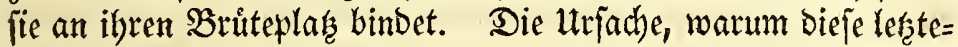

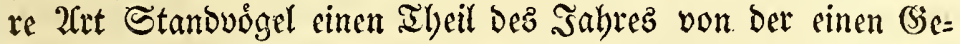
gend ibrer Syeimatl) zutr andern ftreid)t, ift auper Der Nalyrung aud) bie $\Re$ uideficht auf bie $\mathfrak{Q u f t t e m p e r a t u r . ~}$

Şseil bie borealen Standuogel Der Strenge Dez $\mathfrak{B s i n t e r z ~ i n ~}$

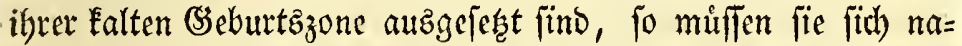
tưrlidh fo viel als mơglich vor ber (Eimwirtung ber Sålte baburd)

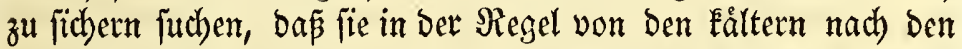

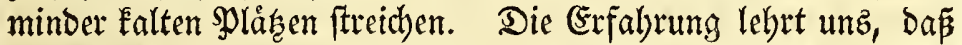
ber Strich Der borealen Standodigel gegen bie ftrenge Jabreşzeit

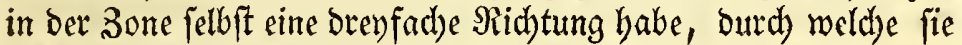
Sdulus gegen bie 2 Sitterung fudden.

Die meiften ftreid)en von ben nơrblid)ern nach Den fübli= dern \$uncten ber Bone, andere bleiben in Derfelben Begend, in weldher fie im Sommer waren, nur baj fie fith vom offenen Meere in bie $\mathfrak{B u d}$ ten zwifchen Dem $\mathfrak{a} a n d e$ Gineinbegeben; wieber

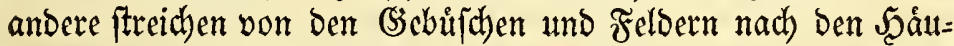
fern unb von ben 2 Saffern nad) ben warmen Sueflen. Einige haben audh einen aus mel)reren biejer zufammengefesten Strid); fo bålt fich Lanus leucopterus ben Sommer ủber an ben nơro=

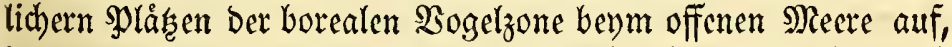

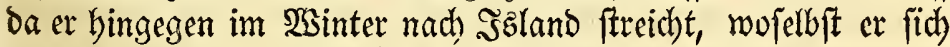
in bas Snnerfte ber fohmalen $B$ utchten hineinbegiebt.

Beyfpiele ber izlándifden Stridyógel erfter $\mathfrak{i} \mathfrak{i}$ t. Haematopus ostralegus, Canbo cormoranus, Colymbus glacialis, Avas histrionica und Lanus glaucus balten fich ben

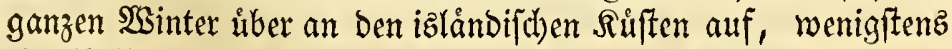
ein Ih heil Der Sndivibuen, weldye im Sommer auf biejer Infel brit= ten; gegen Den J̧erbit aber zielyen fie von Den norblid)ern (Gegen=

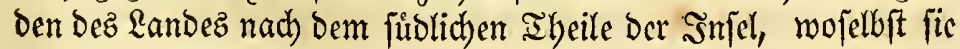
verbleiben, biz fie im Frübjabr wieber zurutck zieben. Satr allein 


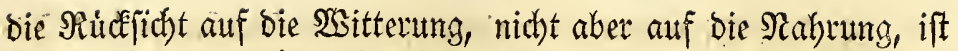

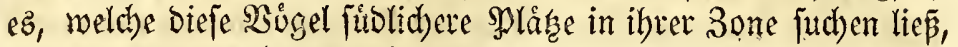

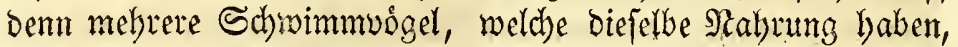

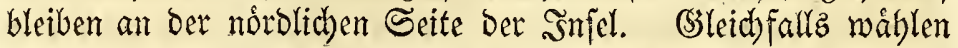
fich) z. $\mathfrak{R}$. Uma alle, Alca impennis, Monuos fratercula, Sula alba, Procellara pelagica, ja mobl aud zumeilen Lanus glaucus, Leucoptenus and Lesturs catarractes and andere ber borealen Bone beftimmte Stanovoigel, bie fitblichern

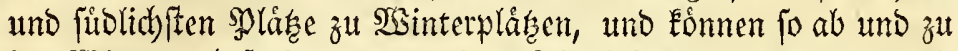
im Sinter, befonders unter Der Nitwinkung von Sturm uno Siebel, fid) biz liber die (sirenze Der anftopenden feptentrionellen Bogelzone veritten, und fitt) auf biefe 2 seife an Den banifiden

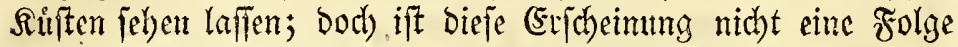

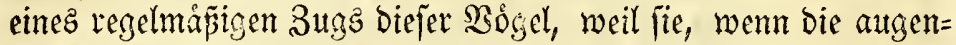

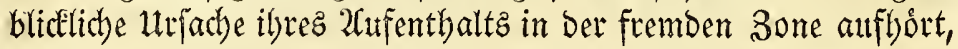
(ich aud gletch wieder nach il)ter wabren Seimath zurielbegeben. Sogar Conmsus glacialis erfcheint zumeilen auperbalb bet bo= realen Sogelzone; fo habe id) citt, in ber (Segeno um Seambutrg

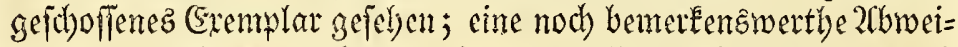

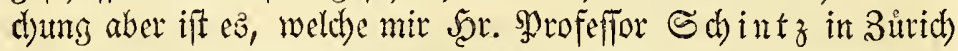
berichtet bat, baj eine alte Courmbus glacialis mitten im Som= mer in voller Sommertiacht alf Dem Surderice gefdoffen mor= Den ift.

Beyfpiele der izlånoifden Stridudgel zmei= ter $\mathfrak{A}$ t. Trivga maritima bleibt den $\mathfrak{2}$ sinter bindurch im norblichen ŞBland, im Serbfte find fie in ungebettern Sabaren beym offenen s) Reere verfammelt, in ben ftrengften Sintermonaten aber etjheinen fie im Snmerften Der fohmalen Buchten, um Sdyus zu fuchen; Uria grylle, Uria troile und Arca torda, von welden unlågbar einige sndivibuen wandern, mittlerweile anDete in ber borealen 30 geljone verbleiben, nebmen in ber Mitte

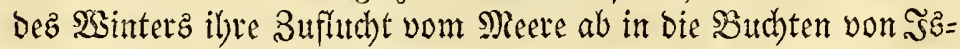
land, weldies aud ber Fafl mit Aras mollissima tmo glacialis iff; am meiften altfallend aber ift ez mit Una Brünnichii und alle, von weld)en fith) allezeit einige ben 2 sinter $\mathfrak{u} b e r$ um bie $i z=$ låmbifchen Riften her aufbalten, Denn in ftrengen Szintern, be=

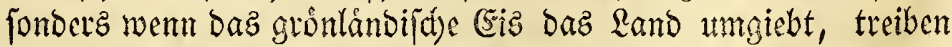

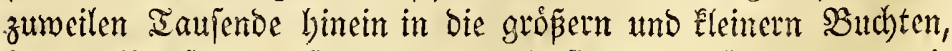
ja zuweilen jogar auf das Land und siz, wo fie ermattet mit J̧anben gegrifien werben, ober angefroren lebendig von den Saubvógeln und Raben verzebrt merben. 
Dagegen giebt ez unlengbar andere Stanobòget unter ben borealen Sdymimmoosgeln, weldhe fich allezeit, jogar in bèn freng= ften Wintern, im offenen Meere aufbalten, uno fid baber febr felten im 2 sinter unter bem $\mathfrak{a} a n d e$ felsen laffen. Sie gelen, jo

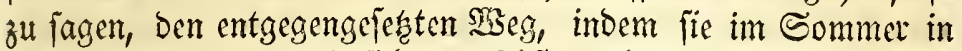

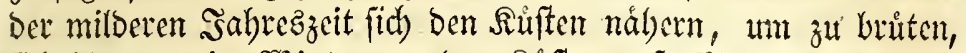

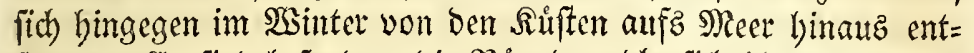

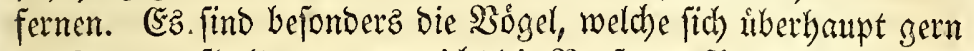
im Meere aufbalten, wenn nicht bie Borforge fít ihre $\mathfrak{B e r m e l}=$ rung fie ans \&ano lockt, z. B. Monnon fratercula, Alca impennis, Sula alba, Lestris catarractes, die (Satitumg Puffinus umb Procellaria. Berichiedene von biefen ftreiden, wie

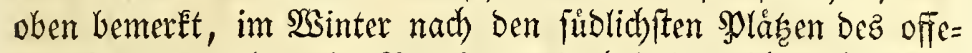
nen Meeres ber borealen. Sogelzone, bod) halten jidd autch melyre=

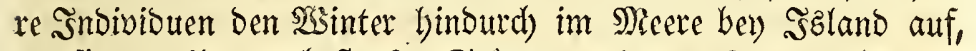
wo fie zumeilen nad) ftarken Stitrmen tobt ans $\mathfrak{L} a n$ treiben.

Beyfpiele ber iztándifden Stridugógel orit= ter 2 rt. (Ëz find vorzliglid) Şslands Ranovỏgel, weld)e alz

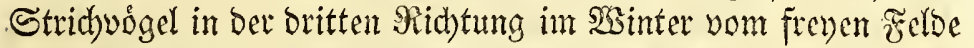

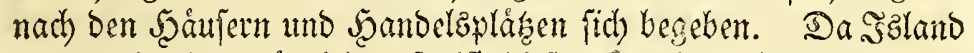

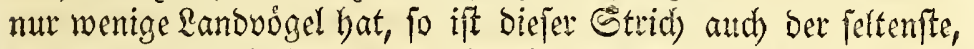

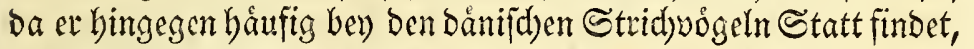
z. $\mathfrak{B}$, bey Emberiza miliaria und citrinella. Conves corax fommen fo von Den Feljen, wo fie Refer hatten, Den Şåufern nåher, wo fie fich ben ganzen 2 Ssinter aufflyalten; wenn bie Stür= me in biefer Sabrezzzeit withen, fuchen fie હdhut auf ben Då=

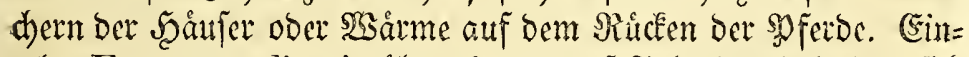
zelne Frivgrula linaria itberwintern auf seland und yalten fith

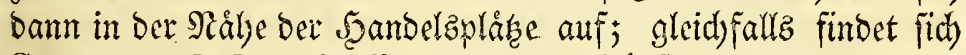

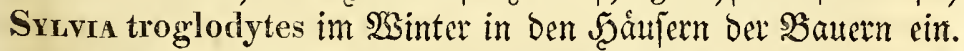
Naur Tetrao islandorum uno bie ber Enemenza nivalis, wel=

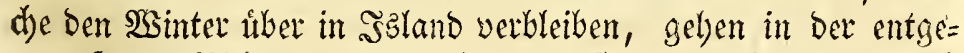

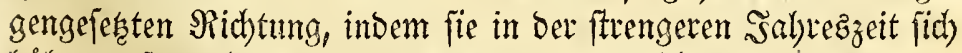
bỏher auf Die Ģebirge binautibegeben, und firb Da einem lyartern

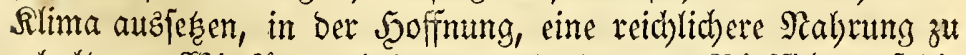

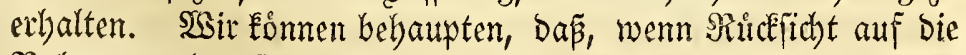

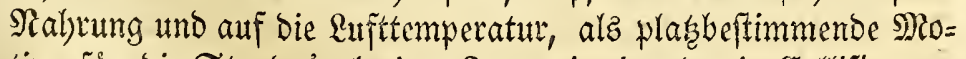
tive für bie Stanbobgel einer 3one mit cinander in Sollifion ge= rathen, bieje offter jener, als jeme biejer weidje, fo daj bieje $23 \delta^{\prime}=$

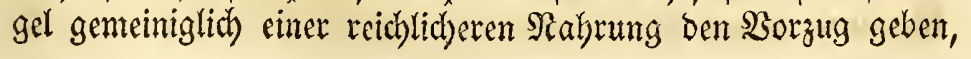


wenn fie gleich bieje an ben bom ßlima weniger begunftigten splågen der 3one fudden músten.

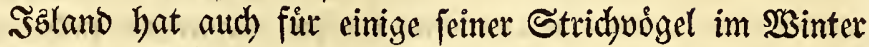
sinen eigenthümlichen localen $\mathfrak{C}_{\mathfrak{u}}$ fenthalt3ort in ben vielen war= men Suellen uno (Setwáfern. Sie werden in Der ftrengen Sab)= rezzeit von Mergus merganser, Avas boschas uno Cygnus musicus benuf̧t, weldbe in ber Winterzeit ba Wánme jucben; RaLLus aquaticus nimmt audj feine Bufludbt babin. Uebrigens balten fid ald Phalaropus cinereus uno Poniceps arcticus im Sommer gern bev Den rarmen $\mathfrak{B a ̊ d}$ en uno Teiden auf, uno

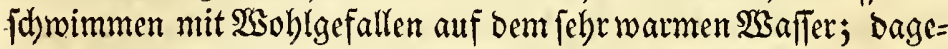
gen balte ich ez für (Eroid)tung, was man mir nod) auf meiner

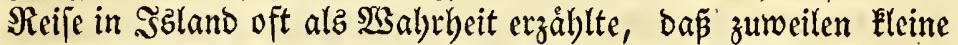

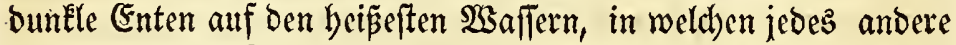
Ihber in furzer 3eit gefodbt fenn mưroe, fdwimmend und fogar untertaud)end gejeben werben. Die Erzáblung ftreitet gegen bie

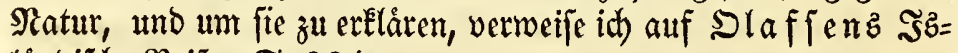

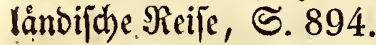

Daß̃ biefés locale Dajenn ber warmen Sucllen im Stande

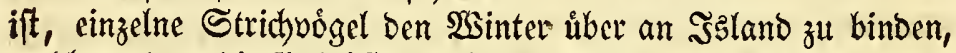

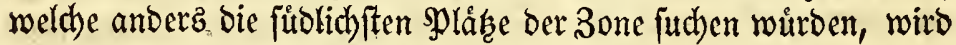
unter anderen bey bem Singidrwan bemerkt; Dagegen Eann man

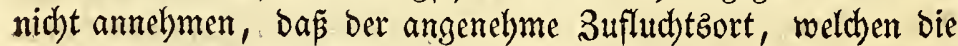
warnen suellen im 2 sinter geben, auth jogar im Stande feyn follte, ben $\mathfrak{B a n d e t u n g s t r i e b ~ b e y ~ b e n ~ w i r k l i c h e n ~ 3 u g b o ́ g e l n ~ e i n z u = ~}$

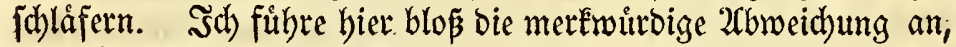

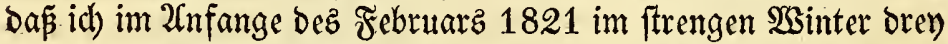
Scosopax gallinago in ber $\mathfrak{A a ̊ b e}$ von warmen Suellen aufflie= gen [al), obgleid) Diejer Sogel ủbrigenz 3uguogel ber borealen Sogelzone ift. Dod verliert biefe 2fbweidyung in etwaz baourd) ihre Jiraft, das bieje Sibnepfe johon in ber feptentrionalen $\mathfrak{B o =}$ gelzone, in weldber bie bånifden Șneln liegen, anfängt ein Stand= vogel zu fenn, meil einige snbivibuen jåbrlich in berjelben $\mathfrak{u} b e r=$ wintern.

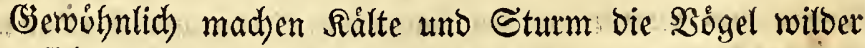
uno vorjichtiger, , fo wie fie andererfeits bey warmer $\mathfrak{B s i t t e r u n g}$ zabm und unvorjidytiger fino. Dicies bemerkt man aud bey ben Stanboogeln eincs \&anbes, weld)e alfo nidt buth bie (sin=

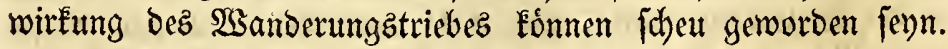
Axas mollissima, clangula uno boschas, wie die 2 rten bes Mengus, welde zur Sommerzeit, befonders wenn fie Eyer le= 


\section{5}

gen, fo fehr zalym find, fliegen im Winter will bey jeber anjedei= nenden (Sefabr umber. Diejes bemertet man fowob) in Jaland,

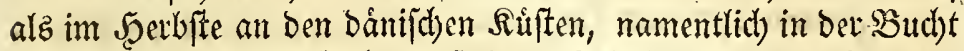
bey Sorfent, wojerbit id) ez oft bemerkt habe; Demn int Rovem=

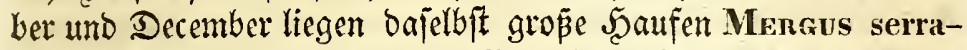
tor, Anss mollissima, glacialis, clangula, marila, fusca,

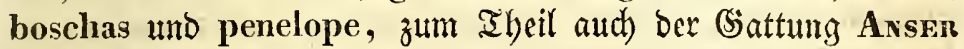

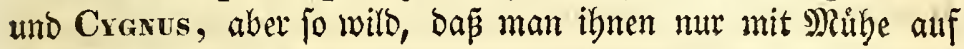
Den Sdur $\tilde{s}_{\mathfrak{s}}$ fonmt.

Dod) bat ftrenge Rálte uno ungenitter nicht immer biefe 2Bithung; fo waren $z$. $\mathfrak{B}$. Convos corax und Lanvis leucopte-

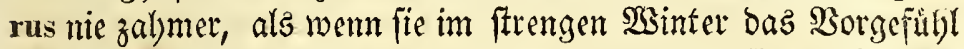
eines $\mathfrak{U}$ ngemitters batten; Denn alsbann nal)men fie mit ftraubi=

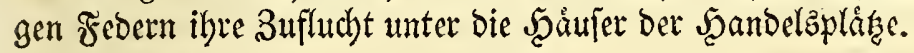

\section{§. 21.}

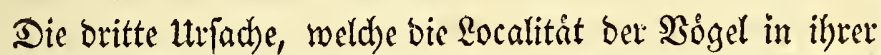
Sone beftimmt, ift c) Die $\mathfrak{R}$ abrung. Siabrungemittel fino eine abfolute Bebingung ilyer thierifhen (Exiffenz; es ift Daher

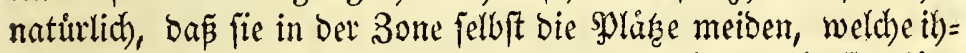

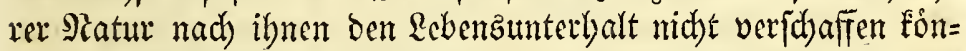

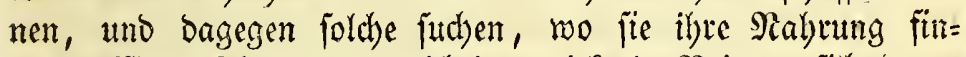

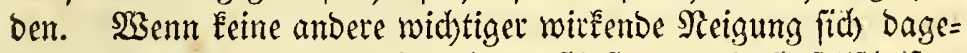

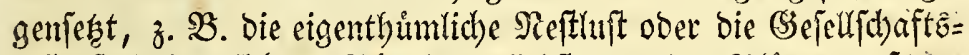

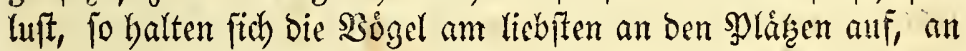

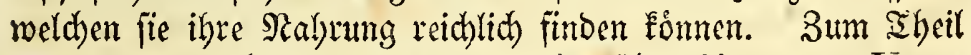
auz biefer utracthe findet man bie islänbijhen 2irten von Unia,

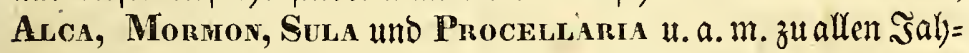
reszzeiten am Meere, und fie bringen nie ins Lano felbft Vinein,

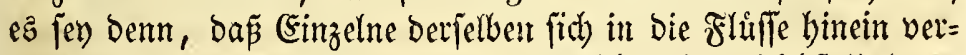
inten; bie 2arten bez CoLymsus balten fidh baher gleidjallz beym Meere auf, wenn fie bas Bruiten an ben füpen Seen beendigt baben. Das Sdjneebuhn witro im Sommer anf J̧eiden, Şsiejen und in Ssebuifichen gefunben, wo es fich von ben Bláttern von

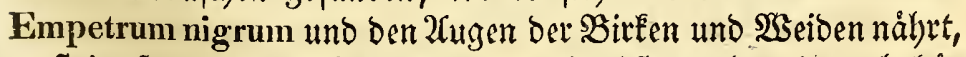
ez fteigt fo wie ber Sdhneeanmer im Scerbfte nadh und nach ho:= ber auf bie Gebirge, wemn ber Sanme ber Sergpflanzen reif ift;

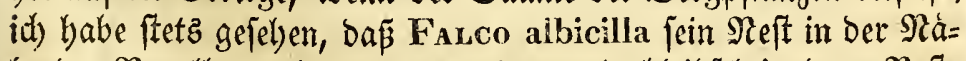
be ber Sogelberge batte, uno viele Heberbleibjel in bem Refte

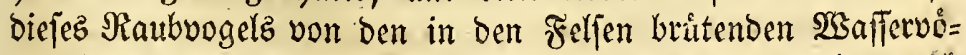

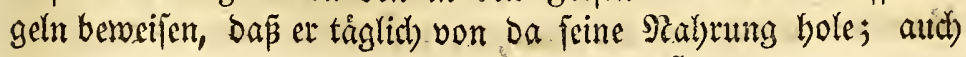


Convus corax bålt fid) sern im Sommer in ber Nåbe ber bru=

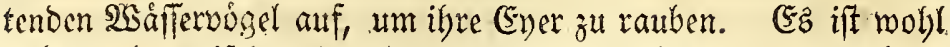

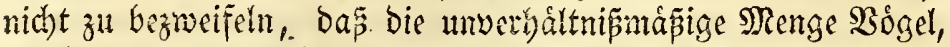
welde im Sommer ber Dem Ranbjee Minvatn nid)t allein von ben Entenarten, fondern aud von Avruus pratensis, Saxicola oenanthe, Numerus phaeopus, Phalanopus cinereus und von methreren gefunden wirb, zum Ihail von ber unglaublichen

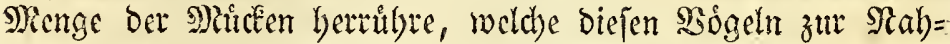
rung bienen, wenn fie nach einem Sisinbe bie Sberfluche uno das Utfer bes Sees bedrden; wir fonnen aud baritber nicht

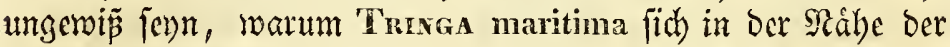
Sdberen auflyalt, weldye zur 3eit ber (Ebbe uiber ber sber= fláche dez Swaflers erfabeinen, wenn man bie Sorgfait be=

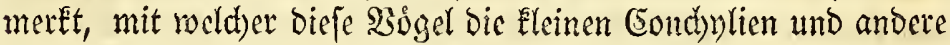

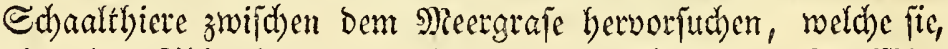

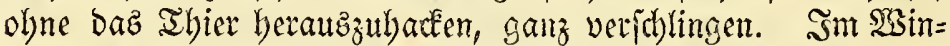
ter ift Der Sabe allezeit in grospter 2 nzabl an Den Sertern, wo man Fijd he trodinct, um bort jeine Beute zu bolen. Somol)l Lestris parasitica, alz pomarina, werden nid)t felten auf ber

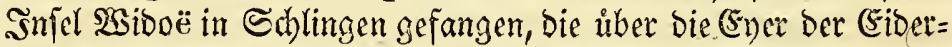
vogel geffellt find, weldbe dieje Ráutber gern ausjanfen wollen. Sn guten Fijdjabren werden grope Sautfen von Puffinus areti-

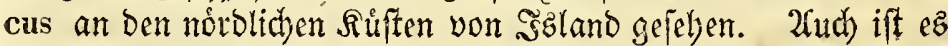
Eeinem 3weifel unterworfen, baj̃ viele ber Saamen effenden $280^{\circ}=$

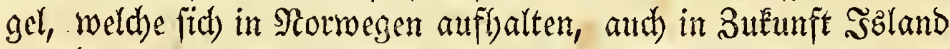
bejuchen witrben, wenn bieje Sinfel Şálder båtte, beren Saame fie crmabren $\mathfrak{k}_{0}$ nnte.

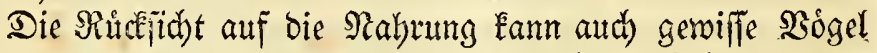
beftimmen, Den \$lás in ber Bone unabgebrochen auf lingere ober fürzere Beit zul veråndern. Procelaaria glacialis uno Larus

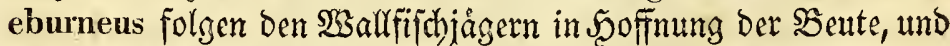
Procellaria pelagica andern ifr begegnenden Gdifiten; LeSTris catarractes folgt den Booten lange nad), weld)e Squalus glacialis mihi (bie izlándifthe Squatus carcharias) fübren, Lanus leucopterus und tridactylas folgen mit gropem (sejderey) dem (sange der fdurell folwimmenden Phoca groenlandica in bie SBuchten, um die Fifate zu fangen, welde die Seehunde vom Soden bez Meerez heraufiagen. Die Seelundjåger begeben

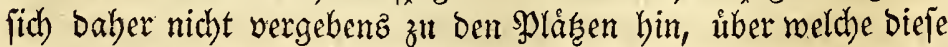
Meven fdrweben. Jal) babe fogar in meinem Sprodromus be= mert, baj die erfte biefer Meven ben Einwohnern auf bem Síd= 


\section{7}

lanbe im Sabre 1821 cincn $\mathfrak{B i n t}$ gab, Daf́p Ganus morhua

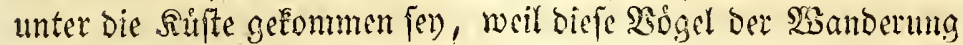

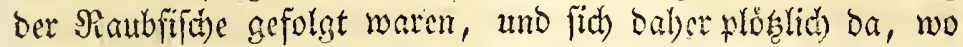
fie vorber nicht waren bemert worben, in Mienge feken liepen. Dex Falke folght Dem (s)ange bez Sothechubnz, fo wie man fagt,

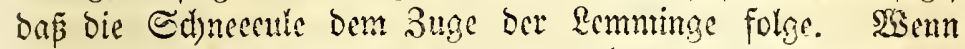

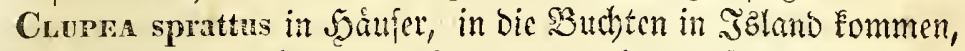

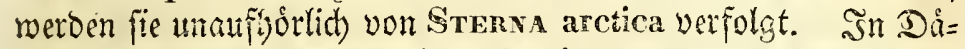

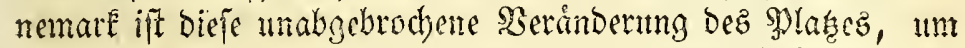
Siabrung zu fuden, beponders bey einigen Grrichvögeln unter ben Singuogdln dez Randes auffarlend, z. BB. bey Pands candatus uno Sruva regulus, weldye in bor Siridzeit mit bar

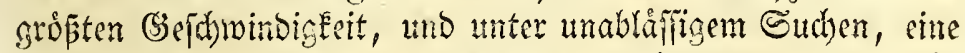
Gtaube nad) Der andern, cinen Saum nadi) Dem andern Durd)= ftreiden, uno fich Eaum Beit laffen, Die gefundene Pabrumg zu

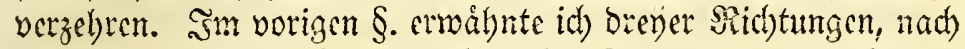
melden bie Ctranovogel der bolcalen 3one gegen ben Kyinter freiden. Diefe Stridje nelymen fie jebod) cher Dep̧yalb vor, um in eine milbere Enfttemperatur zu fommen, als ttm cine reichlichere Nabrung zu erbalten; wenigftens ftreichen einige Fifiche effente

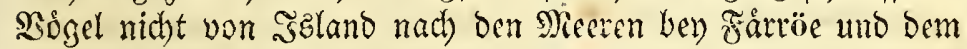
füblichen Norwegen aub Nangel an Nabrung, Da gerabe in ben. Wintermonaten bie berfatebenen Fifdatten in. Menge in bie bie Infel umgebenden sneere fommen.

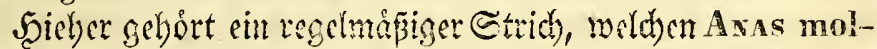
lissima táglidb vornimmt. Sid) babe oft in Szland bemertet, und. Fabriciuz erwábnt Deffen in dei Fauna groenlandica, S. 69

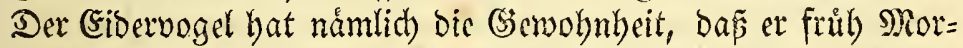

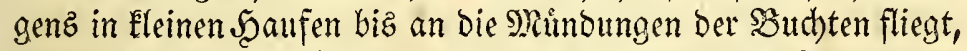
um Rabrung zu fuchen, und Des 20 bends in Daz Snnere Der Budften roieder zurudfebrt. 2TuF biejem Stride folgt ar ben Srimmungen ber şudbten io senau, daî er mit feinem Fluge, fo zu lagen, die linie befchreibt, weld)e burd ben Bufammen= ftố bez Randes mit dem Meere bervorgebradyt miro. Da ez ben Stoptaucbern, weldhe gemeiniglid) zugleich febr gefrảpitg find,

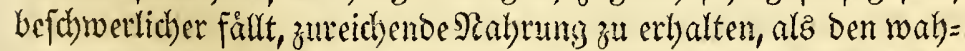

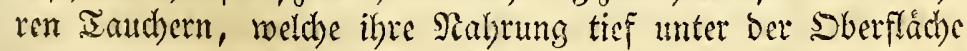

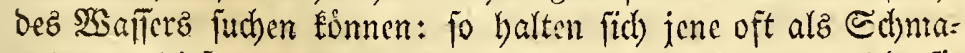
roter zu biejen, um Ibeil an Der Basute zu nebmen, meldse fie fid) felbft bolen. 3ut Saufen fdowimmender Enten, Itrien ober alfen gefellen fich) oft Lanus marinus uno glaucis, in Dåne= 
maik Lanus argentatus unt canus, und $e \mathfrak{E}$ zeigt jid gleid), Dap

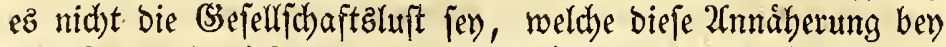
ben Reven bewirkt, weil bieje gleich zum Streite fertig find, wemi fie cinige Beute bey ben Sabinmmtauthern entbecken. Die Lestris - 2frten verfolgen jogar fliegend andere Sdywimmer, befonderz Stenxa arctica, um fie zu zwingen, bie gefifd te Beute fal)ren zu laffen, weldbe fie mit einer ifnen eigenen Fertigkeit el=

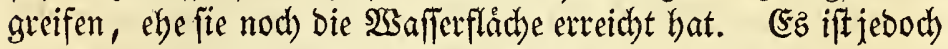

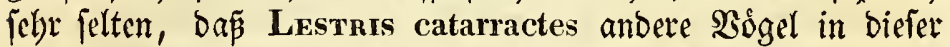
2lbjicht verfolgt, und gejhieht ez, fo find ez nut bie gróperen Reven unb der Todlpel, weil diejer Lestris, in noch bóberem (3)rabe ráuberijô, alz Lestris parasitica und pomarina, fich

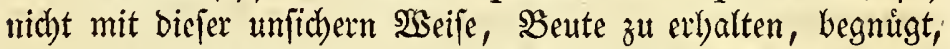
jonbern franke Sógcl birect angreift, uno bie Sungen ber $\mathfrak{B a}$ af=

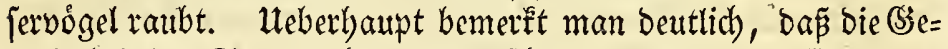
wohnheit ber Stoptaucher, ibren fdwimmenden ober fliegenden Sronungzverwandten ifren Raub abzuzwingen, in Demjelben

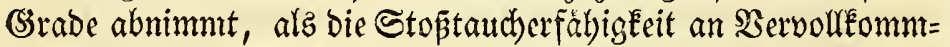
nung zunimmt. Daber wirb biefe Schmarofernatur gar nicht bey ber Sura alba bemertet, welche aud Reprájentant bes auts= gebildeten Stoptautchers ift; fo ift fie aud bey ben 2rten ber Sterna oder Larus tridactylus allgentein, weldhe alle gute Stoptaucher find, und baher felbft fưr ibren unterbalt forgen Eỏnnen; Dagegen ift biefe (Sewobnheit bey Den vorerwåhnten Reven und Raubureven allgemein, weldhe von ber Natur nut geringe Stoptaucherfåhigkeit erbalten baben. Sine andere (5i= genichaft, welde alle 2irten ber Stoptaucher ber (S)attungen Sula, Sterna, Larus, Lestris, Procellaria, mit meldyen fid aud) Puffinus vereinigt, ohne 2 uznabme befifen, ift biele,

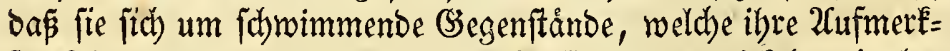
jamkeit exregen, verjammeln uno fie fliegend umzinfeln, insbe=

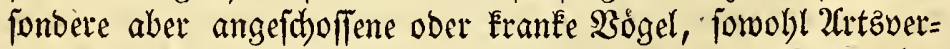

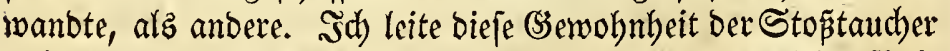
nidht blop von ber Reugierbe, nod) weniger von einem Mitgefüble ber, fonbern da ihr jharfez 2uge gar bald jebe (Stelegenbeit,

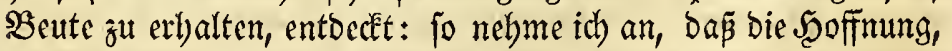
einen $\Re a u b$ zu finden, fie nach jedem ungemóhnlichen (Stegen= fande hinzicht. Dod ift ez fonderbar; bấ vornebmlids STErsa arctica und einige 2 rten von Lanus, namentlich L. leucopterus und argentatus, wenn fie fid to um ihre verwundeten 2 rttz= verwailtoten herum verfammeln, fdreiend fortfabren, nach $i \mathfrak{b}=$ 
nen zu ftopen, uno fie gleid)fam zu neckér.. Die Såger, meldse bieje (Eigenjchaft ber M) Reven und Meerid)walben jeht mohl Eennen, werfen Daber gejhoffene Sögel ober andere (Segenftánde, Die ibre 2 ufmerkjamkeit erregen Eonnen, in bie $2 u f t$, wenn fie jene berzuloden wollen.

\section{§. 22.}

d) Die Siberbeitslu fit ober Die Neigung ber Bỏgel,

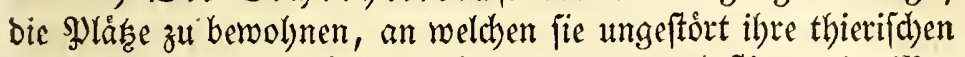
Functionen aushben fonnen, ift bas leşte plaţbeftimmente Ro= tiv fir jie in ibrer Geburtbzone. Sie jud)en aus Den (Segenden, wo fie oft beunrubigt und verfolgt werden, rach ficherern splásen. Feinde Eónmen die Bógel jowobl an lebenden, alz an leblolen Giegenftầnden baben.

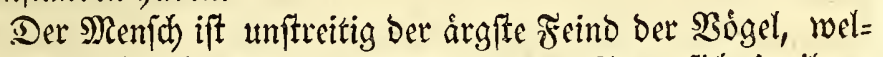

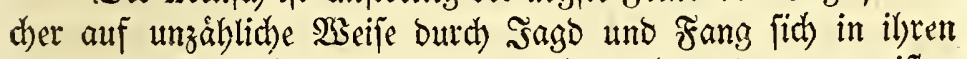
Befit zut jesen jutht. Daher fino aud bie (S)genden am meiften

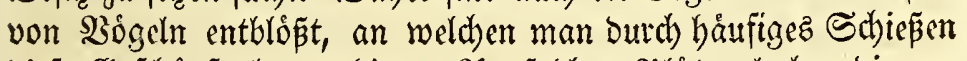

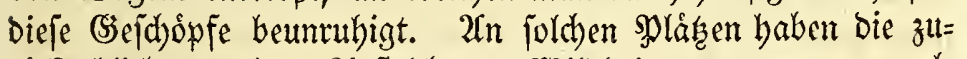

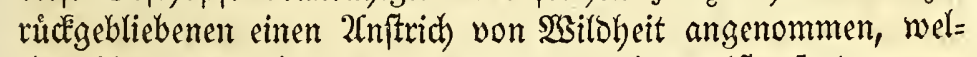
d)er ubrigens nicht in il)rer Matur gegrimbet ift, fonbern von ben håufigen Serfolgungen herrilyrt, benen fie atzegejefst find.

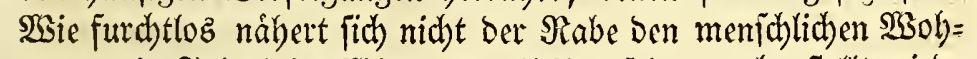
nungen in Szland im Ssinter, weil ifm felten nad) $\mathfrak{S e f t e l l t}$ wirb; in Dánemare ift er bingegen zu Derfelben Seit focheu und vorfidjtig.

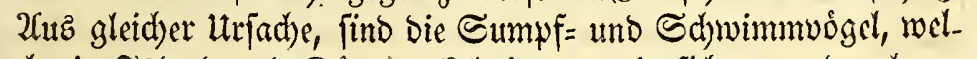
dhe in şzland und Sánemark bruten, weit fidserer uno zalymer

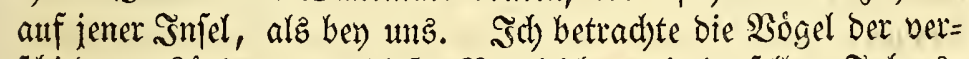
ichiebenen Ránder unter diejer Bergleichung in berjelben Sabres= zeit, weil es nid)t allein 2 erfolgung ober Friebe ift, weld)e $23 i l(d=$ beit ober 3abmbeit bey bem fondern aud veridbiebene Sitiebe, welde zu veridjiebenen 3citen

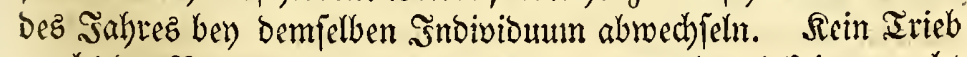
madt ben Bogel zallmer, alz ber \$paarungstricb, und Eciner madbt ifn wilder, als ber $\mathfrak{B s a n d e r u n g s t r i e b ; ~ b e s b a l b ~ f i n d ~ z . ~} \mathfrak{B}$. NuMErius phaeopus, verjobiedene 2arten ber Enten und (3̧ånje,

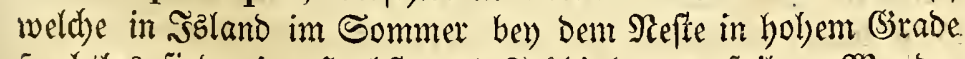
furdjtlos find, im Sperbfte und Frubjabre, auf ilyer $\mathfrak{B a n b e}=$

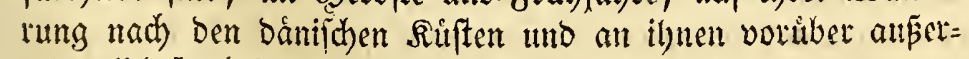
orbentlid) furdtian und wild.

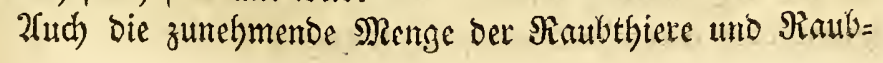


vógel Eann bie $\mathfrak{B} \delta g e l$ babfn bringen, Dap fie fid) alts einer (Siegeno ber 3one nad) Der andern binbegeben. (Fin auffallendes Seipiel biefer 2rit haben wir in Dem leşten Decennium in Dånemare ge= babt. Sn biefem 3eitraume námlid hat fid) ber Şausmarber in zunelymender Menge in Fifhnen uno Dem o̊ftliden Sittano ausgebreitet, utb zat berfelben 3eit ift Corvus pica nad) gerabe beynah ganz auz biefen (Segenden verfdrwunden, wo fie vorker

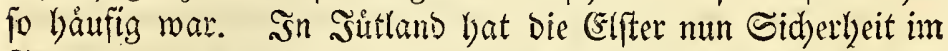
Snnern bes Randes in ben Seibegegenden uno auf ber 2 seft=

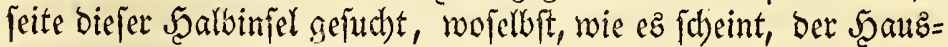
marder fich nicht in Mense berbreitet lat.*)

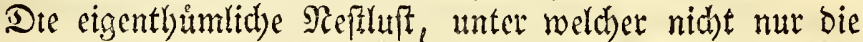
Neigung bes Bogelz, unter Der lumgebung von Materien einer gerwiffen 2rt, fondern vorziglid) unter ber utmgebung gewiffer befannten inbiviouellen Materien zu bauen, verftamben wird,

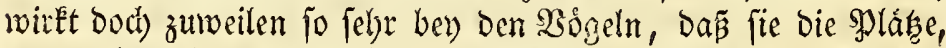

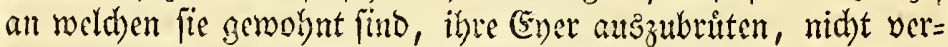
laffen wollen, ob fie gleidh unablaffig ourd) bie unmittelbare siábe eimes raubgierigen Feindes bedrobt werben. So babe id fhon

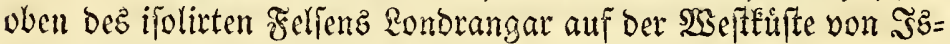
land crméhnt, auf befîen Geiten eine Menge Auca torda und Larts tridactylus mit mebreren jo̊brlich bruten, objobon Faco albicilla fein Sieft auf dem Sipfel Deflelben Felfens bat, uno im= met bie unten britenden $\mathfrak{2}$ affervogel buth feine Serwegungen et=

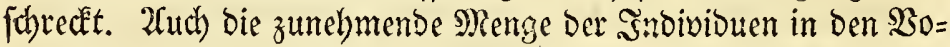
gelbergen, obfdon bie (sinwolyner jâbrlid) einen gropen Ih seil ber Eyer und Sungen ber $\mathfrak{W a f f e r v o g e l ~ m e g n e b m e n , ~ f o w i e ~ d i e ~ j a ̊ h r l i d b e ~}$ 2nkunft Der Eidservogal und anderer (Enten bei ben alten Brute= pláfen, ob fie gleich jåbrlich ibrer Dunen und Eyer beraubt wer= Den, zeigen, mit weldber (Ergebenbeit die \$ógel Der Regel nach an ben şláken bången, weldye fie einmal zu Brutepláken ge= roảblt baben.

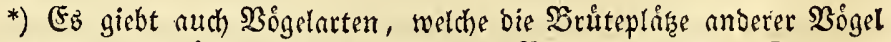
zu bem ihrigen erwiblen, um badurch ihre Brut zu firtern. Dab aufz fallendite $\mathfrak{B}$ eifpiel hiervon in J̈lano findet man bey ANas mollissima, bie fehr gern in ecr Mitte ciner Rolonie von Sterva arctica brittet, woburdh Die Ever Diefer Ente gegen Die Slachfteillungen ber Siaubmeven gejhhitht werden; benn, wenn ein folcher Mläuber fid ben Bruteplátsen ber nordi= fohen Seeftwalben nakert, fo verfolgen biefe ilgn haufenweife, uno verthei= bigen auf bieje $2(r t$ bie Ener Der (Eiber=Ente zugleid) mit ihren eigenen. Die= fes ift Den Einwohnern befannt, tund fie fehen ez Daber gern, bas bie

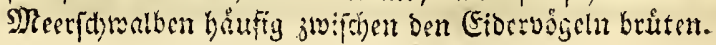


\$senn man im weitlåuftigften Berfiande die leblofen phyfix

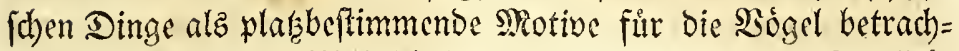
tet, fo werden zum Iheil die orey vorlyergehenben, die socalitát begrindenden utraadien barunter begriften; es giebt aber audb fol= che leblofe Dinge, beren Berilyrung die Bögel furduten, Dabev

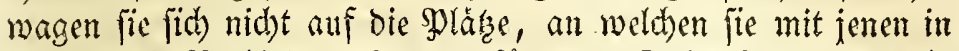
eine zu nabe Sherbinbung fommen tonnten. Daber fommt ez auch,

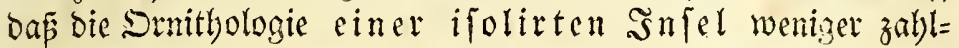
reid) ift, als fie ber $\Re e g e l$ nad) fenn Eonnte, wenn fie (Sontinent

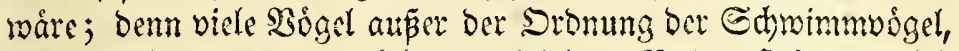

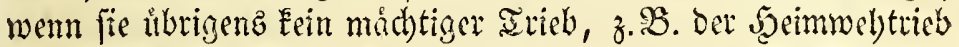

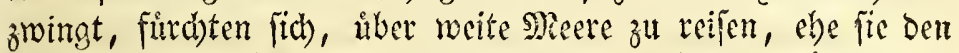
Punct, auf weld)em fie librigens ihr Leben zubringen E⿱ónen, zu erreiden im Stande find; fie verbleiben balser lieber in Den (Segen=

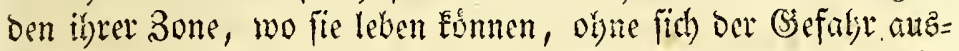

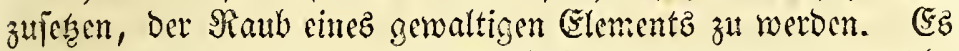
giebt verjdiedene $3 u g=$ und Etriduodgel in Slormegen, weld)e ihrer Satur nach in ŞEland leben fonmen, uno wetde gemiz aud) ba gefunden wurben, wenn dieje Injel mit Scandinavien land=

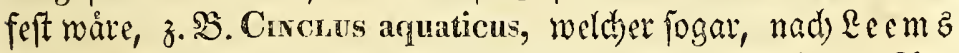
Berict) von biciem Rande, in Rappland Gefimben wirb. 2Tus

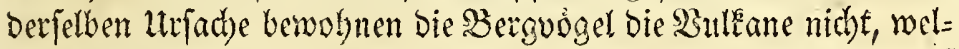
che oft im 2 fubbudse find, wenn fie aud gleid) ilyre labrung auf bisfen finben fonnten. Sie nádblten Gegenden, weld)e bie bren=

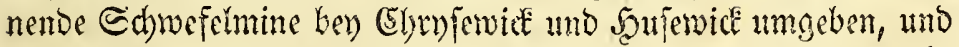

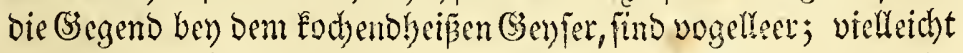

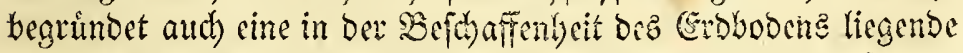

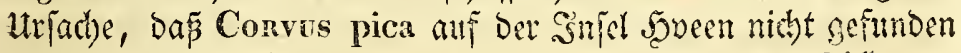
wirb, ob fie gleid) auf ber geiabe gegentberliegenden Silfe von Scelans båufig ift.

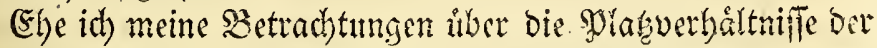

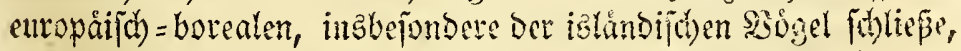

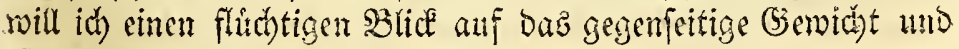
Şinken biefer \&etbattuiffe werfen.

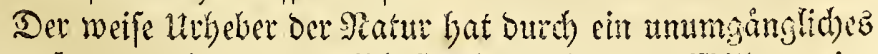
Naturgefes, Durd) cinen in fid) ferbit gegrinbeten Stillen, eine

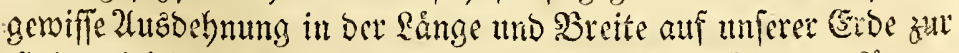

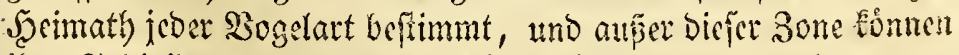

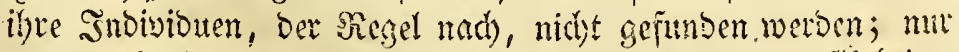

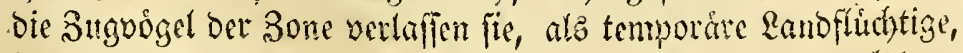

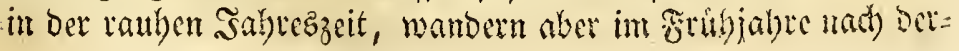




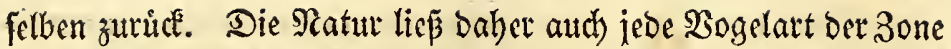
bie Bebingungen in berjelben finben, weld)e zur (Erbaltung ibres Rebens erforberlid find. Saenn wil uns nun ben Fall benken

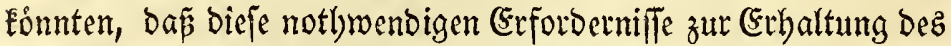

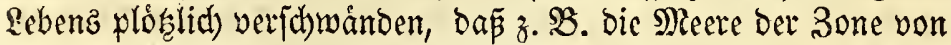

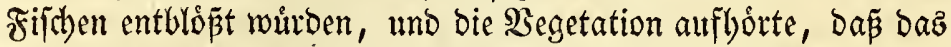

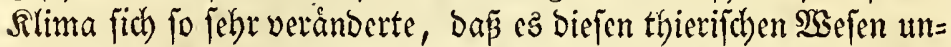
ertråglid) witrbe: fo ftánde ez bahin, ob bie Stantoỏgel biefer 3one, burch ein Naturgejes an biejelbe gebunden, cin Spfer bie= fer plyyfifd)en Revolution berfelben werden wirben, obne fie zut verlaffen, ober ob fie in biejem Falle in bie zunád)ft angrenzende Bone hineintreten witrden, um in ber Folge bajelbit Standvoigel

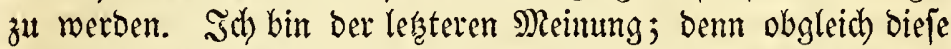

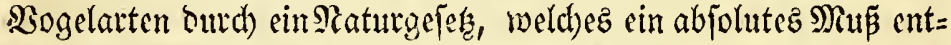
bielt, eben an biejen Slates ber Frbe bingejef̧t, und barauf ein=

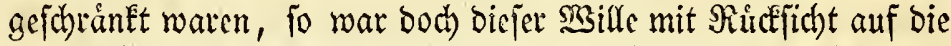
gegennartigen Bebingungen motivitt, weld)e bas thierijche \&eben

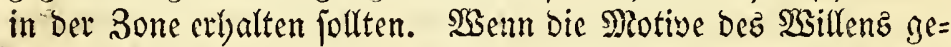

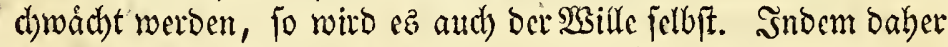

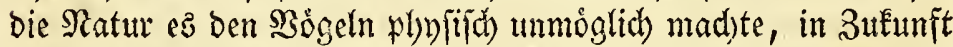
Das Notlywendige zur (Exiftenz ibres \&ebens in Der Sone zu finden,

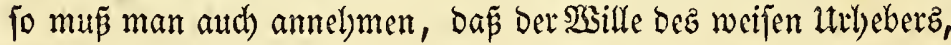
weld)er jenes saturgefer grimbete, es wieber aufgeboben, und

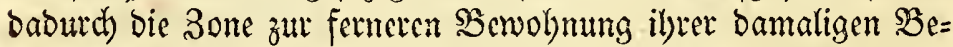
wobner anmullitt babe. (Es wurtbe daber logifd) móglid) fenn, baßj die Stanbodgel einer 3one bicje vetlaffen fonnten, um Stand= vógel in einer angrenzenden zu werben, objd)on biep in foweit unmoglidy ift, als bie phyfijchen thifachen, weldhe biefes zut= nád) peranlafien follen, nie eintieten werben.

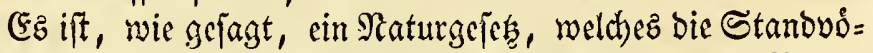

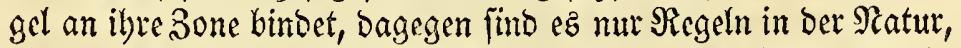

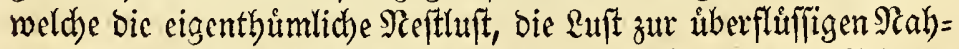
rung, zu einem milben Slima, und zur Sidjerl)eit vor Feimben

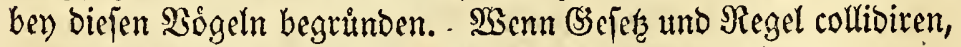
fo mus bie leştere weichen. Wir Eonnen baher nidbt annebmen, baß ein Stanowogel anz ben beroobnbaten Grengen feiner 3one (d) leiten wetbe, ob et gleid) in einer andern 3one bequemere Bri= tepláfe, beflere Sabumg, befieres Slima und grópere Sidberheit finden Eonnte. SEir finden biefes atth nid)t burd) bie Erfabrung beftatigt. Sim Gegentbeil giebt es vicle Stanobogel in ber borea= len 20gelzolie, weld) cin Spfer eince cillzelnen eintretenden Mi 
wadbfez wurben, was ihnen nicht miberfabren wuirbe, wenn fie (ich) nach einer fiblid)ern 3one begáben. In ben Sabren, in rel=

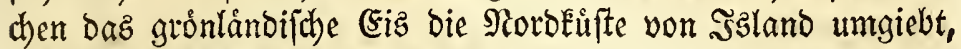
nebmen Una Brünichii $\mathfrak{u}$ o alle verbungert uno erfroren, fd)aarenweife ibre 3ufludtst zu ben großen und Eleinen Budten, unb begeben fich) fogar aufz \&and linauf, wo fie entweber verbun= gern oder eine Beute ber Menfochen und der Raubthiere werben, anftatt baj fie, wenn fie fublid)er gewandert wåken, ben gewiffen Tob vermieben bátten. Sula alba, weldber ein Stanbyogel ber borealen Mere ift, treibt in gerwifjen Sabren, wenn bie Fi=

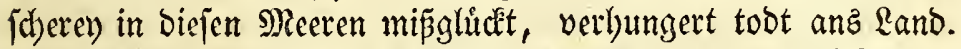
Larus lencopterus und eburneus, Proceluarra glacialis und andere Bewobner ber norblicbiten Meere, kónnten, wenigftens in gerwiffen $\mathfrak{W}$ intern, in ber Sone, in welcher die bảnifben Siften liegen, beffer ibre sabrung finden, wenn fie nidjt burd) ein

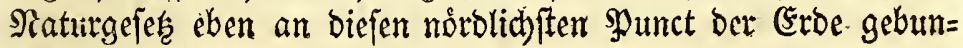
Den roárent.

Sbgleid) bie eigenthumliche Reftuft einen bebeutenden (sin= flup bey ben Bogeln Gat, um ibren splás in ber 3one felbit ju be= fitimmen: fo rourde fie bod) aud nid)t vermogend jenn, ben Stand= vogel auz ben (Srenzen feiner Bone zu ziehen, wenn er gleid) in ber 3one jelbit keine guten Brútepláke melyr finden konnte, er wurbe eher den minder bequemen ben \$orzug geben, ebe er die

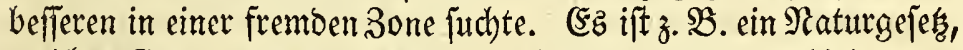
weldes Conmbus glacialis an bie boreale. Sogelzone bindet; es ift eine Siegel in ber Satur, baß̄ biejer Bogel feine Ener bey jüpen Ranojeen zwifhen ben Gebirgen ausbruten foll. SSenn es bentbar

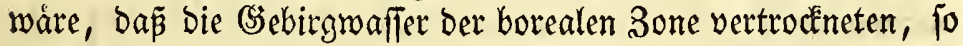
wurbe biejer Courmbus lieber feine (5yer am jalzigen $2 \mathfrak{b a f f e r}$ ber borealen Sone auabrutten, alz nach ben Bergíen ber jeptentrio= nalen Sone zieben, um ba zu bruten.

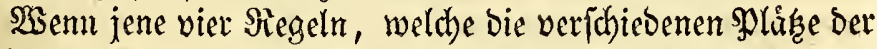
Bógel innerbalb ber 3one beftimmen, unter fich in Collifion gera= then, fo babe idy fchon, bew der abbandung jeder einzelnen, ge=

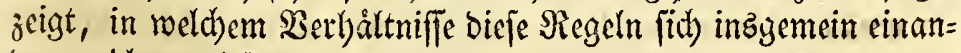
Det meid)en mitfen. 


\section{It}

II.

\section{Bon ben Saarungzberháltuiffen ber

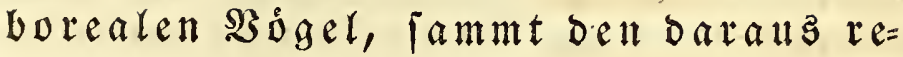 fultirenden oder damit verbunde= nen $\mathfrak{B e r h a ́ l t n i f f e n . ~}$}

\section{§. 23.}

Benn die 3ugoógel im Fritgjabre durch ifren Şeimmeltrieb

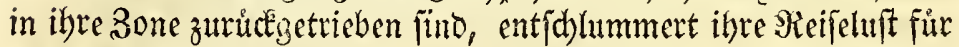
biejes Mal, und ein Irieb, ber fie Eraffiger an bie ermáblten Mlăbe feffelt, ermacht, nåmlich ber şa arungztrieb. Die= fer Eơnnte befinitt werben als Der Irieb, welder bie Bỏget ver=

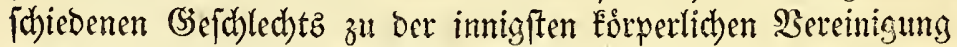

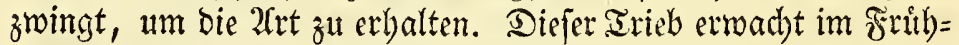

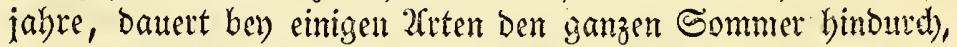
entichlummert aber wieder im berbjte uno S3inter. Der $\Re e g e l$ nach åtreert er fich eber bey ben Stand =, alz bey Den 3uguoggeln

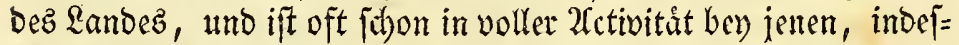
fen bieje fich nod) auf ibrem 3uge befinden. Der paarungstrieb

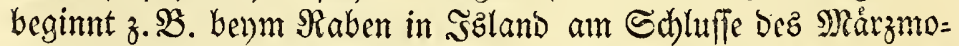
natz, ehe noch einige 3uguoigel bes Lanoes angetommen find; in Dånemark babe ich feime bernah fluggen Sungen in oer Mitte bez Raymonats gefunden, ebe nod) unfere zullest ankommenden Syl= vien zu unz gefommen waten. Procelcaria glacialis legt in

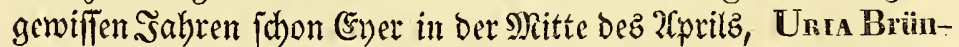
nichii, troile uno Alca torda, nátern jid) segen daz (Ende Deß

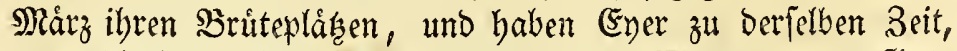

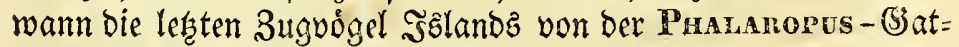
tung nadb Der Infel fommen.

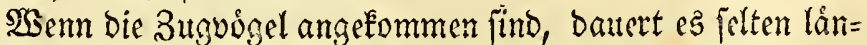

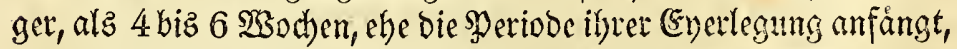

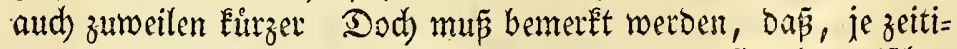

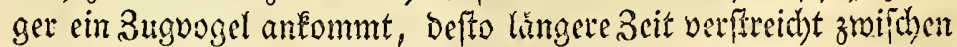

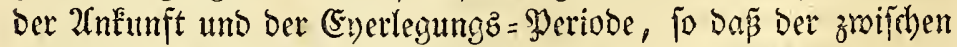

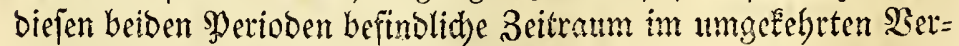

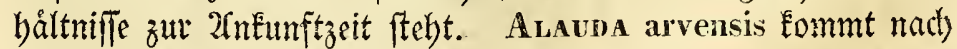

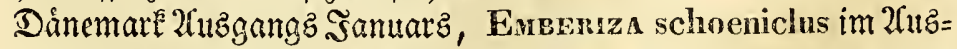
gange dez Februars, Cuaradrivs hiąticula in 2infange dę 


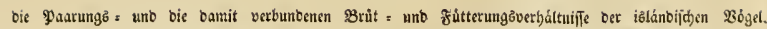

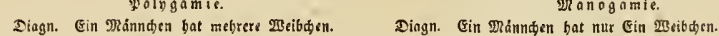

Die s a f a m m a gefetiste.

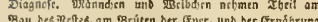

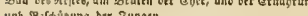

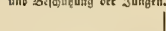

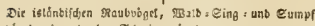

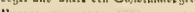

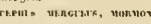

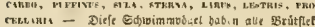

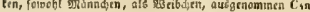

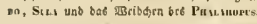

3 4 1 rage

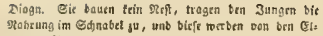
turn rendibrt

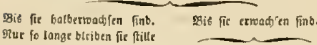

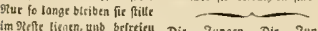
im Sirfte likgten, unb brirrieu Die 3ungen, Dit 3ungen,

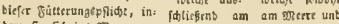

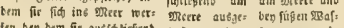

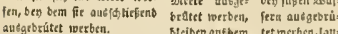
A.r., I HIS. Stetiben aufbem tetrocrben, Iatt

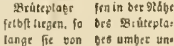

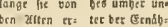

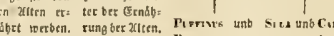
$\left.\right|_{\text {crmertamer- }}$ Crprrtimer-
Eulur, Mun-

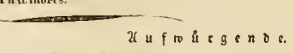

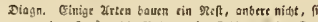
tragen sen 3urgen bie शrabrung im Edtunbe ober Sro.

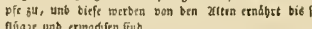

Die 3ungru Striben unter ber ₹ütterting

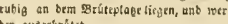
ub fotiefertib am 2Recte fet 6 ft, too bie zetten

in seft bast Ein serf bau

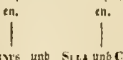

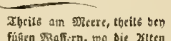

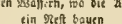
। C⿺Rso corenorant.
Diem mitiex

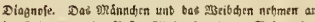

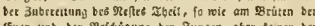

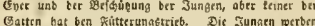
glcid nafl ber zustritung ine

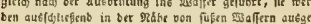
brite

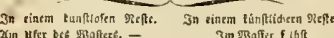

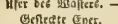

|

Cตnเงอ

.

and

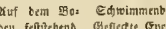
ninarficets

Mnacfict.
Ener. I

Dic is

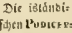

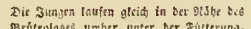

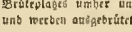

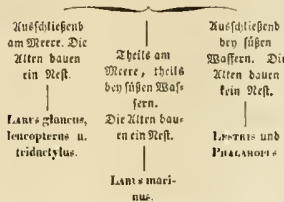

Xuefdiliegent פroffern. Dit

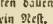

$\operatorname{lom}_{x \rightarrow \text { the }}$ nuk.

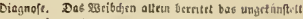

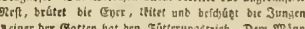

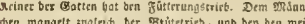

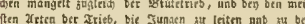

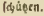

$-$

at Diefe

bem gante

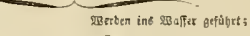

Lacoeri

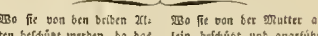

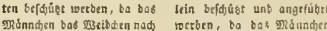

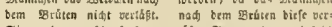

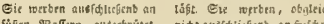

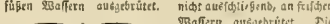

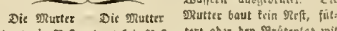

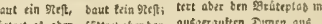
nidet mils aus gRriteptos mit

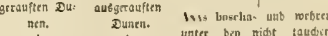
| 1 uater ben midet taldidin:

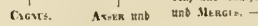

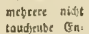

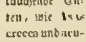



Mårz; fie legen aber bod) nid)t yor Der Mitte dez 2fprits (Eyer, und fo verfle $\bar{\beta}$ te fdhen ilyrer reppectiven 2 fnkunft und bem Eyerlegen. Dagegen

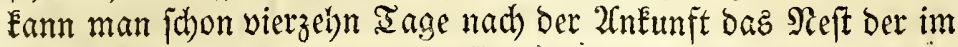

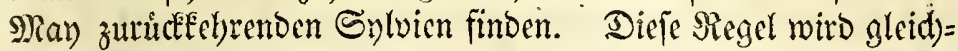

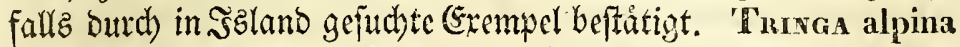
und Scolopax gallinago fommen zu 2 fügang 2 farils nach biejer

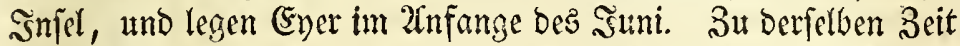
haben jogon Phalaropus cinereus umb Stersa aretica autch Eyer, ob bieje fichon beynah einen ganzen Monat jpáter antom= men, als jene Sumpipógel. -

Die Berlyáltriffe, weld)e zunådyt aus bem (Erwadjen bes Paarungstriebes rejulticen, fỏnnen \$aarunģuerbåltniffe genannt

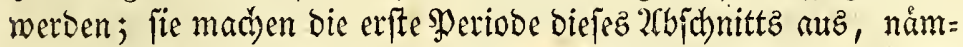

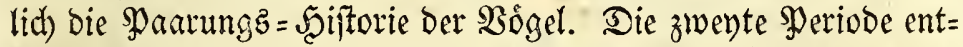
hålt bie Şiftorie bes Eyerlegenz uno des Sruitens. Die britte \$yeriode ilyre Fortterungs = Șiftorie.

\section{§. 23.}

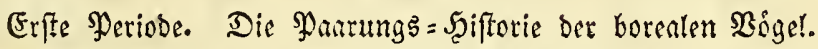

Das (Erwadhen Dez Maarungztriebes bewiefte eine gro

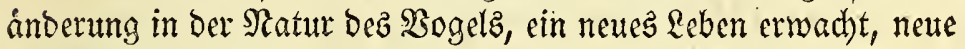

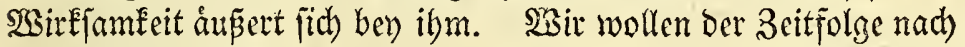

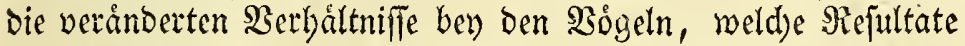
Des erwad)enden paarungstriebes find, betrad)ten, námlid): a) Dic $\mathfrak{B}$ ruttrad)t. b) Die $2(6$ bonderung Der in Şaufen ziebenden

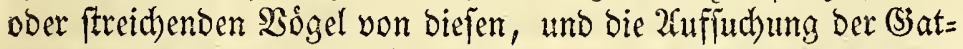
ten. c) Shbre partweife Bereinigung. d) Dic $\mathfrak{s a b ! ~ b e s ~ B r u t e = ~}$ platęes. e) Die Berånberung ber Stimme oder bą (srwadhen einer neten. f) Die Berånderung îyres åuperen 2 sejeñ. g) Die Sergenwart der Brưteflecken. h) Die 3ubercitung ober ber Bau

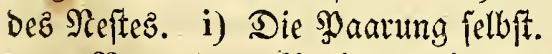

Bon Der SBruttrad)t. Bevor idh den Begrifi Der

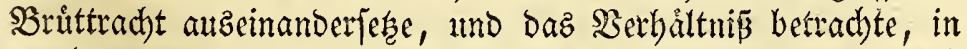
welchem fie zut bem erwad)enden şaarungstriebe frellt, werbe id, verfudjen, bie allgemeinen Momente allugeben, weidde in bem

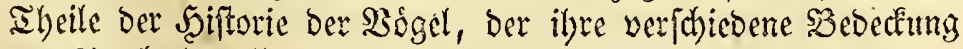
und Iracht betrifit, ein (Segenftand unferer Unterfudyung werben

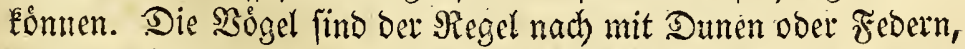

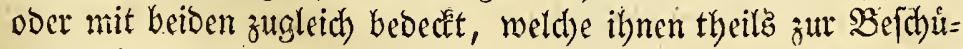
fent bienen, theils ibre Bewegung beforbern. Diefe Bebeckung 


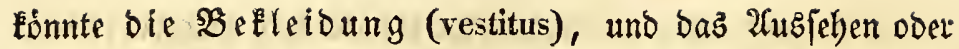

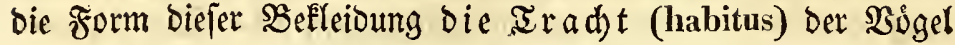
genannt werben. Die Sefleibung Der Sogel theilt fich in zwen Ibeile, nacbdem entweder Dunen (plumulae) ober Febern (plumae s. pennae) die práboninirende şekleibung find; Daburch ent=

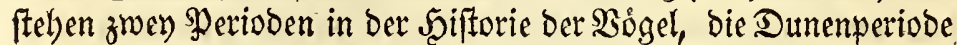
und die Feberperiode. Da bie Dunenperiode gemeiniglith bie erfte Speriode im Leben ber $\mathfrak{B o g}$ el ift, in weld)er fie als sunge nod)

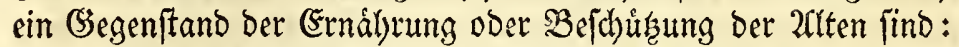
fo werbe id bie Betradtungen der Dumenbefleibung ber fpatertin abzubandelnden Futterungshiftorie benfingen, uno bier gleid) bie. Sógel in ibrer Feberbelleibung betrachten. Diefe bat nicht beftán= dig biefelbe Farbe, fondern verandert jich, forwie die 2fugen, ber

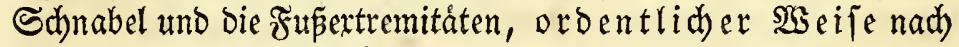

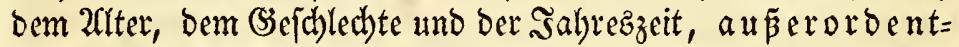
(i d) nach Den Snoivibuen. Saber bie 2 usobruke : alte uno junge Iradht, Sommer = und SSintertradht, SBrittrad)t u. j.w.

In Betrad)t ber Dunen lann die Tradht ber Bogel bie vorabergebende (habitus transiens) genamnt werden, wenn bas Indivis fie mut bis zu einer beftimmten 3eit belyált, und fie barauf verliert, z. B. Die Sradt ber jungen $\mathfrak{B o g}$ gel, und bie fort= bauernbe (habitus permanens), wenn fie, nachbem jie erhalten

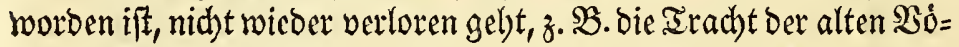
gel nad Dem (sejd)ledte. Die voribeigehende Irad) Eann wieder die ver $\{\mathfrak{d}$ windende (habitus effluens) feyn, wenn bie Tradt, nachbem fie verloren worden, nid)t wieder erbalten wirb, $z . \mathfrak{Z}$. bie Tradt ber jungen $\mathfrak{B o g}$ gel nach bem 2Uter, uno bie a bwed)= felnde (habitus alternans), wenn bie Irad)t mit einer andern vertauid wirb, weldhe nach einer gemifien Beit wieber mit ber erften abwechjelt, z. SB. Die Tradbt nad) Den Sabrezzeiten.

Sn $2 \mathfrak{n}$ jebung ber $\mathfrak{s}$ abrezzeiten (habitus tempestatis) ift bie Iracht oie Sommertrad)t (habitus aestivus oder nuptialis), weldye im Frufjialure und Sommer, bie $\mathfrak{3}$ intertrad $t$

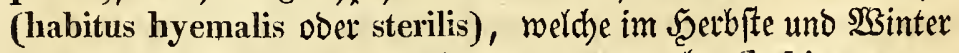
getragen witb, und bie $\mathfrak{u}$ ebergang $z$ trad)t (habitus accedens), welche zut ber 3eit getragen wirb, wenn bie Irad)ten nach ben Sabreszeiten mit cinander abwed) jeln.

Sn $2 \mathfrak{n}$ jelyung bez (Sechlechtz (habitus sexualis) iff fie bie mánnlidhe (habitus masculinus), weldbe bie Mănnchen be= bect, uno bie weiblithe (habitus foemininus), weld)e bie Weibd)en bedect.t. 
In 2 njefung bes afterz ift bie Iracht ble junge (habitus juvenis), wenn fie von einem jungen, und bie alt $\mathfrak{e} \mathfrak{i} \mathfrak{r} a d t$ (habitus adultus s. perfectus), wenn fic von einem alten 20 gel getragen wirb. Die junge Iradyt ift ferner bie Sefttradt

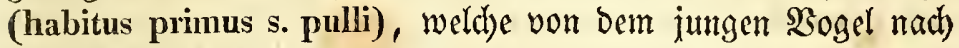
Der 2luabrutung aut Dem (Ev), ehe bie Febern bervorwad)jen, die jågrige (habitus hornotinus), weldbe vom jungen Bogel nacb) ber (Erlyaltung Der Febern bis zur erifen Maujerung, bie cinjábrige (habitus annotinus), weldhe von bem jungen $20=$ gel nad) ber erften und vor ber andern Serbftmauferung getragen witb, bie zweyjálige (habitus biennis), bie breyjál)= rige (habitus triennis) u. f.w.

Nade der Materte ift die Trad)t bie Febertrad)t (hatbitus plumatilis), wenn bie B̧efleibung, auE ber fie befteht, F̌e= bern find, bie Dunentrad)t (habitus plumulis tectus), menn die Befletoung Dunen fino, bie na dit te (habitus nudus), wenn

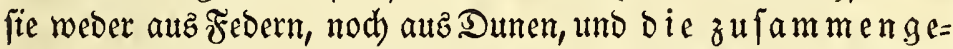
fer te (habitus compositus), menn fie ati biejen beiben beftelyt.

Die Serånberung ber Irad)t bez Bogetz ift to tal, wem

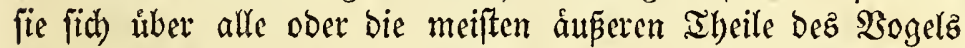
verbreitet, und partial, wenn fie nutr einen einzelnen Ibeil bez

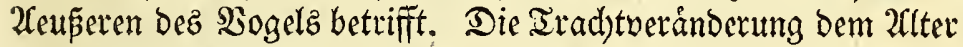
nach ift ofters total, nad) ben Sabreszeiten hingegen oft partial.

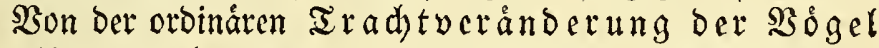
bem $\mathfrak{a r t}$ er nadb. Wsenn die jungen Bógel bie Federbedectung

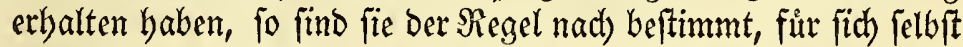
zu forgen, und ber Dpflege ber 2atten entzogen zu werden, ez fer)

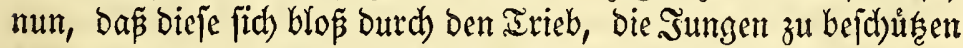
und anzuffübren, áuperte, z. B. bey Awas, ober zugleid) burdh ben Irieb, fie zu ernåbren, z. B. ben Alca. Diefe Triebe entid)tum= mern baber gemeiniglich ben ben 2flten, wenn bie ștngen federn erbalten Gaben, uno wirken mur fporabifd bey einzelnen 2(rten auf bie mit rebern bedeeften Sungen. Daber ift bey den Jungen ber Arten, von weldhen bie 2Olten ben Futterungstrieb zeigen, bie Err=

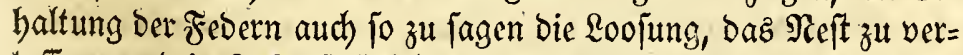

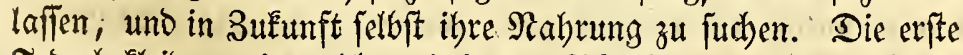
Federbekleibung, in welderer bie jungen Bogel unmittelbar nach ber Dunenperiobe erfdceinen, ift gemeiniglid febr von ber Iracht ver= fabieben, welche fie fpáterbin erbalten werben, unb ibr 2 fus fehen náhert fidh mebr bem des alten $\mathfrak{3 s e i b d y e n z ; ~ a l z ~ b e m ~ b e z ~ a l t e n ~}$

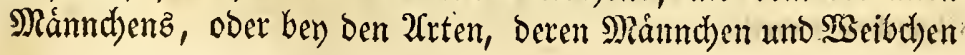


Diefelbe farbe baben, mebr ilyrer Sinter =, als ĭhrer Sommer= trad)t, , no die SBerinderung nad) Den Jahrezzeiten Statt findet: 3uwcilen konnen bieje Siegeln auf bie erite Freberbefleibung Dev Jüngen nidht angewendet wetoen, z. B. bey Den Saubvỏgeln uno bey eimigen Singuogeln.

Beyjpiele. Saz junge Edynel)ubn gleidht in ber Sommer=

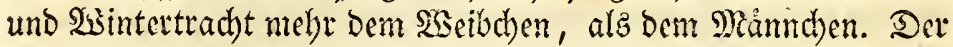
junge.Charadrios pluvialis, 'Totanus calidris, Strmesuas collaris, 'Privga maritima uno alpina, die Šungen det (Sattungen Phalaropus, Uma, Sterva, Lamus umb amberer 20 gel, de=

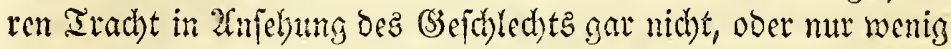
varitrt, wobl aber in 2 njebung ber Jabreszeit, baben in ber Far =

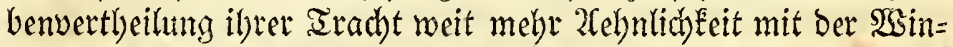
ter $=$, als mit ber Sommertracht Der 2fiten.

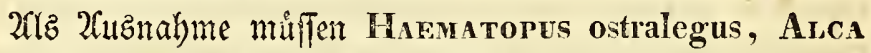
torda und Carbo graculus angefühtt werben, weldice, $o b=$ gleich bie 2llten biefer 2(rten bie Iracht nidht nad) Dem (Sie= fibledhte, fondern nach ber Sabrezzeit veråndern, boch Junge haben, Deren erfte Freberbetleibung mebr ber Sommer =, alz Der WSintertracht ber 2atten gleid)t; benn bie Sungen bes Eriten und

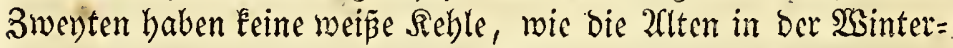

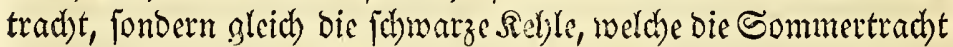
ber 2(1ten auzzeichnet; auth fehlt ben Süngen bez Resten bie crista

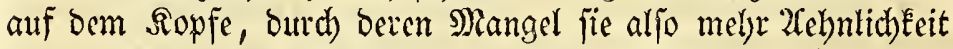
mit ben 2Aten in ber Sommer =, als in Der \$isintertradbt baben.

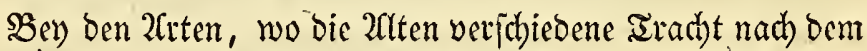
(3)ejd)led)te haben, gleidhet ber junge $\mathfrak{B}$ ogel mebr ber Matter, alz dem $\mathfrak{B a t e r}$, z. $\mathfrak{B}$. Trivan pugnax, Mergus und Avas, uno wemn biefe zugleidh, weldhes jebodh jeltener ber Fall ift, bie Trad)t nad) bet Sabreszeit veránbern, bam gleid)t ber junge Bogel zu= weilen ber Mutter in ber Sommettrad)t, z. $\mathfrak{B}$. Tetran Islandorum, zuweilen ber Mutter in ber $\mathfrak{B s i n t e r t r a d h t , ~ ซ . ~ B . ~ A r a s ~}$ glacialis.

Ben ben 2(rten aber, wo die 2lten weber nad) bem (siejd)led)= te ober ber Sabreszeit varitren, baben bie Sungen offters eine Tradht, weldbe in Eeiner SRluefficht ber ber 2alten gleidht, uno wel= dhe zumeilen febr verichieden ift, z. B. bey. Monmon, Poniceps, Crgnus, Sula, Lestris parasitica unb pomarina, zumeilen minder verfobicoen, z. B. Fulica, Anser, Puffinus, Procellaria und Lestris catarractes. 
Şaz bie Farbe Der Feberbefleibung Der jungen 20 digl betrifft, fo ift biefe als eine Frolge Dez Sorhergebenden minder prad)twoll, als bie ber 2(lten, nad) bem Die Irad)t Der Måmtá)en

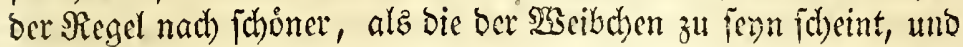

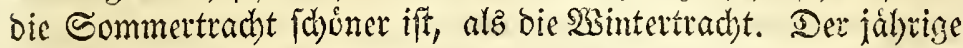
Sogel (avis hornotina) zeid)net fid) indeffen oft burd) eine melyr

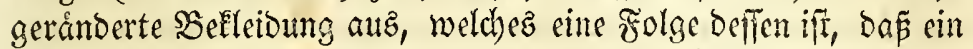
SRand von verifhiedenen Farben ben ben verfhicdenen 2 arten bie

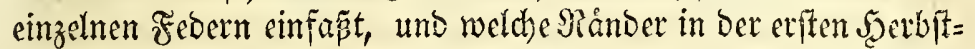
malferung veriftwinden. Sine foldhe gerånderte Sradtht tragen bejonderz bie jungen Singuogel, aud einige $\Re$ aub =, Sumpf= und Sdywimmbogel, $z$. S3. Sterna arctica, Lestris parasitica und pomarina, Procellaria und Pufrivus. Beel den mcijten

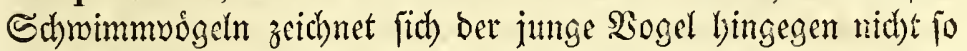
febr butrd eine verbråmte, alz burd) eine geflectete Trad)t aut, weldhe Flecten mit bem 2rlter verfdbminden, und fià) in bie ein= farbige veråmbern, bieje fen mun bie bunfle ober helle. Die jungen Bógel baben évenfalls zumeilen einen Dunkleren Edbnabel uno eine bunflere Jriz, alz bie Zlten.

Bevipiele. Die F̂lecten ber jungen Unis grylle veridjwin=

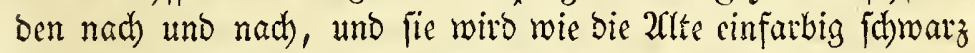
mit nei gularis verlieren fich bie weisen fledien melyr uno methr, bie bunké len, braunen ober jow warzen Flecten auf oem. jungen Cranus uno Sula alba verandern fidt) mit bem after in bie gefbweise, bejon=

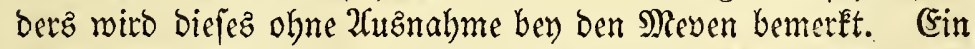

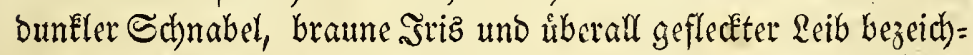
nen unverkennbar ben jungen Sogel, ba im (Segentheil ein ftark= gefảrbter gelber ober rother Sd)nabel, hethe Jriz uno ungeflectéter Reib auf Den 2llten (in ber Sommertradbt) binbeuter. Sie jungen Meven baben dunflere Flecten ober Bänber auf einer belleren. (3rumbfarbe, weldbe nadi) und nach veridhwinden, und fich ben Larus marinus umb fuscus in bie cinfarbige $\subseteq d$ wa arze auf bem

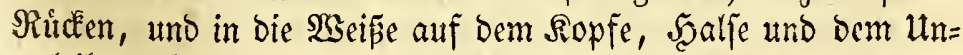
terteibe veråndert; bev Lanus glaucus, leucopterus, argentatus, canus uno tridactylus in einfarbigen graublauen ßricten,

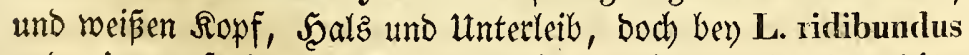

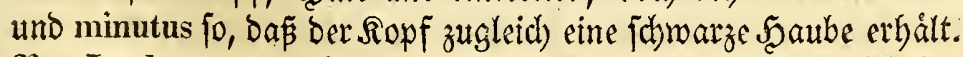
$\mathfrak{B e n}$ L. eburneus veråndern fid) bie fd)warzen viereekigen Flecken in bas હdneeweipe. Wsenn bie junge Sula alba baz Reft vet= låpt, ift fie bennah einfarbig braun. Die Flecten verichiwinden 
zuerft am Lnterleibe; in Der Darauf erbaltenen Irad)t gleidt fie Dem alten L. marinus, zulést betid)mindet bas Sdywarze anf bem Rưcien, bem Sdhwanze und ben Fredern ber Flugel, und fie ift mun in britffábiger Tradbt. Dap Dronnden exulans in $\mathfrak{2} \mathfrak{n} \mid \mathrm{e}=$ bung ber Iradht ber Șungen und ber Farbenveranderung Diefer ber Sula alba vollfommen gleidhe, bavon babe idh mid) ourd) bie Bergleidhung mebrerer 2flterbariationen biejer Diomedea mit meinen vorber gemachten Erfabumgen von ber S. alba uberzeugt.

Wenn bie Sd)wimmvógel ibre junge Trad)t nad) und nad) in bie alte Irad)t veråndern, fo befolgt bie $\Re$ atur aud bierin ge= wiffe Regeln. Die Farbe bes jungen $\Re$ sogels verliert (id) zeitiger auf Dem Sopfe, Dem Şalje und Dem Unterleibe, alz auf Dem SRit= d'en, Den Dedefebern ber Flugel unto bes Schrwanzes, am fpáteften aber berliert fie fich auf ben Schwanzfedern. Ebe man

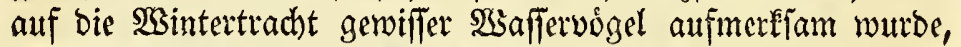
fab man bie Fleden bez Sopfez und Șaljes alz Heberbleibjel ber Tradjt ber jungen Bogel an.

Waz die 3eit, in weldher bie jungen 2 sogel ibre Iracht tragen, betrifft, to ift (ie.nad) Den verid)iedenen 2trten febr ver= fhieben. Die Sisenigiten ber Sdywimmuógelordnung find im fol= genden Fruthlinge nad) ifrer 2 tibbrutung in bie alte Tradt $\mathfrak{g e}=$

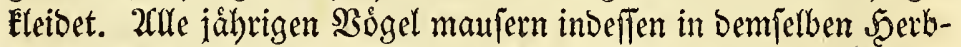
fte, ba fie im Sommer autgebritet worben; bie frubber autsgebri:=

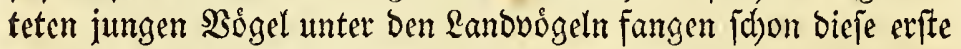
Raujerung in ber Mitte bes Suli an, und jie erhalten bann ein

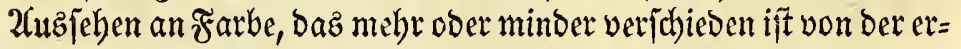
ften Federbelleidumg, weldhe fie gleid) nad) Der Dumenperiode trugen. Sad) biefer erften Serbftmaujerung hoirt Der junge Sogel auf, jåbrig (avis hornotina) zu jeyn, und wirb cinjáályrig (avis annotina); nad) ber andern Setbitmauferung wito er zwer)jáarig (avis biennis), brevjábrig (avis triennis), uno wirb in allen feinen Frarbenverånberungen nad) bent 2flter jung (avis juvenis v. junior) genannt, im (Segeniase des in Der Farbenbefleioung vollen= beten Sogels, weld)er bieje nicht mebr nach bem 2alter verånbert, uno alt (avis adulta) genannt wiro.

Die erfte Serbftmaulerung bringt folgende Refultate:

Die Jungen ber 2rten, welche idon im Frutbialyre nadh ifrer 2uabritung in ber alten, uno alfo. britffábigen Irad)t fino, be= ren alte $\mathfrak{B o g}$ gel aber Eeine $\mathfrak{B S i n t e r t r a d h t ~ b a b e n , ~ v e r l i e r e n ~ b i e ~ l i d ) = ~}$

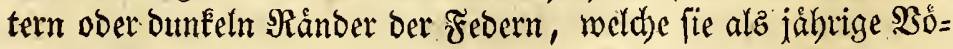
gel tiugen, haben aber boch nach ber Scrbftmaufert!ng ein von 


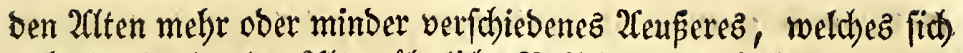
nicht in eine ber ber alten åbnliche Befleibung veránbert, ebe bie erfte Frublingemaulerung eintritt. 3. SB. viele Singoógel, Manmon, Puffinus, Proceluaria.

Die sungen ber 2frten, weldye zwar im naduften Frubjabre nach Der 2 uabrutung in alter Stadht finb, aber: zugleich bie Iltadjt nach ben Jabrezzciten baben, erbalten bey ber Scerbftmauferung

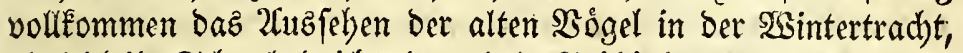
obgleid) ibr Sdhabel nid)t elser, als in Frubjahre ausgebildet wirb; nod) ibre Füpe elyer Farbe etbalten, z. B. Ha Ematopus ostralegus, Charanrius pluvialis, Tringa alpina und islandica, Uria troile auctorum uno alle, Alca torda, Stersa. Son diefen mur

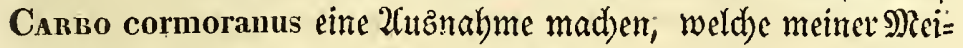
nung nad) im Sabre nad) ibrer 2 (usbrutung britet, beren $\mathfrak{S i n}=$ tertrad)t aber boch ber Trad)t bes jungen $\mathfrak{B o g e l}$ nad) ber erften Serbftmauferung nidht gleidht, weil bie alte Scharbe im $23 i n t e r$

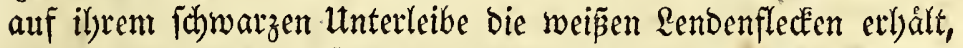
bie junge hingegen auf bem ganjen Unterleibe fdomusig weip ift.

(Enolid bey Den jungen $\mathfrak{B o g}$ geln ber Bogelarten, weldbe nidjt

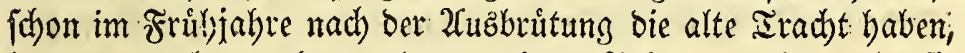
bey benen aber mebrere ober menigere Šabre vergeben, elde fie

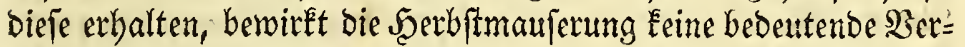

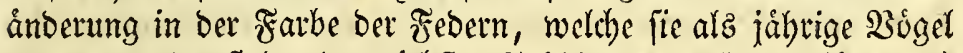
trugen, uno erft bey ber nåchften Frubjabrzmaujerung fängt ber junge Bogel an, feine Irad)t in etwas zu verandern. Diefes fiebt man am beften bey Sula und Larus, ja id) bin jogar un= gerviz̈, ob eine foldbe Serbftmauferung bev ber Sura vorgetse, ba fie oft bis Midhaelis im Nefte liegt.

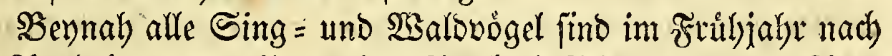
ihrer 2 uzbrittung mit ibrer alten Tradjt befleibet; mebrete 2 Ut $8=$ nahmen von biejer Regel finden bey ben $\Re a u b=\mathfrak{u n d}$ Simpipe:= geln Statt, uno viele 2fuznabmen bey Den Sdymimmvogeln. Sb= gleidy Seobad)tungen einer fold)en Satur fid oft 'auf negative Data ftutren, uno baber nidht allezeit ganz zuverláfitig fino: 10 werbe id bod hier verfuchen, bie borealen Sdbwimmbog gel nadj ber långeren ober Furzeren 3eit, weldhe fie in ber Tracht ber jun= gen Rogigel zubringen, zu oronen.

Sm Frubjabre nach ber 2lusbritung find in alter, aljo brut= fåbiger Iradht: die 2reten Phararopus, Unra troile, Brïnichii, alle, Alca torda, Marmón fratercula; bie $2 \mathfrak{i}$ tent von Cairbo, Puffinus, Procellaria uno Steriva; id bin ungemí̈, 
ob Lestris zwey $\mathfrak{B}$ inter zubringen, ebe fie bie Srutetradt er= balten. Die jungen Bögel det 2rten, weldbe den Mangel bes Fůtterungstriebez zu etfemen geben, bringen zwen $\mathfrak{M i n t e r}$ zu, ebe fie in ber $\mathfrak{B r u t e t r a d ) t ~ f i n d , ~ z . ~ B . ~ P o n r c e p s , ~ F u r r c a , ~ C o - ~}$ mymibus, Anser, Mengus unb Avas, wenigftenz die Mánn= d)en biejer zmen leseten 2 rrten; einige bringen jogar brey ober

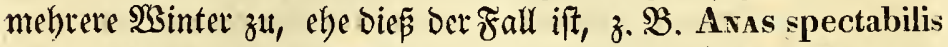
und mollissima." Fine 2CuEnabme macht bie Crgvos-(Şattung,

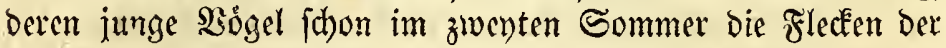
Tracht verlieren. Die borealen 2Crten ber (3)attungen Sura uno Lanus, fowic Una grylle, verblciben bren $\mathfrak{2}$ inter in ifrer jungen Trad)t, und find erft im Frullinge vor dent vierten Sommer (ber 2(übruttunge fommer mitgered)net) in ber alten Tradbt. In biejer

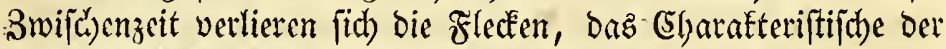
jungen Befleioumg, nach uno nad). Die Bogel, weld)e eine Irad)t tragen, weld)e von ber Farbe ber Sutugen in bie ber 2alten úber=

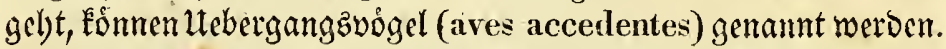

Sn Demielben Berbáltnifie, in weldhem bie Froerfarbe der Sungen fid) Der Brutetrad)t bet 2uten nåbert, bilbet fid aud bie

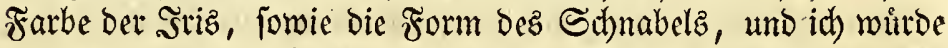
feble irten, wenn nidgt Alca torda uno Monnox fratercula nach Bertauf bez erften 2 inters ilyren fonderbaren Sdonabel fdon voll= fommen gebildet erbalten baben. Sad) habe wenigftens nie eite junge Alca torda oder. Monmon fratercula vom $\mathfrak{C}_{\mathfrak{u}}$ gzange dez

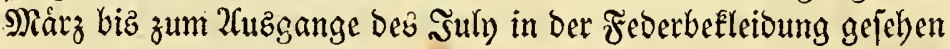
(Arca pica und deleta).

(Es ift nodh nicht entfojieden, ob bie jungen $\mathfrak{B o g}$ gel, weldhe mebrere Sabre zubringen, ebe fie ifre alte Tracht erbalten, uno weld)e zugleich zù ben 2(rten geboren, beren alte Inoiviouen be= ftimmt bie Iradbt nad) ben Sabrezzeiten veråndern, fdoon mit ber Sommer = uno wisintertrad)t abmedh jelm, indefien fie nod bie Trad)t Der. Sungen tragen, ober ob bie Beránberung ber Iracht nach ben Sabreszzeiten erft anfángt, wenn bie Beranderung Der Iracht nach

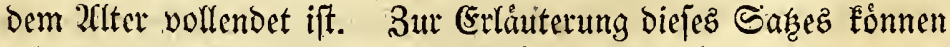
wir nur wenige boreale Sdbmimmoógel unterfuchen; weil mur bic beioen vorauzgeferten Faflle bey Unia grylle, Aras glacialis und ben 2fiten Lanus eintreffen, uno bev Der Unterjuduung bicjer Zrten foheint bie erfte Meinung bie geltende zu werben; Denn U. grylle wechjelt mit frinem fobmarzen uno weipen Unterleibe nach ben Săbrezzeiten ab, indeffen er nod) daz Merfzeichen ber Sungen, bio Juerbånder auf: bem Spiegel ber F̂lugel, bat. Die 


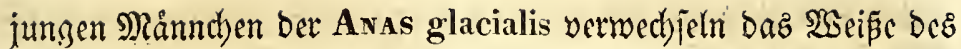
Salfes mit bem Sdymarzen und umgekelyrt, Sommer und Ssinter, ebe fie nod) die Rennzeichen ber alten Rögel; bie mittleren jebr langen Schwanzfedern, erbalten baben; bey Den Neven ift ez (ch)werer zu beftimmen, weil bie Şintertiad)t ber aften, naimlich bie grauen Fllecken im Siopfe und Şalfe, zugleid) cinen sheil Dev Iracht ber Sungen ausmadht; Dod) babe id) melyrmalz bie zwey= jåbrigen $\mathfrak{B o g} g e l$ von Lanus marinus, glaucus unb leucopterus

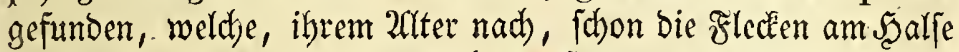
verloren haben mutzten, bie bod im $\mathfrak{3}$ sinter mit biejen verfében waren, und ich habe Lanus tridactylus im $2 \mathfrak{S i n t e r}$ mit bem blauen

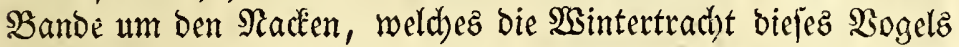
ausmadyt, zu einer 3eit gejdyoffen, ba biefes Snoivio nod) Das

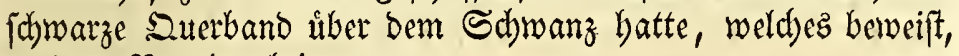
Dáp ber $\mathfrak{B o g e l}$ nod) jung war.

Die alten $\mathfrak{B}$ gel baben gewóhnlich ftänete Farbe, alz bie Sungen, und bie Federgierrathen bey den 2 rten, weldye fie tra= gen, geboiren beynab auefchliepend blop den alten.

Benfpiele. Der jungen Frivgrula linaria feblt bie rotbe Scheitel, den jungen Charadrius hiaticula det jowarze Scals= Eragen, und Char. pluvialis und Tringa alpina daz fdymarze Bruftichild. Die jungen Enten månnlicken (sejd)ledts, befonderz Der Aras mollissima, spectabilis, histrionica, crecca und m.a. fteben ben 2 (ten febr an Gdbonbeit nadh. Die ftarke rotbe Farbe bey dem alten Prazaropus platyrhinchus und Tringa islandica, utmo an der Reble von Convibus rufogularis, Podiceps cornutus unb arcticus mangelt ben Sungen biefer $2 \mathfrak{r t e n}$; Der, Metall= glanz ift fdywader bey ben sumgen bes Corvus corax, Carbo graculus, cormoranus and der Uria grylle, als bey den $2 \mathfrak{l l}=$ ten. - Der Sdhnabel der jungen Alca torda, impennis und Mol:Mon fratercula ift bey meitem nidjt fo auggebildet, ober, wie aud bey ben Meven, fo ftar gefárbt, als ber ber alten $\mathfrak{B j o g}$ berfelben. 2urten. Den jungen (Entenmånnd)en feblt ber Sdhna= belhócker Der 2flten, jowohl wenn biefer Enodhig ift, wie bey Avas nigra uno fusca, alê fleifhig, wie bey Avas tadorna und spectabilis. Die junge Andea cinerea, Vaneclus cristatus und Carbo graculus bat kaum ein Rubiment vom Ropfbuifhel ber Alten; bem jungen $\mathfrak{B}$ ogel von Tringa pugnax, und von ben

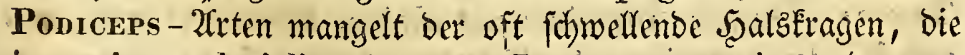
junge Aras glacialis und acuta, Lestris pomatina und para- 
sitica find nidht mit ben mittleren febr langen Sadjwanzfebern bet 2atten gefdymuictst.

Bon Der orbinåren Berånderung ber Iracht ber Bỏgel nach bem (S) efdeledte. -

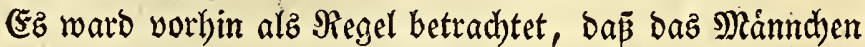

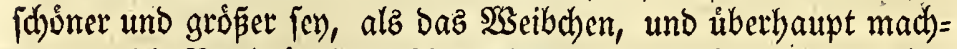
ten nur bie $\Re$ aubvógel eine 2 fub̆nabme, bey weldhen Die $\mathfrak{S}$ seibden jabon lange alz bie grósten, und zumeilen als bic fohoniten aner= kammt waren. Diefe Theoric aber hat in ben lesten sabren be= Deutenbe (Eimfthrånfungen erbalten, theils burch bie Nad) forjd)un=

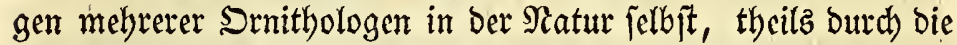
Ëntbectumg Der Wsintertrad)t vieler Sigel, weldhe man früber zum Theil fưr bie Irad)t ber 2 Seibchen bielt. Sefét ift ez mur al= lein in ber \$ronung ber Şaub = und Singuogel, in welcher man ófterz findet, Da

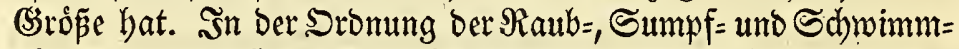

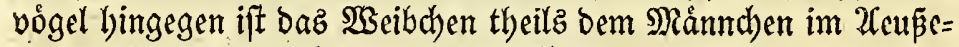
ren volffommen gleid), unb ủbertrifft $e z$ fogar bierin bey mehre $=$

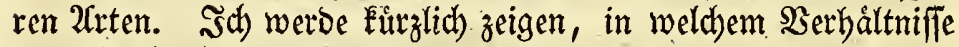
Daz (Szefhlecht bey Den borealen Sogelarten zu ihrer Iradht uno (šrópe ftebt.

Bey Den (̧attungen Fatco, Strix, Caumnis, Limosa

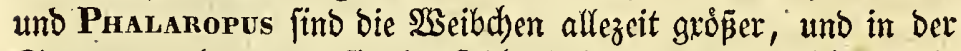
Sommertract)t, wenn fie eine foldhe baben, zumeilen jhobner, als bie Månnd)en. Bon Den Rauboógeln ift biejez eine alte (Erfah)= rung Rillfon bemerft in feiner Ornithol. suec. 2. S. 12, Dá Charadnius morinellus $\mathfrak{e} \mathfrak{z}$ mit mehreten Sumpfógeln gemein

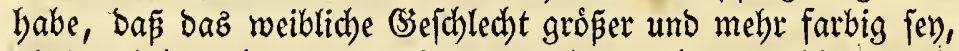
alz baz månnlide; ben bee Limosa iff es autd) in bie 2lugen fal=

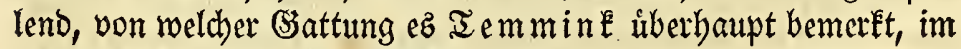
Manuel d'ornith. II, p. 663, zu berfelben 3eit, als id) ez in

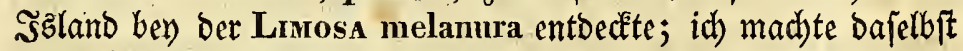
zugleid') Die Beobachtung, Daß daffelbe der Fall mit Calmoris und Phalaropus fey. . Bon Haematopus ostralegus fand id and

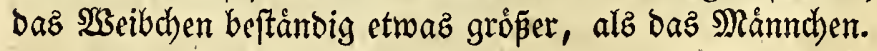

Bon etwa gleidyer (strópe uno Farbe fino bie verfóbiebenen (3ejh)led)ter ber Aitten von ben (Sattungen Convus, Charadrivs hiaticula, Ardea cinerea, Numenrus, Totanus calidris, Tringa islandica, maritima uno alpina, Scolopax gallinago und Ralusus aquaticus; dex 2frtent von Uria, Alca, Marmon, 
Puffinus, Sula, Sterna, Larus, Lestis, uno PnocelaLARIA.

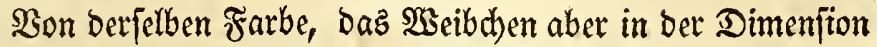
etwaz fleiner, find die verfdiedenen (Sejd)lediter von Vaneulus cristatus, der 2frten Canbo, Colynbus, Podiceps, Fulica, Axser und Crgnus.

Berichiedene Farbe und (Srópe unter ben (Gejd)lechtern, fo

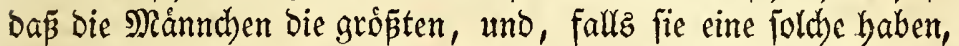
in ber Sommertrad)t bie jobnften find, wirb bey Tetrao, Emberiza, Fringrlea, Turdus, Motachlla, Saxicola, Sylvia, Anthus, Hinundo, Charadrius pluvialis, Strepsilas collaris, Tringa pugnax, den 2irten Mergus uno Avas gefunden.

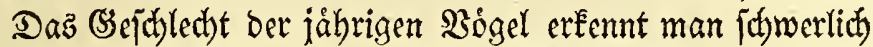

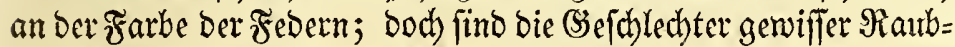

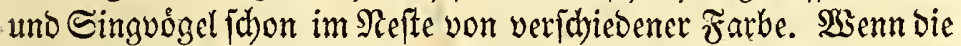
jungen $\mathfrak{B o g e l}$ im erften Serbite gemaufert baben, unter/d)eibet man ber) Den 2frten; weldhe mebrere Sabre zuturingen, ebe fie in bie alte Irad)t Eommen, bie jungen Månndben fdon leiduter von ben

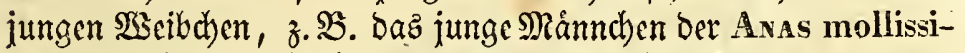
ma unterficheibet fid fidon am Ende bes erften Sinters von bem

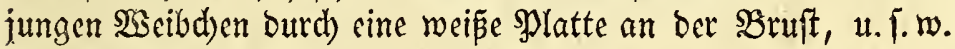

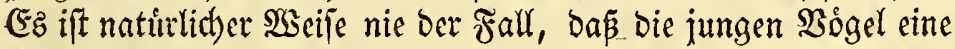
Dem (Sejd)lechte nach veridhiebene. Iracht baben, wenn fie zu fol=

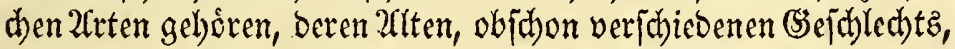
fich boch an Farbe gleiden, z. SB. Das junge Mannnchen ber Lanus-2irten, ber 2 rten Cocrubus und mefteter, gleidhen ganz

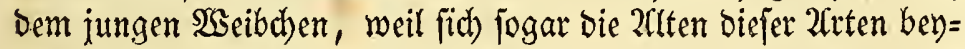
berley (Gejolled)tz cinander gleidhen.

Bon ber orbinåren Trad)t Der $\mathfrak{B}$ gel nad) oen $\mathfrak{S a b r e} z=$ zeiten. Die meiften alten $\mathfrak{B o g} g e l$ maujern nur einmal jábrlidy, mandhe maufern zweymal, im Seerbfte und im Fruiblinge; Daraus aber folgt nid)t, bas fie bie Farbe nach ben Sahreszeiten ånoern, weil bie auswachjenden Febern oft micoer bie Farbe ber gemau= ferten erhalten; wenn bagegen bey ben alten 1 Bogeln, die im Serb= fte und Frubjabre gemaujerten Febern burch Febern einer andern Farbe erjegt werben, to erbált ber Bogel eine anbere Tradt, weldhe Sommer = und Ssintertradht genannt wirb, je nachoem er fie bey ber Frublings = ober Seerbftmaujerung erbalt; und fie beftimmt ift, im sisinter ober Sommer getragen zu werben.

Dieje Farbenverånoerung findet nad) ben Sabreछzeiten bey 
Den $2(r t e n$, weld)e fie haben, ebenjowohl bell ben alien 23 cibchen,

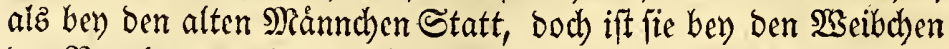
ber Bogelarten, bey welchen biejes cine minder gefárbte Som= mertrad)t bat, alb baz Månndhen, z. B. bey Emberiza nivalis. und Aras glacialis, minoer kennbar.

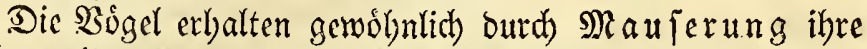
Iradte nadj Den Sabreszeiten; bod nid)t allezeit. Die Srnitho= logent $\mathfrak{R} a$ umann uno $\mathfrak{I} e \mathrm{mminf}$ baben neulich barauf auf= merEfam gemadht, Daß bie meiften alten Singuogel, weldhe im Sommer ein anderes 2fusjeben haben, als im sainter, foldhes nicht burch bas Maujern erbalten, jonbern burd) bas $2($ bijhleisen

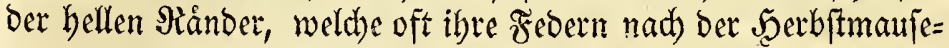
rumg umgeben. Dieje Bögel haben Daber im $\mathfrak{B}$ Sinter ein matterez

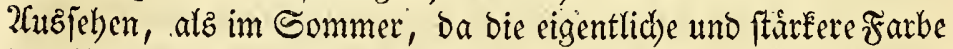

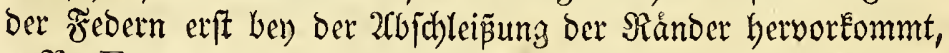
子. $\mathfrak{B}$. Embersza nivalis uno calcarata $\mathfrak{u}$. $\mathfrak{m}$. Ser. \$rofefior

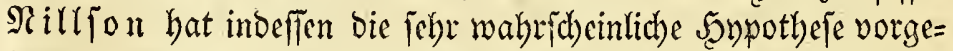

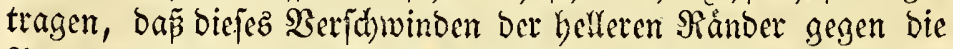

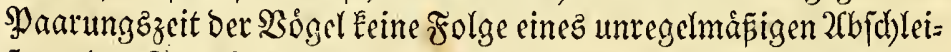

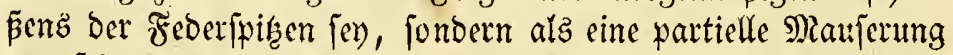
angefeben werben miffi, welde mit ber ganzen Maulerung auf bemferben Grunde beruhe, námlich Darauf, Das bie feinen (Se=

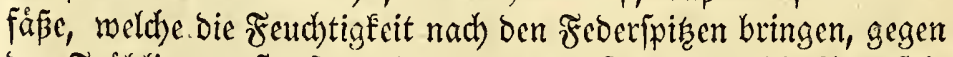
ben Fribling verftopft werben, worauß folgt, baß bie Feoerjpi= Gen felbft vertrodfnen uno abfallen. Bergl. Fauna suec. II. p. 293 , annotat.

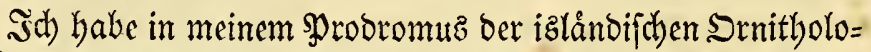
gie S. 13 einen 2 sinf von einer mógliden britten 2(rt ber Irad)t=

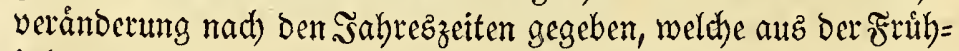

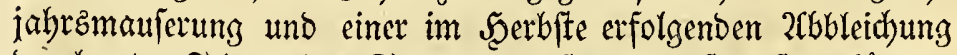
ber bunten Febern dez Sommerz zujammengelefét fenn fónnte.

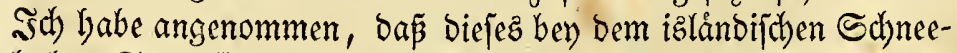
hubne Statt finde; im Scerbfte fand idh bie weiß̄en Federn nidft

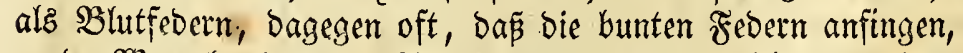

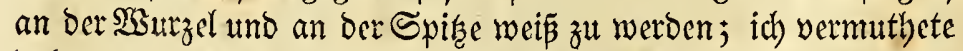

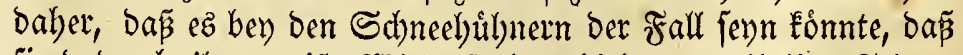
fie baburdh ihre meiße Winterfarbe erbielten, weil ifre Febern aus Mangel ber färbenden Sáfite in Serbite erbleidten, und alio

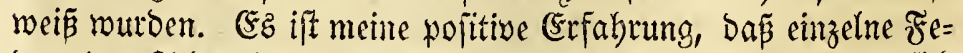

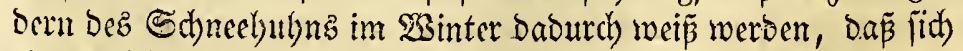
cime Bloffe von beiben Enden ab úber bie ₹eber verbreitet, uno 
bieje partielle (Erfahrung fann burd) keine anberen (Erfalyrungen wiberlegt werden. Dagegen Eam ith) nidht mit (Gerwipheit be= ftimmen, ob biefes Erblaffen total Fen, uno aljo bie meipe $\mathfrak{2 s i n}=$

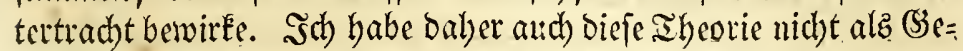

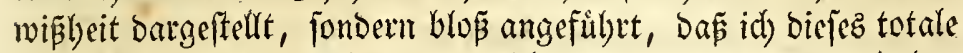

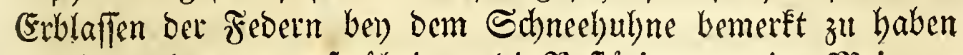
glaube, uno unterwerfe ùbrigens bie Beffátigung meinet Meinung

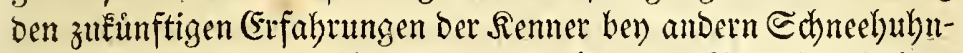

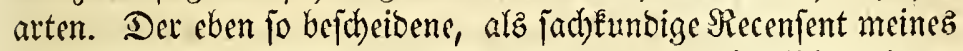
\$probromus (Riteraturzeitung, 1824. Nio. 3.) erflárt fich berb nur

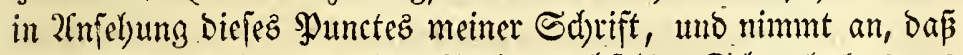

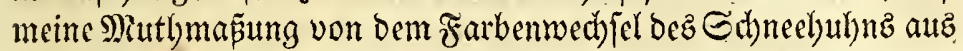
Dem Rangel Der unterjud)ung Diejer Sadje entftanden (el), mit

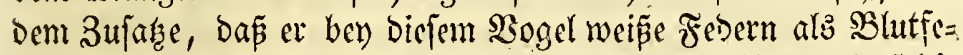

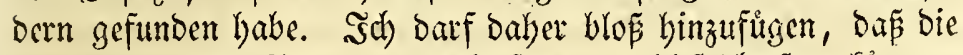

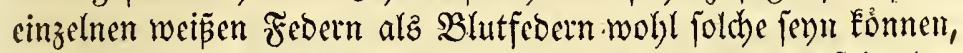
weldhe extradordinår fónmen verloren fenn, iund baher, zufolge ber Reproductionzeraft mit berfelben Farbe, welde bie vertornen Fe= Dern hatten, wieber erfeget werben; fowie id) ald bas Sdmee=, bubn nid)t allein im Sommer, fonbern zul aflen Jabreczzeiten un= terjudbt habe, und jebr aufmerkfam darauf gewejen bin, baj die

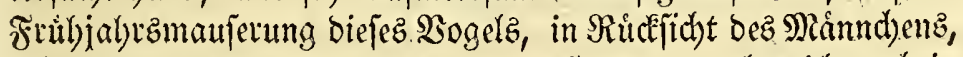
jich bis weit in ben Sommer binein erftrecit, weld)es id) aud) in

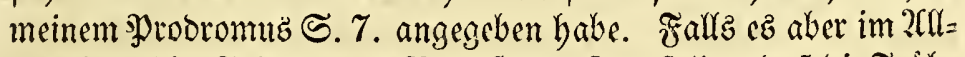

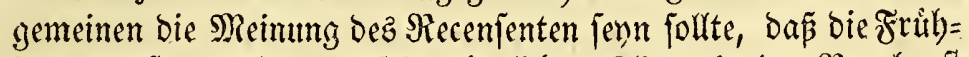
lingsmaujerung in bem fel) norbolichen Rlima in Der Regel crift fpàt in Sommer vorgelye, jo wiro ljewon baz (Segentlyeil gleid) unten bewiefen werben.

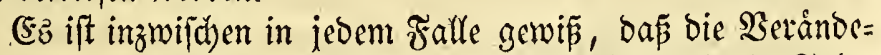
rung ber Iracht nad) ben salnezzeiten orbentlid)erweife eine Fo!ge Dez Ma M jernz jey. Den Farbenwedjel ber Edneebuilner kamnte man fibon lange. Sdjon vor vierzig Jalyren madhte utmjer: Fabriciuz in feimer Fauna groenlandica auf bie verfobiebe: nen Iradben nad) Den salfreszzeten bey der URIA Brünnichii (Alca pica Fabric.), Uria grylle, Alca torda uno alle alif= merfiam; er erlangte aber bietin, jowie in mebreten andern Fåal=

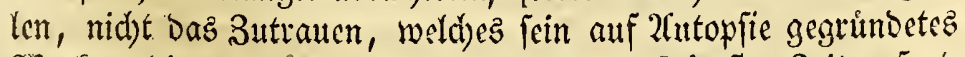
SGetk veroiente, uno man fulgr bis in bie fpảtef́ten Beiten fort,

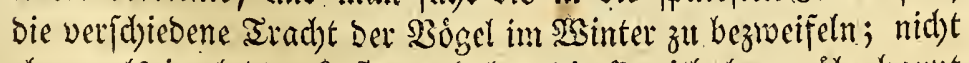

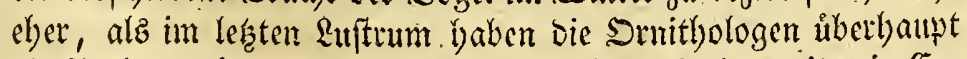

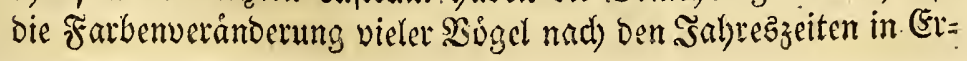


fabrung gebradyt und angenommen; befonders ift burch $\mathfrak{I} \in \mathbf{m}=$ minf $\mathfrak{z}$ Manuel, Edit. 2, 1820, diefe Sache, im Sanzen ge= nommen, ins Reine gebrad)t worben; ich fann aber mit $\mathfrak{W a b r}=$

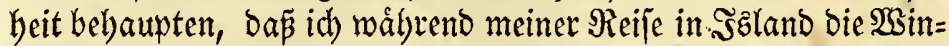

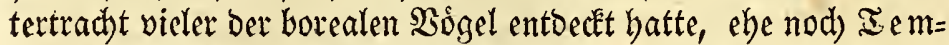
minf nidht alfe Bogelarten, weldhe Die Iradht nad) Den Sabrezzeiten betåndern, und es geht mit biejer, wie mit andern (Entbectungen,

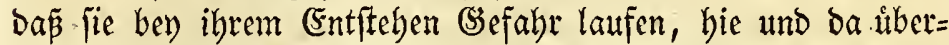
trieben zu werben. Fa.miffen wenigftenz viele uno genaue $\$ \mathrm{Db}=$ ferbationen vorlyergeben, elye man einer gewiffen 2art verjchiebene Tradst nach Den Sabreszeiten benlegen fann.

Die Irad)tweränberung nad) Den Salyreszeiten if bey ben borealen Bogeln nie volffommen total; nidht einmal baz Sdhnee=

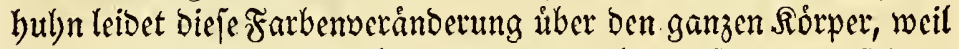
Die Sommerfarbe ber Sdhnimm = und Sdhwanjfedern im Sisterter benbebalten wirb; fie if bingegen ofters partial, jo da pa nur ein einzelner Ibeil die Farbe ándert. Dieje bie Farbe ándernden Iheile werben melyr am Ropfe, als auf Dem Rumpfe gefunden, uno mebr am lunter =, als am Sberleibe. Die Schwingfedern und Schwanzfedern find am wenigiten der Beránderung, fowobl bem (5)ef(h)lechte, als ber Salveszeit nach, unterworfen.

Wsir haben idyon ober betrad)tet, in wie meit man anneb=

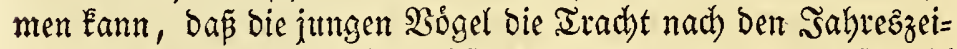
ten veråndern, und es ift gleichfalls bemerft worben, baj fowohl

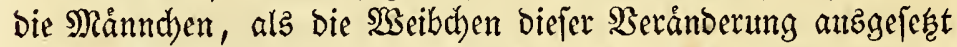
find. Die 2Ulten verichiebenen (sideldechts, weldhe cinander in ber Sommertrad)t an Farbe gleid)en, bebalten bieje 2(ebnlidbeit in ber veránderten $\mathfrak{W}$ intertracht, z. B. Una, Alca, Lanus. Die

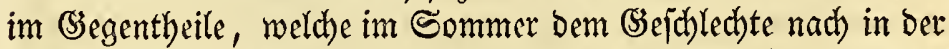
Farbe variten, erbalten auth zuweilen bem (siejolechte nach eine berjdiedene $\mathfrak{B}$ sintertradht, $\mathfrak{z} . \mathfrak{B}$. Embeniza nivalis und Aras glacialis, zumeilen biefelbe Wintertradt fiur beibe (Sefdhled)ter, z. B. Chamadrius pluvialis, Lmosa melanura, Strepsilas collaris, Trivga pugnax, und wie id vermuthe, PhalanoPus cinereus uno plathyrhincus.

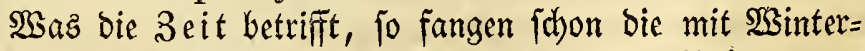
tracht verfebenen Sỏgel nad) Der Sollendung Dez Bruitenz an,

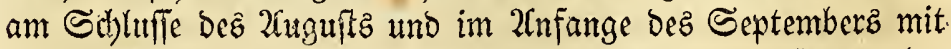
biefer befleibet zu wetoen; in bem lestern Monate trifft man be=

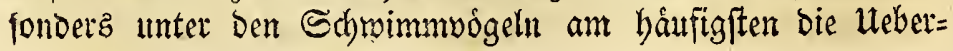


gangstradbt. Noch, indem Uria troile auctorum und Alca torda ibre erwachienen Șungen im Meere anführen, fangen bie Zlten an, bie weipjprentliche Sieble zu erhalten. Sum Theil im Sctober werben nod) ab uno zu Bógel, weld)e nad ber. Sal)rezzcit bie Farbe ánbern, einzeln entweber in ber Sommer = oder in ber Ulebergangstrad)t zur Ssinterfarbe gefunden, im November aber; im December, Sanuar und Februar find fie alle in Der $\Re$ rgel in reiner Wsintertracht. Der 2fusbrud Derjelben ift Das fidherfte

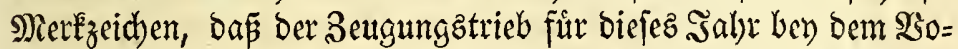
gel eingefdhummert fer). Die Stridboogel haben fic oft erhalten; ehe fie baufenweife berumzuftreid)en anfangen. Die 3ugoogel, weldse inte Sone verlaffen, fino ofters mit ber SSintertracht be= Eleibet, ehe fie austwandern, und den lefeten Reft der Sommer= tracbt werfen jie auf der $\mathfrak{s a n d e r u n g ~ f e l b j t ~ a b . ~ D i e ~ v o n ~ S z l a n d ~}$ randernden Sogelarten haben fidon in biejem Lambe bie Shinter:

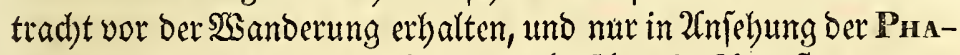

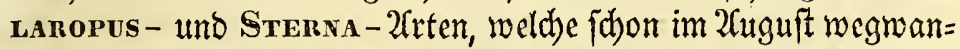

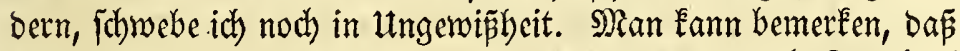

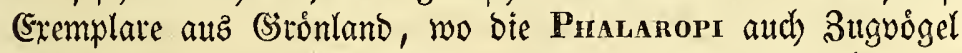
find, fowohl in ber Sommer =, als in ber Ssintertradht zum

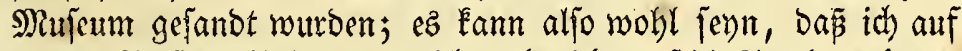

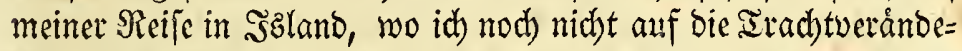
rung ber $\mathfrak{W}$ affertweter nad) ben Salyeszeiten aufmertam genor=

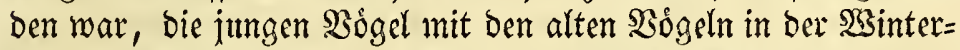
tracht vermedyflt babe; es ift cin Eraftiger $\mathfrak{B e r w e i z ~ b a f u r , ~ b a ß ~}$ bie auz det borealen Bogelzone auswanbernoen 3ugvogel gentei=

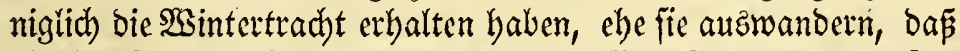
die Şaufen, reld)e von Emberiza nivalis, Charanrus pluvialis, Trunga islandica und alpina, Uria grylle, troile und alle, Alca torda, Aras glacialis, Larus tridactylus, marinus und mebreren, im September und Sctober von Norden bey

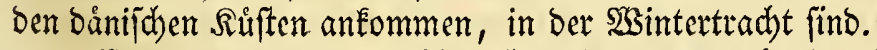

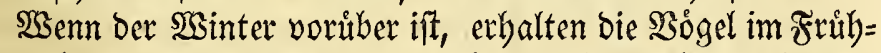
linge nach und nach bie Sommertradyt; biejes gejdiebt aber be=

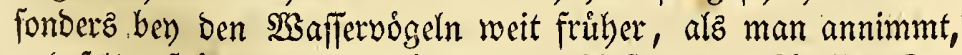
und felten fpåter, als im Mårz ober im 2 nfange bez 2(prils. Da= her fito aud bie im Frubjable ben ibren Brutepläen anfommen= ben 3ugvoigel bey ber 2 nêunft, fowohl in Der feptentrionalen, alz ber borealen Bogelzone, mit ber Sommertradyt befleibet, obgleidh einige Drnithologen annehmen, bas̄ fie auf iłrem 3uge maujern.

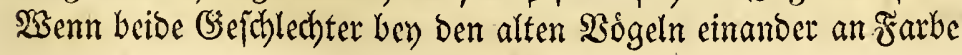


gleich jind, jo erfalten fie aud); obne Rudefidht auf bas (sejdblecht, ibre $\mathfrak{B s i n t e r}=$ uno Sommertrad)t zu Einer 3eit, z. B. Una, ALca, Lanus mit.mebreren; wenn bie (Sefdhledter bagegen un= gleid) in ber Farbe find, fo erbalt baz alte Weibd)en oft bie Som= mertracht, ebe bas Marmen die feinige vollfommen erlyalten bat,

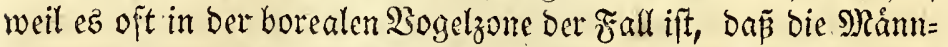
(b)en, unter ben mit verid)iebener Irad)t nad) Den Salleszzeiten verfel)enen $\mathfrak{B o g}$ geln, weldhe zugleich an rarbe von Dem $\mathfrak{B s i b d}$ en veridbicoen fino, ebenfalls zum oftern Eeinen Brutetrieb baben, und Daber nod) in ber Farbenveranberung fino, indeffen bas SEeibd)en, ebe es nod) anfänst, Ener zulegen, die volfêmmne Sommertradbt eribalten hat, Denn ber Feberwed) jel ift allezeit vollendet, ebe ber Bogel bas Brüten beginnt, Damit bie zur $\mathrm{Er}_{\mathrm{r}}=$ wărmung ber Ener notbwendigen Federn nid)t feblen follen, z. S. Tetrao Islandorum und Axas glacialis. (Doch eilyalten bie

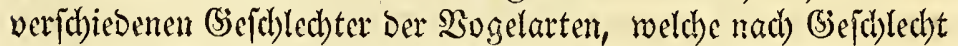
uno Sabreşzeit in Der Faibe varitren, zumeilen die Sommartradht zu berfelben 3eit, wie z. B. Cranadrus pluvialis.

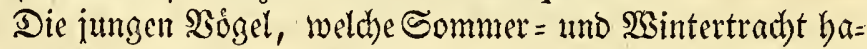
ben, erbalten zuweilen bie erftere mebrere Monate nach ben $2 \mathfrak{a l}=$ ten. Die satur jobeint bier zu zogern, ba fie in bem zarten atter nidbt briten follon. Nan triftt ben jungen Una grylle im Monate May mit vielen weifen Flecken am Itnterteibe, uno nicht eher, als im Suly und 2(ugurt in voller Sommertrad)t, Det alte Uni grylle wirb fibon im 2 nfange uno in ber Nitte bes Miriz mit diejer befleidet gefunden.

Sisenn dic 2feten von Haematopys, Una und Alca im: Mårz, umb die Xuten Canbo, Larus uno Avas glacialis im Trpril jich bey Den SBriteplägen zeigen, fo baben fie in Der Regel alle ibre Sommertrad)t. Daffelbe gilt von ben in Jzland antom= menoen 3uguogeln im 2(pril und Miay, z. SB. Motachla alba, Charadrus pluvialis, Calmus areharia, Totanus calidris, Strepsizas collaris, Limosa melanura, Thurga islandica und alpina, die Phalaropus-20ten und Sterna arctica. Nim

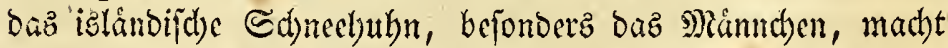

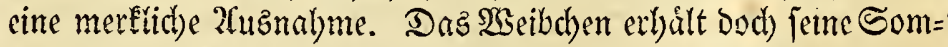

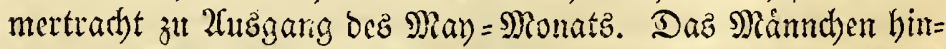

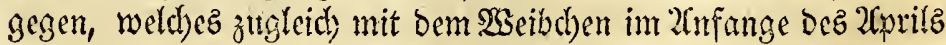
anfängt, bie Sonmertrad)t jut erlyalten, ift nid, elyer, als ju

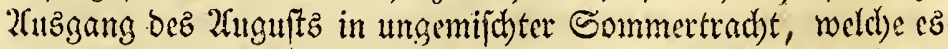
wieber gegen das Ende Dez Septenlbers nit Der Wintertrad)t fu 


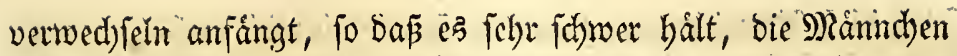
ber Sdinebulbnet in reiner Somntertracht zu erbalten, bagegen fie leidter in ber reinen 2 sintertradbt zu betommen find.

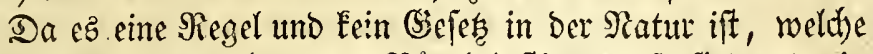

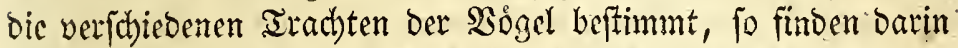

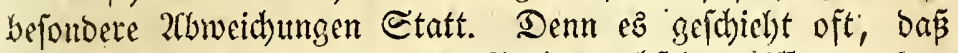
nan einzelne snbividuen in bem Frarbenwedjal antrift, zu cimer 3eit, Da bie meiften berjelben 2rt ubrigens bie reine Iradht baben. üm bey ber borealen 230 gelzone zu bleiben, fo babe id) nod) im Nay alte Sdnesammern in voller Sintertrad, gefunden, uno im Rovember einige in boller Sommertracht. Fabricius

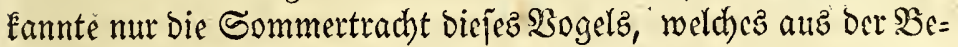
fhreibung in Det Fauna groenlandica, p. 118, ctled lut, und zum

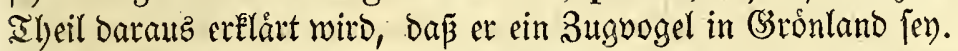
Eingelne Charadnus pluvialis, Strepsiuas collaris, Trivga alpina und Aras glacialis, werden nod zu der 3eit, mit ber= vorfted)ender Winterbetleibung gefmben, Da Die 2rten ủbrigenz in ber Sommertracht fino. Sod) 2Unfangs Sumb babe id) (Sinzclne ber Canzo graculus mit Ueberbleibjeln dez Ropfbuifhels gefun= Den, weld)en fie im S3inter tragen, und zu Derjelben Beit bie uno Da Lanus glaucus mit Heberbleibjeln ber graten Flecken ber Sisin= terbefleibung am Spalfe, obgleid) bieje \$gogel in ber $\Re$ egel zu 2uffange ?prilz in Der Sonmeitrad)t fino.

Gin anderes \$gbanumen, welches eben fo wenig zu bezwei=

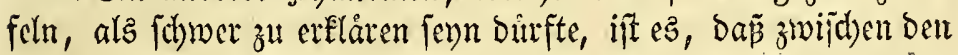
Jndiviouen einer 2 rt, sie nach den Jabreszeiten die Farbe verăn= bert, allezeit einige alte 3 oggel gefunden werben, weld)e bicje Farbenveranderung nid)t Durd)geben, fondern im sinter in Dei vollen Sommertracht, und im Sommer in Der vollen Ssintertradist angetraffen werben. Daj biefe fold)e Bogel Fern follten; Deren Zubbutung aus Dem (Eve, und beten Irad)tmed)fel babutd) verpatet worben wåre, fann nicht angenommen wetben, ba bic= fez Mbånomen ebenfallz unter ben Sogelarten gefunden wiro, welche mebrexe Sabre Durthleben, dye fie als afte nit ocr Som=

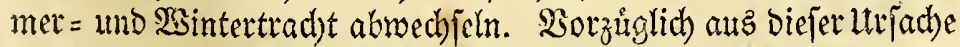
ift es, dáp man Uria grylle uno der (\$attung Corrusus die SSintertrad)t abgeprodben hat, weil man den ganzen Sainter bin= Dutch einzelne Snoivibuen in ber Sommertractit findet, uno aus Derfelben litjache fprach man aud ber Aras glacialis dic Eommer= trad)t ab, weil man ben ganzen Sonmer bindurd (sinzelne mit

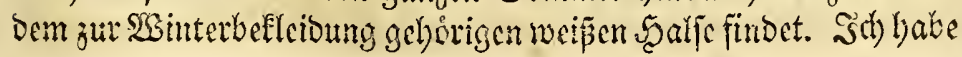


fetbft biefe 2Tbmeidhungen bemerft, fo wie ich mich auth ủberzeugt

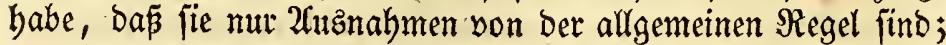

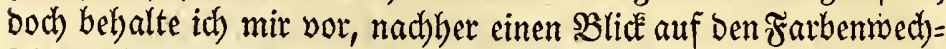
fel des Colymbus nadh den sabrezzeiten za werfen. Siedurd

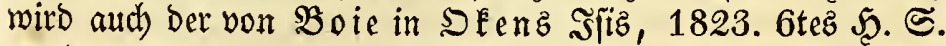
665 , von H. ostralegus vorgetragene Sak erflånt. Diefer $D r=$ nitholog zielt indeffen aud) auf bas lier erwáhnte \$glánomen im

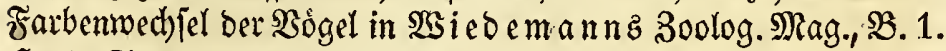
5. 3. S 96, 107 und 108.

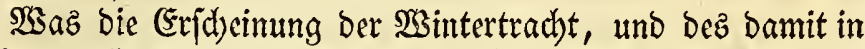
Berbindung ftelyenben 2Cbnehmenz ber Sommertrad)t, fowie umge= keyrt, betrifft, fo beginnt biefelbe nidte auf (Sirmal an allen Ilbei=

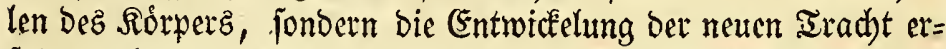
folgt nach einer gewifīen Sronung. Die Theile bes Rórpers, wel=

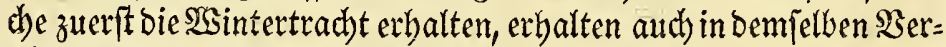
båltnifie zuerif bic Sommertracht, und umgekehrt. Sen den mit

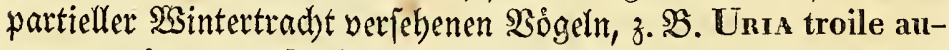
ctorum, Alca torda, Lanus und Stenna, bey weldhen mur ein

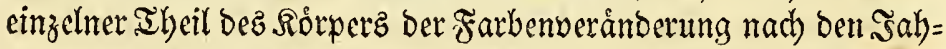
reszeiten unterworfen ift, ift biefes ftufenweife $\mathfrak{2} b=$ und 3 unch $)=$ men ibrer Iradht unmerElids; bod) verlieren bie $\Re$ Reven bie grauten Streifen eher auf bem Ropfe, alz am bealje. W̧o hingegen ber

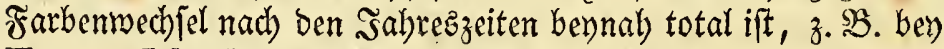
Tetrao Islandorum, Uria grylle und Tringa islandica, ba Eann man bie fafufenweife \$ronung, in weldher bie verichiedenen

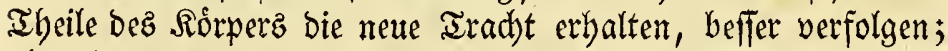

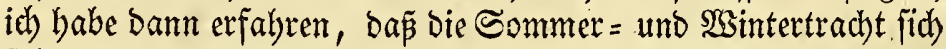

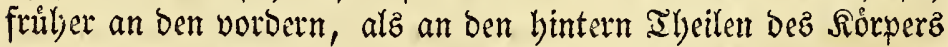
zeigten, und frúlyer an ben obern, als an ben untern alyeilen, fo

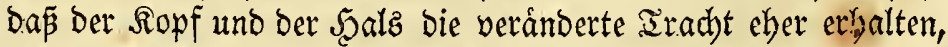

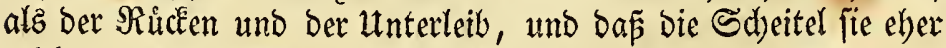

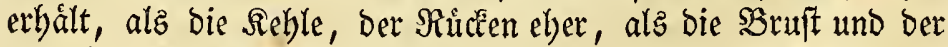
Baud). Şch fenne Eein (Exempel, nad) weldhem bie Febern Der

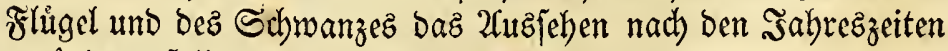
veråndern follten.

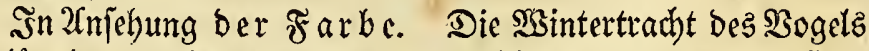
ift unlåugbar ber $\Re$ Regel nad) weniger fdjơn, uno von minder ftar= ker Farbe, als bie Sommertracht. Die Iheile, weldhe im Som= mer ftarke und glánzende Farben hatten, vertieren im $2 S i n t e r$ theitz ihren (słlanz, theils werben fie weif, und bie Feberzierra= then bez Sommers gehen oft vertoren, 子. B. bey Trivas pugnax, 
bod) nicft allezeit, z. B. bey Aras glacialis. *) Defto auffal=

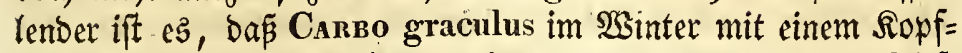
buifdel geziert wird, weldhen er wieber im Sommer vertiert. Dieje (Entbectung, weldbe idh allein gemad)t zu baben glaubte, theile

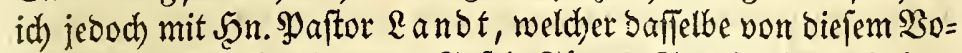
get in feiner Seidareibung ber Smjeln Fárroe S. 258. Gemertet hat.

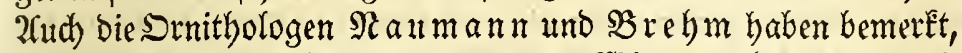
Dá̧ die (Entenmánndyen Sommer = und 2 Sintertrad)t haben, und

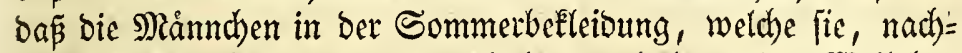
bem bie $25 e i b d e n$ Eyer gelegt haben, erbalten, Den $\mathfrak{S B}_{\text {seibden }}$

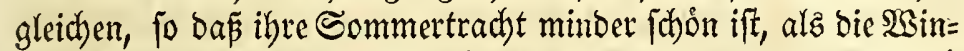
tertracht. Diefes bezweiffelte id) in meinem \$rodromus, weil id)

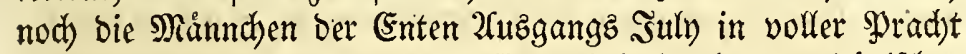
antraf, umb fie auperdem, wenn fie im Sctober bey) ben bánif chen Rúften ankamen, biefelbe Irad)t batten. Sodh habe idh nad)= ber (S̈elegenbeit gehabt, bie $\mathfrak{B a} a b r h e i t$ der Beobachtungen diefer Sonithologen im 2argemeinen zu erkennen, und Dáp bie Mánndhen

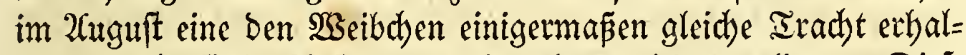
ten, weldhe fie im 2 infange bes Sctobers micber verlieren. Dieje Regel gilt nidht allein von ben nid)t taud)enben, fondern autd yon ben tauthenden (Entridgert. (Es war mir ja)on in şsland auffal=

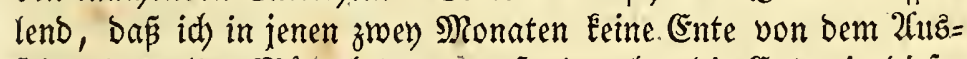
feben bes alten Mánnchenz antraf: Da aber bic Ẽnten in biejer

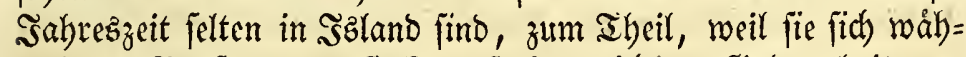
reno ber Mauferung verftecten, fo hatte id nur (Selegentheit, we=

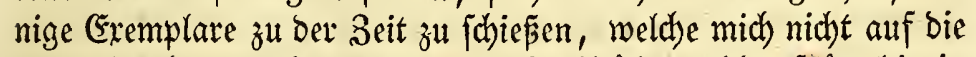

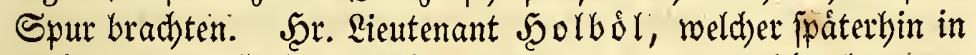

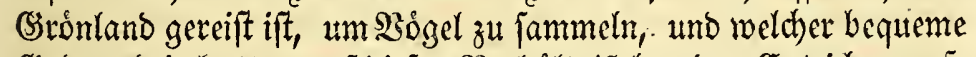

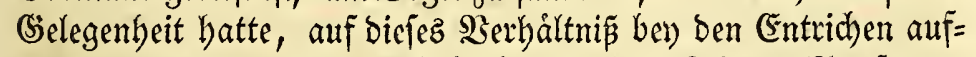

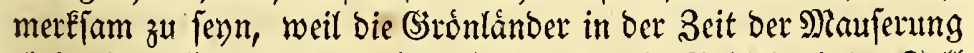
einige Bogeljagben barnad) anftellen, was in J̈slanb nie ber Frall

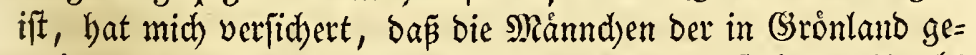
meinen (sntenarten im September mit einer einfacheren Trardt

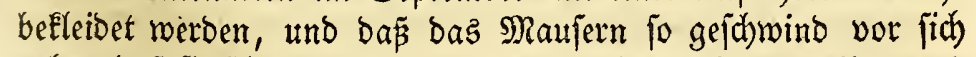
gehe, baj fie faton im 2lnfang dez Sctoberz wieder in ihrer-vo=

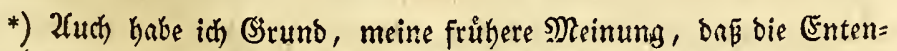

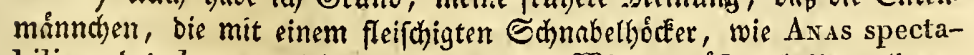
bilis uno tadorna verfeben fino, Diefen im Binter grógtentheilö vertieren, aufzugeben, ba viele Entriche von erferer jener Enten im MBinter mit biefer Schnabelzierrath ben Den groonlonbifhen Siuften exlegt wurben.

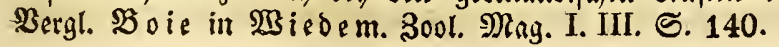




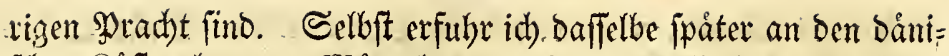
fd)en Rúften bey Dem Mánnd en von Aras mollissima, boschas und crecca, unb babe aud (Enten=Mánndi)en von andern 2(rten, 3. $\mathfrak{B}$. Aras nigra, in biejen Monaten in voller mánnlidber Iracht betommen, to bas ich nod nicht mit Sidjerbeit bebaupten Eann, .ob jene Megel fid) autf alle 2(rten bet Enten = Mlánnd)en exfirecte.

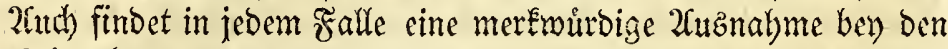

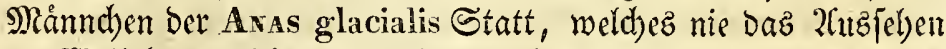

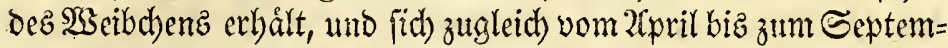
ber it feinet fdomften Iradht zeigt, wie es geroblynlid bet" Den

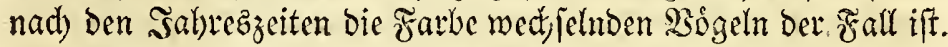

Sd)lieplid) will idh berubren, weld)e izlånbifde So̊gel, mainen Seobad)tungen zufolge, bie Sommer = und Sintertradht baben, und weldben biefelbe mangelt.

Die ialandifichen 2irten der (3)attungen Falco, Strix, Convus, Turdus, Srlvia, Annea, Numenus, Pafleus; Monmon, Puffinus, Poniceps, Fulica, Mergus, Sula, Lestris und Procellabia veråndern die Farbe nid)t nad) den Sab)= rezzeiten. Die meï̈baudbige Lesmes parasitica ift eben fo wc=

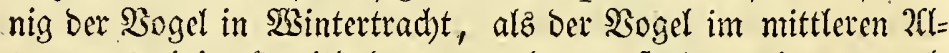
ter, was einige Stnitlologen annebmen, fonbern eine untegel= máp̆ige 2Cbånderung.

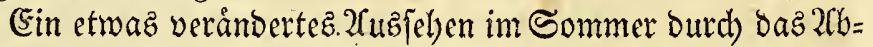

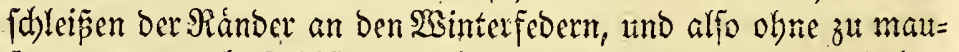
fern, ober nach Sillon butch cine partielle Maufer, erbalten

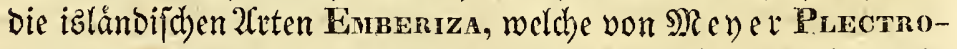
Phanes genannt wiro, und beren Sibnabel audd bie Farbe wed)= felt; Motacilla alba, Artuus, Tringa maritima, Arser, Crgnus.

Die cigentliche Sommer = und Şintertracht $t$, Deten verån= berte Farbe ein Repultat einer wirklid)en Maurerung ift, wirb in einer beynab totalen Farbenveránderung bey Tetrao Islandorum, Charanrius pluvialis, Camioris arenaria, Limosa melanura, Totanus calidris, Strepsilas collaris, Tringa islandica und alpina gefunben, fo autd) ber ben 2fiten Pralasropus, Uria grylle, der meiften Entemmaimachen, namentlid Aras glacialis, bey weldten allen ez nibyt allein bie unterfiten Iheile find, weld)e die Farbe veråndern, fondern aud cinige ber obern Theile bez ßórperz, bie fomft Der Farbenveránbertmg nad)

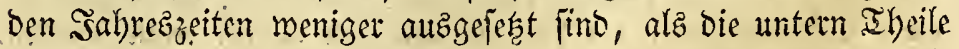
beffelben. Eine partielle Farbenverảnderung nad ocn sableszei= 
ten, bey weldher nut einzzlme, und bann zum óftern die unter" Thyeile bez Rórperz bie Farbe åndern, leiben Hawmatopus ostralegus, Unna troile, Brünnichii, alle, Alca torda uno impennis, ber weldhen Das Braume doer Sdymarze am Ltnterbalfe im

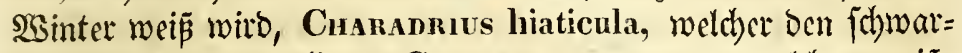
żen Şallafragen verliert, Carso cormoranus, weldher weipe Qenbenflecten erbålt, uno graculus; weldter im $\mathfrak{s i n t e r}$ cinen

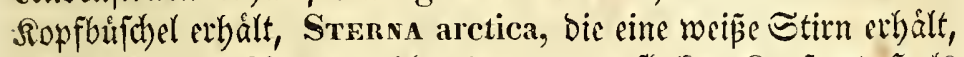
und die Larus - 2frten, weld)e einen graugeflecten Sopf uno Şals befommen, Dod) nit 2(utznabme ber 2(rten, weld) im Sommer

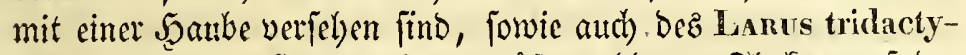
lus, welche im $23 i n t e r$ einen grésern blauen Flecten auf Der

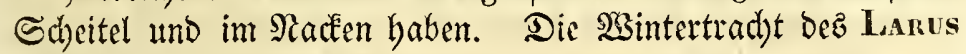
ebarneus ferme idh nidt.

Slop in Rưceficht einer $\mathfrak{B o g e l g a t t u n g ~ b e r ~ b o r e a l e n ~} \mathfrak{B} 0=$

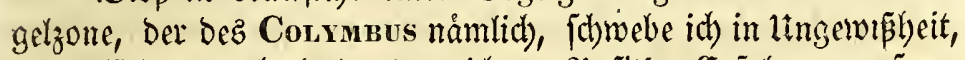

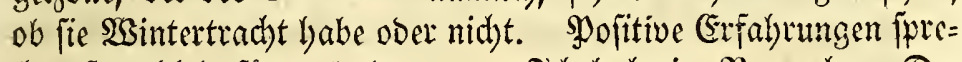
d)en forobl bafur, als bagegen. Sall lyabe im Sioventber, De= cember uno Samuat CoL. glacialis uno rufogularis in volfemm= ner Sommertradt gefdoplen. Diejes 2rigument Eonnte zwat in

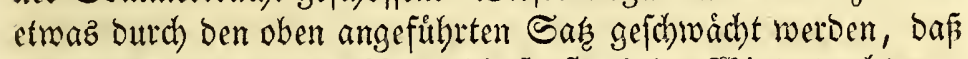
einzelne Snbivibuent ber 2(2ten, bie fonft mit ber 2 Ssintertrad)t ver= feben find, jälyrlich gefunden werben, weldhe bie Farbe nidht nad)

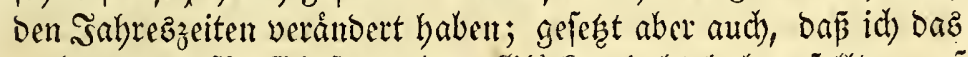

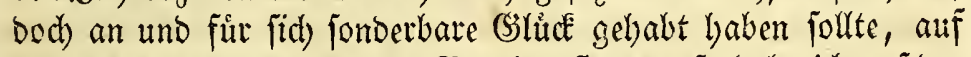

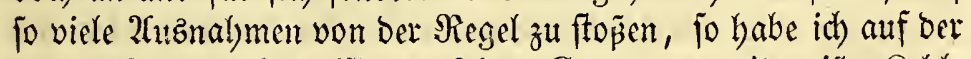

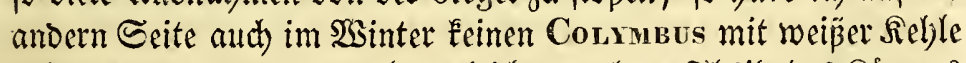
gefunben, obne Daß er aud) zugleid) am obern. Ibeile bez Sörperz

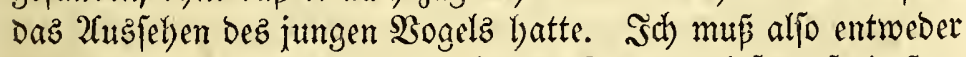

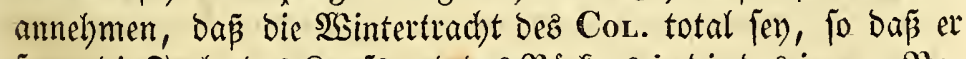

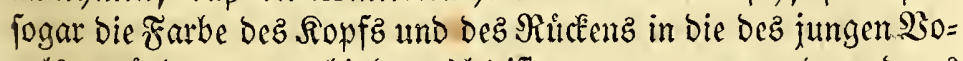

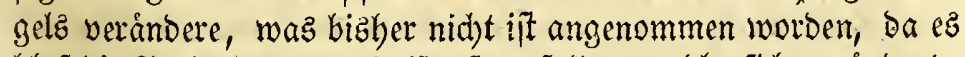
blof bie raarbe bez ltnterbalfes fernn follte, welche fidd veránderte,

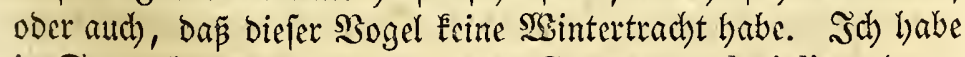
im September und \$itober einzelme Corrmbus glacialis uno rufogularis in Der $\mathfrak{H}$ eVergangabefleibung angetroffen, Den Erftern mit fahwarz uno weip geflecteter, und ben Resetern mit roth) unto

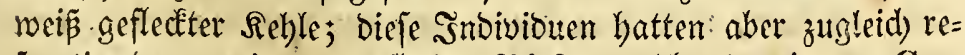
ipective ben wenig weipgeflectten $\Re$ iucten, weld)er ben jungen Cor. glacialis, ober Den fel)r weipsgeflecten 3rủden, weld)er Den jungen Con. rufogularis djarafterifirt, und id glaube balyer ridbtig ange. 


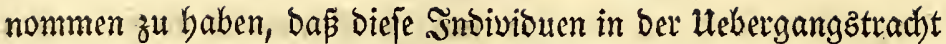

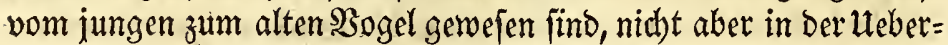
gangstrad)t alter $\mathfrak{B}$ ógel yon der. Sommer= zu ihrer 2 Sintertradbt. Temmink. fprach Dem Colymbus in feinem Manuel bie Som=

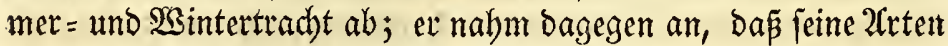
in melyreren Sabren bie Iradbe Der Šngen tragen; id läugnete sleid) falle biejen Farbenwed) pel nad) ben Jalurezzeiten in meinem

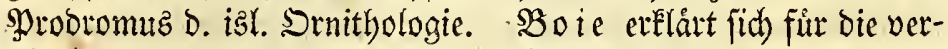

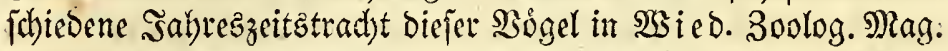

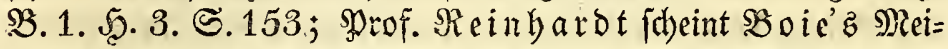

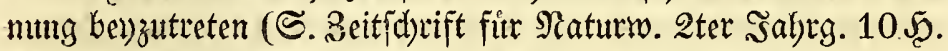

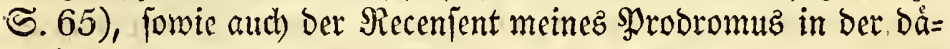

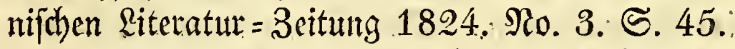

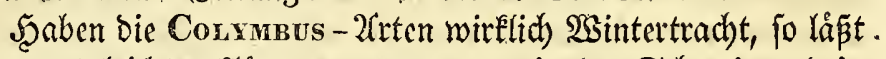
fich baraus leidjt erflúren, warum man in ber Sdhweiz und in

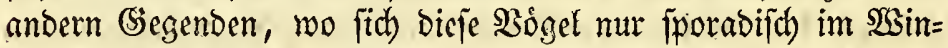
ter zeigen, fie nidht anders, als nit weiper אiehle uno (S)urget antrifft.

Bon ber extraordinaten $\mathfrak{I}$ rad t ber $\mathfrak{B}$ ogel nadh

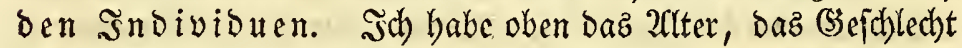
und dic গalyreszeiten als die reguláren Motive ber eintretenden Berånderungen bey Der Tradt ber Böget angegeben. Man fin= Det aber aud Bebifiele in gerwiffen Sogelanten, weldhe, ohne

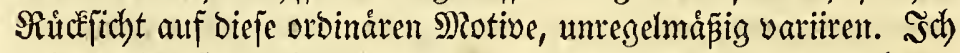

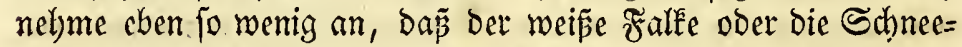

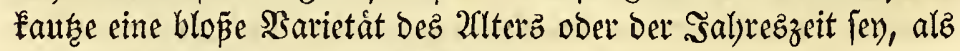

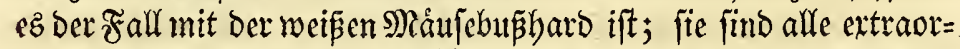
binåre Barietáten; man trifitt bie mit ber hervorfted)enden wei=

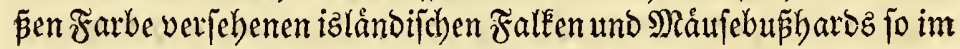
Refte. Die merfwuirbigfte extraorbinâte Farbenveránoerung zrwi= fäjen den izlåndifchen $\mathfrak{B} 0$ gelarten baben wit an Lestris parasitica, Denn fie fino nad) Den snbivibuen burd) einen weisen uno braunen unterleib verfobjeben. Da fie in ber Mitte bez Sommerz

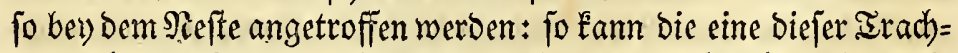

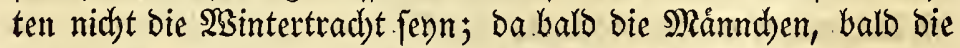
Wseibdhen Diefelbe Farbe tragen: jo Eann fie nicht bie. (Je eidhlechts= trad)t felyn, aud nid)t bie der jutngen Bógel kaum die eine biejet Irachten Fenn, weil man theilz biefe ber Eefteteren ennt, uno theils bie vom ermábnten 2fuzjegen bey Enern uno sungen trifft, fondern muß bic alter Bógel, jeyn. (Eine ábnlid)e Barie= tât unter ben Sâugthieren ber borealen Bone baben wir an bem 
blauten uno wei pen Cavis lagopus, in Dánemate an ber rothen uno braunen $\mathfrak{B a t i c t a ̂ t}$ von Sciunus vulgaris ut. [. $\mathfrak{w}$., uno bel) Den Miånden ber Trivga pugnax.

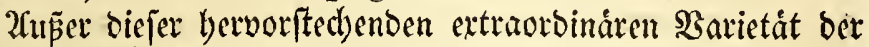
Farbe werben audh einzelne 2Cbånderungen nad) den Snbividuen bey andern 2 ogelarten gefunden; man Eam lib berbaupt nid)t bar=

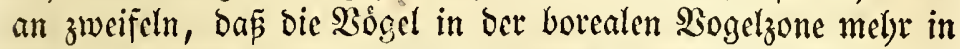
Dem $\$$ seisen, als in Dent Farbigen variiten. 2(ud) Darin findet man bas Beftreben Der Shatur mieder, bie weipe Farbe in ben

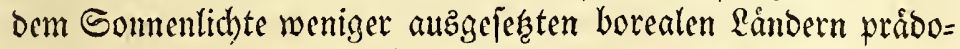
miniren zulaffer. Mandbe Shierarten in Denjelben find an uno fít fich weip, 3. B.: Unsus maritimus, Lepus groenlandicus, zum Iheil Strix nyctea, Larus eburneus, Sula alba, Cr-

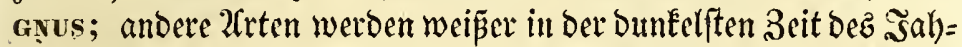

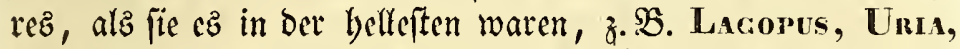
Alca, Aras glacialis, utub unter ben Sántgthieren einige 2(rten von Mustelia, andere variiren wieder ertraorbinár inz $\mathfrak{B}$ seipe mit cinzstnen sndiviouen, alz Falco islandicus, Lestras parasitica, Avas histrionica, Uria grylle unb alle, von meldien 3 Eecteren fogar ganz weipe Exemplare in Grónland gefunden worben fint; Canso graculus uno Conves corax, von weldyen eine wei $\bar{\beta}$, und von ber legertern eine weisbunte Barietát auf Den Snjęn Farroë gefunden mirb. Sold)e 2atbinos = Barictåten findet man and zumeilen in Dánemark, $\mathfrak{z}$. B. unter Mus domesticus, Fringilla domestica und cannabina, Alauda arvensis, Hinundo rustica, Conves pica uno monedula.

Nadjoem id bie vier Sautptgrimbe zu ben verfdjicbenen

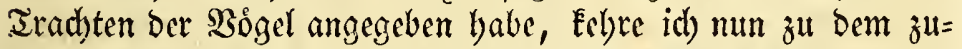

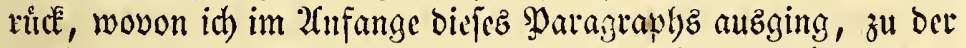
Beftimmung bes Begrifïs von ber Brtitetrad)t ber Bògel, uno bem Serbáltniffe, in weld)em bieje zum \$ুa aarungstriebe fteht. -

Die Britetracht ift aus zwell Iradten. Jufammengejegt, námllich aủ ber vollfommen alten Tirad)t, uno auts ber Som= mertrad)t bei ben R(ten, bey weldben ber Farbenwed) jel nad) Den Salhregzeiten Statt findet.

Diefez lófet fidh in zwey Sádze auf:

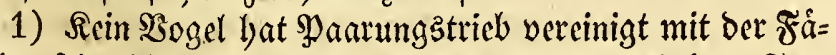

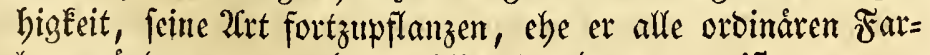
benveránderungen-nadb bem 20 (ter burd)gegangen ift.

2) 'Ben Keinem \$ogel erwad)t Der \$aarungztrieb mit ber ebengenannten ráabigkeit vereinigt, elje et bie Saintertradht 
abgelegt bat. Daber wirb bie Sommertrad)t aud jumeilen bie Sodzzeitstrad)t, oder bie Brauttrad)t genamit.

1) Da idh vielfáltige Erfalyumgen in biejer Sache gebabt babe, fo batf itb als allgemeine Regel feffecen: ba gel brüfábig fey, fo lange er bie junge Iradjt trågt. Diefer. Sas wiro fdwer zu beweifen fern, da er fids

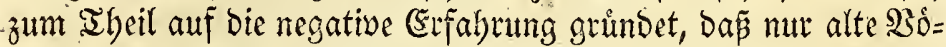
gel bey Dem Siefte angetroffen werden; zum Ibeil Eann er aber

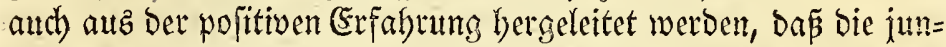

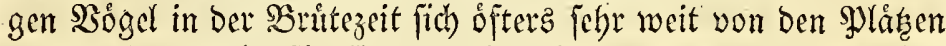
aufbalter, weld)e für fie zu Brutepláfien bequem feyn wurben.

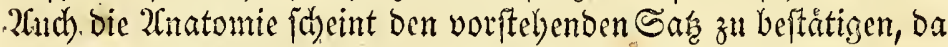

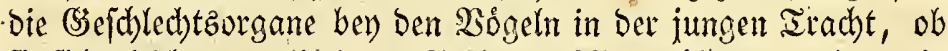
fie fid) gleid). Der vollenbeten Farbe ber alten náljern, Dod) wenig ausgebildet angetroffen werben.

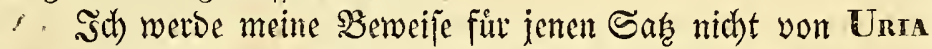
Brinnichii, troile, ringuca uno alle, ober Auca torda uno Monмо fratereula berboleir, obgleich keine ber Taujende, wel= d)e ich bel ben SBrutepláken gefunden babe, die Iradbt Der Stu= sen trugen; benn bieje 3rten fino fdoon im nádhiten Fruibjabre nad) iber 2utsbrutung, meiner Meinung nach, in brittåabiger

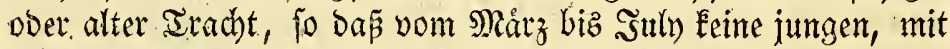
Febern befleibeten Bogel biejer 2frten exiftiten; fondern id) werbe meine (Exempel unter ben \$Jogeln wáblen, von welden wir mit

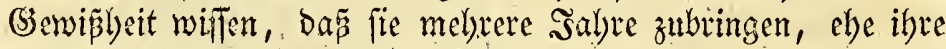
Iracht volfendet ift. Facco albicilla habe id) ntu mit bem wei=

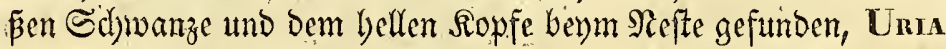
grylle wito nie gepaart gefunoen, fo lange feine Epiegel aufoen

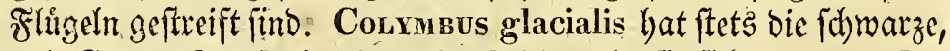
und Cor. rufogularis die rotbe Sithle, ebe fie fich paaren. Die Poniceps - 2urten haben vornebmlid Den (Signern biejer I beorie

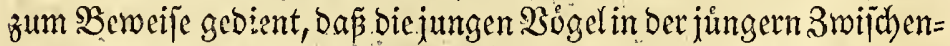
trad)t aud bruten. Namentlid betuft fid) Me ever im Tafdenb.

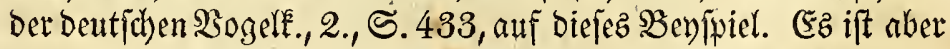

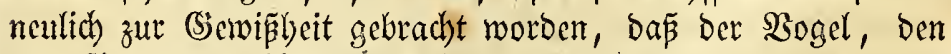
man für eimen einjályrigen $\mathfrak{B o g e l}$ von Poniceps cornutus anjall, und weldber fidon britend gefunden wirb, eine von Pon. corn. ganz verjdhiedene Species ausmadjt, ba er nie ben fdweflenden

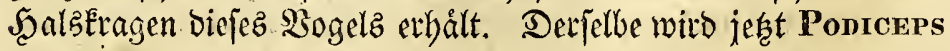
areticus genannt (f. meine 2Obhandhng in SEen $\mathfrak{G}$ Sitz, 1824, von Den norbifd)en Pinnatipedes). Mebrere' Entbecfungen 


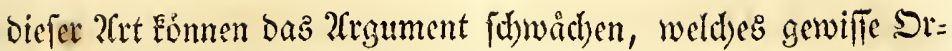

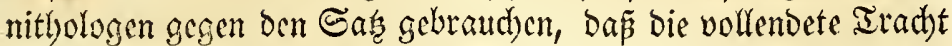

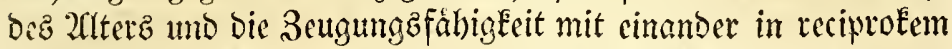
Serbâltniffe fteben. Unter ben viclfáltigen Mergus serrator, Avas mollissima, glacialis, clangula, marila, hiștrionica,

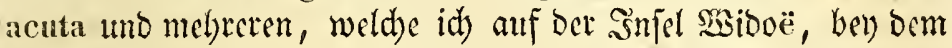
Ranojec Siyuatn und an mel)reten Stten fanb, traf id nidyt eimen (Fimzigen, Der auth nut cinen Flecten ber jungen Irad)t gebabt batte, ob ich glcich ju berferben 3cit bie jungen 3 ögel biefer $2 \mathfrak{r}=$ ten haufenweife am Strande von Den 2 ften abgejondert fano. RHe Indivibuen dez Cranis musicus und von Svea alba bey bem PRefte, batten ganz uno gar bie seflecte Befleidung Der Samgen vertoren, und waren in vollendeter Irad)t. Sbgleich Laros tri-

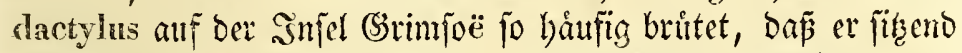
die Edtecren uno Felfen bedeclet, unb anffliegeno bie Sonne ver= Dunerlt: jo hatte Doch nicht cin Einziger von allen Dicien bas

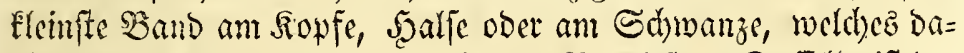

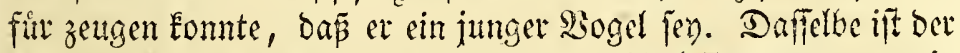
Faff mit Lanvs marinus uno glaucus. 2(udd) Lestris parasitica babe id) niemals in ber jungen Iracht bey bem Sifte gefliti=

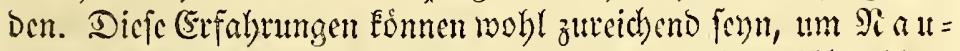

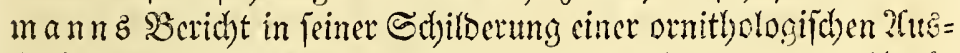

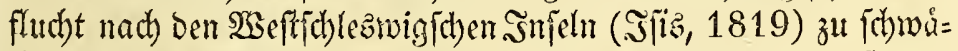
d)en, Daj̄ er Dajelbft Den jungen Lanus argentatus bel) foinem

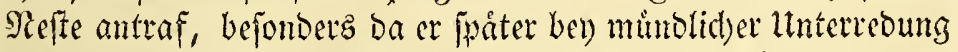
mix mitgetheilt hat, baj er bieje jungen Mieven nidbt unter bem

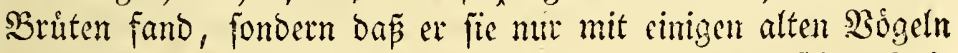

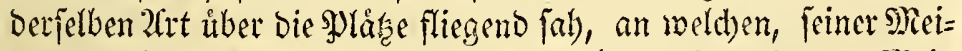

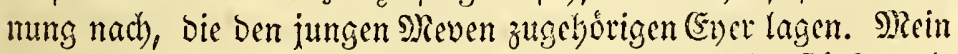

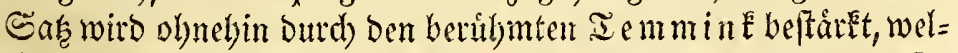

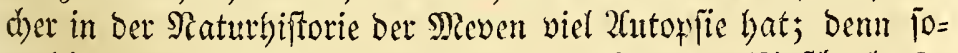
wobl in feiner Mittbeilung an Sofrath Mever (Tajd)enb. 2., S. 475), als fpater in feincm Manuel d'Ornithol. 2., p. 755 ,

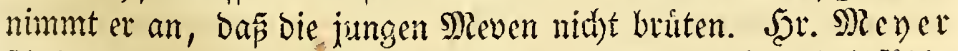
fcheint Dagegen iberbaupt zu glauben, baj bie Bogel britfällig (even, ebe fie nod in Der alten Irad)t fino. STn feinen 3ufäan

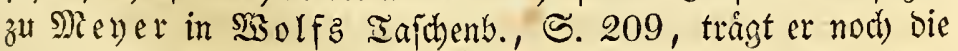

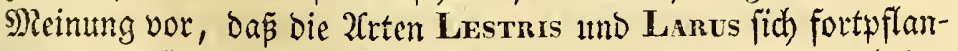
zen, ebe fie ilnre reine Farbe erhalten baben. (Fin, nad) ber

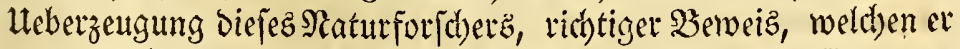

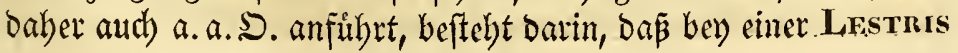


catarractes, bie in Dettifhland gefdoffen wurbe, uno grope (Ever im Evyerftocke lyatte, alle Sabwanzfedern von gleicher Iånge wa=

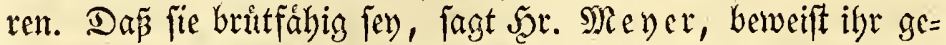
idwollener Eyerifock, baj es bagegen ein junger $\mathfrak{B o g e l}$ gewejen, glaubte er barum annebnten zu minjen, weil fie noch nid)t bie zwey cinzelnen langen Schwanzfebern erlyalten batte, weldbe er fîr ein (Sattungakennzeidben aller Lestris - 2liten bielt. Da aber Scr. $\mathfrak{R}$ e $\mathfrak{e r}$ in ber Neinung geivet bat, baf Lestres catarractés, fowie bie andern Raubmeven in ber alten Irad)t, zwey febr lange mittlere Schnanzfedern crbalte: fo war bie in Deutfid)=

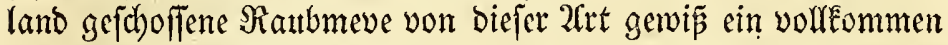

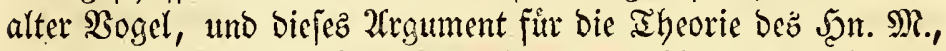

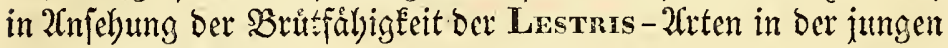
Irad)t, fállt aljo weg. Sod) barf folglid) bie entgegengejefte Mei= mung befaupten, ba iid miemalz eine junge Lestrus bey bem Mefte gefumben habe. Bon ben Meven babe idh oben gehandelt.

Die mit ber nod) nidjt vollendeten. Irad)t verjebenen, und alfo zur Fortpflanzung untüd)tigen $\mathfrak{B o g}$ el finben wir baber ber Regel nad), in ber firt ihre 2(rt beftimmten Sititzeit, nicht bey ben Bruteplągen, fonbern fie treiben ibre Sefonomie abge= foubert von ben 20 ten, und man trifft fie felten zu biefer Beit in jener (Sejellfdaft an; bic jungen Sdhmimmoogel balten jich ge=

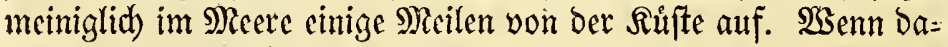

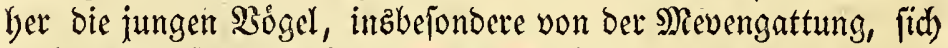
zufälligerweije ben Sláf̧en ber Alten nålsern, fo follen fie fogar nadj Saumann und Temminf (l. c.) von ben $\mathfrak{X}$ (ten verjagt merben, weldbe boch gegenfeitig einander in ber Nảhe ertragen; id) babe jeood) nicht felbft (şelegenbeit gebabt, bieß zu beobachten. Nur zwen Mal babe idh Den einjåabrigen Lanus tridactylus im Bogelberge aufGrimpö gefehen, wo Sdbaren ber alten brüten. Diefe Sungen blieben Da nut einen Tag; ihr Erfdeinen im Berge ferte nicht fo fehr bie alten brenzehigen Meven in Bewegung, alz bie Bewohner ber Sanjel, weldhe bavon alz von einer jeltenen Erjedei= nung fpraden. Dagegen traf ich bie jungen Lanus tridactylus auf meiner Uteberreife nad) Э̧land im Man 30-70 Meilen weit in bem offenen Meere, und alfo zu einer 3eit, ba bie 2lten an Der

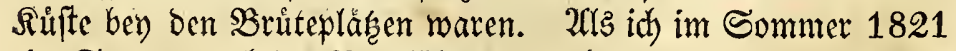
eine Seetour nach Den Bogelidseeren madhte, hielten jidh mur einige Stưk junger Sula alba bey biejen auf, meldhe ofnebiép nicht

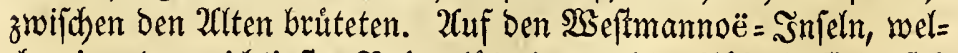

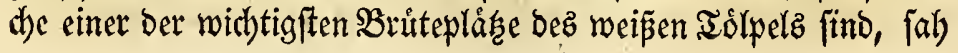




\section{1}

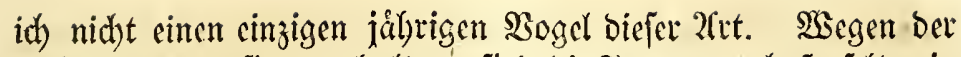
Schwierigkeit, fie zu erbalten, find bie Sungen and) fo felten in Den Mufeen. Son Larus marinus uno glaucus, Aras mollissima uno histrionica mit megreren (Enten, erinnere id) mid) mid)t,

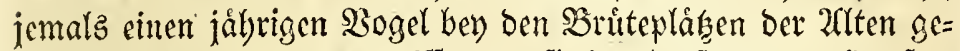
fchen zu haben; Dagegen trift man fie in abgefonderten Saufen.

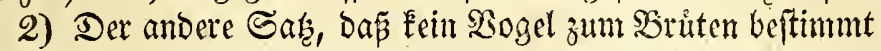

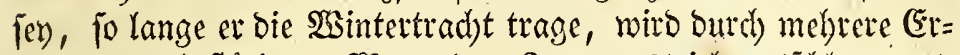

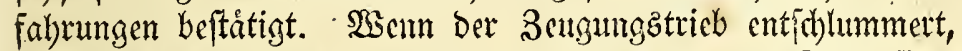
uno bie 2Ulten mit Dem 3eugen und ber Fütterung fertig find, weldhes im 2hazgrange bcz 2ruguftz uno im September gefohiebt, To fängt aud) bie S(sintertrad)t an, fich bei) ben 2 rrten zu zeigen, weldhe Damit verfechen find. Einige ?frten fangen fichon an, fie zla erl)alten, elge fie bie sungen vertaffen baken, z. B. Unia troile, Alca torda und Lanus glaucus. Die Maintertradbt tragen fie

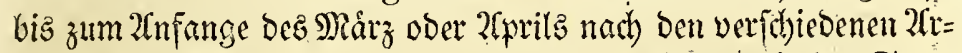

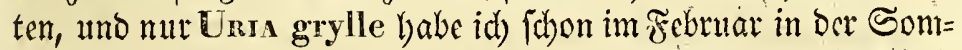
mertradbt gefunden. But Der Beit, Da fic bie Eommertrad)t erhal= ten, fảngt audb Der \$aarumgstrieb an bev Den 2(lten zu erwacherr.

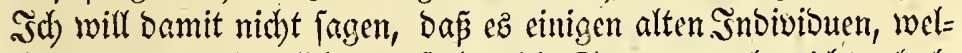

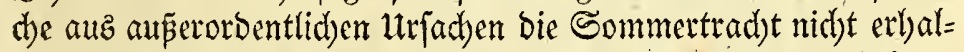
ten hatten, unmóglid) feyn follte, fiur biejes şalyr zu britten,

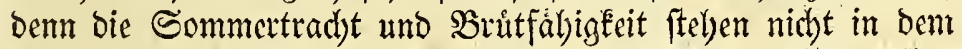

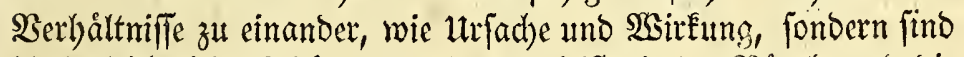

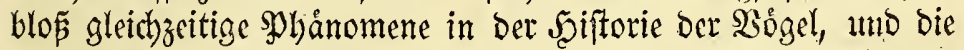

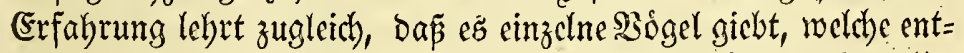
weber in ber Utebergangstradtet von ber $\mathfrak{Y} 3$ interfarbe ober in woller

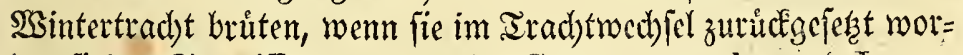
den find. So trifft man zumeilen Carbo graculus und Laris glaucus bey Dem Siefte, jenen mit Leberbleibjeln Des SGinterbir=

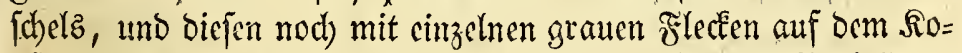
pfe und Şaffe; ferner werden bie und ba einige alte Snotibibuen

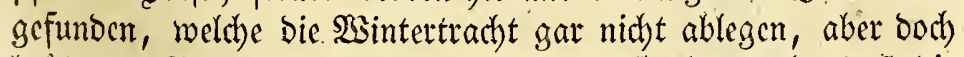

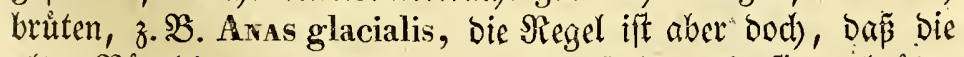
alten Siggel in ber Eommertradyt feyn follen, ehe fie zul bruten anfangen.

Bevipiele. Unter Den anzåblbaren Schaaren Der. Uria Brünnichii, troile, alle, Alca torda, melche in ben iłlámbifchen Sogerbergen braiten, babe id in Den bcioen Sommern, in welden meine ganze 2Gufmerefameeit auf bie in ben Stranbfeffen braiten=

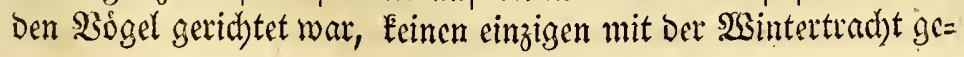


funben. 2alle waren fie in vollfomminer Sommertradt mit brau=

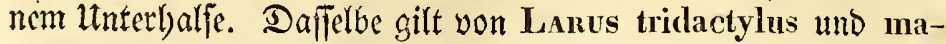
rinus, Hanmatopus ostralegus, Chamaneus pluvialis, LiMosa melanura; zumeilen trifft man, wie oben gejagt, Aras glacialis, Саnвo graculus uno Lanus glaucus mit eingen lteberbleibjeln Der $\mathfrak{W}$ intertrad)t bey Dem Nefte. SBen Muvatn f(b)oz ich im Sulty 1819 cinen Phalaropus cinereus, und bey Serebaffe in Demfelben Monat 1821 einen Phas. platyrrhinchus mit einigen weipen Flecken am Ropfe. Sion biejen Sndivibuten glaube id inderfen elser, bas fie foron anfingen, bie Sommer=

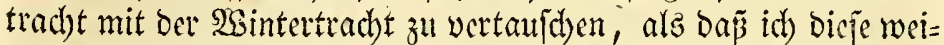

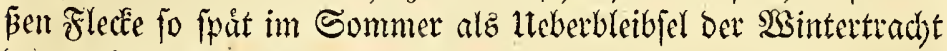
des vorigen Saljecs annelsmen folfte.

\section{§. 25.}

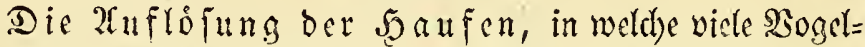

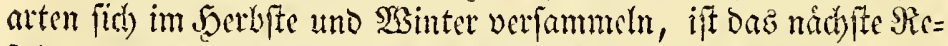

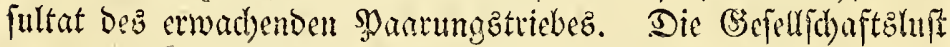
mus lier Dem ftårfer witfenoen Sharungstriebe weidyen. Die Stridbuogel bes Randes, weld)e haufemweije von bet cinen (5):= gend ber Sone zut andern manberten, und feine Stugoogel, weld)e in Frubjabre foaremieije auz einer andern Bone antamen, ver= theilen fich mun bey Dem erwadjenden Paarungstriebe, jeber zu

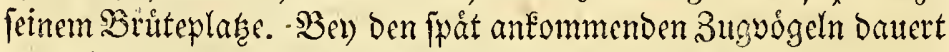
es nidbt lange nach) ibrer 2Cntumft, bis fie bie Scaufen verlaffen, in weld)en fie anfermen. Ni verues phaeopus, Lrmosa melanilra, Charadrus pluvialis, Phalaropus cinereus, Podiceps cornutus, Colsmeus rufogularis, Sterna arctica, Lestrus parasitica uno mel)rere Suguogel entfernen fith fon $8-14$ Iage nad) ibret 2 nekuft von Den Rufften, uno werben paarweife bey ilyren Brutepläen an den fipjen Seen uno Teidjen gejeben.

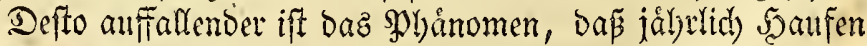
verfd)iedener Sogelarten angetroffen werben, weldhe fid nid)t mit Dem Bruten bejabaftigen, fondern ben Sommer baufenweife ver= fammelt in (5) felydjaft zubringen, ja jogar mitten im Sommer in ber 3one gefunden werden, in weldber bie 2Trten ùbrigens nid)t

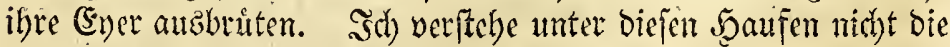

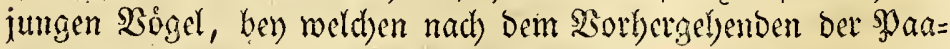
rungetrieb nidi)t etrodet iit, fondern voffentmen alte, and bem

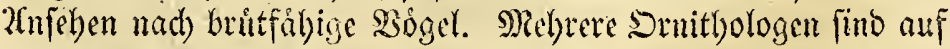

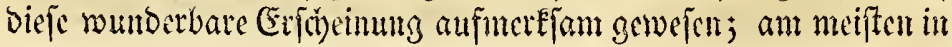


bie 2 ugen falleno babe id) fie in ber Soromung ber SumpF = und Sdymimmbogel gefunden. Sie fommt jo baufig in ber botealen 3one, námlich in şland vor, bas ber gemeine Mann unter ben: szlsnoern felkit barauf aufmerefam ift, uno foldhe alte Bogrt, weldye ben Sommer in Şaufen zubringen, ol)ne fid) fortzupflan:

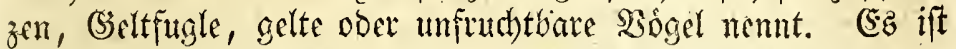

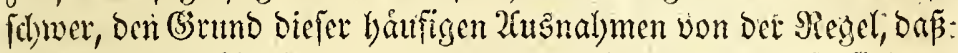

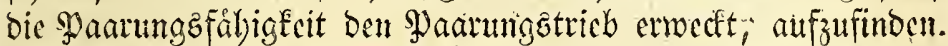
San Eann nidyt annelymen, baj alle bie nid)t britenden. Indivi= Duen burd eine whyfind fehlerhafte Sildung ber Bcugungevorgane

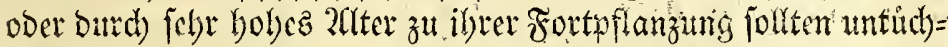
tig gemad)t worben fern, befonders ba id), beym 3erlegen meb)=

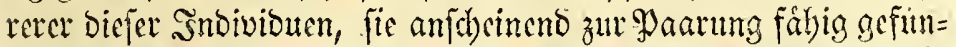

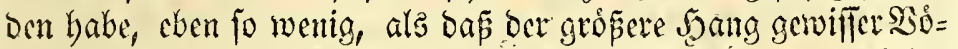

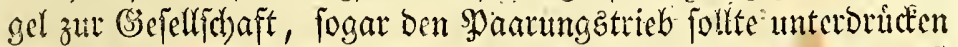
formen; Denn man fann fich wohl nid)t Denten, bajs biefe \&ult

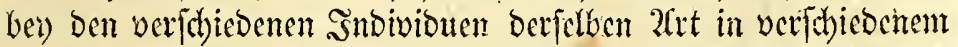
(Srabe wixfe, auferdem find bie Paarungèverlialtniffe nicht unbe= bingt cine Berbinderung Der Geiellichafteluft, da viele Bógel in

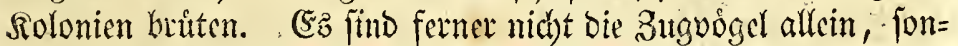
Dern aud) bie Ctandoogel, bey weldhen biefes ber Fäll ift, fonift

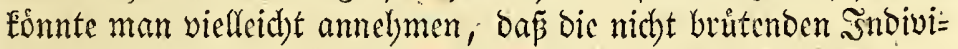
buen folche wooren, weld)e auf ilyem 3uge fid berfpatet batteut. Dem cinzigen fobcinbaren (sirunde, Der nod) fich Denenen láp̧t, nám=

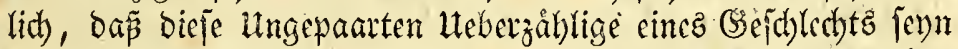
Eomten, meid)e zufolge der Monogamitåt ber meiften nordij den Sögel obne (satten bleiben misten, eann id beftimmt wiberfpre= (b)en, ba id) unter biejen nid)t brittenden sogelbaujen berfalben 2rt ebempwobl alte Máned)en, alz alte Şseibdon gefunden babe. (Es if eine 206weid)ung in ber Satur, welde eben fo in bie 2utgen fallend, als mir bisher unerflarbar gewejen ift.

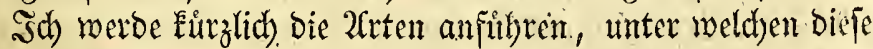
fonderbare Erifbeinung am meiften in bie 2higen falleno geful= ben wird.

2⿰亻弋 Der Meerebfufte bemerft man Den ganzen Sommer bin= ourch fleine Seaufen Charadrius hiaticula uno plavialis, 'lotanus, Carinnis, ingbejondere aber von Trivga niaritima und alpina, weldbe jich nicht nach Den Bruteplågen begeben." Şamfen von Pha naropus cinereus babe id) melyrere Meilen von der Rufte

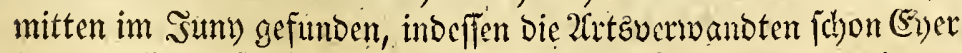

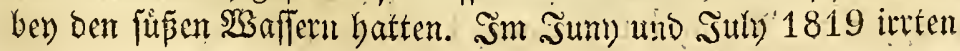


grop̃e Şaufen ungepaarter Numenius phaeopus, und Lestris parasitica bey Mnvatn auf Den Feldern herum, inbeffen bie Hebri= gen (5yer und Sunge batten. Die erftere und Limosa rufa fitebt

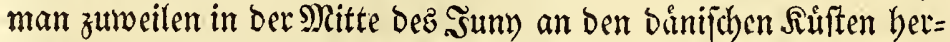
umftreichen. Unter Den isläbijd)en Enten witb faum eine 2irt gefunden, von weldyer ich nicht alte Sndivibuen Den ganzen Som= mer in ben Buthten zu ber Beit gefunden habe, in ber ihle 20rtz= vermandten, Der Regel nad), mit Dem Beugungswejen ben Den

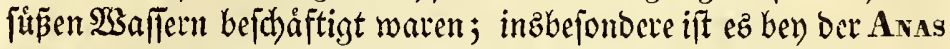
mollissima, glacialis uno histrionica in bie $\mathfrak{A}_{1}$ gen falleno. Da= gegen erinnere ids mich nicht, alte S̈ndivibuen ber borealen (Sianje oper Sabwáne in ber Brütezeit anderswo, alz an ben Bruteplá=

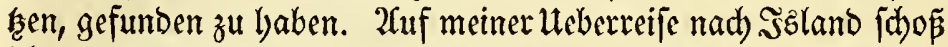
id) im May vollfommen alte Proceldaria glacialis 30 Meilen von ingend einem zum Bruteplate bequemen $\mathfrak{p}_{\text {uncte, }}$ uno id) barf baber aud) von biejen Sndividuen vorausję̧en, oap fie in bemjelben Sommer nid)t bruten wiurben.

Sieber gelbort bas Spgånomen bey den meiften norbijchen,

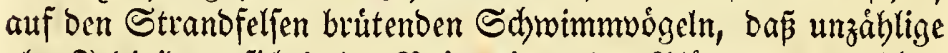
alte Șniviouen jid) in ber Britezeit an ben Pláţen, an welchen bie 2hit úbrigens brittet, verjammeln, obne fid) felbit zu paaren,

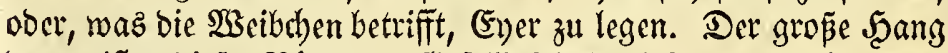

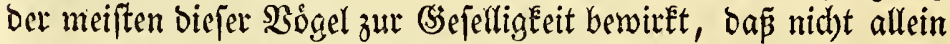
bie Brutenden ibre gegenjeitige (sefellid)aft juchen, fondern audh, bas foldse, weld)e fich in Dem Sommer nidht fortpflanzen, bod) zu biejer Sabrezzeit fid in Den Solonien ber Brittenden auffilten.

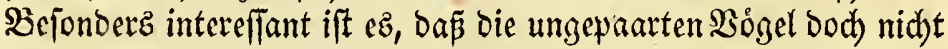
ganz iljre Bebcutung fî̀ bie brittenden Rolonien verloren haben, unter weldhe fie jith mifhen, indem fie der Regel nadh vicarirende Brůter find, uno in bie Gorge der Eltern für ibre Eyer eintreten, wenn biefe auper Stand gejef wert wen, jie felbft auşzubruten, fo baj ber Bruttrieb bier (poradijd) wirft, aud jogar bann, wenn ber Paarungatricb nicht zuvor in 2letivitât getreten iff. Slaffen

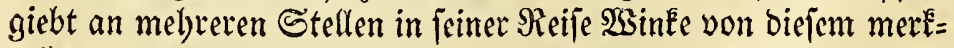

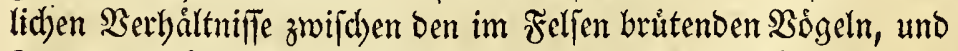

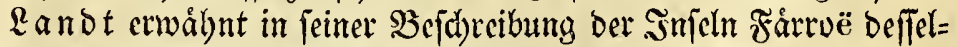

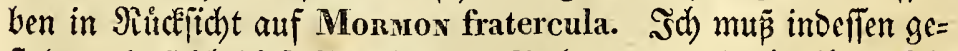

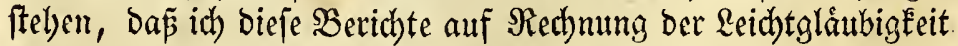
ferticb, weldbe bev einigen Meifenden gefunden wirb, mit welther

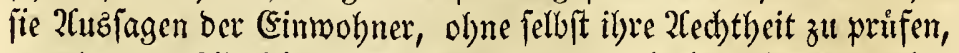
annelymen. 2(tz id) im Sommer 1820 nad) (Srimpö fam, be= 


\section{5}

baupteten bie glaubwuirbiglten (simmohner, weld)e fid) viele Săbre

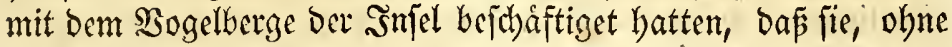
dic Sungen zur Spcife zu verlieren, die 2alten von Den Evern wegfangen fonnten, weil andere ungepaarte 2Crtzverwanden bie

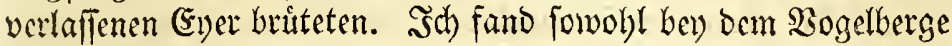
auf (Srimpoë, alz bev Denen Der $\mathfrak{S c f t m a n n o e ̈ ~ = ~ I n t e l n , ~ f e h r ~ v i e l e ~}$ yon Uria Brünnichii, troile, Alca torda, Marmon fratercula, Lanus tridactylus und Proceldaria glacialis, und cini= ge von Carbo graculus (bey oen $\mathfrak{B e f t m a n n o e ̈ ~ = ~ S ̃ n j e l n ) , ~ S u l a ~}$ alba und Lanus glaucus, welde gemi $\mid d$ t unter brutenden fda $a \mathfrak{a}=$ renweife japen. Diefe fonnten indeflen bie nidat brutenoen (S)atten gewejen fenn; ich fing aber beide (Satten von UnIa Brïnnichii und Lanus tridactylus von ifren Seftern, uno bie verlafienen (Eyer wurben nod) an bemfelben Iage von cinem britten Snbivid gebritet; im folgenden Salbre zog id 6 Monuos fratercula auf

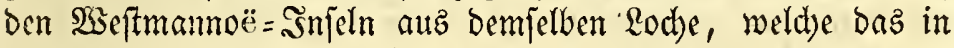
demielben liegende (Ev) etróarmt batten, obgleich diejes lefte Bey= fwiel an und fưt fid minder beweifend ift, weil Mormos frater-

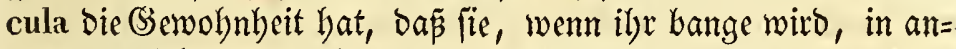

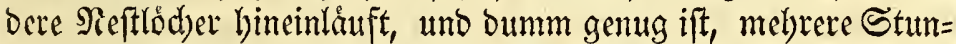

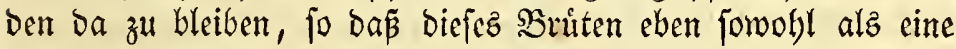

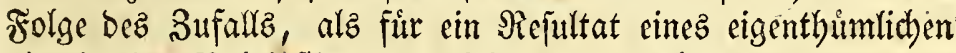
vicarirenden Srittinftinctz angejeben werden fónnte. -

Der Recenfent mcines \$robromus will biejes \$ghånomen in ber Britebiftorie Der Boggel nicht von einem 1 teberjed uffe Der brut= begierigen $\mathfrak{B} \delta$ gel herleiten, fondern madbt Die ridhtige Bemerfung,

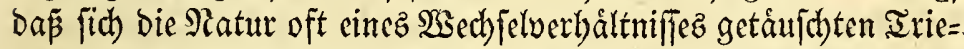
bez uno vermip̈ter Triebwirkfamkeit bebiene, um 3mecke zu errei=

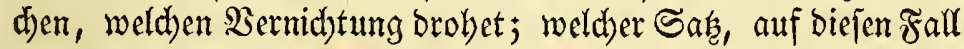

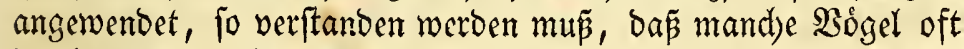
burch extraordinåre ltriachen iljer (Eycr beraubt werden, fo oaj bey Diefen Der SBritetrieb Der Siegel nad) nid)t befricoigt werden Eann; bey andern ift cz der Fall, dáp die Aften von Den Eyern genommen werben, weldye legetere baher die in ben Brutetriebe

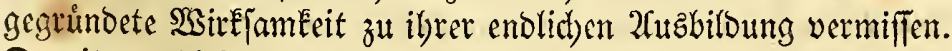
Damit mun bieje Ener nidbt unnus werben follen, fo treten jone,

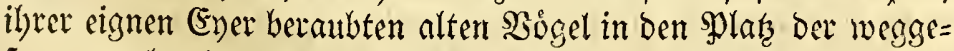
fangenen bey Dem Sritten. Sec. evtautert diejen Saç Durd ein

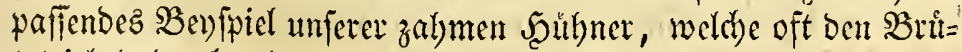
tetrieb baburd), Daf̧ fie fid) anderer J̧ubnernefter bemád)tigen, zul befriebigen fudden. 
Dáp biefce oft bey ben in ben Strandfelfen britenden Edymimmboggeln ber Fall fenn fann, will ich zwar einráumen, ba

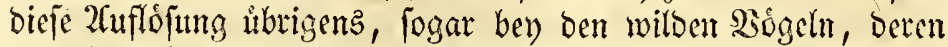

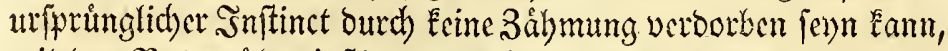

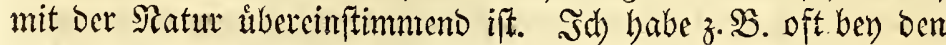

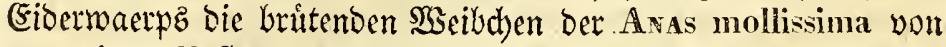
bom einen Siefte zum andern gejagt, weldse frembe Refter fie gleich in Befits genommen, utno als ihre eigenen gebrutet baben. (Es ift ferner bey Mayatn cime befannte Sadbe, da pis ftreituare Aras glacialis oft bie frómimere Aras marila von ilferm Neffe verjagt, uno ibee (Ener aubbritet. SBen ben in Den Etranofel= fen britenden 20 gefn Earn man hingegen nid)t unbedingt amely=

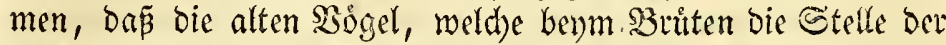

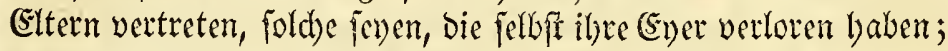
benn theils hat bie $\mathfrak{R a t u r}$ úberhaupt auf eine regetmápigere Rirt bafür gejorgt, Dáp bie ilyer (Ener beraubten 23 ógel bod) ben er= weckten Bruitetrieb befricoigen fómmen, da ez̉ oft bey ben borealen Sd)mimmugigeln gerobiebt, ba fie, wenn ihve (Ever weggenom= men werben, 2 bis 3 Mal bie 2fnzabl ber weggenommenen (Eyer

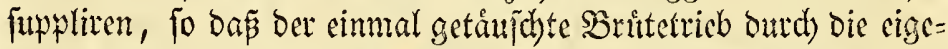

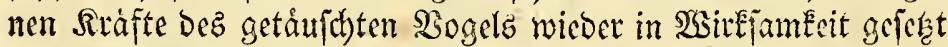

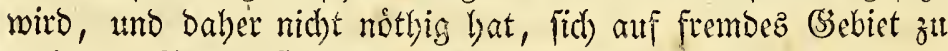

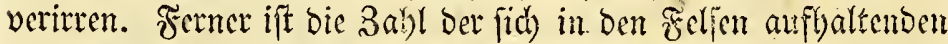

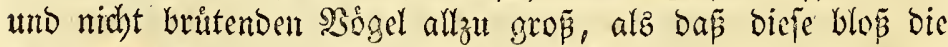
gepaarten (Satten ferbn folten, welche the eils im ?rugenblicke nid)t bruteten, theils zufálligermeife igrer (Ener beraubt wâren. Endlid'

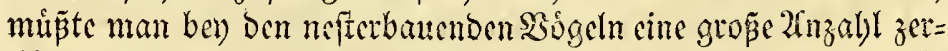

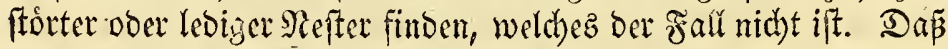
Daher viele ungewaatte Bögrl in Den Bogelbergen gefunben werden, meld)e nid)t felbft (Eyer legen u. F.m., fann nid)t gelengnet wer=

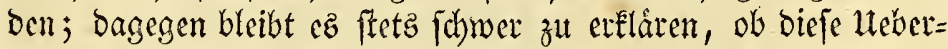
complete Da feven, um mit bent (sepaarten im Briten zu vicari= ren, ober ob bieje vicarirenden Sriuter elyer bie (Şatten fencu, weld)e entweder felbft ibrer Ener beraubt find, oder welche bie verlafferen (Ever briten, zu einer Beit, ba fie Midjt auf ibren eigenen liegen.

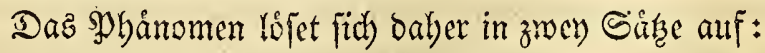

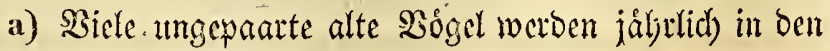
bowealen $\mathfrak{B}$ ogelbergen gefunben.

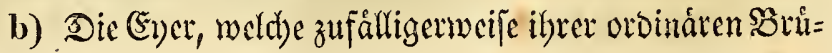


ter beraubet morben, werden barauf extraorbinåt von andern 2rtzerwandten ber Eltern gebrutet.

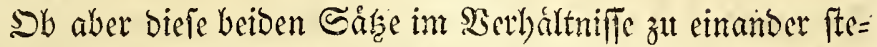

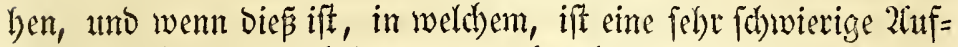
gabe, weldbe nur Durdh bennal) unmoglicbe (Erfal)rungen erlåttert werben Eann.

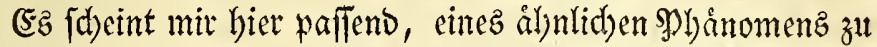
ermålynen, weldyes fitd) bey einigen ber an bell fiupen şaffern

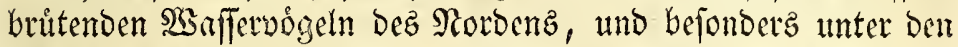
Enten, zeigt. Der auf Der norbufitichen Scite von Jaland lie= gende Ranbjec Myvatn ift ohne Bmeifel ber intereffantefte Shat im Rorben, um bie Selonomie Der borealen Enten zu beobadbten. Die meifien Der borealen (Snten bruten bier in foldó)er Menge, Das ilye (Gegenvart von keiner geringen SBebeutung für bie Saushal= tung ber Minvatinger ift. Ben biefen Randjee fand id oft bie

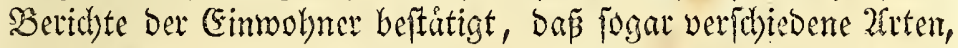
bejonders ber tauchenden Enten, cinander van ifuen Enern vei: jagen, welde fie nadber als ifre cigenen aubbutten. Diejez $\$$ by nomen fann zum Theil Durd) Die vorbergelyenden 2 ctrachtungen erflart werden; bagegen fand id) aud) oft, baj bie cine (Ente ber andern Neft in SBeitis genommen, uno Eyer unter bie fremben gelegt batte, und fomobl jene, als dieje brittete. Diejes fam

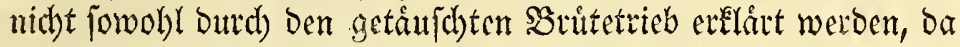

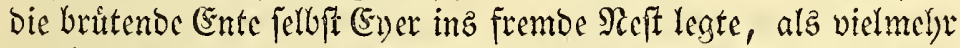

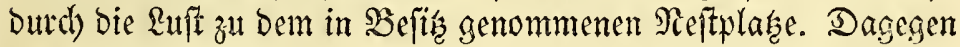

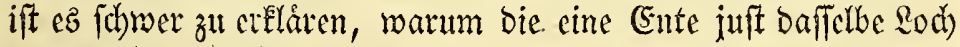

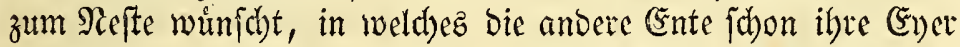
gelegt bat, Da febr viele eben fo paffende Stellen zu Meftern ben

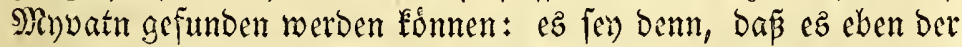
Shlas fenn follte, an weldhen baffelbe snoivid im vorlyergeben= Den Sabre feine Eyer hatte. Denn es ift offers Der Fall, als

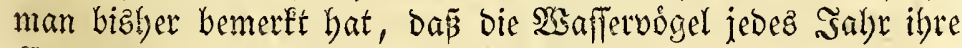
(5i)er in eirrem uno bemielben Seft auzbriten.

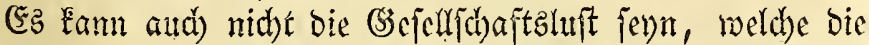

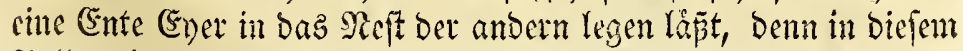
Fralle musten fie batbe bie zulammengelegten (5yer briten; man

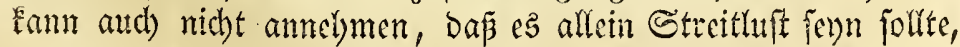
ob man gleich dfferz biefe Secmáchtigung ber Sefter ber ?ittzver= wanden ber) ber zântijchen Avas glacialis findet. Sin jebcm Faffe ift e's cine ausgemad)te (Erfabrung, baj melyrere Enten; fowoljl von berfelben, als auch von verfdjebener atet, Ever in baffelbe 
Reft legen, bā̄ biefe (Eyer nur von bem 23 eibden gebriolet wer=

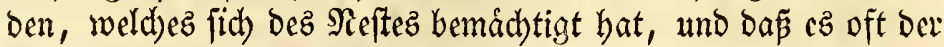
Fall zwi johen Avas marila und glacialis iff, feltenter zrwifden ber erftern und Axas clangula uno Mergus serrator. $\mathfrak{R} a d$ d Der

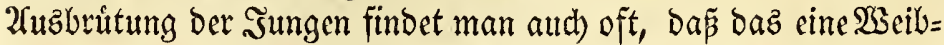
d)en bie Jungen bez andern an fid) zieltt, jo ba man zuweilen eine Avas marila mit 20-30 jungen Enten, und eine andere mur mit einer oder zweyen jdhimmen fielyt.

Bev Den $\mathfrak{B o g} g e(n$, weldye in Solonien brüten, am meiften

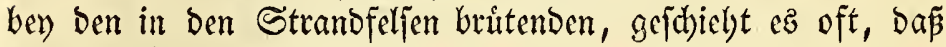
Die 2 Seibden ihre (Ener bid)t neben einander legen und in langen

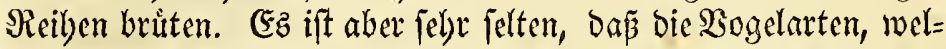

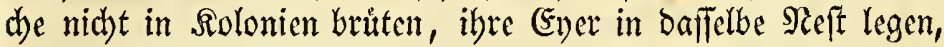

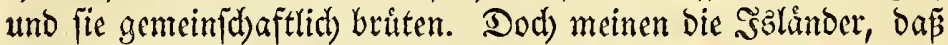
biejes zumeilen mit bem Sdhnelyulyne ber Fall fen. Nar ein ein=

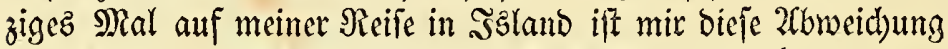
vorgetommen. 2Cuf einer Seibe bel) Sefjorben fano id) auf einem Erbbåuflein 4 (Eyer von Lestris parasitica bevfámmen liegen,

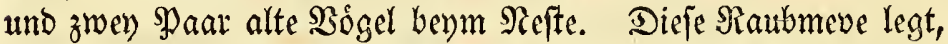

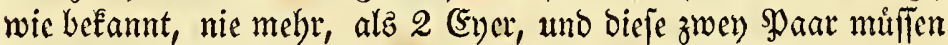

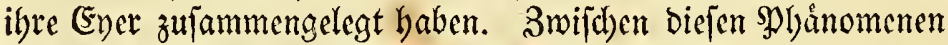
in ber Sruitthiftorie ber borealen Bógel, und bem befáanten, wel= d)ez bey Cuculus canorus Statt findet, Daj er feine (Eyer in

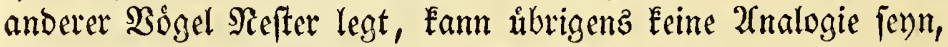
weil bieje 2(bweid)ung ben Dem אutudutef eine Folge bez totalen Mangelz dez Srutttriebes ift.

Die Singuógel, weldhe nur einmal im Sommer Enyer legen u. f. w., bauten, meiner Meinung nadh, nidbt oder falten wieber cin Meft, wenn ihnen biefes bas erfife Mal getaubt worben ift,

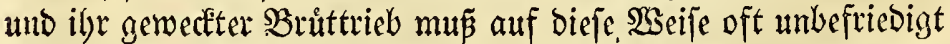
bleiben. Snterefīant wưrbe bie Gitånterung Der 2 Uufgabe fenn, ob bieje zumeilen ibren Brúttrieb auf anderer Bógel verlaffene Miefter wirken laffen. Shane im Ganzen biefes aušmad)en z̆l kỏnnen,

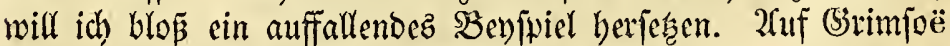

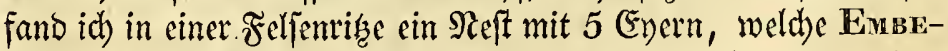
nuza nivalis bruitete. Sab fano melysere Tage nad) einanber bas

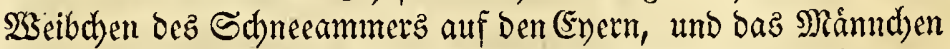

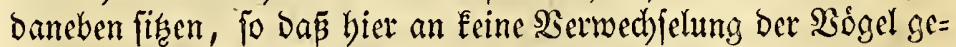
bad)t werben Eann; baz Aeft lingegen war in ber Bauart voll= fommen Dem Der Motacilea alba gleid), forie bie (Eyer benen

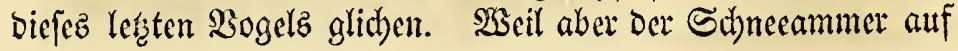


Den Enern lag, fo babe idh in meinem Probromuz naturrlicher=

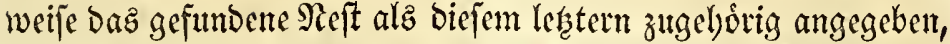
und ber (Ener, als benen ber weipen Badb/felze áf nllich erwálynt.

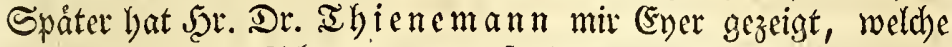
er audh unter bem Sdynceammer gefunden zu Gaben bebauptet, und weldye von ben meinigen jebre verfachicden find, wober id nidjt

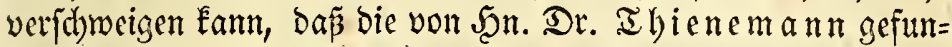
Denen (Eyer, mefre als die meinigen, nit ber Bejchreibung Der Ener bes @dnneeammers in $\mathfrak{F a b r i c i i}$ Fauna groenlandica

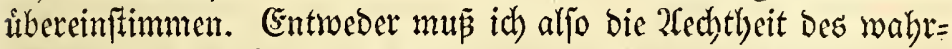

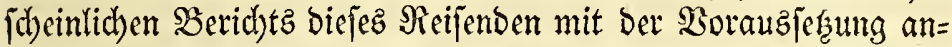
nehmen, báp die (Eyer ber Euberiza nivalis metellid) fowoly an

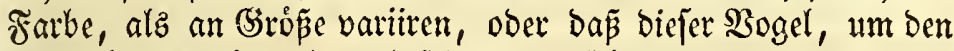
getånjehten Sruittrieb zu befriedigen, fid zumeilen ber von an= bern 20 igeln vertaffenen (Eyer bemádytige, und fie brite.

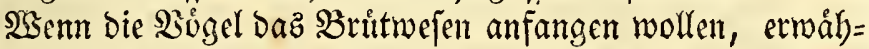
len fie fid) ibre (Satten oder fuchen fie auf. Diefes aber gefolelyt bey Den verjhiebenen 2irten zut verjobiebenen Beiten.

(Einige 2riten Fommen paarweife nad) Der borealen 3one,

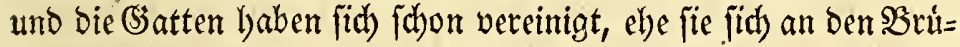
tepláen zeigen. So werden Colymbus rufogularis, bie Ponr-

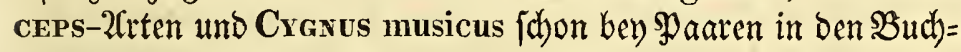

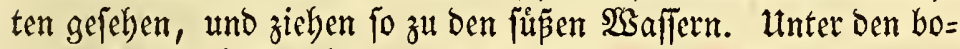

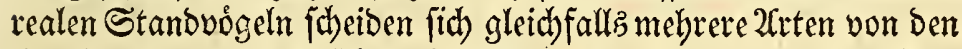
Scaufen, indem biefe fid) nod) im Neere auffalten, und bie (5)at= ten begeben fid) blö in ibrer beiberfeitigen (Sejellydhaft zu ibren Bruteplágen, z. B. bie Mergus - 2reten, Avas mollissima, histrionica, Colymbus glacialis mit mefreren. $\mathfrak{B B i e b e r}$ andere

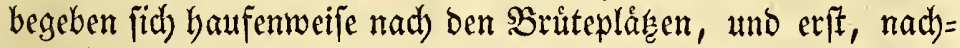
Dem fie ba angetommen find, vereinigen fid) bie (Satten bey \$̧a a = tem, z. B. Tringa, Numenius, Uria, Alca, Mannon, vet= fodiebene 2 Irten ber Enten, Lanus tridactylus, Lestris parasitica, uno Proceldaria glacialis; endlid giebt es cinige $2 \mathfrak{r}=$ tem, weldhe fidh gar nidht in gegenjeitiger (Sejellyd)aft nad) ben Brüteplåken begeben; bie Bsatten aber treffen zu verfohiebenen Beiten bey diefen ein, z. B. Saxicola oenantlie uno mejrere Cinguógel, wojetbft bas Måand)en eher, alz bas $\mathfrak{B s e i b d h e n ~ a n = ~}$

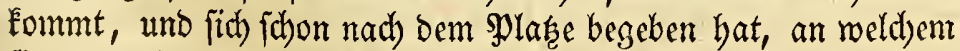

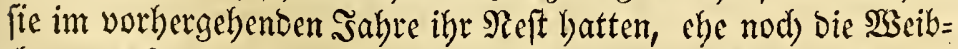
d)en angekommen fino, und bic (Satten an ben beEannten Brite= pläkęen aufgejucht baben. 


\section{§. 26.}

$23 e n$ bie (5)atten, weldye fitd) utm zat briten vereinigen wollen, fich einander gerumben baben, fo halten fie fich paarweife zufammen, und vertafien bie Şaufen, wenn fie nid)t in Solo= nien briten.

Die Serbindung, in weldye bie snoivibuen mit einander

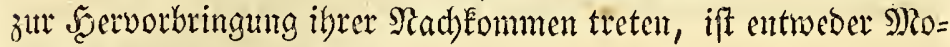
rogamie ober Sুolngamie.

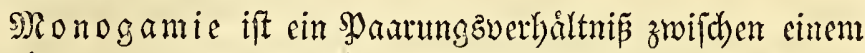

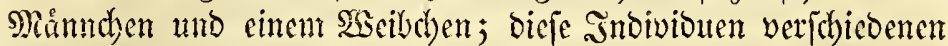

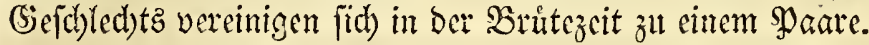

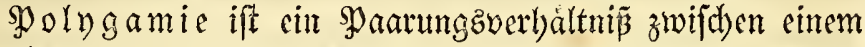

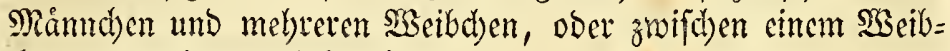
d)en uno melyeren Månnd)en. -

Sim erfern Farle ift ez \$olngamie, im leştern Molyandrie.

Die Molyanbrie wiro wobl felten unter ben Soggeln ange= troffen; in Der \$olugamie leben verfibjicbene 2frten ber (Sallina= ceen; bie Monogamie aber ift bas allgemeinfte \$aarungzberl)âlt $=$

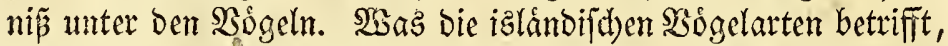
fo finbet Keine \$olngamie unter biefen Statt. (Es ift cine meiner interefianteften Beobadytungen ber ben borealen Sdinimmuỏgeln,

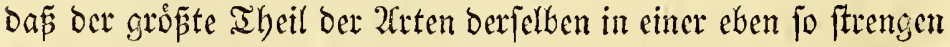
Nonogamie, alz bie Singoögel leben, obgleich einige ber neteren Sonithologen geneigt gewefen fino, bie meiften für polygame an=

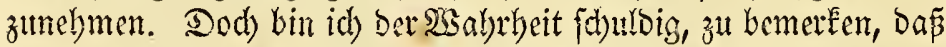
sontoppiban in feiner natirtlichen Siftorie von Norwegen, und $\widetilde{F} a b r i c i u z$ in ber Fauna groenlandica, fobon auf bie Nonogamitát mebrerer ber borealen 3 Sogel aufmertfam gewe= fen fint.

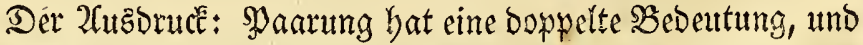

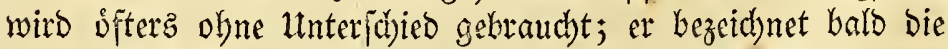

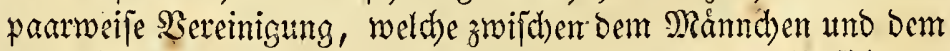
জseibchen ber monogamen 20 gegel Statt findet, wenn fie fich cin=

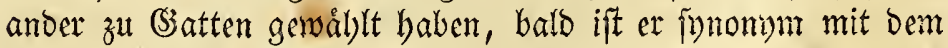

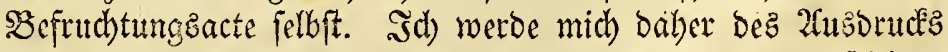

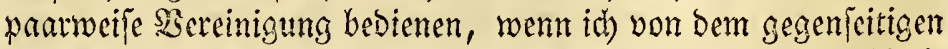

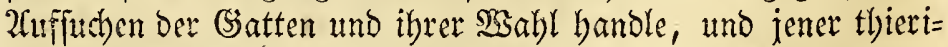

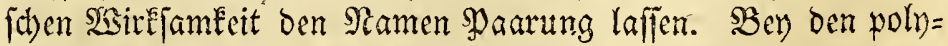

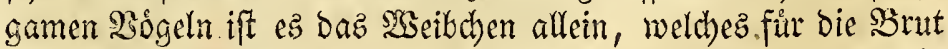
Sorge trágt. Sogar bey manchen 2irten Der monogamen $230=$ 


\section{1}

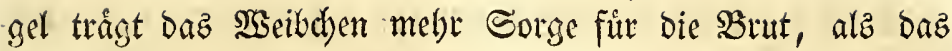
SRanndben.

Sth) theile bie Ronogamie in bie zufammengeferte, bie mittlere uno bie cinzelne.

a) Die zujammengeferte Monogamie. Daz Månndhen und bas Weibchen nefmen an ber Bubercitung Dez

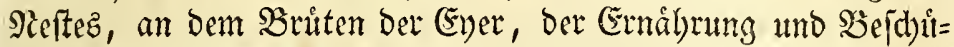

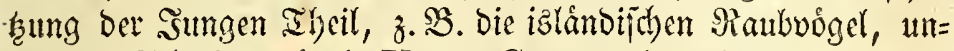
tet ben Sd)mimmudgeln Uria, Canbo mit mef)reren.

b) Die mittlexe Monogamie. Das Manndhen uno

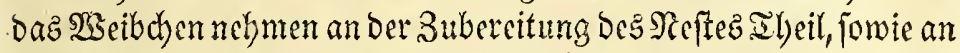
Dem Bruten ber (Ener und ber Befthiugung Der Sungen; Keiner aber ber (şatten liat ben Fittertungstrieb. Die sungen werben baher gleidh nach ber 2fuzbrittung inz Şaffer gefút)rt, wo fie jelbft die Sialurung juchen, z. B. Colymbus.

c) Die einzelne Monogamie. Das Bseibchen bereitet allein Das ungekimftelte. Reft, bruitet bie Ener, leitet unb bejhưfict bie Șungen. Sieiner ber (Satten bat ben శ̧utterungstrieb. Dem sRannd)en feblt zugleich ber Britetrieb; und bev ben meiften $2(t=$ ten Der Irieb, bie Sungen zu begleiten und zu befduthen, z. Anas.

Bey Der Darftellumg biejer (sintheitung ber Monogamitat l)abe id) auf Den gróperen ober geringeren Ģrab Der Sorjorge

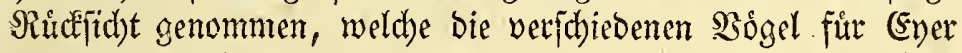
und Junge baben, und inzbejondere wie weit, uno in weldhem

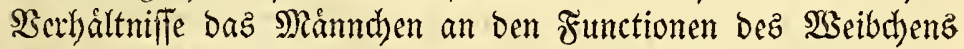
Theil ninmt. Die 2alten ber zulammengejerenten Monogamitåt ba $a=$

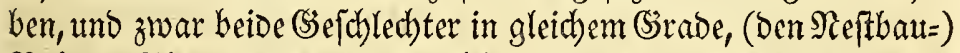

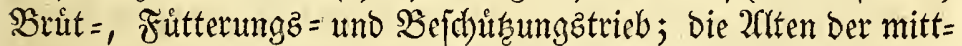
Leren Monogamität baben, ebenfarts beibe (S)efdyled)ter in gleidhem

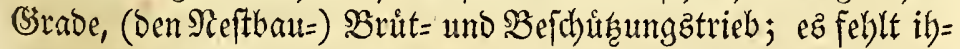
nen aber Der Frutterungstrieb; Den 2ltten ber einzelnen Monoga= mitåt mangelt, und zwar beiben (seldoled)tern, ber Frutterunģ=

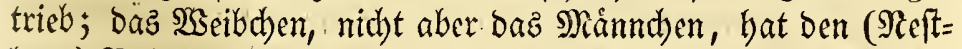
baul=) Bruit= uno Befthut

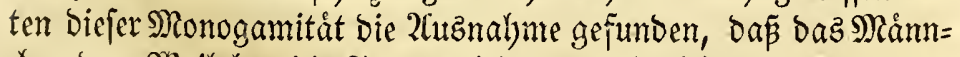

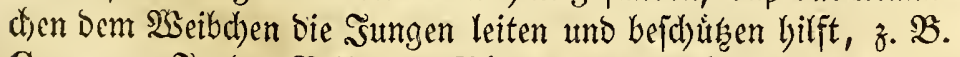

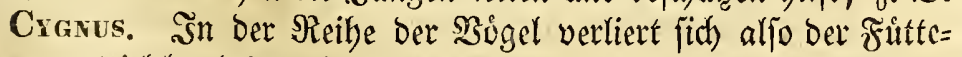
rungstrieb bey beiden (Sejhled) tern jogar eher, als ber S3rutterieb bey

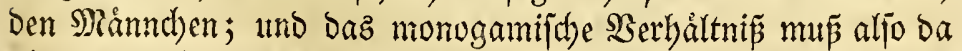

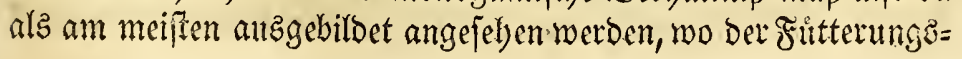


trieb bey ben 2ftten in SSinffamfeit ift; baher ift biefes : Berbålt= nip am volfemmenften bev a, minder vollfommen bey $b ;$ und am mindeften vollfommen bein $\mathrm{c}$.

Bon b bis c ift baz Serbåltniz grabweife abnebmeno, nám= lic) vom Brittriebe bey beiben 2(1ten olne Fitterungstrieb zum

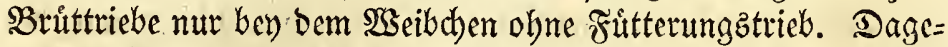
gen gejdiebt ber $\mathfrak{H}$ ebergang melyr plóflich von a bis b, namlich vom Brut = und Fiutterungatriebe bey den beiben alten zum blo=

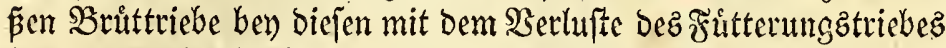
bey beiben (Sefdhled)tern. Sielleidht finbet man in einer andern

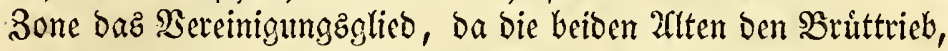
aber nur einzelne von biefen ben Futterungstrieb haben. Mit

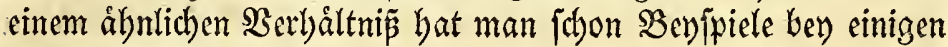
oånifden Singuỏgeln.

Sch habe in meinem Shrobromus ber islandifd en Srnitbolo= gie S.33 bieje (sirabe Der Monogamie bie uneingefdrânkte, bie mittlere, unb bie eingejdrante genannt. Der Recenjent biejez Budbes (Riteratur = Zeitung, 1824, গRo. 2) glaubt nid)t, biejen Serminis fưr Serbáltnife, weldbe aus spaarung, 2usbrutung uno Futterung zufammengejeft fino, bentreten zu fonmen.

(sz ift unleugbar, bã ber Begriff Monogamie fich nur auf

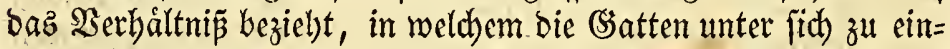
ander freben, uno ftricte nicht auf bas angewandt werben fann,

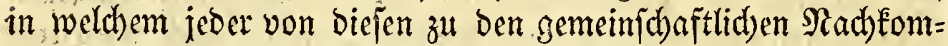

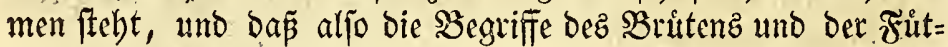
terung nicht bilecte als (sintheilungeprincip bet verifhiedenen $\mathfrak{2} \mathfrak{r}=$ ten ber Mlonogamie fonnen angerwanbt werben, wobl aber, mei= ner Meinung nad), inbirecte; Denn bas monogamijd) Berbåltni ift meljr ober weniger vollfonmen, je nad)dem die SBander ftärêt

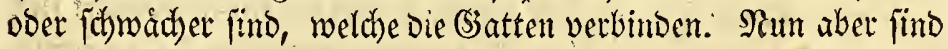

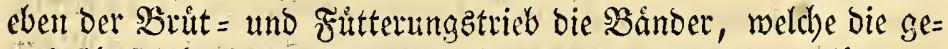
meimichaftlidse Berbindung Der (şatten erbalten uno verlangern, umb aljo bie Monogamitát vollémmner madjen. Die paarmeije Sereinigung bey ben (Satten wird nid)t allein viel geidywimber bey ben 3rten gelsoben, bey melchen ben Männchen ber SBrut = uno Futterungstrieb fehli, weld)ez bejonders bey Dein meiften 2fiten ber Einten bemerft wirb, fondern'man finbet aud nid)t, oap fie unter fid) fo viele (Ergebenljeit fitr einander haben, alz bie 2trten, bel) weld)en fich eine gemeinfd aftliche inftinctmás̄ige liebe in bev

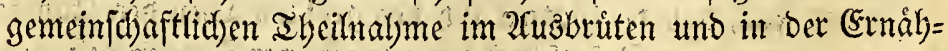

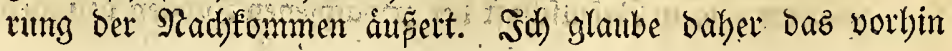


gebraudbte (5intbeilungzprincip ber Monogamitát mit einiger $\mathfrak{B e r}=$

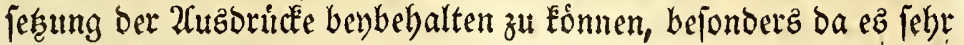
fdower ift, ganz genau paffende 2tusbruide zu finden, um bie burd) die Bereinigung fo vicler Iricbe zufammengeferten $23 e r=$ ' båltniffe zu umfalfen.

(5z ift ben weitem nod) nidbt ausgemadbt, ob bie monogame

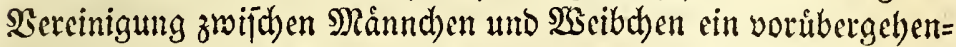

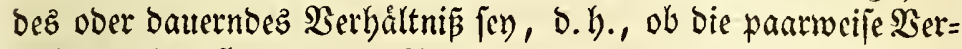
einigung der (Ssatten nur für einen paarungstermin gclte, uno barauf fun beftánbig aufgeboben fev; ober ob ez baffelbe Mánnd)en

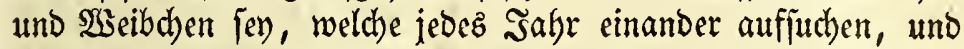
biejelbe monogamijche Berbindung eingelyen. Şier Énnen nur (Erfal)rungen ben 2 fusfd)lag geben, und biefe, in fo weit id fie Gabe erbalten fonnen, fipred)en fưr bie lef̧tere Meinung. Sach

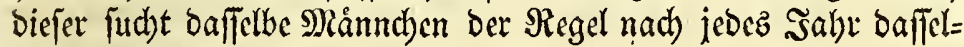
be $\mathfrak{W s}_{\mathrm{s}} \mathrm{ib}$ ben.

Es ift ein Safs, der gar nidht auper unfrem Erfahrungs

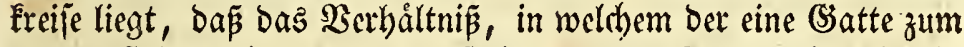
andern fteht, nid)t mit bem entid)lummernden Paarungstriebe für beftåndig aufgeboben werbe; wir haben im (3)egentheil Data, auz welcben man vermeintlid) fidhließ̄en Duen veridhiebenes (sejhlechtz jebes Sahr aufs গieue bie paarmeife Bereinigung zur Serborbringung iljer $\Re$ ach tommen eingeben,

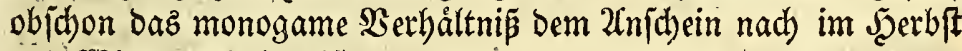
und $23 i n t e r$ geboben ift.

Denn man findet robl fehr felten, dap dieje Berbindung ab=

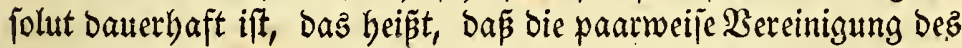
Månndbenz und, SEeibchenz nod idheinbar fortbauern jollte, nad)= Dem jene Triebe fuit bicjen \$aarungs = Berein ent jhlummert find. Der Irieb zu zieben, ober bic \&ult umberzuftreichen, heben tempo=

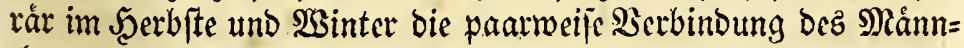

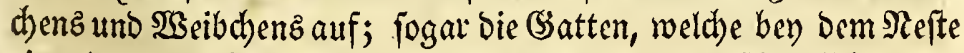
einanber bie grojpte (Ergebenbeit gezeigt haben, milchen fid) in Der 3ugzeit unter bie andern 2frtzyerwandten, ohme anjheinend baz snbivib zu bemerken, mit weldhem jie ben Sommer bindurch ver=

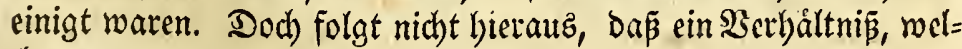
dhes temporár auper ßraft gefest ift, fưr beitåndig aufgeboben iey. Bey einzelnen 2 rten, z. B. bey ben (Eulen, Eslftern, Sd)wånen,

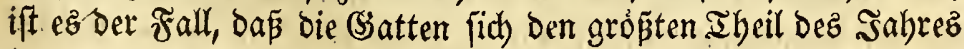
bey einander und in (se felujd)aft bet etwadh fenen sungen befinden, 


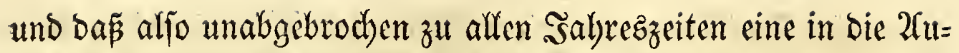
gen fallende Serbindung erlyalten wird.

Es ift, wie fchon oben bemerlt worden, weit of fer der Fall, Daf die genaue Berbindung, wéldye ben Sommer ủber zwijhen Den monogamen (Satten Statt findet, butch ben 2 Sanderungetrieb im Serbite temporår geboben wirb, und dá⿱ ez erft ber wieber erma= d)ende Sparungstrieb fen, weldber bie vorigen (Satten eimander entgegenbringt. Einige Sogelarten wandern einzeln, z. B. ver=

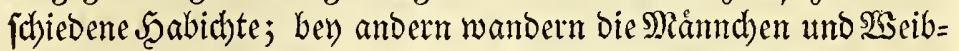
(d)en in veridbiebenen Şaufen, z. B. veridjiedene Singuogel. Die

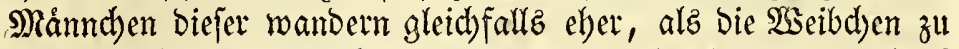
Den verlaffenen Brůteplągen zuruek, und baber Eann zu Der 3cit, in weldher fie ausgewandert waren, feine Serbindung zwifhen ben (Satten Statt gerumben haben; wieder andere wandern oder ftreid)en in gropen Scaufen, weldbe aut beiden (Sefdhlechtern zu= fammengefert find, z. B. Aras mollissima und viele andere Enten,

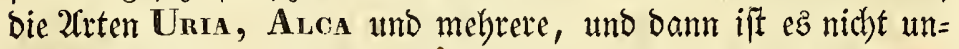

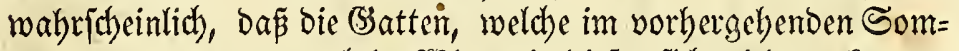
mer gepaart waren, aud) im ŞSinter in biefen fid) wieber etennen,

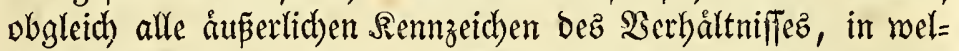
d)em fie zu eimander ftehen, z. B. gegenfeitige Sareflen und ge= genfeitige Nǻberung, mit bem entichlummerten Paarungstriebe zugleich entichlummert jind.

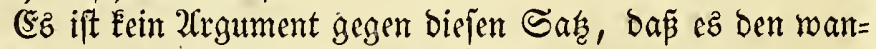
bernden ober umberftreichenden $B \delta g e l n$ idhwer fallen wurbe, bie alten (3atten wieber zu finden. Denn bey ben Sogelarten, bev

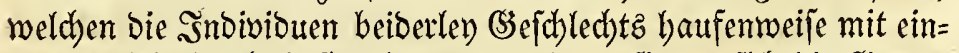
ander in (siefellychaft ftreichen ober ziehen, finden fich bie (S3atten einander leidht wieber, uno bey ben Sogelarten, bey weldyen bie verichiebenen (Sefidhled)ter fid in ber 3 utg = ober Stridyzeit ganz uno gar von einander entfernen, Gaben fie bod) ifhe alten Brite=

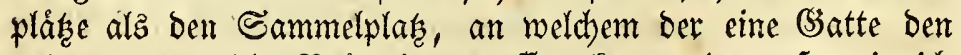
andern gegen bie Britzeit antreffen fam; benn fo wie id

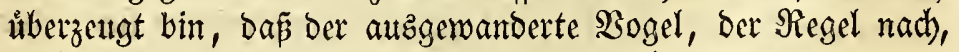

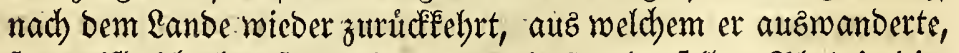

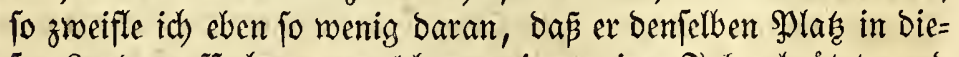
fem $\&$ ande auffuche, an weld)em er im vorigen Safbre brütete, und bap er aljo jedez Jahr nidht allein nach derfeltsen Seeimath zurueck= Eebrt, foubern aud nad) demfelben Sritteplate und bem \$uncte in ber Sceimatb, an weld)em er vorber feine (5yer auzgebritet batte; was ich fpaterbin zu beweifen futben werbe. 


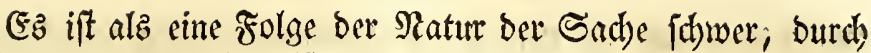

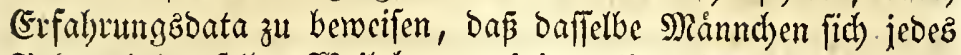
Salyr mit bemfelben 23 eibd)en vereinige. Man Eann bier nur ein=

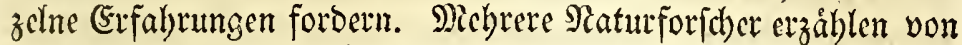

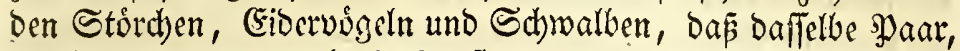

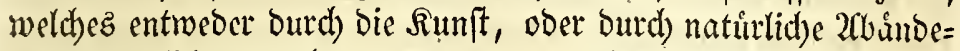
rung feuntlich gemad)t worben war, melyrere Sabre nad) cinan= ber benm $\Re e f f e$ mit cinander angetrofien wurbe. Im Jable 1819 tno 1820 bruitete ein einziges $\mathfrak{g a a r}$ Aras spectabilis auf.

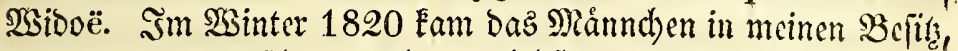

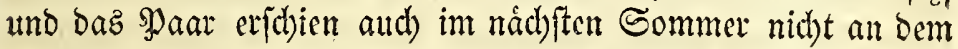

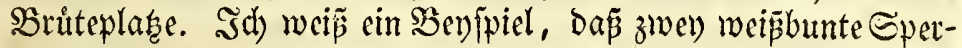
linge zwely Jahte nadh einander gepaart angettoffen wurben u. f.w.

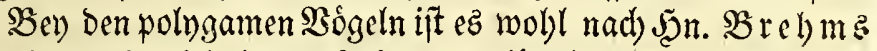

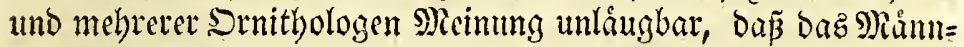

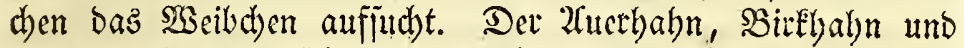

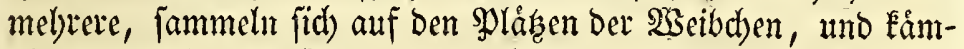
pfen um biefe. Es? findet aber aud Eeine bauterbafte $\mathfrak{B e r b i n d u n g}$

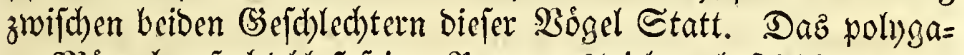
me Månnd)en fucht blop feinen \$̧aarungstrieb zu befriebigen, olyne in weitere 2 Serbindung mit bem weiblichen snbivio, welches es befruditet, einzutreten. So wie das (Segentbeil bey ben mono= gamen $23 \dot{g} g e l n$ Statt findet, fo glautbe id) aud) nid)t, $D a \tilde{\beta} \mathfrak{e} z$

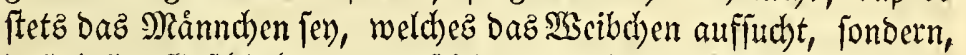

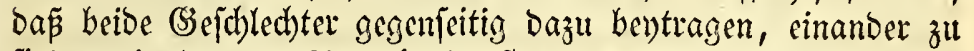
finden; ja ber den Singuógeln ift ę wobl fogar ófter Der Fall,

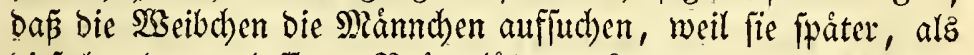

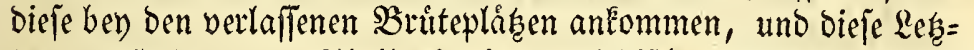
teren auperbem zum sheil mit einer metodijchen Stimme begabt

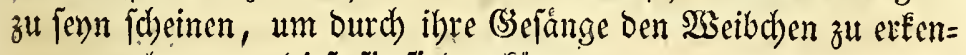
nen zu geben, wo biefe fie finden founnen.

2̧aenn bie 3ugzeit im Fruiblinge verftrichen ift, hat alfo jeDer alte Bogel feinen vorigen (Satten gejud)t. (Es ift naturtlic),

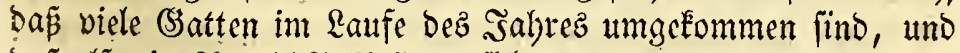

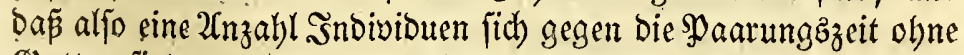
(Satten finden werden. Die Drnitbologen fino ủber bie grósere ober geringere \&eidftigkeit nidjt cinig, mit welcher ber feinen vo=

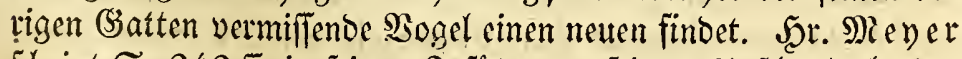

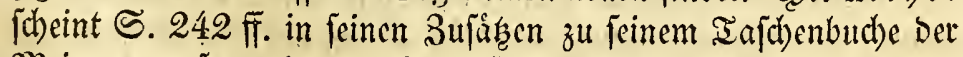
Neinung zu fenn, ba per Derluft einez (S)atten fogar in wenigen

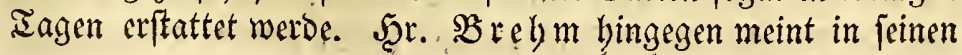


Bentrágen, III, S. 908 fi., bã̃, wenn ber 3ug der Bógel einmal vorbey jey, fo wirtben bie mangelnden (Satten in Demjelben

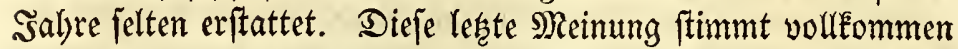

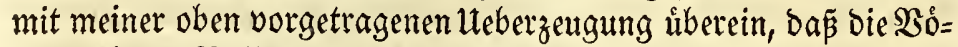
get nach ber 20 ollendung ibrer 3ugzeit ihre vorigen. (Satten auffiu=

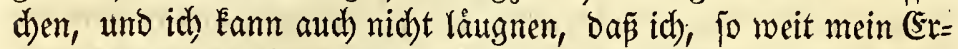

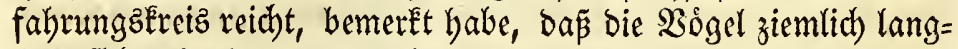
fam fich mit einem neuen (Şatten vereinigen, und dap̃ fie offter ben Sommer, in weldyem jie ilsres (satten beraubt worben find, ungepaart zubringen, als ba pie eine neute monogame $\mathfrak{B e r b i n}=$

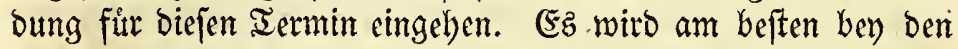
ijolirt lebenden Bógeln bemerkt, von welchen jedes. Saaar einen gemifiten Diftrict einnimmt. 2⿰l木z bie (Satten yon Conymbus glacialis $\mathfrak{u n d}$ rufogularis bey Myyatn weggenommen wurben, $\mathfrak{E} \mathfrak{a}=$

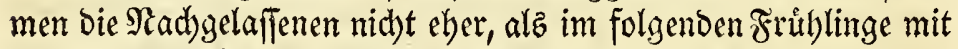
einem neuen Satten zuriute. SSenn man Daz eine Sndivio von Poniceps cornutus doer arcticus megidjespt, verlápt bag andere feinen 3riuteplá fư den Sommer. Utno follte bas mertwoirbige

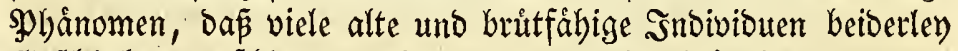

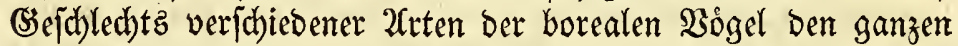
Sommer ungepaart in Saufen zubringen, nid)t baburd) erfelart retben kónnen, dap bieje foldhe find, weldhe ilye vorigen (Satten nidbt wieber haben finden E⿱ónmen, unb Daber für ben Sommer

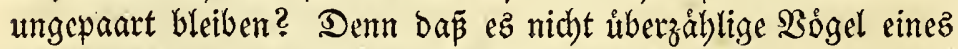

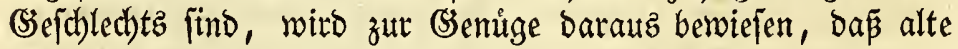

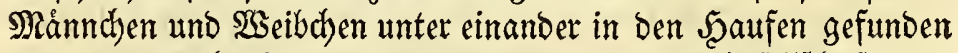
werben, welche fo ungepaart in gegenjeitiger (Sejellfd)aft um= berfifreidhen.

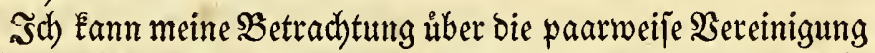

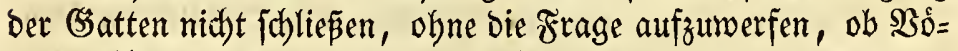
gel verfabiedener 2frt im frenen Buftande mit einander ins mono=

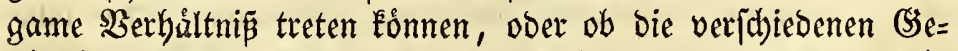

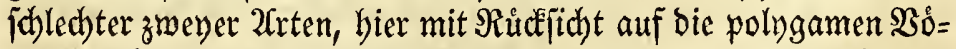
gel; audy nut blop bie \$aarung mit einander verlangen Eónnen. Bey Den gezábmten $\mathfrak{B} 0$ getn findet biejes oft Statt, z. S. Ben Dem Eanarienwogel uno Stiegliş; Dieje fónnen fogar $\mathfrak{R a c h}$ Eom=

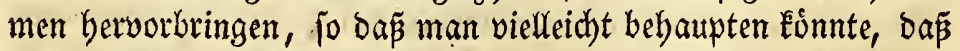
Das, was eine natưrliche Scervorbringung bewirke, nidht natur= ftreitig jey. Die Rojinng jener Frage ift yon um fo gróperem In = terefle, weil fie viel bazu bentragen wuirbe, eine fibarfe Grenze um ben Begriff einer $2 \mathfrak{r t}$ za ziehen; befien genaue Beftimmung 
fůr Den Srnithologen vom grópten 9 (uf

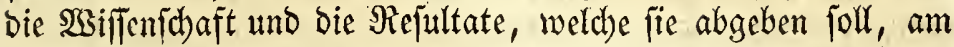
zuttåglichften, anzunelymen, Daß bie Bogelinbivibuen, weldhe im frenen Suftande fid ungezwungen mit einander paaren, zu einer

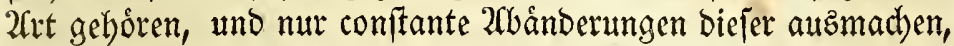
ob fie fichon åutere Sennzeichen haben, weldhe bauerno von ber Scaupttype verichieden bleiben. Finige Srmithologen tragen jedoch Eein Sebenfen, wegen ber Berfdiebenheit einez einzelnen Tlyeilez dez Sorperz von Der Jauptart veridhiedene Speciez zu billoen.

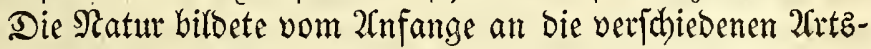
formen, indem fie einem ober melsteren Bogelpaaren jeder 2trt die Rennzeid)en mittl)eilte, weldhe fie als 2 rt tharafterijitren foll= ten, feste barauf biefe primåren, die (Srumbtype bilbenben Indivibuen an einen ober mebrere shláe Der Erobe, von wel=

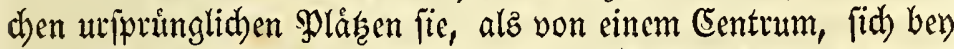
zunebmenden Indivibuen, íber eine gewiffe Strecke verbreiteten. SSenn bie Nadb fommen jener erften Inbividuen ber 2 (rt fid) melyr und mebr von biefem Sentrum entfernten, fo erlitten fie, bejon= Ders roen fie Standodgel an bie jen fernern uno nad) cinzelne 20bänderungen in ber Form uno Farbe, weldse fich auf bie fie umgebende locale (siegenftande grundeten, baz

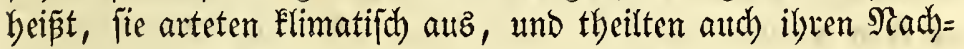
Fommen biefe 2usartung mit, weld)e, ourd) mel)rere (Sieneratio= nen verpflanzt, zuleft einen conftanten (Sb)arafter annabmen. So

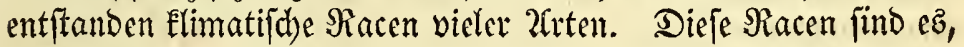
welde mebrere Srnitbologen jeft als cigene Arten aufzuftellen ge= neigt.find; Doch, meiner Mciming nad), obne (Snund, benn, ob= gleich aubgeartet, find fie bodh ád)te 2Cbémmlinge bet erften S̃n= bividuen ber 2art, und gehoren Daber abjolut Der $\mathfrak{u}$ trorm ber 2 ret an. Das Sriterium, nach weldhem man biefe Elimatifhen 2lbat= ten als etrwas veránderte Rad) fómmlinge Der $\mathfrak{u}$ rform erfennen

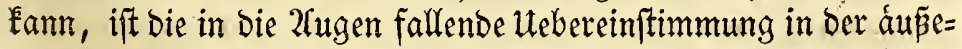
ren und inneren Biloung, in ben Sitten und ber Şiftorie mit ber

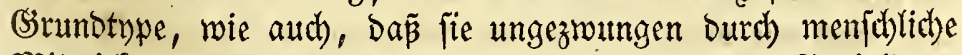
Mitwirtung, unb obne Mangel an ltmgebung von Šndividuen von berfelben 2tbart, ju ber fie felbft geboren, frevwillig tmo obme Unterjated fid ebemjowohl mit benen zur (sirundtype, als zut 2Cbånderung gebórenden Sndivibuen paaren, indem fie im

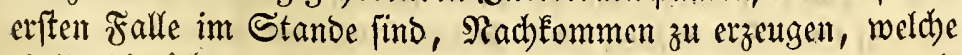
theilz bie åd)te, theils ber abgeånocrten (Srundtype Form und Farbe exlyalten. 
SSir haben nicht wenige SGenfpiele, baj die zu berfelben 2 rt geborigen Indivibuen fel)r geneigt fino, gewiffe conftante flima= tifd)e 2Cbánberungen in Der Form uno Farbe anzunebmen, jogar unter nid)t febr bivergitenben (Sraben ber Lánge lutb Breite; un= ter andern Benipielen Fann id aus Erfabrung verfotcdene von ben Єdbwimmbogelarten anfuhben, weldbe sndivibuen jowohl in Grónland, als in Jaland haben; und gewif werben joldhe $\mathrm{kli}=$

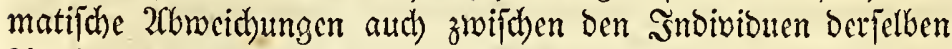

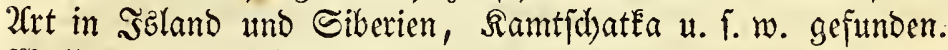
2Gollten wir indeffen alle biefe localen 2 bänderungen als eben jo viele ád)te 2iten aufnebmen, fo wirto zulefet Eein Naturinftem alle biefe 2arten melyr faffen, Ecin Srnitholog fie oronen, und Eein Gse=

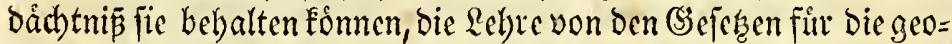

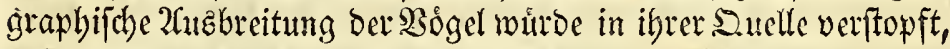

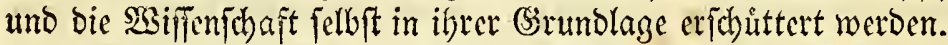

$\mathfrak{N a d}$ meinem $\mathfrak{B e g r i f f e}$ ift Unra hring via $\mathfrak{k}$ einc von U. troile verjhied one 2lat, Monmon glacialis feine von M. fratercula, Lanus medius feine von $\mathbf{L}$. glaucus, Platypus histrionicus keine von PL. minutus u. f.w., weil biefe von Denfelben Uteltern berftammen, und fich gewiß mit einander paaren und sunge ber= vorbringen, weld)e beiben gleidhen. Man wirbe vielleidt fragen, ob denn Temao urogallus audh feine verifjiedene $2 \mathfrak{r t}$ von Tet.

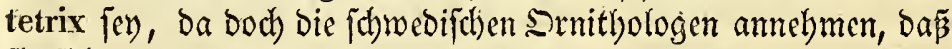
fie fid) mit einander im freben Suftande paaren, und baburd) TeTrao medius erzeugen. Seicrauf fann aber geantwortet werben, baj bie beutichen und bollandijd)en Sinithologen bieje Mcinung verwerfen, uno Tetrao medius nidbt als cinen Saftaro von

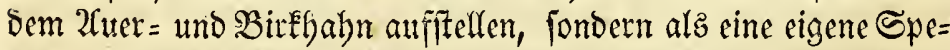
ciez. Sn jebcm Falle paaren jid) bieje beiben 2 trten nur gezwun= gen, und ber 2 retabegriff wirb baber burd) bieje 2(bweidhung nid)t verructe. Sie wid)tigfte Einwendung fann für ben 2 utgenblick unláugbar in Convus cornix und corone gejucht werben, weldhe fich in Deutfchland oft paaren und Sunge-vom 2 tuefelen ber bei= ben 2 rten bervorbringen. Einige Srnityologen jeben aus biefem

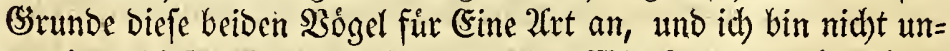

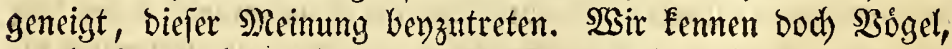
welche åuperlich eben fo jebr in ber Farbe bifferiren, alz biefe bei=

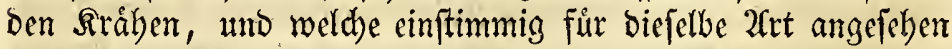
wetben; 子. $\mathfrak{5}$. Lestris parasitica mit der weipen und braunen Bruft; unter ben Săugthieren ber blaue und weipe Fudbs, baz fdwarze uno rothe Eid)horn u. f.w. 


\section{§. 27.}

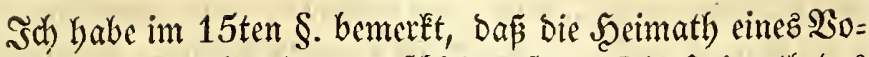
gelz von feinem Britteplaţe verifhicoen fen. Die Seimath bes

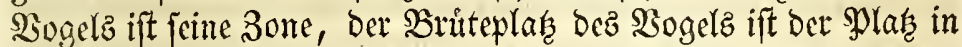
Der Bone, an weldhem er fein Sieft lyat; zut Sceimath wirb ber

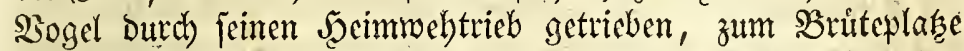

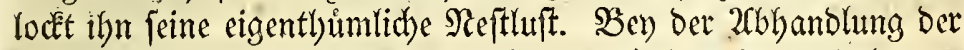

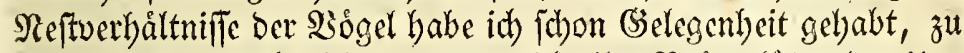

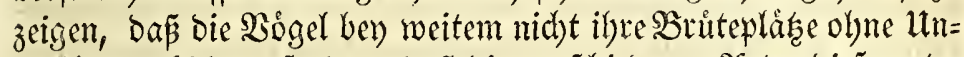

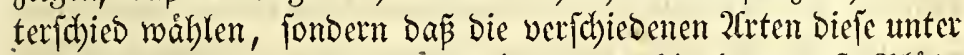

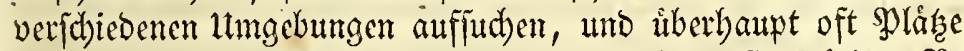

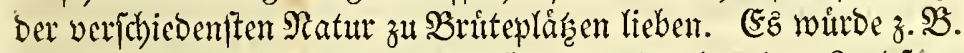
eben fo vergeblid) fenn, baz Meft ber Utrien ben Den Lambléen,

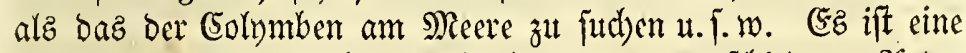

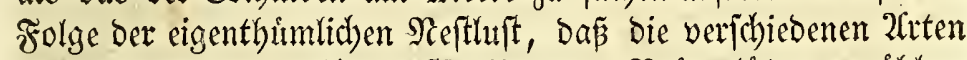

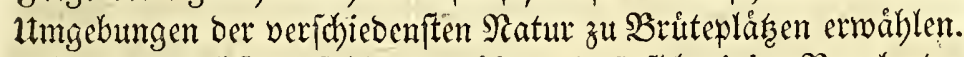

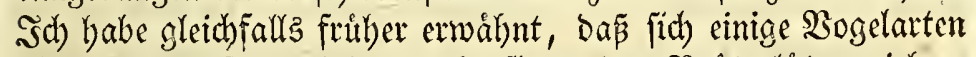
fdon paarweife vereinigen, ebe fie zu ben Brüteplågen ziehen, 3. 3. Connubus glacialis umb Cravus musicus; wieber andere ziełen haufenweife von beiben Gefalled)tern zu biefen bin, und

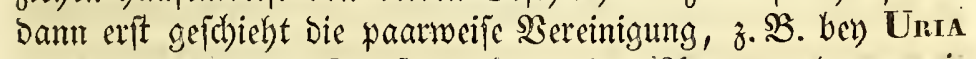
troile und Alca torda; ferner bey andern' 2 rten, und an mei= ften bey Den Singuogeln, findet fid) Der eine (3atte abgefondert bey Dem Şruteplase cin, und wird von Dem andern aufgejucht.

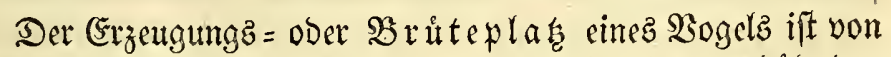

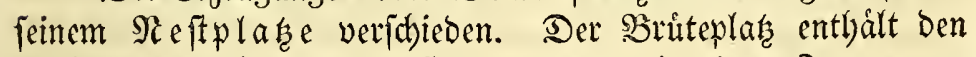

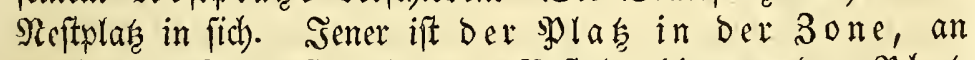

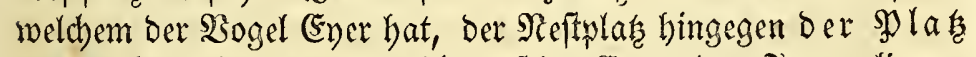
im Bruteplase, an weldhem feine (Ever ober sunge licgen.

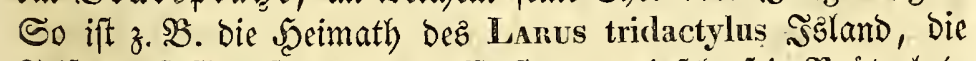

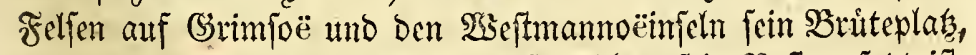

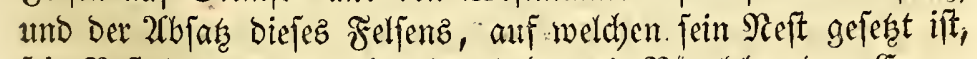

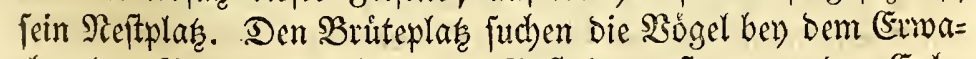
chen bes spaarumgatriebez, Den Sieftplas erft, wenn Der. (Enle= gung = und Brittrieb erwacht. (Da ber \$aarungştrieb ein frú= her erwadbender Irieb, alz ber (5ilegungstrieb ift, fo miffen bie

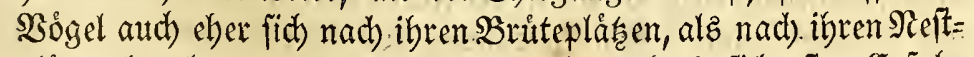

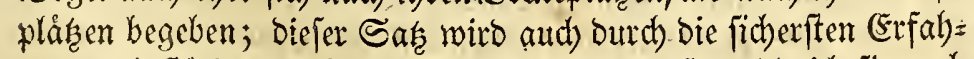
rungen beffätigt. Sich) werbe meine (Exempel, fo zablecid) fie audh gefunden werben E⿱⺊口𧘇nten, nicht in ber feptentrionalen 20 gelzone 


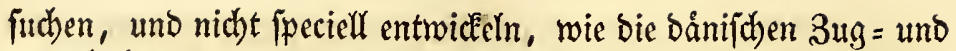
Stricluogel im. Frtithlinge paarwcife fich einen gewiflen Diftrict erwablen, in weldbem fie ein Neft bauen wollen, und innerball Der (Sienzen befferben Gerumitren, biz fie beym (Etwad)en bez (Ey)= legungstriebcs einen 3weig, ein $\mathfrak{L}_{0}$ ) in einem Baume u. f.w.,

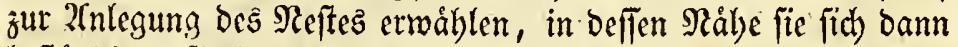
beftándig auflyalten, wenn fie fid lubrigens nidbt bavon zu entfer= nen genótligt werben, um Futter zu fuchen; in jebem Falle ift

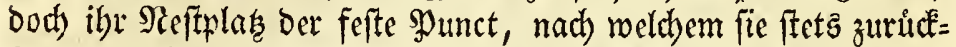
felyen. Sald werbe aber ben vorfetehenden Sage burd) einige (Exem= pel, aus ber borcalen Bogelzone hergenommen, erläutern. Pro-

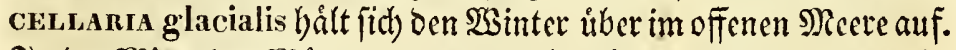
In ber Mitte bes Mårzmonatz etraad)t fdhon ber Maarungstrieb; Der $\mathfrak{B}$ ogel nál)ert fíd) bann feinen Brủtepláąen, ben Bogelbergen

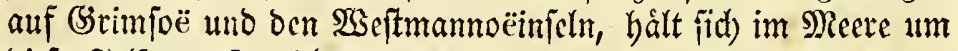
bieje Feljen auf, nid)t elyer aber, als in ber Mitte bes 2tprils, wenn ber Eylegutugs = und Britetrieb etroadt, fliegt er zu ben

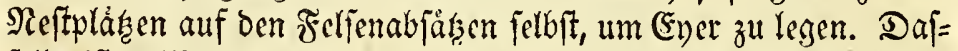
feltbe ift volffommen der Fall mit Uria troile, Brünnichii, Alca torda, Marmos fratercula ut.f.m., weldhe alle in gropere Men= ge im Meere ben den Brittepláąen in ben Strandfelfen lange 3eit zuvor erid)einen, elye fie in Dieje binauffliegen, utm (Eyer zu legen oder zu brúten. (Einige 2frten fommen fruber zu ben Brü=

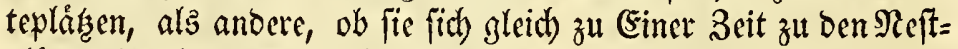

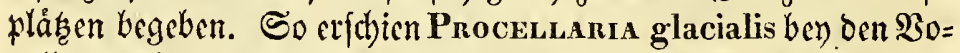

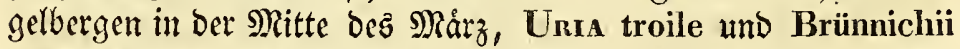

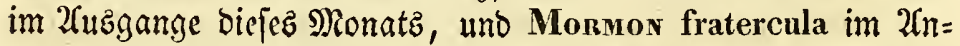
fange bes Maymonatz, ob fie gleid) alle obngefábr zu berfelben 3eit Ener legen. Die Gegend um den Landjee Mrypatn herum ift ein widstiger Sritteplats ber meiften borealen 2irten ber Enten.

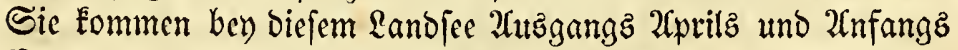
Mays an, und werben bann balb bier, balb bort, aut bem See gefeben, ehe fie bey) bem (Erwachen bes Enlegungstriebez fich

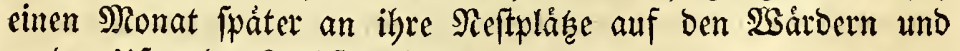
an ben $\mathfrak{U}$ feen ber $\mathfrak{L a n b j e e n ~ b i n d e n . ~}$

W3it haben zwat vorhin gefeben, baß bie Bógel ibrer cigen=

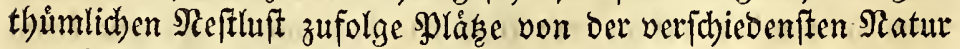

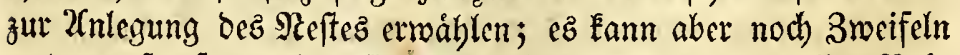

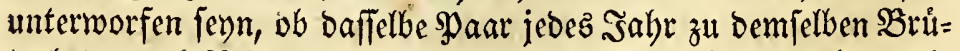

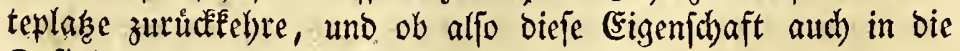
Definition ber eigentluimliden Reftluft mulfe einbegriffen fenn. 


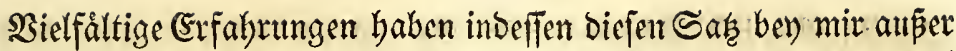

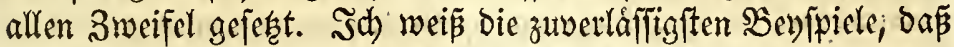
bie Bógel nid)t allein ihre alten Bruitepläge, fondern jogar ihren

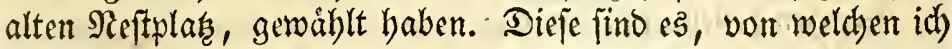
bie widhtigiten mittheilen werde.

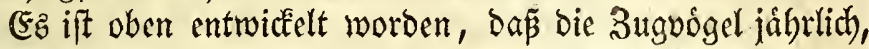

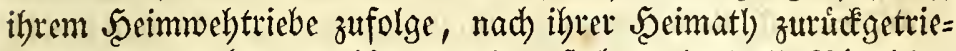
ben werben; id werbe Gier zu zeigen fuchen, baj alle Sógel ber 3one, fowohl Stand = als 3uguogel, jâhurlich vermittelft inver

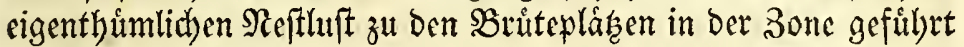
werben, an weld)en fie im vorigen Sabre brüteten. Mehrere Dr= nithologen find fdoon zum Ih heil barauf aufmerefam gewejen.

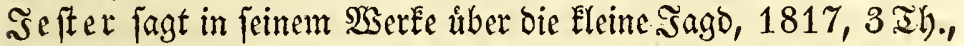

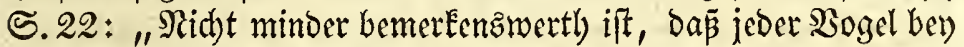

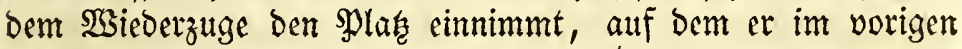
Sahre gebritet hat. Die Edywalbe bezilht bas alte Reft, Der

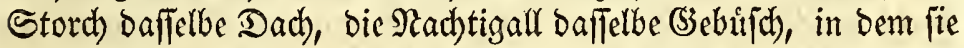

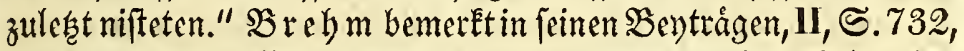
in einer Fleinen 26bhandlung von Dem zigcunerartigen Qeben Der

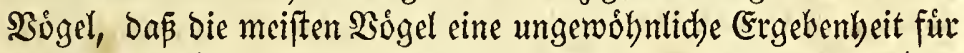
ibre Sruétepláge zeigen; fie fino das Standquartier, in weldhem

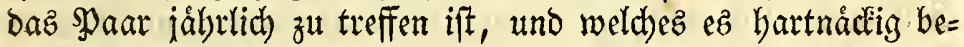

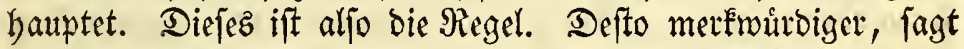

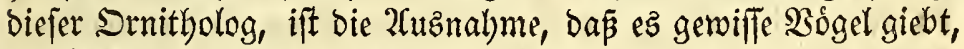
welche Eeinen beftimmten Brinteplats Gaben, fondern bie in einem

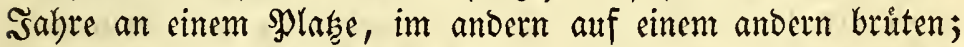
biefe Bógel haben Kein Baterland, uno fúbren, feiter Termino= logie nach, ein zigeuncrartiges $\mathfrak{R e b e n}$.

2Uuf Der Eleinen ifolitten Rlippe bey Stappen, Sondrangar genannt, bon weldher $D l a f f e n$ jobon fagte, Dáp ein 2 coler ba

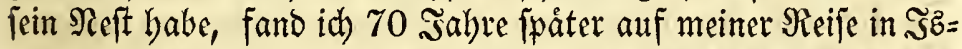

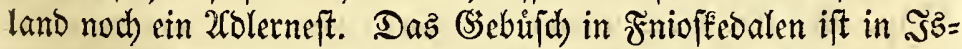
lano der cinzige Brưteplaţ der Fringrula linaria. Motacilla alba und SAxicola oenanthe finden fidc), nadb Den Berid)ten ber Şzlånder, jedez Sabr an mehreren Sertern ber Snjel ben Dem= fellen Steinwalle ein, und batten in bemfelben Qodje. Limosa melanura und Phalanopos platyrhincus haben mut eine Eleine

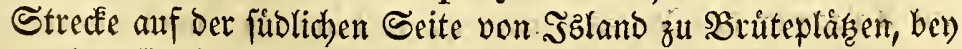
welden fie jåhrlich, uno nidht an andern Sertern ber Smjel, fich

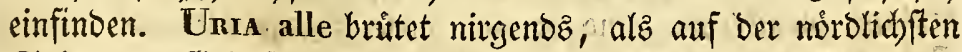

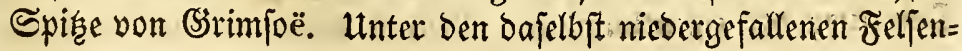


ftucken baben obngefábr 50 \$aar feit unoenflichen 3eiten jẩ)rlich gebritet. Die Şblánder glauben, dap Mannon fratercula jebe\& Sabr baffelbe Seftlod) benule, powie Purfinus areticus, wel=

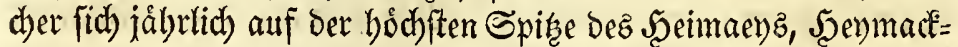
let genannt, einfindet, um ba, uno auperbem nirgends in $\Im s=$ lano, zut bruten. Sorbem waren zmey ifolirte Silippen Szlano gegen Suben, Ģeirfuglejejer genannt, der einzige Srriteplacis ber Alca impennis in šland. Man trifft audb bier auf ber Sn= fel soláke, weldhe von gemilfen Sogelarten Den Samen haben, die an biejen jäbrlich briten. So trift man oft bie Ramen Skat: faflet und Sutuffier, auf welchen Rlippen Carbo comoramus uno graculus uno Sura alba jäbrlid) bruten, die uml)er liegen= ben Scheeren aber zu Brutepláfen veridłmál)en. SBen Novvatn fand idh ber) dem Bauembaufe Studrftabr zivel kleine Teiche,

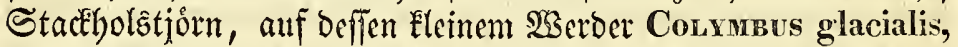
uno Irebirningztjorn, auf DefTen nod) Fleinetem Şerber Cou. rufogularis in melyr, alz 10 Jalyren jeden Sommer ifrer Seft ge= babt baben follen, und zwar an berjelben Stelle dez Şerderz, obgleich viele eben to gute sBrutepláge umber gefunden murben. Der Eigenthümer hatte mehrmale ben einen Der (Satten wegge= fangen, ber noch lebende aber batte wieber einen andern gefunden. Im Sommer 1819 fing id beibe Syaare, uno feitbem follen bie Werber von feinen andern 2 frtzuertwandten bejud)t worden fern. Ponrceps cornutus und areticus finden fid) jảbrlid) bev ben. Dám= men ein, welche fie im vorigen Salyte zu Bruteplásen lyatten, uno

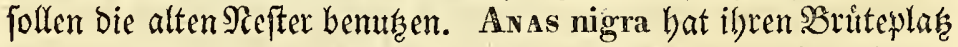
allein bey Muvatn; Ar. mollissima låst fich mut jålutlich bey einzelnen SBerbern finden, auf weldzen fie Eyer legt; cin einzigez \$aar An. spectabilis brutete in ben Sabren 1819 uno 1820 auj Sצsiboë, blieb aber nadb)er auz, ba daz 刃ånndben gefangen wor= ben war; jåhrlich begeben fich grope Şaufen verichiedener 2(rten Enten zum \&andjee Nyvatn, um ba zu bruten. Cravos masicus, fagt man, hat jedez Jabr in Denjelben SBergmalfern fein

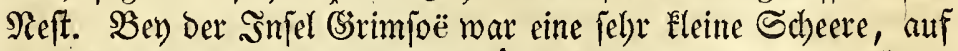
weldber Lanus marinus uno glaucus mebrete Jalyre ibr Seft ge= babt batten; fie briteten aber nicht auf ben umberliegenden.

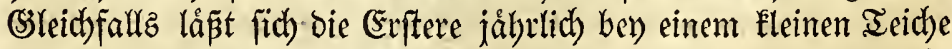
in Snappadalzinffel, Fiffevatn genannt, finden, um ba zu brú=

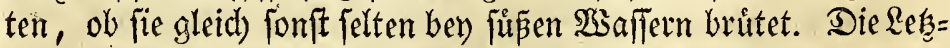
tere biejer Meven bewolnt jebez salbre eine kleine Felienftrecte bey Slafswide; bägegen brittet fie nid)t in ben benad)barten Slippen; 


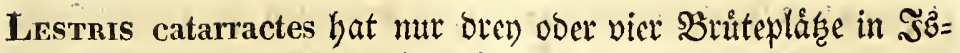
lano, bey weldhen er fid jållyrlich einfindet.

In Dånemarkz Srnitbologie merden viele SBenfpiele gejun=

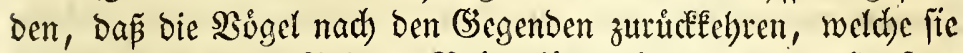

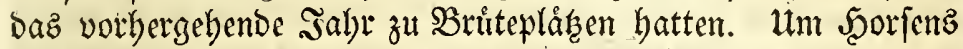

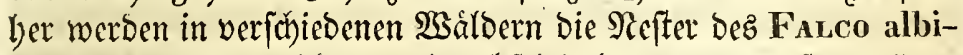

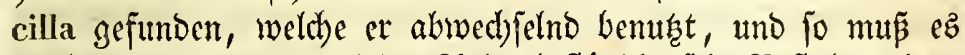

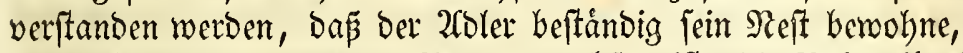
ba er ủbrigens, wenn bie Siut ermachfen ift, bie Britteplátge verláp̈t, weil er ein Stridjuogel ift. Falco milvus uno buteo baben gleidfafls, wie idy beftimmt beobad)tet lyabe, melyere Jabre

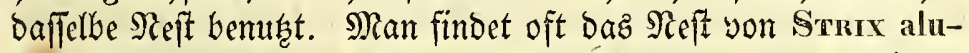
co, Picus major, Stunniss varius, Colmmba oenas jebcs Sabr in Demfelben bohlen Baume. Convus frugilegus bat hie

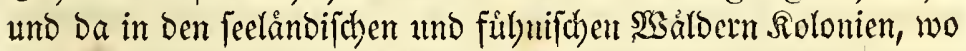
er fidd jåbrlid einfindet. Convvs pica und Fringrula dome-

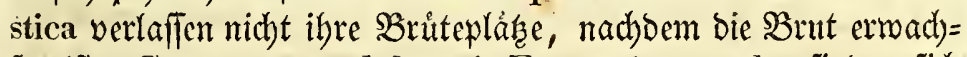
fen ift. Convus monedula und Falco timunculus finden fid).

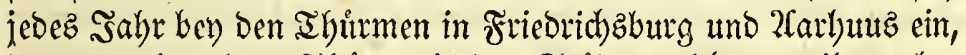

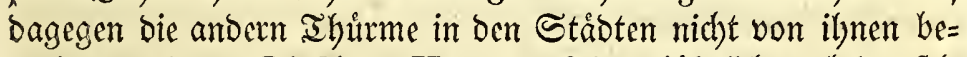
wohnt merben. Die 2frten Hunundo kehren jåhrlid, nach demifel=

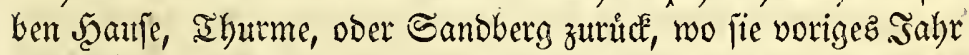

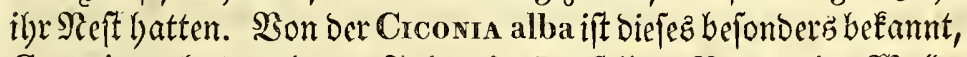
Crc. nigra hat melyrere sabre in demielben SBaume im $\mathfrak{B a l b e}$ bey Matterup in ber (Segend von Jeorjenz gebrutet. Ardea cinerea findet fidd) jebez sabr bey ben Båumen auf einer Eleinen

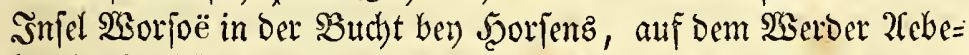
loë im Lanbjee ber Sfanderborg, und auf einer andern im See

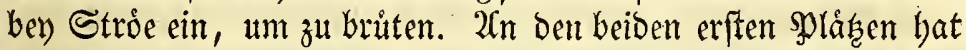
(iid) Carbo cormoranus mit ilynen vercinigt, und brutet jeoce

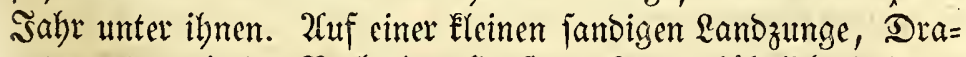

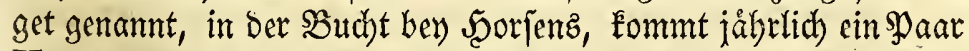
Наematopus ostralegus, obgleich) Eeine anderen auf cinige $\mathfrak{M e i =}$ len im $\mathfrak{L}$ metreife gefeben werben; eben fio mit Sterna minuta.

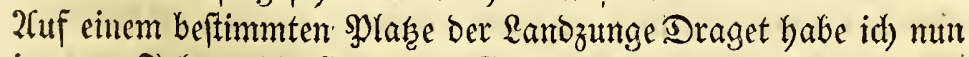
in gwey) Safbren bie (Eyer von Charannus hiaticula gefunben. 2huf Saltholmen wiro cine fleine Strecke gefunden, auf weldher Recunvinostra avocetta jåbrlid) bruttet, ob er gleid) úbrigens in biefen Ģegenden felten ift. Diefe und unzádlyge SBenfpicle melyr,

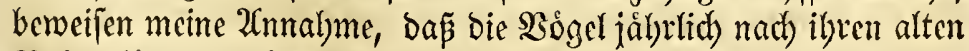

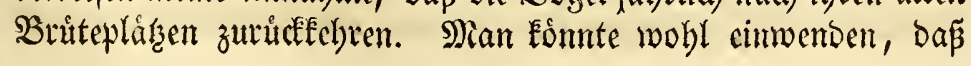




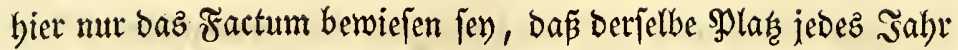
zum Sruiteplake, ober wohl gar zum Neftplake, für biejelbe 2art Der $\mathfrak{B o ̊ g e l}$ biene, Daß aber barauz nid)t folge, baßj ez biejelben

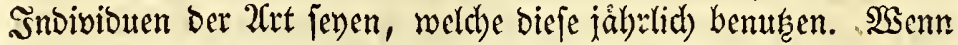

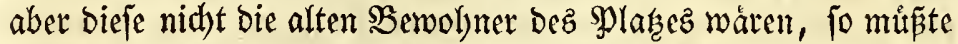

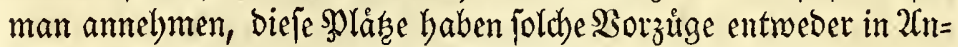
febung ber Bequemlidjeit zum Sieftbaue, ober bez Ueberfuffez

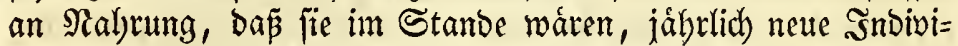

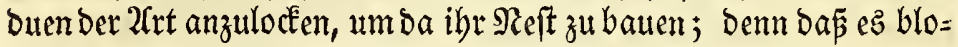
Ber 3 ufall jeyn follte, weld)er beftándig neue Sindividuen an ben= felben Brut = oder Neftplak fitbren follte, Eann nidht angenom= men werben. SSir finden aber boch Spláze, bicht neben ben febr

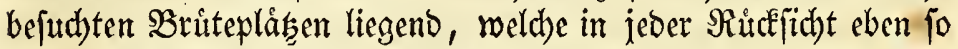
bequem, alz die benutenten jenn fónnen, und bod liegen bieje ganz unberwobnt. Utno warum follten z. $\mathfrak{B}$. Motacilla alba und $\mathbf{S}_{\mathrm{A}-}$

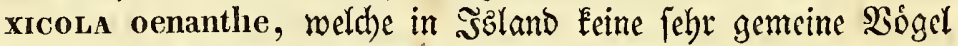

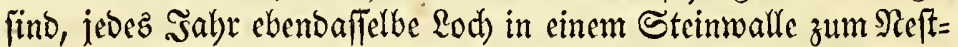
plafe wåblen, wenn fie nicht alte Bekannte máren, bie fid) ba cinquartirten; warum eben Colvmbus glacialis und rufogula-

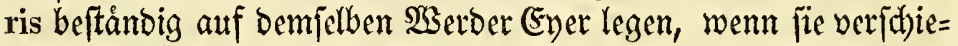

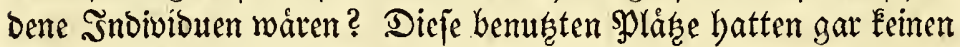
Sorzug vor manden in ber Siábe liegenden. Sid) glaube, ez

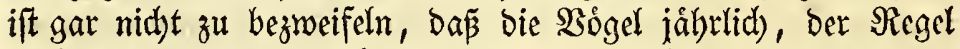
nach), bie alten Brutepláţe auffuchen, und fich ba entweber an=

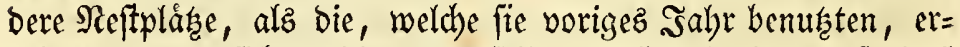
mál)len, oder fich wol)l gar beffelben seftes bedienen, fo bas aud) bie jungen $\mathfrak{B o g} g \mathrm{el}$, fo lange fie nid)t brutfahig find, fid wobl im Sommer von ben spläłen entfernt halten, an weldben fie felbit ausgebrutet worben, baj fie aber bodh, wenn fie erwadbjen fino,

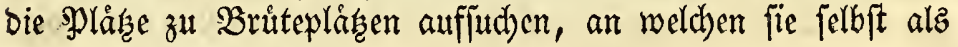
sunge in Siefte lagen.

গach biefer Şypotheje erlyalten bie beflugelten $\mathfrak{B} e$ wobner unjerer 2 ufenthalteggegenden für unz ein boppeltes Snterefle; benn wir feben bann nid)t jedez Sabr neue Şndivibuen, welde fith nur eine futrze 3eit bey uns aufbalten wollen, fondern es fino alte

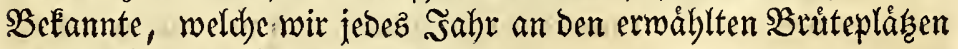
anzutreffen verfichert fenn tomnen.

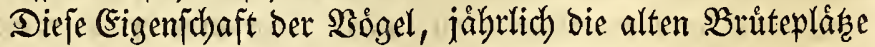
zu fud)en, hat zumeilen keinen unbebeutenden (5influp auf bie

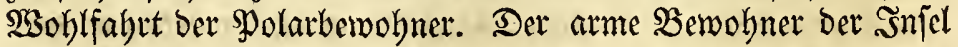

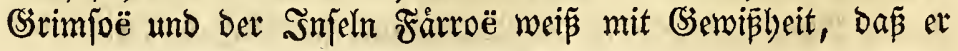


im Sommer in bem Bogelberge feinen Rebensunterbalt finden

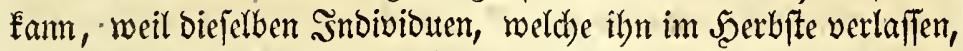

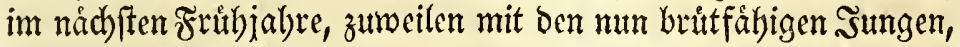

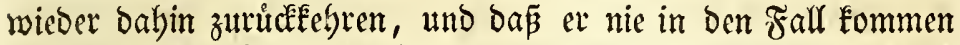
werbe, bieje widytige Suelle bez lunterhaltz zu verlieren, jo lange

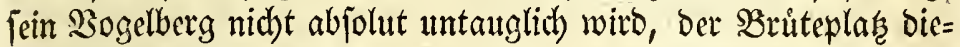

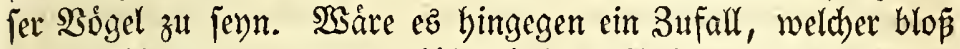

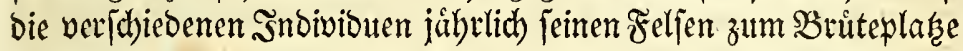

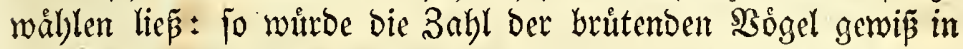

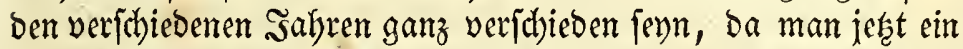

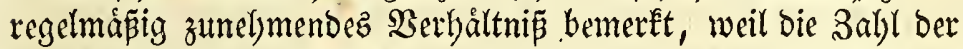

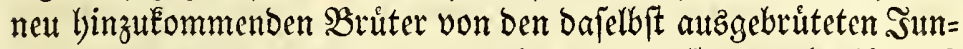
gen allezeit bie 3abl ber alten Bỏgel ůbertrif̈t, weldhe jåbrlid

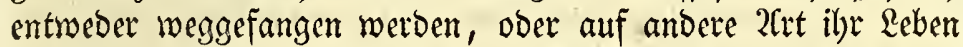

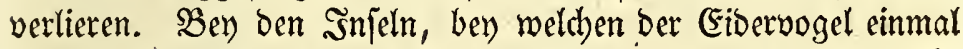
zu bauen angefangen bat, wiro biefes als eine bauternde Seerrlid)=

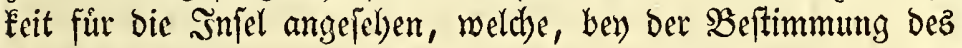

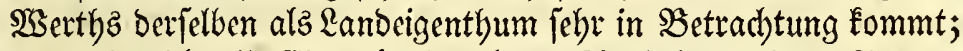
benn obgleich alle (sibervógel nad) ber 2luzbrutung ihrer Sungen

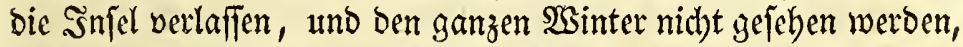

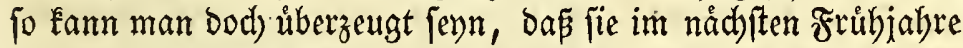
nach) berfelben zurueflemmen, um zu bruten; fie jind baber, ihrem

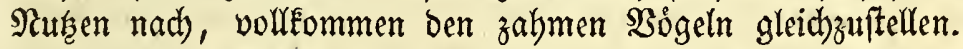
Daffelbe ift ber Fall mit ben andern (Entenarten bey Minvatn, mo fie feit unbenflichen Beiten ganz vorzinglich auf ber Injel gebrútet

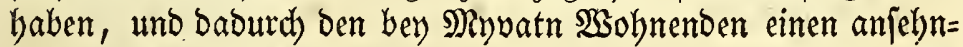

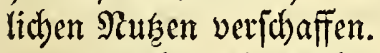

\$bichon ich gleidhfallz ủberzengt bin, baß es biejelben : Sn=

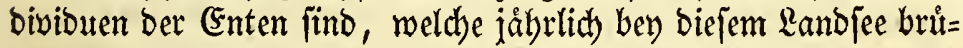
ten, fo hat biejer boch an uno für fich felbft einen Borzug, wel=

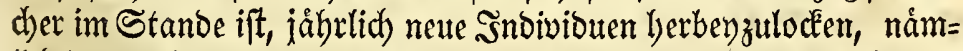
lich bie unzåblige MRenge Muicten; Deren Aejer Die Sberflåche bez SSaffers uno bie $\mathfrak{u}$ fer bez Seez bebecken, uno cin bebeutendez

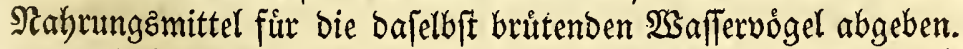

Zuch mus noch bemerft werben, wie es für bie gleiche $B e r=$

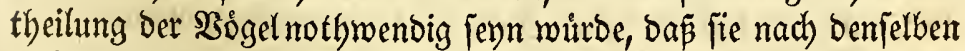

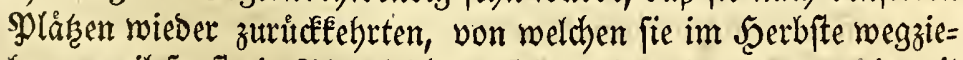

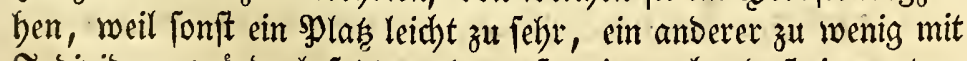

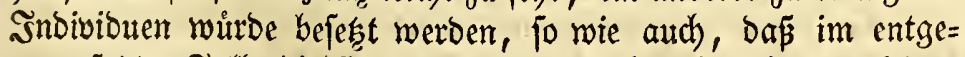
gengefereten Falle bie (Satten einanber audi) nid)t wuirben mieber=

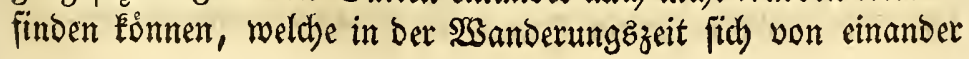


entfernen; Dagegen ift ber alte Bruteplaf ber gemeinfdaftlide Srt, an weld)em fie fith im Frutjiabre fidber wieberfinden. 2rber burd) weld)en mádbtigen Snftinct finden fid) bieje fleinen (Gefdbópfe

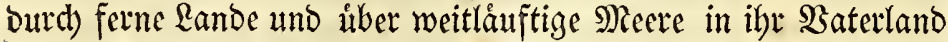

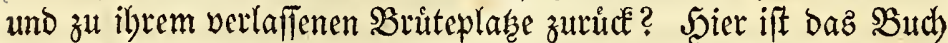
ber Natur verfidlofien, uno nod) Seiner hat ez lefen fonnen.

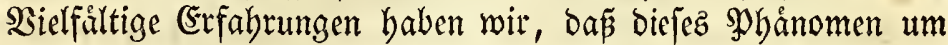

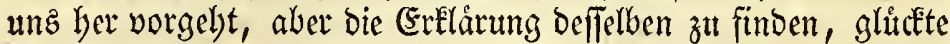
nod) Sieinem.

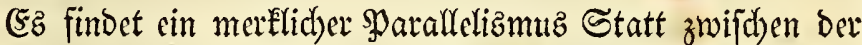
verfdhiedenen Ronogamitat ber borealen Sdhwimmógel uno ber

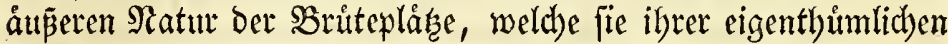

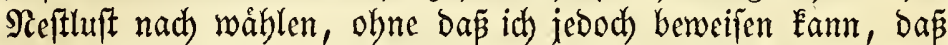

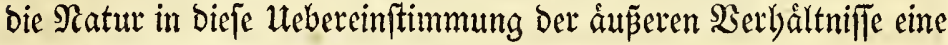
innere Sebeutung gelegt habe.

Folgende (Erfalvungefác berweifen meinen Safs:

1) Zulfe borealen Sdhmimmoigel, weld)e unbedingt bey bem Neere bruten, fino von ber zufammengefesten Mono= gamitåt.

2) 2tue borealen Sdywimmbógd, weldye von ber mitt= leren Monogamitat: fino, bruten unbedingt, fowohl in Ruck=

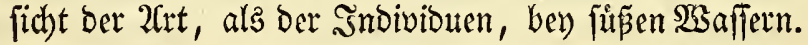

3) 2alle borealen Sdymimmoigel, weldhe von ber einzel= nen Monogamitåt fino, bruten in Rudepid)t Der 2 rten unbe= bingt, in sitdificht Der Sndividuen aber zumeilen bedingt, bey jüpen Şaflern.

1) Die borealen Sdhwimmoỏgel, welde unbebingt bey bem Meere britten, find bie 2riten der (G)attungen Unia, Alca, Marmon, Puffinus und Procelraria, Сarbo graculus, Sula alba, Lanus tridactylus, canus, argentatus, leucopterus, glaucus uno eburneus mit melyrern. Dieje finto audh alle von ber vollfommenften oder zufammengeferten Monogamitat. Bon ber

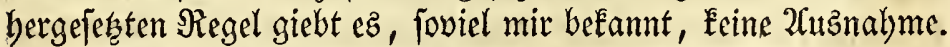

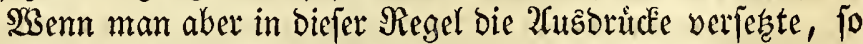
wurbe fie in ifrem ltmfange etwas erweitert werben; es witrden Dann aber aud fdon einige 2 usmabmen anzufúbren jeyn.

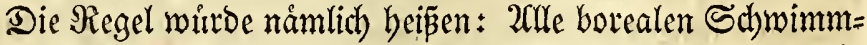
vogel, weldhe von ber zujammengefeçten Mlonogamitat fino, brü= ten bey bem Reere. Durd) biefe Serferung wutroen zwar vel= [d)iebene 2itten, weld)e wirflid) unter vie Regel geboiren, un= ter diejelbe gezogen werden, z. $\mathfrak{B}$. Сanbo cormoranus, die 
2itten ber (Şattung Sterna, Labus ridibundus und marinus, welche alfe von biejer Monogamitât find, uno zugleid) alle in

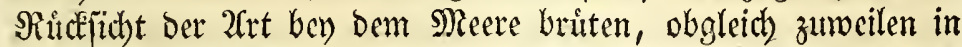

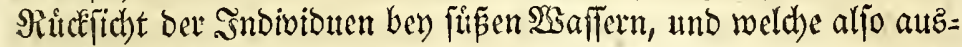

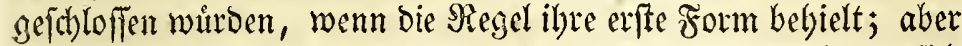

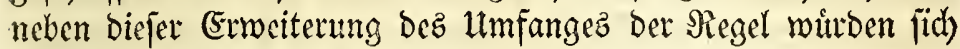

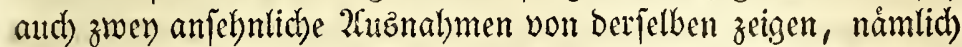
die 2fiten Phalaropus und lesstris, weld)e, obgleid) fie von ber zufammengejegten Monogamie fino, bod) unbedingt ber füpen 23 affern, uno nie bey Dem Mecre briten.

2) Die borealen Edbimmoúgel, welche von ber mittleren Monogamităt fino, find bie 2irten Convubus, Podrceps und

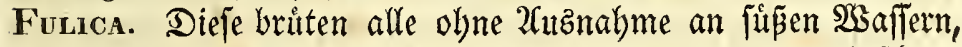

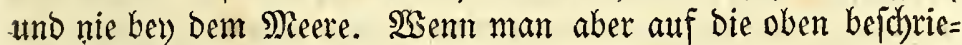

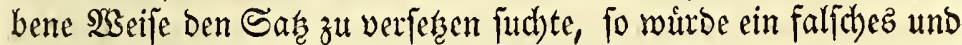

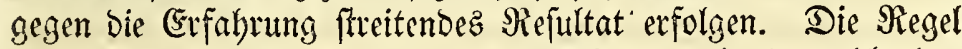

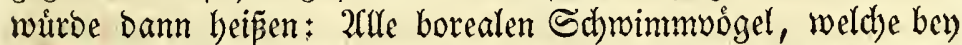

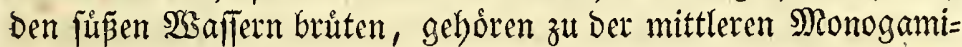

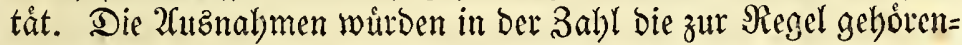
Den 2rten weit úberfteigen. Denn erftlich bruten alle 2 rten ber (5)attung Phamanopus und Lestris allezeit und alle 2Trten Sterna, forvie Canbo cormoranus und cinige 2fiten Larus, zum Theil

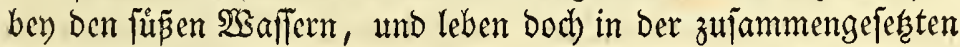
Monogamitát; fodann bruten bie 2riten Cranus und Anser

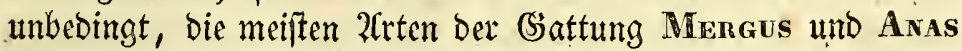
gleichfalls unbedingt, uno num einige 2 trten Diefer beiben lef̧ten

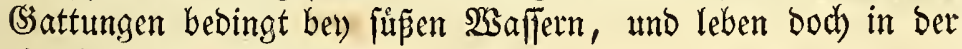
einzelnen Monogamitåt.

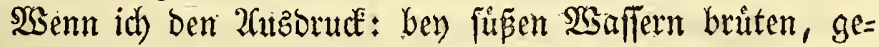

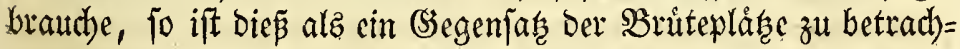
ten, weldche unmittelbar am Meere gefunden werden, und id ver=

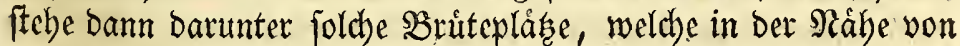

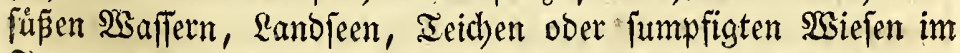
snnern bez $\mathfrak{R}$ andez, in weiterer. ober geringerer Entfernung vom Meere und yon ben gróseren und Fleineren \$Budbten befielben ge= funden werben.

3) Die borealen Sdymimmoógel ber cinzelnen Monogami=

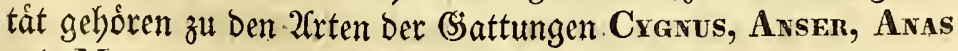

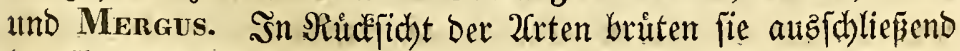

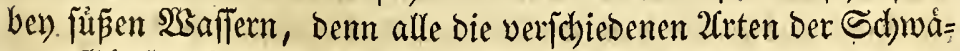

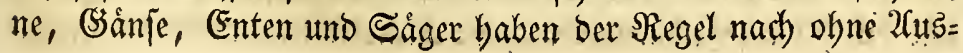


nahme Dajelbft ibre Bruttepláfe; bagegen giebt ez einzelne 2trten, and zwar nur von ber (s)attung Aras und Mergus, weldye zugleid) mit einigen Snbivibuen am Seere bruten. 2(m båufigiten ift es bet Fall mit As. mollissima uno spectabilis, weldbe bennab

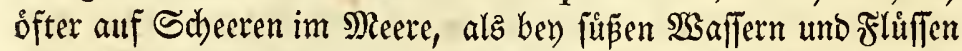
bruoten; zumeilen trifft man wohl aud baz Neft ber Av. boschas und Mergus serrator am Strande; Dod) weit offter im Snnern

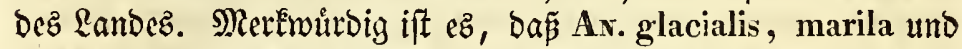
histrionica, weldbe fich fo getu bie úbrige 3eit im Mcere aufbal= ten, boch mit allen iben Indivibuen ins \&ano bineinzieben, am bey) Den Seen uno Fluffen beffelben zu brüten. 2fud boreale Sdyrimmoógel anberer (Sattungen, weldbe ůbrigens bie grópte Reigung haben, fich bey bem Neere aufzubalten, zichen bod) unbedingt in ber Brutezeit nach den füpen $\mathfrak{S a f l e r n , ~ z . ~} \mathfrak{B}$. CoLYмвus glacialis und Lestris catarractes. Dagegen wiro in ber borealen Sogelzone fein Beyipiel bez Entgegengeleften ange=

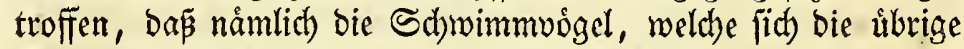
3eit bez Sabrez neben und auf ben Füpen Saflern aufbalten, in Der-SButzeit nadb Dem Meere zieben follten, um ba zu brüten. Ueberbaupt trifft man bie bey füpen $\mathfrak{B a f f e r n}$ britenden $\mathfrak{B} \delta$ gel auper Der Brútzeit weit ófter am \$lecre, als im Snnern Dez $\mathfrak{Q} a n=$ Dez bey ben \&anbjeen und Teichen, weil fie theils am erfteren. Drte reidblichere Nabrung finden, theils bas Meer aud nidbt fo ge=

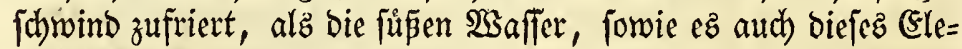
ment ift, úber unb auf weldbes bie ziebenben Sdywimmbogel wandern. -

\section{§. 28.}

Weenn fich bie 3eit nål)ert, in weldher ber Befrudhtungzact

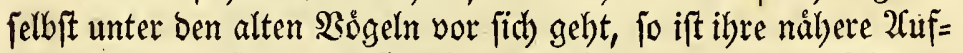

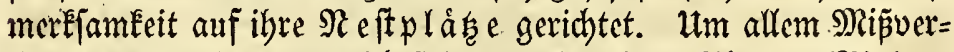
ftand zu entgeben, mus id) folgenbe Termini erflåren. Mit Dem 2usbrucke $\mathfrak{R}$ e ft verbinbet man gemeiniglich ben $B$ egriff einez burch ben Runftrieb Der $\mathfrak{B o g} g e t$ aus - zujammengebradten Materialien zubereiteten funftlidben \&agers fưr bie $\mathfrak{B r u t}$. Sa bie meiften bo=

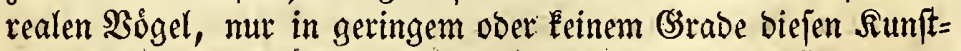
trieb bejisen, fo bin id) genóthigt, bem 2usbrucke Seft einen er= weiterten Segriff zu geben, und ez mit Neftplas ober Dem Spuncte, auf roldhem bie (syer liegen, gleichbebeuteno zu machen,

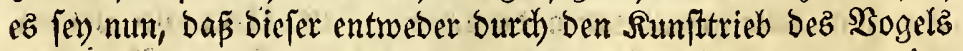
uno Durch bie zujammengebradten Materialien nur etroas verån= 


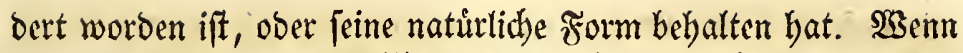

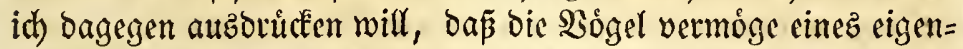
thümlichen Runfttriebes bie Materialien zufammenbringen, und fie in ciner gewiffen Form auf oen Meftplägen oronen: po bediene

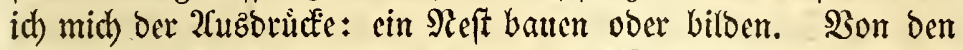
Bo̊geln, weldhe Eein Seeft bauten, fann man baher mohl fagen,

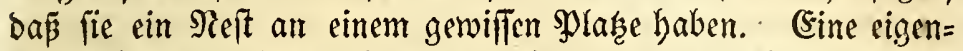

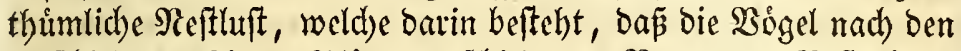

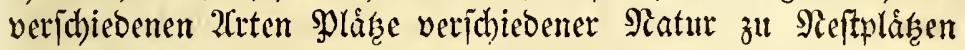
wåblen, Eann eben fo gut bem $3 o g e l$ bengelegt weeten, weldher Eein Meft baut, alz bem, ber Sorge bafiur trágt, ein folches zut

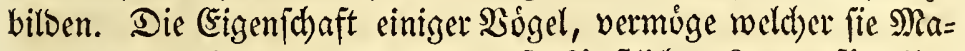
terialien zu einem warmen und oft kumftlid)en $\mathfrak{a} a g e r$ fîr ibre (Eyer uno sungen zufammenbringen uno oronen, ift bas Rejultat eines Iriebez, weld)en id) ben $\Re e_{\text {eft }} \mathfrak{b}$ a trieb nemne. Diejer Irieb wirb unter allen Slafien am meiften ausgebilloet bey Den Sögetn gefunden, nutr fporabija) bey ben Såugtlieten, z.

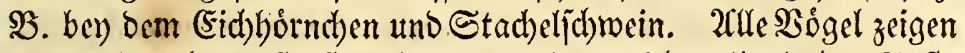

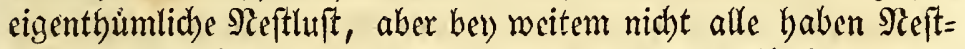

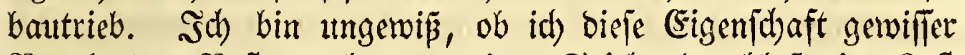
Sogelarten, Siefter zu bauen, einen Irieb ober blö cine $\mathfrak{Q} u \mathfrak{t}$

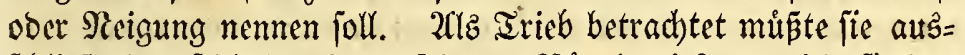

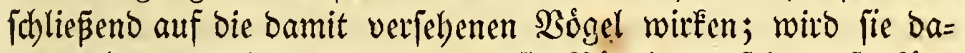

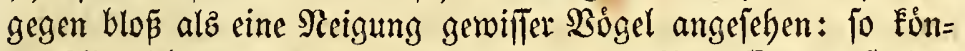
nen 2 Cbroeidhungen gebuldet werben, ohne ben Begriff zu entiftellen.

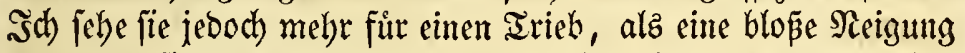
an; Denn fie wirkt unbeoingt ben gewiffen 20iten, und wirb ben andern ganz und gar vermišt. Die 2loweichungen gehen mur bie sndivibuten an, indem theilz einzelne snoivibuen ber, ber Regel nach) neftbautenden, 2irt gefunden werden, weld)e in bem eimen oder Dem andern \$aarungstermine Kein Mefít zu ibrer Brut bauen, theilb einzelne snoividuen andere Materialien bazu ge= braud)en, uno ifnen cine anbere Form geben, als für bie Şaupt=

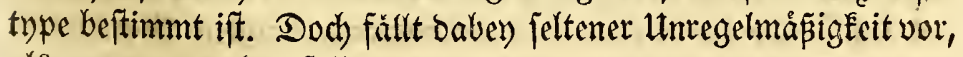
als man vermuthen follte.

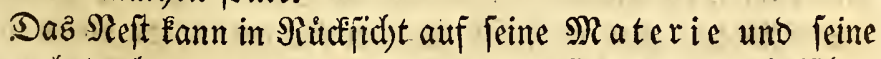
Form betrachtet werben. Biele ber neftbauenden dánifáden Singuogel wenben eben fo grope Corgfalt auf baz Sromen ber Saterialien in einer künftlichen $\mathfrak{F}$ orm an, als auf bas 2 Uuffitu= dhen und 3 ujammenbringen Derfelben, $\mathfrak{z}$. $\mathfrak{B}$. Hinunno urbica, Parus caudatus, Fringilula coelebs. Die neftbauenden 


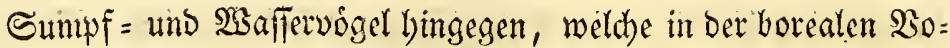
gelzone prábominirend find, wenden mur bernab allein Sorgfalt auf Das 3ujammenbringen ber Materialien, aber mur wenige auf Das Srbnen Detifelben zu einem Eunftlicben (sanzen. Daher Eann von manchen borealen $23 a$ apervógeln gefagt werben, baj fie ein gropese Seft bauen, aber keine Der mir vorgefommenen 2 reten

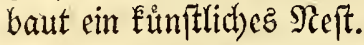

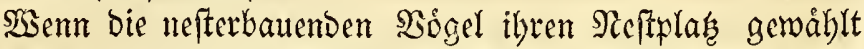
baben, fo fucht fowohl bas Månndyen, als bas Weibchen Der zu=

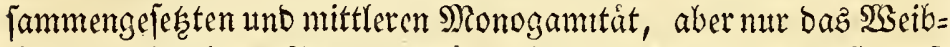
(hen ber einzelnen Monogamitat, Die Materialien zum Mefte auf, und trảgt fie zum Neftplake. Dieje werden gemeiniglich im Fluge berber getragen; Der 2 doler, Der Falke und ber Sabidht unter ben isländifchen Bogeln tragen bieje Matertalien in ben

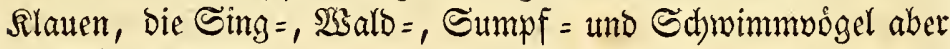
im Sdyabel berbey.

Şir baben bey mand)en unjerer Dåni chen Singuogel (Gide= genleit, bie Sorgfalt zu bemerken, mit weld)er die 2uten Stoff zum Nefte aufiuchen unb zujammentragen; aud) bey ben neit= bauenden Sd)wimmoogeln ber borealen Sone wiro biefes in bie 2 ugen falleno bemerft. Sn Der 9 ieftbauzeit fliegt Lanus tridactylus beftảndig mit Erbe und andern Materialien in Sdyabel, und idh habe Sucia alba zmey Meilen vom Reftplafe ben Stamm von Fucus digitatus ergreifen und ihn zum Reite tragen jeben. Da biejer leşte Sndiviouen hat, weldbe zu Derielben Beit Slefter bauen, in welcher andere 2rt3verwandte Sunge haben, und Diefe Tangarten in einiger Ferne wie Fif nige Srnitlyologen bey biefer (Selegenlyeit zut ber 2(nnabme verlei=

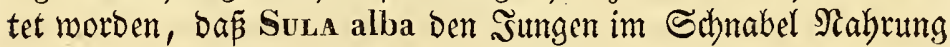
zutrage, weld)es nie ber Fall ift, ba fie den Sungen bie Naburung im Sihlunbe ober Sropfe bringen.

Die $\mathfrak{B o g}$ el in J̧sland, meldhe für Den Saau bes Sieftes Sorgfalt anwenden, find: Falco albicilla, islandicus unb caesius, Convus corax; die islándifłen Singuỏgel; Саrвo cormoranus uno graculus, Cocrmbus rufogularis, Podiceps cornutus and arcticus, Cygnus musicus und Sula alba, Lanus tridactylus, glaucus und marinus.

Sn 2Unfehung der Materialien wenden die izlándifdyen Singuogel auswendig Stroh und Mloos an, imwendig Federn

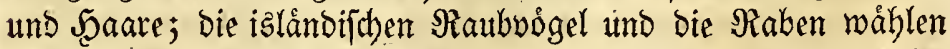
Tangarten oder $\Re$ eijer zur Unterlage, und Stroh uno Noos im 
Disłus. Die islånoifhen Sd)wimmudgel, weldye bev bem Meere bauen, legen ilyr sieft von veridjiebenen Iangarten an, weld)e Gel) Den Meven, nid)t aber been ben Sd)arben und $\mathfrak{I}$ ólpeln, untell mit (Siras und (stbe gemificht fint, und im Diskus mit Federn uno Stroh. Deß̧wergen ift bas Rieft ber Meven nie fo fettht, als baz jener beiben (3̧attungen, beren Ener eine bebcutende Fend)tigkeit vertragen zu kỏnen foheinen. Connmbus rufogularis und Cravus musicus gebrauchen verictiedene 3 flanzen ber

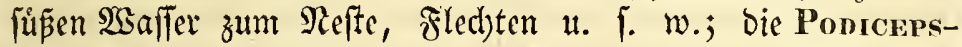

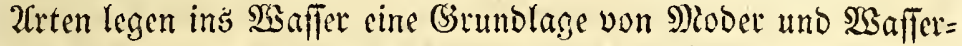

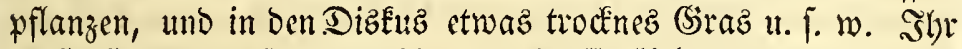

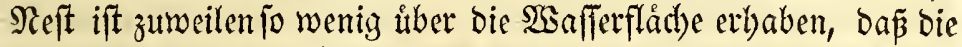

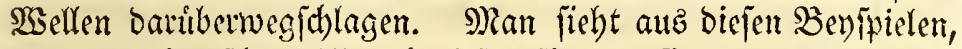

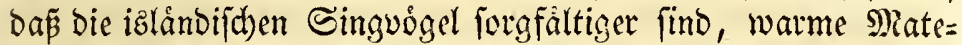
rialien zu wáblen, alz bie Sdhwimmodget, beren (E)er eime bide=

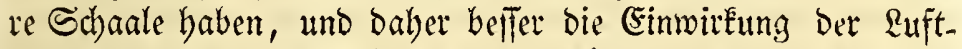

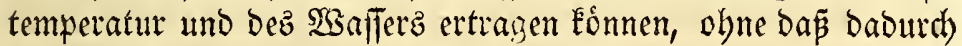
ben werbenden Sungen gefdabet ruirbe.

Die meiften Soogel lieben gewiffe Materialien, uno wedbjeln

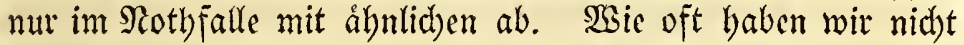

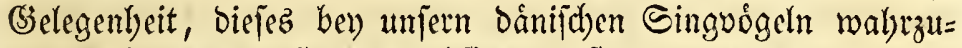

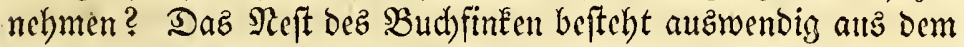

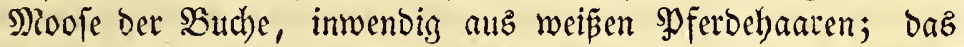

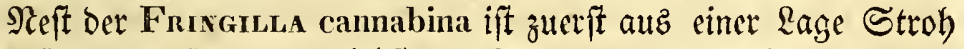
zujammengejeçst, bemuách ft auz

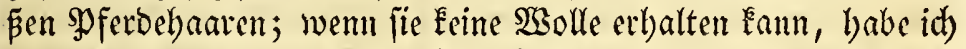

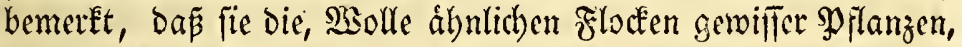
bejonoers ber Familie ber Snngeneififen, anwendet. Fabri=

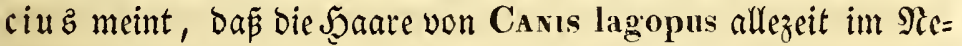
fte bez Sdhneeammerz gefunden werden. 2(ndere $\mathfrak{B o g h e l ~ w a ́ b l e n ~}$ ourch) cinanber unter nabe verwandten Etoffen zut iifrem Meft= baue. Ser 2Cblet gebrautcht $\Re$ eijer oder Iangarten zur $\mathfrak{U}$ nterla $=$

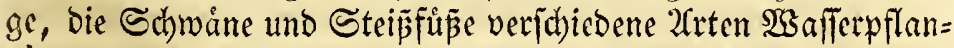
zell, unt bie Sdjarben und Iólpel verfdirbene Iangarten zum Serite.

In 2fmiehung ber For m bez Reftes wird noch bennal) melyr

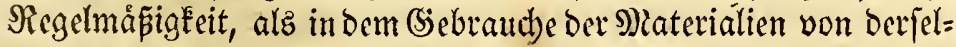

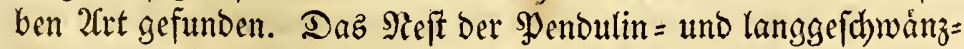

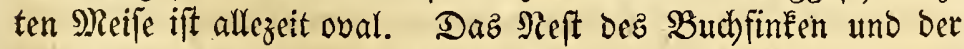
Dorf = und Stabtidywalbe hat bie Form eines Backofenz. Da

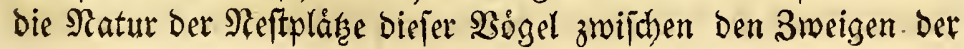




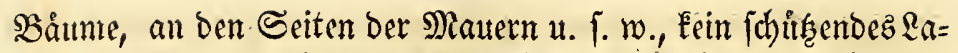
ger fur bie Eyer abgiebt: fo milfen diefe Bögel, burd) ibren

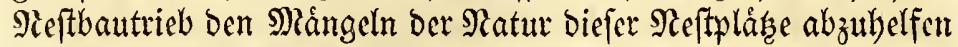
fuden. Die $\mathfrak{B}$ ogel, weldhe baber auf Der (Frbe, in Den Felfen ober in hollen Báumen Sefter bauen, wo aljo Der (segenítano,

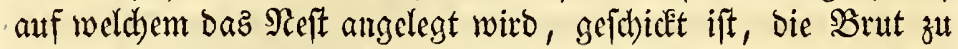

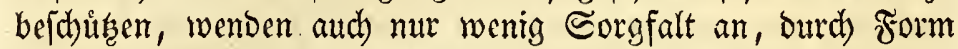

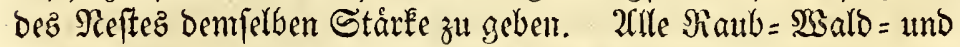
Singoógel, weldbe auf ber Erbe oder in hohlen Báumen brůten,

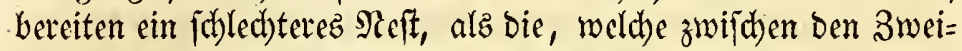
gen bauen. Man verglcidje dic Siefter ber Alauda arvensis, Emberiza milliaria, Stunus vulgaris, Frivgilla domestica, Upupa epops, Prous, Strix, mit Denen ber verjdiedenen Sylvien und einiget Meifen t. $\{.1$. WSenn biejes auf bie ver=

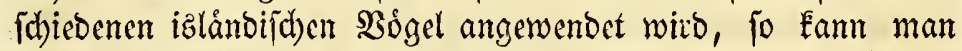
nicht erwarten, unter biefen Siefter von fchỏner Form zu finden. Rur menige Riten, alz Tundus musicus, und Fringrala linaria, bauten in Den Eleinen $\mathfrak{B} e i b e n$ und $\mathfrak{B i r k e n b u ́ p j e n , ~ M o t a - ~}$ cilla alba, Saxicola oenanthe, und Emberiza nivalis bau= en in Den Rifínen Der Stcine, Anthus pratensis uno Sruvia troglodytes auf ber Froe felb/f. Dod) verwenden alle biefe Sing= voigel in Şsland mebr Sorgfalt auf bie Form ibrer siefter, als die auf ben Felien bautenden Shwimmoogel Canbo, Sura und Larus, welche eine Menge Neftmaterialien an cinen genif $=$ fen solas obne eigentlidbe Stomung fammeln. 2lud) wenden bie islánbifhen Meven mehr Sorgfalt auf bie Form des Neftes an, als Canbo uno Sula, und bie Sdhwáne und Steipfápe wieber mebr, als bie rotbhalfigen Tauther. - Sn ber Form ber Refter aller biefer 2 rten finden wir bie runbe Figur wicber, welde úberbaupt bey den Reftern ber $\mathfrak{B o g e l}$ die prábominirende

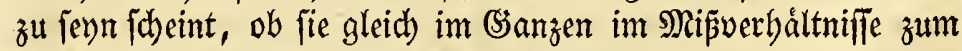

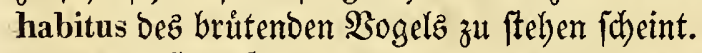

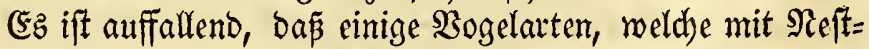
bautrieb verieben fino, bods zuweilen Indiviouten baben, weldbe benjelben nidyt benuthen, fondern entweder in einem gewiffen Tet= min Eyer legen, obme ein Neft zu bauten, ober auth anderer Bögel verlaffene Sefter verbeffern und bemtsen. Dieje 2lbwei= chung ift es vorzinglid), weldise bie Frage veranlapt, ob die (Fi= genflaft ber Bógel, Nefter zu bauen, den Namen Irieb ver= diene. Unter der Rolonie von 30 - 40 Neftern der Sula alba fand ich ood) $2-3$ (5yer, weldbe auf den blopen Felien ohne 


\section{$-133$}

Untertage bingelegt waren. Сanвo cormoranus baut in $\Im \xi=$ land ein gropeses Sieft, legt aber in Dänemarl (Eyer in bie ver=

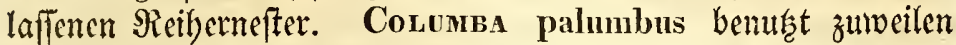

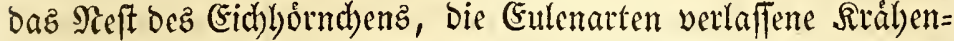
neffer. Es' ift befannt, wie gern bie fonft neftbautente FrusgILLA domestica Hinundo rustica und urbica von $i$ ren $\mathfrak{A}_{\mathfrak{e}}=$ ftern verjagt.

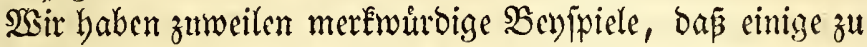

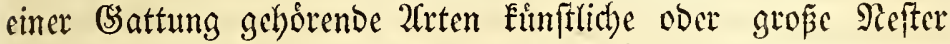
bauten, indeffen andere 2ruten Derfelben Giattung entweder gar Eein ober nur ein fd)lechtez Reft verfertigen. Man vergleid)e HIrundo rustica uno urbica mit $H$. riparia, Panus pendulinus und caudatus mit $\mathbf{P}$. major und coeruleus.

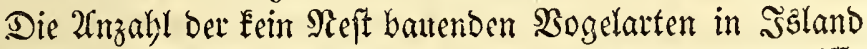
íbertrifit bey weitem bie $2 \mathfrak{n} z$ ahl jener. Da ez zum Begriffe

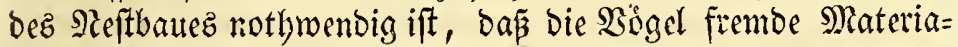
lien nadh einem gewiffen $\mathfrak{p l a f e}$ zufammenbringen follen, und ib)=

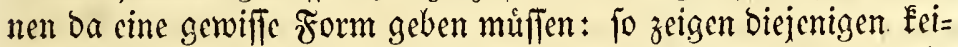

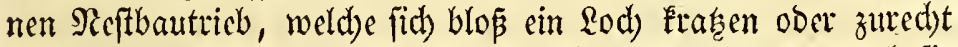
madyen, in ber Materie felbift, alf weldher fie Ener legen, ob fie

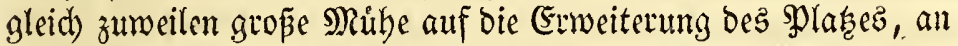
weldben fie biefe hinlegen, verwenden. Tetrao Islandorum.

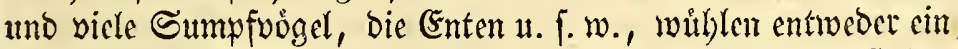

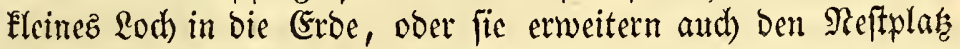
etwaz, uno fratsen ein wenig welkes Ģraz oder $\mathfrak{a} a u b$ zul von ihnen Eann aber bod nicht gejagt werben, baj fie sin Reft. bauten. Daffelbe ift aud im lyódfften (3rade ber Fall mit Monmon fratercula, Puffinus arcticus und Proceldania pelagica, weldhe fich ellenlange Rócher in bie (Eroe graben, in weld)en

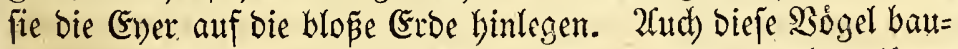
en nadh meiner Serminologie keine Aefter, ob fie gleid) unláang= bar ibren Sumfttrieb, in bie Eroe zul graben, allein aus Sorg=. falt fừ ihre Brut anwenben, unb nidht, wie gemiffe Saáug=.

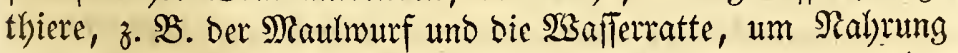

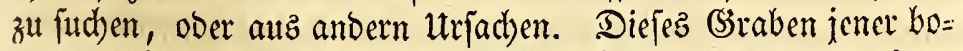
realen Bógel ift analog derfelben (Sigemfdaft ben Hinuspo riparia, Alcedo ispida uno Merops apiaster, uno zum Iheil mit Dem (Sraben gewiffer Sángthirre, z. B. Canis vulpes uno lagopus, Mus sylvaticus uno Sonex araneus, bod nidjt ganz,

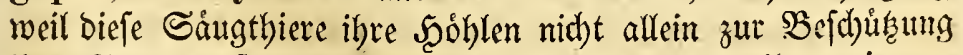
ilyrer Sungen, fondern aud auker ber Bengezeit zu ilyerer eigenen 
Bejdhithung benuken, ba hingegen die eben genannten $\mathfrak{B} \delta$ gel ih)= re (Erb!d́d)er nid)t lánger bewohnen, alz bis bie Sungen ausge= flogen fino.

2(ud) bie Enten bauen nad) Der oben angegebenen Termino= logie kein Neit, weil fie fich) Dunen auz bem unterleibe auzici= Ben, und biefe alz cinen Sranz um Daz \&odh) in ber (Erbe herum= legen, in weldyes fie Eyer legen wollen. STm (Segentheil ha= ben jie bie Eigenjofaft ethalten, bas Neftloch mit Dumen zu futt= tern, weil fie Éeinen Inflinct exbielten, aus ilynen fremben (Sie= genftånden ein bequemes lager fü ihre Ever zu bilden.

Die Bogelarten, weldye kein Sicit bauen, Geboren in ฐ̧s= land zur Sromung der Sd)minm = und Sumpfoogel, fammt Dem izlánbijhen Sdhnebulyn. Ututer biejen futben folgende die na= turtiche Befdaffenlyeit Der Seftpláfe gar nidbt zu verbeffern, fon= bern legen die (Eyer auf den blopenen Stein oder die blope Erode, námlid) die 2erten: Uria, Alca, Sterna arctica, Procelhanda glacialis, Hakmatopus ostralegus, die 2fiten Chananrus. Die ielåndijden Sumpjodgel yon Nunenius, Totanus, Scolopax, uno Tringa, atth die Sdmimmudgel der (Sattung Phacanopus, Commers glacialis, die ?tten Mergus, Anas, Axser, Lestris und Procelnaria glacialis, wenu diefe legete auf die Sberflädbe der אippenimfdn (Ever legt, flaten ein wenig welfes (şras zufammen in bas lod), in weldhes fie ifre Eyer legen. Monmos und Puffinus graben, wie ge= fagt, tiefe \&od)er zu Den Evern. Sod) findet man aud zumei= len bie (Eyer bez Monxor fratercula zwijhen benen ber Alca torda in ben Felfenrifen.

Unter bem Bau bes Neftez gebt die spa arung felb ft,

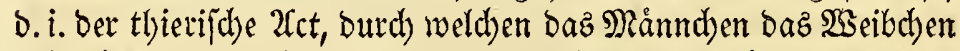

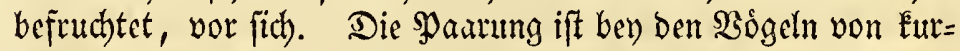
zer Dauer, wirb aber oft wieberlyolt, uno fie find, wie befannt, wálbreno berfelben febr leibenjachaftlich. Sich habe die Gatten mebrere Tage zuwor fich paaren fehen, ehe bas selt fertig war, uno man fann wohl annebmen, das bie erften Paarungen oft unfruthtbar find, fo bas Befrutbtung nid)t allezeit eine Fol=

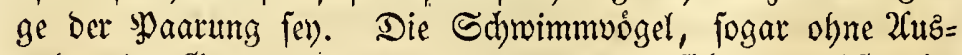
nalyme der (Fattung Phalaropus, paaren fid am liebjten im Sasaffer fdummend, menn fie im fieven 3uftande fino. Dod) babe id) offer Lestris parasitica und Stensa arctica fich auf Dem \&ande paaten fel)en. Die Ranovógel paaren fich in ber $\mathfrak{N} \mathfrak{a}=$ be ibrer Seftpláse, ja bey mebreren Singuogeln, z. SB. ben 
Frivgilua coelebs habe idd bemerft, dáp bie Paarung in dem

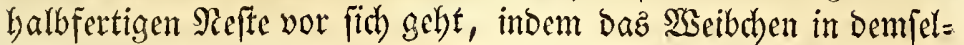
ben firat und ez bildet.

Die Bógel, bejonders bie Ránndyen, find in beni 2 fugen=

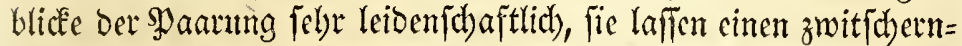
Den Raut bóren, vereinigt mit einer Bewegunt ber Flingel und ftráubigten Febern. Es? ift befannt, bap̃ FungmLa domestica baz 2 Seibd)en unter beftåndigem @d)reyen in einemweg 10 bis 20 Mal tritt. Die Raben und die Raubmeven zeigen bie munderbarften (J)eberden unter Der \$aarung; bie Reidenfchaft Dez Iruttljabnz ift befamnt. Die Maanndben von 'Traras pugnax

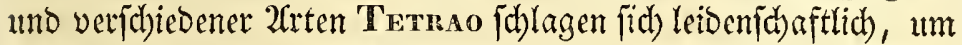

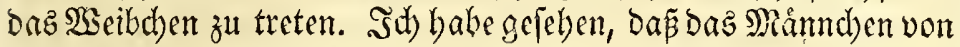
Aras glacialis daz 23 eibchen laut forderyend im Fluge verfolgt lyat.

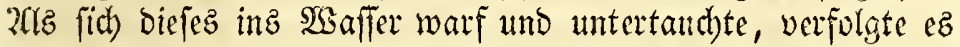
bas Månnchen unter bas $23 a$ fer, uno kam erft auf Der Sberflá=

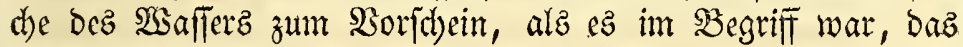
Wseibden zu treten.

Benn Der Saarungstrieb in 2fetivitát getreten ift, fo ift

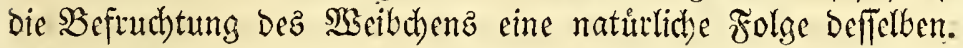
(Ez ift fdbwer zu beftimmen, wie lange 3eit zwifhen Der Befrutch=

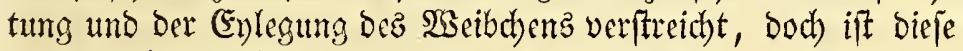

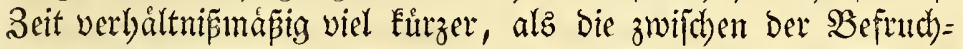

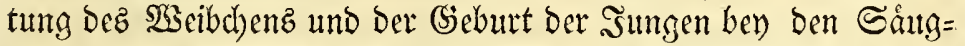
thieren, weil bie ganze (Enlegungz = uno Srütungzperiode Der 3ógel Der \$eriode Der \$ervollfonmmung Det Frutht im Mut= terleibe bey den Sángtlieren analog iít.

(Es ift jonberbar, dâs man zumeilen ziemlich ausgebildote

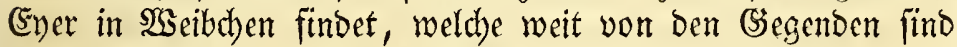
gefdoffen worden, wo ibre Bruteplafe fino. Sol) babe febre ent= widfelte (Ey)er in Scolopax rusticola, weld)e in Suttano gefflyof= fen worben, gefunden, und cbenfalls in Saland in Axser tor-

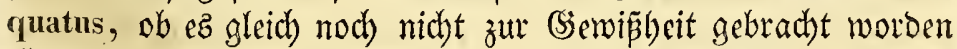
iff, ob biefe 2Grten refpective in Den benannten Lándern Eyer le= gen.

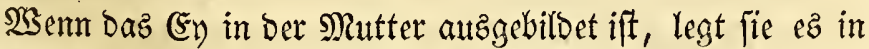

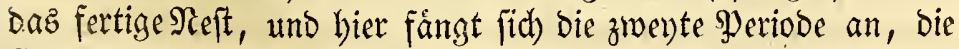

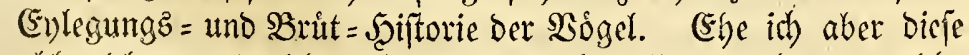
abbandle, werbe idh noch oren Serbaltniffe betraditen, welche

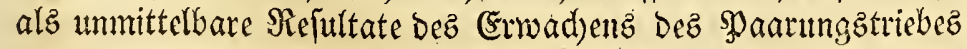

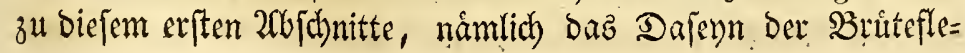


dien, bie Berånderung in ber Stimme ber Siget und in ilfrem áūeren Şsejen, gebơren.

\section{§: 29.}

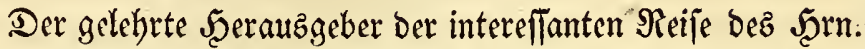

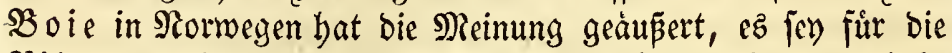

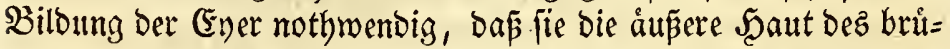

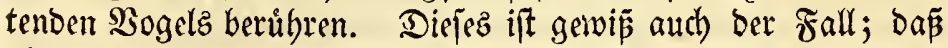

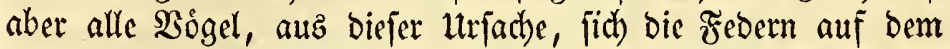
Unterleibe austupfen follten, bezmeifle idh; · ç giebt jogar gemii =

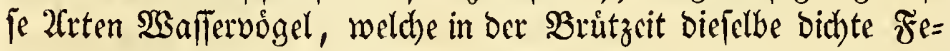

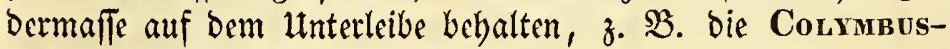
2(rten. Dod finden wir unlåugbar bic meiften $\mathfrak{B} \delta$ get in ber Brùtzeit mit einer weit bưneren Feberbebectung auf bem $\mathfrak{u n t e r}=$ leibe, als fonft, weld)e, meiner seinung nad), theilz ben bem Bruten abgerieben wirb, theils burd) bie gróperte thierijd)e WSarme, weldhe fich in ber Brưtzsit beym 2(6boomen concentrirt,

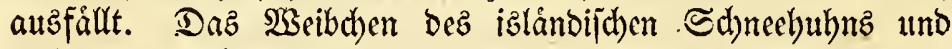
viele Sumpfougel fino bennaly Eabl auf ber Bruft und bem Bautche zu ber Zeit, wann fie briten. Diefez 2fuzfallen ber Fee Dern aber ift eine Folge bez Brưtenz, umb geloórt aljo zu ber

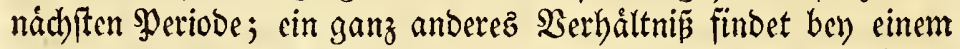

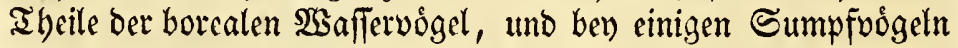

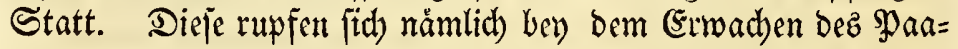
rungstricbes, che fie nod) Ener gelegt und gebrutet $\mathfrak{h a b e n}$, eine

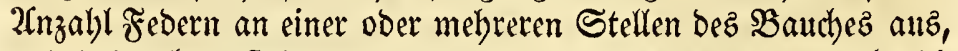

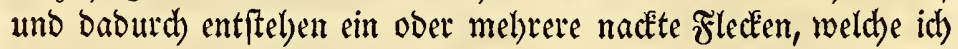

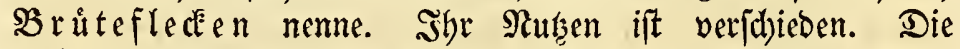
Sdymimmoogel find gemeiniglidy jo bick gefiedert, bap bie Ener jobwer mit ber Şaut bez brütenden (Şatten in Berúbrung gebrad)t werben fơnnten, wenn bieje nicht fetbft baburd bazu beytrugen, indem fie fid) bie Febern aužtupfen. Bmentenż bauen bie meiften Schwimmoógel kein $\Re_{e f t}$, fondern britten ihre Eyer, fogar in

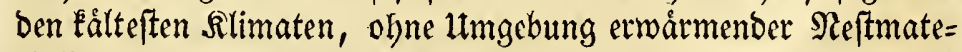
rialien auz. Die Brütflecten bilden baber, jo zu jagen, baz

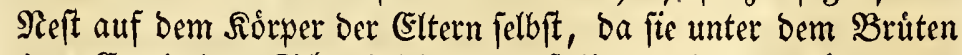

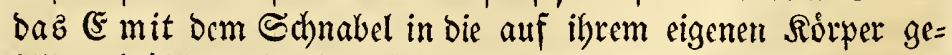

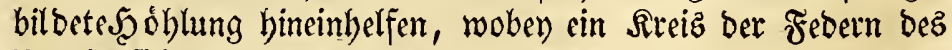

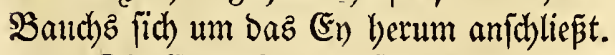

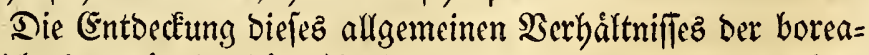
len Sdbmimmoóget get)ơrt úberbaupt mir zu. Nat in einzetnen 


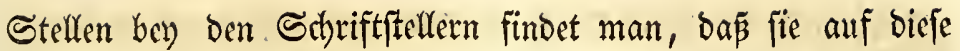
Bruttflecten aufmertjam gewefen find, obne jebod) ihre Bebeut=

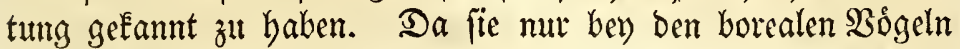
in ber Brủtzeit gefunden werben, fo war auth) ilyre Entbectung einem Naturforfder vorbebalten, weld er (S)elegenheit l)atte, fith

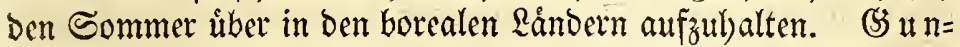

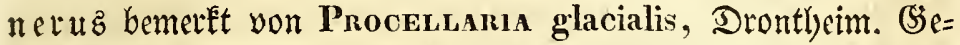

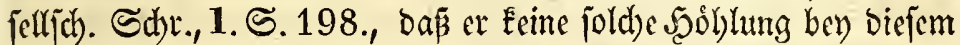
Boget gefunden, Das̃ aber ber Med. Stud. Martin in $\mathfrak{F} \dot{b}=$

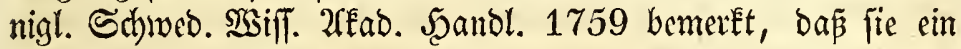
Lodh unter dem Magen auper ben groben Febern laabe, wel= d)eb, wie er glaubt, viefleidft zum Brîten der (Fyer bienen fónne. $\mathfrak{F a b r i c i u s ~ b e r i d h t e t ~ v o n ~ b i e f e m ~} \mathfrak{B o g e l}$ in der Fauna groenlaudica, S. 86, baf́ er audd bicfe (Strube gefunden labe; er jagt bafelbft: aream deplumem sub abdomine etiam reperi. Ser. Boie bemert in feiner $\Re$ eife S. 192, weldhe gleidzeitig

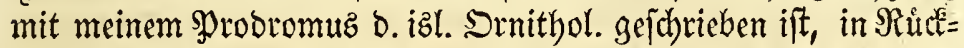

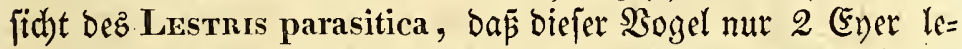

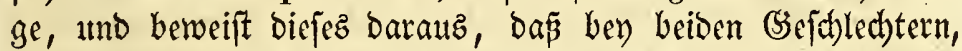
weld)e feiner richtigen Meinung nad) wechjetswẹife brutten, auf beiben Seiten des Sautchez ein nacterter Flecéen von ber (Siróse bes Eyes gefunden werbe, uno der Seerauzgeber jeiner Reije äußsert

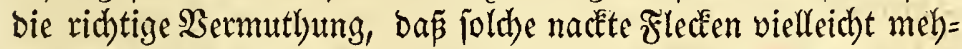

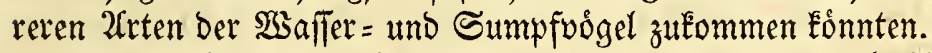

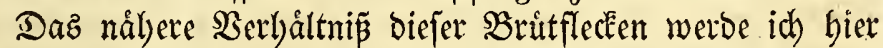
mitzutheilen verfuchen. (Ez ift wobl fegr jelten Der Fall, Daß

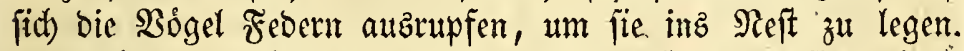
Die Bógel, welche in ber Brủtzeit am meiften nactet find, bau= en entweder fein Reft, oder haben Eeine Federn im Refte. Nur bie Enten umb die Såger reisen fich) Dunen au: , um bamit ben

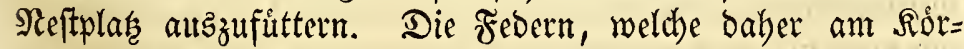
per ber britenden Bógel vermi gel nach, bey weitem nicht in ihren Meftern micber. Damit bie (Ener nicht burd) zu grope Febermafte auf bem Baudbe follten verfindert werden, in eime nábere Berubrumg mit ber Epider-

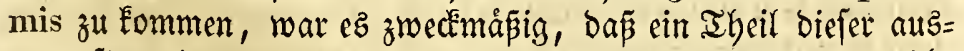
gerupft merbe. Diefez war ein 3wect ber Brutflecten, wellibe man bey ben borealen Sd)mimmbógeln findet. Doch Eann bie= fez nicht bie einzige Seftimmung berjelben fenn, ba e's gemiffe

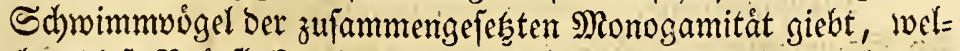
then biefe Britffecten feblen, uno beren Febermafle überbaupt, 
mie oben gefagt, in Der Britzeit nid)t bưner mitd, z. B. Sula und Санво. Sie mitifen baler audh beftimmt fenn, bie (Ener cinzufd)liepen, und burch bie umgebende Federmafie zu erwár= men.

Sch) habe nur biefe Britffectéen bey Den boreaten Schwimm= vỏgeln gefunden, tand nur bey ben Rrten, weldhe zu ber volf-

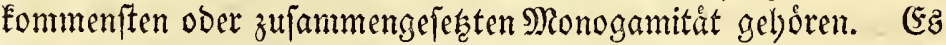
wůroe felyr intereifiant jeyn, wenn fpåtere Erfalynungen fie unz ben Den ভd)mimmbỏgetn in andern Sonen follten wiederfindon laffen. *) Ber Denen zu ber mittleren Monogamitát gehórenden. 2(rten Der (Sattung Colymbus uno Ponicers fand idt fie nid)t.

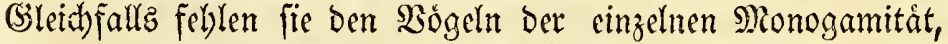
nămlith Den 2(rten Mergus, Aras, Arser, Crgnus. Dieje baben bingegen bie oben erwahlute (Eigenfd)aft, fid) Dunent auts=

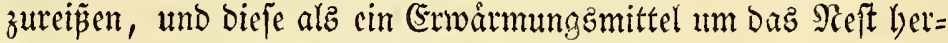

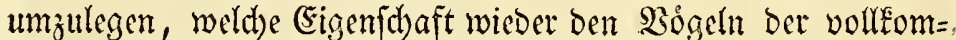
menften Monogamitát mangelt. Su ber zufaumengefersten $\Re_{0}=$ nogamitât gehỏren unter Den Sdhwimmoógeln bie 2rten der (Gat= tung Phalaropus, Uria, Alca, Mormov, Carbo, Pyffinus, Sula, Sterrac Larus, Lestris uno Procelachia. Ben allen biefen $2($ rten fand id) auth Brưtffecten, mit $2($ tusnal)= me dev 2(rten uon Sula und Canbo, weldhe fie befitimmt nidht baben.

Da bas Månnthen und $\mathfrak{x}$ eibchen biejer Bogetarten im Brưten mit einander abwed)jedn, fo werben bie Srutffecten eben fowohl am Mánnd)en, als am $\mathfrak{B}$ eibchen gefunden, bod) mit

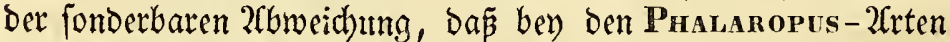

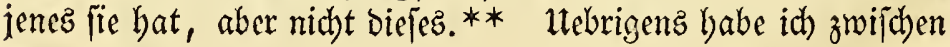

*) Rachdem bicie 2lbhandung gefdrieben war, habe ith auf einer zoologifthen (Ercurfion nach Den Snjeln im Rattegat im Sommer 1824

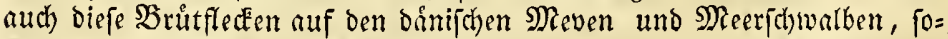

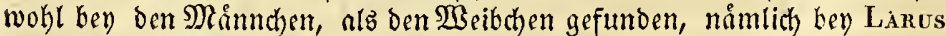
argentatus, Lanus ridibundus, Sterna arctica, caspia, nigra uno minuta, und der Sis uno die Bahl der Bruttflecten ftimmen mit benen ihree Battungguerwanden in ber borealen $\mathfrak{B}_{\text {ogelzone }}$; nuch ben einigen Sumpfooigein beioerley (Sefchlechtä, alz Charadnius hiaticula und albifrons, fand ich einen $\mathfrak{B}$ rútflecten auf Der Mitte bes Bautho außer einer minder dicken Federbedeckung auf ber Bruft, meld;e马 lestere fie mit ben meiften $\mathscr{L}$ and $=$ und andern Sumpfvógeln in ber Brütjeit gemein haben.

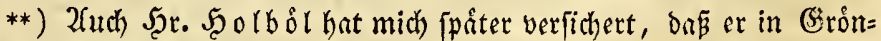
land mur Brittflecten ben ben Mlanndyen, und nicht bey ben Meibthen ber

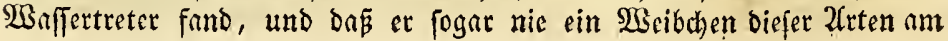


Den vielen Şunberten von Snbivibuen biefer verfahiebenen 2 rten, weldye id in ber Brutzeit unterjud)te, fein einziges Sevjpiel ge=

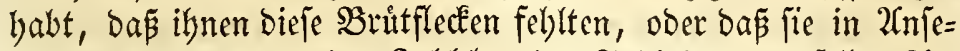
bung des Sifes oder ber Salyl bey den Individuen berfelben $2 \mathfrak{i t}$ variirter.

Dem bie Brittlecken find bey weitem Eeine Folge cines un= orbentlid)en Feberaubraufenz bey biejen $B \dot{g g c h}$, fonbern fie fol=

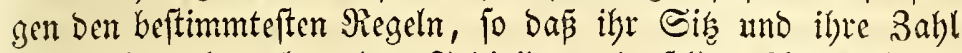

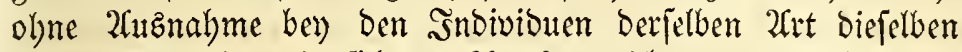
find. Sie geben ein fidheres 2rtzkennzeid)en ber verfidicbenen borealen Schwimmuogel ab.

Der $3 \mathfrak{a b l}$ nad) find ibrer nur zwey; ich habe zwar in mei=

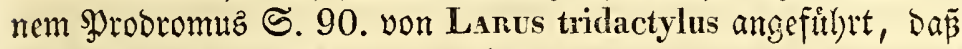
er 3 biz 4 Britflecten laabe; idy babe aber damals (Exemplare vor mir gebabt, weldhe fdon bas 2uteraufen der Febern an ben verjebiebenen Plásen in ber Mitte Der Baudhregion angefangen batten, und zweifle nicht baran, daş fie fich, wie bey ben ůbri= gen boreałen Meven, zu einem einzigen gropen Brütflecten auf

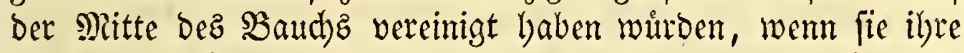
volfeommne Geftalt wurben erbalten haben. Die, weldbe zwey Bruttflecken baben, find die 2arten Phalaropus, Unia grylle, und alle, Alca torda, Monnos fratercula, alle 2fiten ber Lestris - Ģattung. Die, weldbe cimen Britfleden baben, find Una Brünichii, und troile, Puffrnus arcticus, Stenna arctica, Lanus tridactylus, glaucus, marinus uno ProcesLARIA glacialis. (58 madyt eine Der widhtigften Differenzen in Der Şiftorie der Aluca torda und der Unia troile auctorum aut, dá⿱ jene zmen, uno bieje nur einen Brutflecken bat.

Waas ifren Sis betrifft, fo wetben fie allezeit auf Dem $\mathfrak{B a u}=$ d) gefunden, nie auf ber $\mathfrak{B r u t}$, und wo es mur einen einzelnen

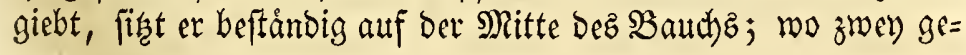

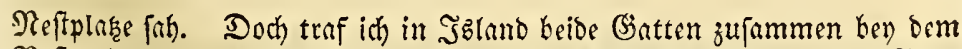

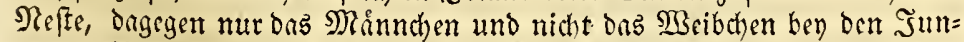
gen. Sollte man etwa von ben fehlenden Brütflecken ben ben 2 Beibehen

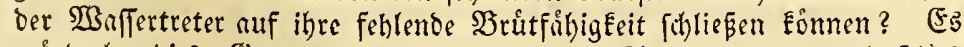

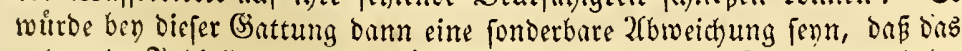
enlegende Indibibutum nicht brittete, und umgekegrt. Dod) mus ich be= merfen, Daßs man im aftlgemeinen zwar von eriftirentoen Bruttflecén auf

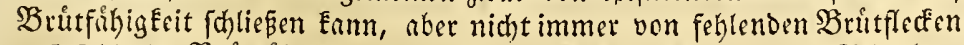

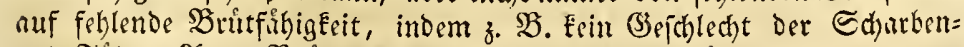
uno $\mathfrak{T}$ ólpel = 2(rten Srutflecken hat, obgleidy beibe britten. 
funden werden, fithen fie einander gegeniber auf beiben Seiten deflelben.

Was bie Form anlangt, fo find fie rund und verbåltni $=$ måpig zur (Srojpe und zu ber 2 nzabl ber (Eyer, weld)e fie ein=

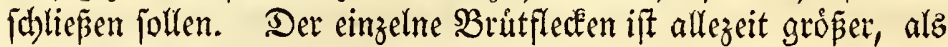
jeber Der gepaarten.

Die Babl ber SBrutflecten rid)tet fidh zumeilen, bod nid)t allezcit, nach Der 3abl Der Ever; Denn zuweilen baben "bie $\mathfrak{B} \delta=$ gel mehrete Eyer, alz Brůtflecten, z. B. Lanus, zuweilen mebrere $\mathfrak{B r u t f f l e d e n , ~ a l z ~}$ (Eyer, z. $\mathfrak{B}$. Alca torda uno Morмох fratercula. Die Bogelarten, weld)e mebrere (Eyer, alz

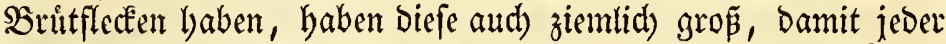
Derjelben mebr, alz ein Ey faften Fónne. Bey Den Bogelarten,

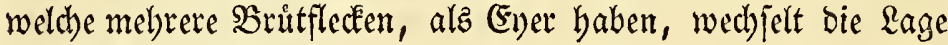
Der Eyer in benjelben.

Die Bógel, Deren Ener uno Brưtflecten an ber $3 a b l$ gleid) find, find Unis grylle, Lestris catarractes, pomarina uno parasitica, welche zwen Eyer und zwen Srutflecten baben. Uria Brünnichii und troile, Puffivus arcticus und ProcelLARI A glacialis, weldhe cin (Ey) und einen $\mathfrak{B r u t t f l e c t e n ~} \mathfrak{b} a b e n$.

Die నo̊gel, ben welchen bie 3abl ber Sirutflecten gróper, als bie ber Ener ift, find Unia alle, Alca torda und Mommon fratercula, weldhe alle mur cin (Ey) legen uno zwel) Bruttflecten baben.

Die Bógel, Deren Babl ber (5yer gróper, alz bie ber Brut= flecten ift, find Phamaropus cinereus und platyrhincus, wel= de vier Eyer legen, und nur zmey Sritfledfen, Stensa aretica, Lanus glaucus, marinus und tridactylus, weldbe mit bren

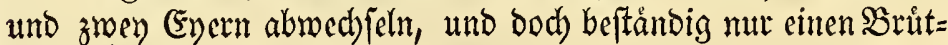
fleckén haben.

Die Britflecken find, wie oben bemert, nidht ganz allein beftimmt, ben Nangel bez Neftes zu erftatten. Daber ftehen fie aud nidbt allezcit im umgekebrten Berbáltmiffe zum Seftbaute, fo Daßj bie Sdyoimmoógelarten, weldbe Nefter bauten, keine Sruttflecken Gaben follten, und umgekebrt. Swar bauten bie $2 \mathfrak{r}=$ ten, ben weldhen bie SBritflecten vermi (Gattungen Sula und Carbo, auch ein Neft; bemnádbit bauen die meiften mit Brutfleden verjebenen 2rten zugleich kein Seft, 子. $\mathfrak{B}$. die 2irten Phalaropus, Uria, Alca, Mormon, Puffinus, Sterna, Lestris umo Procellaria, aber die 2irten von Lanus baben $\mathfrak{B r u t f f l e c k e n , ~ u n d ~ b a u e n ~ \Re e f t e r . ~ S ̧ i r a u z ~}$ 


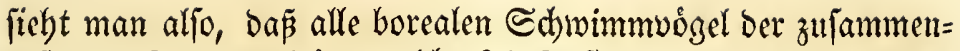

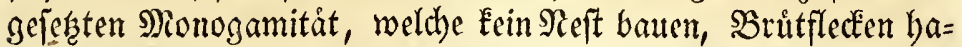
ben, und da a alle, bie feine Srütflecteren haben, Sefter bauten;

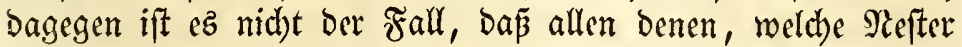
bauten, bie Bruitflecten feblen, weldyez mit den 2Trten Larus berwiejen wirt.

Die O̧egenwart Der Srütflecken ift blop ein Beweiz bez (Frrachens bes \$aarungstriebes, bey weitem aber nid)t bafür, oa bem mit ben Brutflecken verjelyenen Snbividuum follte Statt ge= funben baber. Die SSogel rupfen fict biefé Febern auz, nod) else fie fith mit ibren (Gatten vereinigt haben, und obne verge= wifert zu feyn, ob fie in bemfelben sabre britten werben. $D a=$

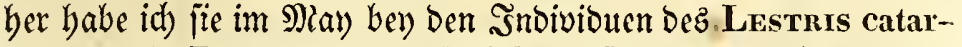
ractes und Procellaria glacialis gefunden, welde fo weit im Meere, uno fo entfernt von ben Brutepláken der 2frt waren,

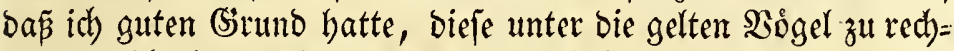
nen, weldhe jeden Sommer, obne zu briten, gefunden werben. Ebenfalls wurben Brütflecten auf ben Indivibuen von Lestris parasitica gefunden, weldye baufenroeife ungepaart bey Mlypatn berumwanbern.

Die aus ben Fledten auşgerupften Federn und Dumen,

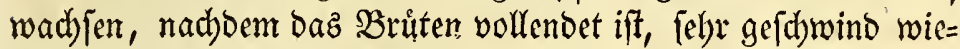
ber. Sm 2fuguft und September, indem noch bie sungen ei= niger $2 \mathfrak{r t e n}$ im Nefte liegen, ift bie Spur ber Brutflecten bey Den 2Itten veridbwunden. 


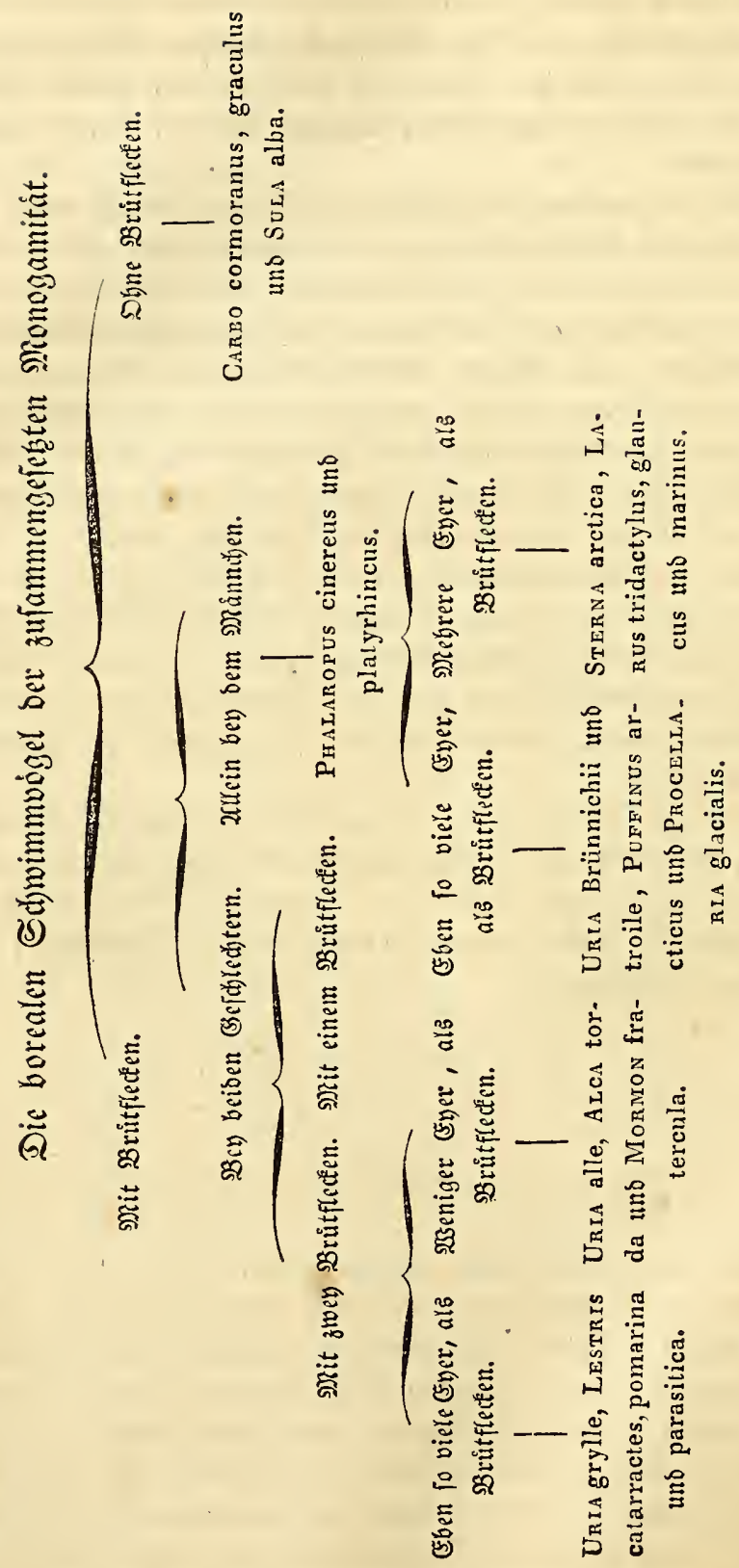




\section{$\S 30$.}

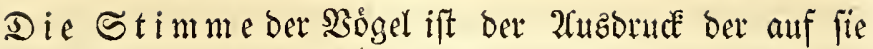
wirfenden angenelymen ober unangenethen Empfindungen; dir=

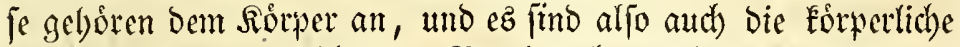
Ruft uno Untuft, weldhe Der Regel nad) veridbicbene Etimmen

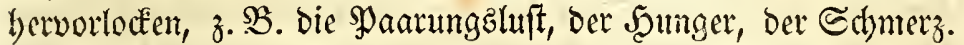
Die verichicoene Modulation ifrer Stinme ift nidgt articulirt;

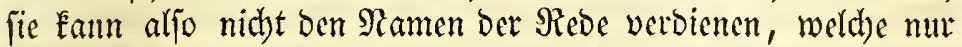
Durd) bie Sernunft und hơlhere Seelenfálhigkeiten beoingt ît, und

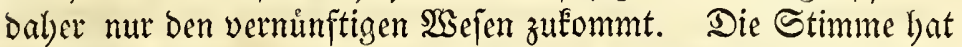

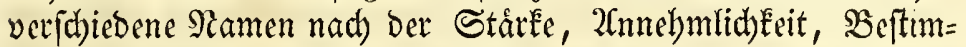
mung berjelben u. \{. wo., z. B. PFeifen, Sceulen, Sabreyen, (See= fang, Edblag, Paarnnglaut, Locefitimme.

(5s ift von groper WSichtigkeit fur Den Drnithologen, bie

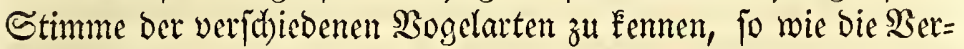
ánberungen, weldhe biefe, nach ben auf fie wirkenben (Empfin=

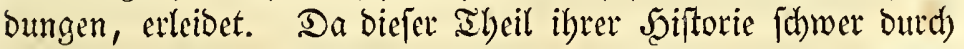

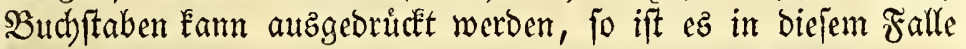

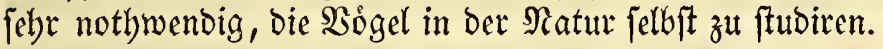

Die meiften 230 gel fommen hoch in ber $\mathbb{Q} u f t$ nach ihrer Şei= math geflogen, uno ziełen gemeintiglich bey der $\mathfrak{R a c h t . ~ S i e ~}$ werben baher eher gebort, als gefelen. Um aljo genaue $\Re e=$

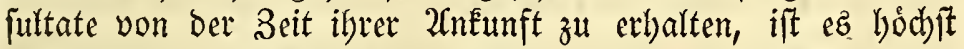
notlywendig, ihre Stimmen zu kennen. WSenn baz Sha cimmal

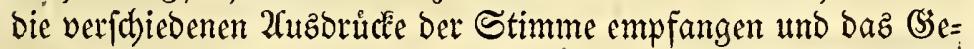
Dádbtrie fie aufbewabrt bat, jo erfjalten wir burd) bie Şülfe

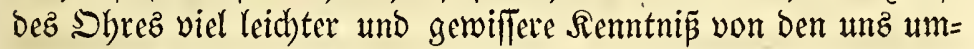
gebenden Sögetn, alz burchs 2 fuge, ba viele 2 rten in einigem 2loitande cinander gleiden, und fie nur fohwer zwifhen ben 3wei= gen, Flect)ten und andern fie umgebenden Materien entbeckt werden, fich aber bagegen burch ilgre veridsiebenen Stimmen verrathen.

Rein Bogel ift ber Stimme ganz beraubt, obgleich bie ver= fabiedenen 2frten fie båufiger oder feltener hơren laffen. Esz findet

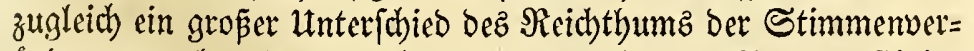
änberungen bey Den verichicbenen Bogelarten Statt. Einige

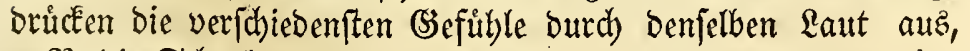
3. 3. Die Scharbe uno einige 2frten ber Enten, andere verån= bern bie Stimme unenolid), nady Der Leibenjdhaft, weldbe auf fie wirft, z: $\mathfrak{B}$. Die meiften Singuỏgel, Die Neven. Die Ber=

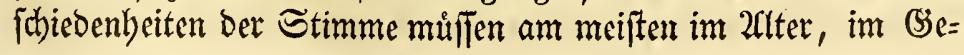




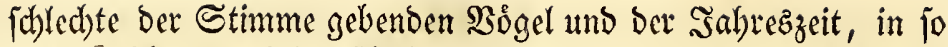

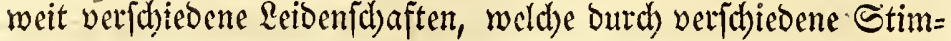
men.auzgedrúd werben, in ben verjdbiebenen Sabreszeiten prábominitend find, gefud)t werben.

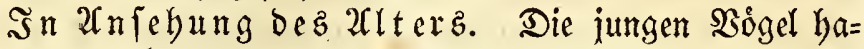
ben gemeiniglid) eine von ber ber 2Alten verfdjiebene Stimme. Sie ift meiftenz bolber und mebr pfeifend, als ber biefen. Die Empfindung, weld)e bie @timme ber Sinngen berborlockt, ift entweder Sounger, Sålte ober Furdt. Sie kennen nodh nid)t Den \$aarungstrieb, und andere måd)tige Iriebe, welche im ip $\mathfrak{a}=$ teren 2flter bie verichiedenten Stimmenverånberungen aus ibrer Sieble locken. Dic jungen $\mathfrak{B o g}$ gel zeichnen fich baher nicht burch Bariationen, fonbern burd) bie båufige Sisieberholung beffelben Sautes auts. SSie oft entbecken wir nid)t burds bie beftänbig

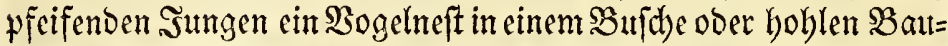
me? Das (sejdrey ber jungen Sd)arben, Dummer Lummer und Meven ift oft unaus(tel)lid).

Emige junge $\mathfrak{B o g}$ gel baben eine andere Stimme in ber Du= nen $=$, alz in ber Federbekleibung, z. $\mathfrak{B}$. bie Sungen bes Larus leucopterus, marinus uno glancus; anbere Sungen baben bie= felbe Stimme in beiben biefer Selleibungen, z. S. Uria troile; wieber andere erbalten gleich bie Stimme ber 2flten, wenn fie Febern befommen baben; 3 . $\mathfrak{B}$. Procellaria glacialis; enolich giebt es auch einige, weldbe gleid) in ber Dumenbefleibung wie bie 2Alten fdreyen, z: $\mathfrak{B}$. Stenna arctica, Larus canas, Strepsitas collaris $\mathfrak{u}$. $m$.

Berfpiele Der borealen Sogel, beren Sunge eine ganz ver= \{djedene Stimme von ber baben, weldhe bie 2alten gemeiniglid bóren lafjen, find Tetrao islandorum, und die 2irten Pharanopus. Die Reftiungen von Uria Brïnichii, troile, Alca torda, Mormon fratercula, von ben 2(rten ber Carbo f(t)rey= en laut und durchbringend, ba boch bie 2atten eime janarrende ober beijere Stimme haben. Die jungen Meven ber .21ten glaucus und leucopterus in Den Dunen baben eine ftare fabrey= ende, bic Jungen in ben Febern cine zitternde pfeifende Stimme, weld)e fie nad) bem 2Cblaufe bez erften Sahrez verlieren.

Boreale Bogel, ber welchen bie Stimme ber Sungen fidon

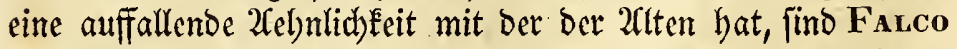
albicilla, Vaneuhus cristatus, Sula alba, Sterna arctica.

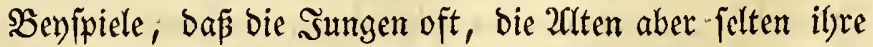
Stimme borren laflen, fino bie 2frten Carbo, und von bem Ent= 
gegengefefen Conrmbus und bie 2 reten Sterna. Beypiele dev

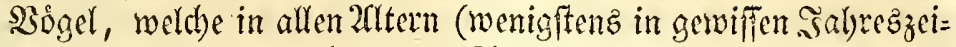
ten) viel, aber je nach Dem verfdiebenen $2(t e r$ mit veridjiedencr Stimme fdyreben, fimb: Urra troile, Brünnichii und larvs glaucus. SBevfpicle foldber, weldye in allen $20($ tem folten forel $)=$ en, bann aber mit verfdiebener Etimme, find: Lestris catarractes uno Procellana glacialis; uno mit beriflben Gitimme afle 2flter ber Sora alba. Die zarten Sungen lafien zubcilen ilye Gtimnte boren, ebc fie nod) anb dem (E) gefrochen find.

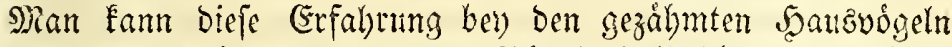
machen. 2utch bey Den wilden Bogeln habe ith es beobachtet. sch babe die sungen der Procelnana glacialis, Lanus tridactylus umo Cosrmous rufogularis in (Ene zart pfeifen horen,

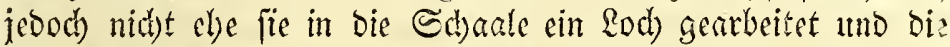

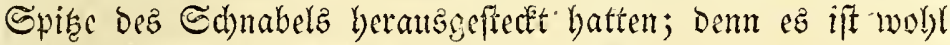

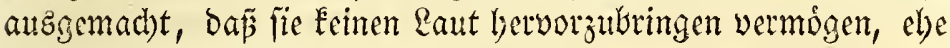
ibre Qungen bie Ruft eingeatbntet baben.

Die Stimme ber Sogel variit uberlaunt weniger nad)

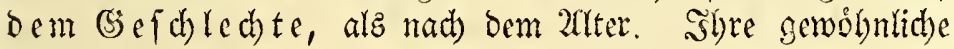
Stimme, weld)e die 2 odeft imme leipt, weil ïe angewanot

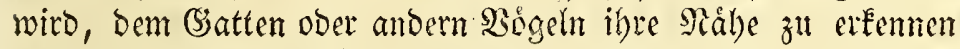
zu geben, aber zugleich gemeiniglich bie Stimme ift, mit weldser

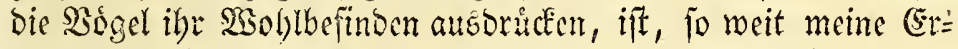

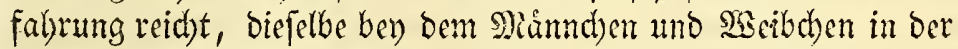

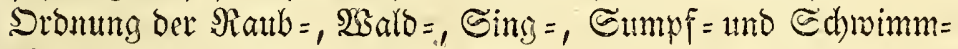

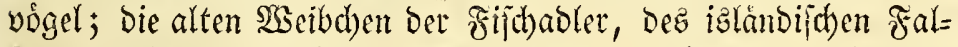
fen, Der Raben, Rråben, Shneeammer, Edywalben, Gjoldre=

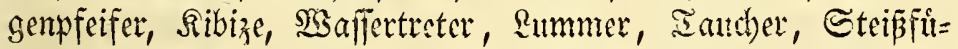

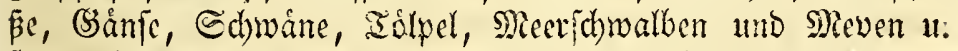

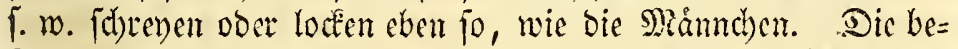
fondere melobijabe Etimme, weldbe allein bie Miánndyen unter Den Singuogeln befizen, ift von bem Eocklante verichicben; er erwacht erft mit bem Saarungstriebe; von biejem aljo nadbyer. Unter ben şaflervógeln wird eine mertliche 2CuEnalyme unter ben Enten gefunden, Deren Maannd)en nicht allein foboner von Farbe fino, fondern anth eine melyr wohllautenbe Stimme baben, als die Saeibchen; fie laffen fie am ofteriten in Der SBegattungszat boren; uno fie wiro Daber vielleicht analog Dem (jejange ber Mainnd)en unter ber (Sattung Der Bassures.

Die Månnchen der Aras nigra, acuta, penelope, crecca, baben eine flótenartige Stimme, aber bie ber SSeibden ift 
beifer und ubellauteno. Die Enteridbe ber Aras mollissima

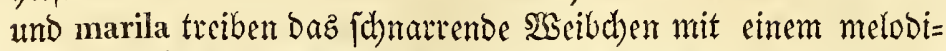

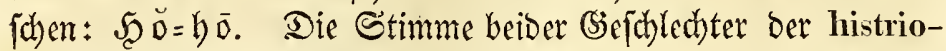
nica und boschas ift einander ålynlieber. Die charakterifiti= iche Etimme ber Aras glacialis lautet wie $\mathfrak{a} \breve{\mathfrak{u}}=\mathfrak{a} \breve{\mathfrak{u}}=l \mathfrak{l i t}$; id habe biefe nur vom Måmnden, aber nicht vom 23 seibchen gehoirt. Die Mengus-2irten laffen felten ibre Stimme, bie alth beifer umb faynarrend ift, bo̊ren.

Da Der Saat ber $\mathfrak{R}$ uftrófye hiberbaupt cinen bebentenden Einflup auf Den verichiedenen 2husbruce ber Etimme hat, fo fin=

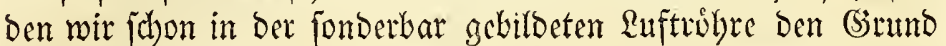
zu Der von ber Stimme der WSeibden verfatedenen Etimme ber Rånndhen bey Mergris serrator uno Avas clangula. Den bohlen Ion, weldyen bas erfe bicjer 2Trten aus feiner erweitet=

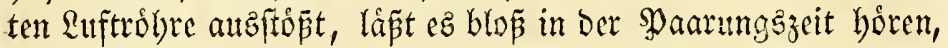

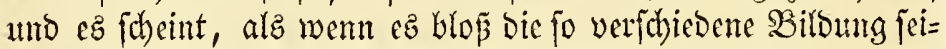

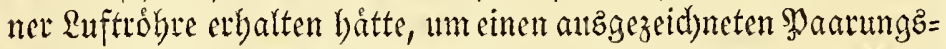
laut za haben. Daffelbe ift bernah aud ber Fall bey Axis clangula. $\mathfrak{C}$ udh Crasrs musicus bat eine fonderbar gebild ete Enftróbere, aber von Derferben Bitloung ber beiben (Gefd)lect)tern, und fie baben baher beide bieferbe pojaunenábntiche Stimme.

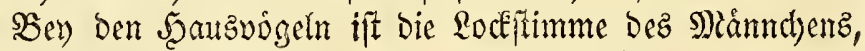

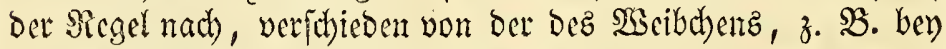

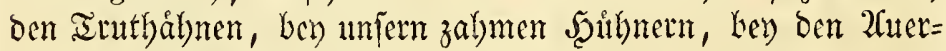

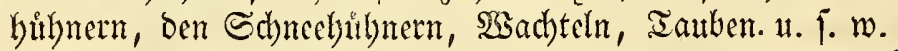

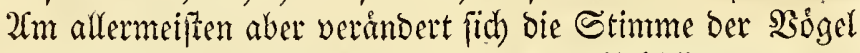
in den verfabiedenen Sabrezzeiten. Der Frábling und ber

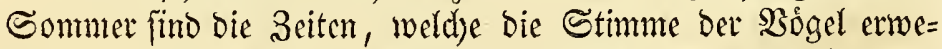
deen; Der Scerbit und ber Winter bie, weldhe fie zum Sdyweigen bringen. Denn der Irieb, welder iłnen befonderz die Stimme ablocet, nåmlid ber \$aarungztrieb, und ber bamit in \$erbin=

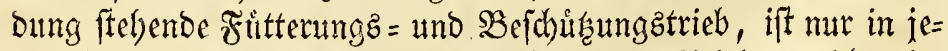
nen beiben Sabrezzeiten in 21ctivitát. Der Irieb, welcher im

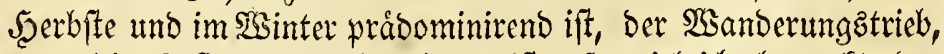

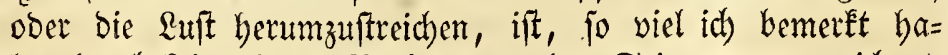
be, burd) keine eigene Berånderung ber Stimme autsgezeidnet. Unter ibren WSanderungen laffen fie bie gewofhnliche Rodiftimme, weld)e fie baz ganze saly behalten, hơren.

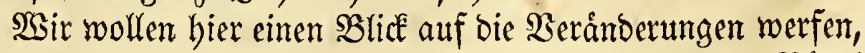
welche ber etrachende \$aarungstrieb auf bie Stimme ber \$öget bervorbringt. Er wirft auf eine orenfache $\mathfrak{Y}$ seife. 


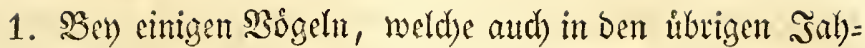
rezzetten Ctimme baben, erwadben in Der \$aarnnggzeit neue Serandenungen ber Stimme, weldae fid) wicber mit Dem ent= [d) hummetnoen Syaarungstricbe verlieren.

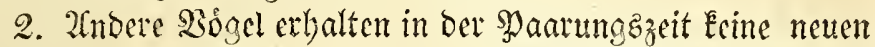
Beranderungen Det Stimme, fondern fie laffen ibte gewólynliche Grimme in berielben viel ofter boren.

3. Wieber altoere 2riten laffen bloźz in ber Syaarungęzeit eine Stimme looken, fint aber in Der ubrigen Beit Des Salyrez ftumm.

1) Dic Beffatigung des etften biefer @ałse findet man ge=

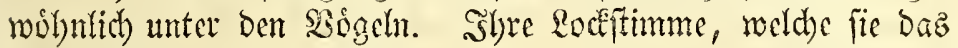
ganze Sabr binourd) bel)alten, tritt, obgleid) fie in diejer 3eit nicht ganz verloren geht, in ber. Spaanungzzeit vor anderen

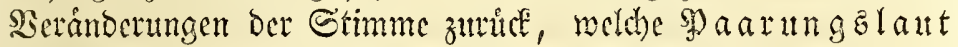

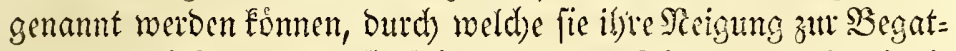
tung ausbouden, und bie fie fpaterhin in ber Futterungszat mit ciner verid)iedenen Stimme verwedjeln, mit welder bie 20lten bie

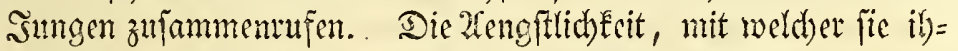
re Ctimme anffofopen, verrath oft, z. SB. bey Dem Sibice und

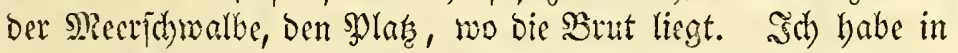

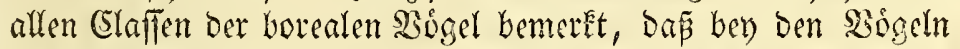
mit Dem Erroacten und Dem Entid)lummern Des \$aarmigtrie= bez auth nete Gtimmen etwad)en und veridowinden. IJd) will

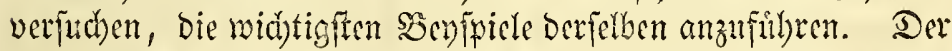
Syarung glatt bez Conves corax ifitein wobllattendes clong=

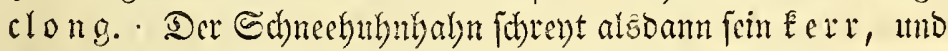
baz 2 seibden ruft ilye Sungen mit einem gludenden Raute. Charadrus pluvialis giebt in ber Bcit cinen pfeifenden Ton von fid), weldhen er weit mebr, als feine flotende Rodiftimme, in dic Långe zielbt. Der Şaarungelaut bes Nunesus phaeopus ift lang uno triflerno, weld)en er, wenn ber frutterungstrieb

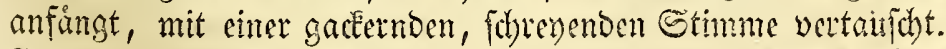
Strepsilas collaris fibrent viel berm Refte, obgleid fein Lode

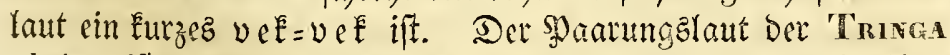
alpina ift cin trilferndez $r y(t)$, weld)er ify in allen bånifichen Provinzen Den Namen Mivlle verid)afft hat. Der Maarungs= laut DeE Scolopax gallinago ift febr ausgezeict)net, brumment, balb wiebernd, weldber fid mit einem wieberisolten $b$ ie $=$ a endigt. Schon im 2üsgange bez Jitly bat or Diefe Śtimme vetloren, unb wito bann mit feinem gewóhnlichen Eatte, einem beifern 


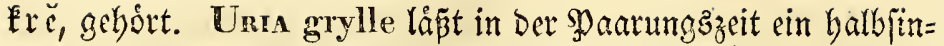
gendes wobllautendes iftifi =ift boren; ihre Rodeftimme bagegen ift pfeifend. SBen dem Refte wito dab (d) narchende or $\mathfrak{x}$ dez Monnov fratercula unb Alca torda gebort, weldbez fie erfit, wenn fie Sunge haben, mit einer Stinme vetwechjeln, weldbe auffal= lend Der cines gálynenden Memịd)en gleidht. Die beulende und jammernde Etimme der Cosymes glacialis und rufogularis

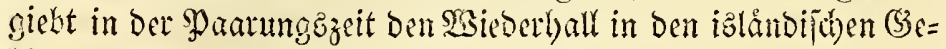
birgen. Courubus rufogularis fubrt feine Sungen mit einem fulzen ă felten eine Estimme gebort; in Der \$paanmgezeit aber (d)weben

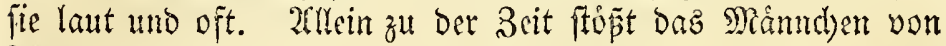
Mergus serrator unter ben fomberbarften (Sjeberden eine boble Etimme aus friner \&liftrobre. Daj bie Friblingsfimme bes S) Kannd)ens der Axas nigra in Den andern Sabregzeiten nicht gebort werde, lyat fichon $\mathfrak{B}^{2}$ ie bentert, f. Wu iedemannz Ma= gazin, Th. 1. St. 3. S. 145. Das slianndhen des (sibervo=

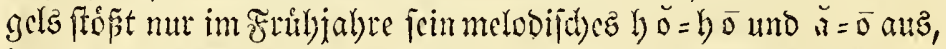
indem ez dą $\mathfrak{W}$ cibd) groenl. p. 6.\$. Die Mevenaten zeid)nen fith Dutd) Die vetidie= Demften Stimmenveranoerungen berm Sefte aub. Die şeróhn= lid)e Stimme bez Larus glancus ift ein $a=g a=g a$, unb die beg L. marinus lautet wie $a=g a \mathfrak{u}=g \mathfrak{a} u$, wobev) ber lestere oft mit

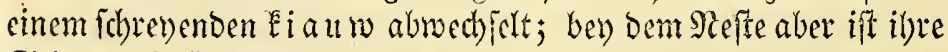

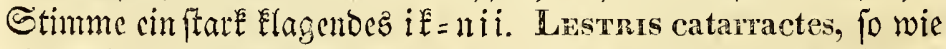
Die Sdarben und Iolyel, find bie unter Den borealen Siogeln, welche felten ibre Stimme looren lafien, Dodh ift Der gersignliche Raut Diefer Raubmeven ein tiefes l) $\overline{0}$; ben Dem Sefte aber ift ibre Stimme balb gacererno.

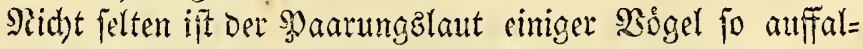

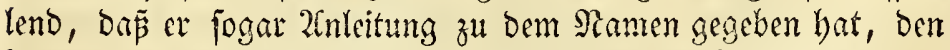
jenc bev) Dem genteinen Mamme tragen. Sn Dánemark fommt Davon der Dånijhe Rame dez Cuculus canorus: Siticker. Aras glacialis beipt iberall in Dánenark Sablit, von feiner Étimme, uno in Normegen und ş̧land Syavelli. Xuz Derfelben

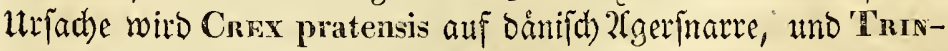

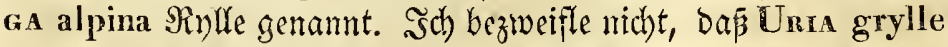
von frinem Frulylingslaute ift = ift in Sdbweden Site, aut Sam= foë sifte, und in šlano scifte genaunt werde.

Daz Månnden von Tetrao Islandorum und Riberiza nivalis; fermer Convus corax, Scolopax gallinago, Nune- 
nius phaeopus, Mergus serrator, Stenna arctica, LanuS tridactylus, Lestris parasitica, baben ifyen izlandifden $\mathfrak{R a}=$ men yon ibrer paarungsftimme.

Crex pratensis, Trunga maritima, Scolopax gallina-

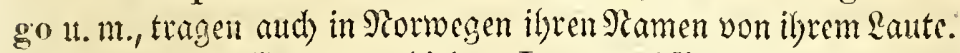

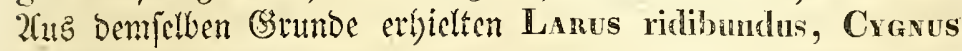
musicus, Columba risoria und turtar u. F. w. ifre lateini= (d)en Namen.

$2 \mathfrak{m}$ meiften auffallend aber ift bie mebr boer minder melo=

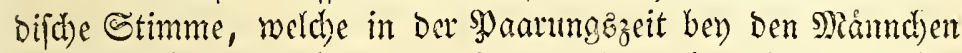

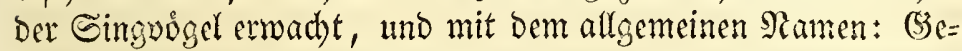
fang benannt witb, weldyer wieder, nad) ben veridiedenen Mo=

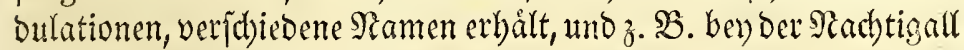

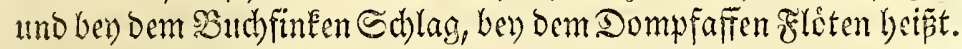

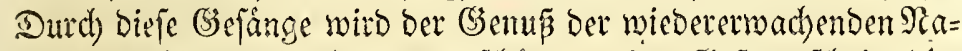
tul im Friblinge belebr und verfibonert. Der (sejang icheint bie= fer Sronung ber sioogei eigen zu fern, obgleid) einige 2irten an= berer Stomungen aud cine red)t angenelyme Stimme baben, z. SR. Lanius collurio, verid)iedene Gumpfoigel u.f.w.

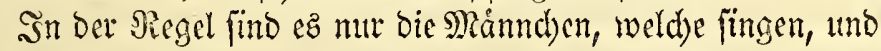
bie Şseibchen fónnen gegen diefe frumm genannt werden. Die jungen Mrinnd)en fangen fdon im 2ubbrutungsjabre an, ibre Eingorgane zu liben, jingen aber nid)t ebcr, als biz fie brutfä

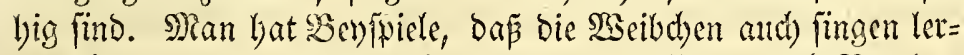

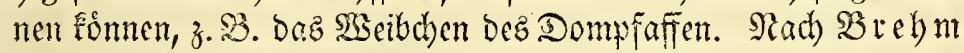
foll bas $\mathfrak{2}$ eibden von Loxia pytiopsittacus und curvirostra aud) im willen 3itfande fingen.

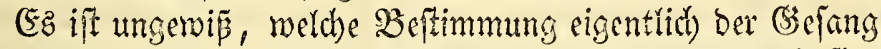
bez Månnd)ene babe. Einige Srnitbologen nteinen, dẩ fie fin= gen, um bie şscibchen berbeyzulocken. Diefes fann indeffen nidst

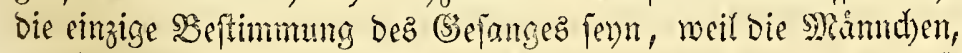

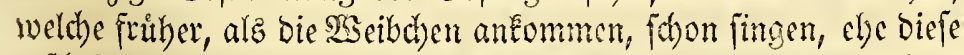
cricheinen, und aud nadbem fie fid)on ibre (satten gefunden baben.

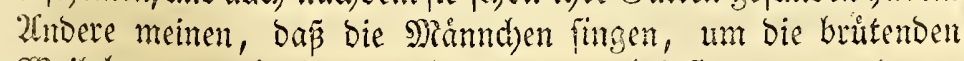

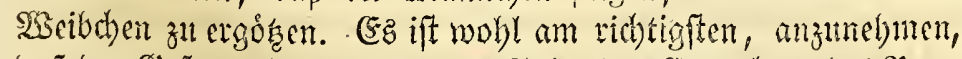

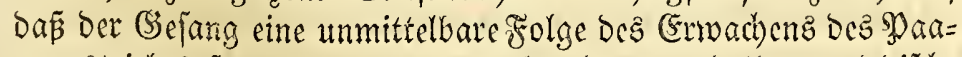

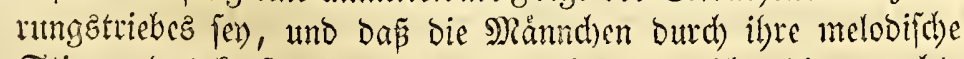
Stimme das Eraftwollere Reben autsbricten, weid)es dic crmachte Saaungefabigkeit ibnen mittheilt.

Die Singuogel werden feltener in ber borealen $30 n$ e, in wel=

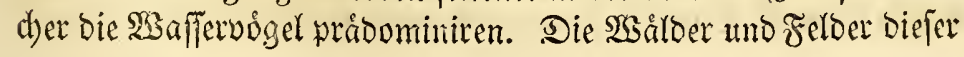


nórdliden (B'egenden ertónen daher nid)t, fowie in den temperir= ten Rámbern, vom (3efange der flecinen Bógel. Diefelbe Bemer= fung ift in 2(mfelutmg ber bei land find Axtruvs pratensis und Enвenza nivalis bie ange= nelymiten Sänger; bon ben Seiten ber (Bebirge wird and bie red)t angenelyme Stimme des Tundus iliacus geboort; verfdoie= dene Sumpfoogel, z. B. Nunevius phaeopus uno Charadrius

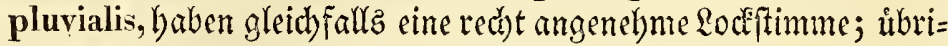

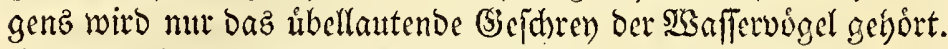

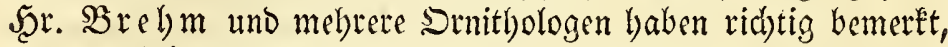
oaj die Sögel auf ilyrem Buge felten vollfommen jingen; man

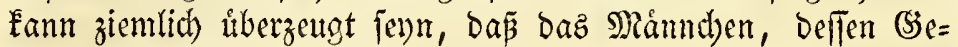

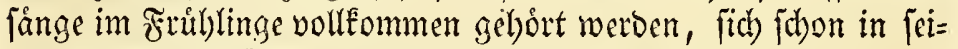
ner \$eimati befinde, und nicht weiter gegen 2 orden ziehe.

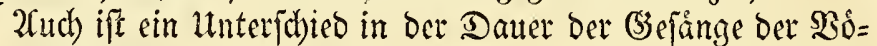
get. Finige find mebr antyaltend, als andere; bod) fingen bie

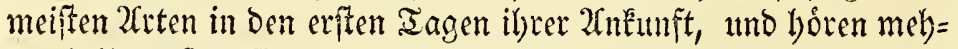
rentlyeilz alf zu fingen, wenn bie șungen aubgebrütet fino, ob= gleidf Tunnus musicus und merula, Sruvia hippolais und hortensis t. m., fogar jingen, wenn bie sungen erwadjen find. Alavds arvensis ift in Dänemark ber gemeine Sänger, weldher am erften anfångt und am langften antbált; jie fingt yom sa $a=$ nuar bis zum September. 2fud) Hrnusno rustica fingt pait im Sherbfte; andere, z. B. Der Baunfónig, jogar ben ganzen $\mathfrak{B S i n t e r}$

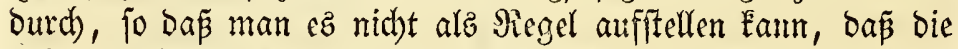

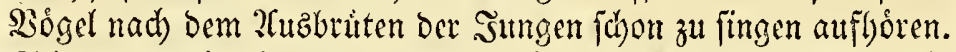
Schon im Márz fangen die Standuógel ber Passeres an, bie $b \hat{a}=$.

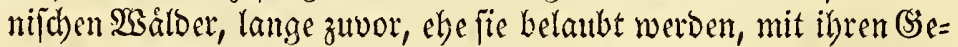
fângen zut beleben; im Mian find die angetommenen 3uguogel am fleişigften im Singen. Bejonders beym 2Uufgange ber Sonne werben fie in den şálbern geborkt, mux wenige fingen, wie bie

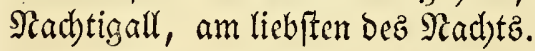

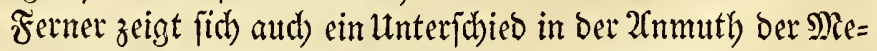
lobien, welde im Mårz und im May in umferen $23 a ́ l b e r n$ geboirt werben. Sm Mlárz Gơrt man nur die minder angenelymen (S) ejânge Der Dánifchen Standoógel und ber zuerft anfommenden 3ugvógel, 子. B. Embenza citrinella, Panus major uno palustris, Fringilba coelebs und cannabina, Sturnus vulgaris; biefe (Gese jánge werben im Maymonate, in Bergleidsung mit ben angenth)= men Relodien ber angetommenen Drofleta uno Sylvien, mur wenig bemertt. 
Nidjt alle Bogel laffen, wie bie Mainnden der Singuoggel,

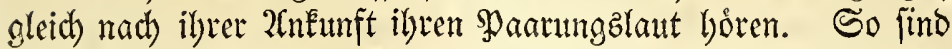
Cuculus canorus uno Tetrao coturnix in Der erften $250 d$ de nad) ifrer 2 (netuft ftumm.

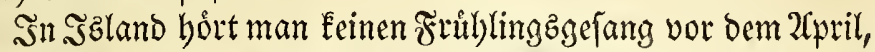
da Artuos pratensis anfommt; Dod) baben Euвегіza nivalis

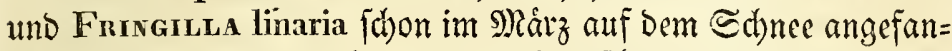

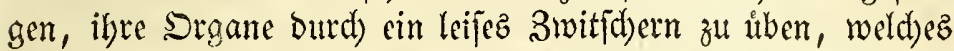

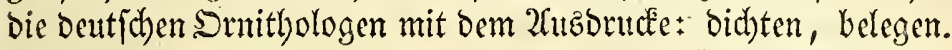

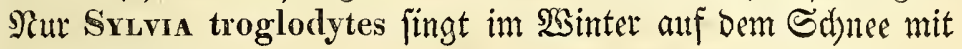
lauter Stimme.

Die Singoógel benelymen fidh ben Dem Singen auf perfetie=

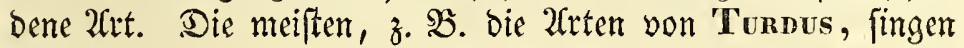

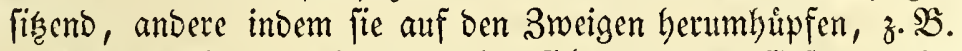
die Parus - 2frten. Einige erbeben fidi) unter dem Ġejange wir= belno in die $\mathfrak{u}$ ft, z. B. Alavida arvensis, Anthus pratensis, rupestris und Emberiza calcarata; wieber andere erheben fich in einem Sogen in bie Ruft, und werfen fich gleid) uno noch fin= gent auf ben 3weig u. j.w. Gerab, von weldhem fie aufflogen, 子. B. Sylvia cinerea, Алthus arboreus.

Die berúlymten Raturforidher, Şerr Spix uno Rartius (Sicife in Brajitien, 1., S. 190 u. F.w.), bemerfen ez alz cine nicht uninterefiante phyfiologifole Utnterfuchung, in wie weit bie

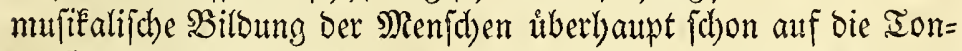
funft ber Thiere genuirt lyabe, uno bemerten es als dentebar, Da viele ber gefieberten Sänger in $\mathfrak{B r a f i l i e n}$ verfeinerte Melobien

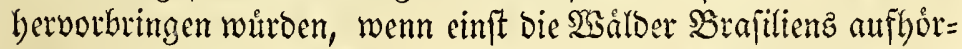

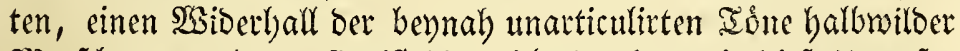
Nenjohen zu geben. (Es? ift bier nicht ber Sort, in bieje Utnterju=

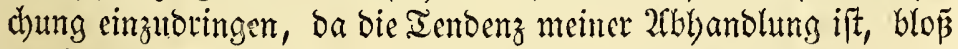

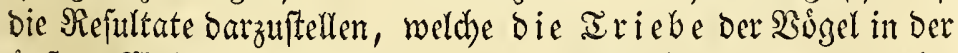

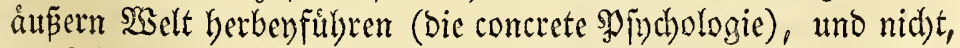
bie Rebenzuerbåltniffe biejer (sefdrdipfe zu unterjud)en, in fo fern fie auts Seelenfábigkeit refultiren, weldhe man wohly nidgt unbebingt ben IIbieren abiprechen Eann (bie abftracte \$Pind)olo= gie). Ssth will baber mutr Folgendes bemerken:

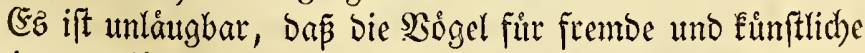
Melobien empfånglich fino, bap igre Shren fie auffangen, ihr

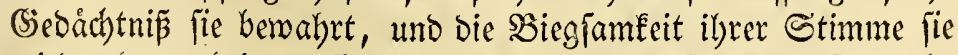
wieber Gerborbringt. ŞBie oft erfabren wir biefez bey unjern zal)= men Singbo̊geln, 3. B. Dem Staare, ber 2 mmiel, Der Siachtigall 
u. f. w., weldye Melobien ganzer 2rien externen; aud Bỏgel aut= fer bar Singuogeloromung, als Der Rabe, die Doble, Die Elfter, Der Shapagen, fonmen articulitte Tone bervorbringen lernen.

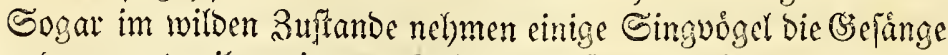
anberer unter ibue eigenen Melodien auf, z. B. Sruvia hippolais, ja fie feren zuweilen ilyren ganzen Gejang aus ben sơnen anderer Sánger zujammen, movon Lawis collurio cin meté wurroiges Bey jpiel ift.

Dod) Ean idh midyt mit jenen Berfafiern annelymen, baf

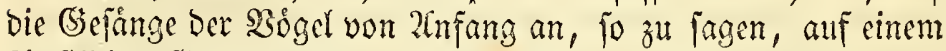

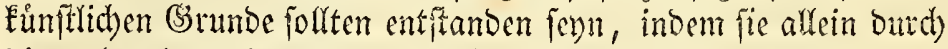
die mebr ober minder harmonifden Giegenfirnde, weldhe fie um= gaben, follen gebildet worben fenn. Sn ber angebornen $\Re_{\text {latuts }}=$

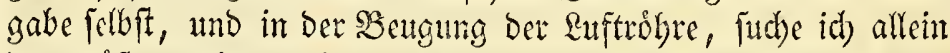
ben gro̊äeren oder geringeten Sorzug Der Melodien unferer Sing= vógcl. Der (Sirauammer lebt in náberer und unabgebrodineter

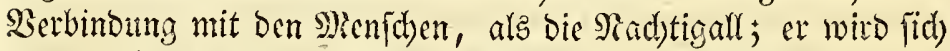
aber bod nie biefem fdjonen Sanger in Der Grimme nályern. Eben bie Bogel, weld)e sabrlbunderte hinourd) mit ben am mei=

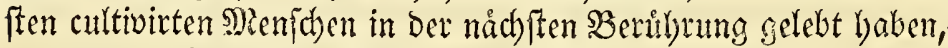
und leben, nåmlid) bie Sperlinge und Schwalben, find bie fd)led)= teften unjerer Sånger. Die Şogel bagegen, welde (id) an mei=

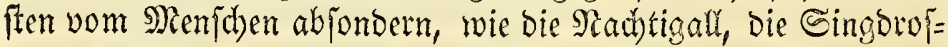
fel, bie 2 miel at. m., baben bic jdoonfte Stimme. Sn beniflben

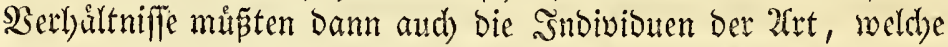

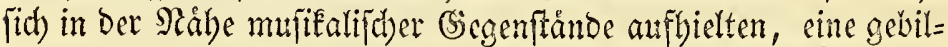
betere Stimme erbalten, alz bie andern 2rtswerwandten, weld)e ibre Seimath) in oben uno unbewolynten (Segenden unter ummuli=

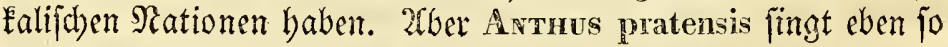
angenel)m auf ben izlåndifden Jeiben, als in Den bănijchen be= wobnten Ebenen, und der (Sejang Dez 3auneonigz in Šbland,

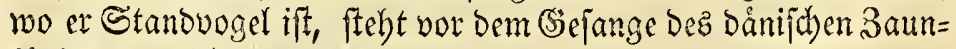
fónigs am nichts zurùcê.

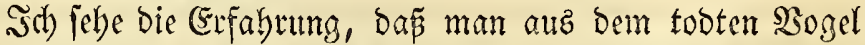
ganz medjamifoc den Laut aubpreffen Eann, weldyen er lebendig

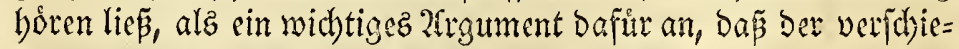

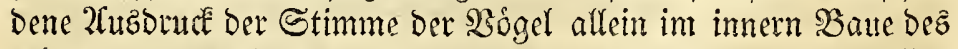
Soirpers, und nid)t in Der (Seldibrigkeit, frembe Stimmen zu fafien, gegrimbet (ei). Sch lyabe es melyrmals bey Larus canus erfalyren, Dẩ man jogar einige Stunden nad ilyrem Tode bie Stimmen= veranberung bervorbringen Eam, weldhe fie levend boren läpt, 
indem man die Seiten bes Unterleibez an veridjebenen Stellen zufammenorudet; wenn man bie todte graue Mebe in ber (Segend

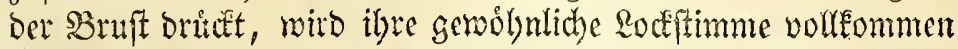

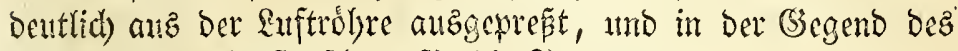

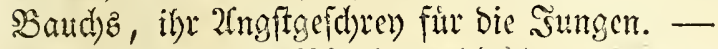

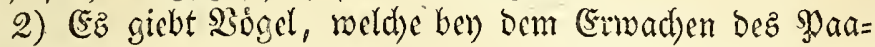

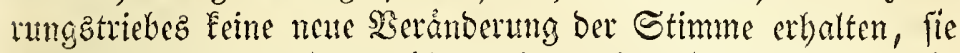

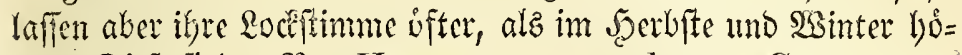
ren. Diefe find z. 9.: Haenatopus ostralegus, Chamadnus hiaticula, 'Totanus calidris, Vanelus cristatus, Aras glacialis, penelope, boschas, Crgnus musicus, Sula alba, Sterva arctica $\mathfrak{u} \mathfrak{b}$ Lesturs parasitica. Dả $\overline{\mathfrak{a} \mathfrak{u}}=\overrightarrow{\mathfrak{a} \mathfrak{u}}=\mathfrak{l}$ it Der Anas glacialis uno bas piw der $\mathbb{A}$. penelope ift nid)t, wie $a=\bar{o}$ Dez Eibervogel= mánnchenz, blop ein ber Şaarungzzeit allein zutgeburender Paa= rungslaut; benn fie laffen aud) Diefe Stimme im Sisinter boren.

3) (Endlid weroen gewiffe Sogelarten gefunden, melde in Der úbrigen Sabreszeit ganz ffumm find, ber) weld)en aber in ber Saarungzzeit, in cincm fonderbaren Gegenfaze, zumcilen eine unzáblige Menge Ctimmenverânberungen crwad)en. Diefez ift Dev $\widetilde{J a l f}$ mit Una Brünnichii, troile, alle, Alca torda, Larus tridactylus, Carbo cormoranus und graculus. Dieje Regel fann naturlicherweife mut nach negativen (Erfabrungen beftimmt worben, baj man jie auper dor \$paarungzzeit Eeinen Laut von fid) geben bort. (5s ift nidt fo auffallend bey den Canbo-2trten, weld)e aud im Sommer felten ibre Etimme boren laffen. 2fuper=

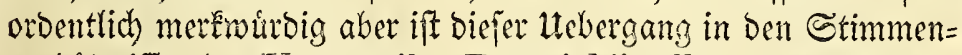
verbáltniffen bey Una troile, Brïnichii, alle und Larus tr:-

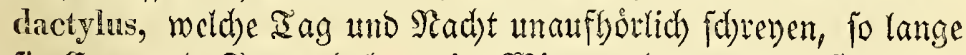
fie Eyer und Sunge baben, im 23 inter aber ganz verftummen. Secjonderz ift $\mathrm{eE}$ bey Las. tridactylus auffalleno, weld)er fid) vor allen andern nidyt allein burd) feine fiererere, fondern aud) Durch feine abwechjelnde Stimme in ber Nectzeit auszeid)net, fo

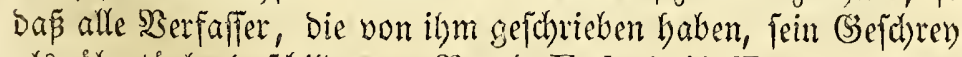
als hibertåubend fdildern. Sergl. Fabricii Fauna groenl. p. 99., faberz Syrodr. Det izl. Srnith., S.91., Qandt von Den šmjeln Farroë, S. 263. SWenn er Den Sritula verlaffen lat, wirb ex auf eimmal ftumm. Socrichiedene şslånder, mit

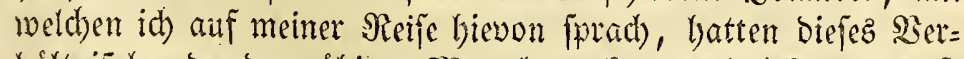

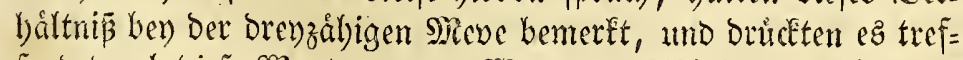

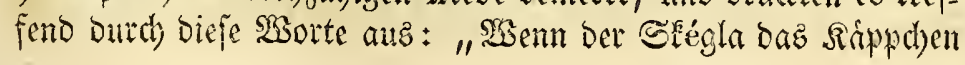


aufnimmt, wird er ftumm." Daz blaugrume Suetband tiber ben

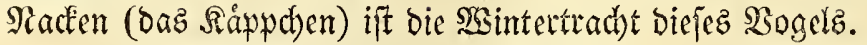

Die alten 3 bogel baben gewobnlich eine andere Stimme fur bie 2Ungft, ben Sidmerz 1 . ..w., und eine andere, mit weldyer

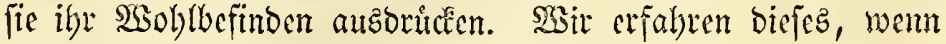
unjerem zalmen (Seflingel vor einem Ratbogel bange, ober wenn ein angef(t)offener $\mathfrak{B o g e l}$ ergriffen wird u. f. wo.

Das (3ejchrey verichiedener 2 sogel l)at Beranleffung zum 2Cberglauben gegeben, ber nod) jest unter Dem gemeinen Manne

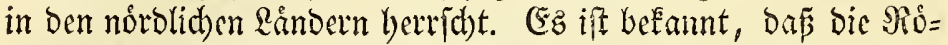
mer auf bas (3efderey gewiffer $3 \dot{g e t}$, beponders ber Saben uno

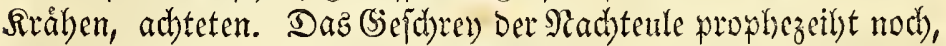
nad) Der Mcimung Des gemeinen Rannes, eine Reide im Şaule; aud foll bas (jiefdyen der Strux bubo die Cage von ber Sago

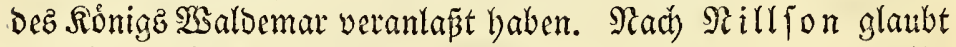

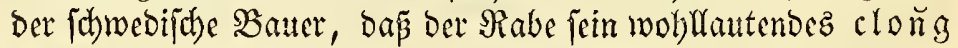
clong nicht eber erbalte, als biz er bundert sabre alt fer).

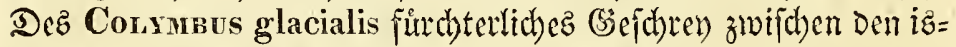

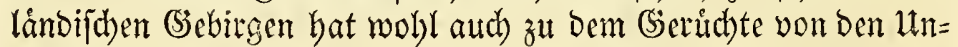
teritbifchen beygetragen, weldye biefe (Sebirge bewolnnen follen.

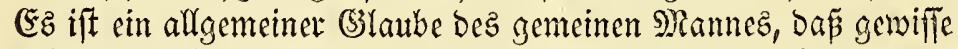
Sógel Durd ihr (Sefd)rey bie Sitterung vorberjagen Eonmen, und eE fann molyl nid)t grláugnet werben, baj fie in gróperem oder geringerem (Siade cin Borgefithl ber \$eränderung Der Tempera= tur haben, und diefes (Sefüll auf verfdiedene Siseife áupern.

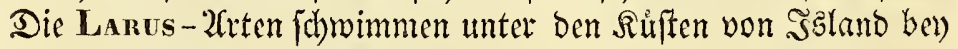
Dem Sorgefúble cinez Stumes mit aufgedunfenen Febern. (5E

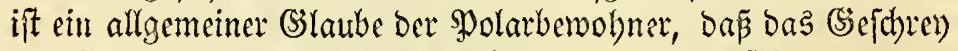
DeE Colymbes rufogularis Beranderung in ber $\mathfrak{s i t t e r u n g ~ a n = ~}$ fündige, vergl. So ntoppioanz natirliche Sifrorie von Sior= wegen, II., S. 137. Strómz Sonomór, S. 236, $\mathfrak{A} \mathfrak{n}=$

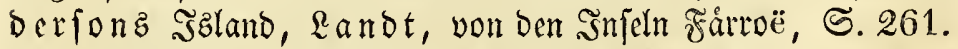
Sontoppioan ermálynt einez Sogets, II., $\subseteq .145$, unter

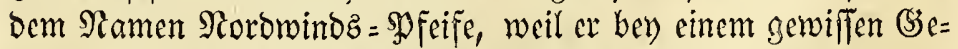

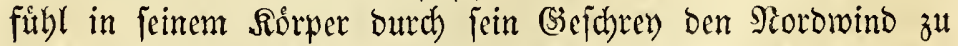

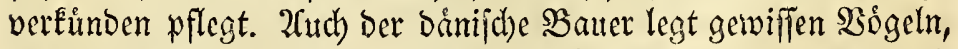

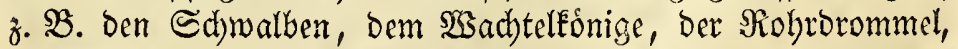

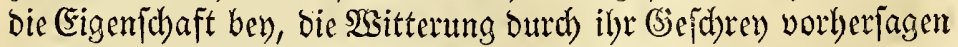
zu fónnen. Ein foldhez Borgefúbl der Berånderung ber Tempe= ratur finden wir analogifd unter ben Fijden bey Cobiris fossilis $\mathfrak{t}$. $\mathfrak{m}$. 


\section{§. 31.}

Daz leşte ummittelbare $\Re e$ fultat deb erwad)enden \$aarungs=

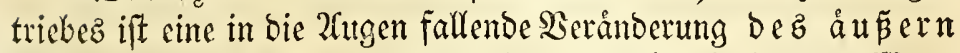

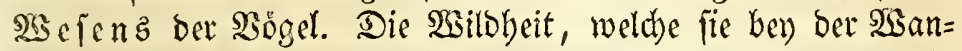
berung zeigen, wito plóflidy in eine Futchtlojigkeit verwanbelt,

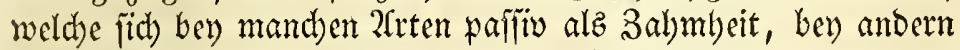
aber fogar burch activen Mut!' im 2(nngriff gegen biejenigen áußert,

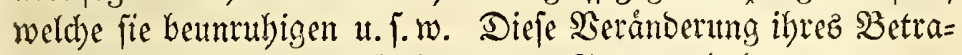
gens nimmt zu, fobalb fie Ener ober Stunge erlyalten.

Die W̧affervógel, weldhe auf Den Seiten ber fteilen Felien briten, find von Siatur bie jorglofeften, und werden baher ben

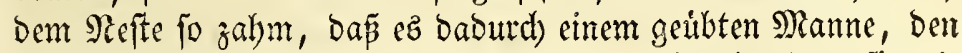
man auf bie Gelfenjeiten heruntergelaffen, móglid) wirb, fie mit

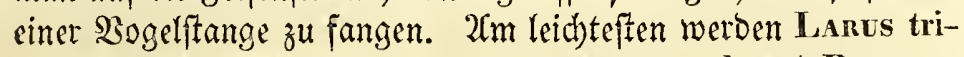
dactylus, Unia Brüinichii, troile, Alca torda und Procenraria glacialis gefangen, weniger leid)t die 2urten Carbo. Snlua

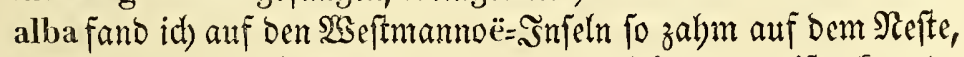
baś id), fo viele idh mur wollte, mit ben Şäanden greifen Eonnte.

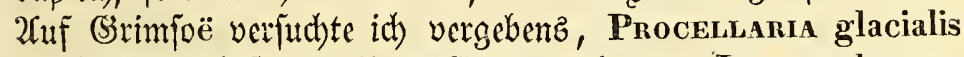
Durd) Steinwuinfe von ilyren (Evern zu jagen. Larus glaucus, marimus und Stersa arctica brutten bingegen nidbt fo bart; fie

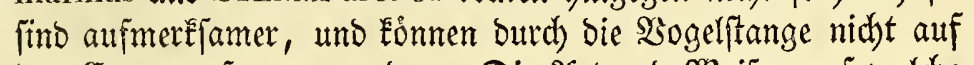

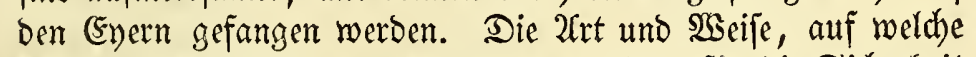
Monnos fratercula und Pufrinus arcticus fưr bie Gidherbeit

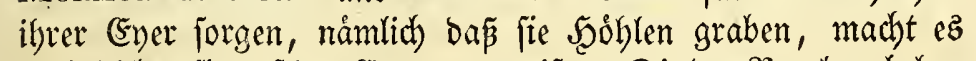
audd) leid)t, fie auf ben (Eyern zu greifen. Die ber $\Re$ egel nadt bery

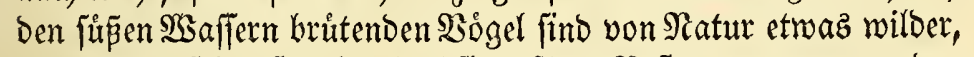

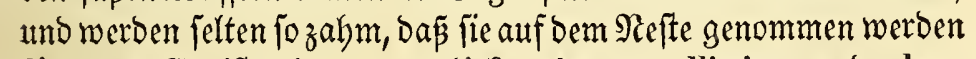

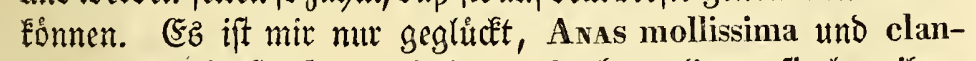
gula auf biefe Sseife zu erbalten. Dod) vertieren fie bey ifrer

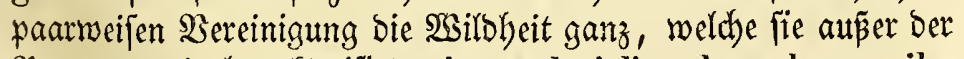
\$aarungezeit d)arafterifirt. Axas glacialis, clangula, marila, mollissima, boschas, penelope, acuta, crecca, weldhe im

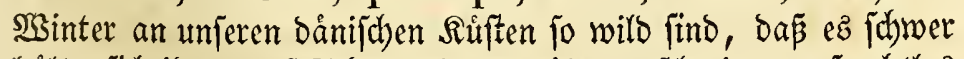

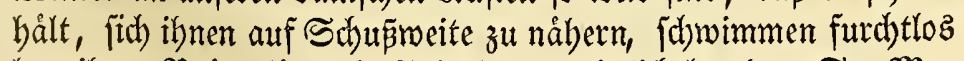

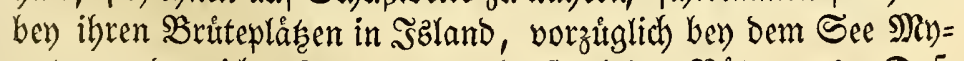
vatn, und weidjen kaum Den vorbenjegelnden Sơten aut. DaF= felbe iff der Frafl mit Cyanus musicus in Den Şebirgwaffern.

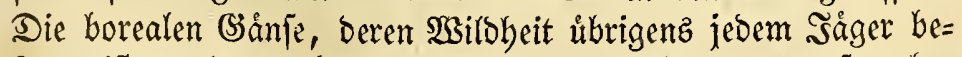
Eannt ift, werben nad) ber Berfidjertung ber 2fugenzeugen fo zahm 


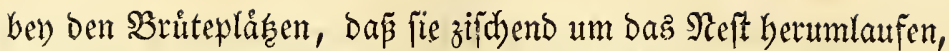
indem man ilynen ifre Eyer nintmt. Die Poniceps-2fiten find gleid) fall? obne Futcht bey Dem Seffe. Sorfid)tigev find bie Co-

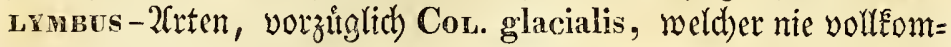
menes Butrauen zum IRenjdhen erbålt. Wuch die Sumpfoogel find in ber Meftzeit ficherer. (Ez ift berannt, wie fideu Hawnaтopus ostralegus, Nunenrus phaeopus und Totanus calidris ubrigens find: bey dem Nefte aber umidrweben fie furchtfrey den Menichen, und bieten fich leidht dem Edumfe Dar. Der in ber 3ugzeit fo wilde (solbregenpfeifer if fo wenig id)en in Saland bey ben (Evern, bas er neugierig um bie berumlåuft, weld)e fie weg= nelmen. Selbit die Fifd)abler nebmen fid nidht allezeit in 2(dht, in bie Shusweite zu Eommen, wenn fie ångftlid fdreyend um ibl Neft berumfliegen.

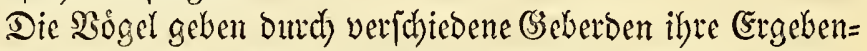

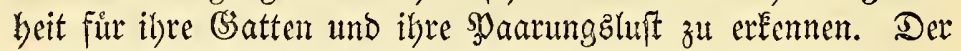
siabe blábet feine Febein auf, und madid Serwegungen mit Dem

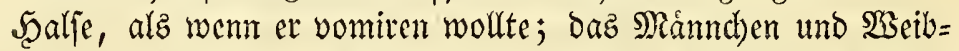
d)en der Phalaropus-2irten und Crgnus musicus balten fid beftandig zufammen, und careffiren einander mit bent Schnabel. Uria troile neigt, fich bem zuldwimmenten (Satten entgegen. Das Månnchen bet Podrcers-2iten treibt bas $\mathfrak{B e i b c h e n ~ i m ~}$ SBaffer mit aufgedunfenen Federn und Enartender Stimme; wenn

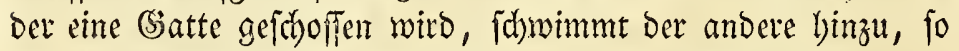
wie Aras histrionica, und fiofst ibn mit bent Edhabel an, um iln zt ermuntern, fich wieber aufzurichten. Das Männd)en von Mergus serrator zeigt die fonderbarften Geberben in ber \$aa= rungzzeit; ez bebt den Şalz und den Sopf perpendiculår in bie

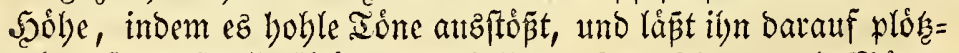
lich) anf bie 2 bafferfläbe nieberfallen. Das (sibervogel= Mann=

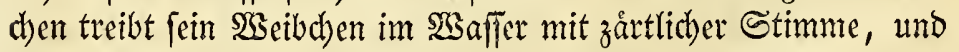
careffirt es oft mit bem Sdnabel; baffelbe iff ber Fall mit Aras marila uno melyweren (Enten. Larus tridactylus fdonabelt fid) zut= meilen mit Dem (Satten, wie bie Iauben, und die Lestris - 2Crén geben die \$̧aarungzhuft burd) Das Sd)leppen ber Flugel auf oer (Erbe, und burd) aufgedunfene Febern, wie die Inthál)ne, zu etkennen.

Şann bie Rogel Eyer ober Sunge ethalten baben, fo geben fie ifre Sorge für bie SBrut auf verjhiedene SBeife zu crfennen. Finige bezeigen nur paffive Furdht fiur diefelbe, andere wagen fogar, fie actio zu vertbeidigen. 


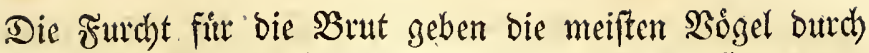

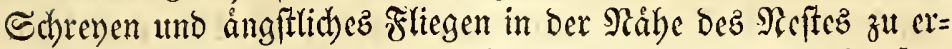
$\mathfrak{f e n n e n . ~ D i e f e s ~ i f t ~ b e r ~ F a f l ~ m i t ~ F a l c o ~ a l b i c i l l a ~ t m o ~ i s l a n d u s , ~}$ Haematopus ostralegus, Numenius phaeopus, Limosa melanura, Totanus calidris, den Phalanopus - 2Giten und Lanus tridactylus.

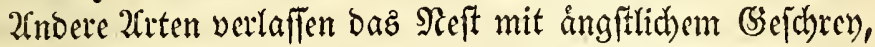
inbem fie fid) auf bie (Eroe werfen und mit ben Flingeln flatterli,

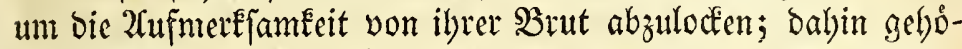
ven verfobiedene Cinguogel, 'Trivga maritima, Chamadrius

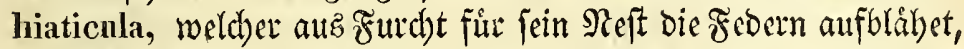
bie Flitgel und ben Sdhwanz auf ber (Erbe fobleppen läpst, als wenn er Erank ober verwundet wáre, Tringa alpina, die 2irten von Mengus uno Aras.

SBieder andere 21rten zeigen wenige Serandsung in ibrem aurereren $\mathfrak{B e r b a l t e n , ~ w e n n ~ i b r e ~} \mathfrak{B}$ rut in (Sefalyr ift. Diefe fino

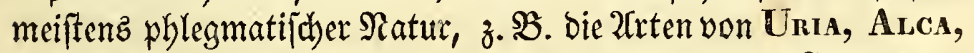
Mormon, Carbo, Puffinus, Procellaria uno Sula.

Die wenigften baben ben Muth, Denjenigen anzugreifen, ber

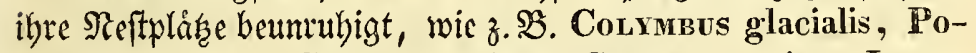
niceps arcticus, Cygnus musicus, Sterna arctica, Larus glaucus, marinus, bie Lestnis-2fiten, Vanelcus cristatus, von welchen bie brey exiten fanwimmend, und bie finn lestenten flie= gend fid) nicht fürdten, ben anzufallen uno zu ftosen, Der firth ihren Enern ober sungen nål)ert; befonderz zeigten Lestris ca-

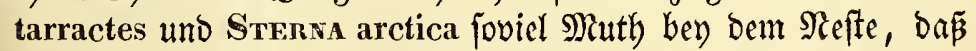
fie mich unaufbỏrlich auf ben Siopf fdulugen, und ber erftere midh Daburd) beynal) zwang, feinen Briteplace zu vertaffen. STd)

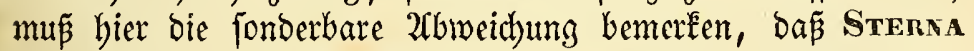
arctica auf gewiffen Bruteplågen ighe Brut bartnàdtiger vertl)ei= bigt, als an andern. 2tuf Saltholmen im Sunde griffen fie midh fo ftark an, bas fie mir ben Şut vom Ropfe fdhlugen; auf eini=

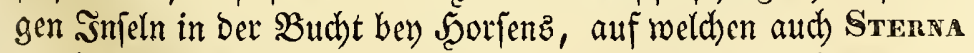
arctica uno nidft Hinunno Temm. brutet, madhten fie bagegen nur $\mathfrak{B}$ ogen gegen unz herab, obne unz nabe zu kommen. Boie

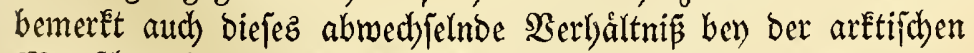

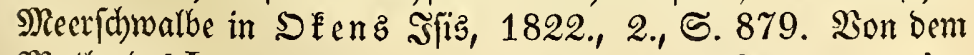
Ruthe dez LESTRis catarractes, parasitica und STERNa arctica bey Den Reftern beridten Fabriciuz in Der Fauna groenl.,

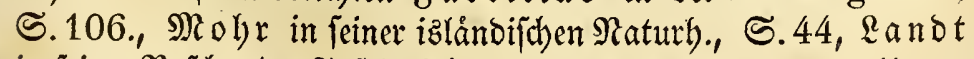

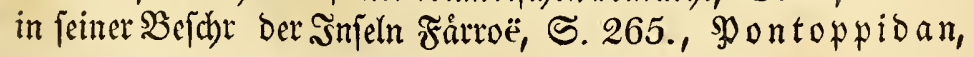


in Der Naturf. bon Norroegen, II., S. 157, (Ss unneru $z$ in ben Sdurift. D. Dronth. (Sefellfd., న్ Id) Eann bieje Betradhtungen nidht jhltepen, obne auf baz zálye Leben aufmertfam zu machen, weldbez in ber Brutperiode

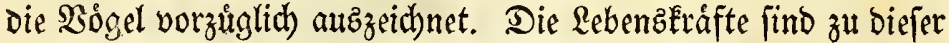
3cit bey Den brütfábigen Bügeln z̆lt einem fold)en (S)rade geftiegen, weil fie andern (S) ejobopfen ibrer eigenen 2(rt Leben unb Dajeyn ge= ben und jidern follen. (Fz ift bem saager befannt, wie fohwer ez

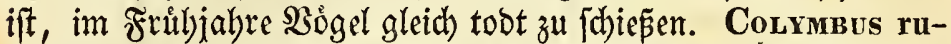
fogularis, Podiceps arcticus und mebrere (Enten find nod) ge=

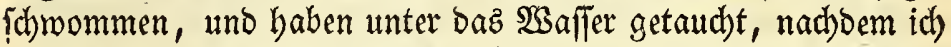
ihnen Schrot burd) ben Sopf gefhoffen batte, indem fie die (3)e= fabr von ibren Eyern ober Jungen abwenden wollten. 2Cuf (Sirim= foë $\{(d) o \tilde{\beta}$ id) eine Una alle tóbtlich an, weldbe id) bod einige Tage nadber beynab von ber $\mathfrak{S} 3$ unde abgezebrt auf ibren Eyern liegen fano.

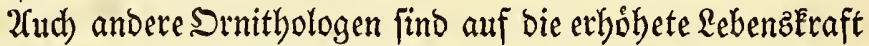
Der $\mathfrak{B}$ ogel in ibrer Britezeit aufmerkfam gewefen. (Bergl. Bo iez Reife in Normegen, S. 155., in ber 2(nmerk., aud Şorn=

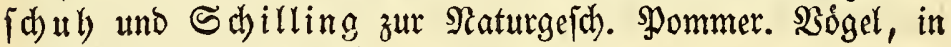

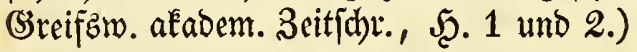




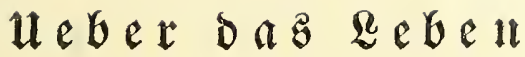

$$
\text { b } \mathfrak{c}
$$

bodf notbifden şóger.

$$
\mathfrak{n} \text { n }
$$

Friedrith Faber. 

$\mathfrak{u} \mathfrak{e b e r}$

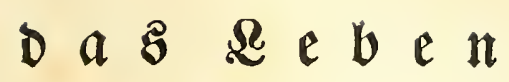

ber

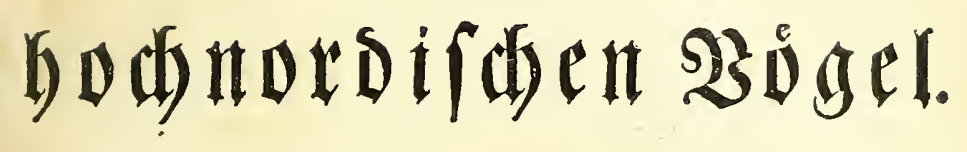

$\mathfrak{B} \quad 0 \quad \mathfrak{n}$

Fratedrith $\mathfrak{F} \mathfrak{a} \mathfrak{b} \mathfrak{e} \mathfrak{r}_{+}$

3weytez uno létez Seft.

$\mathfrak{d} \mathfrak{e} \mathfrak{i} \mathfrak{p}_{\mathfrak{j}} \mathfrak{i} \mathfrak{g}:$

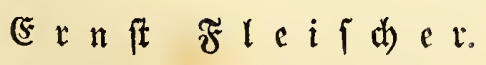

1826. 



\section{Ueber}

\section{$D \mathfrak{A} \mathfrak{Z} \mathfrak{\mathbb { E }} \mathfrak{b} \mathfrak{e} \mathfrak{n}$}

ber

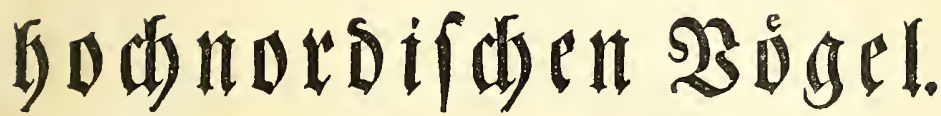

$\mathfrak{B} \quad \mathfrak{n}$

\section{$\mathfrak{F} \mathfrak{i} \mathfrak{e d} \mathfrak{i} \mathfrak{i} \mathfrak{d}$ F́a $\mathfrak{b} \mathfrak{e}$}

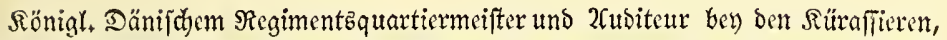

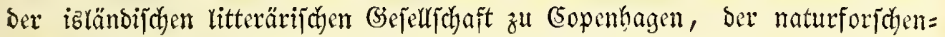

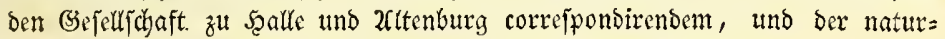

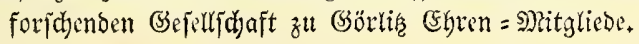

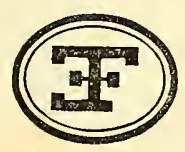

Mit vier $\mathfrak{T a b e l l e n .}$

$$
\begin{aligned}
& \text { U } \mathfrak{e} \mathfrak{i} \mathfrak{p} \mathfrak{j} \mathfrak{i} \mathfrak{g}:
\end{aligned}
$$

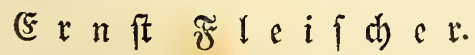

1826. 



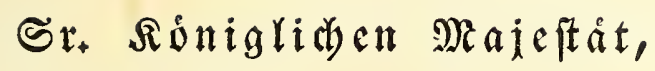

\section{F̌riedridh Dem Sechiten,}

Ánige von Dånemate, $\mathfrak{C}+\mathfrak{2} \cdot \mathfrak{x}$.

meinem allergnabigften Serra,

bem bohen Befdúf und Beforderer

ber

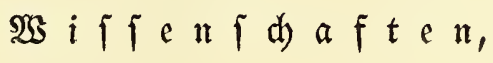




$$
\text { in }
$$

arlertiefiter untertbónigeit

getoid met

von bem Berfaffer. 


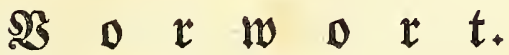

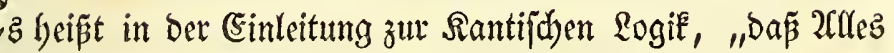

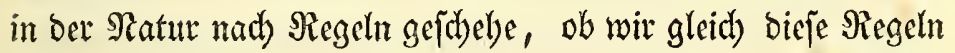
nidht Eennen. Das Warfler fâllt nad) ben (sejęen ber Sdywere, und bie Bewegung Dez (Ģangez beb Den Thieren gejchiel)t gleid)= falls nach Regeln. Der Fifd bewegt fitch im $\mathfrak{B a f f e r}$ und ber Bogel in ber $\mathbb{Q}$ fuft nad) Regeln. Die ganze Natur ift úber=

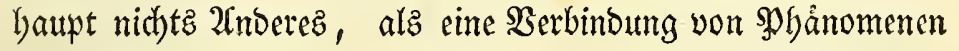

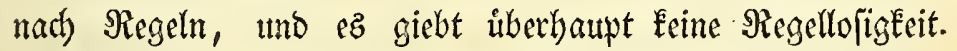
Şenn wir cime fold)e zu fimben glauben, kỏnnen wix in eimem folchen Falle nut fagen, Daß̧ uns die Regeln unbefannt fino."

Die Seit ift nid)t meldr, ba bie Raturgefdidbte mur bie Namen und bie (šefdichte einzelner Saturgegenftánbe entbielt, uno ba ibre Serebrer keinen bỏberm 3weck batten, als bie Sa= men ber meiftmóglichen Saturproducte zu kennen und aufzu= zålen. Die Naturgejhidyte behauptet jeft ibren eignen

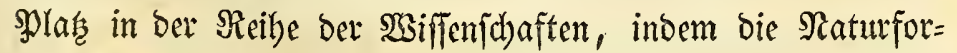


Ther volltig einfehen, ba⿱

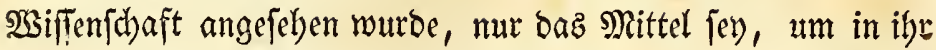

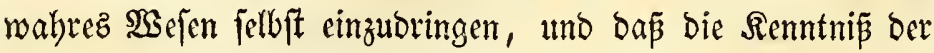

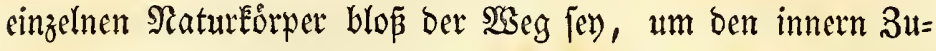
fammentyang nad) Megetn zul finben, ber nach ben $\mathfrak{B o r t e n ~ j e = ~}$ nes berůgmten \$hilofoplyen nirgends in der Satur vermiß̈t wirb.

Şaz yon Der ganzen Saturgeffhid)te im 2olfgemeinen

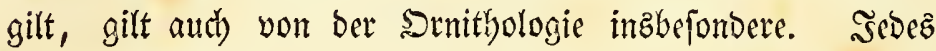

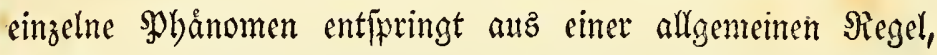

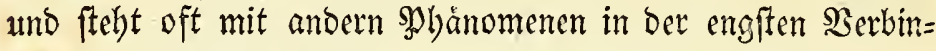
oung, weld)e fich in ber Şiftorie ber ßsỏgel ganz ijolint her=

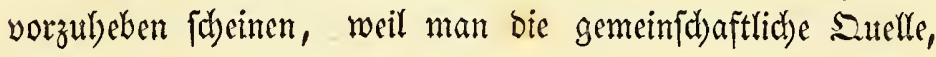
aus welcher beibe entfprungen fint, und bie Faben, weldbe fie mit einander verbinden, nod) nidjt entbect hat.

Da aber bie Srnitfologen nod) nidyt fo tief in ben (Seift

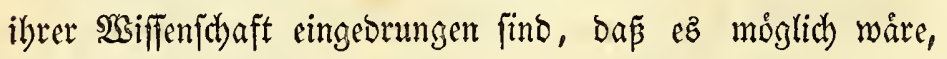

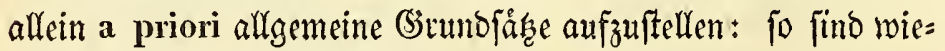
Derbolte umb genaue $\mathfrak{B e d b a c h t u n g e n ~ i n ~ b e r ~ N a t u r ~ F e l b f t ~ d a z ~}$

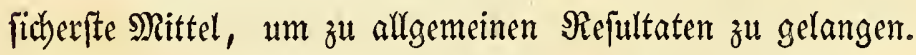

ș biejer 2(bjicht brachte ich, zum ahbel mit o̊ffentli=

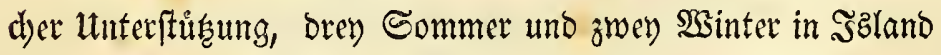
ว̆u, nåmlich bie Jabre 1819 bis 1821, um in ber wabren

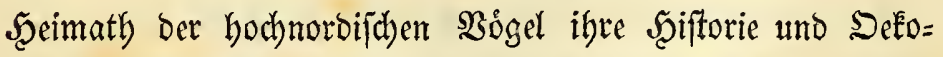
nomie zu fubiren, welche bamals mur wenig befannt waren.

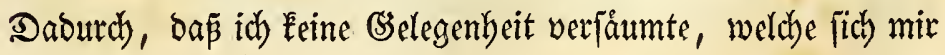




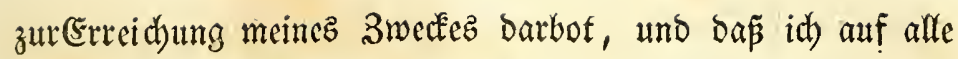

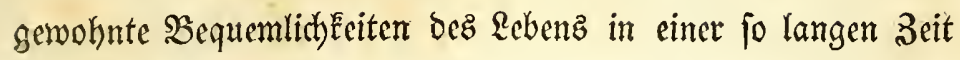
in einem Ealten und traurigen Polarlande Serzidft that, gelangte id) alz Beobachter zu febr intereffanten Mejultaten. Dod verfaumte id) aud nidbt, auf andere Saturgegenftånoe aufmerkfam zu fenn, uno babe meine Beobadtungen itber

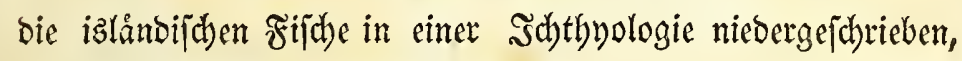
welche für ben Drud bereit liegt.

Sm Sabre 1822 ủbergab ich bem gelelyrten \$yblicum in

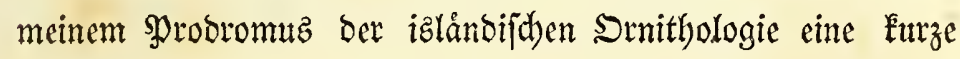

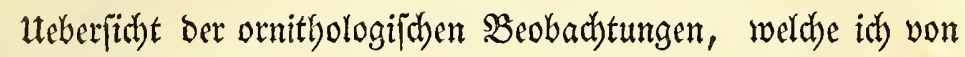
meiner $\Re$ eife in Şּland mitbrad)te, uno id babe die unverfenn= barften Bemeije erbalten, dap̃ bieje Eleine Sdyrift von ben Sr= nithologen mit allgemeinem snterelle aufgenommen worben ift. Seit meiner Burủefenft nach Dånemark fand ich in biejem,

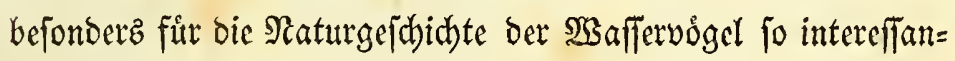
ten Ranbe oft (sielegenbeit, bie fidon in Szland gemad)ten all= gemeinen Semerkungen burd) vermebrte Erfabrung zu prüfen uno zu beftåtigen.

Reine $\mathfrak{B}$ eobachtungen úber Die hodhnordifden Boogel babe id) in ber gegenwårtigen Sdyrift in ein zu[ammenbångendes (Sanzez gebrad)t, und auf bieje W̧eife bie allgemeinen Berbålt= niffe, bie in iłrem åupern $\mathfrak{e}$ ben Statt finden, zu entwidkeln ge= futcht. Da meine 2 rbeit fid) auf eigene Beobad)tungen grün= bet, weldye in ben meiften Fällen fo fidber fino, als meine Sirafte fie nur zu machen erlaubten; fo barf id) boffen, baj fie 


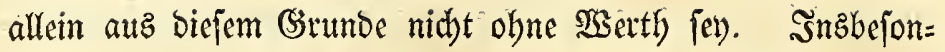
bere aber wuirbe $\dot{e} \mathfrak{s}$ midh freuen, wenn kunbige uno unpar=

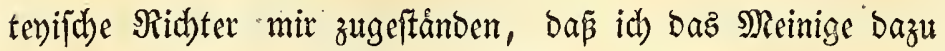
bengetragen babe, um eimen idwadhen Sdbimmer in bie Dun= Eclfeit zu bringen, welde nod immer ůber bas eigentlidye $\mathfrak{S e}=$ fen ber Srnithologie verbreitet ift.

Sorfenz, in Suttland, ben 15. November 1825.

Der Berfaffer. 


\title{
$\mathfrak{s} \mathfrak{n} \mathfrak{b} \mathfrak{a} \mathfrak{i} \mathfrak{z} \mathfrak{a} \mathfrak{n} \mathfrak{z} \mathfrak{i} \mathfrak{g} \mathfrak{e}_{+}$
}

\author{
Erftez Rapitel.
}

Non der geographifaen 2 usbreitung und óm $b a=$

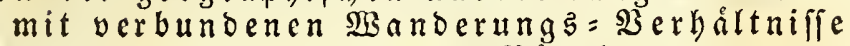
ber borealen $\mathfrak{B}$ ógel.

(. Seite

§. 1. Stanbvogel und 3ugvoigel _. . . . . 1

\$. 2. W3anderungetrieb und Sceimathtrieb . . . 5

§. 3. Die Richtung Der MBanderung . . . . 7

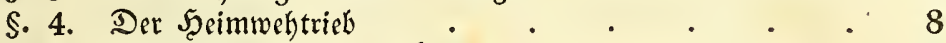

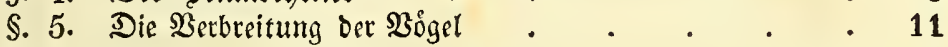

§. 6. Die Manderungzzeit $. \quad . \quad . \quad . \quad . \quad . \quad 18$

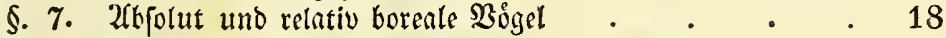

\$. 8. Die Eufttemperatur alb 2 Banderungamotio . $\quad 21$

\$. 9 u. 10. Sugreget ber Manderungen - Mengenverbi̊ltniffe ber $\mathfrak{B o g}$ gel $. \quad . \quad . \quad . \quad . \quad . \quad .2 \%$

§. 11. Wanderungszeiten ber verfchiedenen (Sefdhlechter und 2(tter 33

\$. 12. Der Dlate aufer Der $\mathfrak{B o g e l} z$ one . . . . . 34

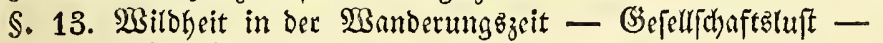

Die $23 a n d e r u n g z$ tweife . . . . . . 35

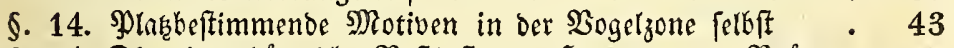

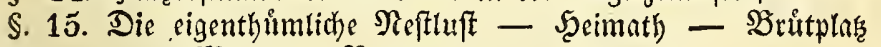
nim Meere - Bogelberg $. \quad . \quad . \quad . \quad . \quad 43$

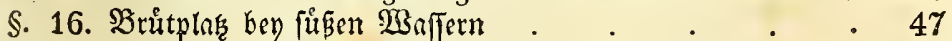

§. 17. $=$ in $\mathfrak{B}$ åumen.. .5 .50$

§. 18. = auf Den Bergen - Bergornithologie . .52

§. 19. Die sigenthümliche Ruheluft . . . . . 56

§. 20. Die Luftemperatur als plaf̧efítimmendes Motio Strichuógel and Standvógel . . . . 58

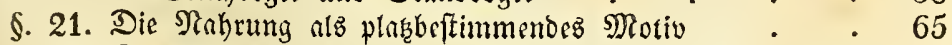

§. 22. Die Sicherheitsluft ale plabeftimmendes Motiv - In= $\mathfrak{f e l}=$ Drnithologie - Bergleichung oer plaţbefitimmen= Den Motive 


\section{3weytez Rapitel.}

Bon ben saarungsyerbåltniffen der borealen $\mathfrak{B o ́}_{\mathrm{gel}}$ fammt den daraus refultirenden ober bamit verbundenen $\mathfrak{B e r b a ̊ t n i f f e n . ~}$

Seite

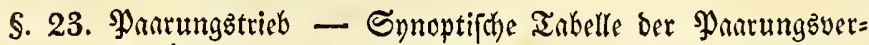
håltrilfe . . . . . . . .

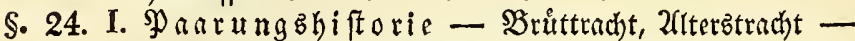
Sabrzeitztradht - Mau[ern - sinige Mghinomene bes Maruerns

§. 25. 2fuflófung Der Bogelhaufen - cinige \$Phỏnomene in ben Bogelbergen $\mathfrak{t}$. f. w.

§. 26. 2uffudben und Berbindung ber Gratten - Monogamie uno Polngamie, und ifre Eintheilungen - 2frtsbegriffe 110

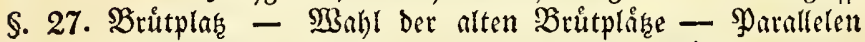
ziwifhen Der Monogamie Der Sdywimmodget und ber Natur ihrer Brütpláse

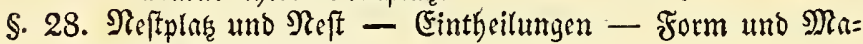
terie Dez Neftes . . . . . . . . 128

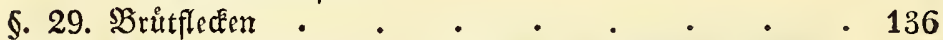

§. 30. Stimme ber Bógel - Lodéftimme - Şanrungglaut Besang . • . . . . . . 143

\$. 31. Paarung = Gebarden - 3ahmbeit - Steigen ber $\mathfrak{L}_{\mathfrak{e}}=$ benberifte . . . . . . . . 155

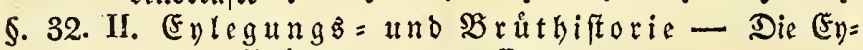
zeit - Sghånomene in ber Enjeit . . . . 161

\$. 33. Dab Ey - Feine Materie - Enerithanle - Enamabl 167

§. 34. F̧arbe bez Eyez - Ģrópe . . . . . 172

\$. 35. Seftalt beb EneB . . . . . . . . 176

§. 36. Farbe bes Enes - einige 2(brecidungen in Der Farbe . 179

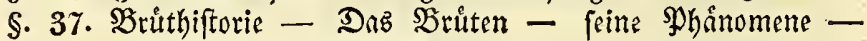
Nadétheit in Der Brittzeit

§. 38. Brützeit - bns Șunge im Ene - Sein F̧ervortreten aus dierem . . . • • • • . 195

§. 39. III. Fútterungshiftorie - Dunenperiode - Shre Dauer - andere ghanomene in ber Dunenperiode 200

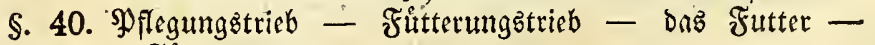

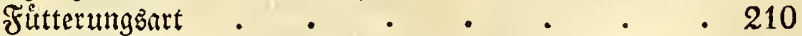

§. 41. Leitungstrieb . . . . . . . . 222

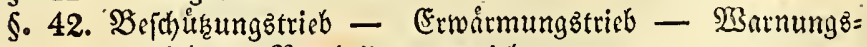
trieb - Bertheibigungstrieb

Drittes Sapitel.

Bon ben Bewegung zoerbåtniffen berbo= realen $\mathfrak{B}$ ógel. 
Ssite

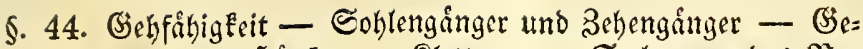
ber uno Şîpfer - Siletterer - Steliar - bas $\mathfrak{b}_{\mathfrak{r}}=$ ben - Ennoptifche Iabelle der Gebfóhigkeit . .

§. 45. Flugfáhigkeit - Flug = Momente - verticaler und ho $=$ rizontaler Flug - unwillige uno fiblechte Flieger Segler uno Siuderer - Synoptijae Iabelle ber Flug= fóhigkeit . . . . . . . .

§. 46. Schlwimmfơhigkeit - Bitbung ber Schwimmoogel Sithe unter bem Sdhnimmen - 3eit des Edtwim= menz - Sdyimmen ber Sumpfodigel . . .

§. 47. Eintheilung ber Sdhmimmfahbigkeit - einzeln und zujam= mengeję̧t - Unterichied der Sdywimmtnuchfóhigkeit uno Sto und Stoptautber - Synoptifthe Tabelle ber Sanwimm= fóbigkeit

§. 48. Seorizontales und verticales Iauchen - Springtaucher und Stechtnucher - Flügeltaucher und Fußtaudher . 262

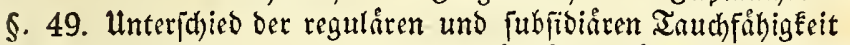

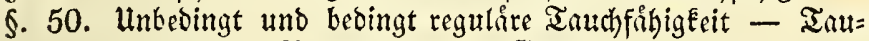
(hen nach Nabrung und in (Gefahr

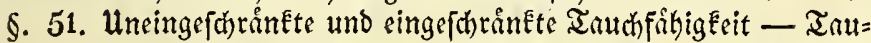
der in Den Dunen und Federn - Parallelizmuz zwi.

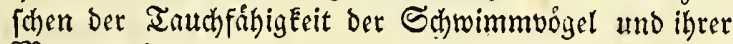
Monogamie

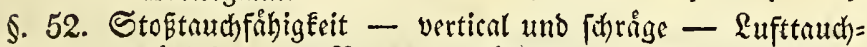
267 fäbigkeit - Bogentauchfóhigkeit - Stoptauchfónig= feit bey andern $\mathfrak{B o g e l d r o n u n g e n ~}$

277

\section{Biertez $\mathfrak{R}$ apitel.}

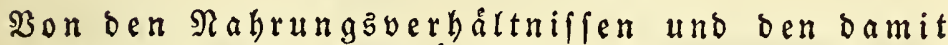
verbundenen Serbáltniffen der borealen $\mathfrak{B}$ igel.

§. 53. Fintheilung ber $\mathfrak{B o g e l}$ nach ihrer $\mathfrak{N a h r u n g}$ - Ihierfref= fende, MPlanzenfreffende, Multivoren, smmivoren -

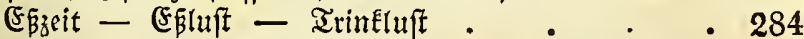

§. 54. Sanabel, 3unge uno Mragen, betradtet im Berbáltniffe zu ihrer Nahrung - Steine im Magen zum $\mathfrak{B e r}=$ bauen

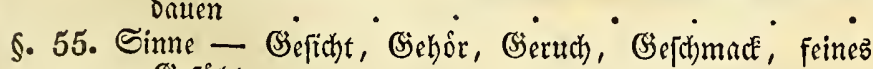
Gefůhl •. •. . • . . 298

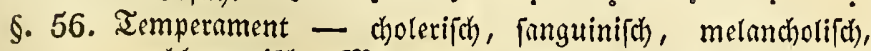
Seite

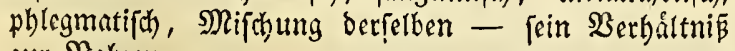
zur $\mathfrak{R a b}$ rung 


$$
\text { Funftez Siapitel. }
$$

Bon ber ébensmetamorphofe ber borea len $\mathfrak{B} \dot{\mathfrak{o g} g} \mathfrak{l}$.

57. Sugeno - 2flter - Rranlheit - Freube - 2ngft Seite Siuhe und Sdilaf - Tod... . . 306

$$
\mathfrak{A} \mathfrak{n} \mathfrak{a} \mathfrak{n} \mathfrak{I} \quad \mathbf{I} .
$$

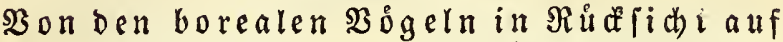

bie Dekonomie und Technologie or Bewobner bes Stordens.

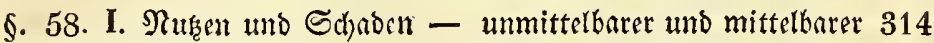

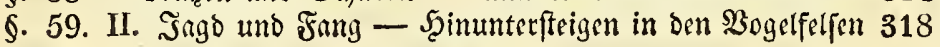

$$
\mathfrak{A} \mathfrak{n} \mathfrak{b} \mathfrak{n} \mathfrak{\text { II. }} \text {. }
$$

Bon der Romenclatur ber Bewobner des Norbens in Rúdidat ber borealen $\mathfrak{B} \mathfrak{B} \mathrm{gel}$.

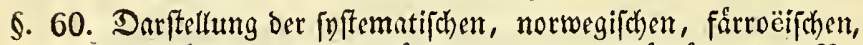

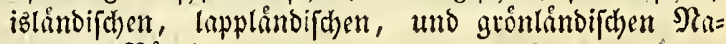
men ber $\mathfrak{B o g} g e t$ 
3weyte Deriobe.

\section{Die Ěylegungs = und Brůtbiftorie ber bo= realen $\mathfrak{B o g} g e l$.}

1.

Die Fylegungzhiftorie.

\section{§. 32.}

Die monogamen Mánndben ber nefterbauenden 2rten nebmen mit il)ren Şeibden am Sieftbaue Ilyeil, und find bey einigen Singuogeln fogar in bem 3ujammenbringen ber Materialien

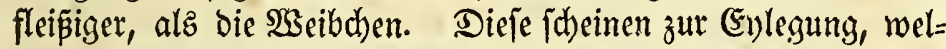

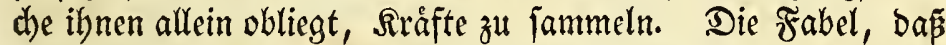

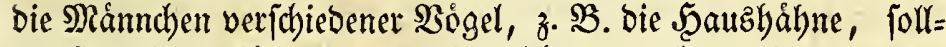
ten (Eyer legen fónneu, witb hinteicheno burd) ben innern $\mathfrak{B}$ au bez månnliden Sogelz wiberlegt. -

Sm 24. §. ift bemertet worben, da

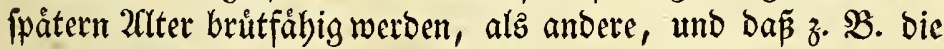
Tỏlpel, Meven, utno mebrere Enten, mebrere Sabre zubringen; ebe fie fich fortpflanzen fonnen. Die zur Fortpflanzung unfá $=$ bige Speriode ift für beide (seid)ledter ber 2Trten gleid) lang; De=

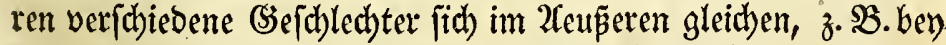
ben Meben; bagegen werden bie Manndben fpåter brütfåbig,

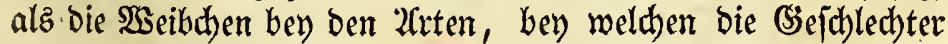
von jebr verfohiebenem 2 atujeben find, z. B. bey ben (Enten.

Das (sibervogelmånnd)en kann fid nidht fortpflanzen, biz es vier 2 sinter gelebt hat; Dagegen ift baz $\mathfrak{W}$ eibdben fdbon im oritten Sommer bruitfåbig.

Die Enlegungszeit fállt bey ben borealen $\mathfrak{B o g} g e l n$ fpåter im Sommer ein, alz bey Den 2 sigeln, fogar berjelben 2 rtt, in ben fublicbern 3onen. Der allgemeine Grumb biebon if daz fpatere Eintreten bez Sommerz in ben nórblichen \&ánbern, mo= burdb bie \&uft erft fpăter bie milbere Temperatur erbált, welde 
vereint mit ber thierijhen Särme bes brutenden Sogetz, fum 2uzbruten bcz Enez nothwendig ift. Dic Standvogel legen geroblynlich eber Ener, alz bie 3uguogel; denn theilz find jene an Srt uno Stelle, theilz find fie, wie in Den norbliden \&án=

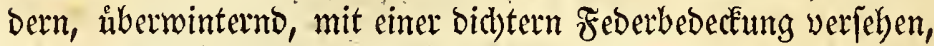
alz bic 3uguógel, uno daber mehr im Stande, bie Eyer ge=

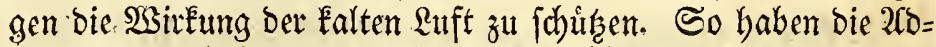

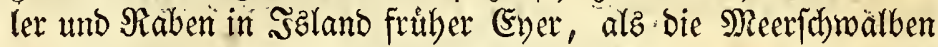

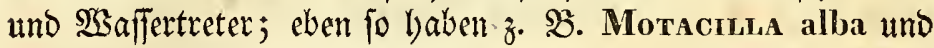

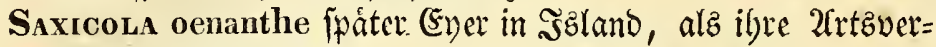
mandten in Dámemarê.

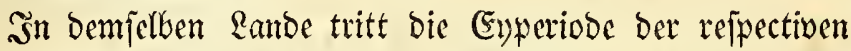
Sogelarten in verfhicdenen Sabren ungefäbr zu berfelben Beit

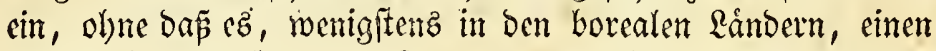
wefentlichen (sinflup barauf loat, ob das (Ener legende S̈ndivi=

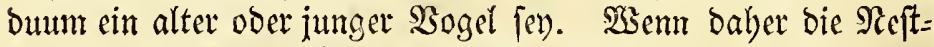
locher ber borealen Sidgel, welde in ben Feljemiten niften, we= gen ber auperorbentlicben Strenge eines einzelnen SSinterz, zut 3eit ber Enlegung von Sibnee und (siz nod) nid)t fien find, fo werden fie veripatet, uno fommen oft in grope Berlegenbeit. So legten UnIa alle im Sommer 1820, als id) mich auf

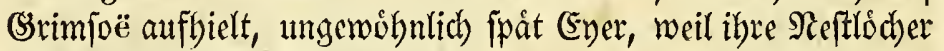
nod) mit Sdinee verftopft waren, und gleid, nachbem bicjer geidhmolzen war, fand man übcrall il)re (5yer; baber fino aud bie Salbre, in weld)en baz grónlåndijche (siz fid) an ben nơro=

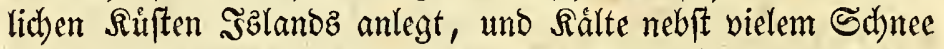
mitbringt, ben in ben Meerfeljen britenden Sögeln ungünttig, uno ibre Eylegung ift zu folchen Beiten unregelmáfig uno fpar= fam; ja man hat fogar Benfpiele, dấ Una Brünnichii und Aras mollissima ifre Eyer aufz (5iz geworfen, weil fie ihre

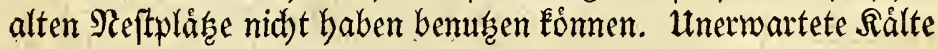

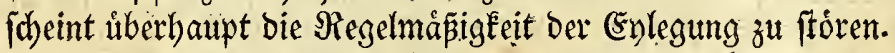

Der Suny ift in ber borealen Bone Der red)te Enmonat, und bic Ënperiode tritt aljo ungefábr einen Monat fpåter ein, als in Dánemark, wolelbit die (sylegungszeit vornebmlich im May ift. Sn Der Mitte des Sumy findet bie Eylegung ber

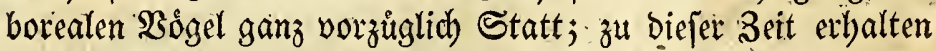

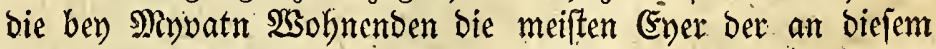
Landfee brutenden Entenarten; zu Derfelben 3eit laffen bie bey

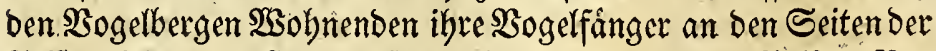
Felien nieber, um Ever zu fammeln. Saul bie 2loler, Falfen, গa 
ben uno Scharben legen (Eyer im 2(pril, und haben beynaly erwadj[ene Sunge, wenn bie librigen Bögel nod) (Eyer haben. Pfud) Haematopus ostralegus, Crgnus musicus umb bie Uften

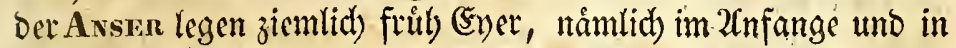
Der Mittc bez Manmonatz. Die Stoptautder legen gemeiniglid) frúler (Eyer, als bie Sctwimmtaucher, am frúbeften Procer-

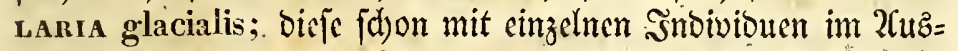
gange bez 2fpril; barnadh Lanus marinus uno glancus, weld)e im 2(nfange $\mathfrak{M a y z}$, Lestris catarractes und Suna alba, weldye in ber Mitte beffellen Monatz (Ey)e baben; am fpatteften von diefen bruiten Stensa arctica, Larus tridactylus und Lestris

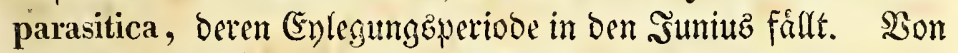
Den Rummen fangen Uns Brünnichii, troile uno grylle fidon am Ende dez Man an, (5yer żt legen, Uria alle aber

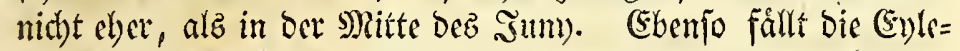
gungzzeit bez Monmon fratercula etwas fpáter cin, âlz bie der Alca torda, utno bell ben istándifden Poniceps - 2fiten etwaz fpàter, alz bev ben Couxubus-2frten. Die (Enten umo

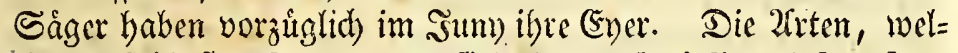
bye am frubeften (Eyer legen, fino Anas glacialis uno boschas, darauf Aras mollissima, clangula, marila, acuta uno crecca, ctwag fpåter Avas histrionica und penelope, fulef̧́t legen Aras nigra uno Mengus serrator. Die (Eyer bet Emberiza nivalis, Tunus iliacus, Motacilla alba, Sa-

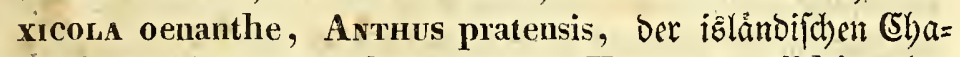
rabrien, Numenus phaeopus uno Totanus calidris, ber izlánbifáden Trengae, Scolopaces und Phalaniopi famb id in ber $\Re e$ gel im Sumy, uno felten hatte cin (Soldoregempfeifer,

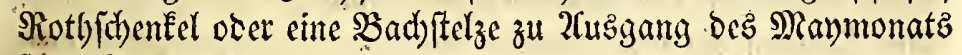
ithon Eyer.

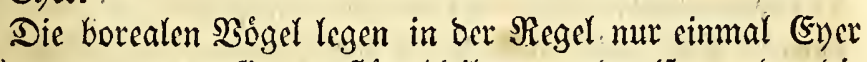
im Sommer, wenn fie ungeftórt bleiben, uno alfo werben bie (Ev)legung, - bas Brîten uno bie 2 fuffưtterung nicht wicberbolt,

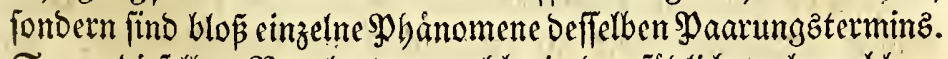
Sogar biefelben \$ogelarten, weld)e in Der füblid)ern benadbbar= ten Bone, namentlich in Dánemark, in Demielben Sommer

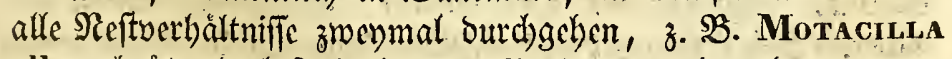
alba, britten bod) fo bod) gegen Norben nut einmal; nut vom

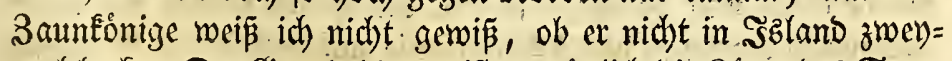

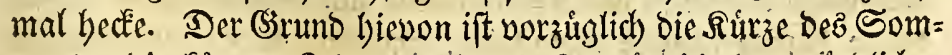
mers, bie Eurzere 3eit, weld)e bie Zugvógel in Den rörolid)en 
Ránbern zubringen, fo wic bey ben Sdhwimmboggeln zugleid) die $2 a n g j a m k e i t$, mit welcher bas (En ausgebrutet wirb uno bie sungen wad) jen, in Sereinigung mit bet jorgfâltigen spflege, meldbe die meiften norbifchen Sdymimmoigel ilben Samgen jouenfen, uno weldbe ibnen nicht erlaubt, biefe zu verlaflen, bis fie erwadhfen find. (Es ift mirklid) bemerfenswerth, Dafs bas (Ey), weld)ez man in ber Mitte Des Maymonatz im Nefte der Sula alba und der Proceluaria glacialis findet, nict $t$ eber, als in ber Nitte bez Septemberz zu feincr vollémmmen 20us=

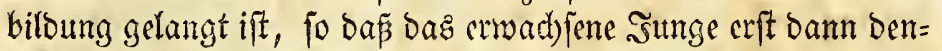
felben Syunct verlaffen fann, auf welchem cz ficton vier Monate zuvor als Sieim im (E) eingejdhloffen lag. Da ber Sisinter

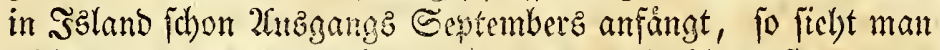

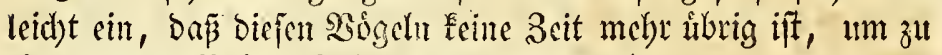
eittent netten Britten 3ubereitungen zu machen.

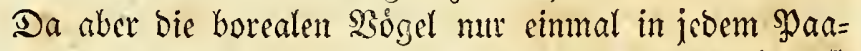

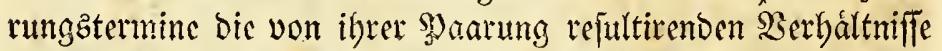
ourd)geben: wober rublt benn unter ben meiften 2irten berjelben

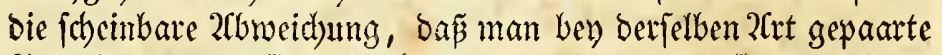
Individuen antrift, welde (Eyer baben, inderfen andere zu berfelben 3eit grop̃e Sunge, ja wohl gar fü biefen Termin bas ganze Brutwejen vollig beendigt haben? Sch habe oft biejes Phånomen fogar bey ben 2Trten angetroffen, weldhen eb ganz unmóglich war, mebr als cirmal im Sommer zut bruten, weil bie Sungen ber erften SBute nod) im 2 ugut und September im Refte liegen.

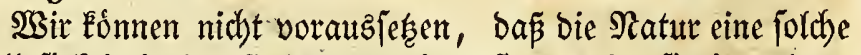
Regellofigkeit in ber Eylegungszeit geftatte, ba fie in andern Berbalttniflen bie beftimmteften Regeln befolgt; auch Eonnen

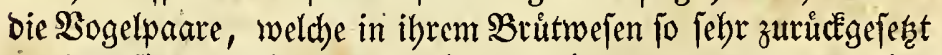
worben fino, nicht alle butrdh bie größere ober geringere (ses: fdymindigfeit verfpatet worben fern, mit weldher ibre alten Neftplåże zur 2Cufnabme der (5yer bequem find; Denn an bem=

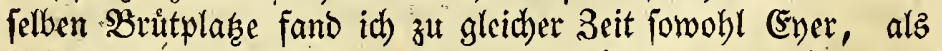

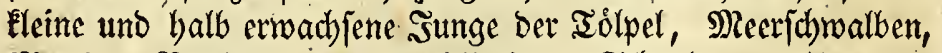
Reven, Raubmeben, Sprocellarien, Scharben, Utien uno 2coler: Sab befam oft an bemielben Iage von ber Unia troile friface (Ener und Sunge, welche die Felfen verlaffen batten; gleid) falls waten in Der Iollpeleolonie auf Dem Felfen Brandten einige Sunge beynab erwadjfen, inbelfen andere neulid aut ben Eyern gekrod)en waren. Dieje Regellofigkeit Fommt nidbt 


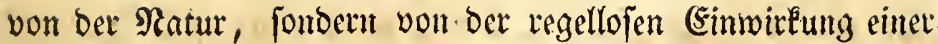
aupern Mad)t, und einem bamit in Berbinoung ftebenden. Be= freben ber borealen Bogel, die Beftimmung ibrer Evlegung u. f. w. zu erteichen, wenn fie aud) gleich ilyren paarungz =

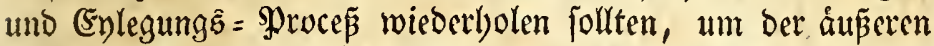
(Serwalt, weldhe ihrer 2(rt mit Beruid)tung brobt, entgegen zu arbeiten. Diefe Gerwalt wird ben. Enern ber borealen $\mathfrak{B} \mathfrak{d}=$ gel von ihnen nadfitellenden Feinden angetban. Der Rabe be= fucht oft bie Nefter Der Sumpf = uns Sdhwimmbogel, uno

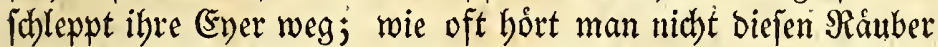
raubgierig im Nefte ber brevjál)rigen Meve fdreven, inbeffen Die um ibre (Ever bejorgten 2alten jammerno umb গeft herum= fliegen! Gogar Lanus marinus uno glaucus ergreifen bie

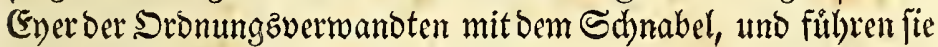
meg. Die Raubmeven faufen mandhes (Ey ber artifichen Meer=

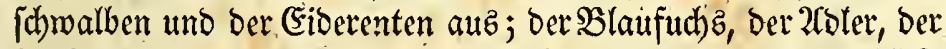
Falke und die grope Raubmeve vernid)ten oft in einem 2 tugenblicke eine ganze Brut von Sungen; insbefondere aber fitellen bie Men=

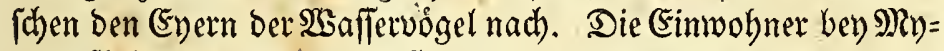
vatn füllen Tonnen und Siften mit Den Enern ibrer Entenarten, unb ein geubter Bogelfänger, ber in bie 230 gelfelien binuntergelaf=, fen wiro, verfeblt felten ein Ev, beffen er anjidtig wirb. Utm nut

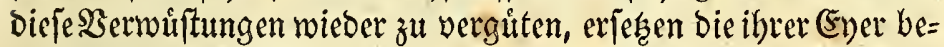

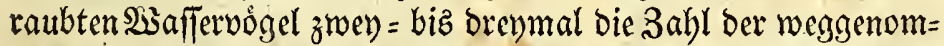
menen. Dieje Eigenjdyaft ift auth Den Einwoljnern befannt, meswegen fie zweymal ifre Eyer wegnebmen, ibnen aber bie baz brittemal grlegten (Fyer zum 2utburtten laffen. Da Die=

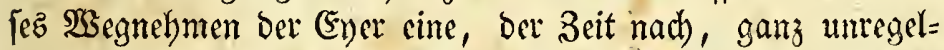

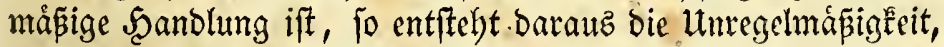

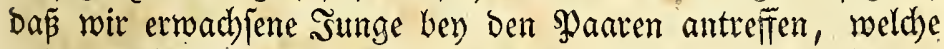
allen Nadhftellungen entgangen find, inbem bie andern 2 rutb: verwandten, weldbe weniger glicklich waren, uno jwey bis brev= mal Saäang, Evlegen und fo weitex baben mieberbolen múf= fen, noch briten. - SBey Den Bogelarten, welche mel)rere (Eyer legen, låpt man gewoilynlid) ein (5y im Nefte liegen, ba=

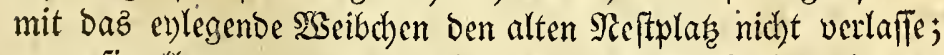
menn fie alle weggenommen werden, malen bie Enjammler zu= meilen cin Stưck Sireibe u. f. w., und lafjen es im গiefte lie=

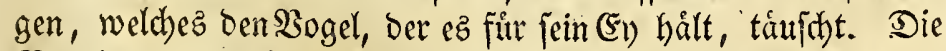
Bogelarten, welde uur cin (Ev) baben, verlaffen ood oft $b a z$ vo= rige Ieft nicht, wenngleid) ifre Eyer weggenommen werben, fon= 


\section{6}

Dern legen wieberum an bemjelben Srte. WBerben fie ibrer (5yer beraubt, ebe fie anfangen zu bruten, jo eilen fie, bie weggenommenen zu erjesen; werben fie ibnen aber geraubt, wenn jie fdon lange gebrutet baben, fo legen fie langlamer von Neutem, und bieje Nerzogerung nimmt zu, je nad)bem bie wegge= nommene Brut zu gróferer Bollemmenbeit war gebradt

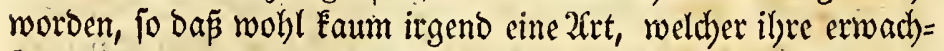
jenen Sungen geraubt werben, bep̧wegen eine neue Eylegung anfangen pollte. Seine Sdbimmoógel werben von ben Ein= robnern in $\mathfrak{A n f e b}$ ung ber $\mathfrak{W}$ egnebmung ifrer (Ever mit mel)r Shonung behandelt, als dic Sharben, der Tolpel und ber Fulmar, weil bie Eyer ber beiben erften flein find, fie alle aber

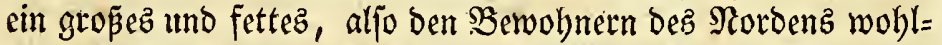
idmeckendes Sunge verfpred)en; dagegen wird ben (Enern ber Enten, Såger, Meven, Meerichwalben, trien uno 2lken (el)r nad)geftellt, uno cin geúbter $\mathfrak{B}$ ogelfänger kann an einem Tage viele Şunderte von ben Seiten ber Felien heraufbolen.

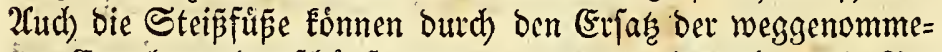
nen (Eyer bennal erfdopft werben; dagegen betrachten bie Şక=

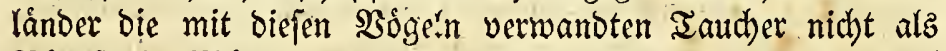
Bårpfugle (ogel, beren (Eycr in il)ter Sefonomic angeroandt werben), und wenn fie bas SReft ber Taudjer finden, lafien fie entweber die Eyer liegen, ober zerichlagen fie, um bie Berwí= ftung zu rảdben, weldbe fie unter ibren Forellen amrichten. Bey ben Sdnnebúbnern uno den iElándifhen Singuógeln, weldbe

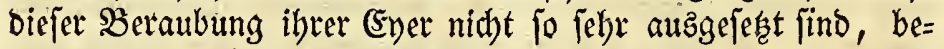

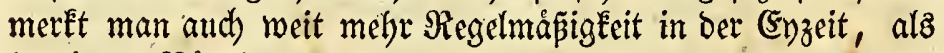
bey jenen $\mathfrak{B}$ ógeln.

Das Weibchen legt fein (5y) am liebiften frith Morgens,

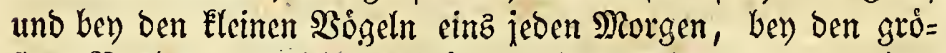
हern $\Re a u b=$ und Sabwimmvógeln oft eins jeben andern Iag, fo baßj jie an einem זage ruben, und am andern legen. Erit bann, wenn bie beftimmte 3abl gelegt ift, fängt bas Sruten an, theilz weil baz $\mathfrak{S e i b c h e n , ~ f o ~ l a n g e ~ e s ~ m i t ~ b e m ~ ( 5 y l e g e n ~}$

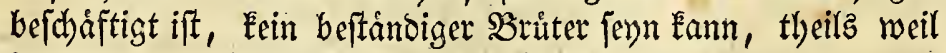
im entgegengeferten Falle bas erfte (5y) bey den mit vielen (Evern verjebenen 2rten beynah zu berjelben Seit würbe auts= gebritet fenn, wenn bas lefte gelegt wirrde. Seft aber frie= d)en bie Jungen ungefâlyr zu berfelben 3eit auz ben (Eyern, und bie Mitter braud)t baher nidbe ibre Sorge unter (Eyer uno Šunge zut theilen. 


\section{8}

\section{§. : $\mathbf{3 3}$.}

Das (5y. legen die Şeibchen in Dem fertigen Nefte. Die Reinung ber åltern Srnitbologen, daß̄ Alch torda uno mebrere bas (Ey) mit einer flebrigen Jaterie an ben Feljen befefti=

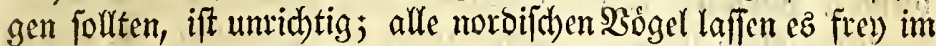
Nefte liegen. Das (E) Eann in Ruckficht ber Materie uno Der form betradtet werden.

1. Daz (5y in $\mathfrak{2}$ fedung ber Ma ter i e. Die falfartige Materie, welde bas (Ev umgiebt, wirb die Sd) a ale genannt. Sie ift beftimmt, bie weidhern Ibeile, welde ben Reim bes wel:

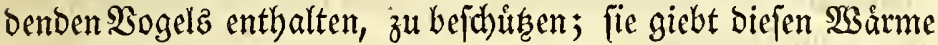

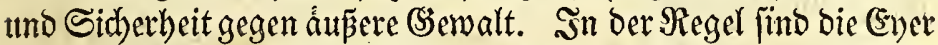
aller Sogel mit einer Schaale umgeben. SSindener,*) ober folde, weldhe obne Schaale gelegt werben, unb boppelfdaalige fino 2(bweidungen bey den gezál)mten Bógeln; id) wenigftens babe fie unter vielen taujend (Eyern ber notbijden Sdummbo:= gel, weldye ich gejeben, nidht gefunden. Dagegen ift die bedectende Sd)aale bider ober bumner, nad) ben veridhiebenen Sogelai= ten, fogar-an Eyern von gleidber (s)rópe. Die Ener ber Sing= vogel find zerbred)licher, alz bie ber Raub = uno Sa aldoógel; uno bie ber bưbnerartigen und Sumpfoogel im 2lílgemeinen binnfdaaliger, alz die ber Sdmimmwógel. Da bie Ever

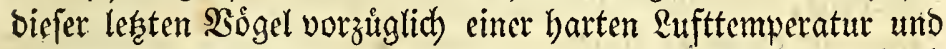

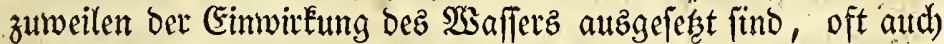
in Eeinem gebauten Nefte liegen: fo ift ibre bickere Sdaale zweckmápig. Dod) bat biefe bey ben verjobicdenen 2rten

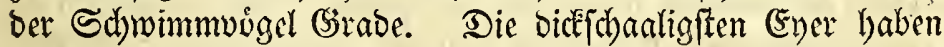
Die 2rten, weld)e unbebingt in ben Felien am Nicre bruten, die urien, 2uken, spapagantaucher, \$uffinen, Tolpel uno Srocellarien. Die meiften diejer 2riten bauten aud kein Sieft. Die Eyer der Un a Brünnichii uno troile fónnen zubeilen aus ben Şånden auf bie (Evbe fallen, ofne zu zerbred)en. Minber lyart= ichaalig find dic (Eycr ber Sdhwane, Ģånfe, Enten, und Sá=

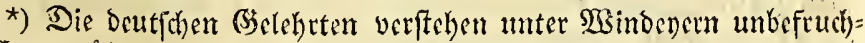
tete Eyer, librigens mit ber gewo̊knlichen Bebeckung. 2(uch sie noroi= fhen wilden $\mathfrak{B}$ ogel legen juweilen unkefruthtete (5yer, uns geben einen

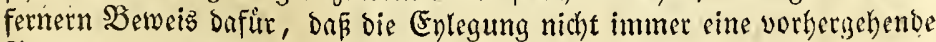
Pancung vormisegt, Der gefangene FAcco albicilla legt zuveilen Eyer in bev Gefangenjehnft, obne fid) gepant zu baben. Die unbe=

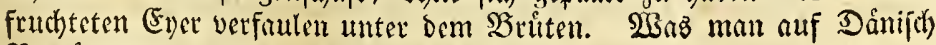

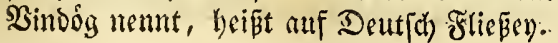




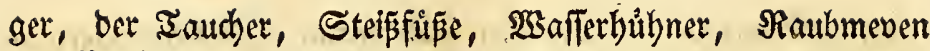

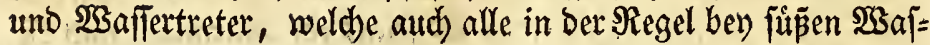
fern brúten, uno zugleid), mebr ober minber Sorge für cin

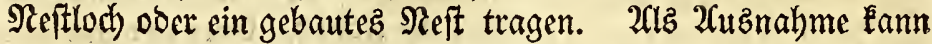
bemerkt werben, Das bie Meewen und Meeridnwalben binn= idaalige (5yer baben, ob fie gleid) in oer Regel am Meere britten. 2rber bie 20rten ber eriten (Sattung bauen aud) Ne(ter, uno fommen burch ben Bau bez Neftez der geringeren $\mathfrak{B} e=$

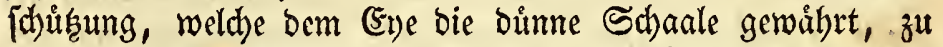
Şülfe; Dagegen legen bie lef̧ten ihre bưnmidaaligen (Eyer auf

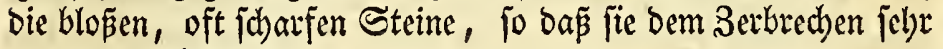
ausgefeft jocinen.

Bon ben in ben Stranbfelfen niftenden baben bie Eyer ber Unia troile bie dickfte, und bie bez Larus tridactylus bie Dunnfte Sd)aale. Die (Eyer ciniger SBogel baben nod) eine Srufte, weld)e bie mirflidse Schaale, bie von einer andern Faube, alz biefe ifit, umgiebt und leidst abgeichålt werben fann, z. B. bey ben Sdarben und Iollpeln; die (Eyer anderer crbal= ten eine foldhe, wenn fie gebritet werben, z. $\mathfrak{B}$. Die ber Steip̃uipe.

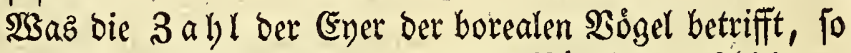
ift es eine allgemeine Erfabrung, Dap die Bógel in berichiebener Inzahl Ener legen. Dod finbet bieje $\mathfrak{B e r j a b i e b e n b e i t ~ v o r z u g l i c h ~}$

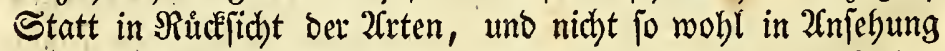
ber Snoiviouen berfelben 2art. Die Srnitlologen find oft ber

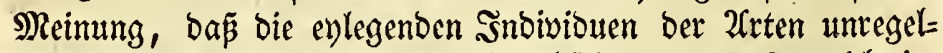

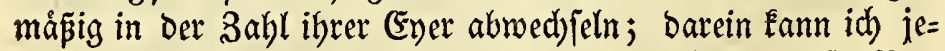
ood) im 2eflgemeinen nicht einftimmen. Der (Sitund biejer $\mathfrak{B e r}=$ fahiedenbeit in ber angabe ber 3abl ber (Eyer liegt oft barin,

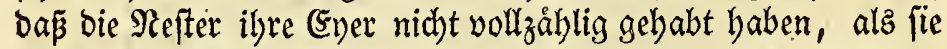
gefunden wurben; die gefundene 3ahl wirb als bas Maximum

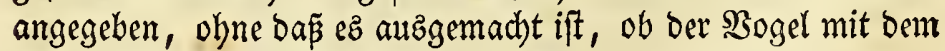

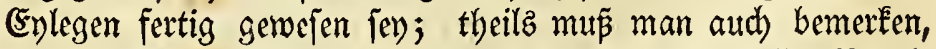

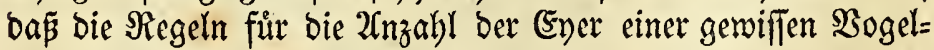
art nicht immer ein abjolutes, fondern zumeilen aud ein $a b=$ wed) felnbez Berbåltniß begrưnden.

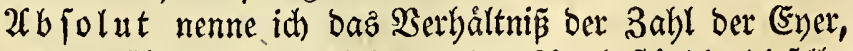

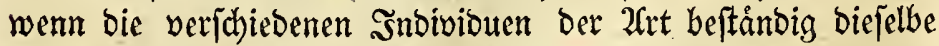
Renge (Eyer baben, wo aljo bas Maximum und Minimum zu= fammenfallen. Lestris parasitica bat nie mefre ober weni= ger, als brev Eyer, und Scolopax gallinago nie mebr ober we= 


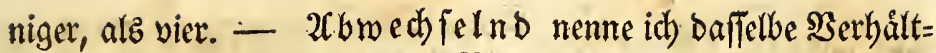
níz, wenn bev) ber refpectiven Bogelart ein $\mathfrak{R a x i m u m}$ und $\mathfrak{R i}=$ nimum ber 3abl ber Eyer gefunden wirb, und alsbann be= ftimmt abwedh felnd, roenn bie Babl ber Eyer nur mit bem Maxinum uno Minimum abwectjellt, und nidst mit ben $b a=$ zwifchen befindlichen (Sirópen, z. $\mathfrak{B}$. Cygnus musicus, mel= d)er mit 5 und 7, aber nie mit 6 (Evern abwedhfelt; unb $u n=$

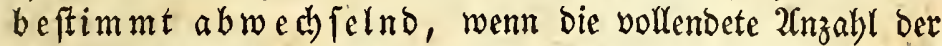
(Ener forwobl mit bem Maximum und Minimum, als mit ben mittlern Grópéen abwechjelt, z. B. 'Tетrao Islandorum, wel= de von 9 bis 14 Eyer legt, alfo nicht inmer bey bem 9 ten Eye aufhoirt, fonbern zumeilen 10, 11, 12 biz 14 alz bie vollen= Dete $2 \mathfrak{n}_{\mathfrak{n}}$ abl hat. Bead)tet man biejen (Erfahrungsjas, jo

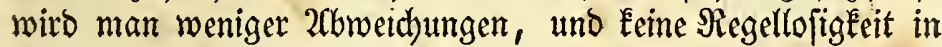
den Mengeverthăltuiffen ber Evyer finden.

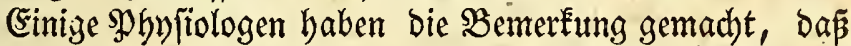
die Bogelarten, weldhe fid) von animalifthen Subjtanzen, be-

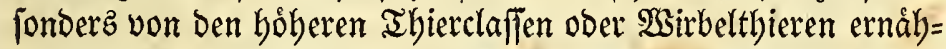
ren, minber frudthar feryen, alz bie, weldye von ben wirbello=

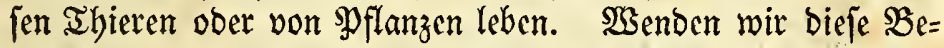
merkung auf bie boreale Sogelzone an, to gilt fie aud ba.

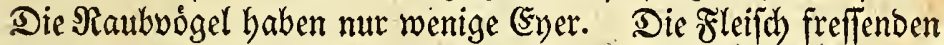
2irten von Uria, Alca, Mormon, Sula, Proceluaria uno Puffinus baben beynah nie mebr, als ein (Ey; bie riijdje

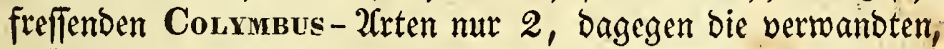
Moflanzen freffenden.Podiceps - 2irten johon biz 6, die Cario und Lestris - 2arten baben audy wenige (Eyer, fo mie bie La-

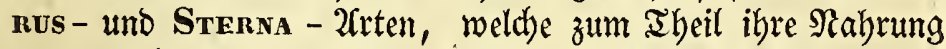
von ber hóbern Thierclaffe erbalten. Die Sumpfwogel, weldhe

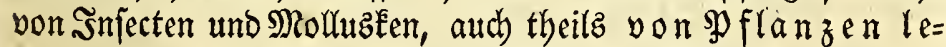
ben, baben ủberbaupt fchon 4 (Eyer alz Minimum, unb bie

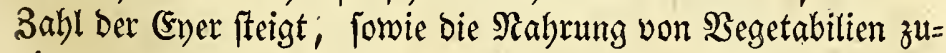
nimmt, z. B. bey Fulica und Galdinula, welche (Sattum=

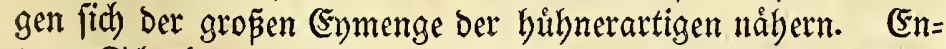

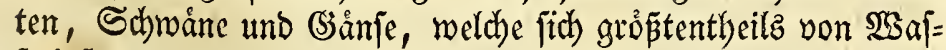

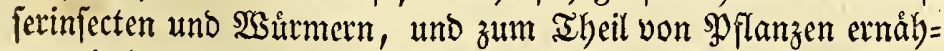
ren, baben bie 3ahl 5 alz Minimum fîn ilyre (Ever; bieje fteigt

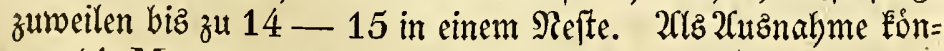
nen bie Mergus - 20rten angefúbrt werben, weldhe allein von Fiijhen leben, und Dod) in ber Zabl ber (Eyer mit ben frud)t= barften Entenarten wetteifern. Die Sd)neebirlyner, uno ůber= 
haupt bie ber Şuifnerarten, welthe ifre vorzúglidje গabrung

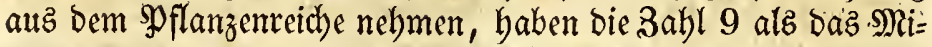
nimum ihrer Ener. - Dap biefe beiden \$Serbåltnifipe alfo in

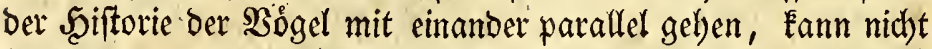
bezmeifelt werben; 'bä fie auz cinander entipringen, bezweifle id) zum Iheil. Einige Srnithologen námlid nebmen an, Da a bie von 2 sirbelthieren lebenden $\mathfrak{B o g} g e l$ fo wenige Ever haben, weil ihnen bie (Ernábrumg vieler sungen bejedwerlider fallen

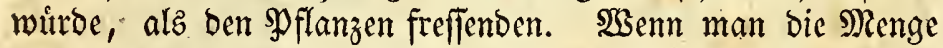
Fifthe in ben Meeren ber borealen Bone bemerkt, und wie aut= perorbentlid fett die sungen der Uria, Proceluaria umb mebrerer von ben hobheren ILbierclaffen lebender Bógel im Refte

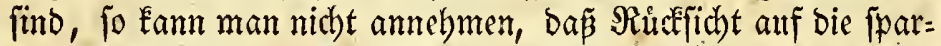

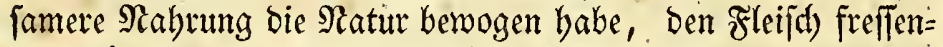
Den $\mathfrak{B o g} g e l n$ eine geringere Frutd)tbarkeit zu ertheilen, vorneljm=

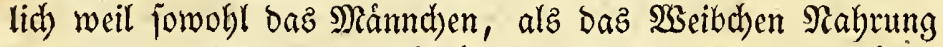
zutragen, und zwar fo reidblich, bas melyrere als bie gewólinn= lichen Jungen gut bavon aufgefiuttert werben kónnten. Dage=

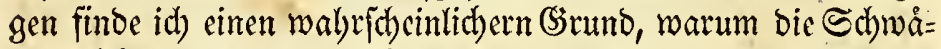
ne, Ģånfe, Enten, Sảger Frutbtbarer fino, als bie thien,

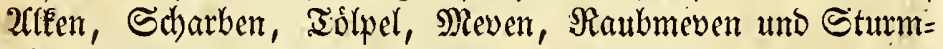
vơgel, Darin, bä jene gar nidbt, bieje aber in hohem (Grade

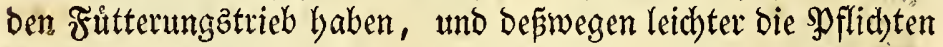
gegen eine zablreidye Brut erfüllten foinmen, weldhe felbft Siab)=

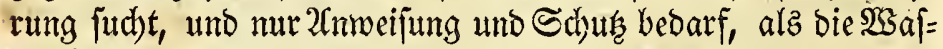
fervógel ber zujammengefesten Monogamie, weldhe auper ber

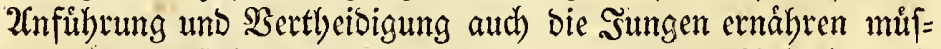

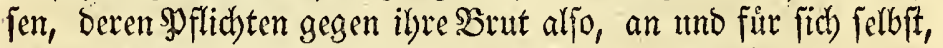

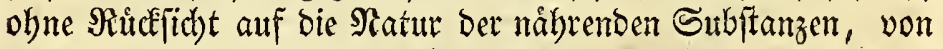
viel weiterem und bejejherlicherem ûmfange find. Man Eann

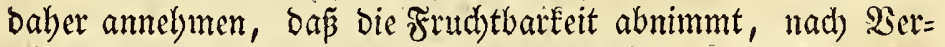

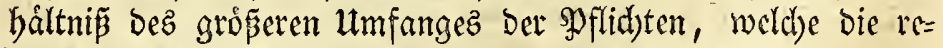

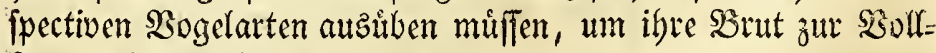
fommenbeit zu bringen.

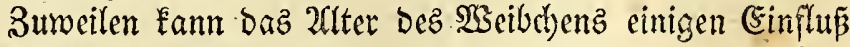
auf bie 3abl ber (Ener lyaben, ba junge ober febr alte Sóget weniger (Eyer, als bie anderm, legen; gleid)fallz lesen bie Seibchen, wenn fie mehrmals ihrer Ener beraubt werden, me=

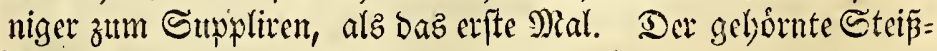

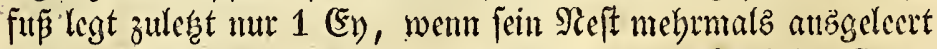
wird; Larus argentatus und canus baben gewobhnlid) 3 (E)er; 
wenn aber bas Seft einmal beraubt wiro, legen fie zum zmen= ten Mal nur zwey.

Benfipiele ber borealen Bo̊gel, ben weldten baś Berbålt=

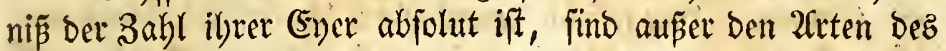
Charadrius audb) die 2irten Numenius, Totanus, Vanelunte Limosa, 'Tringa, Scolopax, Strepsilas imd Pha-

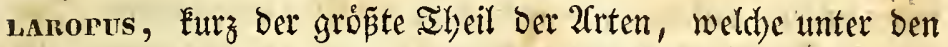

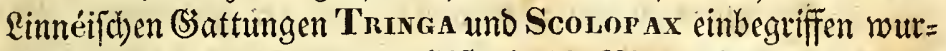
ben, in beren Enlegungs = Şiftorie bie Sierzabl, fo zu fagen, sine beilige Bablift, ba fie nie mebr ober meniger, als 4 (Eyer baben. Die 2irten yon Colymbus uno Lestris baben ftetz 2 Eyer. Die 2(rten Uria, mit 2fusnabme ber grylle, Alca, Mormon, Sula, Procentaria und Puffinus nie melyr, als 1 (Ey. - Beftimmt abmechjêlno in ber Babl ber Ener find Haematopus ostralegus und die Carbo-2idtem, meldhe mit 3 und 4 Eyern, Unia grylle, welde mit 2 und 1, Avas mollissima und Crgnus musicus mit 5 und 7 abwed feln.

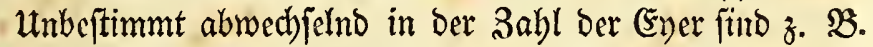
Tetrao Islandorum und RaLLus aquaticus, welde abwed)= feln von 9 biz 14, die Ponrceps-2itten von 4 biz. 6 , bie Sterna-2Crten yon 1 bis 3, bie Larus-2irten von 2 biz 4 , und melyere (Enten, als Anas nigra, von 8 biz 10, Aras clangula von 12 biz 14, Avas glacialis uno histrionica yon 5 bis 7. Sn Den rejpectiven Seftern biejer $\mathfrak{B o g}$ gel werben aljo audd) zumeilen bie Mittelzablen ber bier als bie vollendete $2 \mathfrak{f n}=$ zabl ber Ener angegebenen Extreme gefunden.

Die Bogelarten, welche unbeftimmt mit mehreren (Stro:=

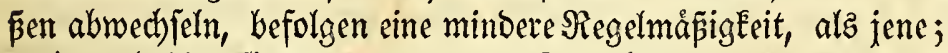
ood) aud hier finbet man bie eine 3ahl sfter, als bie andere. Die Meven baben ỏfter 3 Ever, als 2, uno am feltenften 4; Sterna arctica offter 2 Eñer, alz 1, und am feltenften 3; die Podiceps - 2frten offter 6 , als 5 und 4 ; bafferbe findet auch Statt, menn bie Eyer beftimmt mit 2 (šrósen abmed jelln; io legt Uria grylle offter 2, als 1 ; Нaematopus ostralegus off= ter 4, als 3, uno Avas mollissima offter 5, alz 7 .

$2 \mathfrak{s e n n}$ man kurrz auzbrilden will, bá eine Bogelart ein

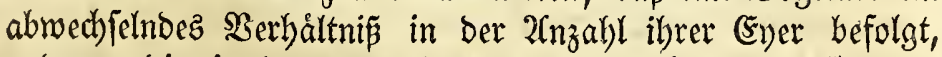

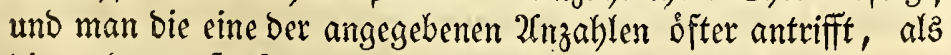
bie andere: fo kann man bie verffhiedene 2 (nzabl Der (Eyer,

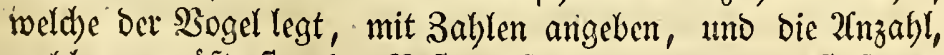
weldbe am ofteriten im Nefte gefunden wird, zuerit feçen. 
3. B. Lanus marinus legt am dfterften 3, feltner 2, unb am feltenften 4 Ener; aljo legt er 3, 2, 4 (Eyer.

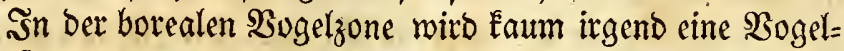
art gefunden, Deren $\left(E_{y}\right)=2 \mathfrak{n} \mathfrak{z}$ abl liber 15 fteigt, auzgenom= men baz $\Re$ ebhuthn; viele aber bringen fie nidbt hơber, als auf 1 .

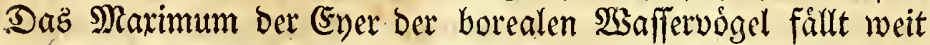

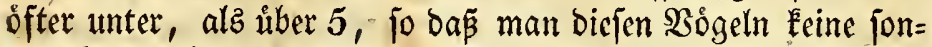

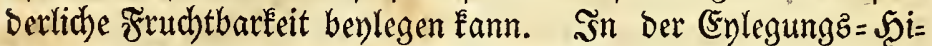

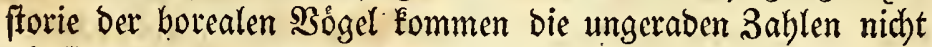
båufiger vor, als bie geraben; unter ben 20 gelarten ber abjoluten (Eyeranzahl haben z. B. Die Rinnéifhen 2rten von Scolopax umo Trunga eine gleidbe, die Utrien, 2alken, Mor-

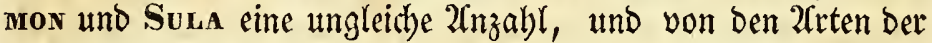
abwechjelnden (Eyeranzabl wechjeln einige beftinmt mit ber ungeraben $3 a \mathfrak{l} l \mathfrak{l} a b$, z. B. Der (Eiberwogel tmo ber Sd)wan, an= Dere unbeftimmt mit ber geraben utmo ungeraden, z. B. Das.

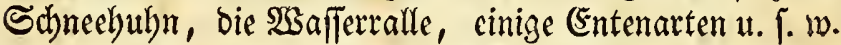

\section{§. 34.}

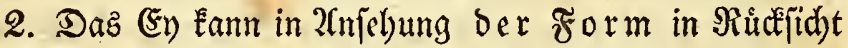
feiner (3irópe, (3eftalt und Farbe betrachtet werben.

a. Die (5) róbe Dez Eyez fann abjolut genannt

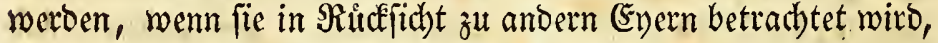
relativ, menn man fie mit ber (joiópe des eylegenden Sndi= vibuums vergleidt. In ber borealen 20 ogelzone hat Cranus musicus daz abjolut grópte, Uria troile uno Procellaria glacialis baz relativ gróste (Ev). Unia troile ift nur $17-18$ Boll in ber Rånge, und ihr (Ey nåhert fich in ber (Sirópe bem ber Iruthenne; Proceluaria glacialis baált nut 19 3oll in ber

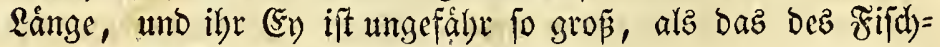
ablers. Das abjolut Eleinite (Ey) im Rorben hat Der 3aun= kónig, uno bas relatio fleinfte bic Sdarben uno Ioflpel; $0 b=$

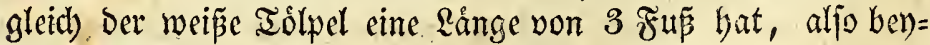
nal) boppelt fo lang ift, als ber Sturmuogel, io ift fein (Ey boch faum fo groṕ, alz Das Des lecteren. - Das (Ey) ftelht

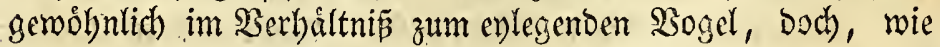
fid)on erwåhnt murbe, nicht immer; warre ez fitetz ber Falk, fo wûrbe bie abjolute uno relatioe (Srrópe Der refpectiven Eyyer in

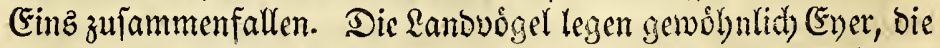

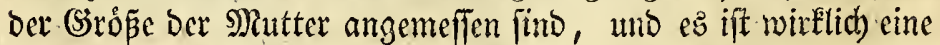

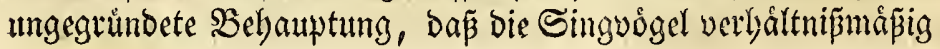




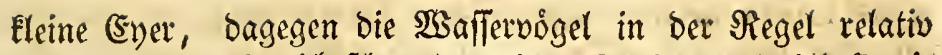
grope legen. Da idj) faton in meinem \$robrom. D. ist. Srni= tyol. bie \&ånge ber (Eyer Der meiften borealen Bógel angegeben habe, fo werbe idh bier bie fpeciellen 2lutsmefintugen nicht wieber= holen. Itnter den Sumpfuogetn haben die 2frten von Haematopus, Charadrues, Numenius, Vanelhus, Tringa,

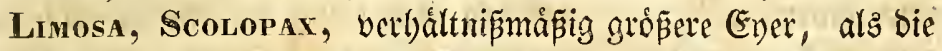

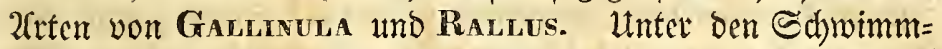

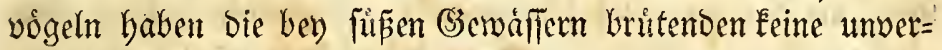

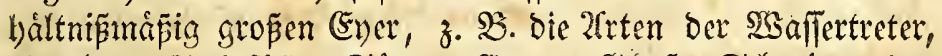

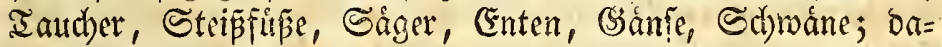

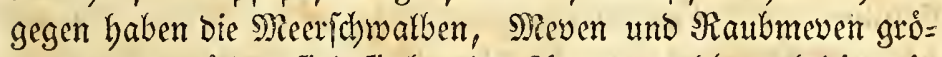
Bele; am grossten find fie beus ben 2frten, weld)e unbedingt in Den Freljenfeiten am Meere bruten, z. B. bey Urra alca,

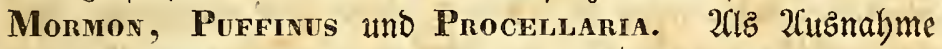

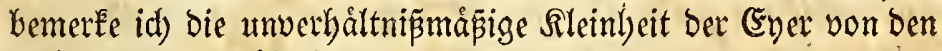
Scharben und $\mathfrak{x}$ ilpeln.

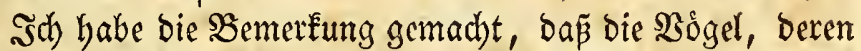

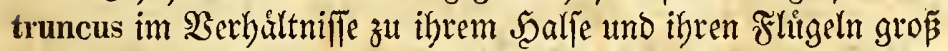

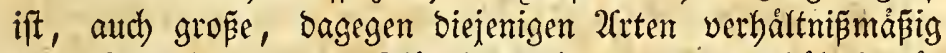

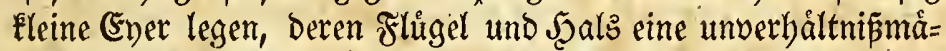

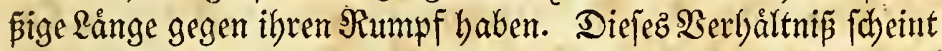
auch in ber Ratur ber Sadbe gegrưndet zu feyn; Demn bie Bauchbóble ift der Sort, wo bas Én feine Billoung erbált, und

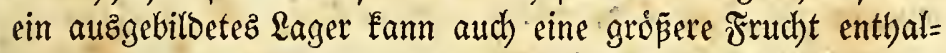
ten. Der mit langen Flügeln uno einem langen Scalje, aber

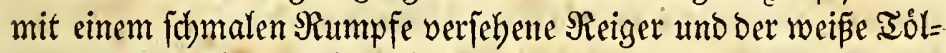

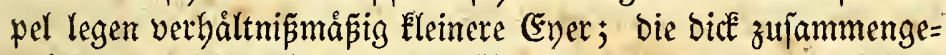

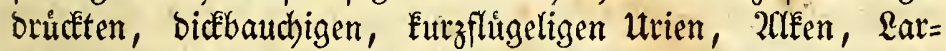
ventautcher baben bie relatio grósten Eyer. Der Sturmwogel; weldjer ein gropese (En legt, bat zmar lange Flitigel, aber auth einen biffen Rostper.

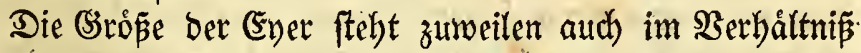

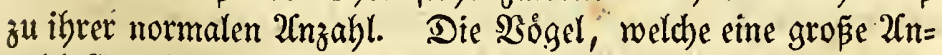
zahl Eyer legen, haben bieje mefre proportionirt mit der (3ro̊je

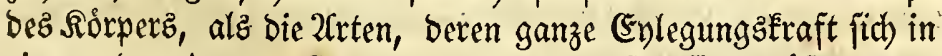
cinem oder ein paar Enern concentrirt. SBir finden ófter; bap

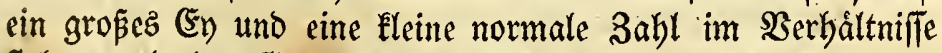

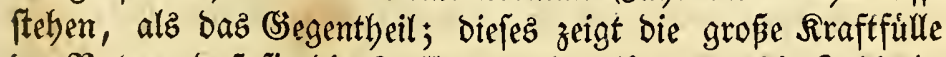

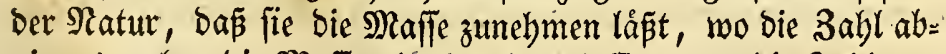
nimmt, obne bie Raffe abnebmen zu laffen, wo bie 3abl zu= 
nimmt. Da bie \&ummen, 2lken, Larbentauther, Sturmod:= gel nut 1 ober 2 (5yer legen, jo find aud) dieje unverbâltnip $=$

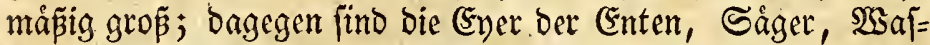

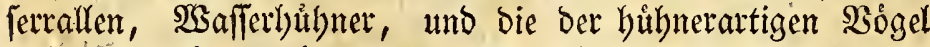
nicht unverbåltmiēmápig flein, obgleid) ibre 3abl bey einigen 2riten jogar bis auf 20 fteigt. Seine norbifde \$ogelait bat

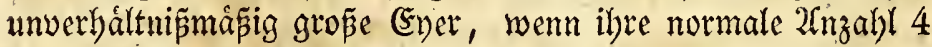
aberiteigt. 2Clz eine 2 Utznabme tann wieber Sula alba be= metkt werben, weld)e fomolyl wenige, alz aud fleine (Ener hat.

Das 201ter Des enlegenden Indivios ift Der Dritte (Sitund, Der zuweilen auf bie (Sirópe ber (5yer, fogar bey Derfelben 2Trt, Einflup bat. Die Sisibden, weldhe zum etfenmale legen, baben gemeiniglich leine (Eyer; gleid) falls legen bie febr alten

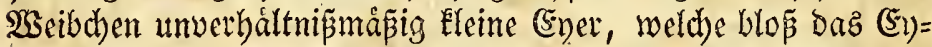
weip entbalten. Die išlåndijchen (Evjammlet kennen fie, und nenten bieje fehr Eleinen (Eyer, weldbe man bie uno ba in Den

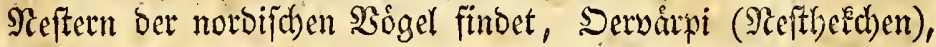
weil fie es mit sed)t fiur baz lef̧te, von einem alten \$ogel ge= legte (5y) anjeben. Şd babe unter ben uibrigen gewóbnli= d)en (E)ern ber Avas glacialis, mollissima uno anbeter Eేn= ten cin (ङy gefunden, weld)ez nidyt gró beney rar; bey ber Unia troile und Lanus tridactylus einige, weld)e bie (Sirópe Der Ritammetzuógel = Eyer hatten. Dieje unte= gelmảsig Eleinen (Eyer find nach ber ridtigen Meinung ber (Fin= wobner aud nid)t befruchtet.

(Endlich wedjfln bie (Eyer in ber (siópe zuweilen nad) ben Sndivibuen ab, ba man jelten alle Ever in bemjelben Nefte ge= nau von Derjelben Dimenfion findet; vielleidht find bie, weld)e

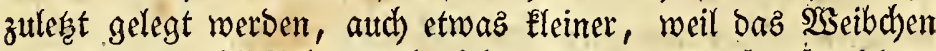
an einet augenblidfliden Sdywade, bie von bem fo oft wieber= holten Eylegungsproceffe herritbrt, leibet. Einen ganz eigen=

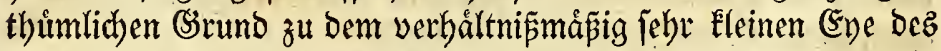

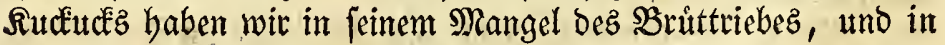
ber barauz, entipringenoen Notbroendigkeit, $\mathfrak{e}$ in bie Nefter anderer weit kleinerer $\mathfrak{B o g}$ gel zu legen, weld) kein (Fy aufneh)=

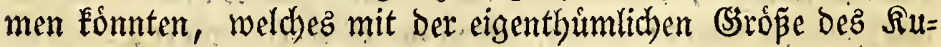

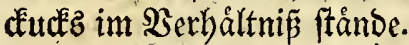

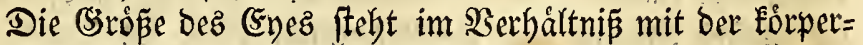

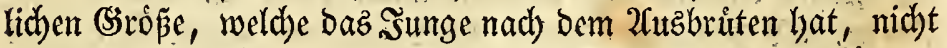
aber mit ber gro̊jeren ober geringeren Entwidelung ber korper= lichen Frertigkeiten, weldhe dą kurz zuvor aubgebrutete Sunge 


\section{$=175$}

zeigt. Man Eann yon einem gropien (5y) anf cin gropeses, aber nicht auf ein mit mebre kórperticher Fertigket begabtez sünges

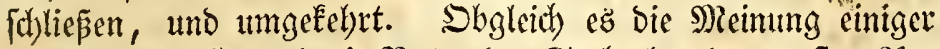

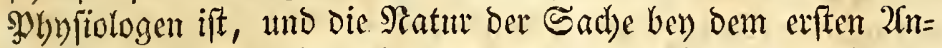
blicke bafin zu jpred)en fd)eint, fo miderfprid)t bod) beftimmt Die (Erfahrung. Davon ift mein Bewcis von ben norbifthen $23 a a^{\prime}=$ fervógeln hergenommen. Die 2Trten Uria, Alca und Mon-

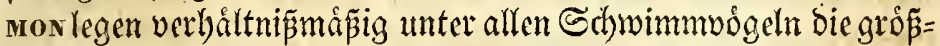

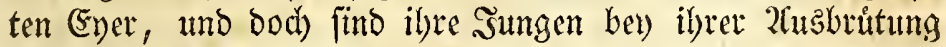
nur im şefis we wenizer Fertigketen; fie Fónnen fid) nicht von ben Meeftpláţen bewegen, fonbern bleiben bajelbft lange Beit lie=

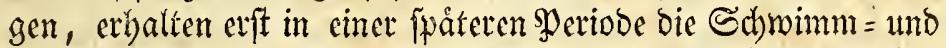
Taudb)ertigfeit, vermógen nicht, jelbft igr Futter zu fuchen oder zu ergreifen, weldbes ilynen von ben 2(lten zugebract)t wirb, fulrz, fie find in bet erften \$eriobe eben fo butlflos, alz

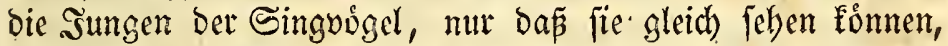
uno febre oft bey Dem 2 tuabruiten mit fraum bebeckt find. Dage= gen Gaben die 2liten von Colymbus, Poniceps, Fulica, Mer-

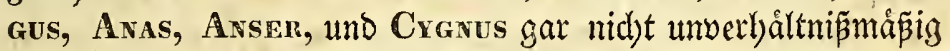
gro mit weit megr forrperlid)er Fertigfeit, als jene, begabt; fie fol= gen gleich ber Mutter, zuweilen weit ins Ssaffer, fdywimmen und tautden vortrefflids, uno oft beffer, als in einer fpatern \$Deriode; fie futhen augenblicklid) গaghrung, und entflieben, wenn fie in

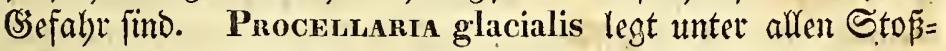
tauchern bas grópte (5n, uno jein sunges ift mit ber gering= ften Fertigkeit begabt; ez liegt mebrere Monate im $\mathfrak{R e f t e , ~ u n t o ~}$

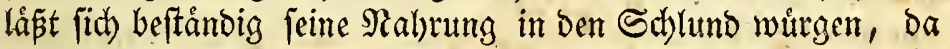
hingegen bie Sungen ber Meven uno Meeridywalben, weldye auz Eleinern Enern ausgebritet werben, bald herumlaufen und felbft daz Futter auffudben belfen. Die neat auggebriteten sungen der Fulrca atra und Galdinula crex find fehi flein, unb nåhern fid) bod) den sungen ber buibnerartigen 230 gel in ber Fảbigkeit, mit weldher fie fogleid) betriebfam fino, ba.bin= gegen die vermandten Scolopax uno Tringa, weldye auz verbåltniß̄mápig grópern Eyern aubgebrutet werben, weit mebr von ber Firuforge Der Eltern abbangen. Die Natur hat ja

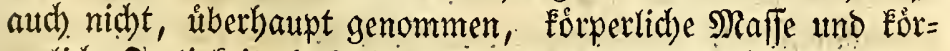

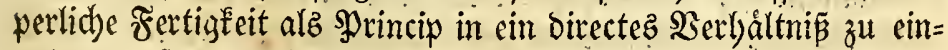
ander gefef́t; die grósten Lanotbiẹe, bie şadyydermen, 


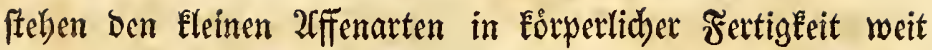
nact) $\mathfrak{u}$. โ. m.

\section{§. 35.}

b. Die (S) eftalt bez Eyez ift jeder Sogelart mehr ober minder cigenthümlid), uno man Eann fie ihrer Normal= form nach in mebrere 2rotheihungen bringen. (5inzelne 206= meidhungen in ber Figur finden wir wohl auth unter ben

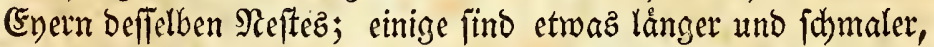
anbere etwas bicker uno kưrzer; was bas (Ey an ber Lánge ver= liert, gewinnt ez gemeiniglid in Der Diefe; boch fint bieje $2 \mathbb{C b}=$ weichungen nicht fo bebenteno, ba fie ben (Eyerfenner in ber Seftimmung ber refpectiven 2frten irre fúbren joltten. Die

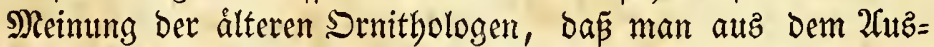

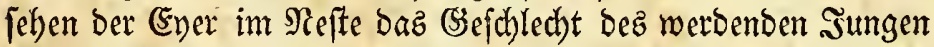
erfennen Énne, wirb von Den neuern verworfen. Monftrófe 206meichungen in ber Figut ber (5yer fommen felten unter Den

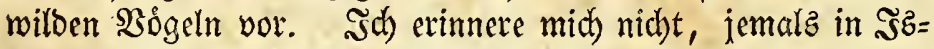

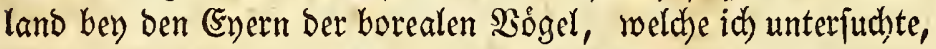
irgend eine auffallende Monftrojitåt gefumben zu baben. Da= gegen legen zabme Şuibner u. F. w. oft Eyer von monftrófer

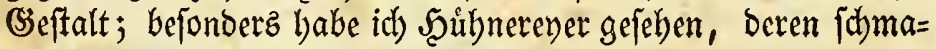
les Ende linienförmig verlångert war.

Serr Proferfor Ia III., §. 39, bie Bemerkung, Dã bie Form ber (Eyer mit ber Form ber in benjelben fich billdenden sungen in einiger $\mathfrak{B}_{e}=$ ziehung ftehe, namentlid mit ber Rånge ihres ßumpfes und

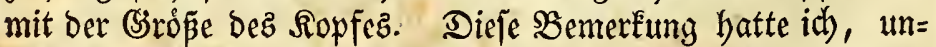
abhaingig von ber Beobachtung biefez Gelehrten, von weldher idi) zu ber Beit nidjtz wuste, auf meiner $\Re$ Reife in Şland ge=

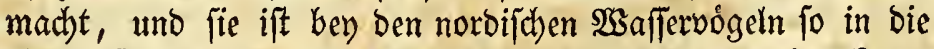

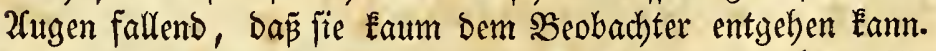
Befonders ridbtet fidh bie Figur bez Enes jehr oft nad ber Fi= gur Dez $\Re u m p f e z$ bez enlegenden Snoivibuums; da biejer ber

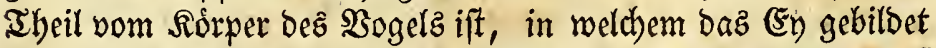

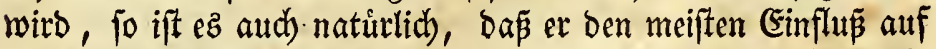
die Frorm bes (5nez haben mus. Se langer uno bơher bie Bauchboble ift, befto lánger und bicker ift aud bag Ey. Der

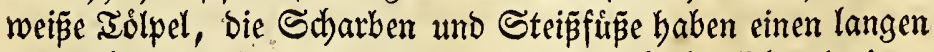
uno nidjt bicken truncus, ibre Eyer find aud linglid) und ziem=

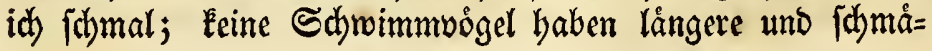




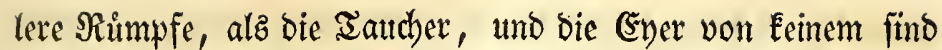

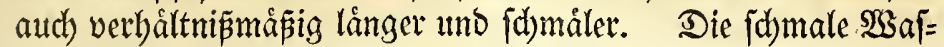
ferralle hat aud fdymålere (5yer, alz die Sdhnepfen und Strand= láufer. Der Rumpf ber Utrien und 2alfen ift lang und ziemlich bick, ibre (Ever find aud) befonders lang und etwas bick; bie Meven uno Meetifhwalben haben einen hoben und kutzgewólb= ten truncus, ihre Ener find aud dick uno geroolbt. Die Entenarten, weld)e den bickften und fiurzeften Simmp baben, 3. $\mathfrak{B}$. Aras mollissima, histrionica und glacialis, baben autch Eurze Dicke Ener; Dagegen fino die Ever etwaz langer ben Den nicht tautbenden Entenarten, weil dic Enten felbit långer find. Das (E)) von Meraus serrator ift fichon merflich lánger,

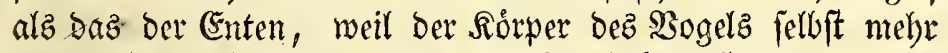
lang seftrectet ift. Der Siumpf ber Rautboogel ift furz uno bid, il)re (Ener find atd rund ober abgerumbet.

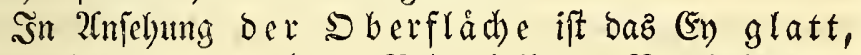

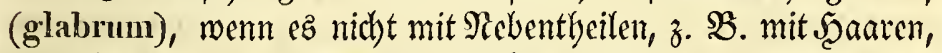
bewach jen ift. Die Eyct aller $3 \dot{s}$ gel fino glatt; nacét (nudum), wenn feine (Srufte die Schaale umgiebt (biefes ift ber Fall bey Den meiften (Evern), b e ded t (tunicatum), wenn eine Dinne Ealfartige (Erufte die @ihaale umgiebt, z. $\mathfrak{B}$. Die (Ever Des weipen Iólpels uno Der Śd)arben. (Eben (leve), wenn

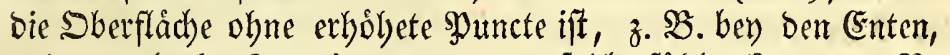

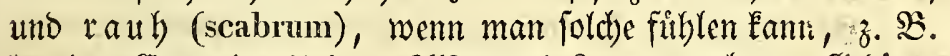
bey den Eyern ber Utrien, 2uken uno Rarbentaucher. (s) lán= zeno (nitidum), wenn bie Sberflád)e daz Ridht reflectirt; z. $\mathfrak{B}$. bey Auceno ispida. Die (5yer der meiften Bogel fino mebr ober minder glánzeno, und dies um fo viel mebr, je ebener

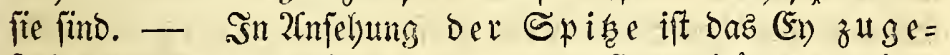
ip if tacuminatum), wenn die eine (Extremitåt ctwaz ber= vorgezogen uno bưn ift, z. $\mathfrak{B}$. Die birnformigen Ever; fd) mal zulaufend (attenuatum), wenn es nach und nad) gegen das eine (Ende, weldhes etwas ftumpf ift, fdumåler wirb, 3. B. bie eyformigen (5ycr, ft u mpf (obtusum), wenn beibe (Extremitaten abgerindet und beynal) gleich) did find, z. $\mathfrak{B}$. Das balbualzenformige (Ey.

In 2njebung ber Fla da e ift baz (Ey) gewoolbt (convexum), wenn es in ber Mitte erbaben ift und gegen bie runben Enden abnimmt, z. B. Das Ey der Procellania glacialis. Scalb gerólbt (subconvexum), wenn es in bet Mitte we= niger erbaben, tund gegen bie abgerimbeten Enden bin weniger 
abnelymend ift, z. B. bie Eyer Der Enten. Schief (obliqumm), wenn ez in bem einen (Ende febr bod) ift, tund nach und nach abnimmt, z. $\mathfrak{B}$. bev Larus marinus. $\mathbb{S}_{\mathrm{d}} \mathrm{m}$ al

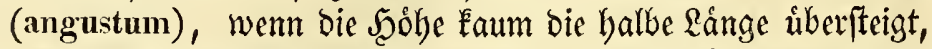
z. $\mathfrak{B}$. bel) Raluos aquaticus. Sjalblinienfórmig (semilineare), wenn es jdmal, und beymab íberall gleid) bod) ift, z. B. bey Colymbus. Di i cke ober fdower (crassum), wenn jeine Rånge bie Didé Eaum um $\frac{1}{4}$ ủberfteigt, z. $\mathfrak{B}$. Fauco albicilla.

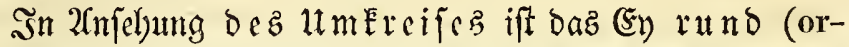
biculatım), wenn fein Diameter itberall gleid) grops ift, z. $\mathfrak{B}$.

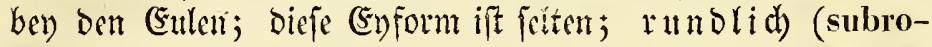
tundum), wenn ber Durd)ichnitt Durd) Die abgerinteten (Extre= mitåten etwaz gróper ift, als Duth) bie Fláche ober bie Seiten, z. $\mathfrak{B}$. Falco timnunculus, caesius and meldet Falcones; länglid) (oblongum), wenn bie Rånge beynah) boppelt fo grop ift, als bie Dicke, bie Seiten mur wenig gewólbt, uno bie abgerumbeten (Extremitåten beynal) gleich bick find, z. SB. Die Eyer Der Eolymben. Das ovale (ovale) gleidht bem vorherge= benden, if aber weniger lang im Sierljaltniffe zur Didke, uno bie Seiten find etwas melyr gewólbt, z. B. Die Ener der Steipfüfipe und ber $\mathfrak{Z}$ a fertafle; to al zenformig (cylindraceum), wenn bas (5y) melir lang, als bick ift, bie Sciten fehr gewolbt find, und abrielsmend gegen die bicken und bevnal) runden (5n= den, z. B. Procellaria glacialis, und Puffinus areticus, balb walzenformig (subcylindraceum), von ber Figur dez vorbergebenden Enez, aber bas Ende etwas büner, als am anberen, z. S. bie ber Sdymåne, Ģånje, Enten, Såger. Diefe (Enform ift jiemlid) allgemein. Evformig (ovatum stricte sic dictum), wenn bas (Ey mel)r lang, als breit ift, bie Seiten etwas gewólbt find, bas ganze (5y von ber einen bicken Extremitåt zu ber andern allnåalid abnimmt. Dies ift die Form ber meiften $\mathfrak{B o g}$ gel, vieler $\mathfrak{W a l b}=$, hủbnerartigen uno ber meiften Singuogel, unter ben Sdymimmbogeln, ber Eyer der Unia grylle uno alle, der 2 rten von Alca, Monmon, Carbo, Fulica, Sula, Larus, Sterna und Lestris. Birnformig (piriforme), wenn daz (Ey Dem vorberge= benden gleidyt, aber plóslid) gegen bie cine Extremitåt fdamáler wiro; weldbe baber beynah zugefpifst ift, z. B. die Eyer der meiften Sumpfoogel ber (Sattungen Haematopus, Charadrius, Numenuus, Limosa, Totanus, Va- 
nellus, Strepsilas, Tranga, Scolopax; ciniger Sdyimm= vógel, alz Phananopus, Unia troile uno Brünnichii, forwie einiger húbnerartigen $\mathfrak{B o g} g \mathfrak{l}$, alz ber. Trutbůlbner.

In biejen normalen Enformen wirb die Hebergangsform bey) einigen 2rten gefunden, indeffen fie bey andern ben (5ya= rafter ber Figut genau auboruofen. So ift das (5y ber CHaRADRI - 2frten vollfommen birnformig, und bas ber $\mathfrak{S a}$ afler = treter uno Stranoláufer mel)r, alz bez Bradbvogelz. Saz enformige (5y der Alca torda uno STEnsa arctica nålyert fid) ber birnformigen, baz ber Reven uno Raubmeven ber balb= walzenformigen (S)eftalt, u. F. m.

\section{§. 36.}

c. Die Farbe Dez Eycz. Serr Profeffor Boigt lyat in Feiner Srbrift: Die Farbe ber organijhen Siorper, bie Ber= nad)laffigung, weldhe \&inné und andere Saturforidher fid in Simficht ber thierifden Fatben zu ઉdulden fommen lafien, im Aflgemeinen in 2 nfprud) senommen, indem fie biefelben alz 2 rrt= Rennzeidben verwerfen, weil fie, wie man meint, tunend= lid) variiren. Der Serfaffer bicjer Schrift verjucht zut

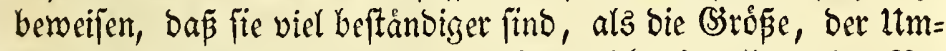

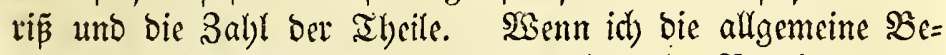
merkung bez Berfafjerz auf bie in ber botealen Bogelzone vor= fommenden Bogel und (Ever anwende, fo mup ich if $\mathrm{m}$ gró $\tilde{\beta}=$ tentheilz Recht geben. Die Farben find uberbaupt genommen gute 2 rt $=$ Rennzeichen, wenn wir mit ben Regeln bekannt find,

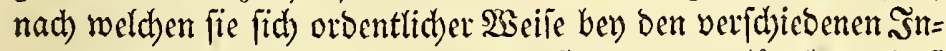
biviouen ber 2trt verándern. Nun ifit ez zwar unláugbar, baß̄ die Eyer mehr, als bie Sogelindivibuen berjelben 2trt, in ber Farbe nad) Den Inbiviouen variiren, aber bod kaum mehr, alz fie unter fich in ber (Sro̊ze uno Figur abreidsen; autd) jo= gar beb ber fdeinbaren umregelmápigen Farbenvariation ber Sógelever finden wir bod aud einige SPlomente, weld)e unz zu allgemeinen Regeln fitbren fonnen; hiebon nadber.

Die eigentbumliche Farbe, welche bie Sdjaale bez ganzen

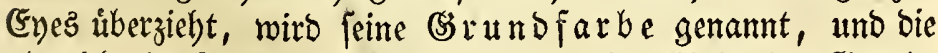
abrweichende Farbe, weldhe wieder einzelne Theile Der (Sinund= farbe bebeckt, fann $\mathfrak{R}$ eb enf ar ve genannt werben. Die $\mathfrak{B e r}=$ theilung ber Sebenfarbe auf Der Srundfarbe nennt man bie 3eid) $n$ ung bez (Eyes. Daz (5y, weld)ez Ecine Rebenfarbe bat, Eann man einfarbig (concolor) nennen, z. SB. Die 
Ever Der (snten; die Ener, weldhe Nebenfarbe baben, nennt man z we $\mathfrak{c}$ farbige (bicolor), brey farbige (tricolor) t. f. w.; fo wic bic Nebenfarbe mur aus einer oder mebreten Farben be= ftel)t; nad) Der Sertheilung uno Der SSeftalt Der Nebenfarben auf ber (S3)mbfarbe ift bas (Ey gefledt (maculatum), z. $\mathfrak{B}$. daz der Una grylle; fichelformig gefledet (clypeatum), wenn bie flecten in einem einzigen gropen zufammenlaufen, z. $\mathfrak{B}$. Dag (Ey) Dez Facco milvus; geftreift (striatum), z. $\mathfrak{B}$. das (Ey) des Capbruulaus europaeus; geádert (venosum), wem bie Striche in Basugungen geben, z. B. beb Unin troile; punctirt (punctatum), o. SB. bev) Charadrius hiaticula; oft hat sin Drenfarbigez (Ey fownol Flecken, als Sुuncte und Streifen, z. 3 ben Stens arctica; wonn fid) biefe Fleden alz cin Sranz um das (Ende ober dic Mitte ber Sd)aale fam=

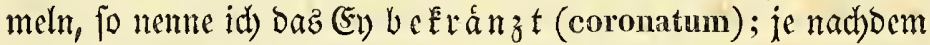
bie Rebenfarbe beutlid) obcr unbeutlid), fwarfam ober reid)lid) auf ber (stundfarbe ift, lyeisen die Eyer beutlich ober undeut= lidy, wenig oocr feldr gefledit u. f. w., uno nad) Der Farbe ber Flecken, fduwarz $=$, braun $=$, roth gefledt $\mathfrak{u} .\{. \mathfrak{w}$.

Die (sinundfarbe kann wicoer rein (purus) fenn, je nad)= Dem fie aus ciner ber einzelnen Sautptfarben beftebt, und $g \mathfrak{g}=$

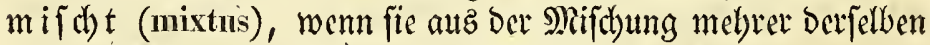
entifanden ift, z. B. grau, bellgrim, fdhroazbraun. -

SBenn id) cinen Blice auf Die Eyer Der meiften borealen Sogelarten, weldse id) felbjt auf ben Reftpláęen bez bohen Norbenz gefammelt habe, werfe, to finde id) yon ben (Eyern

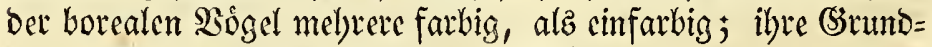
farbe ift nur wenig práchtig, und jelten ganz rein, vornebm= (id) weip̃ mit feinen 2(bånoerungen, braun, fchmubiggelb, ober rothgelb, grau, felten reingrum, nie bluthroth) ober Eoblfdswarz. Die Nebenfarbe ift allezeit Duntler, als bie S3rundfarbe, auth von einem matten 2inftridbe; die Fleden find fdhwarz, braun, gruinlid), graut ober rotbgraut.

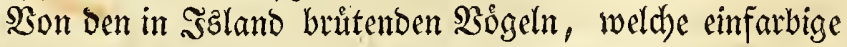
Eycr legen, gebort mur eine 2frt unter bie Raubvo̊gel, nåmlid) Falco albicilla, mit fd)mugigneizen (Eyern; Eemer zu ben $\mathfrak{W}_{\text {Sald }}=$, buhbnerartigen oder Sumpfoỏgeln, einer zu ben Sing= vo̊geln, nåmlid) Saxicoua oenanthe, mit blaumeípem Eye; von ben Sdjwimmoogeln Unin alle, mit blaumeipem, Сапвo cormoranus $\mathfrak{t n d}$ graculus mit bleidbritnem, Puffinus arcticus und Proceldaria glacialis, Podiceps comutus, und 


\section{1}

arcticus, mit reinweipem, 2 2rten ber Gảger, 11 2rten von

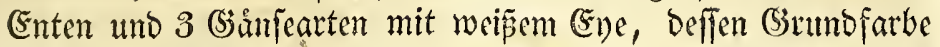

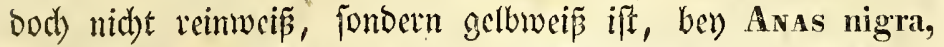
histrionica, penelope, crecca, Arsen segetum, albifrons uno leucopsis, graumeís ben Mergus serrator, Aras boscas uno acuta, bellgrun bev Margus merganser unb Avas clangula, grunlidywei bey Aras mollissima, glacialis, marila, leucophthalmos, getbreip ben Cranus musicus uno

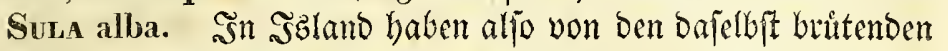
Bỏgeln 27 arten, nåmlid) 1 Raubvogel, 1 Simguogel uno 25 Srbuimmuogel einfarbige Ever; bagegen bruten auf biefer Snjel 40 2irten, welde geflecite (Eyer baben, nämlich von Raubvogeln 2 2itten, Facco islandicus uno caesius, von Balbuogeln $12 \mathfrak{i r t}$, Convus corax, von ben luilluerartigen 1 Rnt, Tetrao Islandorum, von Singoógeln $6 \mathfrak{2} \mathfrak{r}=$ ten, Emberuza nivalis, Fringrlea linaria, Tundus iliacus, Motacilua alba, Sruvia troglodytes und Antuos pratensis, von Sumpfógeln 122 frter, mámlid) Hazmatopus ostralegus, Charadrus hìaticula uno plıvialis, Numenius phaeopus, Lrnosa melanma, Totanus calidris, Strepslas collaris, Trivga cinerea, maritima, alpina, ScoloPax gallinago, Raluvs aquaticus; von Sdfwimmvógeln 18 2rten, námlid): Phalanopis cinerens und platyrhincus, Unia grylle, Brïnichii und troile, Auca torda uno impennis, Mormon fratercula, Colrubes glacialis tmo rufogularis, Funica atra, Sterna arctica, Linus tridactylus, glaucus uno marinus, Lestris catarractes, poma-

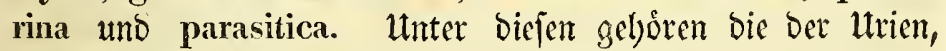
Meerid)nalben, Meven, zu Den am meiften, die ber saudber zu ben ziemlich, bie bez Baunfónigz und Der SEaffertalle zu ben fparjam, und bie bez Monmon fratercula fu ben unbeutlid) und fparjam gefleciten (Evern.

Dab (5y erbált feine Farbe, wenn eb nod) in oer Mutter

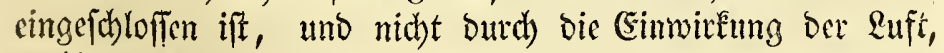
nadbent es gelegt worben. Sch babe in ber Eloaca oer Mutter das (Ey volfeommen von ber Farbe gefunden, welde es im Refte hat; wie aber baz (Ey im Mutterleibe gefárbt wito, ift eine Frage, weld)e bie 2(natomie nod) nid)t ganz geloft zul baben jobeint. -

Ûter Dem Sruten verândert Dab Ev in etmas feine Farbe;

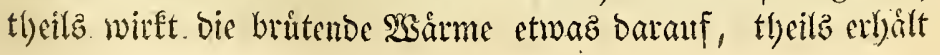


eE gemeiniglich eine ge!blichere Farbe, wenn Das heranwad)=

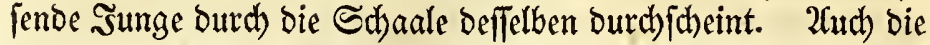
umgebenden Medien wirken auf Daffelbe. Esz ift befannt, das die Sonne die Farben bleid)t; wie abgebleidht jind nidht bie Eyer, welche wir in einem alten, von ben Eltern verlaffenen Bogelnefte finden? Die Farbe einiger Bogeleyer wirb gleid)falls aud mebrentlyeilz mit $\mathfrak{B a f f e r}$ abgerwajchen; cine Bemer= kung für Eyerjammler, dapj fie bic Eyer, weldhe fie fưr ihre Sammlungen beftimmt baben, nidht Durd) Flluffigkeiten reini= gen. Daber werden bie (Eyer ber nordifden $\mathfrak{B a f f e r v o g}$ gel aud

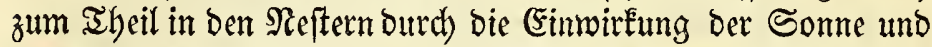

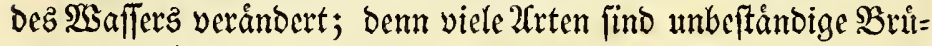
ter, und ftellen il)re (Ener oft bem Richte ber Sonne blozs, an= Dere bauen ibre Sefter fo nabe an Der Sberflache bez $\mathfrak{W a f f e r z , ~}$

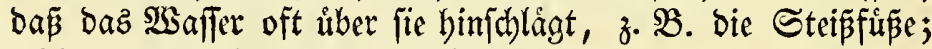
wieder andere bauen bas Neft von Meerpflanzen, weldbe eine beftandige Feudtigkeit bey ben Enern. unterbalten, und alle briten fie gleich, indem jie alis bem Şalfer fommen, alfo ihr Bauch und ifre Bruft nod) feudt find. Daburch erbalten bie

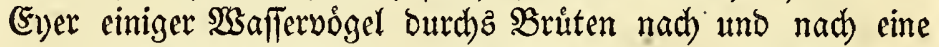
von ber urjprünglicben jelgr veridjiebene Farbe. Die (Ever ber Sula alba, der Poniceps-2irten uno der Aiser segetum werben zuleft von ber Feudtigkeit bez Neftez johmusigbraun,

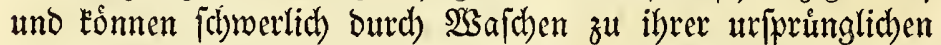

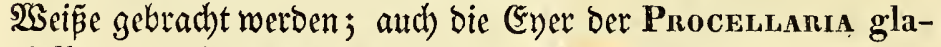
cialis, deE Puffinus arcticus, Mormon fratercula, und

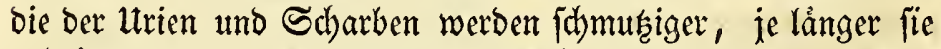

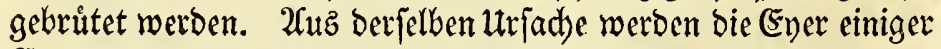
Entenarten von ben Srnithologen für geflectt ausgegeben; alle Entenarten baben einfarbige Eyer, und die jogenannten Flecken auf ihrer Sirundfarbe find nicht von Der Natur, fondern von Der Unreinigleit bez Skeftes̉ erzeugt.

Die Farbe der Eyer ift fiut die verichiedenen 2(rten conftant, ja fie bleibt jogar zumeilen biefelbe für alle bie $2 \mathfrak{r t e n}$, weldbe eine (3attung bilden; and bieje lestere Erfabrung zeigt vornebm=

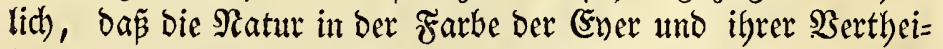
lung nicht regelloz zu Şatke gegangen ift. 2(lle Schneebuhn= arten baben rothliche braungefleckte (5yer; bie (Eyer ber $\mathfrak{R} i n=$ néifden Scolopaces und 'Tringae fino gelbgrau ober gelb= grun mit DunEleren Flecken. Die bekannten 2Trten der (s)attung Phalaropus baben auperordentlid) ábnliche (Eyer. Die (Eyer 
Der nakeverwandten (3attungen Unia und Alca, fo wie von Proceldaria und Puffinus, find einamber in ber $\mathfrak{F}$ arbe feldy ábrlid). Befombers ift daz (Ey der Una grylle dem der Alca torda gleich. Zulle (5ver ber Carbo-2frten find griuntid), bie

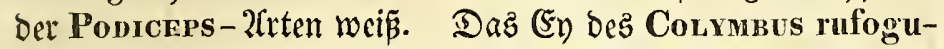
laris hat fo ganz biefelbe rarbe mit ilfrer Berth)eilung, wie bas dez Colymbus glacialis, fo daß̃ ez eine Hleinere Wsiedertholung von biefem z̆u fenn icheint. Die Ëyer aller Sảger, Enten,

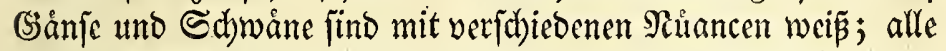
Meven und Rautumevenarten haben ihre Eyer ungefä́ry von

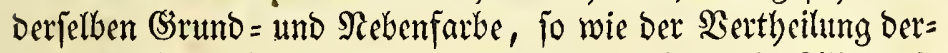

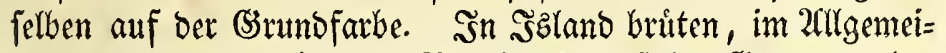
nen genommen, nidht zwen Bogelarten berfelben Ssattung, de=

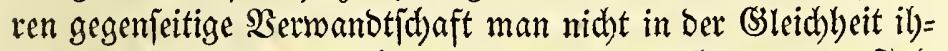

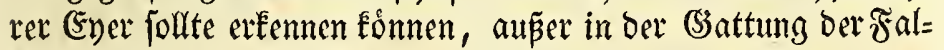
Fen, da die (5yer dez Falco albicilla meíp, die von Falco islandicus uno caesius aber rotthlich uno braungejpreneelt finto.

Dagegen ift es unláugbar, da a bie Farbe ber Ěner oft

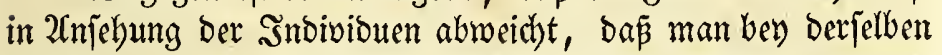
Sogelart, und nicht felten in bemielben Refte, Eyner von etwaz verjdiedener Farbe findet, und baß bieje Farbenverifhiebenbeit nidbt aus ben reguláven Motiven, weldye veríchicdenes 2alter

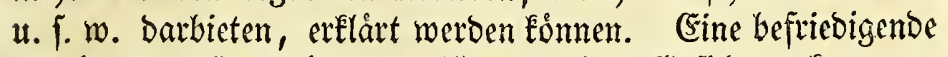

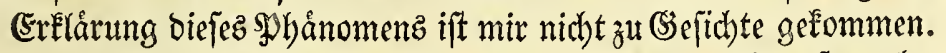

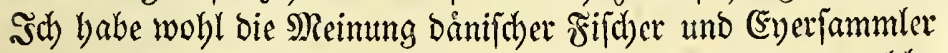
vernommen, da sie einfarbigen grùnen Mevenener, weldhe

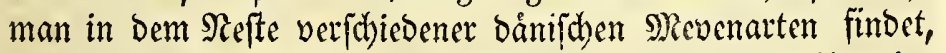

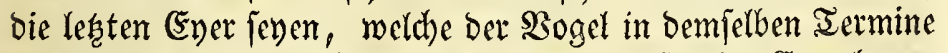

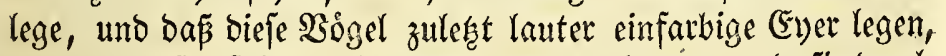
wenn man fortfabre, ibje Brut wegzunchmen, uno fie burch

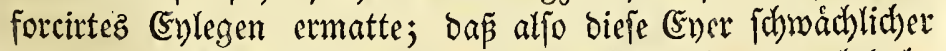
Ratur, eine 2frt Rakertaken unter Den E"yern, wären; Dodh habe idh) nicht ferbft (Şelegenbeit gebabt, biefe Bebauptungen zu unter=

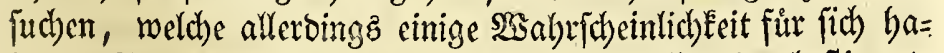
ben. San biefem \$yánomeme babe ich inderfen eine beftimmte

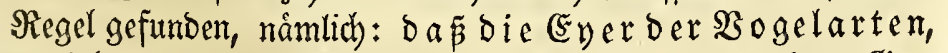
welde in ber segel einfarbig find, nie inz (5)e = fleckte, die gefledten aber oft ins Einfarbige variaren.

a) Seey Den Enten, Şånjen, Gdywanen, Gormora= nen, Tơlpeln, Sturmwogeln, weldye in Der Regel einfarbige 
Enet haben, fand id) unter mebreven Iaujenben, bie id in ben

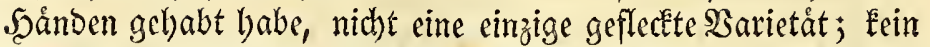
Berid)t von seflecten Scharben = ober Entenenern ift glaub= wuitbig, und die Fleden ftammen von fremben Subftanzen Ger; Dagegen variiten bie binnfarbigen Ever oft in ben গluan= cen der (Sirumbfarbe; befonders werben die Entenener bald grün= lid), bald grlber oder grauer angetroffen; aud bier fand id) bey Der Sergleichung vieler Seundert Entenener ben Minvatn,

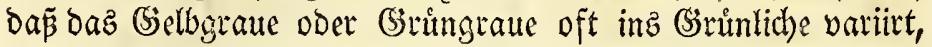
nidft aber umgekefyrt; baber fand idh zwifuen Den in ber $R e=$ gel grünlidben Evern der Aras clangula nie eins, welchez an Farbe mit dem Der aras marila verwed) jelt werben fonnte, wobl aber cinige unter ben lef̧tern, in Der Regel grauli= dben Eyern, weldbe fír die ber Aras clangula genommen weroen Der Meven = und Mecriflwalben = (Eyer oft ins (Sirine, bage= gen bie grinlidbe der Carbo-2hten nie inz Sraue, Gelbe oder Braune.

b) Die in ber Regel geflecteten (Eyer arten aber oft in einfarbige ab. Die Ratur artet offers von Dem. 3ufam= mengeferten zum (sinfadben aus, als umgekebrt. Sm গiefte, zwifhen ben ibrigens geflecten Eyern von Numenius phaeopus, Totanus calidris, Rallus aquaticus, Uria troile, Brünnichii, Monyos fratercula, Sterna arctica, Lanus tridactylus, marinus, argentatus, canus, Lestris catarractes und parasitica fand id zumeilen ein ganz ungeflectez (Ey, weldbes bev ben úbrigen genannten 2(rten bellgrưn, uno bey Mormon fratercula uno Rallus aquaticus ganz weip war.

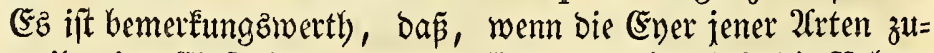

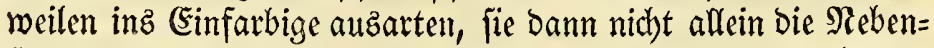
farbe, fondern aud) die (sinunbarbe veránbern, weldhe ge= meiniglich belforin wiro. (Einmal fand id) im Nefte bez LEsTris catarteces bcibe (Eyer ungeflect, weld)ez bas cinzige

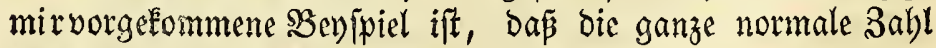
ber(Ever, wenn bas Sefít ibrer mebrere entbielt, zum Einfarbi= gen ausgeartet war.

Uebrigenz find bie gefledten Ener befonders in ber Babl ber Flecken, ibrer Form, Gro̊pe und il)rem Sif̧e fel)r verifhie= Den, und felten, findet man in bem গefte Det Sumpf = und Waffervo̊gel, Deren Eyer unlåugbar fïh mebr verándern, alz die ber Lanovoigel, zwey Eyer, weldbe eine volfemmene 
S3iederhohtung ilyer gegenfeitigen Farbe uno Farbenwertleilung entyjelten. 2(m meiften aber variiren bie (Ever von Stensa ar-

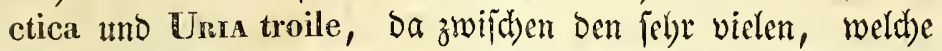
ich) von biefen Icştern auf Den Sogelbergen unterfurbte, nid)t eins bie vollemmene Farbe unb Beichnung Dez andern hatte. Biefleid)t roúrbe bie baaufige 2(bweidyng unter ben (Eyern ber Uria troile L. fertener feyn, wenn man bie (Eyer ber verichiede=

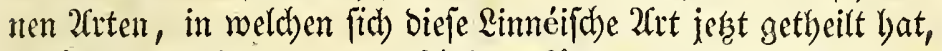
gelbórig von einanber unterfechoiben fónnte; aber bie (Ever ber Una troile und Brünnichii werden von ben (Eyerjammlern ohne Utnterjabied von Den Fellenjeiten uthter einander heraufsebrad)t,

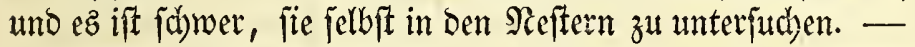

atte bie merêwurbigfte 20(bweid)ung in ber Farbe biejer (Ener führe idh bier an, dáp id) unter ber Barietåt, welde Brünnich hringvia nennt, melyrmalz grưnlidhe braungeflecête (Eyer ertyelt, aber eimmal ein ganz weifes mit einem feinen

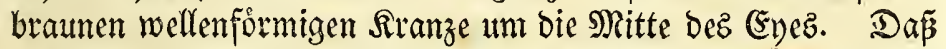
baz (5) wirflich von der Şringuia der Salånder war, beweife

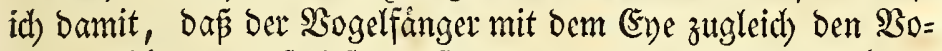
gel, welchen et auf biefem gefangen batte, mit heraufbrad)te.

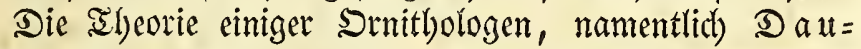
dinz, dap die Farbe uno Zeidhnung ber Eyer Der Farbe

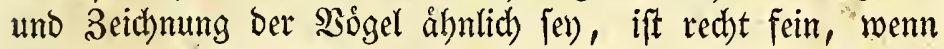
fite nur nicbt unridstig waire, und bie allermeiften (Erfahb= rungen gegen fid) hätte. Wsir wollen mit Syillfe ber borea=

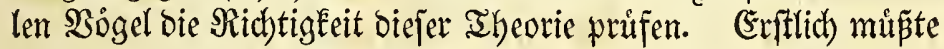
fie auf bie Farbe des eylegenden Individes bejdyränet werben,

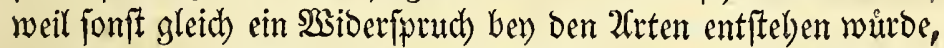

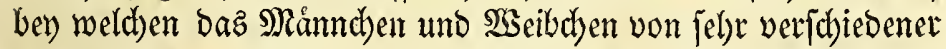
Farbe find. Unter ben norbifhen Bogetarten finden wir bejonderz Falco tinnunculus, die Lagopus-2frten, Andea cinerea, cinige Tringae, die Carbo - Alten, Cygnus musicus, Sula alba, Lestris catarractes und Procelinania glacialis, bev weld)en Die Farbe uno 3eidhnumg bez 20 gele

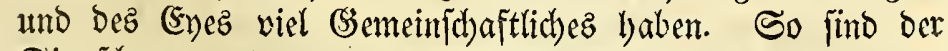
Singidhwan und ber weipe Iolpel felbit weis mit eimem gelle=

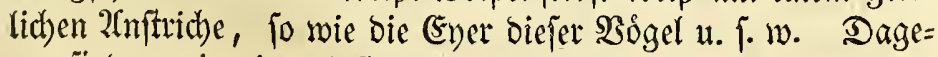
gen finden wir einen befitimmten (segenja bey ben meiften En= tenarten, unter weldyen bie fdowárzeften Enten, als Aras nigra uno fusca, bie weinefter Ener Gaben; uno bey ben meiften Sumpf = und Singuógchn. Die am ichónften gezeid)neten 
Sitern legen oft einfarbige Ener, z. B. Die Sped)te und (sigud:= gel u. F. m. SWollten wir die (s)rundfarbe bez (5yez mit ber Baudffarbe bez eylegenden Individume und bie Flecken der Eyer, wenn fie exiftiren, mit Der Riuffarbe beffelben 23 cib= dhenz vergleichen, fo wurben wir mebrete $\mathfrak{H e b e r c i n f t i m m u n =}$ gen erbalten, namentlich bey Asca torda, Monmon fratercula, bey ben Siteipfirłpen, einigen Sågern uno Entenarten,

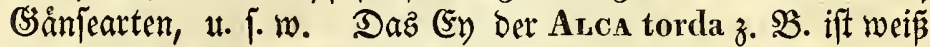
mit fddwarzen Fledten, ber $\mathfrak{B o g e l}$ felbit ift aud weiß auf Dem

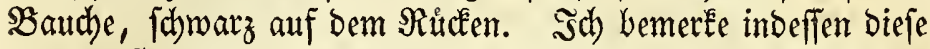
Uebereinftimmung ber Farbe ber Mutter mit ber bes Gyez mur

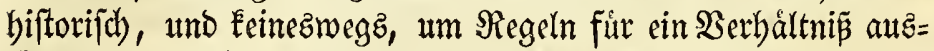

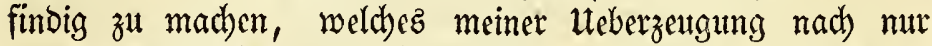
in Der \$phantajie einiger (s)lebrten, nicht aber in ber Natur gefunden wirb.

Die normale Sabl ber Eyer wirb von ben Eittern im Nefte georonet. 250 ibrer mebrere find, werden fie in einen Sreiz gelegt, und daz diummere (Ende ift allezeit cinmártz gegen daz (5en= trum dez গeftez gekehrt, fogar bey denen, welde nux ein (Ev baben, 3. B. Die Utien legen die Spize dez Enez gegen den Frljen. So

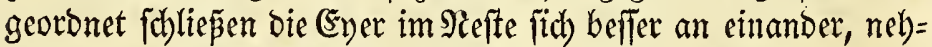
men ben moglidbit Eleinften $\Re$ aum ein, und alfe Eonnen badurch beffer unter Der Mitte bez brütenden Bogelz gejammelt merden.

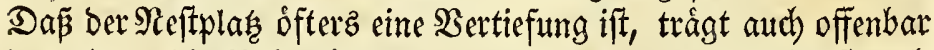
Dazu bey, bie Brutwårme zu concentriren. Sielleidht ift aud) die Spife dez Eyez Darum einwårtz gegen baz Eentrum dez Neftez gefebrt, uno liegt Daher unter der Mitte dez brutenden $\mathfrak{B o}=$ gels, weil ber ebelfte Theil bez Eyez, der Den Reim bes werden= ben $\mathfrak{B}$ ogelz (punctum saliens) enthált; auf weldben sine beftán= oige Brütwårme vorzůglid) wirken foll, nåber gegen bas bủne Ende eingefdlofien liegt.

\section{§. 37.}

2. Die SBruthiftorie.

SSenn bie normale 3ahl ber Eyer im Refte grlegt ift, fo

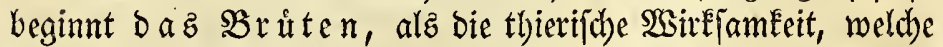
Dem (Ey) feine (Entwickehung geben foll. Das Britten beftebt in rinem anl)altenden Sifen bez brütenden Bogelz auf Den (Eyern in einem geniffen 3ritraume, um ben Fieim Deflelben burch bie thierijche $\mathfrak{b a r}$ arme zu entroideln.

Die S̃ungen Der Săugthiere werben alz foetus im $\mathfrak{a}_{\text {cibe }}$ 
ber Mutter gebilbet: bery ben 2 sógetn außer bem Reibe. Die Brutperiobe bey biefen entipridht Der 3eit bes Irådbtigjeyns bey

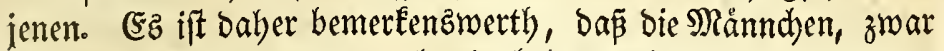
nid)t bey ben polngamen, aber boch bey melyreren ber morioga $=$ men Siogel an ber Bruttfunction ber $23 e i b d) e n$ theilnehmen,

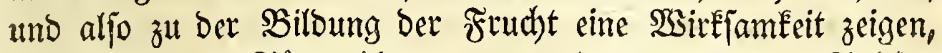
weldye bery ben Sångetlieren ganz uno gar außer ber Sphăre

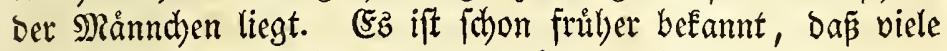

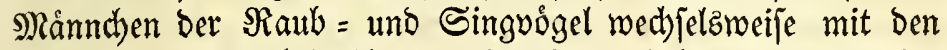

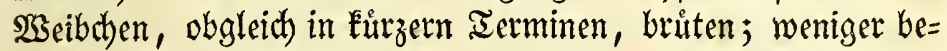

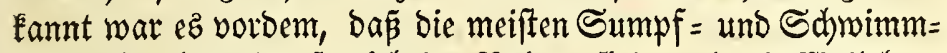

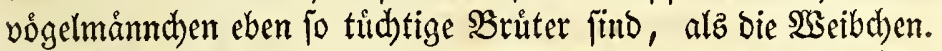

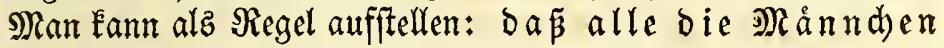
unter ben borealen $\mathfrak{B}$ afferuogeln, welde bie sungen futtern belfen, zugleid bie (Eyer wedh = felsweije gebrattet baben, aber nidat umgekebrt. unter allen islånbijhen Sumpfoógetn und von ben Sdimimm=

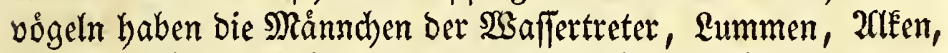
Rarventaucher, Sdbarben, Sturmtaudher, Tólpel, Meer= idwalben, Reven, Raubmeven, Sturmboggel Den Fritterungs=, und aljo auch ben Bruttrieb (jie find von ber zujammengefees= ten Monogamie); Dagegen baben nidht alle Månndjen den Frutterungstrieb, weldhe ben Brittrieb baben, z. B. Die Iau=

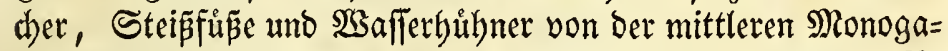

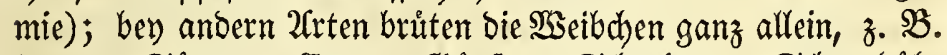
ben ben Sågern, Ënten, Šånjen, Sdhwánen, Sdłneehủh = nern (yon ber einzelnen Monogamie), und bey allen polygamen SBigeln.

So wie es 2 trten giebt, ben weldhen blop bie $\mathfrak{B S e i b c h e n}$

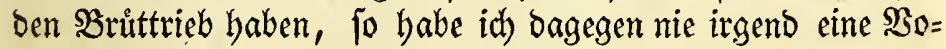
gelart angetroffen, von weldher id mit (Semi bã bie Månnchen allein britten, mur auf bie Eleinen $\mathfrak{B s a f f e r =}$

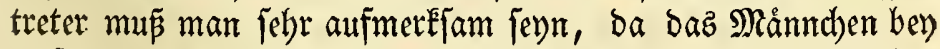
biefen allein Bruttflecten hat, und biejez audd weit offer bey

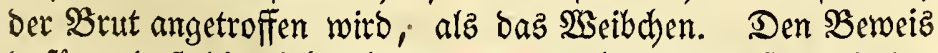

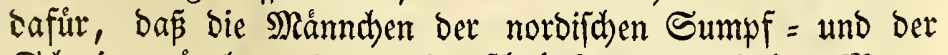

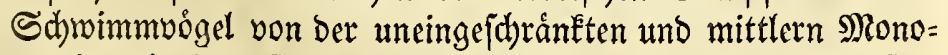
gamie mit ben $\mathfrak{S B}_{\text {Beibden }}$ am $\mathfrak{B}$ ruiten theilnebmen, liefern

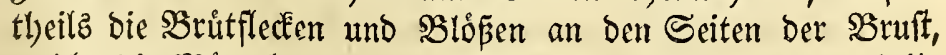
welde bie Månndhen mit ben $\mathfrak{W e t b d e n ~ g e m e i n ~ h a b e n , ~ t h e i l z ~}$

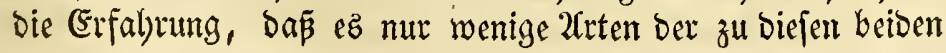


20theilungen der Monogamie geboirenden Sathimmoogel im Sorben giebt, obgletch id) von ibnen weber Männchen, nod) Wreibchen erbalten habe, bie auf bem Eye find gefangen mor:

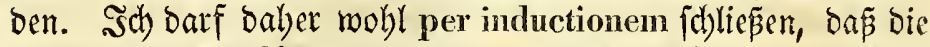
Regel von allen 2(rten gelte; bagegen kann ich beftimmt loung=

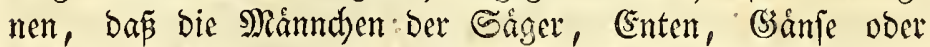

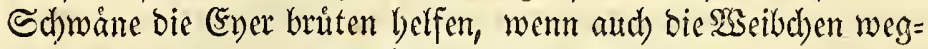
gefangen werben. Sie fdwimmen wobl zumeilen atm bie Sie= fter ber $\mathfrak{W}$ eibchen, wábrend dieje bruiten, z. $\mathfrak{B}$. Aras mollissima uno marila, ernangeln aber jelbjt Dez Sruttriebes; daz Månndyen einiger 2itten, alz Mergus serrator und Anas boscas, entfernt fich logar vom $\mathfrak{S e i b d}$ en, wenn biefes (Eyer ge= legt hat. Die Sage der Bewobnet bez Norbens, Dafi bas

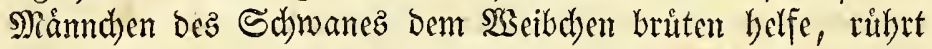
unftreitig baber, weil baz Manneben fo gern auf Dem gropen Refte an ber Seite Dez. NGeibchene zu ruhen pflegt.

Bon ben Srutflecten babe id) fdon im 29. §. gebandelt, und bargethan, bap fie, auper bev eimigen einzelnen Sumpf= vogeln ber (Şattung Charamrus, mut bey den borealen Schroimmbogeln " Der zufammengeferten Monogamie gefun= ben werben. Salh fand fie bey Eeiner andern Sumpfoogel= art, weldbe idh in ber Britzeit unterfuchte; gleidhfalfz feb)= len fie ben Sdywimmuogeln ber mittleren und einzelmen Shono= gamie. Die Tauther baben fie nidbt; zwar babe id in mei=

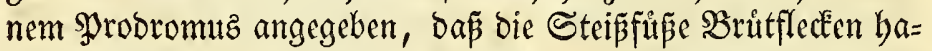
ben; ich war aber bamaliz nicht vollemmen aufmertjam barauf,

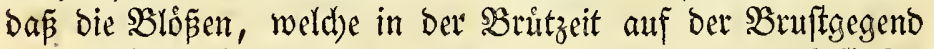

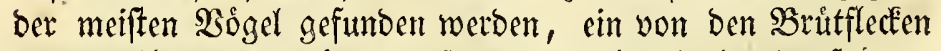

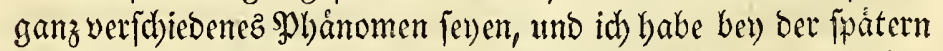

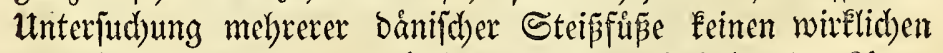
SBrutfleden gefunben; auth fteld bie Eigenichaft bey ben 2(rten

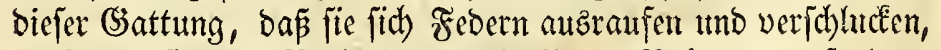
in Eeiner fruicten Berbinoung mit inrem Srutacte, fonbern icheint eber in einer.zut ibrer $\mathfrak{B e r b a u t u n g}$ geljurenden Notlywen=

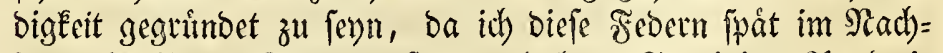
jabre in ibrem Magen gefunden habe. Sil einiger Rnalogie

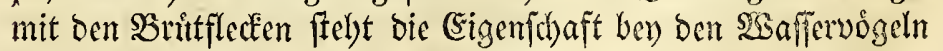
det eirrzelnen Monogamie, den জăgern, Enten uno (Şänjen, fid) vom unterleibe Flaumfedern auzzutwofen, unb. biefe im Sicfte zu oronen. Dem Sdimane feblt Dicje (sigenichaft.

Die Bruffleden entfteben Durd) 2fubrupfen Der Fe= 
bern, alfo burch bie unmittelbare (sinwirkung Der Bruter auf (id) felbit, uno find eine Folge von Dent ummittelbaren. (5rwa=

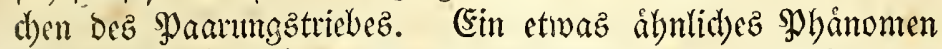

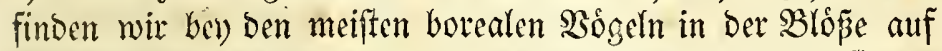
ber Brult, welde in Der \$aarungszeit ber ibnen Statt findet,

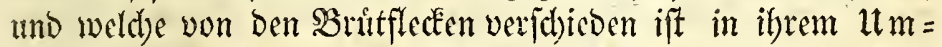
fange, weil fic fid) auf alle sogeloronumgen erftredt, in it)= rem Size, weil biefe Blópe fich uber ben ganzen linterleib verbreitet, aber vorzinglid) attf ber soruft gefumben wirb, uno

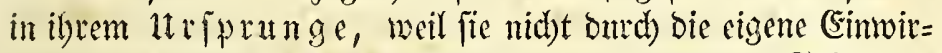
fung bes Sogcle entftebt, fondern cine unmittelbare Folge Des Brutens iff, fowie Der ftarteren Såne, weld)e in Der Brut= zeit nad) bem Itnterleibe bes Sogels ftromt, wobutd) cin sheil ber Federn losgelyt und ausfállt.

Dieje Blópe bez Unterleibes leiftet zum Theil Denfelben গuten, wie bie Bruttflecken, nåmlid) fie erleid)tert bie unmittel= bare Berublung Dez Eves mit Der Epidermiz, weld)e zul fei= ner (Entwidfelung notl)wendig ifit. Sie ftebt nidbt allezeit im umge=

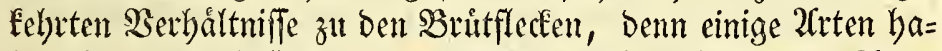
ben fowobl Bruitflecken, als nackte Bruft, namlich bie 2 rten von Phalaropus, Charadrivs, Uria grylle, von Sterna, Larus, andere, weldbe Brutflecten bejicen, baben indei= fen eine vollgefiederte Bruft, alz Uria alle, Alca torda, Mormon fratercula; wicber andere baben weber Situtflecten, nod) nackte SButt, z. B. Sie Sd)arben, Sólpel und Taud)er u. f. w.; bie meiften 2 rten, weld)e obne Bruttflecken fino, $\mathfrak{b} a=$ ben bod) in ber Brutzeit eine geringere Feberbedeckung auf ber Bruft, als alle Singuogel, und fins oft bajelbft ganz nadkt, als bas Schneelulyn uno die meiften Sumpfoỏgel. Da bie Månn= d)en ber Sumpf = und Sdhwimmvógel eben fowohl bruten, als

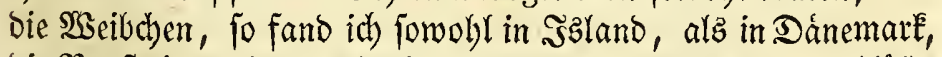
die Bruft jener in Der SBrutzeit eben fo von Febern entblöpt, alz bey diejen, namentlid bey Charadrius hiaticula, albifrons tmo pluvialis, Haematopus ostralegus, Numenius phaeopus, Lrmosa melanura, Totanus calidris, VaneLuus cristatus, Tringa alpina, maritima, Scolopax gallinago, Ardea cinerea, Poniceps subcristatus, Sterna arctica, nigra, minuta, caspica, cantiaca, LAnus mariuus, glaucus, tridactylus, argentatus, canus, ridibun-

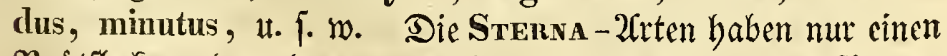
Brưtflecken; Denn bas, waz id) in meinem \$robromuz für ben 
obern Bruttflecken ber norbijchen Meerjobwalben angegeben babe, ift eben biefe Slópe, weldye auf Der Bruft gefunden wirb.

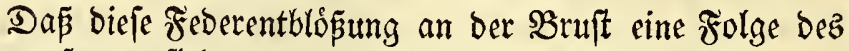

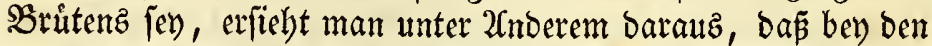

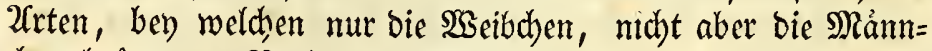
d)en brůten, z. SB. bey Den Sdhneebuhlynern, ez aud) mur baz

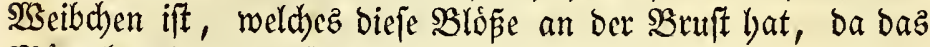
Månndyen bagegen feine volle Feberbededkung bebált. Diefe ausgefallenen Febern werben im 2uguft unb September, wål)= rend bie 2ften nod) in ber (siefelfid)aft Der Jungen gefunden werben, ebenjo geidomind, wie bie Sruitflecken, burd) neue Febern exjefit.

Utnter bem Sruten Eebrt bas brütende S̈ndivid zumeilen die Eyer mit bem Sdynabel um, um ibnen eine beffere $\mathbb{a} a g e$ zu geben, und bilft ibnen aud) $0^{\circ}$ in ben Sirutflecten hinein, wel= dee $i d$ bey Procellaria glacialis gejeben babe.

Die Såger, Enten und (Şänje legen die von ber Bruft abgeriffenen Flaumfedern nicht el)er in bas Neft, biz fie bie nor= male 3abl ber Eyer gelegt haben. Die Flaumfedern werden zumeilen unter bie Eyer gelegt, wie bey ben (5ibervogeln, of =

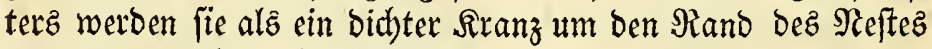
georonet, welden ich meift fidon fano, wie bey ber Aras clangula uno crecca.

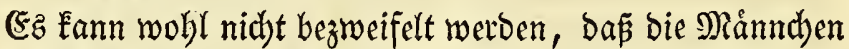
bey ben Singoógeln in fulzeren నerminen und weniger $\mathfrak{r e}=$

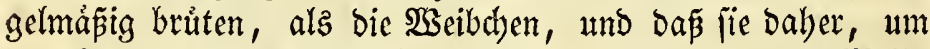
den Mangel ifrer Bruttuft zat erfecen, Dem brůtenden $\mathfrak{W}$ eib=

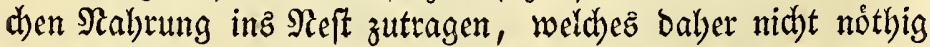
bat, biefes fo oft zu verlaflen. 20ber fo wie ez ganz meinel Erfahrung wiberipridt, daß̄ bie Månndyen ber $\mathfrak{B a f f e r b o g}$ ben brütenden $\mathfrak{B e i b d}$ en $\Re a b r u n g$ zutragen follten, fo finbe idh auch, baj̃ bie Srutpflidbt ber Månnd)en bey biejen zunimmt,

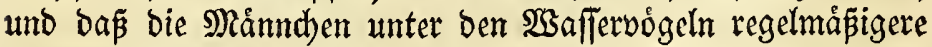
uno antaltendere Srùter find, als bie ber Singvógel.

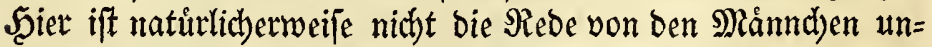
ter ben $\mathfrak{2 3 a f f e r v o ̊ g e l n ~ b e r ~ e i n z e l n e n ~ M l o n o g a m i e , ~ w e l d b e ~ i n ~ b e r ~}$ Brutperiobe ganz unwirkfam find, ja fich zumeilen von ber brú= tenden (sattin entfernen. Sch babe námlich eben fo oft bas Månnd)en bet norbijdben 2(rten von Uria, Alca, Mormon, Carbo, Puffinus, Colymbus, Podiceps, Procelania, 


\section{1}

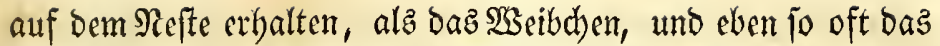
Rändjen von ben Meven, Meeridhwalben und Raubmeven auf Den Evern mit Sdhlingen gefangen, alz bas $\mathfrak{S e i b d} e n$, tmo zrwar fo regelmápig, baf bie zu berjelben Tageszeit gefangenen Bruter aud) von (Einem (Sefd)led)te waren, Des Mittags uno um Nitternadbt Mánnd ben, Dez Morgenz und Dez Nachmit=

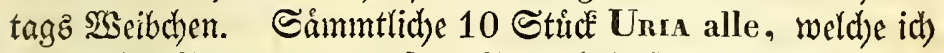

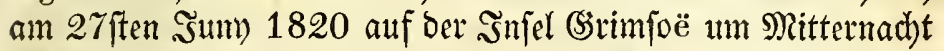
auf ben Eyern fing, waren Mianndben, und von bemfelben (3) $e=$ id) lechte waren 6 Stude Puffinus arcticus, welde id) im Sommer 1821 Mittags auf ben $\mathfrak{S e f t m a n n c e ̈ i n j e l n ~ a u s ~}$ ben SBrutlódbern lyeraugzyg; bie meiften sndiviouen bage=

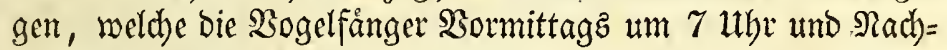
mittags nabmen, waren $\mathfrak{S e i b d}$ en. Ez ift jebr zneckmá= jig, Dap̃ in Den falten (Segender, wo das Ey nid)t lange un= gebrutet liegen barf, Daz Mändben eben fo ftrenge Brutpflicht

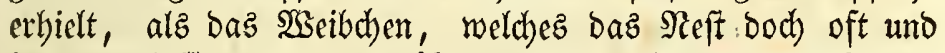
lange verlaffen muta, um offer auf bem (3runde DeE Meerez feine Nabrung zu fudben; Dod bruten Die Manndhen Der mitt=

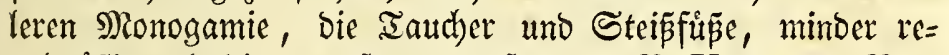

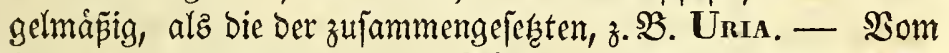

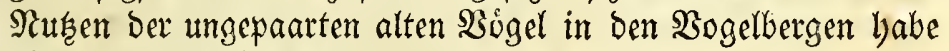
ich idjon im 25ften $\$$ gebandelt.

Die So̊gel liegen gewólynlid fid)er auf ifren (5yern, und fesen fie in Der Regel nie Der Gefabr auz, falt zu werden.

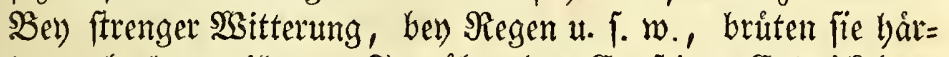
ter, als bey milder. Se náber daz (5y jeiner Entwiďelung

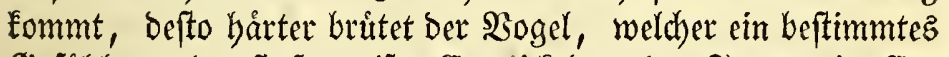
(Sefuibl von Der ftufenweijen Entwidelung dez sungen im Eve

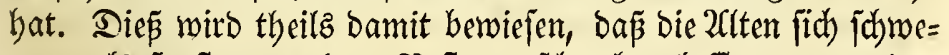
rex, alz fonft, von Dem Nefte verfdyeudben laflen, wenn bas

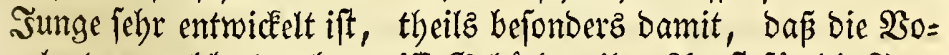
gelarten, welche Durch gewiffe (Sebároen ihre 21ngft für bie Sun= gen zut erfennen geben, dieje fdon zeigen, wenn ibre ber Ent= wickelung naben (Eyer in Gefabr find, nicht aber, wenn fie erft vor. গurzem angefangen baben zu bruten. (Sleid) fallz be= merken bie $\mathfrak{B}$ gel es oft, wenn ibre Eyer verfault find, und verlafien fie alzbann, ohne daz Briten fortzufegen. Man fann fogleid) aus ber 2lrt, auf weldbe viele Singuógel, Enten u. f. w., eridjedet ibr seft verlaffen, feben, ob fie Sunge in ben Eyern baben oder nid)t. Sas $\mathfrak{B S e i b d}$ en Der ANas acuta unb ber pa= 


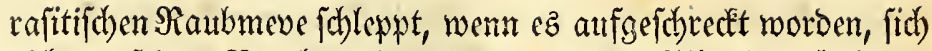

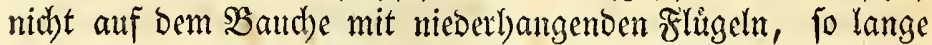
rz. Keine sungen in ben (Enern bat.

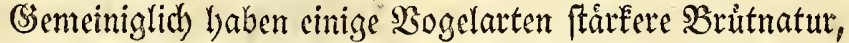
alb ambere. (Ėz if jebr idhwer, Haematopus ostralegus, Charadrius hiaticula oder pluvialis, Numerrus phaeopus, Limosa melannia, Totanus calidris oder Vanelius cristatus atf Den (Enern zu wiberrafchen, da fie ben ber geringften (Se)= fabr baz Nieft verlaffen, und fogar zutweilen fliegend butd) (Ge=

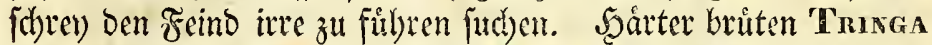
alpina, hypoleucos, uno Scolopax gallinago, welche biz= weilen auf ben (Enern úberrafd)t werben. Llnter ben Sumpfod=

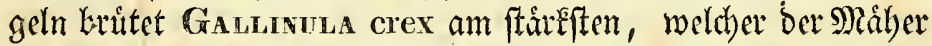
zumeilen ben Sopf mit jeiner Senfe abl)auen $\mathfrak{k}_{\mathfrak{a n n}}$, indem fie

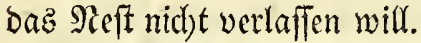

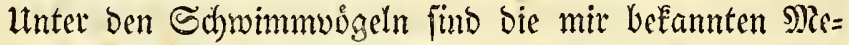
venarten, auper ber brenzelsigen Mieve, bie Meerfd)walben und Raubmeven fo loje tno wadjame Szruter, Daj fie jebesmal, wem fie einen Menfden in ber Fetme gewabr werben, firt) fohreyend vom Sicfte in bie Ruft erbeben, unt-kaum auf ben Eyern liegend augetroffen werben fónnen. Daler läugnen

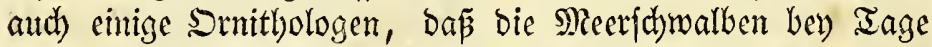
bruten, da fie fo jelten auf ben Enern gefelyen werben.

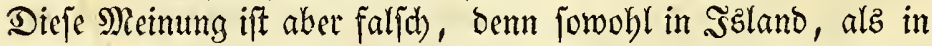
Dánemark, babe id) bie arktifche Meerfdhwalbe z̧u Der 3eit bru= teno angetroffen; fie liegen aber Eeine Biertelifumbe umunterbro= chen, ba fidy affe ber jebem Lante in bie Ruft erbeben, und

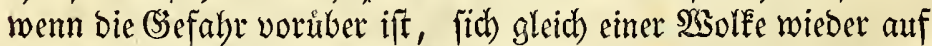

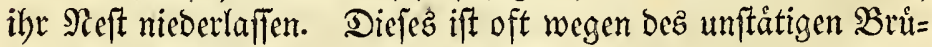

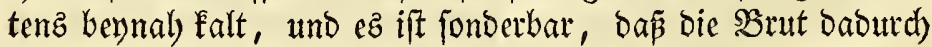
nid)t leibet. 2(ts ich) auf einer zoologifchen Excurfion im Som=

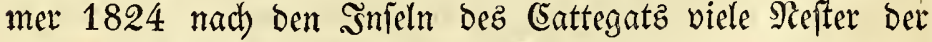
Sterna caspica mit bollzåbligen (Enern fano, waren bieje in

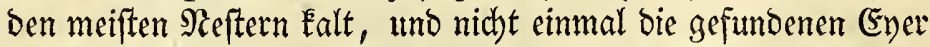
von Larus canus und argentatus, aus welchen bie sungen Den Sdinabel heraubzeftecêt batten, waren fehr warm. Die

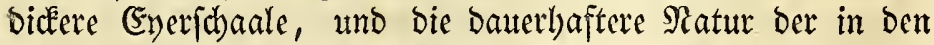

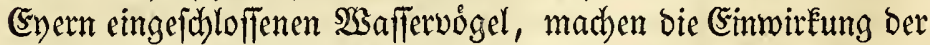

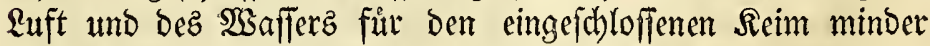

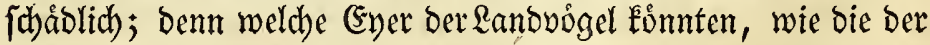

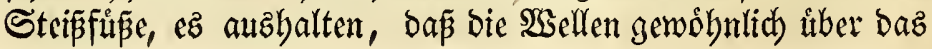


Neft megidhlagen, oder, wie die (Eyer bez Canbo und der Sula, ba

Scairter, als bic Meven tho Meeridwwalben, briten die

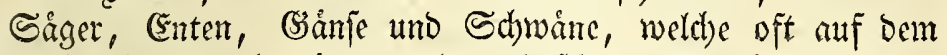

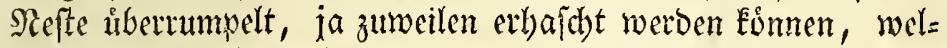

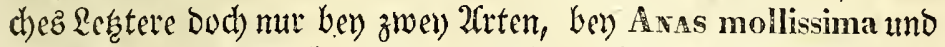
clangula, geghideft ift. (Ében po ficher bruten bie Steip̃fiñe und

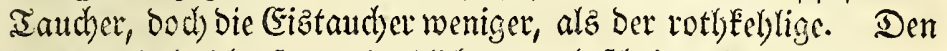

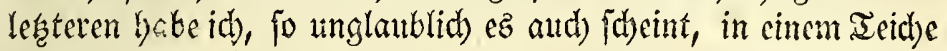

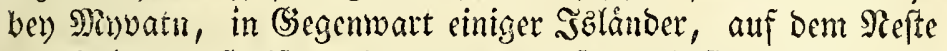

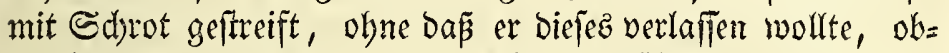
gleich bic (Eyer unter ilym vom Ed)rote zerfhlagen waren, uno nut ber zweilte Sdur

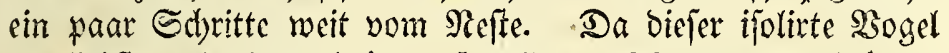
am liebften abgetegen britet, fo leibet er keinen andern briuten=

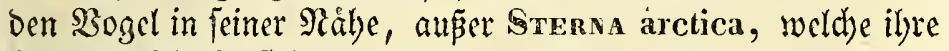

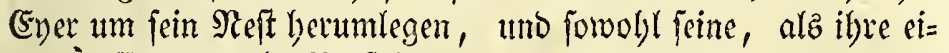
genen (Eyer burd) SBerfolgung ber enbegierigen Raubmeben

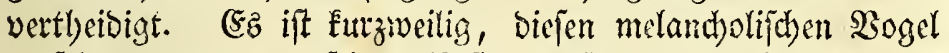
zu fel)en, wenn er zu feinem Mefte angeifthommen fonmt, uno bie ganze Sd)aar ber um ilgn berum britenden Meerifbwalben

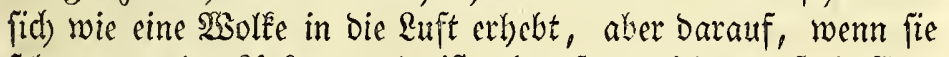
fehen, wer ber 2 nnfommende iff, langjam wicber auf bie Ener berunterfinkt, indeflen ber Saucher, unangefochten von $i b=$ rem (3ejchren, fein Mefít befteigt.

Itnter allen 2frten bruten bie in ben F̌elenfeiten enlegen=

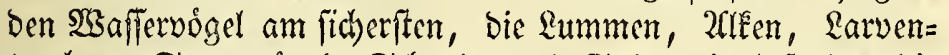
taucher, Sturmbigel, Echarben und Sulen, inabcjondere bie 2frten ber vier erfiten (śattungen, bey weld)en id) bie auffällend= ften Benfpiele einez batien uno futdotofen Srutens gefehen babe. Dieje (Eigenichaft ift Den bey Den 20 gelbergen $\$ 230 \mathfrak{b}=$

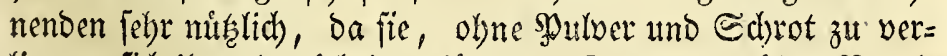

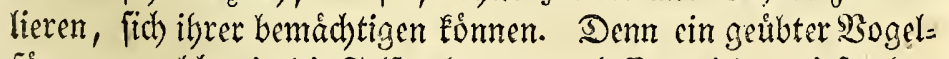
fånger, weldher in bie Felien Yyeruntergelaffen wirb, wirit obne

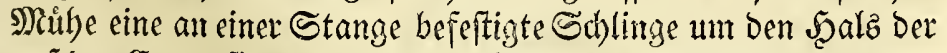

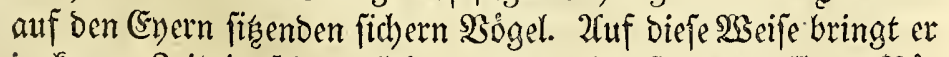

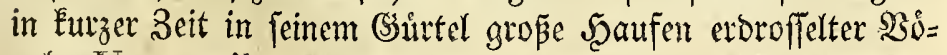
gel: Uria troile, Brünnichii, Alca torda, Monnon fratercula uno Lanus tridactylus, berauf. Da biefe lefgtere 2 frt am leidhteften won alfen auf Den (Eyern zu fangen ift, fo ift baz

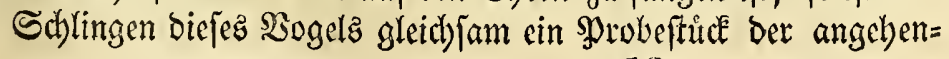




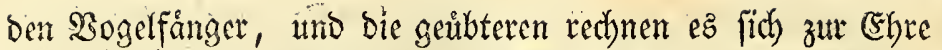

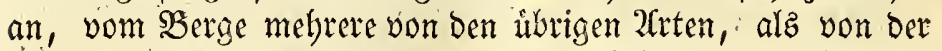

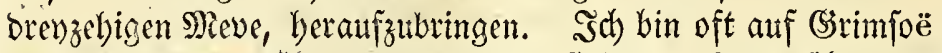

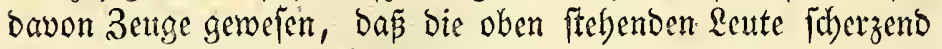

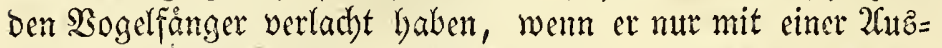
beute von biffen Meven leraufgefonmen, nicht aber im Fange

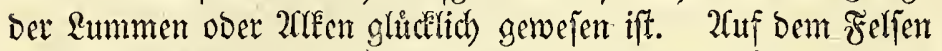
Brandten Eonnte id) in ber Solonie ber weísen Tólpel fo viele von ben alten Bógeln hajden, atz ich wollte, uno bey bem Sogelberge ben Reblevif tonnte Canso graculus mut bund) Sdjepen von feinen (Enern vertrieben werben, ob er mich gleich

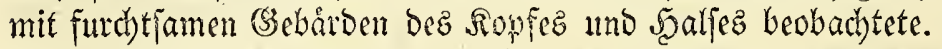

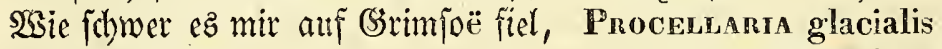

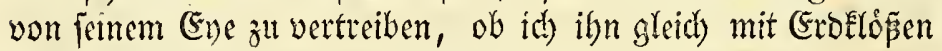
warf, habe ich fdon in meinem \$rosromut errwálynt.

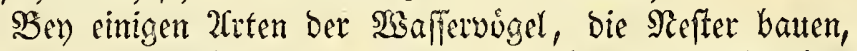
ober Flaum im Refte baben, tho bei) welchen bas Mảnndben entweber gar nidet, oder minder ank alteno britet, bebect ber

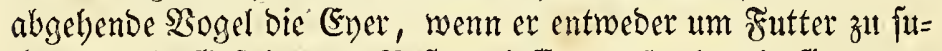

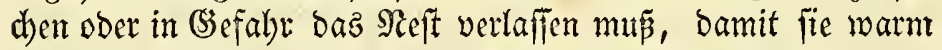
bleiben, uno verborgen feisen. Durb bieje Bebeckung fidyert er jie

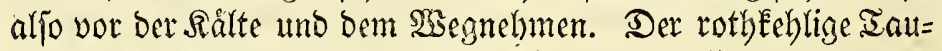

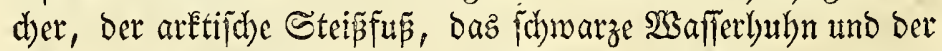

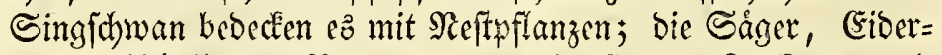
enten, Edhellenten, Şergenten, gemeine Enten, Sireckenten utno

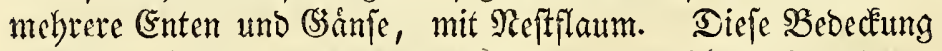
Der (Eyer findet bey Den Sogelaiten, bey welden ein anderes Srnbivisuum gleid) bie Function bez SBrutenden ủbernimmt, $z . \mathfrak{B}$. bey Sula alba, nidbt Statt.

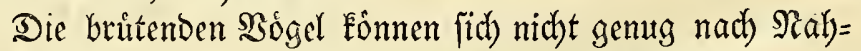
rung umielen, uno werben baher unter bem Sruten mager. Şierin wiro keine $2 \mathfrak{i n a l o g i e}$ bey ben Sångethieren gefunden, da Diefe, z. S. bie Seelyunde, o̊fters am fetteften find, wáhrent fie ihre Frudt tragen. Die Magetkeit nimmt zu, wenn ber

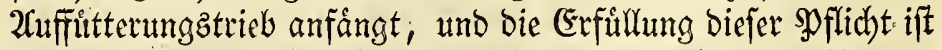
aud im Stande, bie Sángethiere bald zu enteráften. So ver= lieren bie Seehunbe in bem einzigen Monate, in melchem. jie ibre Sungen fåugen, beynah allen ibren Spece. Die ponft fo feiften Procelinaria glacialis und Puffinus arcticus werden in ber Britzeit woblfidmedfender, weil fie weniger fett find, und ich babe Uria troile und Sula alba in ber Enzeit fo ma= 
ger gejeben, baj bie Fettzellen unter ber Şaut ganz leer wa= ren; aud Der Fibervogel and andere Enten verlieren grópten= theils bie Fettlage, weldse fo foft an ilyere Saut fitst; fie fino baher in Der Brutzeit leid)ter, alE fonft, furr Bogelfabinette zu pråpariren.

\section{§. ฌ8.}

Die Entwickenng Des Sungen im (5) zu verfolgen, gebort

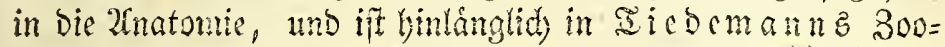

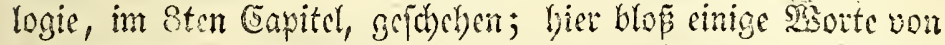

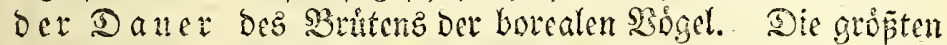

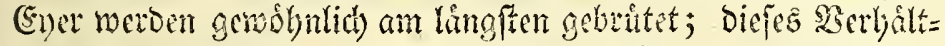

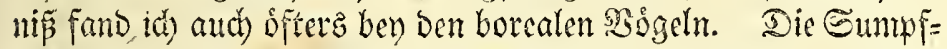
uno Schnimmoogel legen umgetoobnlich grop̃e Ever, bruten

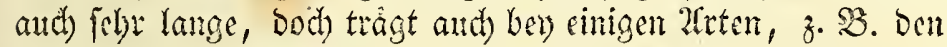

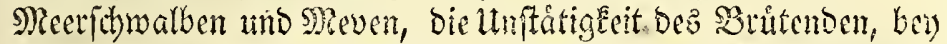
andern, z. S. Den Gteipfinpen, die Einwirknng bes Waffers, ber anderm wieder, z. 23. Una troile, die Bicie der Edjaale,

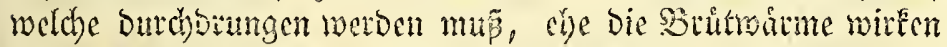
fann, objhon fie in gleichem serboltniffe biefe linger cr=

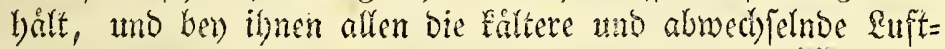
temiperatur in bem bohen Sorder, zu Der ungewdintio longen Srittgeit ber borealen Soggel beis. Sad) babe indefien nidit fin=

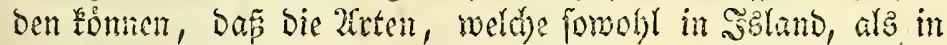
Dámenan briten, z. B. Motachu alba, Asters pratensis ind Chamanues hiaticula, bort mebs 3eit bagu beditfon,

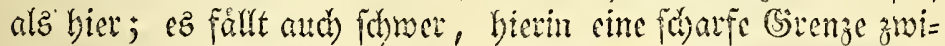
idben zwey benadbarten Bonen zu zielyen. Einige sphnfiolo= gen ncbmen zugleid an, Dap̃ bie Eange Det Brotitgeit mit Dor

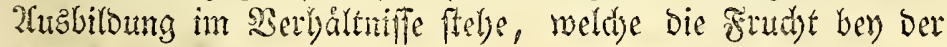
aubivitung babe.

Selen Eann man mit vollemmener (3)enauigect bie SBritzeit Der refpectiven Mogelarten angeber, weil Dağu eifodert wito, Dap Dab beobachtete Neft ungebrittet getvefen, als man es fand, und bas ez unmuterbrochen biz zut 2Tušbrutung oer Jungen beobad)tet

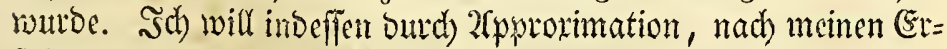
fabrungen, bie Sarutzeit einiger norbijeden Sögel angeben.

Tabelle iber bis Dauter ber SBrutzeit borealer 'Sógel. Die Namen. Falco albicilla Die 3ahl bei Tage.

- caesius 
Die $\mathfrak{\text { Ramen. }}$

Die 3abl ber నage.

Convus corax

Tetraao Islandorum

24.

Emberiza nivalis und Turdus iliacus . . 14.

Fringilla liaria, Motacilla alba, Saxicola oe-

nanthe, Antrus pratensis . . $12-14$.

Hammatopus ostralegus . . . . . 24.

Charadrius hiaticula $\quad . \quad$. $\quad . \quad . \quad 18$.

- - pluvialis $\quad . \quad . \quad . \quad . \quad 20$.

Nonenios phaeopus und Limosa melantra . 24.

Totanus calidiris und Scolopax gallinago . 18.

Tringa maritima und alpina. . . . 16.

Phalaropus cinereus uno platyrhincus - 14.

Uria grylle und alle $. \quad . \quad . \quad . \quad 24$.

Unia troile, Brïmnichii, Alca torda uno Monson

fratercula . . . . . $30-35$.

Сапво cormoranus $\mathfrak{t n d}$ graculus $\quad 24-28$.

Puffinus arcticus . $\quad . \quad . \quad . \quad . \quad 30$.

Procelanta glacialis . . . $35-40$.

Colvubus glacialis . . . . . . 30 .

- — rufogularis . . . 24-28.

Poniceps arcticus und cornutus . . 21.

Mengus serrator, merganser, Avas nigra, mollissima, clangula, marila, acuta, boscas . 28.

Aras glacialis, histrionica, penelope, crecca 24 .

Avser segetum, albifrons . . . . 30.

Crgnis musicus $\quad . \quad+\quad . \quad . \quad . \quad$. 40.

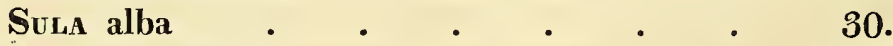

Sterra arctica $\quad . \quad . \quad . \quad . \quad . \quad . \quad 18$.

Larus tridactylus . $\quad . \quad$. $21-24$.

Lanus marinus, glaucus, uno Lestris catarractes

LESTRis parasitica $. \quad . \quad . \quad . \quad . \quad 24$.

Nidft alfe Ever ber borealen Bógel finto befruchtet; bie un= befrudhteten verfaulen burdh bie Bruitwåme. Soldhe verfaulte

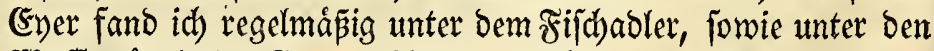
Wsaffervoggetn ber Canвo- 2irten, weldhe 1 - 2 verfautte (Eyer in jebem Siefte haben, bey den Colymbus - 2arten, bey weldhen man of̣t ein verfaulteb (Ey findet; aud war bas einzige (En ber 
Sula alba zumeilen unbefruchtet. In Den Reffto̊chern bez Puffrnus arcticus umb Monmon fratercula fano id melyrmals ein verfaultes (En; auth ift felle oft cin (Ey der Meven, wenn

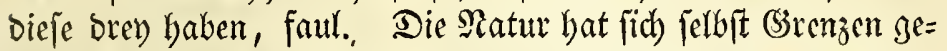

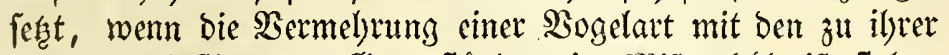

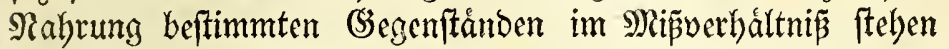

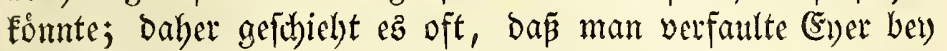

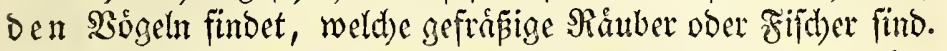
Meine angefiuthten Erfahrungen berweijen biejes. (Ein joldbez unbefrudbtetes En hat, fo zu fagen, feine eigentliche Bebeutung

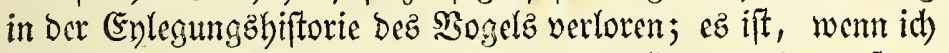

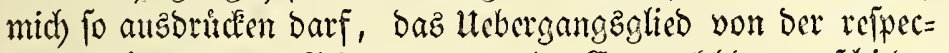
tiven gróperen uno Fleineren nomalen Eyanzahl ber verjojicoe= nen 2 reten, unb hat baher, wie hiberhautpt bie Hebergangzin=

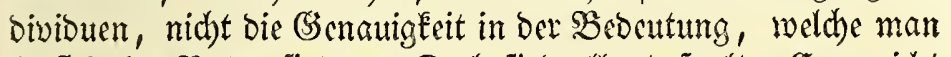
fonft in ber Ratur firmoet. Dod) fino alle verfaulten (Ener nid)t cben unbefrudtet, da einige unter bem \$ruiten burd Stop ober (Erkéltung bejdáabigt werben.

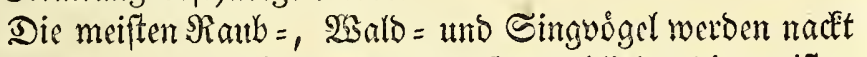
auz bem Ene ausgebriutet, mehrere fogar blino, bie meifîten bưlynerartigen Boogel bagegen, bie Sumpfoógel, uno beymall alle Sdymimmoigel, baben fot)on Flaum im Eye, uno werben alle febeno ausgebrutet. Sn Den erften Tagen jieben fie zwar bie 2 Uugenlieber zufammen, biz fie das Sonnenlicht grwohnt werben, bas 2luge ift aber nid)t abjolut geidhlorter, wowon id) mid) bey ben Sturgen mebrerer borealen SBogel im Siefte uber= zertgt lyabe; bey vielen ber in meinem \$orodromus aufgeführten

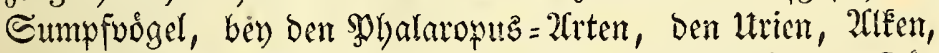

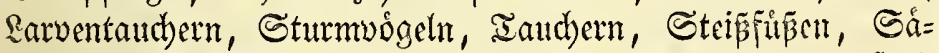
gern, Enten, Reven, Meerid)walben uno Raubmesce, fano iid) bie Sungen im (5y) mit Flaum bedect'; aud) in Dinnmart fand id) daffelbe bey Stenva nigra, Larus argentatus, canus

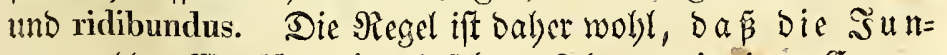
gen aller 23 afferoogel fdon Fla tu in ben Ëyern baben. Dodb babe id) jwey Ztusnabmen ben ben borealen C(d)mimmoógeln gefunden, mámlid bey Савво graculus uno Sula alba, deren sunge Flein und ganz nackt auts den Eycrn Eommen; nach 8 Iagent brid)t erft Der Flaum lervor, Der fie in ifrer Dunenperiode bededft. Ssalyrfcheinlich fommt bicpe atbweid)ung allen Gteganopoben zu.

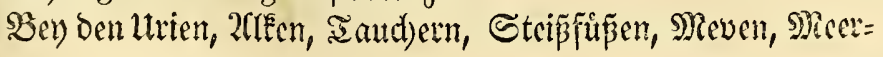


\{chwalben, Raubmeven und Strtmbogeln, fand id) an ber Gohnabelpige Des vor Surzem aubzebruteten Sungen eimen Fleinen erbobren, hornatigen, gefarbten fleden, weip, roth) ober violett, welder in ber parem Dunemeriode wicder ver=

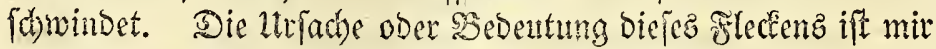

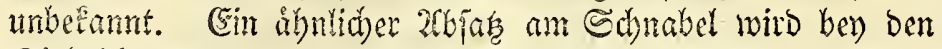

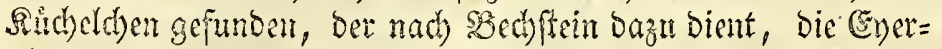

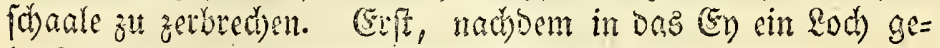
bact war, babe ió daz sunge peifen bòren.

SEem bie befimmie Sritzeir geentigt it, und das be=

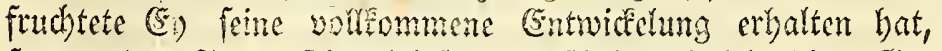

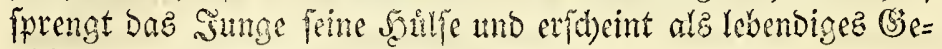

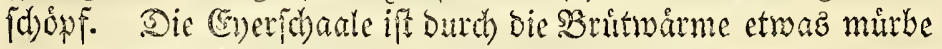
und zerbrecolid gewarden. Sasic bieje zerterodyen wirb, und

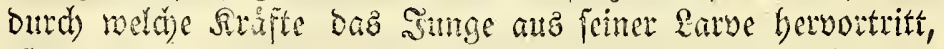
if eine grage, wiber beten Seantwortung id mit ben meiften $5 \mathrm{r}=$ nithologen niat cinfimmig bin. CEz ift betamnt, Dap ber $3 e r=$ bred)ungzact mit cinem Snitie an bem einen Ende Dez (Eyez anföngt, ber wie bie Etrablen in einer zerbrodenen Fenter= fibeibe ansftrlt. Diefe Rise, fagen einige ber Somitbologen,

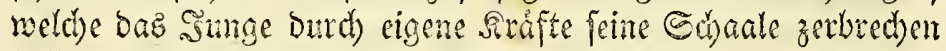
laffen, fei) burch dic Erampfofite Szewegung Des Sungen ent= fianden; aber warm follte benn ber erfte Snice immer ba ge=

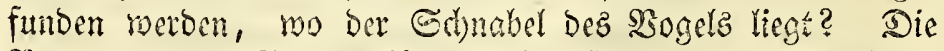

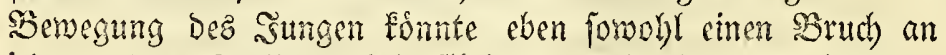
jeder andern Stelle der Sberfiche Der Sd)aale zumege bringen.

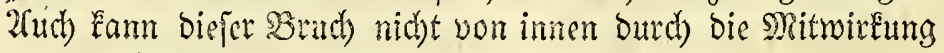

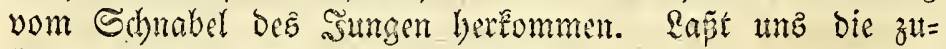
fammengebodite Gtellung betradten, in weldher bas sunge liegt, mit Dem Sopfe unter Dem fritugl, roourch es ilym un=

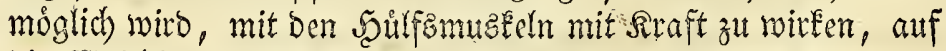

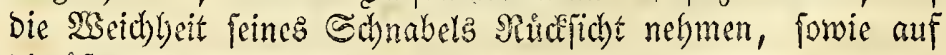
dic offterz febr bicie Gdaale, o. 20 . bey Una troile, und bann fragen: ob es wabrid)einlici) fey, daj daz šunge mit feinem eigenen Schnabel biefe Riśe zuwege bringen Eonne. Dieje

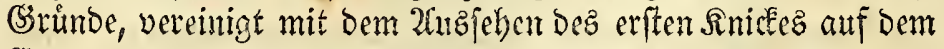

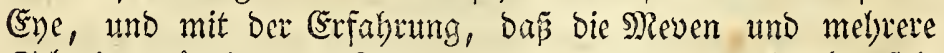

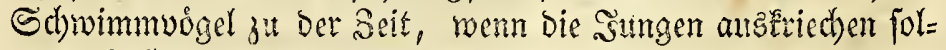
len, oft frebeno bey Dem Sefte unb mit Dem Schnabel barin be=

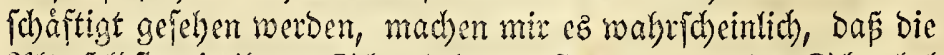
alte felbft mit ifrem Sdbnabel bem Eye ba, mo ber Sdhnabel 


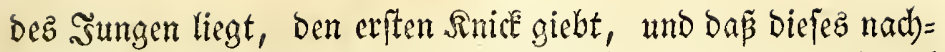
ber frlbft Dutch eigene Sraft Die Saut bes (Eyes und bie einmal zerbrodene" Shaale Durdbridt, woourd es ein, Eleines Rod) erbålt, Durd) weld)es es feinen Sannabel ftedt. Da Der Sd)nabel Des sungen zuterft zum \$orfd)ein Fommt, giebt Eeinen Semets bafur ab, Dáp Dicjes jelbft allein bie Schaale zer= brocken babe, Da Diefes eine Folge feiner Lage im Eye iff, uno zugleich) analog mit ben sinngen ber Saugthiere, walthe mit Dem Ropfe zuerft geboren werden. SWenn Daz Singe feinen Schnabel berauggeftedt bat, rubt ez mebrere Stunden, viel= leicht, um burd Das (Finathmen Der atmofpháriłd)en Iuft Rråfte zu fammeln, unb bann exft fångt ez an, die Sdjaale vollends zu zerbrechen. Şd babe die sungen von Lamus canus ge= feben, wie fie, in bet fohon getheilten Sahale zujammenge= buckt, Durch wurmformige Serwegungen fich von ber num

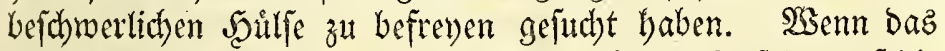
sunge aus dem Eye gekommen ift, fo fâll es Eraftlos auf bie ganze Unterfláche Des Siorpers bin, und wird gleich von Den 2flten errårmt; erft wenn bie Freudjtigkeit Des (Gyes von ibm abgebrutet ift, ziebt es feine (Şlieder, von oer SBritroárme be= lebt, zufanmen, unb erbebt fidt; Dod bletben bie Jungen ber Raubvoigel flach auf bcm Unterleibe im Nefte liegen. Şier zeigt Die fortbauernde 2 ebnlichereit Des neulich ausgebritteten Singen

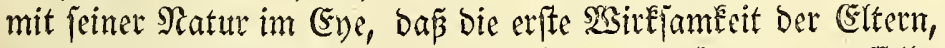
Deren es als Sunges bebarf, námlid) Das (Erwårmen, Daffelbe

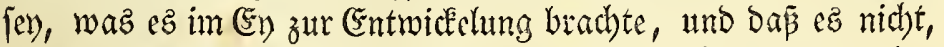
wie bas Junge Der Sảugethiere, augenblictid)e Saabrung beDarf, bis es zumeilen nad) melyreten Tagen burd) bas anbal= tende Grroirmen Der 20rten fein wabres animalijhes Reben er= balten bat. Die zerbrochenen Schaalen werfen bie 2lten gleidh auz Dem Sefte. Einige Sunge, weldbe keine Siafte baben, Den Serbrechungsact auszubalten, fterben in Der Schaale, wie die Frutd zuweilen in Der (Seburt ber Den SMenfd)en und Såutgthieren.

Sebr felten finbet man bel) ben wilben $20 \delta g e l n, ~ d a \tilde{p}$ bie Sungen aus bem Ey eine abnorme (s)efralt mitbringen; unter

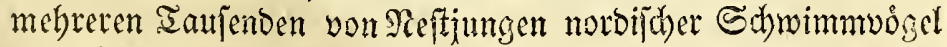
(ab) id) keins mit riberzályligen ober mangelnden (Šliebern, uno

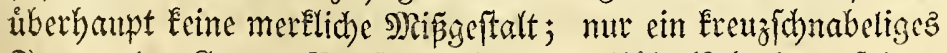
Sungez der Suea alba fand idh in Der Tolperelonic auf Dem 
Felfen Branoten. (Sleidhalls habe id vorber eine treuzidnnabe= lige Barictåt von STrux nyctea erbalten.

(Ez fen mir erlaubt, bier nod) die Frage berzujęen (Dod) obne ben Berfuch), fie zu lófen), ob bie Ratur uno bie Triebe dez Bogelz allein im Seime bez (Eyes eingeid)loffen liegen, ober aud) zum Iheil Dem Sungen unter bem Briten, buth bie einbringende Sirutwárme, uno burd) bie Mittheilung bet Lebensêtáfte von ber Matter mitgetbeilt werben? Da ber Brutact Der $B o g e l$ mit bem Iragen ber Frudt im Nutterleibe bev den Saugthieren in $2 \mathfrak{n a}=$ logiefteld, fo fann bas Briten viefleid)t eben fowobl einigen (Sin=

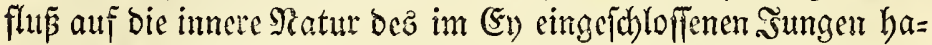
ben, als fie bazu bient, feine phisfifde Natur zur Bollemmenbeit zubringen. Sndom rafle tonnten wir uns aud) die Sonderbarkeit

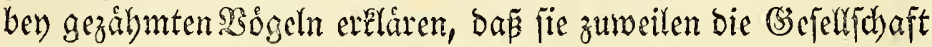
anderer, ja fogar bie \$saarung mit andern, ganz verichiedenen Bogelarten lieber, als mit iber eigenen begebren und fuchen.

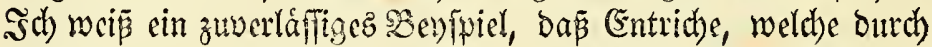
Şitlyer fint aubgebrutet worden, die spaarung mit Şưnern ber mit Enten vorgezogen haben, ob bieje gleid zugegen wa=

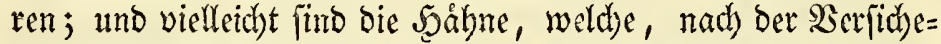
rung melverer Saturyoridher, fich licber mit ben Enten, als mit Sulfnern paaren, durch (Enten auggebritet worden.

\section{§. 39.}

Dritte pseriobe. Die frutterungahiftorie ber borealen $\mathfrak{N}$ ógel.

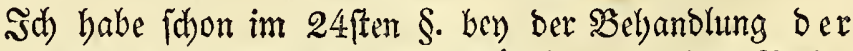
$\mathfrak{F} \mathfrak{l} \mathfrak{a} \mathfrak{m} \mathfrak{p} \mathfrak{e} \mathfrak{r}$ i d e ber borealen SBogel, ober ber Sperio= De, in weldher fie als sunge mit Flaum bebedt find, auf bie Futterungshiftorie biefer $\mathfrak{S o g} g e l$ bingewicfen, weldye in ber Regel bey Den huibnatartigen, bey Sumpf = uno Schwimm= vógeln bie erite \$periode ihres Rebens ift, weil fie damit aus bem Eye fommen; nut Sula und Carbo fommen, alz $\mathfrak{A} \mathfrak{h} z=$ nabme, nact aut dem Ěye, uno betommen erit fpảter Flaum. Dagegen werben bie borcalen $\Re a u b=\mathfrak{B a l d}=$ und Singyogel ge= meiniglid nadft ausgebruter uno erbalten erfit ipảter Flaum; in jedem Falle ift bie Flaumperiode ein \$hanomen, bas in bem $\mathfrak{e}$ ben bes $\mathfrak{B}$ ogelz eher eintritt, als bie Feberperiode; und Flaum ift in ber Regel bie Bebeckung, weldhe bie sungen tra= gen, fo lange fie unter ber Spllege ber alten fino. Deprwegen fino Sefteleid und Flaumfleib oft, bod) nid)t immer, fynonym; 


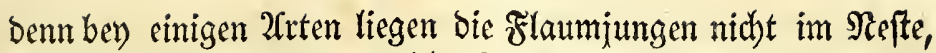
3. B. bey ben (Enten, weld)e Furz nad) ber 2fuzbrittung ben Reftplás verlaffen; zumeilen baben bie sungen, weldye im Nefte liegen, feinen Flaum, wie bie Sungen ber Singudgel, Scharben und Iólpel, weldhe in ben erften Iagen nacfe find, uno zumeilen bleiben bie Sungen noch einige Beit im Mefte liegen, nadbem fie jehon Febern erbalten haben, z. B. Die brenzehige Meve, obgleid) gerwofhnlich bie Feberbebectung für bie Meiticun=

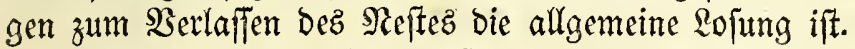

Dunen oder Fla umfedern find weidhe Fajern von verihbiebener Rånge, ofterz kinzzer, als bie Frebern, unb von biefen in ber (seftalt veridojeden. Sie bebeden ben gan= zen אiórper in Der Flaumperiode, nur nidbt ben Edhnabel uno

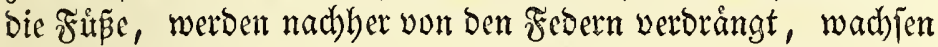

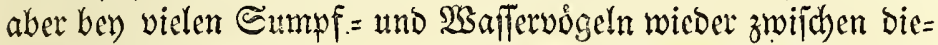
fen heraus, und find, fo zu jagen, daz inmendige Aleid ober bas Şemb diefer $\Re$ Sigel. Sie find bie warme Decke, beren ber (Eibervoget und andere (Enten in Der (Enzeit fid) berauben, um

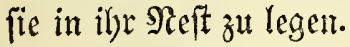

Die Dunen fint bey ben verfhiebenen Flaumjungen von veridiebener $\mathfrak{B}$ il bung und Menge; bod bey al= len ziemlich weidy und elaftijch. Ben Den Sungen der $\Re a$ aub= vỏget bidt, bey ben Singuógeln bưm zerftreut. Sery ben meiften Sumpiodgetn, als beym Regenpieifer, Bractuogel, Steinwelzer, నibis, Den Sdanepfen, Şafferláufern und auth

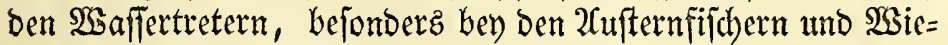
fenenarren, fint Die Dunen ziemlid) bidht. (Ebenfallz bey Den

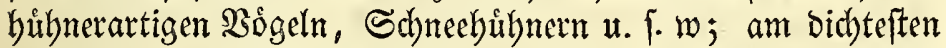
aber bery Den Sdtwimmoógetn. Reine von biejen baben kitr= zere Dunen, als bie Flaumjungen Der Scharben und Iól=

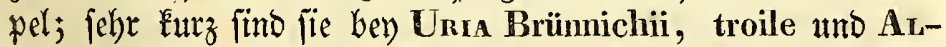
CA torda; weit lánger und weidjer bev Dem an ben vorherge: benden übrigenz angrenzenden Mormos fratercula, beffen

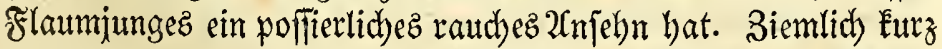

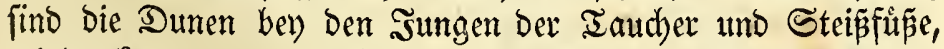
minder futrz und etwaz fteif bey ben Sảgern, Enten, Ssánjen

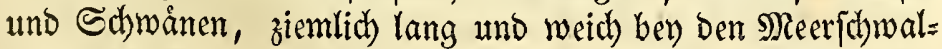

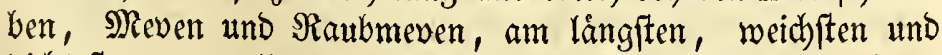
Didhteften unter allen bey Den Sturmvógeln uno Sturmtauthern,

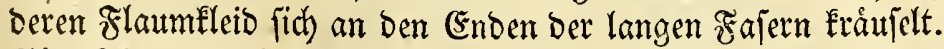
Fin Eeine ber borealen \$ogeljungen im Refte hat bie $\mathfrak{R a}=$ 
tur úberbaupt mebrgeporgt, als für bie dez Sturmoogels. Diefe baben auşwendig einen bichten Jelz $_{\text {bon }}$ Duten, imwendig eine

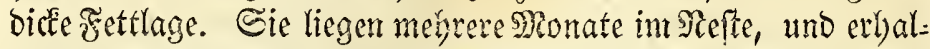
ten uberflufig Nabrung aus bem Golumbe beiber (Eltern, weide ibre ganze Sorgfalt mur anf ein einzigez Junges verwenben; bey einigen 2trten liegen fie in gegrabener Spoblen, und Das Seftiunge Des Cis = Stutrmoogels fann fid fogar vor allen an= bern norbifd)en 30 gelarten gegen ZThriff veitbeidigen, indem eE feine Feinde mit sigran befprift.

Die Farbe ber Flaumiungen ift bey den verjoiebenen 2rten veridhieben, fowolyl an fich, als in Der Farbe, weld)e jebe 2rt nadber beftedert erbålt. Das Flaumiunge Der Utren gleicht nidbt Dem Der Guten, Dieje nicht Denen Der Ireven u. f. w., in ber Frarbe; ebenjo bat bas Flauminge ber Meven eine an= bere Farbe, als die befieberte Nebe 4. \%.m. Dod babe ich bemeret:

a) Dap Die F̌laumiungen Der zu Giner (Şattung gebỏrenden 2rten fid) einander melyr gleichen, als biefelben 30 gel in ber Febertrad)t Den 2lten åbnlid fino. So baben alle Neven und Enten = 2uten als Erlauminge ungefaly diefelbe Farben=

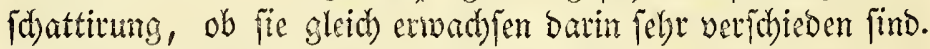
Man vergleid)e Lawus ridibundus, argentatus, marinus uno eburneus, fo mie aud) Aras mollissina, glacialis, boscas; ebento Daz flaumbededte Sunge von verfdiedenen (B)atungen Det Sumpfoigel, als Nunenivs, 'Lotanus uno Trivga, weldhe einander in Der Farbervertheilung febr gleidsen; endlid) aud) Die von Dex Dez Pufrivus areticus verfdiedene Frarbe ber Proceluaria glacialis, obgleid) ifre Flaumjungen ungefál)r diejelbe Farbe baben. Ferner bemerte ich:

b) Daf bie Sogelarten, welche in Der alten Febertractst von einer åbnlicten Farbe find, biefelbe auth of in ber Flaum= tracht baben. Go gleiden fid Larus canus und argentatus, Lestris pomarina uno parasitica, STERA arctica und hirundo, Una Brünichii uno troile, Canbo cormoranus uno graculus cinander fely, wenn fie erwadifen find, uno gleidfafts als Framminge. Da Dawon baben wit cin mertwirdigez Benfpiel an ber Unu troile und Arca torda, welde in Der alten Iradht ganz biejelbe Farbe baben, Dagegen alz Flaumjunge fely verifbieden find, indem

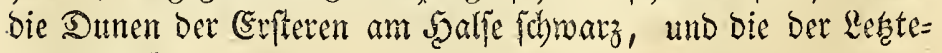
ren weíp find. 
c) Pagegen ift bie Farbe Der ש̌llaumintungen gemeiniglich verfichieben von ber, weldhe fic nadbler, befiebert uns erwadjen, ertyalten. Man vergleiche blop bie Dumen = und Feberfarbe

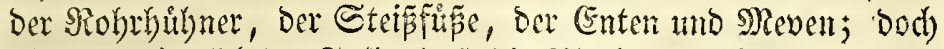

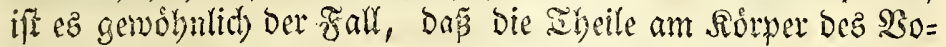
gets, welde befiedert eine Duntere Farbe baben, aud in Den Dunen von Dunfleter Sedattiung find, z. B. bey PurfiNus areticus und Tonmos fratercula, bev welchen ber Sber= leib forwohl in Den Dunen, als in ben Febern bunkler, als Der Interteib iff; obgleich nid)t immer, z. SB. Gen Farco albicilla and Alca torda, beren Sberbalz in bet Flamperiobe weip, in ber febertrad)t aber, wentgftens in ber erften 3eit, braun ift.

Dodh giebt es aud cinige Sogełarten, deren flaumiunge

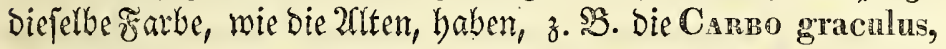
bey we!cher Der Uebergang von Der Dunenfarbe zut Feberfarbe

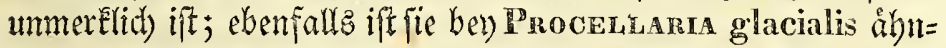
lich. Sev einigen 2tren, welche mit verfobiedener Febertiacht nach Dem ?lter verfeben find, bat bie Flaumtradt in ber Farbe mebr Uebereinftimmung mit ber Federtrad)t ber Sungen, als mit ber ber 2aten, z. SB. bey ben Seven; bey andern gleidst Die flaumtrad)t mefr der Febertradht Der 2atten, als ber Der Jungen, z. S2. bey Der Sula alba, deren follumiungez weifgelb, wie bie vollemmene 2flte in Der Febertrad)t ift; da= gegen if baz befieberte Innge braumfdrwarz, und Eebrt Durdh

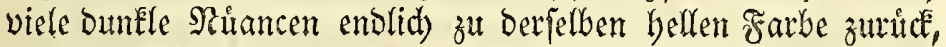
melde Das flaumjunge hatte. Ben andern 2 rten, weldbe, mit Federn bededit, bie Farbe nach) Den Salyeszeiten verandern, nicht aber nad) bem 2atter, hat bas fraumjunge mebrete Farbenåln= (id) ele mit Dent 2(ten in Der Sommertrad)t, z. B. Una troile, Haematopus ostralegus, welche in Den Dunen einen braunen Unterbals haben; andere haben mebr 2 ehnlichee mit ben $2 \mathfrak{l}=$ ten in Der 2 sintertrad)t, z. SO Alca torda, weldher in Den Dumen cinen meisen Unterbals bat, Darauf in Den Febern ei= nen braunen Unterbals erfålt, weldyen er wieber zwey Monate

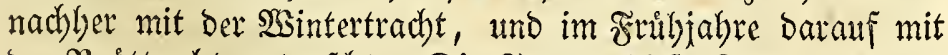
Der Brütradyt vertaujht. Die Sungen biefer Resteren tragen

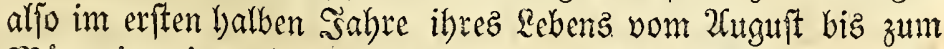
Mårz eine viermal in ber Farbe abwecth jelnde Bethleibung. So bat Der Alca torda in biefem Seitraume 1) Feine Flaum=

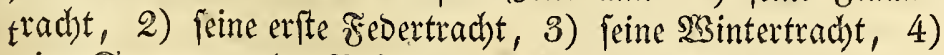

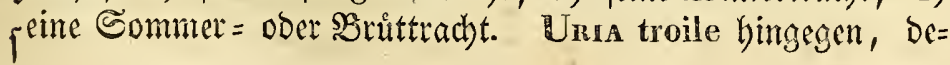


ren erfte Feberbetleibung ifrer Sintertracht gleidft, bebålt biefe Befleibung ben ganzen S3inter bindurch, obne fie zu veråndern, uno bat aljo in ibrem erften balben Salyre nur bren Irad)ten,

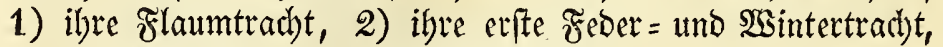
3) ibre erfte Sommer = ober SBrittracht.

Die Farbe ber Dunen ift allezeit ben Den Jungen bet ver= fchiebenen (sejchlechter von Derjelben 2rtt Die námliche, obgleid) biefelben nachlyet nach bem (șejchledte fehr in ber Farbe variiren, z. S. bey ben Månndben uno $\mathfrak{B e i b d j e n ~ v o n ~ A r a s ~ m o l l i s s i m a ~}$ und glacialis.

Daz Flaumfleib der meiften Sumpfógel, die zu Totanus, Tringa, Scolopax, Numenius, Strepsimas, Lmosa, Vaneluus, Charanrius gebơren, ift geppentelt mit

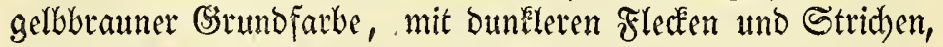

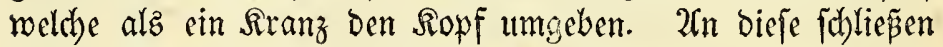

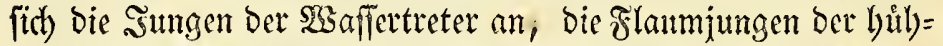
nerartigen Stmpfoigel fino oft ganz fdywarz, wie bey Gatu-

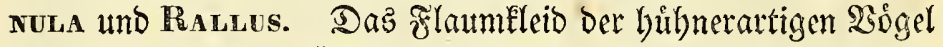
ift gelb und braungefledt, unten beller, alz bey den Lacopus 2rten, Texrao coturnix, Pendix $\mathfrak{u} .\{. \mathfrak{m}$. Der Fifd ablex hat in Den Dunen einen grauen Sortper, weipen Sopf und Şalz; bas Flaumjunge ber Dumnen \&umme ift von oben jobar $z=$ braun mit weißen herborftedsenden baarigen Febern, ebenfallz

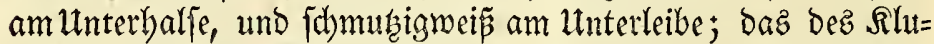
balfs ift weis am Sopfe, Shalfe uno unterleibe, uno weip und

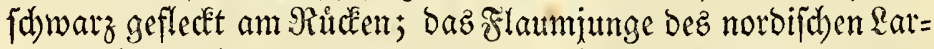
ventaud)erz fdwwarzblau am ganzen Rörper, lyat eimen breiten

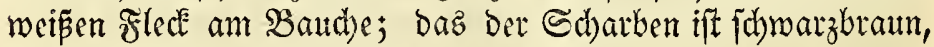

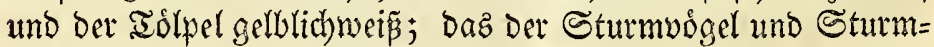
tautder granblan am Siưfen, weip̄lid) am Itnterteibe, doc) ounfler am sRiucéen bey Puffinus arcticus, alz bet ProcerLARIA glacialis; das der Iautcher iff dunfelgraut mit belletem unterleibe; die der Steiffürpe find gelbgrau mit vielen Stri= dhen, Gtreifen und Fleden, fo mie autd), wenigftens bev ben isländifhen 2(rten, mit einem rothen nadten Flede an Dem Cheitel; alle Sågcr, Enten, Ş̉anje und Schwåne baben ein Flaumfleid ofne Stridhe, etwaz beiler von unten, alz von oben, gelbgrau, grau voer bunkelgrau bey den verjdiedenen 2rten. Saz ber Meerfibroalben und Meben ift gelbgrau oder blaugrau mit vielen Flecten, Streifen uno Srånzen; bey Den Siaubmeven find die flaumjungen einfarbig buntelgraut. 
Die Dauer ber Dunenperiode ift bey den verfficbenen 2rten ebenfallz verfd)ieden. Die Cinguoggel erbalten illue Fe= berbefletbung gefdywinder, als bie Nanuboógel, bic billynerarti= gen und Sumpfoógel, uno bieje gefdyminder, als bie Sdiwimm= vógel. Dodh mus bier in ber Sergleichung auf bie relative

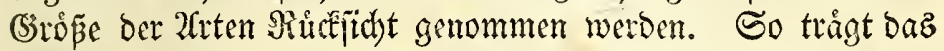
Junge von Prochluaria glacialis feine Dunen weit lángel,

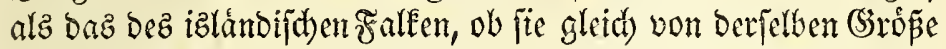

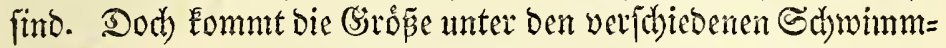

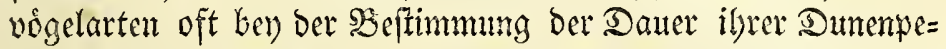

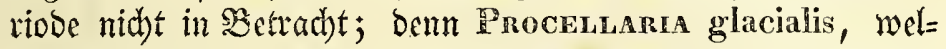
d)et viel Eleiner, alz Conmbus glacialis und Cranus musicus

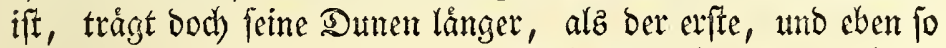
lange, als ber leşte. Itnter Den Sdywimmvógeln mámlidy er= Lalten bie 2irten, beren Junge nicht von ben 2llten gefüttert

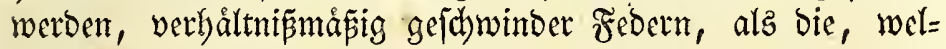
dhen yon biefen Futter gebracht wirb, natưllicherweife, bamit

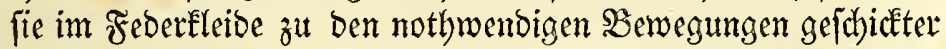

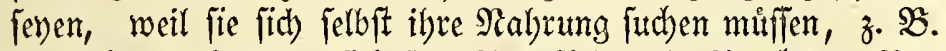

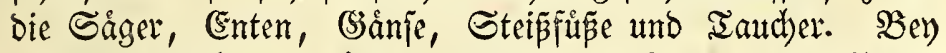
Denjenigen Sdywimmbógeln, weld)e ilyren Iutugen bas Futtet ins Reft bringen, wirb biefe Befleibung länger getragen; ben ben Stopitauthern långer, als bey ben Sdhwimmtauthern, bey Sula, Sterna, Larus, Lestris, Procellaria uno Puf-

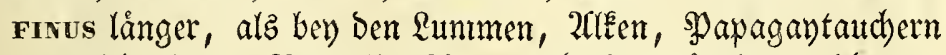
und Scharben. Son allen Zirten Sdjwimmuoigeln, weldye zutr zutammengejeşten Monogamie gehoiren, trågt Uria troile au-

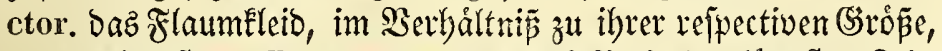
in ber fulrzeften, Proceluara glacialis in ber längiten 3eit.

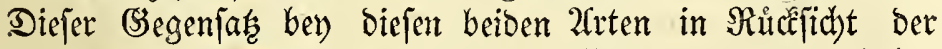

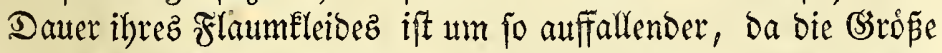
ifrez Sơrpers und ibrer Eyyer, fowie bie Dauter ihrer Britzeit, ungefäbr biefélbe ift.

Iabelle Der Durd) 2(pproximation gefundenen Dauer ber $\mathfrak{D} u=$ nempertode borealer $\mathfrak{B o g}$ gel.

Die Ramen.

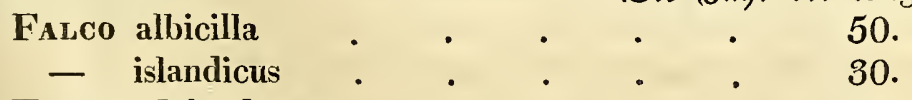

Die 3abl Der Iage.

Tetrao Islandorum $\quad . \quad+\quad . \quad . \quad 20$.

Şlåndifhe Singuogel . . . $\quad$. $10-14$. 
Die Namen.

Die 3aljl bet Iage.

IIacmatopus ostralegus . . . . 28.

Charadrius hiaticula, Scolopax gallinago, TrexGA alpina, maritima

Nunenus phaeopus, Lmosa melanura, 'Гotanus

calidris, Stnepsicas collaris

Pralaropus cinerens und rufus

24.

U⿴囗十 grylle

Unia troile, Brümichii und Alca torda

Momon fratercula

Canbo comoranus und graculus

Puffrnus arcticus

Proceluaria glacialis .

Columbus glacialis . . . . . . . 45.

- rufogularis . . . . $\quad .40$.

Ponicers comutus and arcticus . . $\quad 35$.

Mergus merganser, serrator, Aras glacialis, boscas unb acuta . . . . . . . $\quad . \quad 35$.

Aras mollissima . $\quad . \quad$. $\quad$. $\quad$. 42.

- clangula, marila, histrionica . . 40.

- crecca $\quad . \quad$. . . 30.

Crgnus musicus .

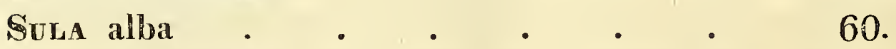

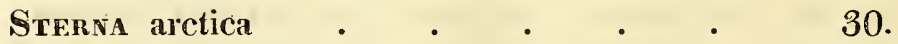

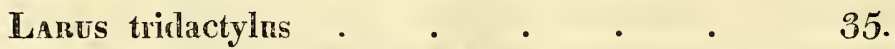

Larus marinus, glaucus tmo Lestris catarractes 50 .

Lestris parasitica . . . . . . 40 .

Sas Servorbredyen Der Febern uno ber erwadjpene Sor= per ftrlyen nidbt immer mit cinander im Berbáltniffe; es ift fogat bod ff felten ber Fall. Š geidwinder ein Süngez feine Dumen nad)

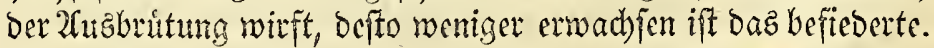
Die meiften Ranboogel, uno vornebmlich bie buit)merartigen, be= fommen fichon frebern, ebe ilys Sorper halb erwady jen ift; bie flei= nen Schnechubnjungen folgen fobon befiebert ber Nutter, wenn fie Eaum 5 3oll lang find; unter ben Sumpfoógeln find bie 2rten von Andea uno Haematopus, womn fie ibre Dunen verlieken, autsgerwadjener, als die 2frten von Scolopax, Totanus, Trivga und Nuienius, Strepsilas umd Phalaropus, uno dieje melbi, alz Charadrius uno Raluus. Unter den Sdjwimm= vógeln fino die Sungen von Uria troile Lin. und Alca tor- 
da ant Eleinften, wenn fie ifr Gramm kleio werfen, bery weitem

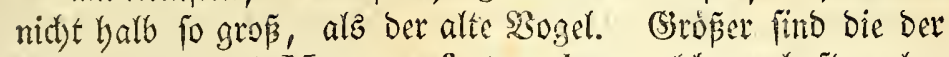
Una grylle uno Monmos fratercula, wald)e autic fiambe=

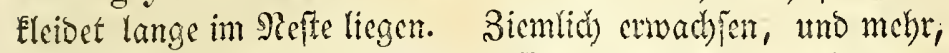

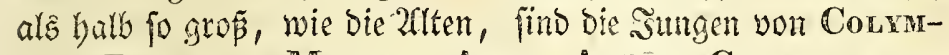
bes, Poniceps, Menges, Anas, Anser, Crgnus, mem

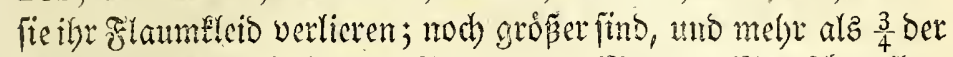

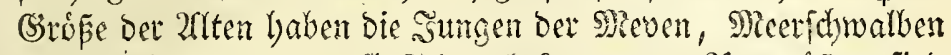

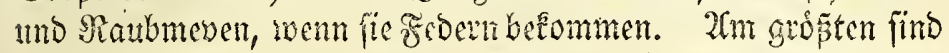
Die samgen ber Eturmoégel, Eturmtauther, Edharben und Tólpel, unb ber brenzerigen Meyen, wemn fic bie Dunen wer=

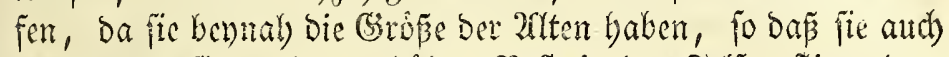
im Stande find, das erbobete Neft in ben Felfen fliegeno zu vertafien.

Die Dunen werben von ben berborwady jenden Féem grabweife riber bem ganzen Sưrper verbrángt, und zuerfit auf Den Edywingen, beren Febern frifh hervorbreaben; bod, ift

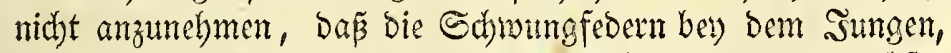
weldes feine Dunen vertoren hat, fo vollfommen ausgenadjen

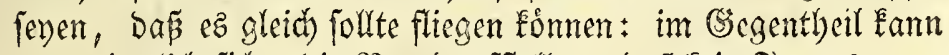

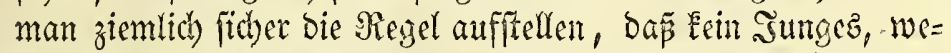

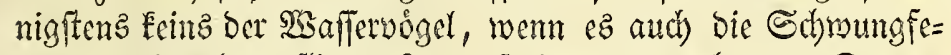
Dern crbalten bat, fliegen fann, fo lange ez nody ganze Dumen=

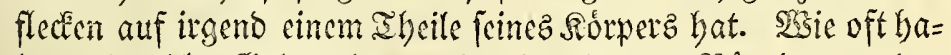
ben wir nidjt (Šelegenbeit, bies bev jungen Bógeln von ben Sànersfen, SBafferláufern, weldye ganz freye Schwungfedern, noch aber einen flaumbetceideten Sonf uno Şatz lyaben, uno

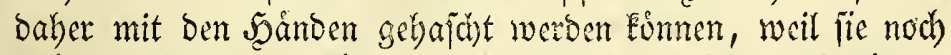
nicht zut fliegen vermogen, zat bemerken. Esinge Siglantor Gatten ebenfallz bieje Eigemichaft bemerté, mo gaben mir bie

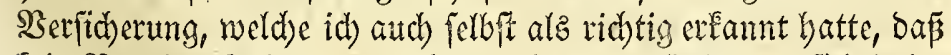

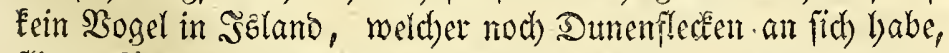
fliegen fónme, ausgenommen baz Gdynelyuth. Darauf werben

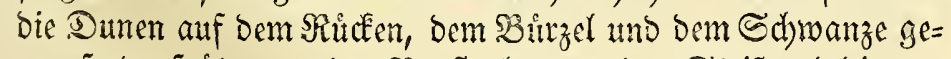

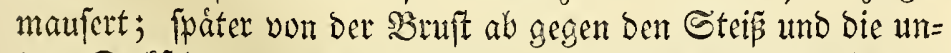

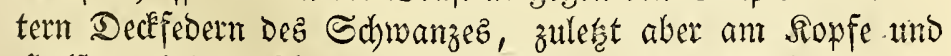
Salje, uno bann fadeiden fich bie Dunen von bem Sdjeitel, uno bitben zutleşt nur einen Dumenfranz um bie Eeiten und ben

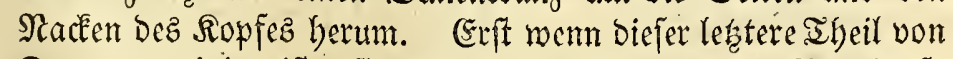
Dumen gereinigt ift, find bie Sdywungfebern bez $3 o g e l s$ fo ausgerwadjen, báp er fliegen Eam. Der obere uno vorbere 


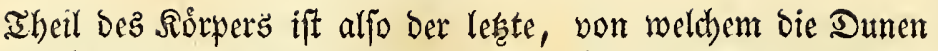
verifdwinden. WSie oft fångt man nicht grope sunge der $\Re i=$ bise, Sidnepfen, Meeridywalben, Meven, weldye beynaly ausgewadbjene Edymungfedern baben, und itber ben ganzen Reib vollbefiebert fins, Dagegen aber nod) Den grópern Thbeil ihrer Dunenpartie aur Dem ßapfe und Salje baben!

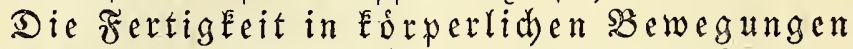
und bie 2fusbilloung ber atriebe der Flaumjungen ift nad) Den

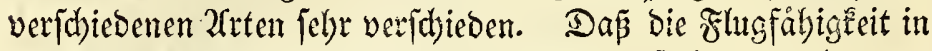
Der Regel Ḱeinem borealen $\mathfrak{B} o g e l$ zufomme, jo lange nod) ganze

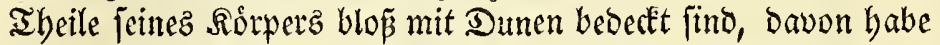

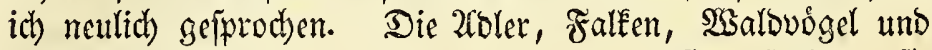
Singuogel liegen in ber Regel rutbig im Refte, fo lange fie mit Frlaum beocect find, bod) jene beftúnbiger, als bieje, uno werben von ben aften gefüttert. Daffelbe ift ber Fall bey Den Ardea -und Crconia - 2frten. Die Sungen anderer Sumpfó-

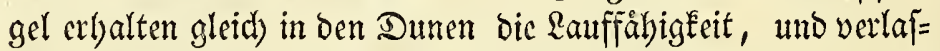

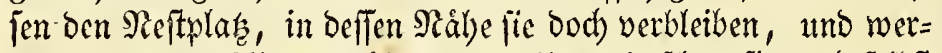

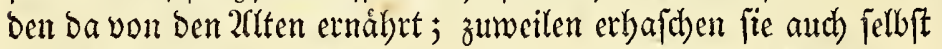

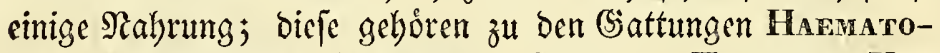
pus, Charadrius, Numenies, Lmosa, Totanus, Vanellus, Trivea, Scolopax, Strepsilas, und bejonderz Gallinula und Rallus, an beten Reife fith Pralanopus

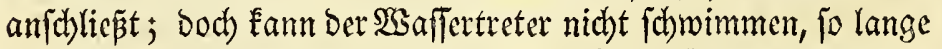
er Dunen lyat. Unter ben Sdymimmoógeln findet in ben Fers=

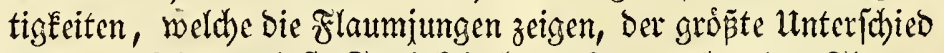
Statt. Die wenigfte Fertigkeit bemerkt man bey ben Flaum= jungen ber Ģattungen Uria, Alca, Monmon, Сanbo, Purfinus, Procellaria, Sula, welche, mie bie Sammen

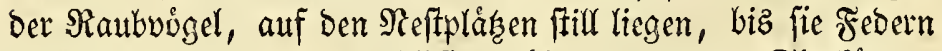
erbalten baben, und dajelbit ernábrt merben. Sie kỏnnen weber gehen, fdywimmen, taud)en. oder fid) falbft nach $\mathfrak{R a b}=$

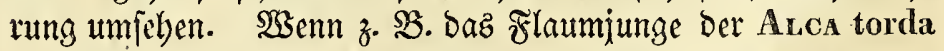
inz Meer fållt, fo ift es vetloren, weil ez in ben Dumen lang=

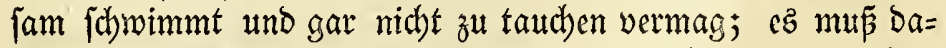
her in einem Elemente verhutngern, in weldhem ify in einer fpåtern \$periode einzig und allein feine $\mathfrak{R}$ abrung angemiejen ift, und welches bafferbe, wenn ez Febern erbalten lyat, fo vortreff= lich) zu benuten weip.

Ģrópere Fertigkeit in ber Dumenperiode zeigen die Šm= gen yon Sterna, Larus und Lestris, weld be, fo wie bie 
2) 3wifthen ben Sumpfoogeln uno Sthwimmuogeln von den (Sattungen Phalanopus, Sterna, Lanus, Lestris.

3) 3wijhen ben hưhnerartigen Bógeln und Schwimm= vógeln von Den Şattungen Colymbus, Podiceps, Mergus, Aras Lin., Anser und Crgnus.

Sn ber Bebecfung und ber bamit in $\mathfrak{B} e r b i n b u n g ~ f t e h e n=$

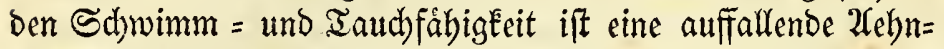

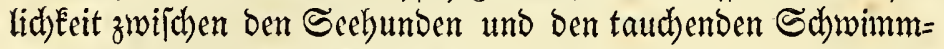
vógetn ber zujammengeferten Monogamie; Denn aud) Der See=

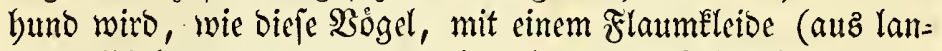
gen gelblichen ooer grauen weid)en Staaren beftebend) geboren, weldhes die Jungen tragen, fo lange fie auf ten Scheeren ober auf bem Eije liegen. In biejer Beit werben bie sungen ber Seelyunde, wie bie jener Sdywimmoógel, von ben 2alten auf

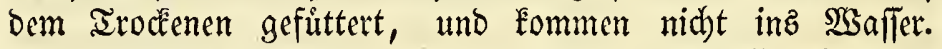

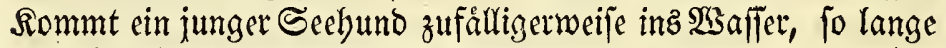
er nod) nidt fein Meftyaar abgeworfen hat, fo kann er, fowie bie sungen biefer $\mathfrak{B o g}$ gel, nur langjam idjwimmen, uno nidht tau= dhen; wenn er aber bie langen Nefthaare abgeworfen hat, bann

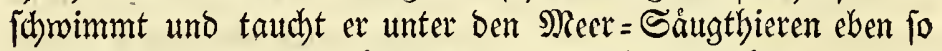
vortrefflich, als bieje Sỏgel unter ben Sdymimmuogetn, wenn fie ilye Nefftounen gemaujert und Febern erbalten baben.

Suly und 2Guguft fint bejonderz bie Monate, in welchen Die borealen Bögel bie Dunen tragen. Die Singuoigel, Raub= vỏgel, bie Sumpf = und Schmimmuogel, weld)e am früheften Evyer legen; alz: Totanus calidris, Charadrius hiaticula, die 2 rten Carso, baben im 2Ulgemeinen genommen, unb an= Dere 2 trten, z. $\mathfrak{B}$. Arss glacialis und crecca, nut einzeln zut= gleid) beflaumte sutunge fichon im sumy. Die am långften bruitemben, z. B. Sula alba, Procellaria glacialis, werben nod) einzeln mit Flaumiungen im September angetroffen.

\section{§. 40.}

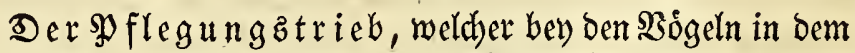

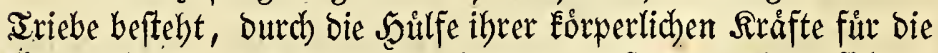
Eorperliche (Entwickelung ibret Sungen zu forgen, theilt fich in brev Iriebe: 1) Den Finterungstrieb. 2) Den Reitungs = ober

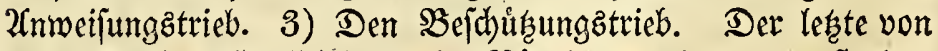
biefen Irieben ift allen borealen Bógeln gemein, ber erfte ben meiften, und bejonders tritt bery ben 2(rten, welchen diejer feblt,

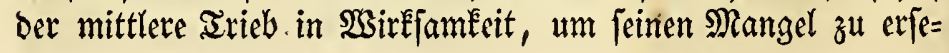




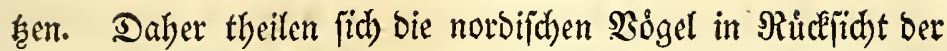
Sorge fiur ilyre Brut in zwey Sauptgruppen, in bie Fitternden ando blóp Reitenden. Der Reitungstrieb zeigt (iid) aud bey den fütternben 230 getn alz ein jubfibiårer Irieb, vornelymlid wenn

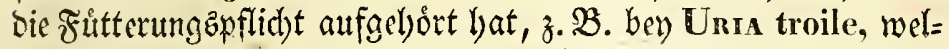

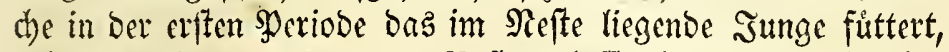

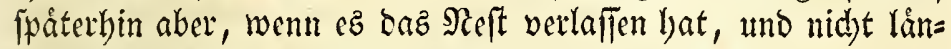
ger gefiuttert witb, baffelbe blop leitet und anweift.

1) Der foitterungatrieb ift Der Trieb der $\mathfrak{B} \mathfrak{s}=$ gel, für ibre Jumgen bie zui (Frnåhrung bienlidsen (5ie= gemftände aufzulutd)en, und fie înnen zuzubringen. Bey ben

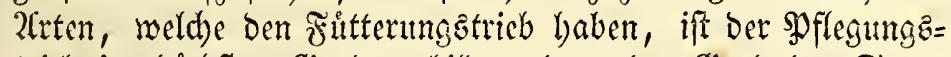

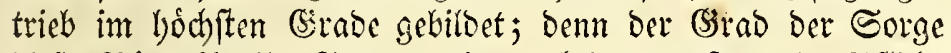

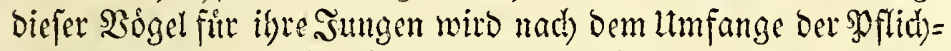
ten beftimm, weidye fie gegen bicje erfüllen, uno Der Fùte=

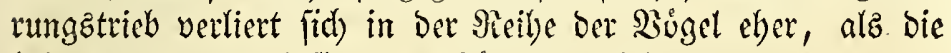

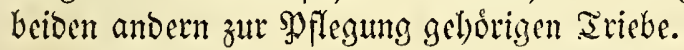

(Er wirft erft, wenn bie (Ey)er auggebritet find, ocr Briot= trieb uno ber Frutterungatrieb fino alfo auf cinander folgende sghånomene in ber Şiftorie ber siogel; gleidjectig fino fie wold

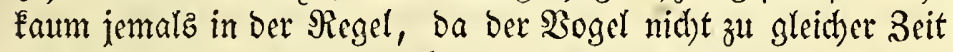
Ener brütet, uno Junge ernåbrt; Denn bic Bogelarten, welche mebr, als ein $5 y$ im Nefte haben, und beren Junge aus bem= felten Refte felten alle an eincm Iage ausgebrütet werben, fan= gen wobl faum an, bie zuerit ausgebrutteten Jungen zut fưt= tern, ehe alle Eyer Dez Reftez auzgebrutet findo. Dafielbe ift Der Frall bey Den Jungen Der mit bem Reitungsttriebe verferlenen, 3. B. Der Enten; Denn fie fúlyren bie auz ben Evyern ausgebru=

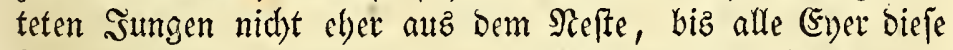

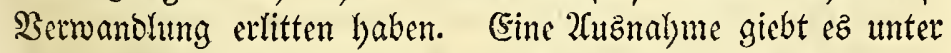
einigen $3 o g e l a r t e n$, weld)e mebr alz einmal brüten, und ocren erwadbjene Sunge lange bern den 2 (lten bleiben; $z$. $\mathfrak{B}$. Die Iau= ben. Bey Diejen wirkt ber Gritterungstrieb nod) (poradija, nachbem fie zum zwenten sale zu britten angefangen haben. Die Taube ảg zutweilen nod) bie erwad)jenen sungen der erften

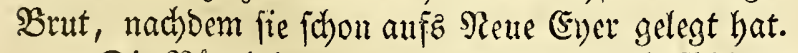

Die Bögel haben ein vollfommenes (Sefúbl von der (Ent= mickelung Der (Ever, weldhe fie unter fich baben, und bemerfen ez

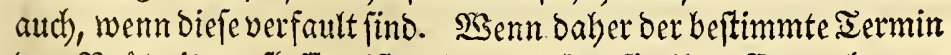
Der Sraitzeit verfloffen ift, fo verlaffen fie ifre Eyer als un= tauglidje. Dodb baben wir bey einzelnen ftaré brütenden bưhner= 


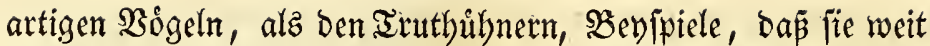
ůber bie gewóhnliche Brutzeit hinauz auf Den Eyern bleiben, uno man fann fragen: ob einige ber wilben $3 g$ gelarten von phlegmatifcher Satur nicht Daffelbe thun. Sn Der Solonie oer Sula alba auf bem Felijen Branoten fand id) nåmlid) meh= rere verfaulte (Eyer, weld)e mir vom Bruten warm zut feyn fdienen. Wenn id aber auch bierin geirrt baben follte, fo ift

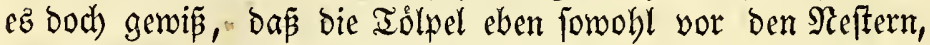
in weld)en (Ever vorlsanden waren, als vor benen, in weldben

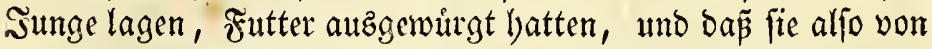
bem Fritterungztriebe irre geleitet worden find, weldher in ber Regel notbwendig gewejen wåke, wenn bie (Eyer nid)t verfault wáren. Sie hatten fogar hier ilyren regulåren Trieb ange= wandt, wo kein Sungez vorbanden war, weldhes ilyn bentren Eonnte. Man fiebt auz biefem Beyjpiele, fo wte auz vielen

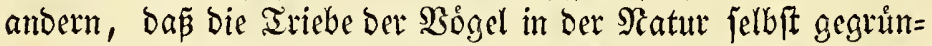
oet find, uno nicht.uripringlid) Durd) áupere umgebende (S)gen= ftánde berworgebrad)t werden. Sie crwad)en zur beftimmten Beit, wenngleid ber erwadhte Irieb nidht im Stande ift, feine $\mathfrak{B e}=$ ftimmung zu erreiden. So erwadht ber Şaarungztrieb aud

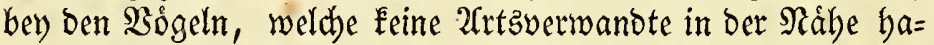
ben, uno fie verfuchen oft, von ber Sceftigkeit bes Iriebes ge= orungen, die parung mit fremben 2arten. Der Bruttrieb mird oft bey zabmen Scithnern gefunden, weldbe keine (Eyer zu brü=

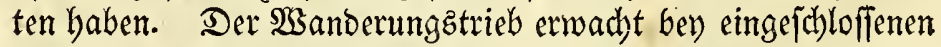

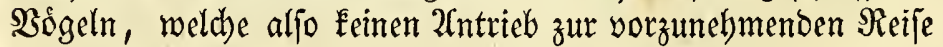
von außen her gebabt lyaben, und in biejem Falle war bey der Sula alba ber Fitterungstrieb zut beftimmten 3eit in 2 ctivi= tåt, obgleich kein sunges gefunden wurbe, welchez alz ber nád)fte (Segenftand biefen Irieb bâtte erwecken fỏnnen.

atle Raub $=$, $\mathfrak{W}_{\text {ald }}=$, Sing = und Sumpfuógel baben Den Fưtterungstrieb, allen, forobl monogamen, alz polyga=

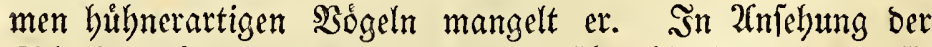
Sd)wimmodgel glaubten bie Naturforjher ủberbaupt, baf fie ihre Sungen gleidh ins $\mathfrak{W}$ affer leiteten, und fie nicht fuitterten; bod) ift biefes offters nicht ber Fall, ba bie ઉd)wimmoogel ber zufammengejeften Monogamie diefen Trieb im lyob)ften (Grabe bejitcen, nåmlich die 2irtem von Phalaropus, Uria, Alca, Mormon, Carbo, Puffivus, Sula, Sterna, Lanus, Lestris und Procellaria. Er mangelt bagegen allen Sdbimmoógeln Der mittleren und einzelnen Monogamie, nåmlich Den 2Crten von 
Colymbus, Podiceps, Fulica, Mergus, Aras, Anser und Cygnus.

Der Frutterungstrieb hat (sirabe, fowohl in Mitcfitid fei=

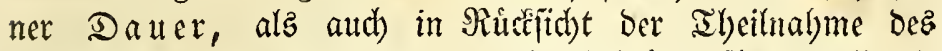
Nämnd)enz an bicjer Function. Dieje Sogel füttern alle bie Sungen fo lange, als fie nod) nadkt find ober bie Dumen tra= gen; man Eann baher auz ber im $39 \S$ angefirlyrten Tabelle, über bie Dauter ber Dunenperiode, einigerma jen die Dauter ber

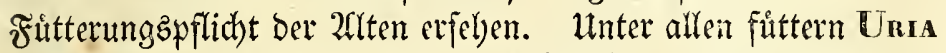
troile Lin. unb Arci torda am fưrzeften, ba ihre Sungen fid) fdyon, Eaum lyalberwad) fen und beficbert, obne fliegen zu Eonnen, von bem bohen Felfen ins Meer ftutrzen, woljin ibnen bie 2ulten forevend folgen; fie tauthen beibe. Bon biejem 3eit= puncte an ermadyt ber Reitungstrieb, und ber Fitterungstrieb

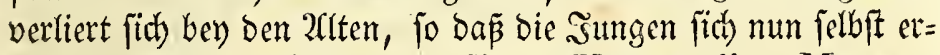
nålyren múffen. Långere Beit fưttern Una grylle, Monmon fratercula, die Carbo-20rten, dod keine Der Sdyminmtau= cher långer, ałz bis bie Sungen Febern erbalten, unb bas গeft verlaffen baben, ba fie bann von ben 2 (lten geleitet, aber midst mel)r ernål)rt werden. Reine ber Sdymimmtauther, weld)e von ben 2frten gefüttert werben, fơnnen fliegen, wenn fie baz Reft verlaffen, auzgenommen die 2frten von Carbo und PrfFrnus; bie itbrigen laffen fich, ebe fie nod) fligge find, von

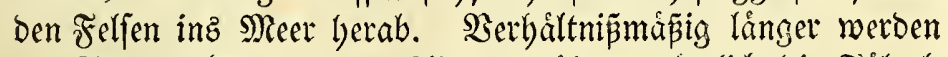

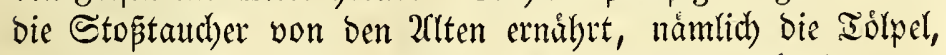
Meerjd)walben, Meven, Raubmeven uno Sturmoógel, benn einige 2rten liegen nid)t allein fitll im Nefte, fo lange bis ibre

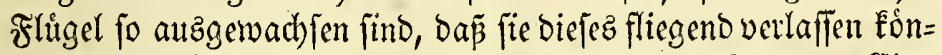
nen, namlich bie weipen Tolpel, brenzebigen Meven, Ěiz= Sturmooigel und arktijchen Sturmtaucher, fondern fie werden auth) nodb, wie bie Iatben und bie meiften Raub =, SSald = und Singuogel, von Den aften gefittert, nadbdem fie baz Ieft vollig befiedert verlaffen laben. SSsic oft babe id nidbt STens arctica, nigra ober: minuta, Larus argentatus, canus und. ridibundus in Dánemark, uno Laros glaucns, marinus und tridactylus in Jgland, bie vollig erwad)fenen Jungen, weldbe zwijchen ben 2atten in J̦aufen waren, futtern fehen! Der Fut: terungstrieb fâllt aljo nicht immer zu derjelben 3rit ben ben $2 \mathbb{U}=$ ten weg, wann Die Sungen Daz Flaumkleid verlieren: Doch find feine frtengften Forberungen Dann fdhon befriedigt; bie \$fllidht nimmt bey jenen $a b$, fo wie bel) biejen bie Mioglideteit, fid 
Felbft zu ernåbren zunimmt. - Die Sumpfipóget, all weldibe

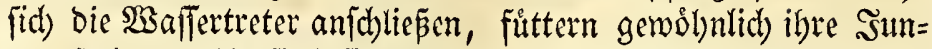
gen fo lange, biz fie befiebert find, am lảngften bey Andea uno

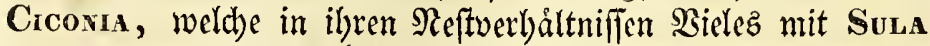

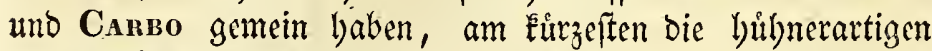
Sumpfoógel, als Galdinula umo Raldis, bey weldhen bie Sungen fid) balo nadd Rabrung umiclen. Die Sogelarten,

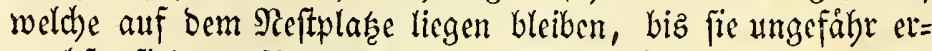

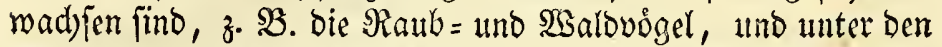
Sumpfoỏgetn Ardea und Cicorra, unter ben @dimimmuógeln Monnon fratercula, bie 2itten Carbo, Puffinus, Procellaria, Sula, Larus tridactylus und glancus, beburifen in gró

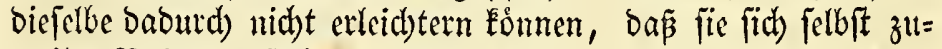

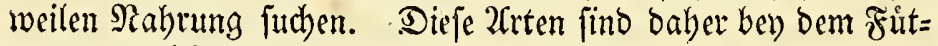
terungsgejd)åft am thåatigiten. Die rettlage, welche bie sum= gen von ben Rarbentaudhern, Sdharben, Sulen, Sturmog:= geln und Sturmtautdern bebect, beweift biefes, fo wie ein

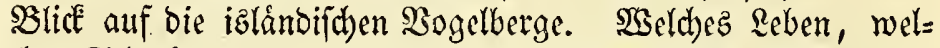

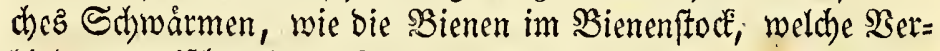
binoung zwijhen bem Reere und ben Felfen unterbalten bieje

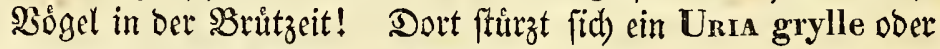
Alca torda ins झkeer, um Futter zu bolen; bier beben fich Monnos fratercula, Uria troile oder Procellaria glacialis vom Miere ber lood) in bie Feljen binauf, um Futtter zu

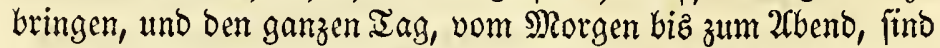

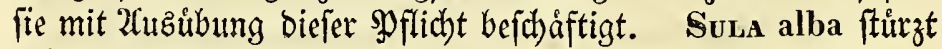

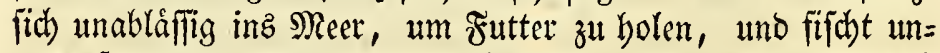
ausgeferst ganze Stumben, bis fie belaftet, fohmerfliegend, nad) ihrem Feljen zuruickelyrt. Sie laffen fid) keine 3eit zum Fref= fen, uno fie felbft werben bey ber (Erfüllung ciner spllid)t, melche ibre Jumgen mit Fett bedeckt, mager uno abgezebrt.

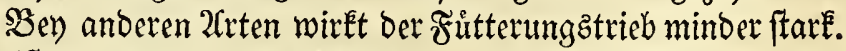
Dies ift ber Fall bey Den 2lrten, beren sunge gleid' in ber

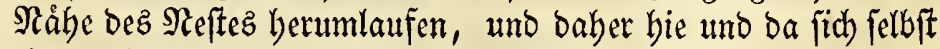

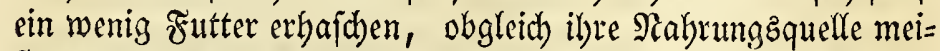
ftens von ben 2Olten Eommt. Dabin gehoren bic meiften Sumpf=

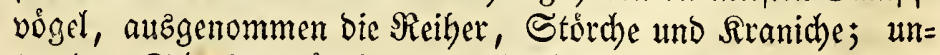

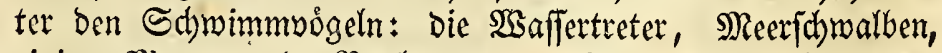
cinige. Meven und Raubmeven. Mit weld)er (Sier ver= fa)lingen nicht bie Eleinen flaumbebectiten Meerfatwalben ober 
Meven die Rabrung, auf weld)e fie felbft ftopen, ob fic gleid) noch unter ber Frutterung ber aften frógen!

(Şmeiniglidy baben, bey den fütternoen 2reten, bei be

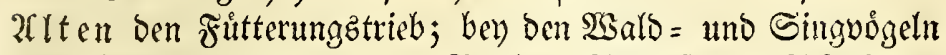
Die Mánnchen melyr, bel) Den Maub =, Sumpf = uno ভdywimm =

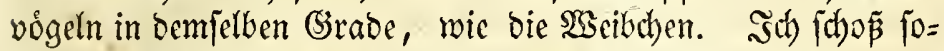
wohl bas Mánnd)en, als daz ŞEeibchen von Una troile, grylle, Alca torda, Monmos fratercula, Sula alba, Lestris catarractes, Procellaria glacialis, wåhreno fie ibren șun=

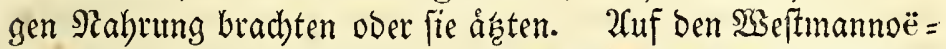

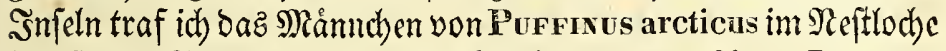
bev) feinem Sungen, umb baz Måndhen von den 2Trten Lestris parasitica und Pralaropus fand id bifter ben oen sungen,

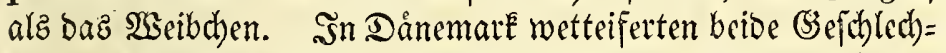
ter von Sterna arctica, nigra uno minuta, ŞSirmer für bie șungen zu fudchen. Da beibe alten alfo ibie oft wenigen sun=

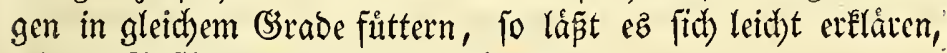
wie bie Reftiungen fo fett fenn kínnen.

2Saz Den Finterungzftoff betrifit, fo tragen fie

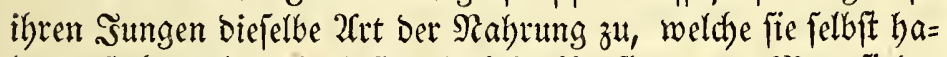
ben, fudben aber bie beften Stucke für fie aut. Man findet

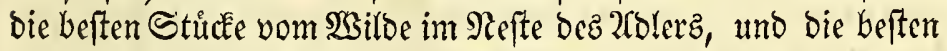

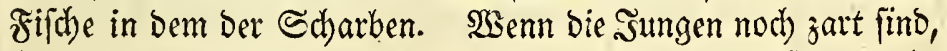
fehen fie mebr auf bie Reckerbeit, wenn fie heranmad)ien, mebr auf Die Menge ber Maghrung. Die, weldhe fïch von melyreren Ihbierclafjen nåbren, ober von Ihbieren uno \$flanzen zugleid), bringen boch ben Sungen am liebften ibre cigene Rieblingŝ́peife, wenn fie fut erbalten ift. Berfdhiebene infecten = uno faa $=$ meneifende Singuoggel, ałs Tunbus uno Srunxus, fütern

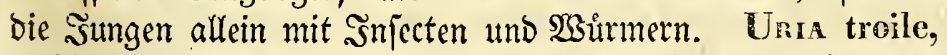
melche am liebften Fifdoe frifft, aber bod) aud oft mit Cancer pulex u. m. vorlieb nimmt, bringt ben šungen Éleine Fifche zut. Die Mevenarten und Meerfabalben, weld)e felbft $5 \mathrm{~m}=$ nivoren fino, uno fogar Meergraz verfd)lingen, bringen ibren Iungen bod) gern Fifiche ober $\mathfrak{X s e i d h t h i e r e ~ z u . ~ U r a ~ g r y l l e . ~}$

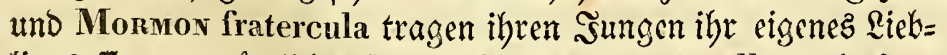
lingzeffen z̧u, nåmlich refpective BLensius gunnellus und Ammonytes tobianus; Sula alba bringt feinen Jungen Dintfijd be, Soáringe ut. f. w.; find bie Stúcte zu grope, fo zerbacten fie bie Zllten. Bumeilen füttern einige Sogelarten aud ibre Sungen

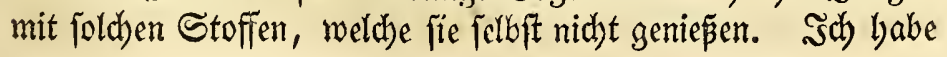


die faameneffenden Frivgilua coelebs, cannabina, und EmBEriza citrinella Madcken uno andere S̈necten Den Şungen im Schnabel zutragen jeben. Die, welde bie Sungen aus bem Sropfe ober ber Speiferobre futtern, bereiten ibnen fogar im zarteften 2 lter in ibrem eigenen Reibe einen Srey, mit weld)em fie biefelben åsen, und erft fpaterbin füttern jie mit andern (segenftånden, z. SB. Die Iauben, unter ben Sdbuimm= vỏgeln bie Sdarben, Tólpel, Stumtaudber uno Stumbógel. So lange Proceldanta glacialis fein Sungez mit diejem Breve

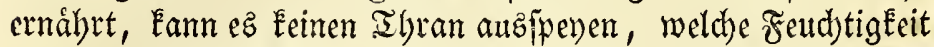
(ic) erft im Selophaguz dez. Sัungen erzeugt, wenn eह von ben alten mit fetten ober thranigten animalifhen Subjtanzen ge= futtert wirb. 2allez Futter wirb fliegend zugevradbt, außer

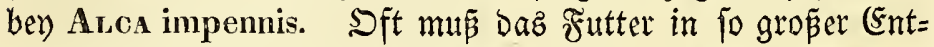
fermung vom Neite gefudht werben, Dap nur Die Surtigkeit uno Flugfábigkeit die zum F̂̉ttern begierigen 2llten befriebigen Eann. Id) babe Monmox fratercula und Sula alba zwev Meilen von ibrem Reftplafe für ibre Jungen fif hen feben; Lestris catarractes ftabl tåglid) Sunge auf Dem Sogelberge auf ben Niseftmannoëinjeln, uno bradhte bicjes Futter fliegeno nad) fei= nem zwev Meilen Davon liegenden Meftplake. Der 2loler und der Falke finden fid) tåglid in ben Bogelbergen ein, um Beute fur ifre Sungen zu rauben. Unter Dem Fitterungzacte felbit firen beibe, ber Fitternde und ber, welder gefuttert wird. Doch

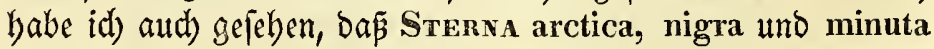
ibre Sungen, indem biefe mit ihnen berumflogen, in ber $\mathfrak{s u f t}$ fliegend gefúttert baben.

W̧as die Menge dez Futterz, mit weldem dic 2lten die Sungen auf einmal verfeben, betrifft, - fo bringen bie Raubvo= gel ez fructweife; bie șiecten fiellenben fangen zumeilen mebre= re Smjecten auf eimmal, und bringen fie Den Sungen. Sab babe Antuos pratensis und Tundus iliacus gejhoffen, indem ifr Sd)nabel mit Rarven und sphalanen gefulllt war; unter den

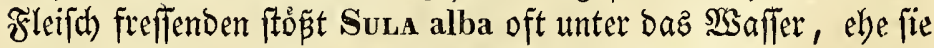

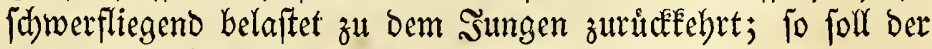

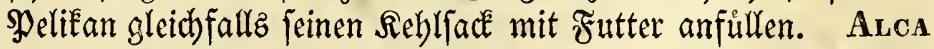
torda und Unia troile, Auctorum, fliegen mit einigen kleinen Scåringen auf einmal, Ura grylle mur mit sinem einzelnen Buevies gunnellus, und Stensa arctica und nigra mit einem einzelnen $\mathfrak{B}$ urme oder Cuvpea sprattus; dagegen fångt Mornos fratercula jebesmal viele fleine Fifdoe. EB ift unterbalteno, 
Diefen $\mathfrak{B} 0$ gel mit 2 fuffuthen bez Futterz für feine sungen

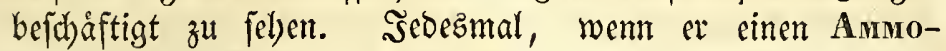

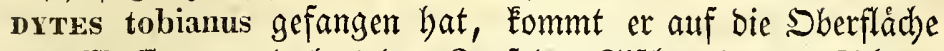

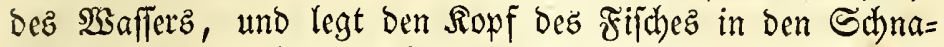
bel, indem ber fihmale Siơrper beffelben berunterbảngt. Err verliert jeood) ben zuerit gefangenen Fifid) nidht, wemn er meb= tere erthajht, weldyes fid) aus ber Billoung feines S(dhnabels

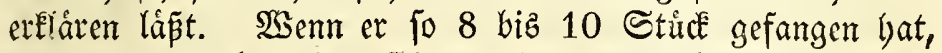
welche er, gleidh viele auf jeder Seite des Sdhnabelz beraus= bángend orbnet, fo fliegt er zal ben Meftlód dern. Bemerkt er bie mindefte $\mathfrak{U}$ nruthe, fo bleibt er melyrere Stunden auperbalb Deffelben fir belbårte lerunterbángen, utno bey jeber Berwegung bez Jopfe z ben 20 gel um bie Shren follagen. So fieht man oft ganze Reiben Larbentaudber firsen.

Einige Bogelarten haben cine eigene Berånderung ber Stimme, weldye bazu beftimmt ift, ibre sungen auf baz ge= brad)te Futter aufmerffam zu mad)en. Diefer $\mathfrak{L a u t}$ Eann ber Fiutterungslaut genannt werben. Befonders unterfacheibet er

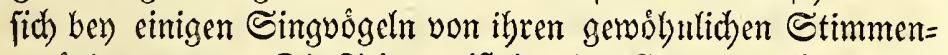
veránderungen. Die Stimme ift bey den Sterna - 2(trten bey= nahj zifcheno, bey Alca torda beynab flótend, bey Monmon fratercula gábnend, wie bey einem fchláfrigen Menichen; bey

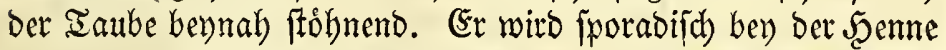

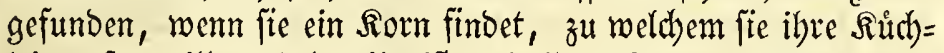
lein rufen will, uno bey ibr ift er balb gackerno. Esinige $2 \mathfrak{f r t e n}$ baben Eeinen eigenen Fitterungslaut, fondern gebrautden ilyren

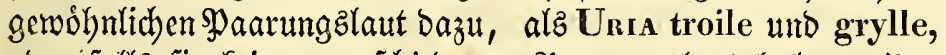
ober fallz fie Eeinen verifdicbenen \$yaarungstaut haben, ibre geroóbnliche lockffimme, als Sula alba uno Carbo graculus.

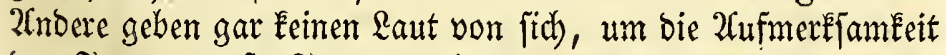
Der Jungen aufz Futter zu lenken, alz Proceldaria glacialis.

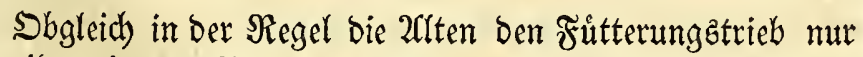

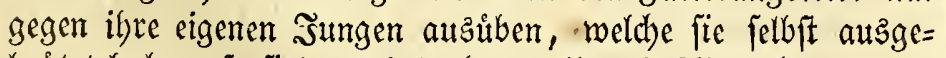

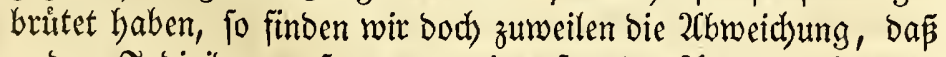
andere Sndivibuen, fogar von einer fremben 2trt, Den Sungen

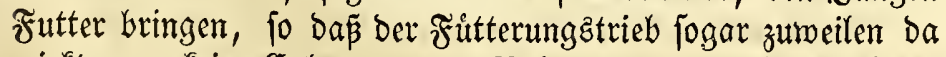
wirkt, wo keine (5ylegung oder Bruitung, wentgftens nid)t in Bezug auf bie gefütterten sungen, Statt gefunben hat. (sin

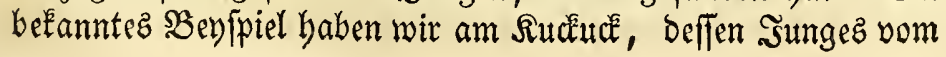


Seime im (Eve an, Durd) Stiefeltern zu feinem volligen $23 a d$ b $=$ thum gebracht wird, und, nad) Dem Serid)te mebrerer গatur=

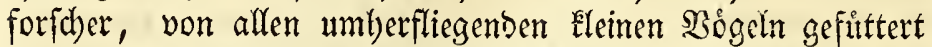
wirb, wenn eb fidreyt. Biele Fleine Bogel, z. B. Frivgilla linaria, cannabina und melyrere baben aud bie (Gemobnl)eit, baj fie fich einander futtern. Sod) babe junge Sperlinge in ei= nem Bauer gebabt, weldhe burd) ihr (Sefdrey andere Sperlinge, bie nidht ihre (Eltern waren, bewogen, fie zu futtern. Afuch bie Tauben auf unfern Taubenjidlagen tåujhen fidh zuweilen, uno åsen, frembe sungen. Es idheint mir baher nidbt umbabr= facheinlidh zu fenn, bap in ben Bogelbergen, wo fo viele Tau= feno Sunge bidht neben einanber liegen, die 2uten bie innen vortommenden Sungen berjelben 2 rt obne Unterfdied füttern, obne eben ủberzeugt zu jeyn, daß̃ ez il)re eigenen sungen find.

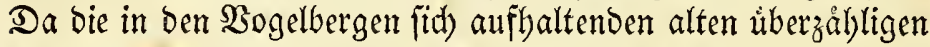
Sndivibuen zumeilen in bie Brutfunction ber weggefangenen

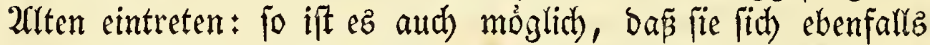
Der Sieftjungen erbarmen, weldhe ibrer gewỏhnlid)en Frutterer beraubt, fonft Şungers fterben witroen. Sn ben norbifich Bogelbergen herrjdt ůberbaupt ein fo gejelliges \&eben, wie man es in ben jưblichern europåifácen Sogelzonen nid)t finbet.

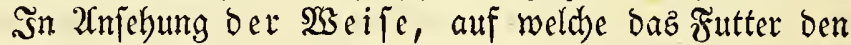
Sungen zugebradt wirb, theilen. fich Die mit Dem Futterungs= triebe verfebenen $\mathfrak{B o g}$ el in 2 Sauptgruppen:

a) Šn bie నutragettion, weldbe Den Şungen Futtter im Schnabel oder in Den Nlauen zutragen.

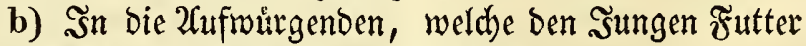
im Sropfe oder in ber Speifero̊bre zubringen.

a) Die $3 \mathfrak{a t r a g e n d e n ~ b r i n g e n ~ e z ~ b e y ~ a l l e n ~ \Re a u b o o g e l n ~}$ in ben $\mathfrak{K} l a u e n$, und werfen $e b$ ben sungen vor, ober fie

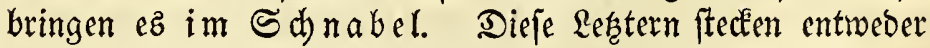
das im Shnabel gebrad)te Futter ben sungen in ben $\mathbb{S}_{4}$ na $=$ bel, z. B. Die Singuogel, oder fie tragen ez im Sdynabel zut bem sungen, uno legen es vor ifm hin, weldbes baffelbe oft bem 3utragenden entreist, ebe es bingelegt wirb, z. B. bie 2urten von Uria, Alca, Mormos und Sterva; indem ez die 20 ten binlegen, lafien jie zumeilen ibren Futterungslaut bòren.

(sz ift von einigen Srnitbologen als Regel betradbtet wor=

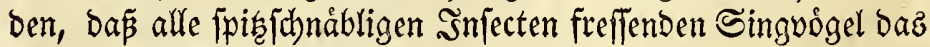
Futter im Sibnabel bringen, und alle dickjonábligen Saa= men freffenden im Sropfe. Dabs. Evfte ift ridhtig, nicht aber Das 


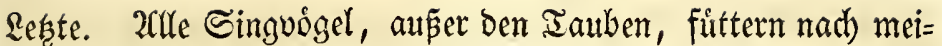
ner Erfabrutng bie Sitmgen auz bem Sd)nabel, fowohl bie fpié=,

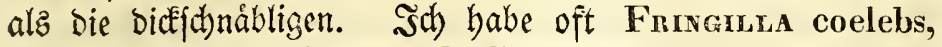
cannabina, domestica, carduelis, Enвения citrinella uno milliaria, fo mie Stursus vulgaris, Tunnes musicus uno iliacus, Lanius collurio und melyrere, den sungen $\mathfrak{F}$ utter im Edhnabel zutragen jeben.

b) Die $\mathfrak{A} u$ fwitrgenden find bie Tauben, bie meiften, uno vielleidht alle Sumpfyógel, z. B. Die 2irten von Ardea, Haenatopus, Totanis, yon den Sibmimmoigeln bie 2frten von Phalaropus, Carbo, Puffinus, Sula, Larus, Lestris,

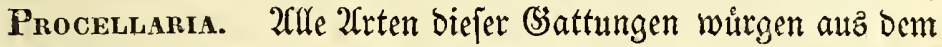
Siropfe ober auz ber erweiterten Speiferóbre in ben $\Re$ adden ber sungen, fo lange biefe Elein find, wenn fie aber heranwadyen, fahren nod) bie Tauben, uno unter Den Sdhwimmbógeln nur nod) bie Sturmtauther und Sturmoigel fort, auz bem Sd)lunbe in ben Sdhlund zu wuirgen, Da bingegen bie Sd)arben, Todpel,

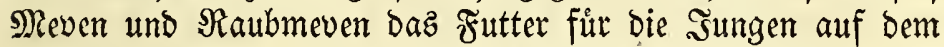

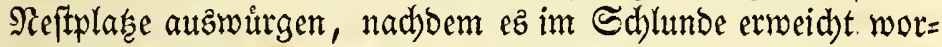
Den ift, und biefe ergreifen ez bam jelbjt, uno verjd)lingen ez.

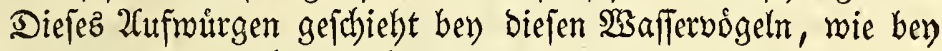
ben $\mathfrak{I}$ auben, Durd eine foulttelnde und gebogene $\mathfrak{B}$ ewegung bes R̊pfez uno dez Şalfes bey bem Fûtternoen, utno bey bem ent=

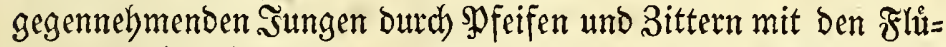
gelm. Sal) habe fowohl bie Scharben, alz Iolpel, Meven uno Sturmbogel, unter biejem Futterungsacte belaujd t, fo baj ich auz vielfeitiger (Erfabrung reden Eann. Dab erwachjene sunge von Larus glaucus fahj id ber Matter mit Bittern und \$feifen folgen, und biefe in abgebrochenen Beitråumen für baffelbe auff= wuirgen. Lestris catarractes und parasitica babe id unter bem

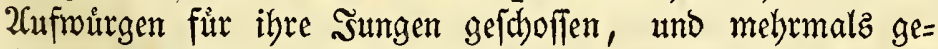

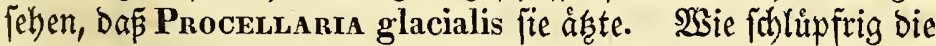
Solonie Der Sula alba auf Dem Felfen Branten vom aufge= wůrgten Futter war, bas auß halb aufgelóften Scåringen.und Dintiifichen beftand, babe ich fichon in meinem \$robromus erwåbnt.

Phalanopus ift in feinen Sleftuerbåltnifiten ein wahrex Sumpfuogel. Utnter Den uibrigen Sdbrimmbögeln ber zulam=

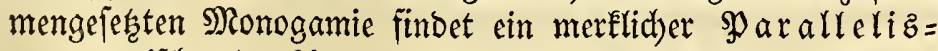
$\mathfrak{m} \mathfrak{u} \mathfrak{z}$ zwif zutragen, uno ibrer Iaudjåăbigkeit Statt. Wlle wirkli= 
d)en $\mathfrak{T} a \mathfrak{u}$ ber oder Sdymmtauder bringen den

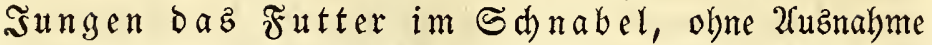
irgend ciner 2frt bon den (S)attungen Uria, Alca, Mor rov; alz $\mathfrak{C}$ uznahmen werden bie fdrmimmtaudhenden Sdjarben und Sturmtaucher angeführt, weldbe bennah in allen autz ibrer Fortpflanzung refultirenden Berbåltmifien 2Celynlicbeit mit den Stopstauchern baben, und auch, fo wie bieje, auz ber Speife= róbre füttern. Wlle Sto Taucher aus der luft, futtern auz der Speiferobre, nåmlich die 2atten von Sula, Larus, Lestris und Procel-

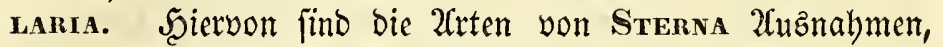
welde, ob fie gleidh Stoptaudber find, bod, wie iene Sdhmimmtaudber, das Futter im @dbnabel zutragen. Diejez allgemeine Berbåltni范 ift Durch meine vielfåltigen Erfabrungen beftátigt. S(c) ward crft Darauf aufmerffam bey bem Sogel= berge auf ber Jnfel (Srimjoë, und folgte nad)ber ber gefundenen Regel burch vicle einzelne Beobadtungen. Nurz nachbem ich Den Faben biefez Serláltniffez gefunoen hatte, . Fradh id mit einem Bauer auf Srimjoë, ber auf biefer ifolirten Sholarinjel geboren, biejelbe nie verlaflen latte, uno gropes Interefle fưr ben Bogelberg der Șnjel verrieth, unter beffen Bogeln er aufgerwad) fen war. S(d) wurde febr itberrajdt, als cr mir feine Beobachtung mittbeilte, weldbe, fo zu jagen, aus meinem cige= nen Ropfe genommen war, und bie Meinung åuperte, daj alle im Bogelberge brutenden Sdymimmoógel, weldbe Taucher wáren, ibren Sungen baz Futter im Sdhnabel zubråd)ten, alle Sichttaudber aber im Sropfe. Eine Benterkung, weldbe ber Satur fo nabe lag, Daj ein ungebildeter Solarberwobner fie finden muste, beftátigt, wie idh glaube, meine oben angefitbrte. Theorie melrx, alz wenn fie auf ber Stubierftube erfunden worben wáre.

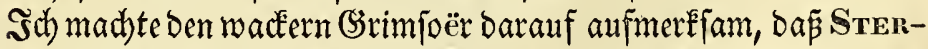
sa arctica, weldhe auf ben Sdheeren um (Srimpö herum brutet, obgleich Sidyttaucher, baz Futter im Sabnabel zutrage; biefes fonnte er nicht laugnen, und ftockte etwas bey diefer (Fimwen=

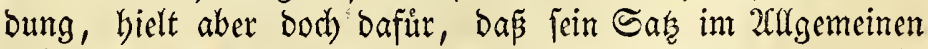
ruchtig jey, worin id ibm, wie fdon bemert, vollemmen Redht gegeben babe.

sch fann indeffen nidyt einfel)en, welde innere Bebeutung bieje beiben allgemeinen parallel laufenden Berbåltniffe haben. Denn marum fann bie Bogelart, weldbe baz Futter fưr igre

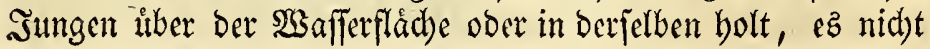


¿ben po gut ben Şungen im Sdynabel zuttragen, alz bie, weldhe

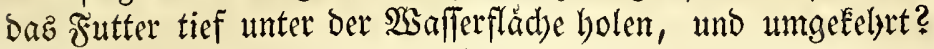
Dodh wir finven oft $\mathfrak{H e b e r e i n f t i m m u n g ~ i n ~ b e r ~ S i a t u r , ~ D e r e n ~}$ (s)runo wir im 2lugenblide nid)t erfeláren Eśnnen, ob er gleid) ge=

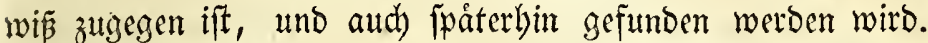
2(lz móglichen Sentrag zur (Erlåaterung ber Eadhe merbe id)

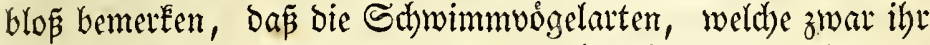
Futter unter bem 2 Saffer bolen, ez Dod) nidbt eber veridhludten,

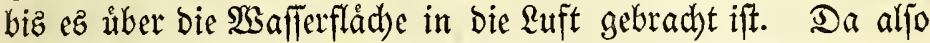

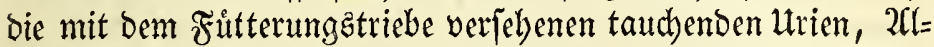

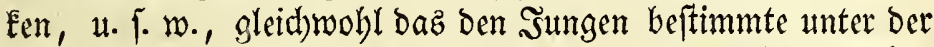

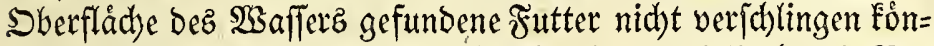
nen, biz es an bie $\mathfrak{Q} u f t$ gebradht ift, fo bat vielfeidht bie $\mathfrak{R a}=$ tur 'ilhnen bie \$plicht aufgelegt, Den sungen baz Futter im Sdanabel zuzutragen, bamit fie nidbt badurd) an ber Fủtte=

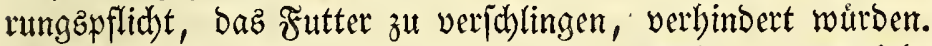

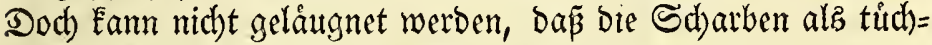
tige Sdymimmtautder bą Futter firr bie Sungen unter bem

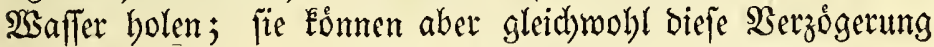
nid)t umgeben, und múffen daz Futter ưber bem SGaffer ver= feblucken, ebe fie ez ben sutungen zubringen, weil fie aus ber Speiferólye ånen.

Fragen wir, warum bie Ratur bie Sungen ber tautchenden Unia, Auca ber in Dem Futterungztriebe ibrer Eltern lie= genden Scutlfe fo fribl beraubte, und ibnen auferlegte, fid jefbit

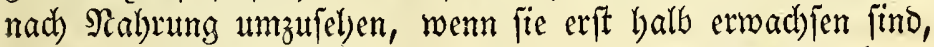
uno gar nid)t fliegen Könmen, Da fie bagegen ben Stop̈taudtern, Den Iolpelm, Reven, Raubmeven, Meerid)malben und Sturm=

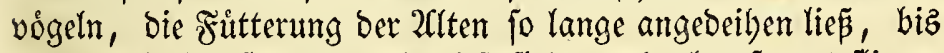
fie beynab eben jo groß , als biefe find, und eben fo gut fliegen

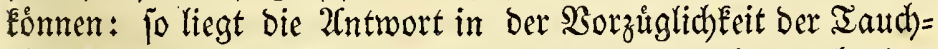
fåljigkeit vor ber Etoṕtaudfertigkeit; Denn bie taudhenden Utrien u. \{. m. find mit einem fleinen Rórper und nidht ausge $=$ wad)jenen Fluggetn gleidynobl im Stande, ihre Nabrumg auf bem

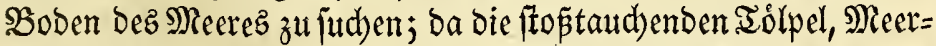

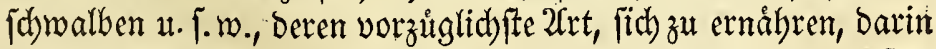
beftelyt, jich fliegend aub ber \&uft unter baz $25 a$ aljer zut werfen, fich) bagegen nidbt felbft ernåbren Eơnnen, fo lange fie nidht zu fliegen vermógen, und alfo vor Seunger umbommen wirtoen,

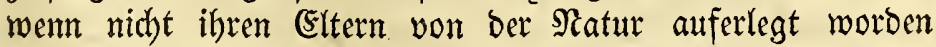

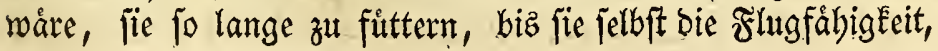


und bamit zugleid) bas Rermogen erbalten, fich felbft zu ernåhren.

\section{§. 41.}

2) Der $\mathfrak{R e i t u n g} z=$ ober $\mathfrak{A} \mathfrak{n}$ eijung $z$ trieb ift Der Trieb der borealen Sögel, ifre Sungen zu Den splásen hin= zuleiten, an weldhen fie ibre sabrung am leichteften finden

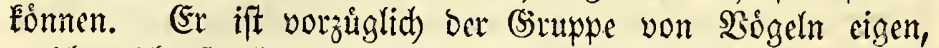
weldbe nidyt felbit ihve Sungen futtert, uno ift aljo cin Trieb, weld)er bem Frutterungetriebe entfpridst, ob er ifm gleid) an

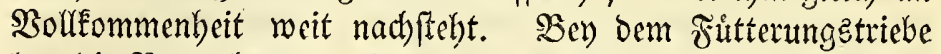
hat bic Natur beynaly allein auf dic Sråfte bes Ernábrerz ge=

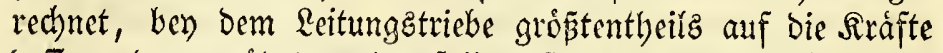

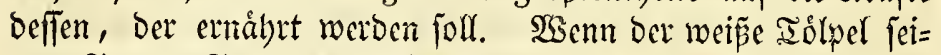
nem Sungen Futter im Sd)lunbe zutrågt, braud)t bicfes blop feinen $\Re a d$ en aufzufperren; wenn bie Enten bagegen ible Juti= gen zu ben \$láken binleiten, an weldhen ibre Sabrung gefun= ben wirb, to úberlaffen fie es ilbnen felbit, bie SBeute zu juchen, und fich ibrer zu bemádbtigen.

Bey Den buhbnerartigen So̊geln und bey Den Sdymimm= vógeln ber mittlern uno einzelnen Monogamie, bey ben 2(rten von Colymbus, Podiceps, Fulica, Mergus, Anas, AvSER, Cygnus, wird ber Reitungztrieb im hódbiten (Srabe, aber nid)t ben ben fütternoen 2 rten, alz ein Dem F̊ůtterungstriebe gleid)zeitiger Irieb gefunden. Die 2rten, weld)e Den autsgebil= beten Reitungztrieb baben, baben Den Frutterungstrieb ganz verloren, und nur bey eingelnen 2 rten finbet er fid) nod) ipo=

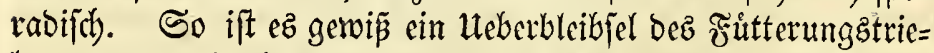
bez, wenn bie Senne cin verborgenes Sorn hervorljackt unb

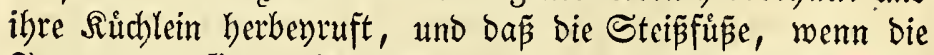
Sungen zart find, eine ober bie andere Wraflerpflanze bervor=

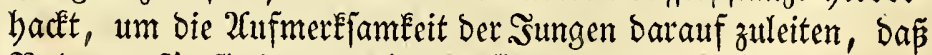
Nabrung für fie in ber Nåabe zu finden fen.

Die Sungen, welche nidht beftimmt find, won ben 2llten gefittert zu werden, zeigen baber gleidh nach Der 2 utabritung ziemlid) grop̄e fórperlidbe Fertigkeiten. Daz izlánoifche Sd)nee= bubn leitet bie fleinen Sungen weit und breit umber, wo fie am

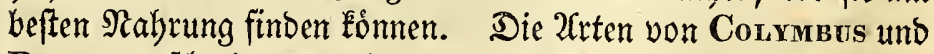
Podrceps idwoimmen mit ben jarten - Sungen, und taudben vor ibnen, um fie zu lebren, auf bieje 2urt felbft ibre Nabrung zu fudben. SSenn Enten ober Ssånfe oben im Ranbe ibre Sungen 
ausgebritet baben, watfdeln fie gleid) mit ifnen in bie Teidbe uno Ranojeen bin, uno jene laufen, fo fehr. fie fónnen, bet Mutter nad). Sobalo der (Eiberoogel feine vor furzem ausge= bruteten Sungen etroab erwårmt hat, ziel)t et von ben jüpen Walfern, fallz er ba brutete, itber Stock und Stein ben watichelnoen Iungen yoran, um ins Meer zu kommen, wo= felb/t fie fich bie ủbrige Seit aufbalten; er fút)rt fie umber, taucht mit ifmen, füttert fie aber nid)t. Şm Ronate Suly waren grope Streden von Mevwatn mit Sungen Der bajelbft brì= tenden Entenarten bebecft, biex Aras marila und clangula mit einem Şaufen, bort Aras glacialis, boscas, crecca und Mergus serrator mit einem andern. Aras tadorna, weld)e

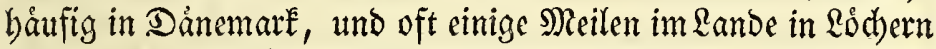
brutet, ziel)t gleid) mit ibren Iungen ins Reer. Wuf ben $\mathfrak{I} n=$ feln Enbelave und Sampë zeigt dieje Ente die Sonderbarkeit, DaF fie bod) in ben (Eichen uno Budben britet, uno gleichnobl fert fie ihle zarten Sungen bem Serunterfallen vom bohen Baume zur (Eroe aus, um gleid) mit ifnen nad) bem Neere zu zieben. STur burd) bie Glafticitåt ber Sungen Eann man ez fich erkláren, dapj fie fich bey bem Falle vom hoben Saume cben jo wenig fdhaden, alz baz sunge dez (Eibervogelz, bas fich von bem Felfen inz Reer fturzt. Daß̃ bie Mutter bie Sungen im Sd)nabel oder auf bem Rucken vom erbabenen Sefte trage,

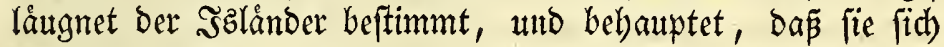

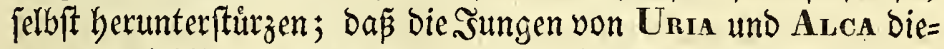

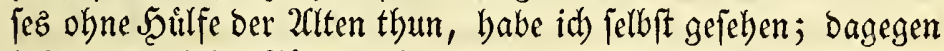
bebaupten einige S̊åger auf Sampö, dẩ bie 2ltte die Sungen von ber Srandente im Sdnabel heruntertrage. - Die

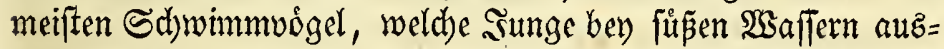
bruten, zeigen úberbaupt eine großze Neigung, bie Sungen ins Reer zu fưbren, wo fie reichliche Nabrung finden, unb zwar

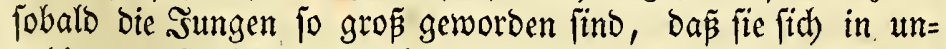
rubigerem $23 a f f e r$ bergen fónnen, alz daz ift, weldhez in 2 and $=$ feen ober Flüffen angetroffen wiro. Bom Eibervogel babe id (d)on gefprodben. Die am Flupufer bruttenden Mergus merganser und Avas histrionica werben jelten nod) mit ben Sun= gen in ben Flitfen angetroffen, wenn fie balb erwadh fen find; aud fichimmt Mergus serrator oft mit diefen im Meere. Die bey Myyatn brutenden Entenarten Ėnnen indeffen nicht ibre sungen jobroimmend inz Meer fübren, da biejer See mit bem Meere in Eeiner Directen Serbindung fteht; bie Enten bleiben 
alfo mit den Şungen fo lange in Demjelben, bis fie ifn fliegend verlaflen fonmen. SEbento zieben die in ben Sebirgjeen brit= tenden Taucher und Striß̄fine nid)t el)er mit ifren Sungen zum Meere, alz bis bieje ez fliegeno erreidhen Eonnen. Da bieje sungen.fid fo ganz auf Den Reitungstrieb ibrer Eltern verlaffen mirffen, fo ift es aud auffallend, wie aufmerkfam jie auf bie Reitung und Stimme ilyer Eltern find. Die 2lten baben oft einen eigenen 2 (nweijungelaut, weld)en jene augenblicklid) ver= fteben. Saz Sdyncebubn fubrt feine Sungen gludtend, wie bie Şenne, Colxmbus rufogularis mit einem wiederbolten $\mathfrak{\Re} \mathfrak{d}$. W̧enn Avas tadorna, Avas mollissima, marila uno Men-

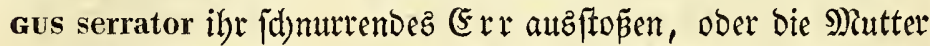
von Aras boscas und crecca ify $\Re \mathfrak{a}$ loóren lápt, fo find bie Sungen gleid) aufmerkfam, und verftehen bie Mutter. Denjel=

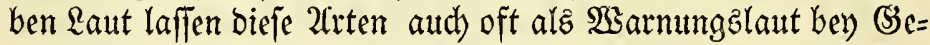
fahr horen. Dagegen fiebt man Phalaropus cinereus, ToTanus calidris und bie Seven jaterenend umifre Jungen berum= laufen ober fliegen, obne baj biefe fid) Darum zu befimmern idbeinen.

Ueberbaupt findet aber in ber 2 rt und 23 eije, wie bie Enten und andere mit bem regulären Reitungstriebe ver febene 2(rten ihre Sinngen anfülyren, und ber, auf weldse bie Meven,

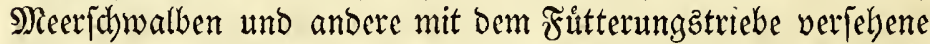
Bogel, bey ben 2rten, beten Sunge gleid) aus bem SRefte laut= fen, diefes thun, ein groper Unterichied Statt. SBey jenen fübrt Die Rutter gleid) die Sungen vom Seftplase neg; dieß thun bieje nidbt, ihre sungen verbleiben in ber $\mathfrak{x a l y e ~ b e s ~ \Re e f t p l a f e z , ~}$ und laufen nur bie und ba umber. SBen ben Enten u. f. w. folgen bie Sungen ber Mutter, bey Den Meven und Meeridnal= ben gebt bie Mutter ben Sungen voran. WWenn ber (5ibervogel und bie willo (Ente z. B. ihre sungen wegfübren wollen, fo ftellen fie fich an bie Spize bexfelben, laufen lockend voran, uno bie sungen waticheln getroft linterber. Bey ben Meven u. f. m., bagegen laufen bie Şungen bin who ber, wohin fie wollen, indem bie 2Alten ångiftlich ủber înen lyerumfliegen, uno bald nach bem einen, bald nad) bem andern sungen juchen.

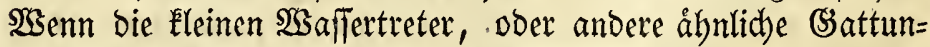
gen unter den Sumpfoógeln, weldhe ibre Sungen füttern, bieje auzgebritet baben, fo laufen fie, daz eine biet =, baz andere oortlin, uno verftecten fid im (sraje, ba benn bie Mutter von dem einen zum andern fliegen mur 


\section{5}

gen alfo ber Mitter gar nicht verfammelt, fo wie bieß bey ben

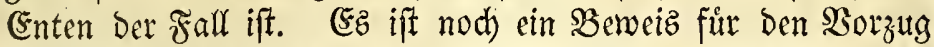

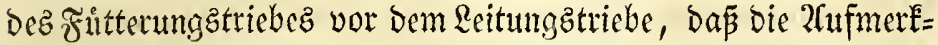
famfeit Der fütternoen 2ilten weit mebr auf Die Jungen geridbtet ift, als bie ber leitenden.

Der Reitungztrieb theilt firt) bey ben monogamen borealen

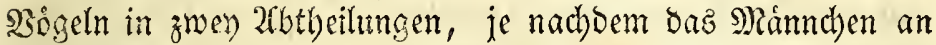

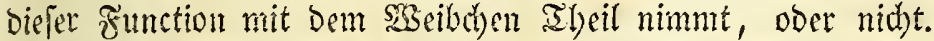

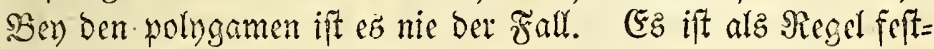

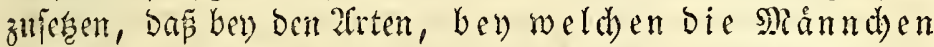
bie (E) erbriten belfen, biefelbenath die sungen leiten, uto ba die Jungennidit leitenbelfen, biefelben aud nicht Die Eyer briten. Ser ben 2trten yon der mittleten Me=

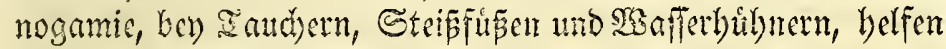
bie Miámitchen fowohl beinm Skriten, als' bel) ber Leitung Der sungen. Cosymers glacialis, rufogularis uno Podreeps arcticus wablen ein ifolittes séting ro fie in $\Re$ rube ibre Sefonomie treiben, uno ben ganzen Som=

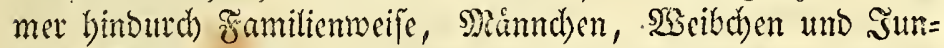

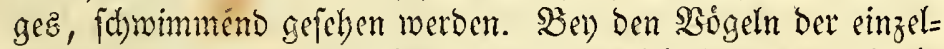

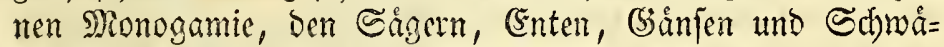
nen, ben weichen bas Şseibdyen alleit briutet, ift biefes and) vorziglid) mit ber Reitung ber Sungen bejd)åftigt. Die Månn= d)en von Mergus serrator, Aras boscas und glacialis vet= latien bie 2 Seibden bald nad)bem fie (Ener grlegt baben, bieje= nigen anderer 2frten, a!b Amas mollissima, nigra, clangula, marila, histrionica, gleid) nachbem bie Sungen ausgebruitet find;

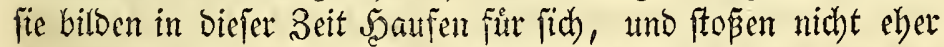
zul ibren Famillen, als im Şerbffe in ber 3ugzeit.

Dagegen bleiben bie Maanndhen ber Schwaine, und waht=

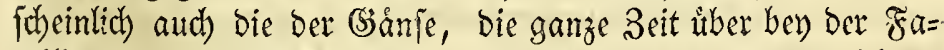
milie, uno belfen ben biejer Der Mutter bie șungen Leiter.

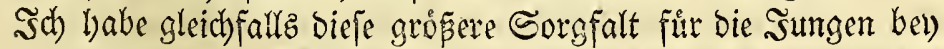
ben Månnchen ber Aras tadoma, acuta unb crecca bemerft,

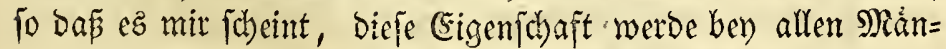
d)en ber nichttauthenden (Entenarten gefunden, rooburd) fie fich Dann mertlich yon benen ber tauthenden (Enten untericheiden.

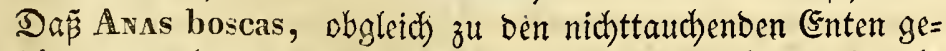
hơrend, Dod), wie bie tautchenden, bie SBrut verlápte wirb als

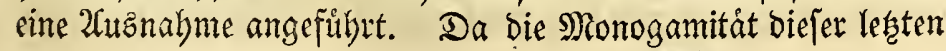


Enten fo wenig, und von allen Entenarten wobl am wenig=

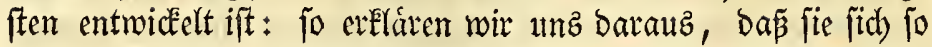
leicht im gezábmten 3uftande bazu bequemt hat, in ber Doly $=$ gamie zu leben.

Die mit Dem 2 eitungstriebe verjebenen 2lrten find ungefåbr eben fo lange mit ihren Sungen bejdåftiget, alz die futtternden, und verlafien fie nicht cher, als biz fie gefiedert find. Sod)

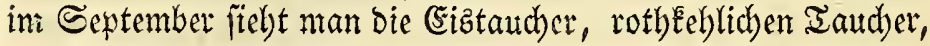
die arktijd)en Stei ten, Schelenten, uno Sarlequinenten ibre beynab erwacbjenen Sungen fübten. Der Singfdroan bleibt fogar ben ganzen şinter binourd mit ibnen in (Sejellidhaft, uno fo zieben fie in (Giemeinjad)aft nach fiblichem Bonen.

Der Reitungatrieb fimbet, wie gefagt, bey den futternden Zrten, wenigftens fo lange fie bie Frittertngspflicht ausiben, nicht Statt. Shre Sutrgen liegen ftill im Sefte, und wenn fie es gleid) verlaften, wie bev Den Meven und Meerfdrwalben, fo habe idy bod) vorbin gezeigt, bas bic 2ufmertiamkeit, weldhe bie Meven uno Meeridywalben ilyren Sungen idyenken, nidbt den Sharater bes Reitungstriebes babe. (Ez ift aber bey einigen ber 2rten, bey)

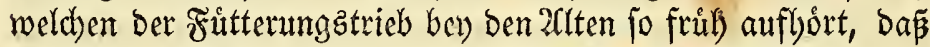
Die Sungen nid)t ganz der Sorge Der alten entbebren Fónnen, Der Frall, dap̧ Der Reitungstrieb an ber Stelle bes aufgeborten

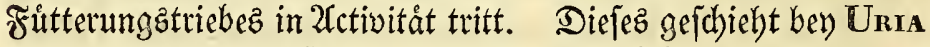
troile und Alca torda, beren Sunge febr fruil) bie Felfen ver= laffen und von ben (Eltern nidht mebr gefüttert werben; Denn wenn bie fleinen feberbefleibeten \&ummen ober 2afken fich ins Waffer geworfen baben, fo fabren bie alten nod mebrere Monate fort, fie zur Nabrung anzufithren, und man fiebt biefe 2roten nod im Sctober ibre erwadjenen Sungen leiten. So wie die Sothwenbigkeit ber Şulfe ber 2riten nad) und nach aufboirt, fo

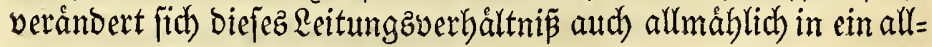

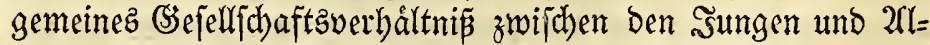
ten, weldse nod eine Seitlang in (serellyd)aft mit einander ber= umitreiden, und eine Familie bilben, nadbent fie ber gegenfei= tigen Şitfe nid)t mebr bedurfen, biz der Wandoerungstrieb bas Serbảltnī̄ ganz aufbebt.

\section{§. 42.}

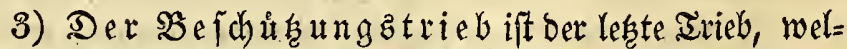
d)en ber \$pflegungstrieb ber 2flten entbålt. Miogen jie nun ibre 


\section{- 228}

Sungen fütte1 n, ober nur zum Futtter leiten, fo erbielten fie Dod) alle ben Irieb, bie Satngen zu warnen, tmb gegen eine brokende (Gefangr zu befdhuthen. Diefer Irtieb theilt fidh in 3 Utnterabtheilungen, a) Den (Erwårmungztrieb, b) Den $\mathfrak{S a r}=$ nungstrieb uno c) Den 2 ertheibigungstrieb.

a) Der (Frwármungstricb beffeht in Der (Figen=

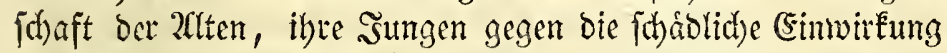

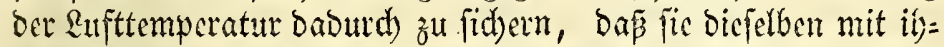
rem Rórper bebectern. (Gr gleid) Dem SBrittriabe in feincr

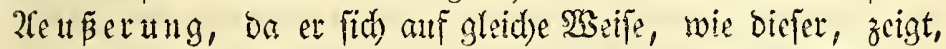

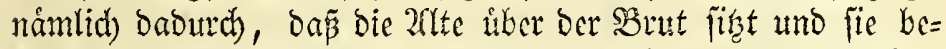
Dedeft; er ift aber von jenem in jeiner szeftemmung verfaje= Den, ba ber Brittrieb zur 2hübildung bez Reimes in (Fy)

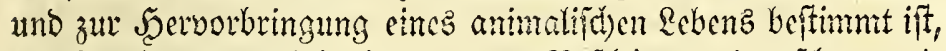

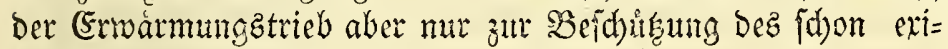
ftitenden animalifhen Rebens; in feitem (s) egenftande, ba bey bem Sriten bie (Encr und bey Dem Erráarmen bie Jumgen bebect werben; und in Feincr $\mathfrak{A}$ otlywendigkeit, ba ber

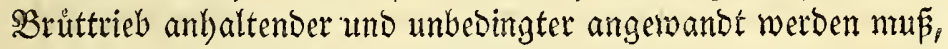
wenn bas Biel errcidyt werben foll.

Der (Erwármungstrieb wirb am háufigften angewandt, jo lange bie Sungen nod) zant find, fo lange ibre thierijaces \&eben nod nid)t volffommen entwidkelt ift; je megre bie Sutungen an (Sirópe uno Sebeckung zunelymen, Defto melyr nimmt Der Trieb ber Den 2(tten

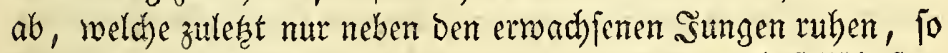

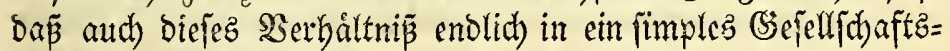

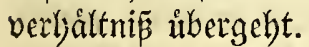

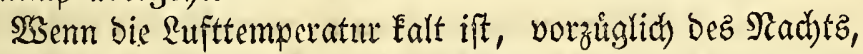
wenn ez regnet ober fturumt, fo bebecken bie 201ten bie Sungen meiftenz anbaltens, rufen bie jufammen, weld)e fidh ben Iag iber zerfifreut baben, uns famnteln fie unter ifrecr Rórper.

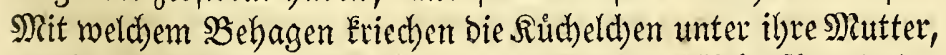

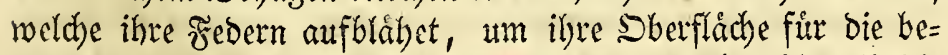
Decten șungen móglidyft zu erweitern, weldhe itberall bie

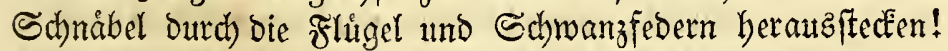
SSie oft wiro nidyt bie erraarmenoe willoe Ente iubernumpelt, weldye fict Dann fo gebårbet, und babinflattert, als wenn fie nidst fliegen fỏnnte, inbelîen fid) bie sumgen im (siraje zer= ftretten, oder bas Edhneehuhn, welchez dem אommenden zwi= fihen bie Seine låuft, um bie eben erwairmten Sungen zut ret=

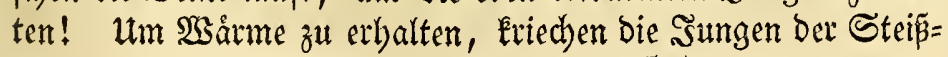




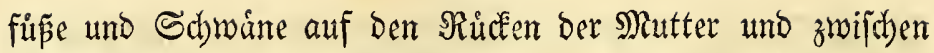
ihre rrebern.

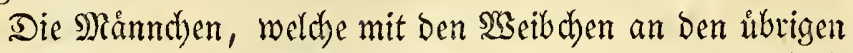
widhtigen Functionen añer Dem Briten uno Futtern theil= nel)men, belfen audd bie sungen erwämen. Dagegen ift bien Eaum ber Frall bey ben $2($ rten, bey weld)en bie Mainndhen, aut=

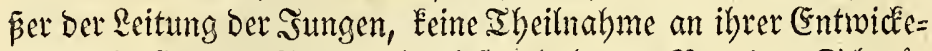
lung als (Ey uno Jumges bemiejen haben. SBen Den Sdina:= nen, GSåmen unb ben (Entenarten, bey weld)en Daz Maannd)en

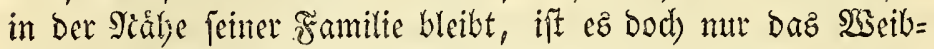
d)en, weldhes uiber ben Intmgen fitst und fie erwårmt.

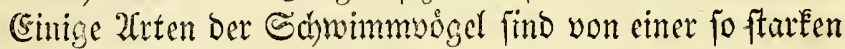

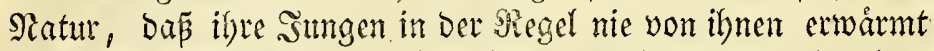
werden; es fint foldte, weld)e fid) felten aufs arodene begeben,

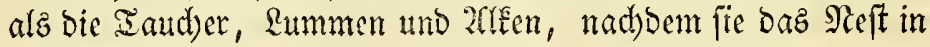
Den Felfen verlaffen baben. Sine eigene 2art und $23 e i j e$, ifre Sungen zu erwårmen, weldhe fidch zugleid) mit ihrem beftánoi=

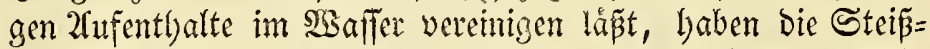

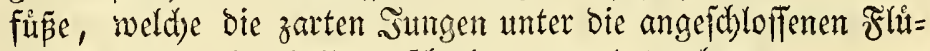
gel nelymen, and mit ilynen idjwimmen und tautd)en.

Die meiffen zarten sungen haben bas Errwarmen ber $2 \mathfrak{C l}=$ ten nothig; bie İmperatur, welche ben sungen mitgetheilt

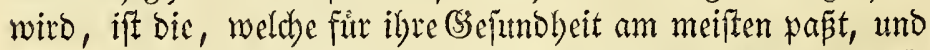

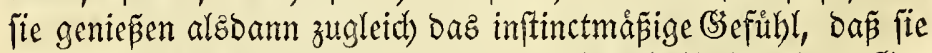
von ifren Eltern erwármt werben, weldyes (S)efinhl zu ibrem (Se= beilyen eben fo nothwendig ift, als bie $23 a$ arme felbft. Daber

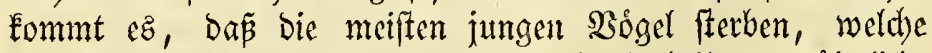
man zum 2 fuffinttern nimmt; Denn ob jie gleidh ilye gewobnhlidhe Nabrung febr gut von ben Menjechen annebmen, fo mangelt.

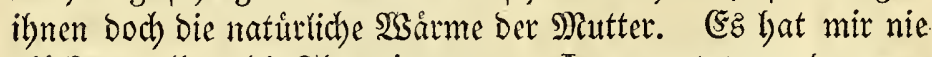
glitceten wollen, bie Flaumjungen von $\mathrm{L}$. argentatus unb canus långer als 8 Iage am Reben zu erlyalten, objthon fie in ihrer (Biefangenjhaft bas Futtter gierig frafen, weld)es ich ihnen vorwarf; ob id fie gleid) warm zubectete, fo flagten fie bods pfeifeno unauffiórlidy; wenn ich aber, um ifren Irieb zu prơfen,

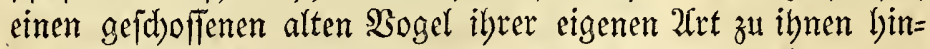
legte, liefen fie zut ilym Kin, Gacten ifn liebreidy in ben Sopf, und frodben unter ben אórner, in Der Meinung, da

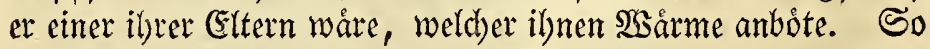
Eonten fie mel)rere Stunden ftill firsen, obne sinen $\mathfrak{L} a$ aut von 


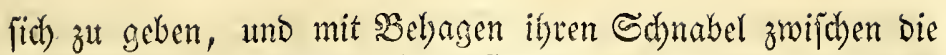
F̌lugel Des tudten \$ogelz hineinftecker.

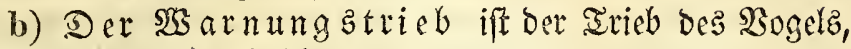

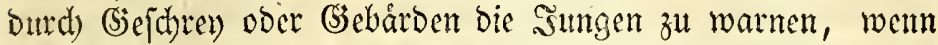

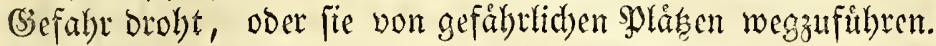

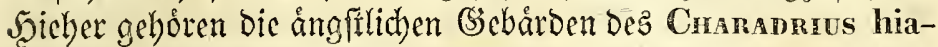
ticula, Trerva maritima, Avas acuta, crecca, uno Lestris parasitica, wenn ibre SItngen in (Sefalyr find ; bieber Das ångftlidye (sejefdren, mit weld)em die Phala ropus - 2(rten, die Totanus - 2frten, Die Hafmatopus - 2frten um bie verftede ten Iungen berumfliegen. SWie forgiam loden nicht bie Sing=

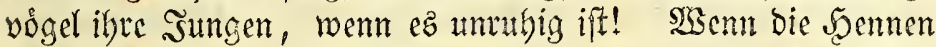
ober bie (Enten bey ifren Sungen beuntubigt werden, rufen fie diefe glutefend obev fonatterno gutfammen, und geben von bem

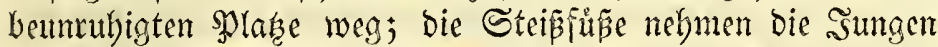

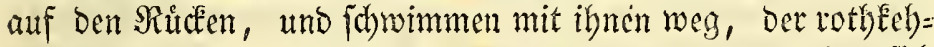

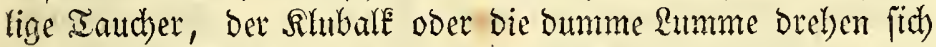

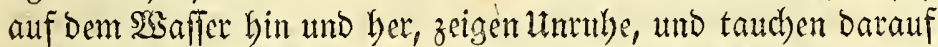
unter, um zut entflief)en, worin benn bie sungen ihnert fogleid) folgen. Bey Mayuatn war ez bemerkungswurbig, wem Der Eleme Farco caesius nad) Den šungen ber (Enten ober Såger

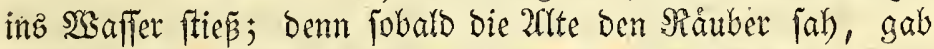
fie cinen $\mathbb{R}$ aut von jid), um bie Sungen aufmerkfam zu madben, und indem ber Falfe einen Bogen gegen fie auz der \&uft berun= ter machte, tautd)te bie Mutter unb bie Sungen in (Sinem İem= po unter; fo oft er feinen Stop wicoerholte, fo oft tandote bie Mutter mit ben Siteinen unter, rief fie jeoesmal angfiflich

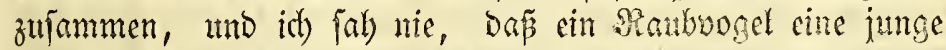
Gente taubte. 2ats idh in biejem salye anf einer Geetom Anas

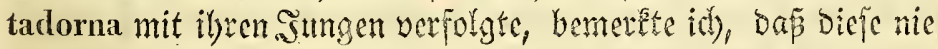
el)er untertautbten, als bis die Zete einen warnenben Raut von fich gegeben batte, und in Demfalben Fugenblice flog biefe au,

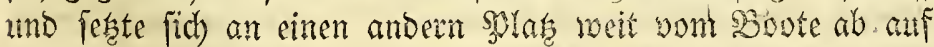
Dem Mieere, wo fie bie sungen wicber um fid verfammelte.

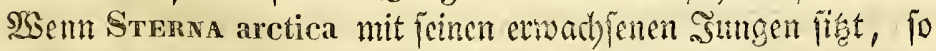
fliegen biefe gleith nach ber zetten auf. So lernen bie jungen

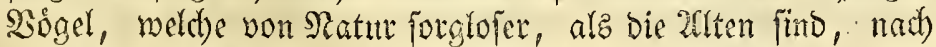

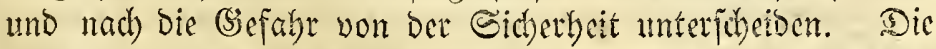

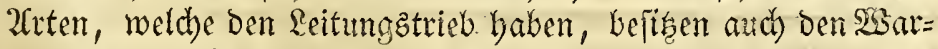
mungstrieb, fowohl bie Måmènen, als bie 23 seibchen.

c) Den $\mathfrak{3 e r t h e i d i g u n g e t r i e b , ~ o b e r ~ b i c ~ E s i g e n = ~}$ 
fhaft ber $\mathfrak{B} \dot{g} g e l$, activ ifre $\mathfrak{B r u t}$ zu vertbeioigen, wenn fie in (Sefalyr find, ober Den Feind anzugreifen, baben nur bie wenigften 2(rten. STh babe fdon in eimet Betrad)tung uiber

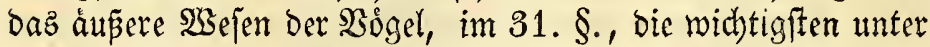
biejen angegeben, fo wie bie $2(\mathfrak{r t}$ und 2 Seife, aut weldye fie itgre

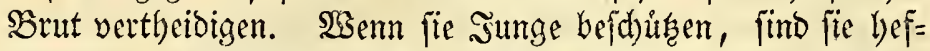
tiger in ifyrem 2fngriffe, als wenn jie nut Eyer baben. STERra arctica uno nigra, Larvs glaucus, marinus uno argentatus, Lestris catarractes unb parasitica ftopenen gegen Men= fohen und alfiere, um ihre sungen zu vertbeidigen. CourmBus glacialis uno Podrceps arcticus fốpen zuneilen denjenigen mit bem Schnabel, Det fie beumuhigen will. Crgnus musicus und olor geben bem 2ingreifer berbe Schláge mit ben Flü= getn. $\Im$ sch babe Nunenues phaeopus und Vavencus cristatus lange einen $\Re$ aben und Falfen verfolgen, und fie mit Den

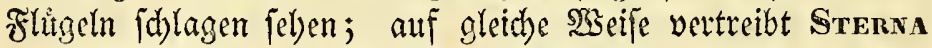

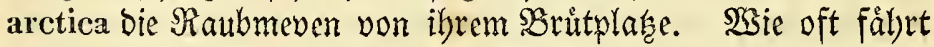

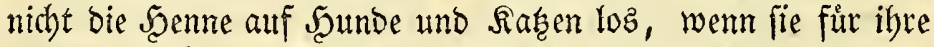
Jungen fúrchtet! Proceldaria glacialis bat eine eigene $2 \mathfrak{i n t}$,

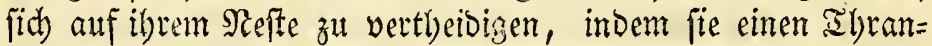
ftrabl gegen den \$serfolger ausfacht.

2fuch die Sorge, weldhe bie \$3ógel fiur ihre Sungen tragen, um fie gegen bie reittoe, welche innen im Sefte wegen $\mathfrak{U n}$ rein=

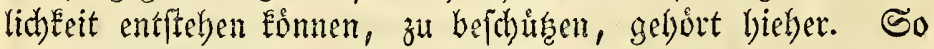
lange bie Sungen zart fino, tragen bie 2ltten Deren Excremente

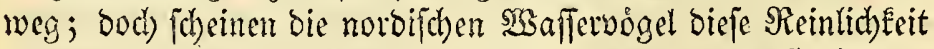

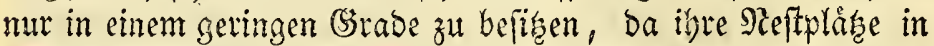

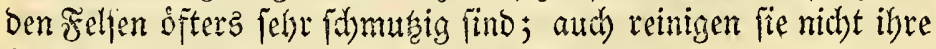

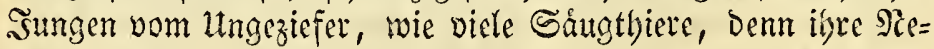
ffer mimmeln, wie ibre sungen, von einer unglatblichen Senge

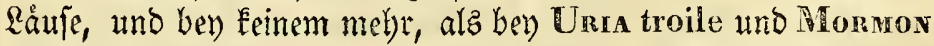
fratercula. Da id), ofye mich befien zu erinnern, midy vor ben

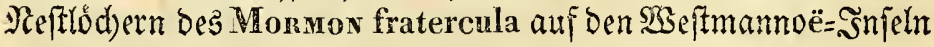
niederlegte, wurbe idh mit feinem gropen blaten ungeziefer jo

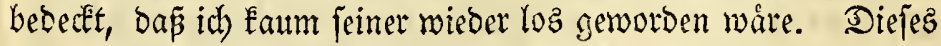

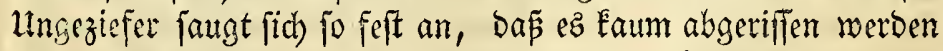

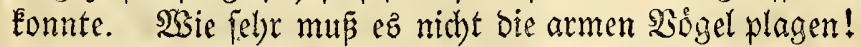

Sn ber borealen 3one werben die Reftwerbáltniffe in dem= jelben 3ermine nicht wiederbolt. Dieje 2oogel haben mat Eine

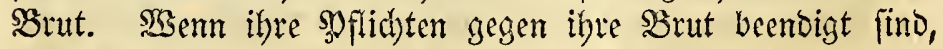

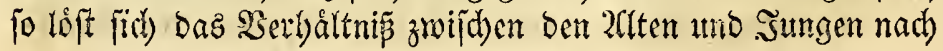


uno nad) auf. Die 20lten fangen an bie SGintertracht zu er=

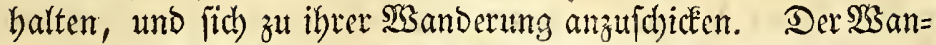

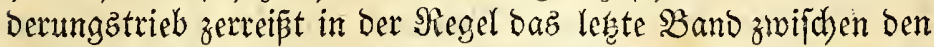
sutngen und 2ltten, ba bieje in verifdicoenem 2Olter, zu ver= fobjebenen Beiten, in verffjiebenen Sautjen randern, unb nur felten in zamilien. Syier id)liefst fich alfo Der Beit nad) bie Manderungabiftorie ber SBỏgel an.

Sn Den norbifden 20 getbergen, wo in ber Britzeit $\mathfrak{T h} \hat{d}=$ tigkeit und $\mathfrak{e}_{\text {eben }}$ herrifd)te, tritt num eine Iobtenftille ein. Stun erft foheint Der Felien nackt uno traurig, welcher, fo lange er von emjigen 2 oggeln bewohnt war, freetnolid) und an= ziebend erfachien. Denn bieje beflügelten (Sejdoópfe verbreiten

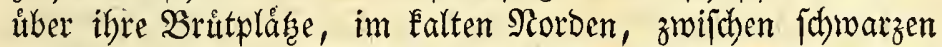
Steinmaflen, in Der Miáhe des braufenden Molarmeerz, ein ei=

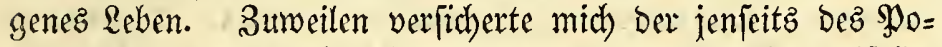
larcirfelz molynende Girimpoër, Dap̃ er auf jeiner Eleinen ifolir= ten Silippeninfel viele Berftreutung in bem \&eben finde, welches bie in feiren Felfen brütenden $2 \mathfrak{S a f f e r v o ̉ g e l ~ v e r b r e i t e t e n , ~ u n d ~}$

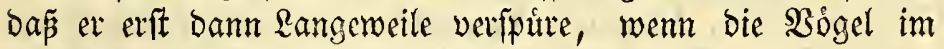
Scerbjte ilyre Brủtplähe verlaffen Gaben.

III.

Bon ben Bewegungaverháltniffen ber botealen $\mathfrak{B} \mathfrak{i g e l}$.

\section{§. 43.}

Die Boggel find mutntre (sefforopfe, voll Reben, uno mit

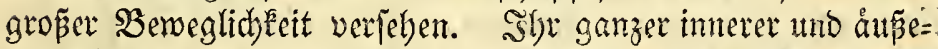

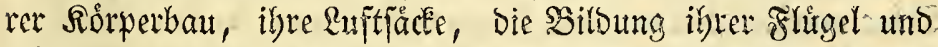

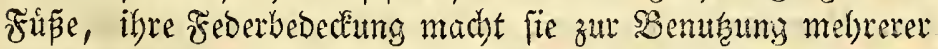
Elemente gefdickt. So wie fie im Stande find, fich auf ber Eroe, in ber \&uft oder auf bem şaffer zu berwegen, fo theilt

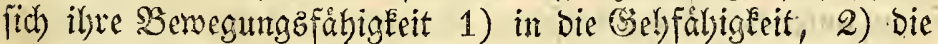

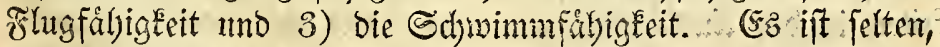

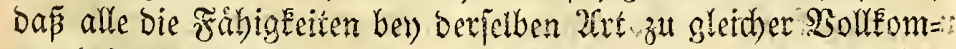
menheit ausgebilbet fino; wo bie cine in ber 2hazbildumg bebeu= teno fteigt, nimmt in ber $\Re e$ gel bie andere ab.-... (Sine vollfom=

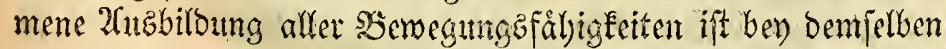

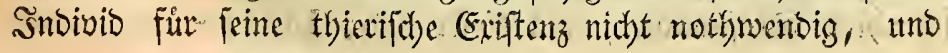




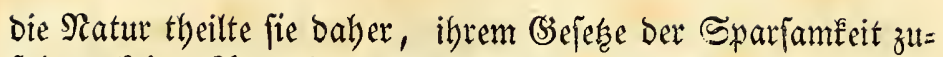

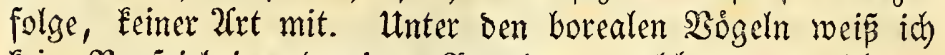
kein Benjpicl ingeno einer Sogelart, weldye auzzezeidnete

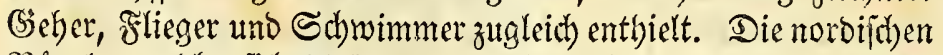
Sógel, weldhe fich biefen am meifen nálern, fino bie 2riten Phalaropus, Anser und Lanus, weldhe fid mit ziemlidber

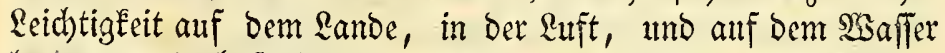
berogen; Doch fehlt ifhen allen, ob fie gleid) gutte Sabminmer

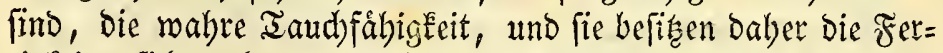

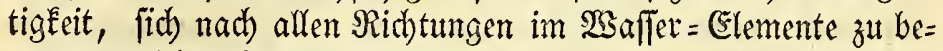
wegen, nicht vóllig ausgebilbet.

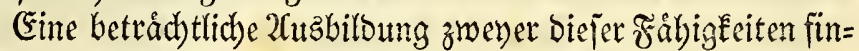

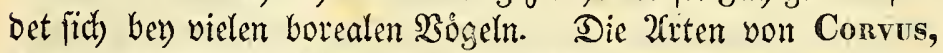
Plectrophanes, Motacilia, Saxicola, Amthus, Haematopus, Charadrius, Calidris, Ardea, Numenius, Lmosa, Totanus, Vanelues, Strepsiras, Trivga, Scolopax, bervegen jich mit Fertigkeit auf Der Erroe uno in ber Ruft; bie 2frten yon Carbo, Puffinus, Mergus, Anas, Cygnus, Sula, Lestris, Procellama, in dev \&uft umb auf

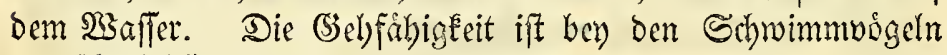

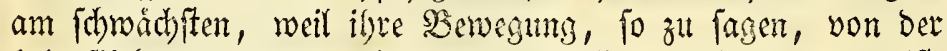

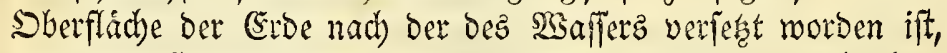
und bie beften Schwimmer find baber gemeiniglidb bie follechte=

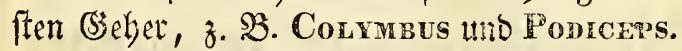

Einige 2rten haben bie eine biejer Frabigkeiten fo volfem=

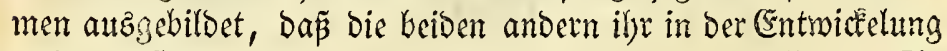
weit nadjitelyen, ober wobl gar ganz veridjumben finto. So

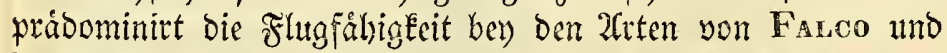
Hinundo, weldhe nidjt gut gel)en; bie Rauffádigkeit bey ben 2fiten von Tetrao uno Ralnus, weldye nidft gut fliegen; bie Sdbrimmfáfigheit bey den 2frten von Uria, Alca, Colvabus, Poniceps, Fulica, welder nidot geen geíen umb flie=

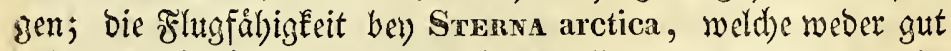
geben, noch fihwimmen. (Fs ift intereffant, za bemerken, wie, fogar unter Den 2Trten Derfelben (S)attung, bie eine biejer F̧ábig= Eeiten in ber 2 fubbilbung zuninmt, wie bie anbere abnimmt, uno umgekefrt. So gehen bie nidhttauthenden Enten befler, als bie tautchenden, weldye Ref(steren aljo im volleren $\mathfrak{M a a p e ~ f i c h ~}$ im $23 a$ fifer zu bewegen verffelyen; ebempo finto Lanus marinus uno glaucus beffere (̧̧eber, alz Lanus tridactylus, weil fie (d)led)tere Stoptaudjer, ald biefer fino; Lestris catarractes 

verlaffen bef́timmt fino, alB Shübner uno Enten, Éonnen fich fehr ge= farwind muf bie Seine erbeben. 


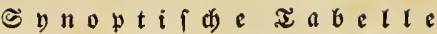

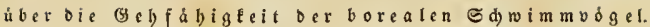

9) I a n t i g raben.

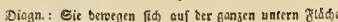

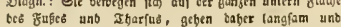
ifileppent.

$$
\text { gieger. }
$$$$
\text { Sletterer }
$$

Diagnn: Eic tónnen nidtt Diagn : Eie befteigen bi thetcern, bo fie felten auf Edjecteo bond meere ber mit

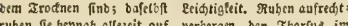

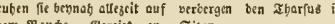

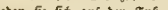
loufen bursig, follen aber gteid) witser anf ben athas: fub nieter.
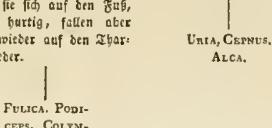

D I gitigraber.

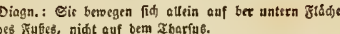

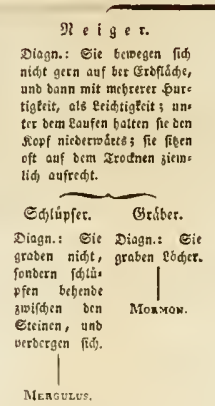

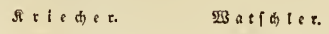

Diagn.: Eit geben foftedts Diagn: : Eie gethen befdiwers

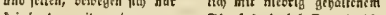

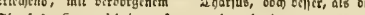

Zharfusi ; fiken niebrig auf vorhergebenten. Eaufen fet

Bratber. Eprifer.

Diagn.: Eile Diagn.: Bil

ten unb tlogig.

Jpripen 3 hroo

|

Purfikus.

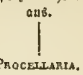

Befir. \&\& $x \in t$

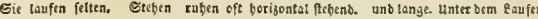
fub.

\section{e tebs}

Diegt.: Eis fathin of auf bect zrodnen, befone

bers aut oen Edecren, be

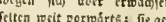

bes alfo nue reetrig.

$B \in f \in t g \in t$.

Ricberfenlet.

Diagn,: ๔ie befteigen oft Diagn, : Cie laffen fid of

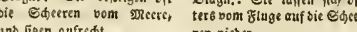
ter6 bom है.

$\left.\right|_{\text {cinso. }}$

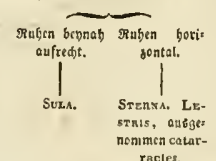

$23 a$ a 6 e

Diagn.: Cie figen oft auf berm Trodnen, befonbers auf flachem sante, ruben bennaty borizontal; Fie geten $\mathrm{mchr}$, als bit Eiper, und Dadt samerlen

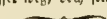

MLRGus. ata bat ANas Busmos. ato (it) ANo

$$
\text { - }
$$

.

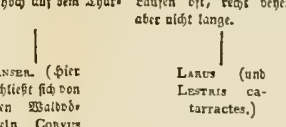
fider, auf bobem Tharius.

sirper fongenge fiebt ber sinter fant borizontal; fie am meifen fúr biefe ₹ertig leit gerousect.

gatn Conves

tarractes.) bernab vonuátro gebeuge.<smiles>C1CCCC1</smiles>

(bier fobtitegen fid, tie meiffen Eumptooger don ten Pinni: Con Scolorar ato Tangex, pas an, Don ben fábneras tigen Texna uno soa de Eingoógeln Axтн18, PLE. ctrophanes and Motacil. LA.) - 
nen aufhalten; bejonderz ift diejez Der Fall mit ben Iaudhern,

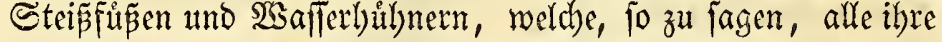
thierifben Serrichtungen im $23 a f f e r$ vornebmen, uno $\mathfrak{N e f t e r ~ i m ~}$ SGafler felbft oder bidht am Ufer bauen. Sefter, alz bieje 2rten, merden Uria, Cephus und Alca auf dem sande gefelgen, uno Dann felten auf Der ebenen Eroe, fondern auf fahrágen Giegen= ftänden zwifhen ben Felfen und auf ben Sabeeren. Şier fommt ihnen ify Soblengang, weldher fie auf einer ebenen Fläche zu geben verbindert, gut zu Statten, Denn butch Sculfe iljerer ab= gerundeten uno rauben Soble Elettern jie, went fie ruben wol= len, mit Bebendigkeit auz Dem Meete auf die Sdeeren, ober

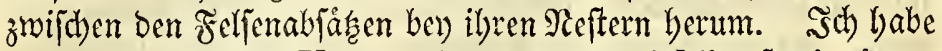
mit $\mathfrak{B e r w u m b e r u n g ~ U r a ~ t r o i l e ~ u n o ~ B r u ̈ n n i c h i i , ~ f o w i c ~ A l c a ~}$

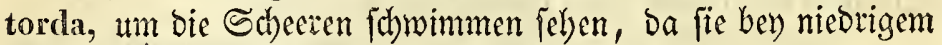
Waffer itber bie $\mathfrak{s a f f e r f l a ́ c h e ~ b e r v o r f o m m e n , ~ u n o ~ i n ~ c i n e m ~} 2 \mathfrak{h}=$ genblicke ben (sipfel berfelben erflettert haben. (Ez läat fid) auth). nur auz biefer (sigenja)aft erflaren, wie bie nidbtfliegende ALca impennis den fteilen Felfen bey Reifianảs hat erfteigen fon= nen, auf weldyem fie in viclen Sabren foll gebritet haben. Monmos fratercula lyingegen, ber nicbt Soblenganger ift, ver= mag audh nid)t, vom Meere ber fteile Felien zu erfteigen, fon= Dern bilft fich fliegend hinauf. Da jene 2lrten, vermittelit ib) rer Soble zum Slettern auf Die Felfen beftimmt find, fo war eb

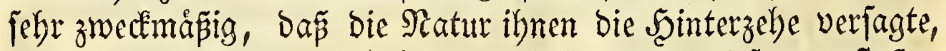
welde beym Nlettern zwijhen den Feljen gegen dieje angeltopen fenn, und fie auf bieje $\mathfrak{B}$ eife im Slettern gebinoert baben wuirbe.

Die thbrigen borealen $\mathfrak{B o g e l}$ find Digitigraden, $\widetilde{F} u \tilde{\beta}=$ ober 3ebengånger, foldbe, weldse fich allein auf ber Spur bewegen. Sie fino mebr mit der wabren (3ebfál)igfeit verjeben, als bie slantigraben; bods ift diefelbe aud) unter biejen bey den ver= fdicbenen 2riten melre ober minder auggebildet. Jith babe auf Der Iabelle No. II. die borealen Edrmimmogel nad) ber ver=

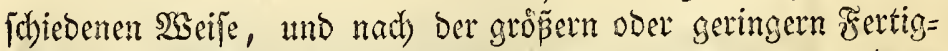
Eeit, mit weldser fie fich auf Dem Rande berwegen, zu oronen gequidst.

Die SBewegung ber 3ebenganger auf ber Groe ift zulefach, entweder find fie (S) eber ober Soipfer.

Die gel)enden 20 gel fésen wechlelsweife bas cine Sein nad) bem andern vor; bie biufenden werfen beibe Soine auf einmal vormártz. 
Shipfer werden nicht unter ben Sromungen ber Sumpf =, Schminm = oder hifgnerartigen 2 ógel gefunden, felten unter Den Raubuógeln, aber unter den $\mathfrak{B a l d o d g e l n ~ ( P I c a E ~ L i n n e i ) ; ~}$ am meiften unter ben Singudgcln. (Es find folde $2 B \dot{g g l}$, wel= d)e eigentlid nicht bazu beftimmt fino, fith auf ber SDberflache be: (Erbe fclbit, ober auf einer zulammentjaingenden flache auf= zubalten, fondern mut auf 3 ăumen uno andern erbóbeten uno febr ausgebreiteten (segenftånden, wo fie aljo, um fich, obne zu fliegen, vorwårtz bewegen zut Eónnen, båufige Sprünge ourd) die Ruft machen minfer. Şưfer find unter ben norbijhen $\mathfrak{B} \mathfrak{D}=$ geln z. $\mathfrak{B}$. Conves pica, einige 2 rten von Loxia, Emberiza, Frivgilua, Parus, Turdus umb Sruva.

Die gebenden Soggel, weldhe indem jie fich fortbemegen, baz eine Sein uach dem andern vorferen, verbienen in verfabie= Deme 20btheilungen eingetbeilt zu werben, fo wie die (3iebfábig= feit mebr oder weniger entwidkelt iff. (5inige bewegen jich bur= tig, anoere langlam, einige ficher, andere wackelno, eimige oft uno gern, andere felten und ungern.

Die eigentliden (Siel)er zeidjnen fid) melor burch einen fe= ften, fichern und anbaltenden, als ourdy einen gefdyinden (Sang auz. Sie beben fich ziemlich bod auf bem Raufe, und

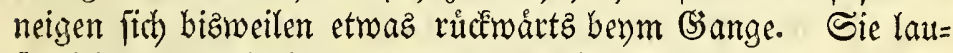
fen felten, und breiten alsbann bic Fligel etwas aus cinander, um ben buttigen (Sang zu bejdhleunigen. Dabin gebóren unter Den nơrolichen Bógeln die meiften ber (Gattungen Corvos, Arnea, Crconia, Anser, die meiften Lart, und zum Theil LesTris catarractes.

Die ̊ăufer find nicht fo anbaltend in ibrer Bemegung, indem bieje mit Utnterbredung Derfelben abwechjelt; Dod) $g e=$

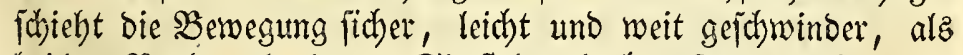
bei den 2 borbergebenden. Sie fteben hoch auf dem Raufe, und

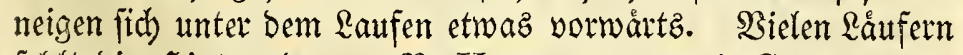
feblt die Şinterzel)e, z. B. Haematopus und Charadnius, body nidbt allen, z. $\mathfrak{B}$. Rallus und Galdinula. Seieljet ge= bóten unter ben nordifden Boogeln: Tetrao, Plectrophanes, Motacilla, Saxicola, Alauda, Anthus, Haematopus, Charadrus, Calidris, die Rinnéifden 'Tringae, und zum Theil Scolopax, Rallus, Gallinula, Phalaropus, und, obgleid) in geringerem (Srabe, Monmox und Mergulus.

Einen umithern, meniger gefdidften, febr langiamen Słang

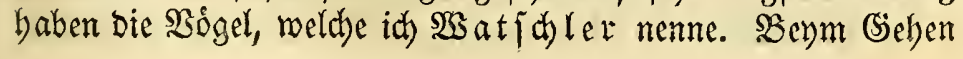


neigt fich Der Sórper von Der einen Seite zur andern. Sie find nicht ganz mit Der (Ssebfálbigkeit begabt, und bewegen fich $D a=$ ber menig uno ungern auf ber (5rofludde; fie find auf berfelben meiftenz in $\Re u b e$. So wie ibre (Sel)făhigkeit abnimmt, fincen fie aud mebr uno mebr auf ben Tharjus. So geben bie 2 reten

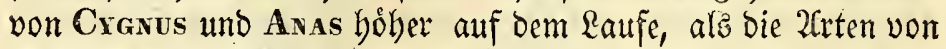
Platupus und Mergus, und audh beffer, alz diefe; fo gelyen audb die 2(rten von Lestris bỏher uno beffer, alz die 2riten von Sterna. Sobgleich die Carbo- und Sula-2frten oft auf dem Irodénen ruben, fo berwegen fie fich bod am foltenften unter allen vorwairtz auf ben Schecren, auf weldjen fie ausruben; und ich l)abe fie baber zu ber lunterabtiseiling gerectonet, weld)e id) Stelyer nente. SBeym (Selyen ift ilyr $\mathfrak{L}$ auf beynaly von den Federn bes Unterleibes bededt.

Den unbequemften und fdled)teften (şang unter allen Di= gitigraden haben bie Sried)er, weldhe mit ganz niebrigem Laufe fich, to zu jagen, über bie (Eroflache binjd)leppen, und fich baber nut febr ungern auf diefem Medium bewegen. Dabin gelsoren unter den Singoogeln die (Sattung Hruwrdo zum Ibeil, und unter den Sdwimmoógeln die 2frten von Purrivus uno Pro-

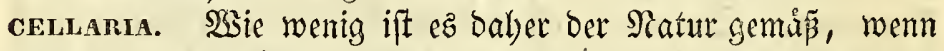
man in ben Sogelcabinettern Procelrania glacialis oder Puffivus arcticus, fo wie bie Mcoen, hod) auf ilyem $\mathfrak{a} a$ fe aufitellt, als wenn fie eben fo bequeme (Selser, als biefe, wáren.

Inter Den Digitigraben ber norbifhen Sdymimmoogel merben feine eigentlid)en. Aletterer gejunden; felbft Mormos und

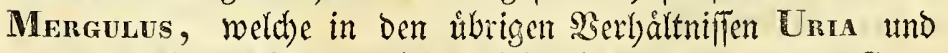
Alca gleichen, fỏnnen nicht betrád htlich lelettern, mur die CarBo-2Crten, und einige ber am niebrigften gelenden 20rten ber Enten, z. B. Aras mollissima, histrionica und die 2frten Mer-

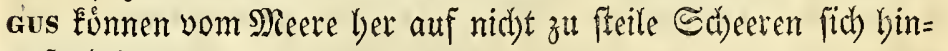
aufarbeiten.

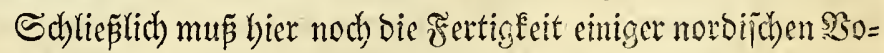
gelarten erwailnt werden, mit weld)er fie vermittelf ifyes (d)at= fen Sdunabels, und vorziglid) ifrer Slatten, Sod)er in bie (stbe graben, was fie, wie man fagt, auf bem Saideren liegend vertidten.

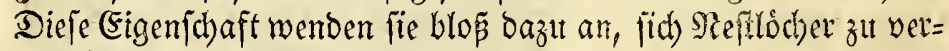
ichaffen, nicht aber, um Nabrung zut fucben. Dem zufolge beist Puffinus areticus auf izlåndijch GFrofa, und auf Den Snjeln

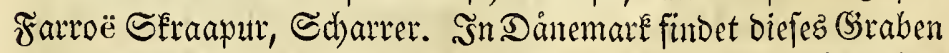
am meiften Statt bey Hrívdo riparia, und in ben norblichen 
Rándern bey Mormon fratercula, Procelcarma pelagica und Pufrinvs areticus. Sejonderz vermag Der erfte diejer Sdywimm=

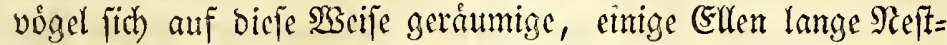
lodher zu veridhaffen. (sin jporabifd)es Heberbleibjel biejer (Eigen= (c) aft zu graben finden wir ber) ben 20 gelarten, welde fids eine Eleime 2 Bertiefung zut igren (Fyern in bie Erbe Erafen; z. B. bev Den Tetraonen, einigen Enten u. m. -

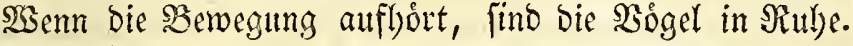
Siele vulgen ftehend, z. B. Haematopus, Charadrius, Annea, Crconia; die meiften wuben bald ftebend, bald liegent, und bann zielyen fie bie S3eine unter fich, und rulyen auf Dem

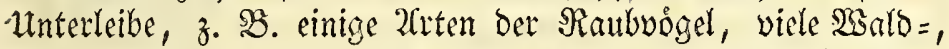
Sing =, hưbmerartige, Sumpfougel, Meven, Meeridhwalben,

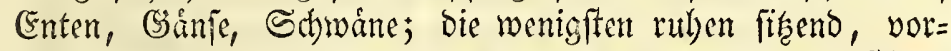

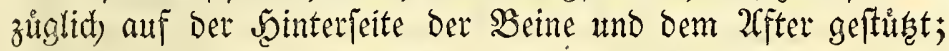
Diefe baben unter bem ๔inen eine aufredte Stellung, z. $\mathfrak{B}$. die Ltrien, 2then, Scharben und Tólpel. Dieje firende Stel=

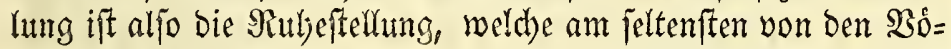
geln benutet wirb, und ez ift mur butch ben Sprad)gebraud ein=

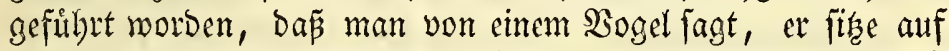
einem 3weige, einem Steine u. 5. w., ba er biejes genteiniglich nid)t thut, fondern entweder auf bemjelben fitebt oder liegt.

Sndem bie SBogel an berfelben Stelle verbleiben, madyen

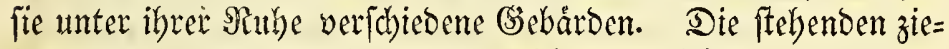
ben zumeilen bas eine Bein unter fid in bie Şobe, und ruben nur auf Dem einen, z. B. Ciconia, Ardea, Haematopus, Aras boscas, Arser und Larus; andere ftehen immer beym Ruben auf beioen Beinen, als Monmov, Tringa, CharaDnus; mebrere Singuógel breben Den $\mathfrak{a}$ etb bin uno ber; bie (sulen orelyen Den Sopf und blinzeln mit ben 2 hugen; aud) Mor-

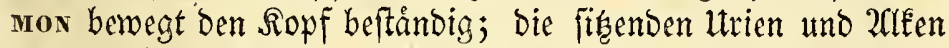
neigen fich mit geftredetem Şalje; bie ftehenden 2 rten von HaEmatopus, Charadrius, Totanus $\mathfrak{u}$. m., mad)en zuweilen mit bem Sorberleibe eine beugende Benegung, als wenn jie vor= wårtz fallen wollten. Die Tringa - uno Phalaropus - 2 Urten zieben Den Şalz zujammen, und machen Den Siorper kirzer und bicker. Die Enten, (şåmie, ઉchwåne, Sulen, Meven, Meer=

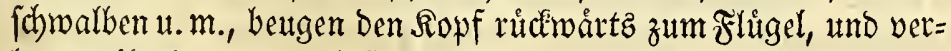
bergen ihn barunter; bejonders aber zeigen die auf ben Sdbeeren

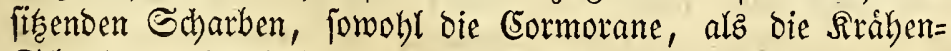

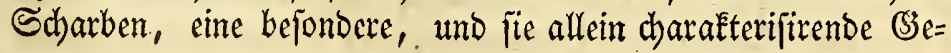


bárbe, ba fie bie Flugel ausbreiten, uno fo mit ibren ausgebrei= teten Flügeln ganze Stunden flatterno fích. Diejes Flattern Darf nid)t mit Dem wieberholten Flitgelid)lage verwed) felt werben, welchen die Şühner, Enten, Tauben und viele

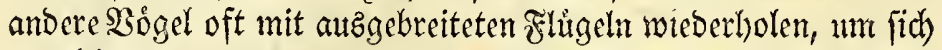
zu fhuttteln, ba biejer nidht fo umunterbrochen und fo lange an= bålt. Die Scharben finden gropez 2 sergnitgen an biejem ifnen

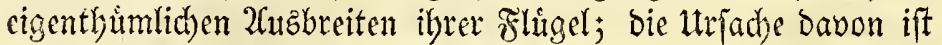
jebod) nicht leidht anzugeben, es gejhiebt weber, um ilyre Flugel zut trodenen, ba fie biefes eben fo oft bev Dunflem und regnigtem Wetter thun, alz beym Eonnerid)rin, und auth nidt, un fich bey warmer Şitterung Sublung zu verfdraffen, ba fie auch in Den ftrengiten sisintertagen fo firsent gefunden werben.

Faft allgemein ift bie Reigung afler Ranovigel in warmen fonnigten Tagen, fith in Den Staub oder Sand zu legen, fid) Darin berum zat walzen, indem fie bie Febern foitteln, und fie

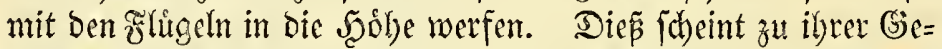
funbheit notlwendig zut fern, und man barf balber nid)t unter= laffen, ben Rerchen und andern gezálymten Singuógeln Samo in ibre $\mathfrak{B a u t e r}$ zu geben. Da fich bieje (Figenid)afí bejonderz

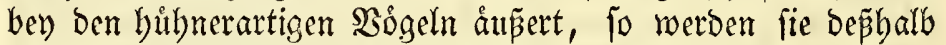
von einigen framzofifdyen Sonithologen Pulverateurs genant.

Die Schrimmoogel baben fid) gern auf gleidhe 2 seife im Saffer, wie die Ranboogel im Staube. Man fiebt ProcenuaRIA glacialis fid) in ben ftărfften Strơmen baden, uno unfere

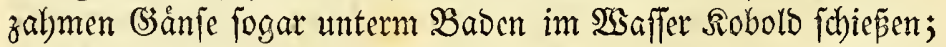

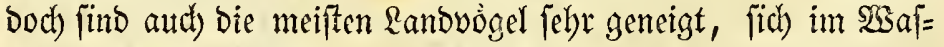
fer zu baben. Man bat oft (3)elegenbeit, biefes bey unfern ge=

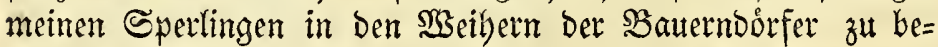
obaditen.

\section{§. 45.}

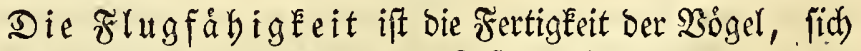
von einem niebrigern Mebium in bie \&uft erbeben, ober von ba fich auf bie (Erbe berablaffen, und fich in ber $\Omega_{u f t}$ nadh allen Richtungen in einer unbeftimmten Beit willélyrlich bewegen zu Eonnen. Dieje Fåabigkeit wird in keiner Thbierclaffe fo allgemein

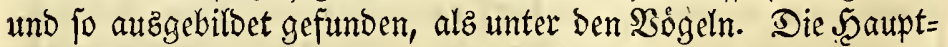
rolle benm Fluge fpielen die Flügel; Doch trägt bie Silbung Dez ganzen Sơrperz, ber fpitze Sdynabel, Die abgerundeten Sdyul= tern, daz Dajenn bez Sahwanzez, Der feberbedecte Sionper, 
it $b$ e

bie zlugfabigleit ber borealen 5 droimmobget.

Fi i ger

283 i 11 i g e.

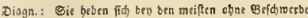

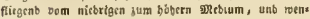

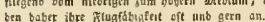

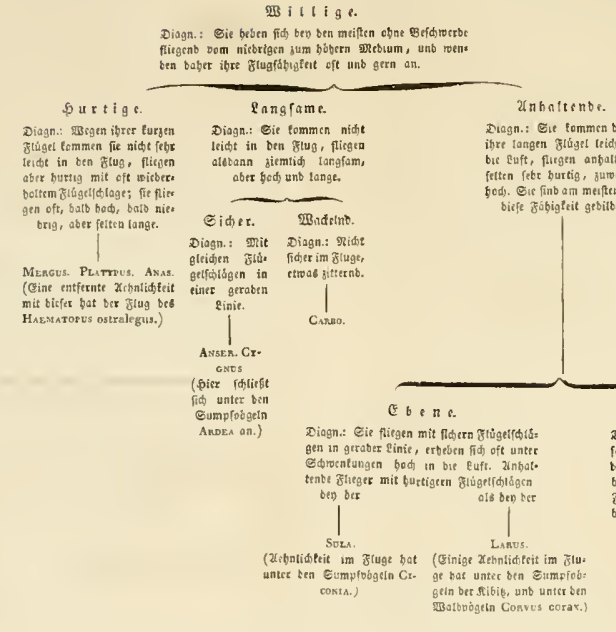

$$
\text { un w } \mathrm{w}: 1 \text { is } \mathrm{c} \text {. }
$$

Diagn: Gie erbeten fid befdipellidy and bem Muere

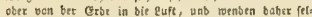

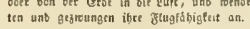

\section{0}

Diagn.: Gie fluggen mit ungleidrn ratigerfoldagen, balb frigenb, balb faltenb, in.

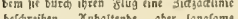
Terarter ben folten ober vis.

Lestrets. STER:A.

5. o d f liegenoe.

शiedrigftiegende. Diagn.: Nur in ber Noarangezelt fliegen Iif giemlidy oft mit einem bertigen, rudst antaltenten Fituge, Meigetn abas fellten bobec

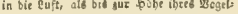
bergeb. zem befen fliegt Menguzes.

Coltsmers. Podterrs, FuEma. Gerrus, Azca. Men. guLUs, Мокиок, Zuznab. menis.
Eक we to no

Dlegn: Sie flieger bentab ohnt gliugele

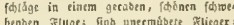
fie gitseen in bet Euft bu pquale, beben

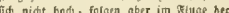
Betreguns bec פinereres.

Proczla arla. Potpinus,

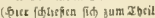
bit Sidivalben unter ben Gingolgrin, unb emige Xr' $^{2}$ ter ber zateen unter ber raulobgein an.)
$93 i+6=1110$

Diagn.: Gie flirgen mit furtigen gftugete foglagen, ctine die gerabe eithie gu befolgen; treigen off fidxag ta bie cuft, unb berwegen

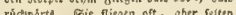

PHazamopus, an metden id

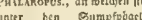
Staetallas, Tamea, Scoropas, Totakus, Camponis,

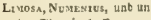
ter ben Gingoigetin Plectao- 

ben Flug Der verichiedenen $20 ̊ g e l$ in eine Fintheilung zu brin= gen, "da er fith bennah bey jeber 2 rtt auf eine eigenthimlidbe

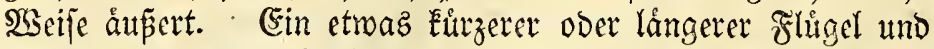

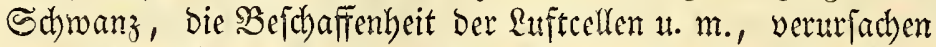
foldhe 2fbreidyungen in ibrem Fyluge, welde febr leidt wabrge= nommen, aber fduerlich befdrieben und in ein Syftem gebracht recben fonnen. Wuf ber Tabelle No. III. babe ich einige (5in= theilungen vom Fluge Der 2 soigel bargeftellt.

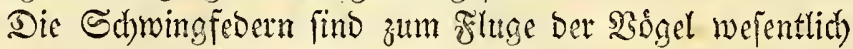

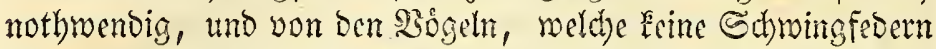
baben, wiffen wir baber a priori, Dafi fie nid)t fliegen Eonnen

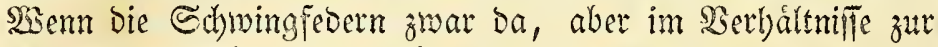

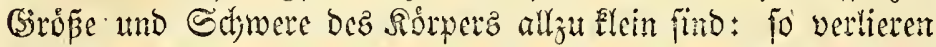

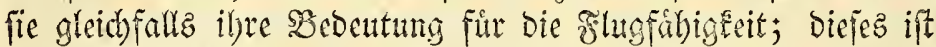
der Fall bey Aca impennis. Sinige der áltern Sornitbologen

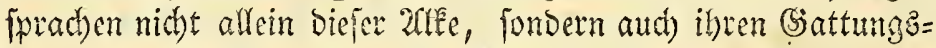
verwanden und Den 2fiten von Una und Monmor, Conm-

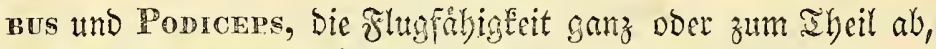
welches bey weitem nicht rictitig ift, Da fie fogat unter gewoif= jen Bebingungen fleipige Frlieger fins. Dieje Serfaffer baben námlich bie Segrifie von einem folled)ten 1tnd einem tnwilli= gen Frieger nicht bimuchend unterichieden. Der idjled te Flieger bat cinen Felyler in Der Flugfábigreit felbit, ber $\mathfrak{u}=$ wirlige, fo zu fagen, nur in ber 2unwendung berfelben. Şe= ner Eann nicht oder nur bejdwerlid fliegen, biefer will es nicht. Sdhledte flieger find z. SB. Die 2irten von Paslus und Galli-

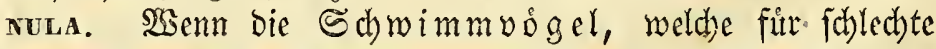
Flieger galten, unmillige genannt werden, to geidhiel)t bies mit

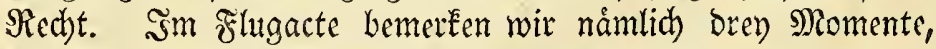
Das Moment Drs 2tuffliegens, daz bez Flugez jelbit, und Daz dez Nieberfinkenz. Den tumilligen Zliegern, namentlich ben Ltien,

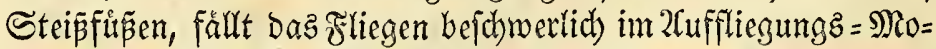

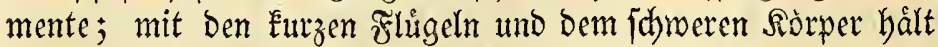
ez hart, aub Dem niebern ins bơbere Mebium zut Fommen. Sie Eonnen baher, to lange fie auf irgend cine andere 2 trt forttom= men konnen, nicht leid)t zu biefer 20nftrengung beroogen wer= Den, die ifnen bas 2 utffiliegen verurfadt. 2 senn fie aber ein=

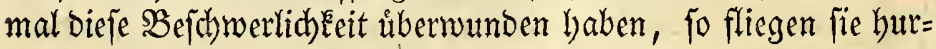
tig, boch und ziemlich anbaltend. Denjelben Befchroerlicbeiten unter bem 2uffliegen find bie mit langen Flugeln und furgen

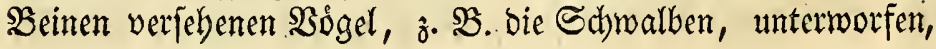


Gebalten, uno mur menige 2rten, wie bie $\Re$ reiber, beugen ifn

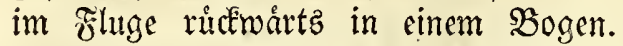

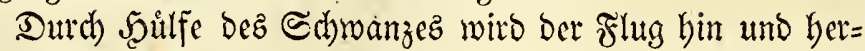

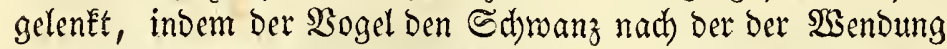

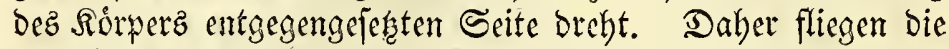
kurzfd)wånzigen, und zu ber Seit, ba fie ihre Sdjwanzfebern mautern, alle $\mathfrak{B}$ gel unjither, wie bie (Sondel, weldhe ihr $\Re \mathfrak{u}=$ ber verloren lyat. SBenn fie fid im fluge wenden wollen, fo oreben fie ben Ropf nach der Seite bin, uno arbeiten an mei= ften mit bem der Sacnoung entgegengejerten Flügel.

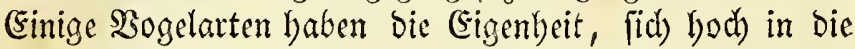
Ruft zu erbeben, ebe fie iljen borizontalen Flutg anfangen, andere bleiben in Den niebern oder niebrigften Regionen ber $\&$ uft. Diejer Unteridbied nute nidbt immer in ber relativen Grópe Der Flügel zum Ro̊rper gejudt werben, Denn unter Den furgfligeli= gen erbeben fid - z. B3. Die 2rten von Colymbus uno Podiceps bod) in bie Ruft, indefien die $2 \mathfrak{i t e n}$ von 'Tetrao, Uria, Alca, Mornon, ziemlich niebrig fliegen, fo wie bagegen unter Den langflugeligen die Stersa-2luten mur cine etwas bohe, umb Puffirus and Procelarara eine nieorige Ruftregion einneh= men, inbeffen verforiedene andere langflugelige 2arten unter Den 2Clern, Sdiwalben, Reilyern, Tolpeln und Neven fich oft

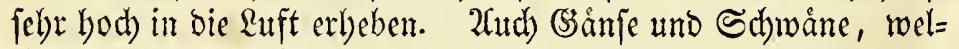
che Eeine relatio lángern Flügel, alb bie Enten unb Såger $\mathfrak{b a}=$ ben, nebmen bod) eine hơbere $\mathfrak{L}$ fttregion ein, als biefe. Esz ift aljo nicht immer Der Fall, dẩ bie Långe ber Flügel im bire= cten Serlbáltniffe zut Şơl)e des Stanopunctez ftebe, zu weldhem bie refpectiven Bogelarten jid) erbeben, ebe fie ibren borizon. talen Flug anfangen.

Der Flug Der verid)iedenen $\mathfrak{B o g e l}$ zeigt fich auf verichie=

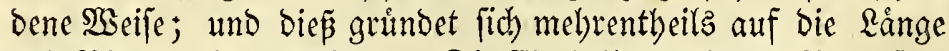
uno Biloung illerer Flügcl. Die (Fintbeilung einiger Naturfor=

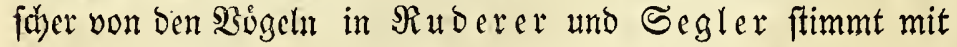
Der Natur ůberein: Die erfteren haben oft furzere, fpisere uno fdhmålere Flugel; fie bewegen biefe Durch burtige wieberbolte

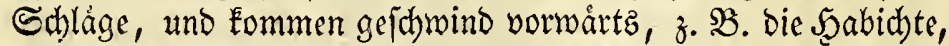
bie meiften Singuogel, \&ummen, 2uken, Taudber, Enten. Die leftern baben lange, mebr abgerundete uno breite, bod) zat=

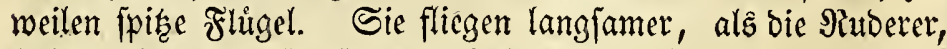
baben aber nidht fo oft wieberbolte Flugelfdláge nothig, uno find bejonderz ausbauernde Flieger, z. B. Die Tloler, Sibife, 
Iolpet, Reeridbualben, Meven, Raubmeben, Sturmtaudber und Stturmudgel.

Die Segler gelloren rigentlid melye in ber Ruft zu

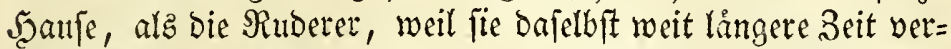
weilen fénnen, obne zu ermuiden. Sie fliegen oft, blós um fid zu beluftigen, uno zeigen alsoann bie ganze Fertigfeit ibrer F̌lugfunft. Sermittelfit ilyrer langen Flügel fónnen vide unter ilynen in einem fohónen Sireisfluge obne mertliche Bewegung Der

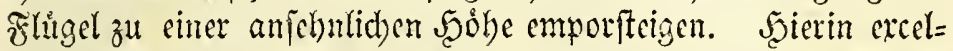
liven bejonderz die 2coler, Milanen, Raben, Stórd)e, Icitpel, Neven, namentlich: Lanus marinus, glaucus, leucopterus.

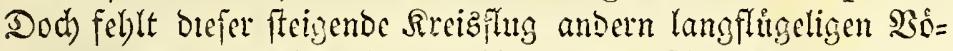

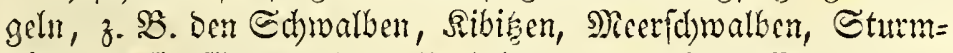
voigeln; fie fliegen aber alle bebende mit vielen 233 endungen,

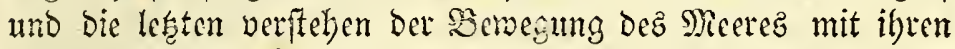
Gurtigen Flugeln zu folgen, und mit SBebendigfeit den aufge=

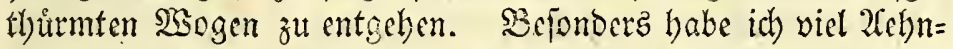

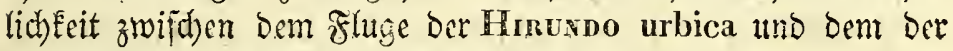
Procellaria pelagica gefirinden.

Die Ruberer geboren ủberlaupt weniger in Der Ruft zu Şauje, als jene. Eise fliegen jelten, um fidd) blo $\tilde{\beta}$ zu belu=

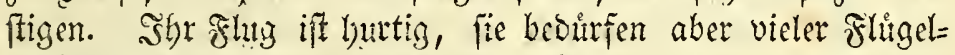
idbläge, um ben relativ fdjweren Sơrper in Der angefangenen said)tung zal erbalten. (Es fd)eint ibnen gailz uno gar verfagt

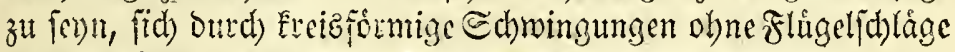
in bie Şoble zu erbeben. Dagegen fino jie, fo zu jagen, melyr

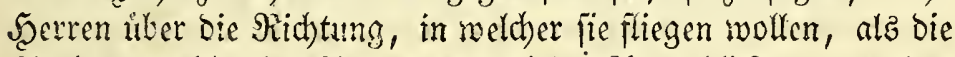

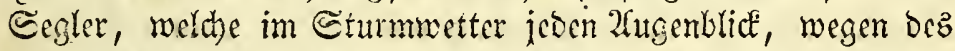

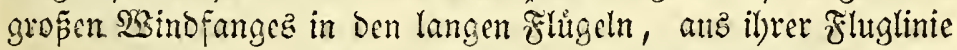
geworfen weiden. (Es find baber aud) gemeiniglid) nur lang=

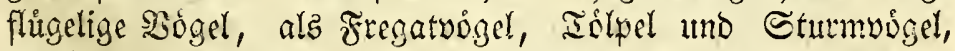
weldbe bey fturmijd)er SSitterung febr weit von ihrem $23 e g e$

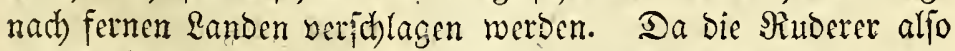

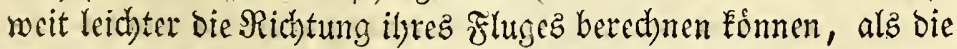

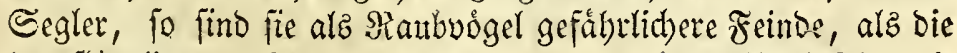
langflutgeligen. Man vergleidye bic weit gróperere Fertigkeit, mit weldhet ber funzflugelige Falco palumbarius uno nisus feime Beute erbafd)t, mit der bes langfluggeligen Falco milvus oder albicilla. - Enblid findet man ber mebreten ber minoer Langfiugeligen 20 gelarten einen eignen $F$ Flug, weld)er mit ben Ereisförmigen Sdbiwingungen ber langflügeligen 20 gel einigerma= 


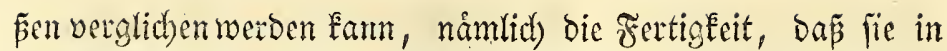
Der \&uft frocken, und auf bemfelben \$uncte mit aut uno nieder= wât bewegten Flingehr Fithe balten. Die Deutid)en Srmitho= logen nenmen biefes ritteln. Diepe Fertigkeit wird z. B. bel Falco timmenculus, larius, excubitor, gefiunden, uno fie wen=

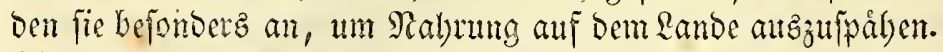
Eine ganz analoge Fertigkeit zeigen bie Meerid)walben, nament= lich) Strenna aretica uno minuta, weldye im foluge ftoden, wenn

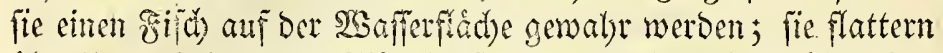
iuber ilym mit bewegten Flingeln, fo wie ber IGurmfalfe hiber einer saus, uno fiurzen fid) Dann, wie biefe sianbvoggel, auf bie Beute nicbet.

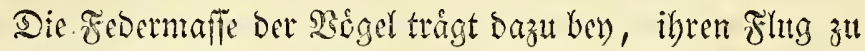

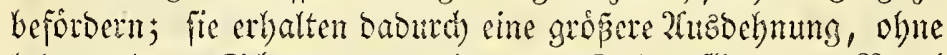
bedetteno an Edjwere zuzunehmen. Dalyer fliegt Der Sogel

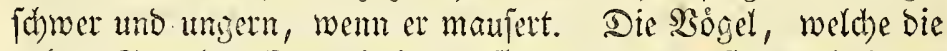
grés̆te Feberbedectung baben, fliegen am meiffen anbaltend.

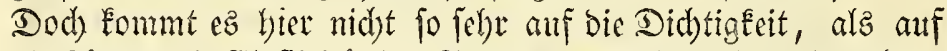

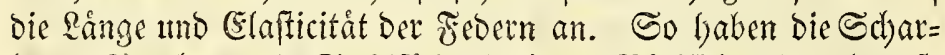

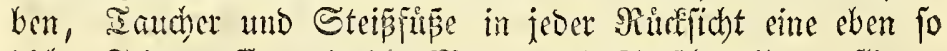
didjte Federmaffe, als bie Meven und Seejdywalben, fliegen aber weit meniger anhalteno, als biefe; ifre Febern find auth

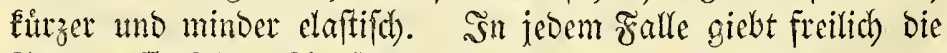

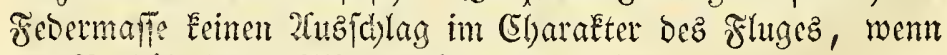

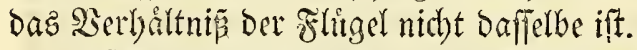

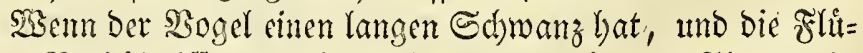

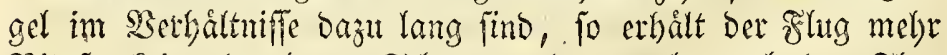
Biegfamestit; Der lange Echivanz aber madbt aud Don flug

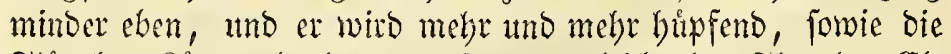

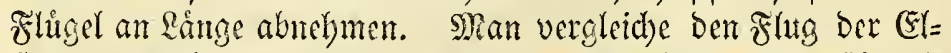

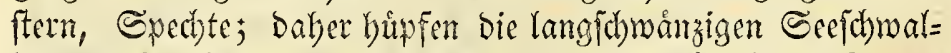
ben unb $\Re$ aubmeven mebr im Fluge, alb bic Tólpel und Meven, und Lestrus catarractes 'hat baher cinen ganz andern Flug, (bennah wie eine Sirálye), alz Lestris parasitica, uno pomarina, eben beß̧lyalb, weil er Eeinen fo langen Schwanz bat.

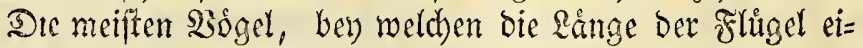

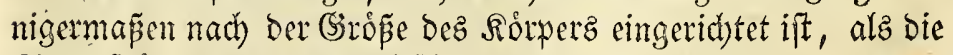
Sumpfudgel bon den Rinnéifon Scolopax, Tringa und Pha-

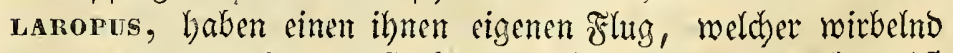

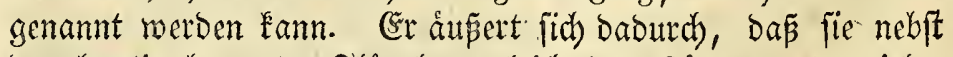
Den Gurtig bewegten Fligeln zugleich Den Rórper unter vielen WSendungen lin $=$ und leerbrelyen. 


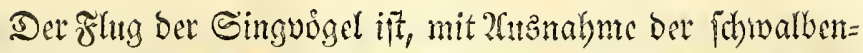
artigen, mebr ober weniger lyipfent, zunseilen flatterno, aber

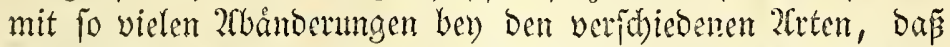

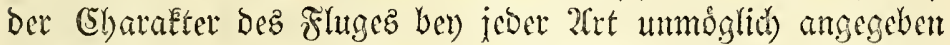
werden Eann. Sie zielen itherbaupt im Fluge die Flighel melgr loorizontal an ben Soirner, als bie Sabimmuogel, de=

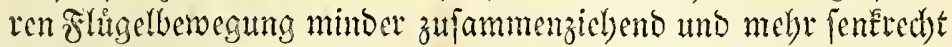
it. Einen eignen Fुht baben zumeilen bie Tauben, wenn fie, fich tummelno, bie Frigel in bie Shoble beben uno fid) in eine niebrigere Quftiegion herablaffen.

Diefelbe 2 bogelart yerámbert ibren Fing etwas nad) ber Reibemidaft, weldhe auf fie wirkt. $23 e m n$ fie gereizt find, be=

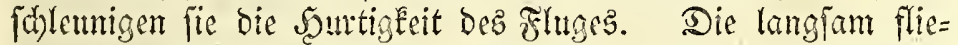

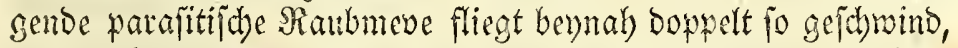

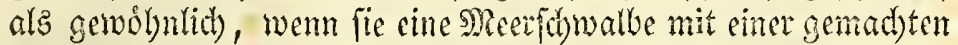

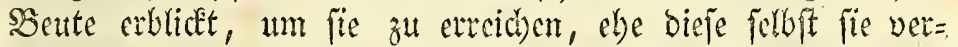
(d)huteft. Sie vermag alsoann vermitterift einer eigenen Fartig= Eeit, fith aur bie ber Serfolgten entfallene B̧eute berabzlt=

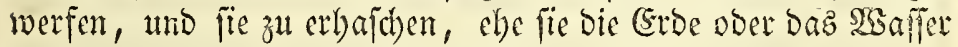
erteidst; wenn fie biefelbe erlyaftht hat, fliegt fie wieder in sinem

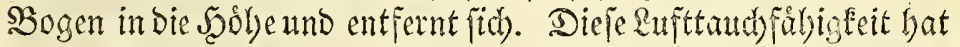

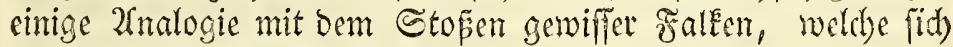

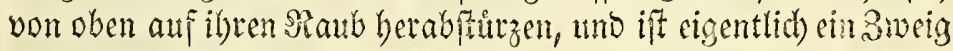

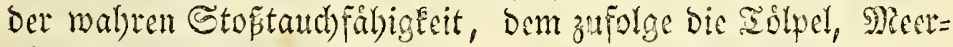

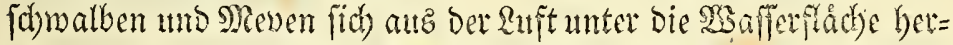
unterwerfen, umifre Nabrung zu erfaffer; bemn fo wie bicje C top $=$

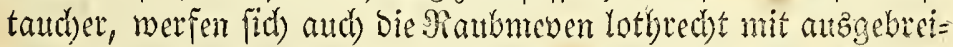
teten Flatgeln auf Die aus bet Ruft berunterfallende Nafrung berab.

Manche Bógel haben einen eigenen frlug zu bar 3cit, wam

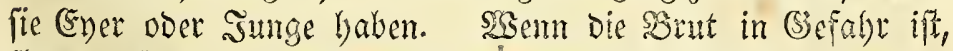
flattern fie uiber bie errbe lyin, wie einige Eylvien, Craba-

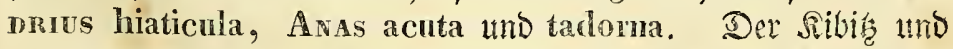
Die 2roocette werfen fid) mit vielen 13 enoungen in bie Quft; Hasmatopus ostralegus unb Numenius phaeopus fliegen mit huntig bewegten Flügeln ůber bie him, weld)e ihe shrut beumulgigen, uno ber Schneelyahn fliegt in Der \$aarungszeit mit zitternben

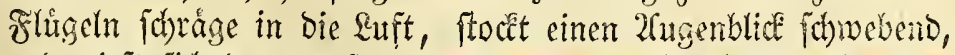

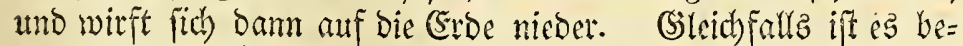

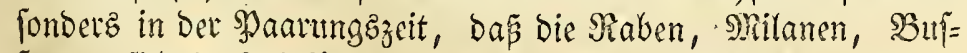

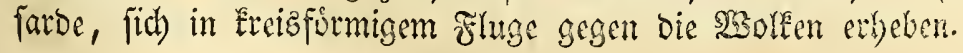


2ud bemerft \$rofeffor $\mathfrak{R}$ illfon ridhtig in Det Scano. Faun., II., p. 297: daß̧ Emberiza milliaria in Der $\mathfrak{B r u t z e i t ~ a n d e r z , ~}$ alš in ben andern sabreszeiten fliege, da fie mit zitternoen

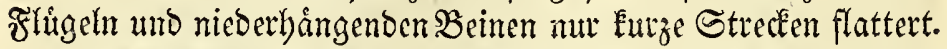

Im Momente Dez গieberfliegenz, wenn ber Bogel auz ber

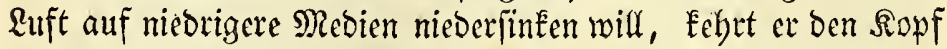

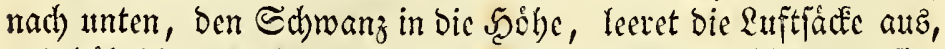
uno bẩl bie ausgebreiteten Flügel fitlle. Die langfliggeligen jin= ken eben und gradweije nieber, Die kurzflugeligen fallen lututiger uno fohråge, wiè einige Falken, Taudher, Sdunepfen t. f. w.

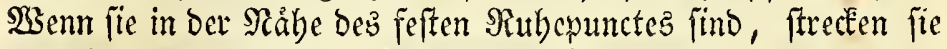

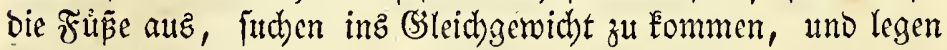
bie flitgel in ibre Lage. Die fehr lang rigeligen, z. B. Der Roler und bie Meerid)walben, ziehen fitend bie Flitgel in bie Scobe, wenn fie fich gegen die Erbe nieberlaften wollen.

ŞSenn ber Boget an einem erbóbeten Srte rulyt, uno von baaus ben Flutg begimen will, wirft er fid blop mit ausgebrei= teten Flügeln bimunter in bie $\mathfrak{Q} u f t$. Der $\mathfrak{X}$ loment bes $\mathfrak{A}$ ufflie= genz ift aljo bier nidht mit fo viel $\mathfrak{B e f d}$ merbe verbunden, alz wenn ber $\mathfrak{B o g e l}$ von einem niebrigeren Ste in bie Şóbe Fom=

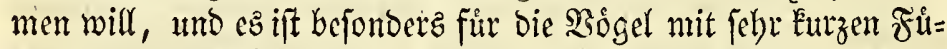
$\tilde{\beta} \mathfrak{e n}$, alz bie Sdbwalben, oder mit febr kuizen Flügeln, alz bie utien unb 2cken, bequem, wenn fie von cinem bohen Site ab ibren Fług beginnen Eonmen. WHenn bie 2rten ber Sdwwimm= voigcl, weldhe ungern fliezen, auf einem erbabenen Shlafe am Meere fteben, uno entflieben wollen, fliegen fie nicht linunter in biejes nicorigere Medium, fondern fie laffen fich, wie cinen Stein, mit zufammengebaltenen flugeln bimunterfallen, umb

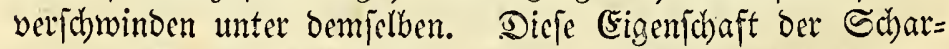
ben uno $\mathfrak{l}_{\text {ummen }}$ betrog mid) $2(n$ fangs, wenn id nad) ifuen in Den Felfen idoop; Denn nach Dem Schuffe ließen fie fidh wie tobt= lich verwunbet ins $\mathfrak{\text { saffer }}$ herunterfallen: ich bemerkte aber leicht meinen Sruthum, wenn fie wieber unbe[dádoigt auper ber Sd)upweite aus dem $\mathfrak{W}$ affer bervoridboffen.

Rein Sogel ift ein fo ausgezeidhneter Flieger, baj cr fich beftånoig in Der suft aufbalten Eonnte. Die wahre Rube et= bålt er nur in ber SBerúbrung mit bichteren Medien. Die Sd)walbe rubt oft auf Dem Dache, uno die Sturmodgel im Meere; aber wie lange fie umunterbrodhen ibre Fłlugfábłgkeit be=

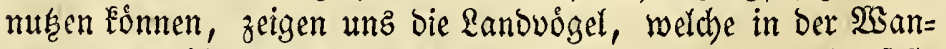

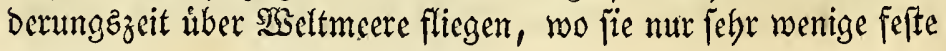




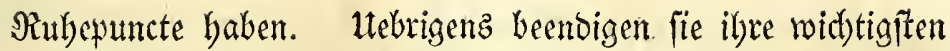
thierifochen Functionen auf ber Eroe ober im Meete. Sur we= nige 2frten, als bie Sperber, Fliegenfänger uno Sd)walben,

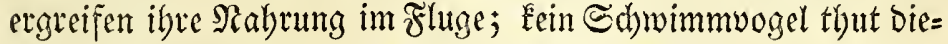
jez, auper zumeilen bie Raubmeven. Reine befannte $\mathfrak{B} 0=$ gelart paart fich fliegeno, viel weniger erfüllen fie fo bie auz ibrer \$aarung refultirenden Berbáltniffe. Die Fabel, Dás ber Parabiesvogel fliegend feine (Ener ausbrute, wiro burd) ifree eigne Utngereimtlyeit miberlegt, fo wie bie Sage ber Sewolnner

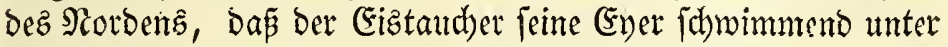
Den Frlugeln ausbrutte. Dagegen verfolgen fid bie Sogelarten

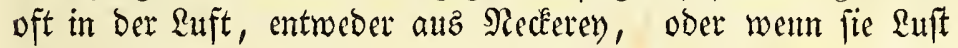
baben, fid zut fdlagen. Sad) babe oft in Szland ganze Şaut= fen von Phalaropus cinereus fid) im Fluge verfolgen, uno fid

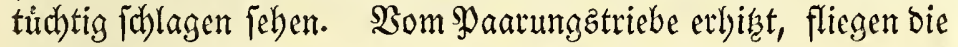
Måmmden ber (Enten, uno jogar bie Mändd)en bez furzfliggeligen

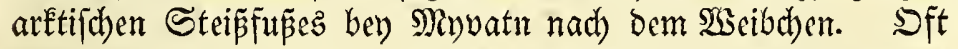
fiebt man im Şerbft in Jizlano bie Falken uno Raben im

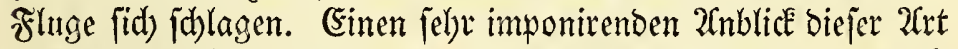
aber hatte id im Sisinter $1819-20$ auf Sefjoro, wo id eine heftige Sdlágeten zrwifhen einem Fifduabler uno einem

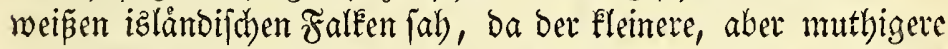
Raubvogel lange 3eit ben 2 coler anzulfallen fortfubr, inoem er

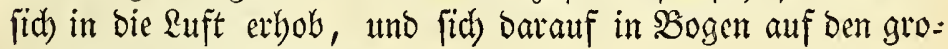
Ben Ģegner Geruntermarf.

\section{§. 46.}

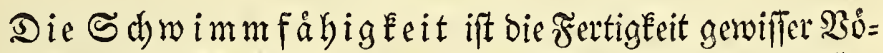
gel, auf ber Şafferfladde rubend, bafelbjt alle ober bie meiften thierifd)en Şandhungen yorzunehmen, weldhe bie 20 ogel úbrigenz

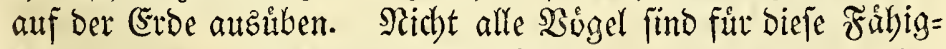
keit gebitbet. In ber Regel getjoren fie in bie sromung ber

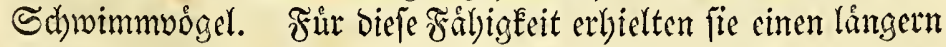

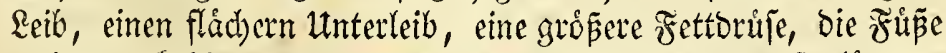

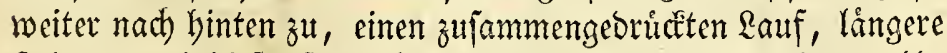
Seben, unb bieje oft burd) eime Edwrimmbaut vereinigt; alle Beben find verbunden bey den Steganoposen; fonft num bie

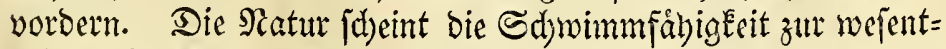
lid)en F̊ábigkeit ber Bewegung ber innen gemadht zut baben; iie fteben baher gemeiniglich in ber (sebffäbigkeit und oft in

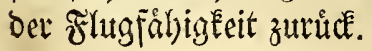


Das Dafen cinet Edwimmbaut zwifhen ben Seben ift gcivis eine wefentliche SBebingung fir bie Sdjwimmudgel; Denn

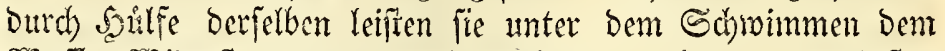
Saffer şiderfiand, und treiben fid fo vorwartz. Die beften

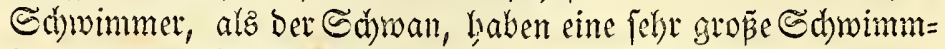

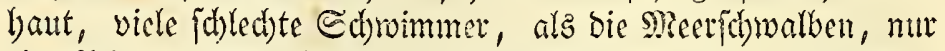
eine fleine. Sie ift ganz bey Den meiften 2(rten, getheilt bey

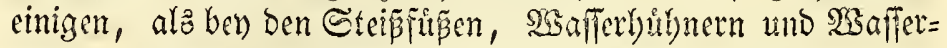

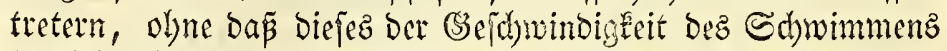

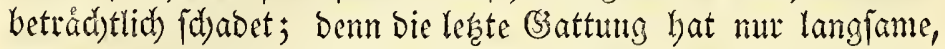
die erfte und zwente bagegen burtige Edwimmer. Bon biejen 2rten gefdicht Dex llcbergang zul einigen 2rten Gumpruogeh mit ficien 3eben, z. 23. Gahlinula chloropus, welde die Sd)wimmfábigfeit regeimápig anwenden, und bie baber eben fowohl unter die Sorbung ber Schwimmodgel zu geboren ver= bienten, alz Phananopus, wenn nidjt einige Somitbologen ge= neigt waiven, die (Segenwart Der Sd)wimml)aut fir ein noth)= wendigez Requijit Der Bogel anzujeben, wemn fie Den Samen ber Sdwwimmvogel tragen follen. Sey einigen Sỉgeln bat bie

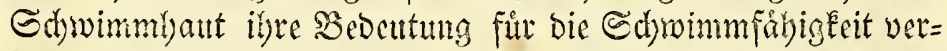
loren, alz bej) Pacunwrostra avocetta und Pratalea leucorodia, welde Gdymmbaut obne Sdimimmfábigkeit baben. Man fann aljo wohl nidht olyme 2lusnabme bie Regel auffitellen,

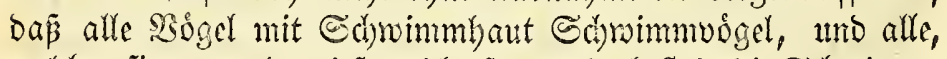
weld)en fie mangelt, biefes nid)t fenen; bod) fteht bie Sdymimn= baut gemeiniglich mit ber S(buimmfálhigkeit, uno ber Mangel berjelben mit Dem Mangel Diefer F̌ábigkeit in Saczielung.

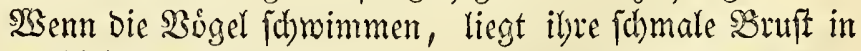

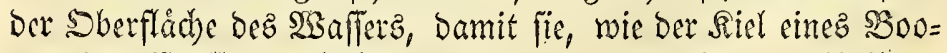

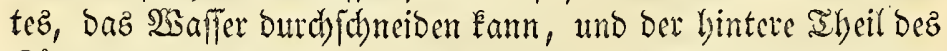

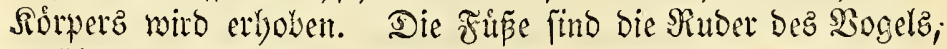

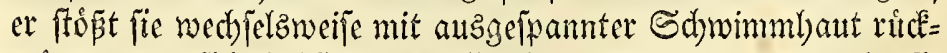
wåntz, um fid) jelbft im $\mathfrak{B a f f e r}$ fortzutcriben, uno zlebt fie barauf mit gefaltener Sd)wimmlyaut vorwartz. W̉enn er fait= wårtz fówimmen will, bewegt ex ben ber Ssendung entgegen= geleften Fuf. Die Fertigkeit, rictings zu fowimmen, hat er nidft; wern er fid) fdhutteln will, fann er fid) beynal) zut einer firenoen Stellung im 2 âfer erlyeben, indem er auf Dem 2 fter

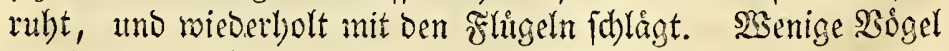
(ril)eben zugleid) bie flitgel, wie ber Gawwan, um mit bieien gleid) Segeln bie Ruft unter Dem Schmimmen aufafangen. 
(5z if ein angenebmer 2Cnblite, biefen eben fo buthigen, als job $=$

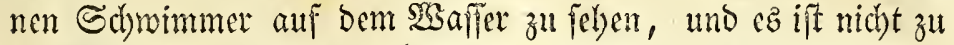
verwundern, baf́p fein Sdumimmen bie Sphantafie ber Didhter befdaftigt hat.

(53emeiniglich) liegen die beften Siywimmer am tieffen im

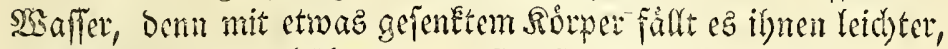

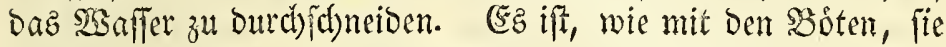
fegeln am beften mit einiger \&abung. 2Tm tieffiten im S2afjer liegen die auggezpidmeten Sdymimmer von Carso, bann von Colvmbus und Podiceps, und fo nad) geradedurch Mergus und Platrpus, weld)e wirflid) nod) geld winder, als Alca, Uria und Mornon idbimmen, biz Aras, Brhm. und Arser. $2 \mathrm{~m}$ bodd)ffen auf Dem 2 bafler liegen bie Stoptautber bon SouA, Sterna, Larus, Lestris und Proceldaria neblt PhaLaroprs, uno bieje jowwimmen aut alle langiam; ja einige

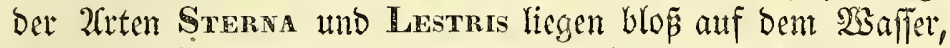
bewegen fid aber faum auf biefem vorwårts; aud ProcellaR1A glaciạlis wito oft auf oem $\mathfrak{B a f f e r}$ gefeben, aber felten fdwimmend, unb utr, went fie angefdoffen ift, verffelyt fie,

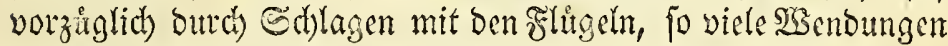

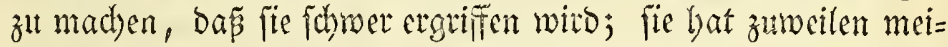
nen Sruberer, weldber ilyren Berwegungen mit Dem Boote nidjt

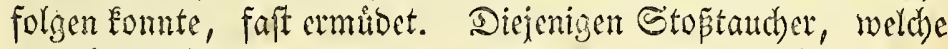
vormarts fdrwimmen, z. SB. bie Sieven, baber att eine tum

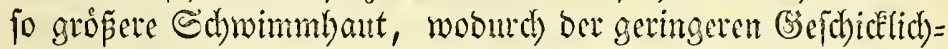
keit ibres ubrigen Rópers zu biejer Bewegung abgeldolfen wirb.

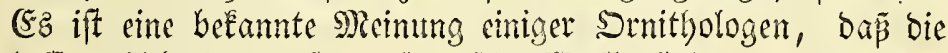
beffern Sdbrimmer fogat fo tief im Salfer fteben, dap nur det

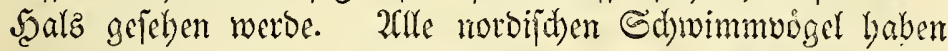
aber Den Rưcen ubber Dem Waffer, wenn fie fdrwimmen; jene Rage mürbe baz Gdninmen binbern, ftatt ez zu beforbern, fo wie ein jegetnoez Schiff, beffen Berbed beftandig unter bent SSaffer liegt, nicht idhell vorwate fommt. STh babe zwat

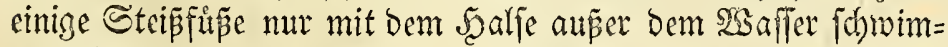
men felyen; bies war aber in 2rugenblicken, in welchen fie aus Furdht vor ciner innen brobenden (Ssefaldr fich nicht feben laj= fen burften; bie 2inglt fergt jebod) bie :Bógel in cinell gefpannten 3uftans, welder von bem natitrliden zu unteridseiben ift.

Die Rỏgel fdymimmen langfamer ober fdyeller, je nad)= bem fie ruthig find, ober von Irieber, wie bem şanberungs:= trieb, vom Saarungstrieb, oder von der 2Angft a. f. w., be= 
wegt werden. Dodh ift die Sturtigkeit in ber Schwimmfábig= feit oft nicht fo auggebildet, alz die Der (S)ebfábigkeit, und nit

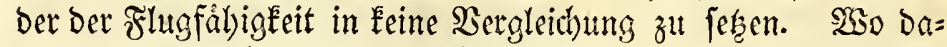

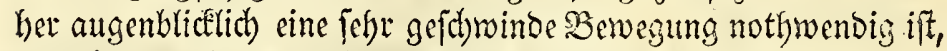
bratthen aud bie Sdynimmbógel zumeilen bie Flitgel, z. $\mathfrak{B}$.

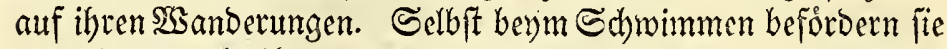
zumeilen bie (Sefhnindigkeit Der Bewegung Durch Die Flitgel; benn wenn fogar bie beflern Sdimimmer von Colrmbus, PoDiceps, Unia, Monmon, Mergus and mebrere, ciner (see= fabr, obne zu fliegen ober zu tauthen, entflieben wollen, fo platt=

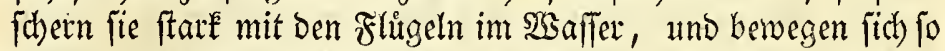
balb fliegeno, balb id)mimmend mit verboppelter (S3efdrwindigkeit.

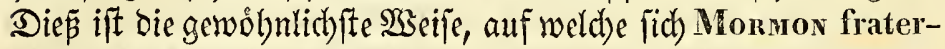
cula und Aras mollissima von einem gefutthteten (siegenftande entfernen, wenn fie nicht taudben; oft enoet fid) aud) biejes \$plát= fockn mit untertauchen. Sn ber spaarungezcit verfolgen fich Ponicers arcticus einander, indem fie fith burch Seulfe ber

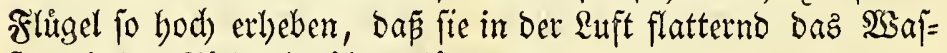
fer mit Den Fitien bertibren fónnen.

Reinen gemadten Bemertungen zu Folge fann id) nicht annelymen, daf ciner ber beflern Sdywimmer *) im rulbigen 3uftande melir, als eine halbe bis eine ganze Biertelmeile in ciner Stunde fonimme; boch fommt bier viel darauf an, ob er mit bem Strome uno ben $\mathfrak{S}$ ellen, ober ibnen entgegenfdimimmt.

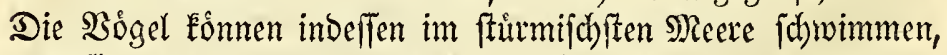
unb fie gleiten, wie cin Soot, leid)t auf bie aufgethuirmten

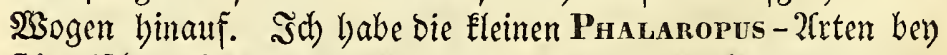
fturmijobem Meere mebrere Meilen vom Ranbe forwimmeno ge= fumben, uno Procellaria glacialis babete fid bev den $2 \mathfrak{b e f t =}$ mannö̈ = Snjeln in ben reipendften Stromen; bod) buten fie fich gemeiniglich alle, in bie Branoungen zu Eommen, unb fliegen getn

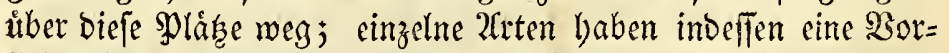

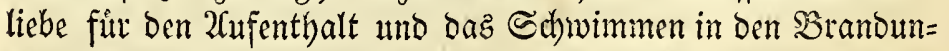
gen. Avas histrionica hat ibren izlándifden Siamen, Srim= ono, Straumónd (B̈randungzente, Gtromente) von ber

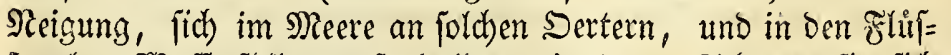
fen bey Şafferfatlen aufzubalten, in Deren Scham fie fidh

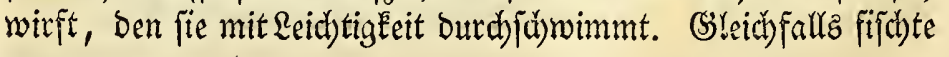

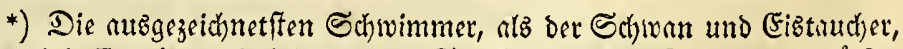
legen indeffen eine weit bedeutendere Strede in biefem Beitrnume zurúck. 
Sula alba bey Seimaey in Den Brandungen, uno ez hat mir oft Belgnůgen verurjacht, Avas mollissima zu betrachten, wenn fie jogar mit ibren Sungen bid)t neben ben Spláen fdroamm, an weld)en bas Mecr am \&anbe brandete, und fie bann jedesmal bel)ende unterzutautchen wusten, went die sbranoung uber fie binzufturzen im Segriffe wat. Sie balt jid an liebfen an pol= d)en umrubizen Sertern auf, um bie Schaaltbiete zu freffen,

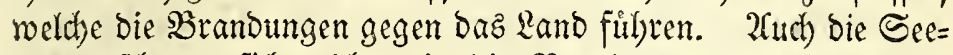

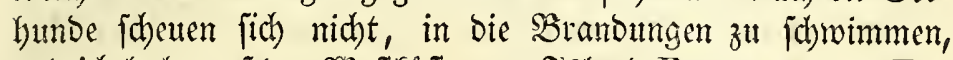
uno ich babe auf Der Sisefteufte von Saland Proca grypus Fabricii auf ber Neeregflúd)e follafend ausgeftred liegen feben, ro eine $\mathfrak{S o g e ~ n a c h ~ D e r ~ a n d e r n ~ u ̊ b e r ~ i b n ~ b i n f t u r g t e . ~}$

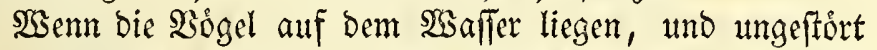
fino, fo fdrwimmen viele mit groperer 2 (nmuth und mit eigenen

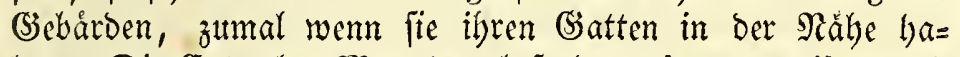
ben. Die Enten bey Mivuatn, bejonderz Aras marila, uno Aras mollissima, treiben bey ifren Britplásen ibre Weibden

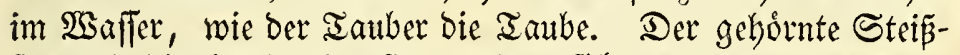
fü und bie Şarlequin = Ente neigen jitc) mit Dem Şalje unter Dem Gdhimmen, und ber erfte bläbet feine Jealsfedern auf; ber zahme Sd)wan erbebt dic Fligel und fdwimmt mit gebogenem Salje der Gattin entgegen; Una troile nicet oft unter dem Sdbwimnten, umb andere 2fiten von Uria, Mormon uno Carвo tauden, babey den Sanabel beftandig gegen die Sberfladbe des $\mathfrak{S a}$ alfers baltend, alz wenn fie trinten wollten, ob ez gleid) ber Fall nicht ift. Sisegen diefer (Etgenjd)aft hat Phalaropus

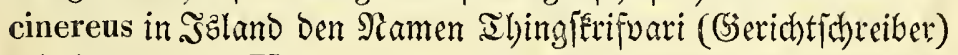
erbalten, uno Uria alle in Normegen Den Namen Syeter Irinfer.

Die Bògel, weldbe lange Flugel haben, fơnnen fich aus bem $\mathfrak{S}$ affer leid)t in bie $\mathfrak{R}$ ft erlyeben, wie bie Meven und Reet= fdhwalben, uno ber Utcbergang vom Sdhwimmen zum Fliegen gejdjiebt jebr gefdrwind; wenn fie aber furzere Flingel baben,

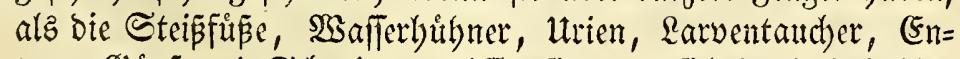

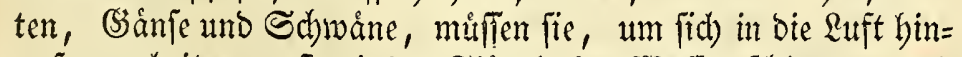
auf zu arbeiten, exft mit ben Flugeln ins $\mathfrak{S}$ affer fdlagen, uno

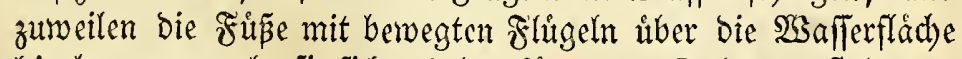
hin berwegen, ebe fie fith erbeben Eonnen. Daber entfteht das Braujen und (sieråuidh, weldbes gebort wirb, wenn ein $\mathfrak{S a u}=$

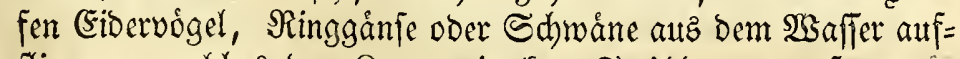

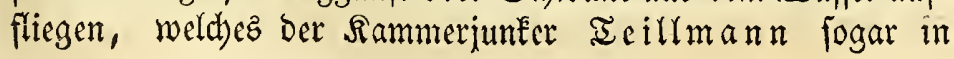


SRúceficht diefer (şanje mit einem Donnerfablage vergleibt; Da= gegen wird ez kaum gebort, renn aud) nod) fo viele Seven oder

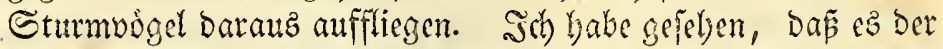
Una grylle und Aras nollissima, wenn fie im jerbffe felyr fett gewejen find, nicht geglucet ilt, fich atis bem 2 saffer zut er= beben, fondern fie find in baffelbe wieber zutuckgefallen. Den Tautd)ern wirb es meit leid)ter, fid) von Der Wsafferflád)e unter

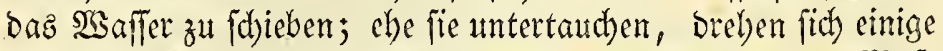
2fiten, als Alca torda und Monmor fratercula, auf Dem $23 a\{=$ fer bin und bet, befonders wenn fie erfichroden find.

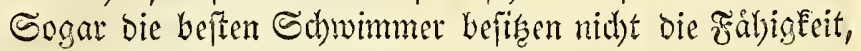

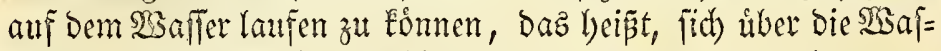
ferfladye allein Durch Das 2njeken Der Beine bin zu bewegen. Daf bie Stumboggel gemeiniglich diefes thun, Darf id) geraoczu leugnen, ob es gleid) von cinigen Satutrorichern bebatwtet wiro, da id) oft Procelnama glacialis uno Puffinus arcticus bidht itber Daz 2 affer fliegen jah, nie aber Die Beine auf

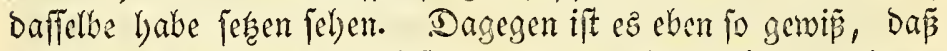
Procelarara pelagica diefez thut, uno fo buted eine eigene

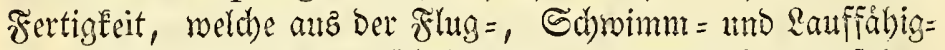

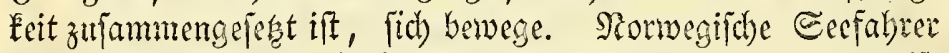

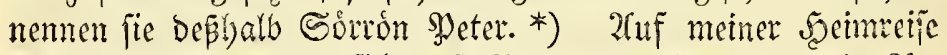
von Saland jammelten fich Dieje fleinen Reerbewobner, im $2 \mathrm{t}=$ lanter Meete und in Der Norbfee, Gaufenroife um unjer

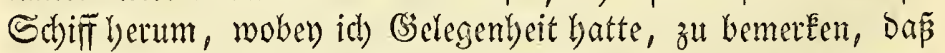

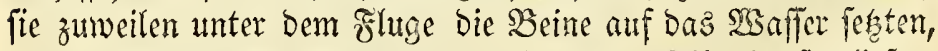
to eine Eleine Strede mit ausgebreiteten Flugeln fortliefen, und zumeilen, wenn fie ibre salunung auspáben mollten, auf

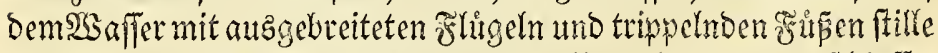
ftanden. Dod in jedem Fafle laufen fie niobt mit angefoloffe= nen Flitgeln auf Dem $\mathfrak{B s a f f e r ~ b i n . ~ M a n ~ b a t ~ ( S ) ~ r u m b , ~ D e n ~ B e = ~}$ richt einiger Schriftifeller zu bezmeifeln, Dap̧ Raurus aquati-

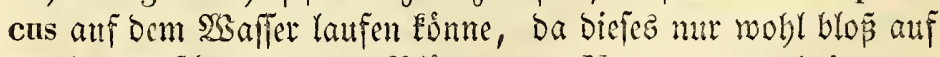
ben breiten fobrommenden Bláttetn von Nymprise und Alsis geichiel)t. Sndem die Sdywane und andere Mogel, benen es idwer fallt, vom Mecre in bie \&uft zut fommen, fich aufarbei= ten, bewegen fie auth, wie oben beriblyt worben, die Beine etrmas auf ber $\mathfrak{s}$ afferfláche.

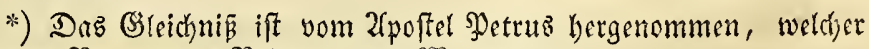
nach Dem Berictete ber Bibel auf den $\mathfrak{W}$ ellen ging. 


\section{$-253$}

Die Bögel werfen fich auf verfdiedene $\mathfrak{B}$ seife aub der Ruft inz Sisaffer. Die kutzfligeligen, als Aras mollissina, bie

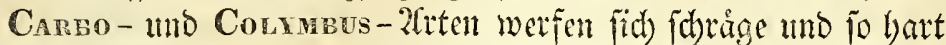

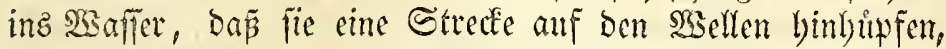
weld)e um ihren Reib herumid)lagen. Die langfingeligen Sdywin: mer von Phanaropus, Larus, Lestris, Sterrata, Proceluaria, weldbe ben Uebergang vom foluge zum Edywimmen

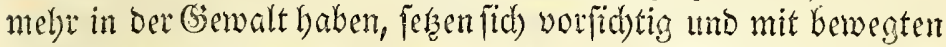

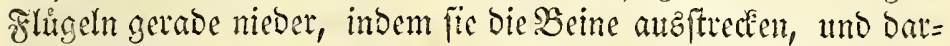
auf legen fie, wenn fie fir

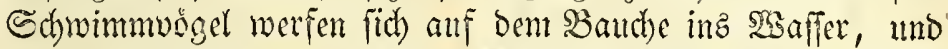
viele, alz Colvabus, Carbo, Cephus, Mrrgunus, bengen Dann gleich Den Crdyabel gegen bie Wafferfiäche, andere zeigen dieje (Siebardoe nidat, als Aras uno Mergus; mut bel) Alca

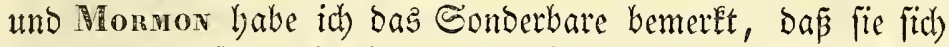
vom ơlthe auf ocm Sopfe inz Meer ftür gegen die Sisafferflád)e beugen, und alsbann ihr ভdywimmen

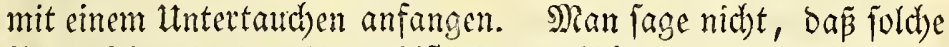

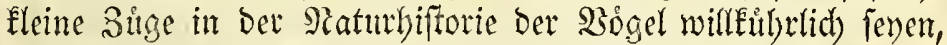

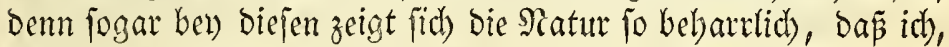
indent id mich molyrere Ermben unter ben 20 gelbergen auf=

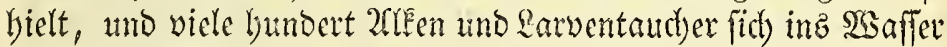
werfen jab, Eeinen bemerkts, ber es nidbt auf bie oben angefilyrte fonberbare ?rit gethan hatte, fo Das ich in ciner weiten Ent= fernung blop baburd) unterfdeiden fonnte, ob es einer biefer Pógel, oder ein Cephus oder Uria jel).

Die Rebenswirefameit ber Sdywimmodget if zum Iheil vom Lanbe zum $\mathfrak{W a f f e r}$ verlegt, und fie hiben baber viele ber Functionen im $\mathfrak{2}$ affer aub, weld)e bie Ranowógel auf bem Rambe ansiben; bie meiften, fogar bie Eleinen $\mathfrak{B a}$ affertreter, paaren fid) fdhimmend, und mur bey Sterna, Lestris und

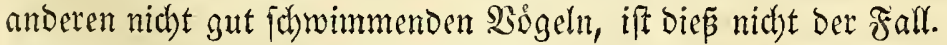
SSie of thaben wir nicht (Sielegenlyeit, bey Den zalmmen Ente= rid)en Die Edywierigkeit, womit fie bie 2 seibchen anf Dem Eande befrud)ten, zu bemerken! Sidh babe baz Manndhen won Aras glacialis baz $2 \mathfrak{s e i b c h e n ~ u n t e r ~ d e m ~} 2 \mathfrak{B} a$ fler verfolgen unb

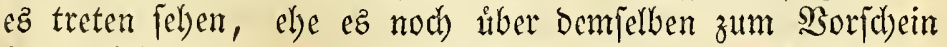

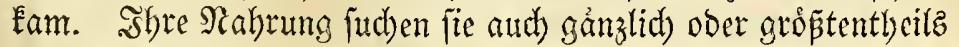

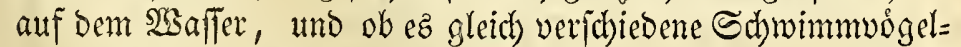
arten giebt, weldye ilyre Nabrung aud auf Dem lande futden, mie Anser, Sterna, einige 2irten von Larus und Lestris: 


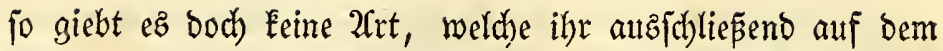
Irodenen nadgebt, viele aber, weldbe fie allein im 2 affer fuchen, z. $\mathfrak{B}$. Die 2irten yon Uria, Alca, Mormon, Carbo, Colymbus, Poniceps, Fulica, Sula und Procenlaria. Die guten Gdwimmer, bejonderz bie, weld)e fich fo weit im Mecre auf=

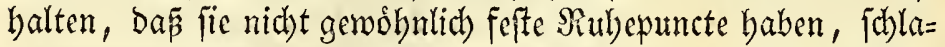
fen fogar beftandig im $\mathfrak{W a f f e r}$, z. B. Procelcaria glacialis, einige 2frten von Larus, Aras, Pobrceps und Colymbrs, uno idh habe Sura alba, Larus tridactylus, Procelcaria glacialis auf Dem $\mathfrak{G a f f e r}$ mit Dem ßopfe unter Dem Flugel alz sinen Ball treiben, uno fo feft auf Diefem unruhigen (Elemente

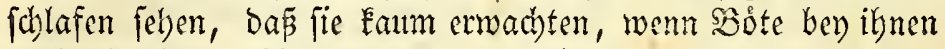
vorbenfegelten. 2Anbere 2rten, welche weniger auf bem $23 a[=$

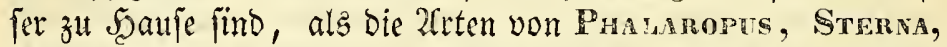
Avas Brhm. und Arser, futhen bas Iend am liebfiten, wenn fie feblafen wollen.

Die Sdyminmoigel verfteben aljo bas Saffer nid)t allein zur $\mathfrak{B e w e g u n g , ~ f o n o e r n ~ a u d ) ~ z u r ~ \Re u b e ~ z u ~ b e n u t e n . ~ S d ) l a = ~}$ fend laffen fie bie Beine lothred)t berunterbangen, und treiben fo mit Den $23 e l l e n ;$ fie seben alsbann fo weit in's Neer binauz,

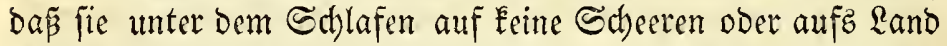
treiben. SSenn fie, obne zu jhlafen, auf einem aufgerůlyten SBaffer fitsen, fo bewegen fie dic Beine mit furzen Streichen burtig bin unb ber, fo wie man, wenn ein SBoot an Demjelben Shlake gebalten, und verbinbert werben foll, bas cz nià)t treibe, bie Ruber leid)t berwegt. Durd) bieje Fertige fit fino fie im Stande, Der (Gemalt bez Meerez zu wiberftelyen, uno bey bem forweriten $290 g e n g a n g e$ an Demielben Srte liegen "zu bleiben. Siep̃ ift die cinzige Fertigkeit, welche die Meerichroalbe, bie nicht vormairtz fobwimmt, zeigt, wenn fie auf Dem 2 affer liegt. Bey Eeinem ift mir diefe Fertigkeit auffallender gewefen, als bey Avas mollissima, wenn fie in ben SRrandungen, und wo bie Bewegung bez Meeres am grofsten ift, fo zuliegen vermodste, baß fie nie von ben Wogen auf Rand geworfen wurbe, fonoern

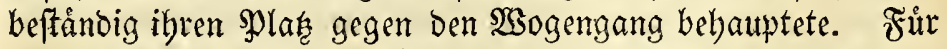

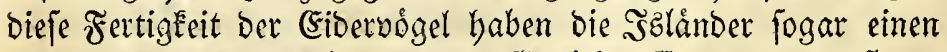
eigenen Samen, weld)er meinem (Şebáchtnifle entgangen ift.

(5z giebt wohl Eaum eine Bogelart, welde umunterbrodben ibre ganze Qebenzzeit fich auf Dem $\mathfrak{W a}$ affer aufbielt, denn ibr $\mathfrak{R e f t}$

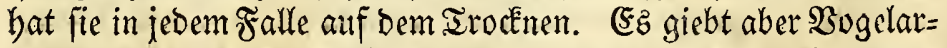
ten, welche auper ber Neftzeit beftåndig auf bem $\mathfrak{E}$ a fler find, auz= 
genommen bie 2lugenblicke, ba fie fliegen, befonderz bie Taudber,

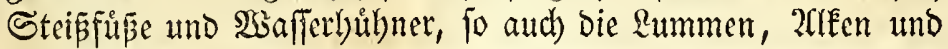

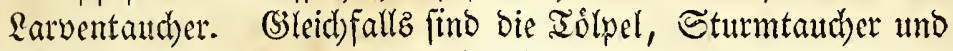

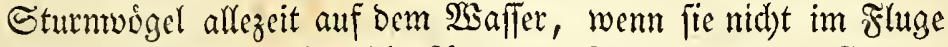
fino. Dagegen rulben dic 2erten von Prananopus, Carbo, Mergus, Aras, Arser, Crgnus, Stenra, Larte, Lestnis, auछgenommen catrraactes, felly gern auf dem Lande,

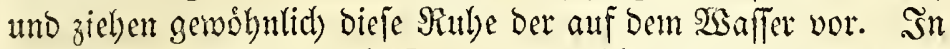

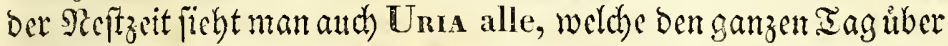

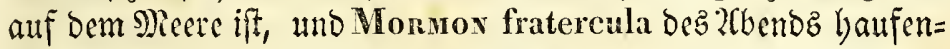

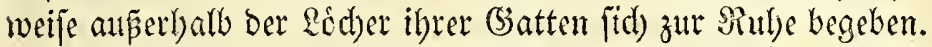

Sidjt bey allen Ed)wimmuigetn finbet bie Sdbwinmfályig=

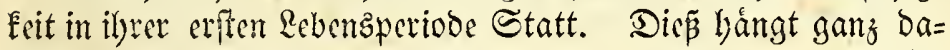
yon ab, ob ifre Eitern ben Fitterungstrieb haben, ober nid)t. Seer ben 2(rten, ben weld)en bie Sungen nid)t won ben a(tten ge=

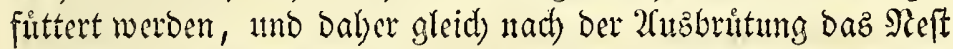
verlafien, verniogen bie Šungen eben fo gut im Flaumlleibe, als

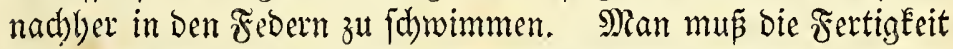
bewotndern, mit wefd)er bie fleinen Sungen der Enten, Çänje

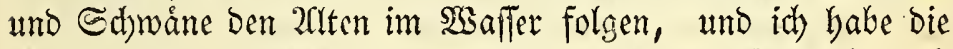
Flaumitungen von Mergus serrator und Aras tadorna beynah

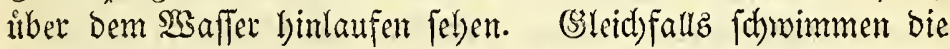

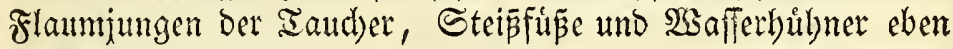

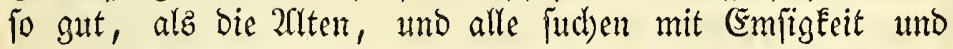
Bebendigkeit fidminmeno ihre Rabrung. Die Sungen berjent=

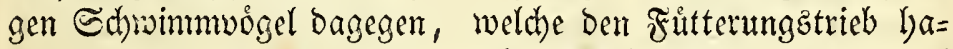

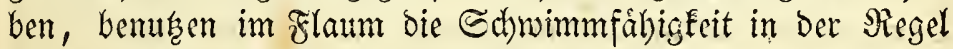
nidht. Untrer biefen bergen fid) Dod) bie Flaumjungen ber Neven, Meeridwalben und saubmeven am beften in biefem Elemente; ob fie gleid) gern auf bem Irodefnen bin = tmo berlaufen, fo buten jie fid) bod), inz şafjer zu kommen, wenn fie noch febr flcin uno jung fino, weil bie Dunen leicht

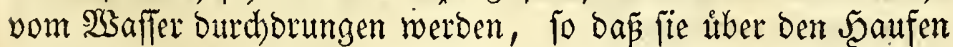
fallen uno ertrinfen; wenn fie bagegen grófer gewoorden find, und bie Sibningfebern Gervorbred)en, fiebt man fie hie unt ba bey guttem 23 etter am Strande fd)wimmen. 2(ud) fommen bie 2 saffertreter nicht alb Flaumjunge inz $\mathfrak{B a}$ afjer, fonbern fie lau= fen, fo lange fie Dunen baben, wie bie Sumpfyógel im Giraje umber; am auffallenoften aber ift biejer Mangel ber Făbahigkeit zum Edjwimmen bey ben Flaumjungen Der \&ummen, 2rfeen, aarventautder, Sdharben, Iollpel, Sturmtaudher uns Sturm= 


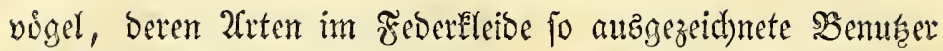
dez Meeres fint. Denn ba jie hod oben in ben Felien augge= brutet werden, und die meiften erft als (5rwach fene zum Säaffer Eommen, fo wiffen fie, wenn fie zufartigerweife aub bem Sefte

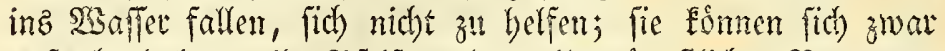
aufredbt balten, ibr spleifen aber, ibre ángffichen SBewegun= gen, il)r Beftreben, ans \&and zu Eommen, giebt gut Sienige z"l erfennen, Daf fie in einem fo zarten 20 ter nicht beffimmt find,

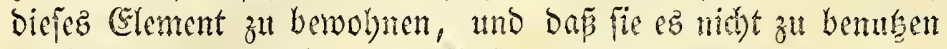
verftelyen. Sin foldes vom Frelfen in bas Meer bermethefal= lene sunges frirbt gemeiniglich vor Salte tno jungcr, da ç in Den Dunen feine Shabrung nidst fuchen fam, uno ber Futte=

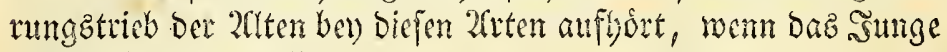
Den Seftplas verlafien bat.

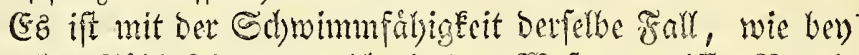

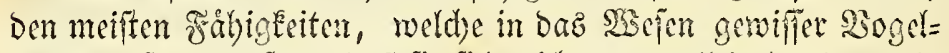
arten tief eingreifen, baf fie fich nicht ganz allein bev ben, in

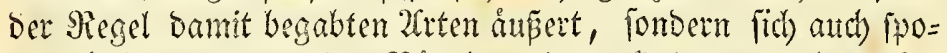
rabifh ber) angrenzenden 320 geln anderer Sobmungen bemerken láp̃t. So giebt es gewiffe Eumpfuỏgel, weldbe zmoeilen frei= willig bie Gdtwimmfälyigkeit ammenden. Siemit meine ich nid)t Die regelmápigen Sduwimutet unter ben Sump Galdinula chloropus and mebrere, ben weldyen man fragen fonnte, ob es nicht burch cinen Febler ber Seaturforforer ge=

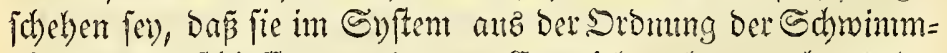
vogel ausgeidlofen worben. (sz giebt aber auth wabre Gumpfuogel, weld)e zuweilen fdywimmen, unb zwat nicht blof,

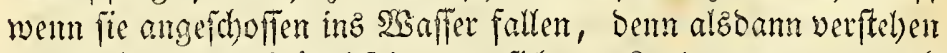
die meiften Sumpfoogel fel)r ght, fid) anz Rano zuretten, aud) nicht, utm einer augenblictid)en (şcfabr zu entgeben, benn als: Dann fturgt fict) fogar bie Taube inz $\mathfrak{B}$ affer, und fommt gut Davon, fondern ganz freinillig, olgne bã ingend eine bringende Soth auf fie cimbint.

Der befte Sd)wimmer unter ben Sumpfoigeln, weldhen

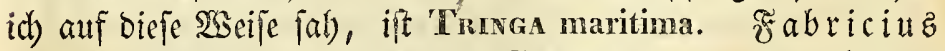
bemerft eb fdon in feiner Fanna Grönl. p. 108, turo id babe fie in $23 i n t e r$ in J̇land bel) ftarkem 2 bogengange auf oem Reere fdywimmen, Durauf ein Stute (Fis befteigen und in bie See treiben feljen. Ebenjo babe ich mebrmali Charadrius hiaticula, Totanus calidris, uno Trenga alpina im fifilfen $\mathfrak{Z a} a$ = fer nabe am Hel fobwimmen feben, wenn fie von einem Steine 


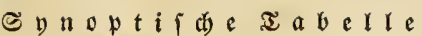

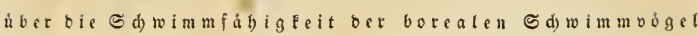

ए $\mathrm{i}$ n $f$ a म.

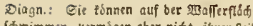
(A)toimmen, sermógen aber nidt, ityren eri

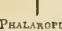

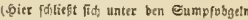

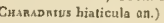
TRENGa maritima, Totasus calidris un

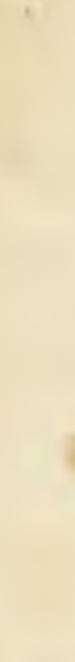

RatLus aquaticus unb cinig

\section{उप}

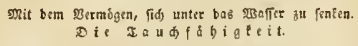

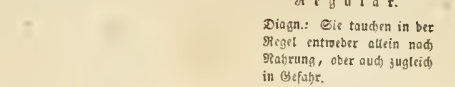

a n bebingt.

$\longrightarrow$

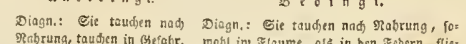

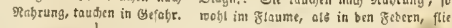
gen in Beffabr; in bicfer taudien fie nux

$$
\text { Thisento }
$$

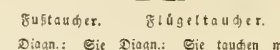

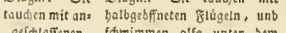

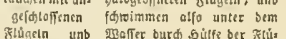
glúgeln unb gBoffer burd s.

\section{nen Eprunge.}

SERGL

$$
\text { । }
$$$$
\left.\right|_{\text {LATres. }}
$$

(Ein onalogeb zautơen bu:

ben unter ben Gumpfobsetn

Gallinurs, Untet ben Ging:

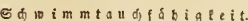

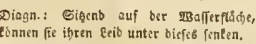

๔ubfibis.

$$
\text { E }
$$

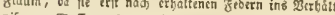

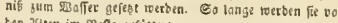$$
\text { (a) }
$$

8 1 น 961 เ

Diagn. : Gie tauden unter bab grafarer mit

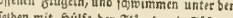

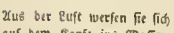

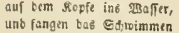

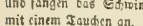

Мокмох, ALCA

\section{₹}

Diagn,: Cie tauffen unter bas शुa fer

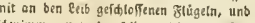
(d)winmen unter bemfectben altzin mit sulle

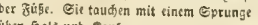
iber palt usb Sopp

c.
Diagn.: Gis tauden ble in ben Betern, niake in ben

$$
\text { - }
$$

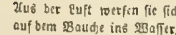

$$
\text { Ein }
$$

unb beugen Eie beugch Edsnabel gess đedjnabet

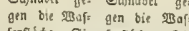

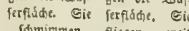
Tointimimen firgen worit

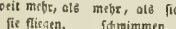

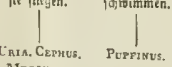

\section{ङubfibisx.}

Detaght: Cis taulden in ber

rung, auth nidt in Befars,

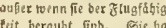

Sen bie Grunbetenffhiofect.

פev) Cresus maden fic ben

Uebergang bus ber einfadf Ed,pinnmfsbigleit.

\section{$x a+110 r$}

Disgn.: Gie Isenjen bie Dlagn.: Git

Jaudfúbighteit

Axas. A.sser,

nit on.
nit.

(Ein analogeb Ed,pimmen

unb হaudjen hat unter ben

ostralegus.)

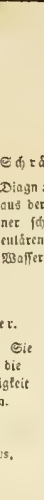

एक

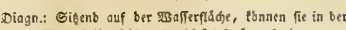
Seegel ibren Reib nicht unter biefé fenten, fonbern nus, tigfeit werf aub ber Ruft berabfoulten laffen. Diefe Jat

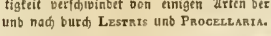

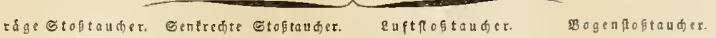

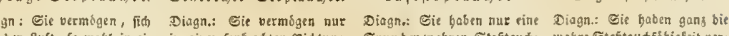

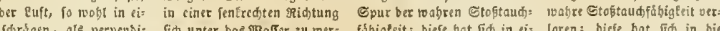

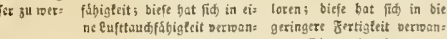

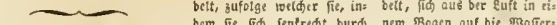

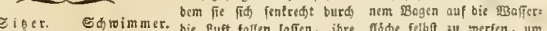

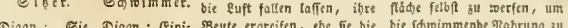

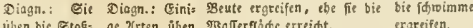

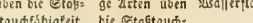

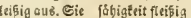
Tîgen auf bem aute, anbere एBaffer, ofine nidt, Xuf bcm

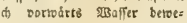
Lestals. zut bevergen. gen rie fid oft<smiles>C1CCC1</smiles>
STERN (.̧itr 「óliefeft Tिiी unter ben TiBalbośgetn
ALCEDO ispida an.)

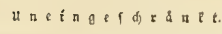

Diagn.: Eie tauden nidte altein im gecertlecibe, fonbcrn

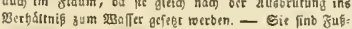
tauder.

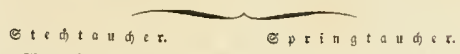

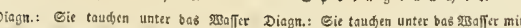

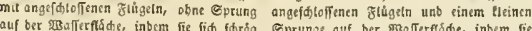
unter biefelec Sineinificbent. -

Courusus.


fum andern wollten, und bey Haematopus ostralegus be=

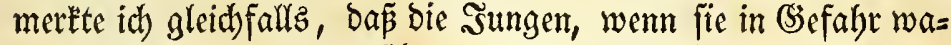

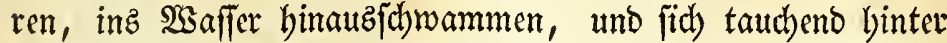
ben Steimen verfteckten. Saffelbe theilt $\mathfrak{T}$ eillmann a. a. $\$$. S. 133. von ben Sdhepfen mit. Dodh gejebiebt bas Schwimmen bey diefen Sumpfoógeln bey weitem nid)t mit ber Behenoigkeit, wie bey ben Sabmimmoógeln, und fie fohwim= men nur jelten, langjam, und in ftillem $\mathfrak{S a}$ âjer; vorzuglich

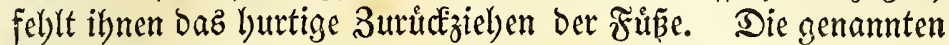
Sumpfoógel nåmlid) zieben unter bem Schwimmen bie Brine nicht unter ben 2(fter zuruek; fie fhrommen flatterno, wenn id) mich mit einem (Şleid)nis̄, bas vom Fluge hergenommen ift, augbrucenen barf, inbem fie bie Beine im $\mathfrak{B a f f e r}$ gern herunter= bangen laffen, fo wie einige fohled)te Flieger, z. B. Raulus aquaticus, unter bem Fluge bie Beine, obne fie unter fidc) auf=

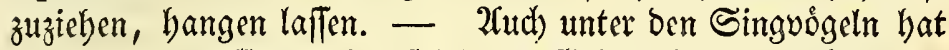
man ein interelfantes Benfpiel bes (sebraud) Der Sdymimm= fålighfeit beb Cinclus aquaticus.

\section{§. 47.}

Siele Der Bogelarten, weldbe fich auf bem Şaffer felbit

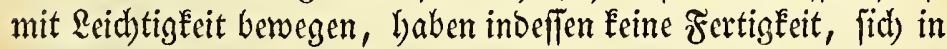
Dicjem Mebium einzufenten, und ihr Sórper wiro baber nie ganz vom $\mathfrak{S a f f e r}$ umgeben. 2fndere Schwimmuogel bagegen vermógen cine Bcitlang ganz in bie $\mathfrak{3}$ affermafle einzubringen, und fónnen fich nicht allein auf, fonbern auch unter bem $2 \mathfrak{s}$ affer berwegen. Sach biejer grofieren ober geringeren $\mathfrak{A}_{1}$ gbildung ber Schnimmfäbigkeit nenne id) lefgtere einfach, wenn fie bloz

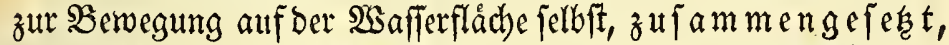
wenn fie fowobl zur Bewegung auf, alz unter bem $\mathfrak{W a f f e r}$ an= genanot werben Eann. Bergl. Tabelle IV. -

Die zulammengeferte Sdywimmfábigket ift eime bobere 2utzbildung oer einfachen, uno jest beynah allezeit bieje voraus; benn unter ben Schwimmooigeln giebt es feime $2 \mathfrak{r t}$, bie fid un=

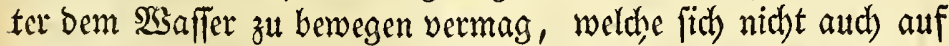
Dempelben bewegen Fonnte; bagegen giebt ez viele Schnimm =

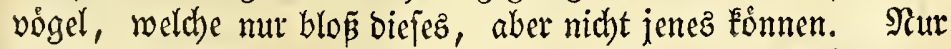
bev einzelnen 2Trten auper ber wahren Sromung ber Schwimm= voggel finden wir bie Fertigkeit, jich unter bas Swafler zu wer=

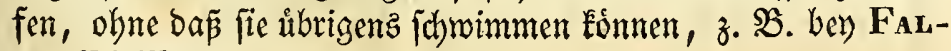
co albicilla und Alceno ispida. 
Utnfer Den borealen Sdymimmoigeln" mirb bie einfache

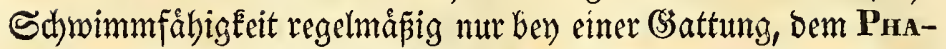
tanopus, gefunden. Dieje fleinen 2 ỏgel fdhwimmen zietlich auf

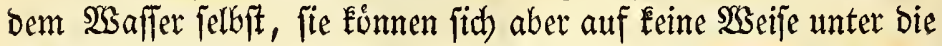

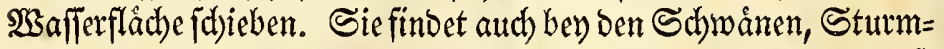
vógeln, cinigen $\Re a u b m e v e n$ und Meven Statt; ba aber bieje Zrten bic Serbindungsglieber von ber zujammengejef einfachen Sdywimmfäbigkeit abgeben, fo werde idh fpáterbin von biejen reben.

Die zufammengeferte Sdjwimmfábigkeit theilt (iid) in

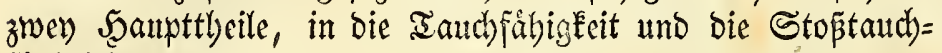
fábigkeit.

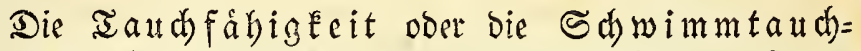
fály $\mathfrak{g} \mathfrak{k}$ eit ift die F́abigkeit einiger Sdjwimmbógel, auf bem Wsajfer rubeno, mit ibrem ganzen Sơner fich unter baffelbe fen= ken, fid) willfeithrlich unter bem Ssaffer auffalten, und fid ba frevwillig in allen $\Re$ Richtungen bewegen zu Eónnen, biz ber

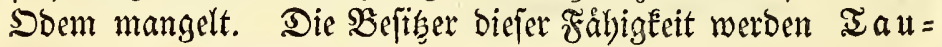
$\mathfrak{d b}^{*} \mathfrak{r}^{*}$ ober Sd wimmtaud der genannt.

Die Stoptaud fábigkeit ift bie Fábigkeit einiger Sdimimmuogel, in ber Ruft jobwebeno, fich burdh eimen Fall

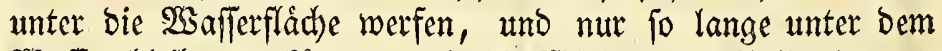

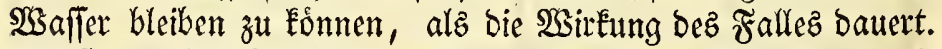
(Es ift biefelbe ráabigket, weld)e id in meinem \$robromus mit

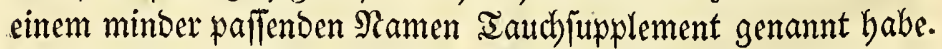

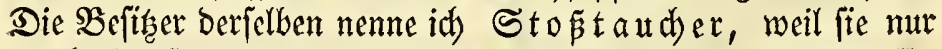

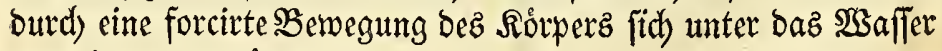
zul zwingen vermoggen. -

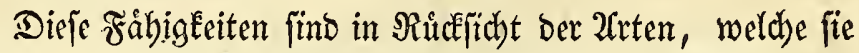
antwenden, einander beftimmt entgegengefert, fo ba je fie nie bey einer 2 ret bevfammen gefunden werben. Rein Sdhwimmtauther ift zugleid) Stoptautcher ober umgefebrt. $3 \mathfrak{n}$ jenen gebóren unter ben nordifchen Sdbmimmoógeln bie 2 trten von Uria, Mergulus, Cephus, Alca, Mormon, Carbo, Colymbus, Podiceps, Fulica, Puffinus, Platypus, Anas,

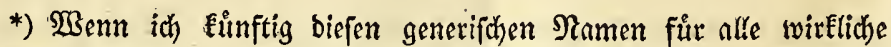
Tauther gebrauthe, fo verwechfele man ibn nicht mit ber Esattung Iauct)er (Cou yueus). 
Anser, und zum abeil Crgnus, zu biefen die 2fiten von Sula, Steria, Larus, und zum Theil Lestris und Procellaria. Wenn die Sulen, Meven, Meerifhmalben, Stutmougel angeichoffen auf bem $23 a f$ er fdwimmen, fo vermógen fie Dennod) nicht unterzutauthen, obgleidh mel)reve andere 2riten, weld)e audh nicht regelmåpig taudben, biefez thun, wenn fie verwunbet fino. 2udb babe id) nie einen wirklid)en Taudber gefelben, rel=

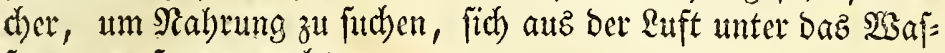
fer zu werfen vermodite.

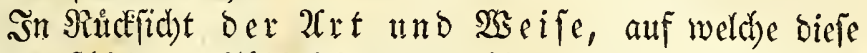
beiben veridbiebenen Fåabigkeiten auzgeubt werden, ruben bie ei=

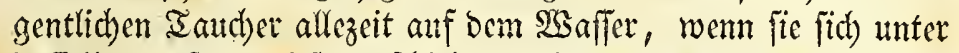
Daffelbe werfen; biejes gejdjelst nit bewegten Beinen, uno zu= weilen zugleich mit beroegten Filugeln. Die Stoptaudber bage=

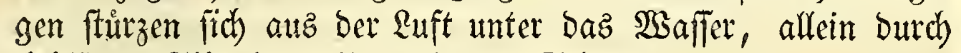
Şulfe Der Flugel uno ibrer eigenen Sd)were.

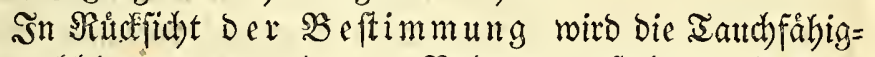
Eeit fowohl bazu angemandt, um Nalyrung zu jud)en, als aud), um in (Sefabr zu entflieben; die Stoptaudsfäbigkeit aber mu allein, um হabrung zu fudben. Uum ber Ģefaldr zu entgeben, fliegen die Stoptantcher.

Sñ Rư(efid)t Der 2 a sbildung fteht die Stoptaud)= fålsigkeit ber Iauthfábigkeit weit nach. Die Tauther babent bie Fáhigkeit, weldue fie anwenden, volllig in ihrer Ssemalt; fie taudben mit Seidstigkeit unter, und balten fich ba fo lange auf, bis ber Soem fehlt. Unter Dem 2 safjer bewegen fie fich in allen Richtungen, arbeiten fid) jentrecht bis auf ben Girund bes

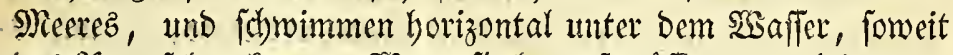
baz 2fuge felyen Eann. Skenn fie berauf múffen, um soem zu fdoppen, fteden fie oft mu ben Sdhnabel heraus, uno wer= fdy winden wieder, nadbem fie geathmet haben. Sie bleiben weit långere Beit unter Dem Sarifer, alz die Stoptaucher. Sie beflern Taudber formen 5 Minuten unten bleiben, bie meiften

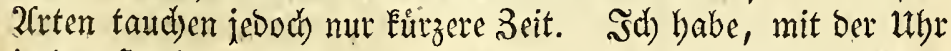

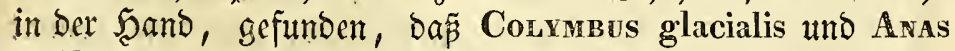
mollissima, wenn ilyr Taudben am långiten bauerte, 6 Mimu= ten unten maren. Sobgleid) biefe Beit an fich nicht lang ift, io ift fie eb boch im Berbáltniffe zu ber, meldye Der Seebund da= zu braudht, indem Phoca barbata, weldher unter ben nor= bifdben am beften taudht, bơchftenz nux 10 bis 15 Mimuten unten Gleiben Eann. 
Da bie Iaudser ilye Taudffalligêteit oft anzumenden pfle=

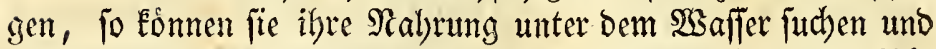
verfolgen; bod) ift es wobl am feltemiten ber Fall, baj bie $2 \mathfrak{b}=$ gel fobon, ebe fie taudsen, ilyer seute anfichtig wurben.

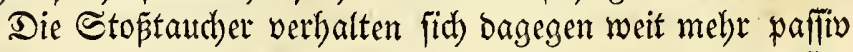
in ber Beit, in ber fie unter ben Şaffer find. Utm unterzufto= ken, find fie genothigt, fich in ein anderes Element, in bie $\mathfrak{L u f t}_{\text {, }}$ u erheben. Daburd), daj̃ fie ihrem Rỏrper Force geben, werfen fie fich) unter; fie bringen ez aber felten zu ber Tiefe von eimigen

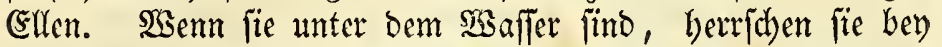
weiten nidbt fo itber ibre Fåbigfeit, wie jene. Esz gejdjiebt al=

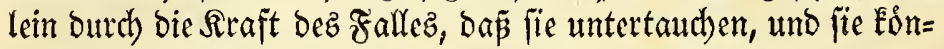
nen jid) bajelbft nidjt lange erbalten; wenn die $\mathfrak{B s i n t u n g ~ b e z ~ F a l = ~}$ les auflyont, werben fie, alz leidyter, wieder zur $\mathscr{B}$ a flerfláche geboben. Ezz find balser nut wenige Seumben, wåbreno wel= dher fie unter biefer verborgen find, und bie 3eit ifrez 2 ufent= baltez unter berjelben Eann allezeit voraus beredynet werben.

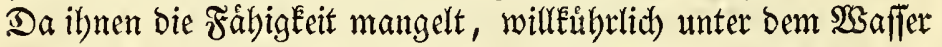
zu bleiben, fo werfen fie fich nidbt unter Daffelbe, um Beute zu

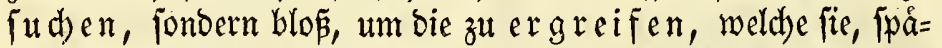

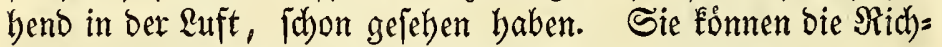
tung ifrez Stopes nidyt ganz regieren, uno ftopen baher oft fehl; felbft bie ausgezeidenetften Stoptaucher, mie Sura alba, ver= fehlen zumeilen bas (semuiturd)te. Finige Szlander baben mich

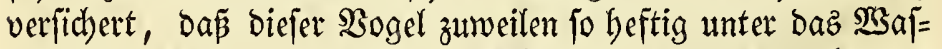
jer ftope, daß er gegen Glinde Scheeren ben Şals breche und todt aufichnimme. Diejez wirbe Eaum dem Sd)wimmtaucher begegnen, wie beftig ex aud feine Beute verfolgte, fo wie es felten ift, baj er diefe verfeblt, wenn fidd ber $\mathfrak{B}$ erfolgte nid)t an und

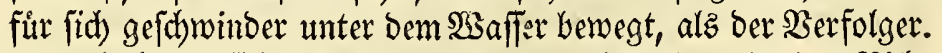

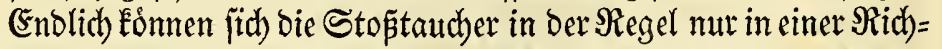

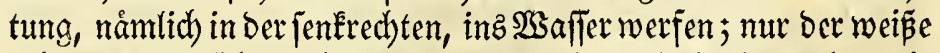
Iolpel Eann fith aud fidrage, uno bennab horizontal, wie

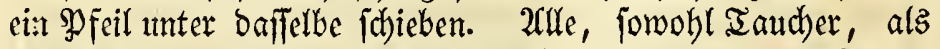
Stoptaudser, ftecken ben Fiopf zuerft unter, und biejer Fommt gleid)falls benm 2Auftauchen zuerit wieder zum Borjdein, fo Dap bie Stoptaucher in ber furzen Beit, in weldher fie unten fino, einen Bogen bejdreiben. Da ibre Stopitaudfábigkeit alz Mittel, Nabrung zul fuchen, unzureidbend ift, fo find fie

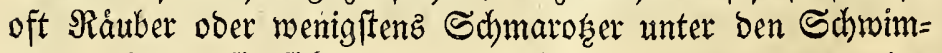
mern, indem fie fidh fut ben Tautbern balten, um an ber 
(Puffinus) ein Tautcher ift, ba er bod wirflich fo viel von ber forperlichen Billung ber Stoptaucher befift. (Fr nåhert fich der Procellaria in ber länge der Flugel. Utm baz Taudben mit den langen flügeln zu beförbern, weldye ex unter bem $\mathfrak{B}$ af= fer offen bat, hat er vor einer jeben mir betannten Gdbwimm= vogelart einen ibm eigenen Snod)en im Fligel voraut erbalten.

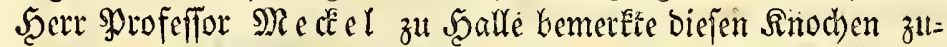
erft an einem Skelette von Pufrinus areticus, weldbes id ibm fandte; nadblyer fand idh ifn, forobl bey biejer 2 (rt, alz bey Puffinus major. Siev Den Flaumjungen ift ber $\Omega$ nodhen bent= lid), aber Enorpelig. Er fift in ber untern Estrbogenbie= gung, auf biefer perpendiculár articulirt, und ungefåbr sinen 3oll lang; er ift flach, breiter gegen bie Spife, auf ber untern Seite Eeilformig, und anf Der redhten Seite mit cinem (Sin= jonitte verieben. Da die Stumboigel, welden biefer Ino= d)en mangelt, eben to gute Flieger find, alz bie Sturmtaucher, fo glaube idh nicht zu irren, wenn idi biefen Snodhen mit ber

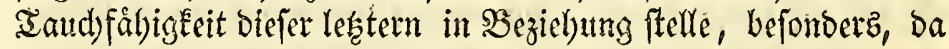

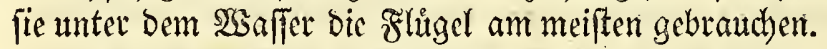

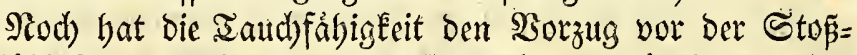

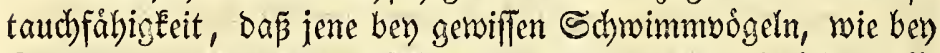
Colmubus, Podreers, Mergus, Peatypus, in jedem 20 ter Des Bogetz angewand wirb, und baf bie Flaumjungen eben fo gut taudben, alb die 2uten; bagegen Eann mut dieje von ben crwachfenen gefieberten Bógeln angemanot werben, weil fie mur mit ausgewad) Fenen Flitgeln fich in bie Ruft etheben Eonnen, um fid) unter bas $\mathfrak{2}$ affer zut werfen.

\section{§. 48.}

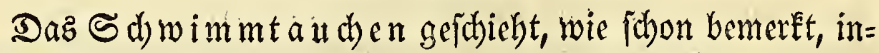

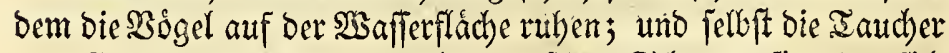
von Carbo und Uria, weldbe, auf den Sdbeeren fichend, fid ourch bie $\mathfrak{Q}_{\mathrm{uft}}$ ins $\mathfrak{W a f f e r}$ fallen laffen, liegen eimen 2 ugenblick auf bem $\mathfrak{S b}_{\text {affer }}$ felbft, ebe fie untertaud)en. Sisenn fie unter Dem Sdywimmen felbft taudsen wollen, balten fie cinen 2 tugen=

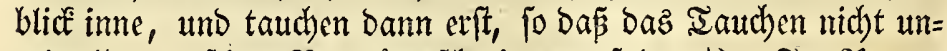
mittelbar auf bas Borrwåtsfdrwimmen folgt. *) Sim 2 fugen=

*) Ezz iff nod) unentfohieben, ob bie Inatcher, inbem fie nuf bem Woffer floden, um fich unterguffoieben, bie $\mathfrak{L u f t}$ ein =, ober aub= 
blicke bes Untertauthens zeigen fie verichicbene (S)ebarben; ei= nige tauthen ohne merflid)e Bewegung, wie Counsus, andere breben fidy, indem fie tauthen, auf Dem $\mathfrak{s}$ affer bin unb ber, wie Alca. Sinige tauthen mit einem fleinen Sprunge auf bem Saffer, uno werfen fich beynaly úber Şats uno Ropf unter. Dieje nenne id) Springtaud dier, uno es fimb bie 2irten von Carbo, Podiceps, Funica und Merguis; andere taudhem,

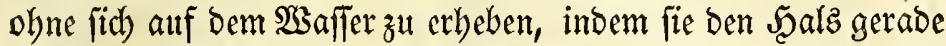
ins $2 \mathfrak{B a f f e r}$ ftecten. Dieje nemne id) Sted tauder, weil fie fid) fobráge unter daz $\mathfrak{W}$ affer ftecken, wie Colymbus.

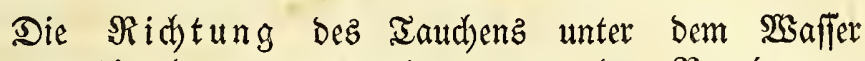
kann vertical genannt werben, wenn Der Bogel gegen ben (s)rund taudbt, uno aljo bie Iiefe jutht, horizon= tal, wenn er fid) gerabe vorwårts unter bem 2 saffer be= wegt, und aljo bie \&ánge fudbt. Das verticale Tauden wiro nur angerwandt, um $\mathfrak{R a b}$ rung zu futhert, und bann am meiften

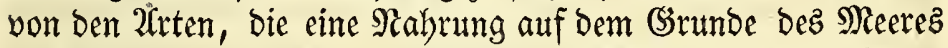

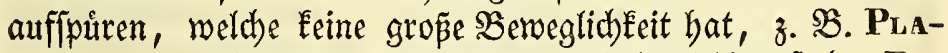
TYPus, Der auf bem Meergrunde Fleine Sdyaalthiere futht, PoDiceps, weldyer $\mathfrak{s a f f e r p f l a n z e n , ~ С а в в о , ~ w e l d h e r ~ b e n ~ i m ~}$ Sande liegenden Cottus, und Monmon, ber benim Sande berftecte= ten Ammodytes fiffdt. Die 2(rten, weldhe mit Shillfe ber Frhu=

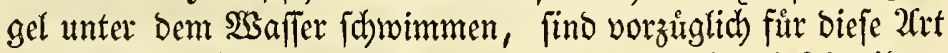

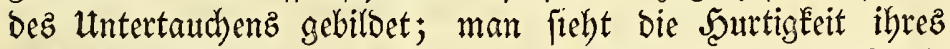
jenfrechten ãaudens, wenn man 5 Sinuten als bas Maxi= mum ber 3eit annimmt, in ber fie unten bleiben, und mant oem= ungeadbtet in ber Iiefe yon 30 Rlaftern Sibervógel im Şarne fángt, aud Uria troile und grylle im Magen dez Squalus glacialis findet, welderer fid) pelten in einer aliefe unter 50 Rlaftern aufláalt.

Das borizontale Tautchen wirb theils von ben $2 \mathfrak{r}$ ten ans

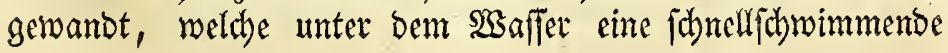

athmen; bas (Erftere fheint ihr fenfred)tes Inuthen in sinem fohwe= ten Mebium zu exfowerem. Das fie jeboch unter bem 2 Baffer \&uft in ben \&ungen haben, nimmt man aus ben \&uftblafen ab, weldes in ber

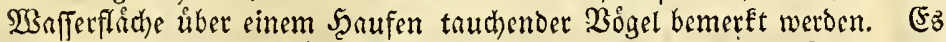

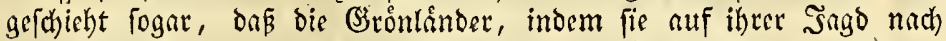
Anas spectabilis biefe Inuther futhen, den Drt meffitroen, wo bie tauchenden $\mathfrak{S o g} e t$ unten im Meere find. Bergl. Fabrici us von Aivas

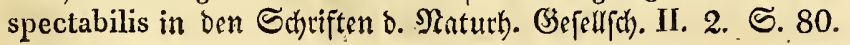


Saburung verfolgen follen, alz von Cocymbus glacialis, ber nad) den Salmo - 2urten, won Uria, die nref den Cuupea - 2arten taudbt, theilz von ben meiften Iauchern, wenn fie entflieben wollen, ba fie alsbann nicht bie నiefe, fondern die Rånge fuchen. Fin biefez Iautchen find bie 2rten am beften gebilbet, weldhe allein

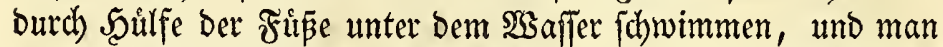
kamn bie Sdjnelligkeit biejer Iauther an Conrmbus glacialis feben, weldber, wenn er erjdyrocken taud)t, nach wenigen Mi= nuten weit auterer ber Sdur weite wieder zum Borfdein Fommt.

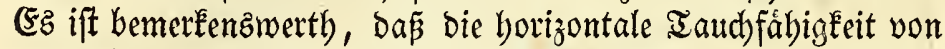

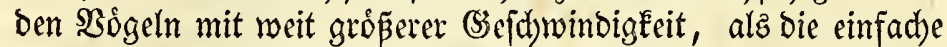
Sdhwimmfåbigkeit auzgeủbt wirb, und dap fie alfo in berifel= ben $\Re$ ichtung fidh weit gefdyminder unter bem $\mathfrak{S a}$ affer, alz auf Demielben bewegen, ob ez gleich fdjeinen módhte, bas ihre $\Omega \dot{R} r=$ per vom $\mathfrak{W a f f e r}$ mebr in ibrer Benegung aufgebalten werben, wenn fie von riefem Medium ganz umgeben find, alz wenn bie= fes nut zum Ilyeil Der Fall ift. Dod kann man bemerken, Dap

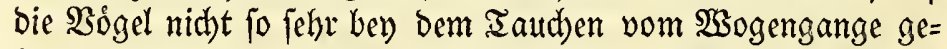
bindert werben, alz benm Sdywimmen, da ez, wie befannt, nux bie Sberfláche biz zu einer gewiffen ßiefe ift, meldbe fich bie und ba in ftarker Bewegung befindet. Man vergleidbe blop bie grópere Strecke, weldye Conmbus glacialis und mebrere Sogel in gleicher 3eit burch Iauchen unter bem $\mathfrak{B a j f e r , ~ a l z ~ b u r c h ~}$ Shbimmen ủber biejem, zurûtelegen Eonnen.

S̃n 2 njelung ber Extremi tả ten, weldbe bie Schwimm= tautcher als actio unter bem $\mathfrak{B a}$ affer gebrauchen, werben fie in zwen Shauptabtlyeilungen getbeilt, in Fl ígeltaudser, weldbe un=

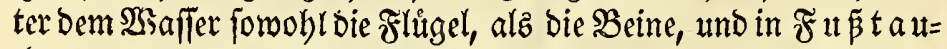
d) er, welcu, mur allein die Beine gebrautchen. Diejenigen $2 \mathfrak{r}=$

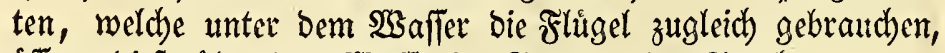
offnen biefe itber Dem $\mathfrak{W a f f e r}$ im Momente bes Tauthenz, uno man fam baber in biejem 2ugenblide leid)t feben, ob ber $\mathfrak{B D}=$

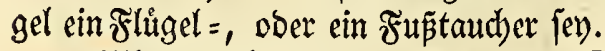

Flügeltaucher find bie 2rten von Unia, Mergulus, Cephus, Alca, Mormon, Puffinus, platypus, Aras, AnsEr. Sie o̊ffuen alle die Flugel, indem fie unter jhiepen, uno man fiebt fie unter Dem $2 \mathfrak{S a}$ afer fich mit ausgebreiteten Flugeln uno zurúckelegten Früen berwegen. Man kamn von ihnen $a=$ gen, daß fite in ber Mitte Diefes bichteren Elementz fli egen, uno fie haben alfo unter ifyem Tauthen eine Stellung Des \&eibes, bie ganz verfidieden ift von ber, weldhe fie unter bem Sd)wim= 
men gebrauchen. Sach babe oft gefchen, oa Ua Una troile; ALca torda und Aras mollissima fich in ben nórolidben Meeren mit Reichtigheit vicle Sllaftern unter Dem $\mathfrak{B a f f e r}$ vorwårtz be= wegt baben. Sie gebrauchen bie Flitgel fowohl zu Dem verti= calen, als Dem borizontalen Iaudben. Dap fie biefe unter bem SGaffer bemusen, geidjebt eigentlid) nidbt, um bas Iaudben

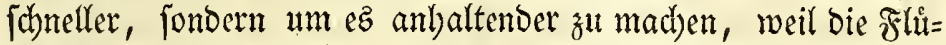
geltaudber gemeiniglid fleinere Bo̊gel find, uno nicht אraft gè= nug in ben Seinen allein baben, um baz volfe Iaudben zu be= werkftelligen. Dap bie Flitgel an und fiut fich bie (siefchmindig=

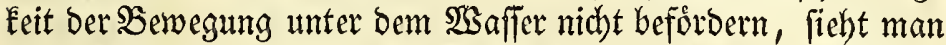

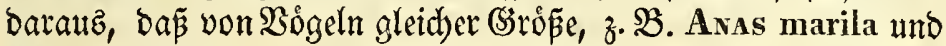

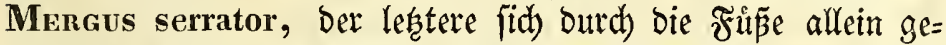

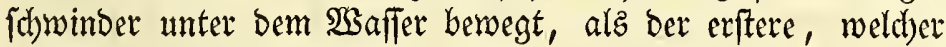

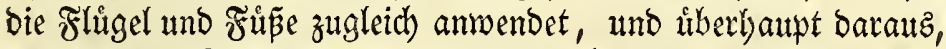

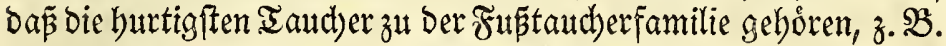
Colymbus uno Carbo. SGeil bie Fligeltauther bey dem Tau= d)en bie Frigel melyr, als bie F̌̉pe gebrauthen, fo erforbert

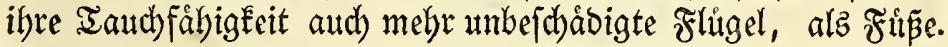
Sath habe eine Alca torda gejeben, deren beibe Beine biz anz Fupglieb weg, wabrjdeinlich erfroren waren, weldbe mit eben jo

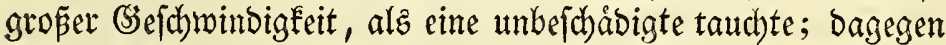
feste ein Sdur inz Flugelbein fie feldr bald auper Stano, zu tauchen. Das Entgegengefeste ift ber Fall bev Den Futatutbern, weldbe gleidhwobl taudben, objobon fie in ben Fligeln vermundet fino, weil fie biefe unter bem Taudjen an ben 2 eib anjebliepen uno nicht gebrauthen, bey weldben aber jebe Bejdjabigung in ben

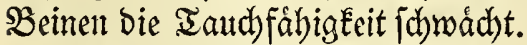

Die Futatacher find die 2rten von Carbo, Colymbus, Podiceps, Fulica, Mergus. Sie fdhliepen die Flugel an; indem fie tauden, und fdivimmen unter bem $23 a f f e r$ mur burd

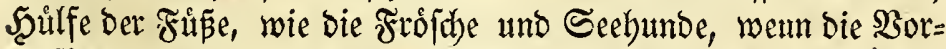
berfüpe biefer Ihiere mit ben Flugeln ber genannten $\mathfrak{B}$ ogelarten

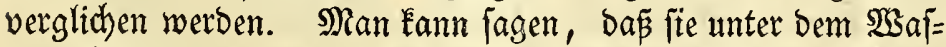
fer fdwimme n, ba ifre borizontal taudende Stellung unge=

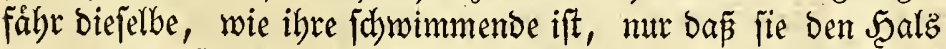
uno ben Ropf ausftreďen, uno ibre Beine ganz hintenaus in ber Einie mit bem leibe liegen; fo (d)wimmen fie allein ourch bie Berwegung Der Frupe. Es fino vornebmlid die Fustaucher, welde im Momente Des Iaudbens cinen Fleinen Sprung auf Dem Şaffer maden, um Dem Nangel Der Unterftutumg ber Flügel 
zum Unterfommen abzubelfen. Sie find bie gróperen 2rten der Taudher, und insbejonbere zum borizontalen Taudben gejdbiciter,

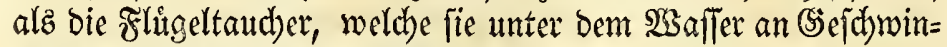
bigkeit und 2 huboauter ibertreffen.

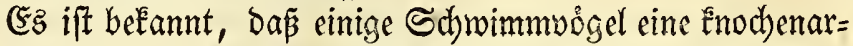

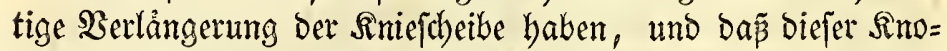
d)en zum Stüfpuncte ftarker Mugkeln bient, weldye Den 3 cinen

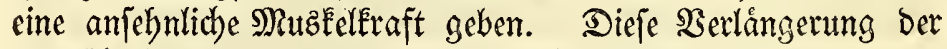
Sinielcheibe fehlt ganz bey ben Nidyttauchern ober Stoptaut= d)ern; fie wirb nux bey Den Sdywimmtaudern gefunben, und

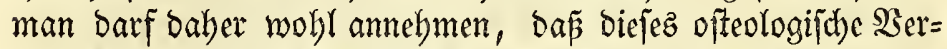

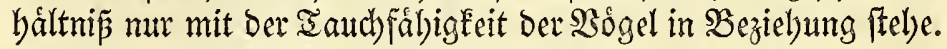
İnoeffen find es nicht alle wirklid)en Iatuder, weldhe diefe ver= långerte Sniefcheibe baben, fondern fie wirb am meiften aubge=

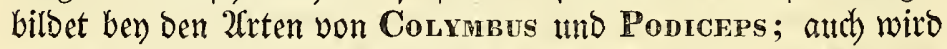
jie, objchon minder, bey den 2riten von Carbo uno Mlergus gefunden. Sie roirs bagegen bey ben gleidf fallz taudbenden $\mathfrak{A}_{\mathfrak{r}}=$ ten von Uria, Mergulus, Cephus, Alca, Mornon, PlaTypus vermipt. Snnom wir mun baz Dajevn ober den Ran=

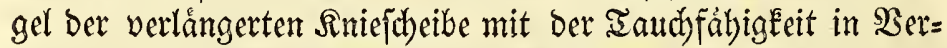
gleidung ftellen, finden wir Daz allgemeine Berbáltuin alle Fuptaucher biefe Serlangerung haben, dap fie aber ben Flu=

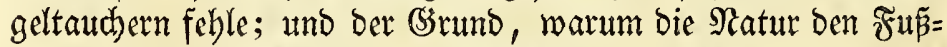

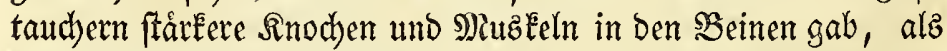
ben Flligeltaudbern, ift unlåugbar, weil fie fich allein burch Şillfe berjelben unter bem $\mathfrak{G a f f e r}$ berwegen, uno bie Seine baher ei= ner gro̊p̃en Stårke bedurfen, als wenn fie in ifrer Function zugleid) von ben Flitgeln unterftutht werben.

Die 230 gel tauchen eben fo gut im aufgeribrten, als im

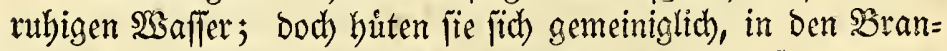
bungen zu tautben; mur von Aras mollissima unb befonbers von Aras histrionica labe ich gefeben, bas fie fich mit lecidstigkeit

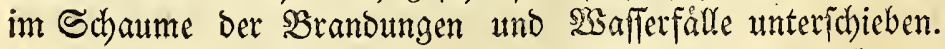

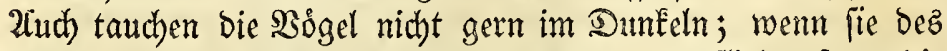
Nadhtz auf bem 2 affer beumubigt werben, entflieben fogar bie 2rten, weldhe fdnwer auffliegen, lieber butch ben Flü̧, alz Durchs $\mathfrak{s}$ autben.

Sinige 2rten bleiben, wenn fie Seabrung fuchen, atf ber= felben Tiefe lánger unter Dem $\mathfrak{B a} a f$ er, als andere, und Durd)ge= ben in bemjelben Berbáltniffe die rauthmomente feltener ober ofter. Colynbus uno Carbo tauchen gewólynlich mu ein paar= 


\section{7}

mal nach einander, verweilen aber auth jebesెmal lángere Beit unter. Dagegen irben andere 2 frten ein flürzerez, aber aud' offter wieberfoltes Iaudhen auz. Diefe lefetern find nidht fo ge= fobickt, als jene, im eine autweidsende Beute zu verfol= gen, weil fie nid)t immer binreichenbe 3eit unter bem $2 \mathfrak{s a f f e r}$ zubtingen kénnen, um fich berfelben zu bemáchtigen. Soldhe Tauther fint 3. B. unter ben Enten Avas glacialis, und bejon= Derz Aras histrionica, weldye man im $\mathfrak{J e r b j}$ ganze Stunden

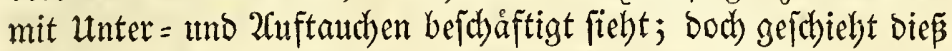

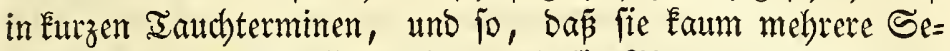
cunden ỉber bem $\mathfrak{B a f f e r}$ bleiben, als fie Minuten unter bempel= ben find.

\section{§. 49.}

Unter ben Sdywimmtaudhern wenden bie meiffen $2 \mathfrak{t r t e n}$ bie Tauthfábligkeit regelmåäig an, und find allo an und fitr fid Tautcher, andere bebienen fid) ibrer nur in ber 3eit, in weld)er ibnen bie Flutgfåhigkeit mangelt, uno tautthen bie îbrige Beit nidht. Daber theile idh bie Iauddfäbigkeit in bie reguläre utno fubjitiåare ein.

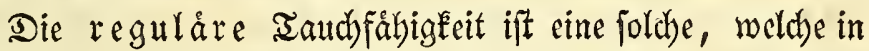
ber $\Re$ egel von ben bamit verjehenen 2 trten angewanot, bie $\mathfrak{j u b}=$

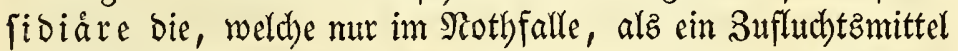

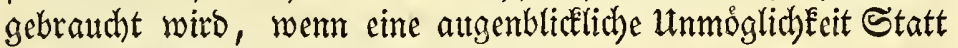
findet, ibre Fługfáhbigkeit anzumenden.

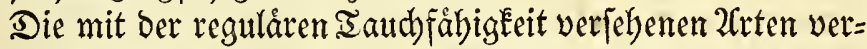

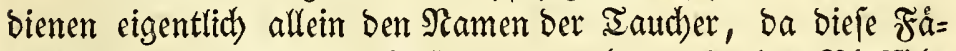
bigkeit einen Iheil ibres 2 sejenz ausmadht, und obne Ritefficht Dez $\mathfrak{B} e j t\}$

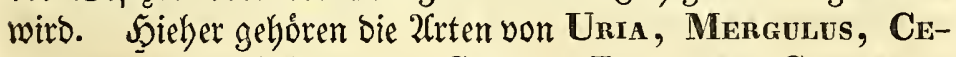
phus, Áca, Mormon, Савbo, Puffinus, Colymbus, Podiceps, Fulica, Mergus und Platypus.

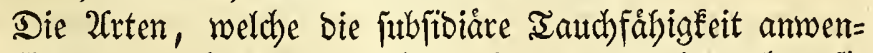
Den, find eigentlich Eeine Iautcher; in Der Regel tauthen fie nie. Doch ift bie aautchfábigheit nicht ganz ben ihnen ver=

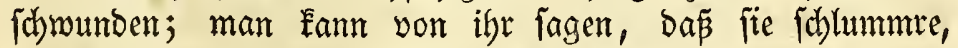

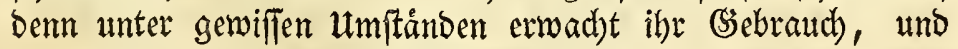
Dann nux, wenn fie auper Stand gefest find, zu fliegen, na=

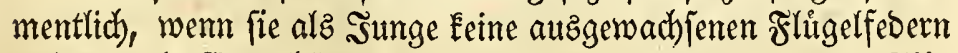
baben, als (Erwadjene bieje maujern, Erante ober in ben Frti= getn angejdofien fint. utnter biefen Bebingungen tauthen fo 


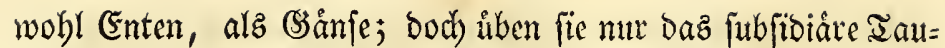
d)en aub, wenn jie entflieben wollen; nad) Nabrung taud en fie nicht einmal, wenn fie ber Flugfåligkeit beraubt fint. SGenn fie mieder zum Befiţe diefer Fåhigheit fommen, entflieben fie auth) allein burch Scưllfe berjelben. Şiel)er geljoren die arten von Aras Brhm., Anser, und zum Iheil Crgnus. S(d) babe

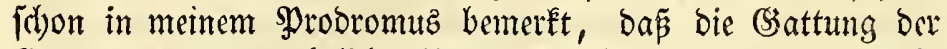
Enten aus zwev natîtlit)en Familien beftebe, auz ben regelmá= fig, und ben blop in subsidium taucbenben; meine geringe Nei= gung indeflen, neute (S)attungen uno 2liten aujzultellen, uno meine Uleberzengung von bem Schaben, weldhen bie Sippma= d)erey itberbaupt ber Wsiffenidhaft verurjacht, machte, bas idh fie nicht fdon bamalz in zmen (S)attungen theilte. Scerr $\mathfrak{B}$ rel $m$

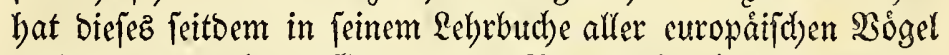
gethan; er hat jener Gattung Den Namen Iaud = Ente, PraTypus, bengelegt, biejer aber ben গamen Ente, Anas, gelaf= fen. Diefe (S)attungsnamen nelyme idh an; zwar wurbe auth daz $\mathfrak{S} \mathfrak{d}$ nabelthier anfánglid) Plntypus genannt, aber biệer

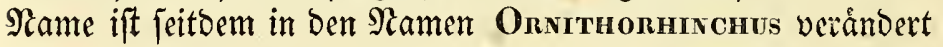
worben; eE gicbt alfo nach Den Regeln ber Romenclatur nid)tz,

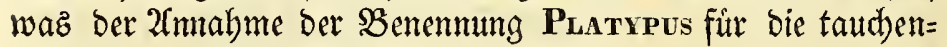
ben Enten im $\mathfrak{x}$ sege ftrbe.

Die nordi jhen 2Trten ber (5̧attung Anas Brhm., alz Aras boscas, acuta, penelope, crecca, tadoma, strepera, taut= d)en in ber Regel nidht; wenn fie aber bie Shwingfedern maujern, und nidbt fliegen konnen, haben wix oft (Selegenbeit,

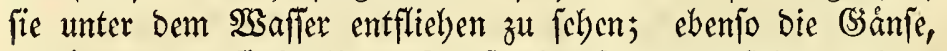
weldbe, wenn fie in ibrer Mauter im Meere verfolgt werben, oft uno lange tauchen. 2ach babe id jie taudben feben, wenn fie entweder angejdoflen oder Erant midht fliegen Eonnten, ba bie Sdhmimmoogel, wie zuwor bemertt worben, in Arantheiten eber ben Flug, als die Iaudfåhigkeit verlieren. Unter bem Taudben offfnen fie, wie Platypus, bie Flugel, umb gebrauthen $10=$

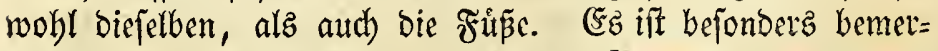
kenzwerth), dẩ bie Sungen von Anss tadorna, boscas, crecca, wenn fie erfhrecken, mit groper Reichtigkeit tauchen, und fidh lange unter bem $\mathfrak{B a f f e r}$ aufbalten, ba fie im (Gegentheil, wenn fie Federn erbalten Gaben, diefe Fåbiskeit wieber verlie= ren, umb gegen bie Flugfályigkeit vertaujden. Sa bieje 2rten in ber fruibeften \$eriode beftimmt find, fich felbft zu verforgen, fo erbielten fie ben temporáren (Sebrauch oer Saudb) fåbigkeit fo 
lange, bis fie, Durth die Erlangung Dev Fłhgfáhigkeit ben Bezint ilyrer Beweglich Eeit nod) mebr erweiterten. Sie ftehen bev Der 2(nwenoung Der Taudbfábigkeit ganz in Sppofition mit den 2rten von Uria, Alca, Monnon, Canbo $\mathfrak{u}$. mehreren re= gulaten Taudbern, weldbe, fo lange fie im Flaume find, nicht tauthen Eonnen, bagegen in ben Febern dieje Fålligkeit erlyalten. Da die Enten und (şånje als errodyjene, zut Der 3eit, wenn fie nicht fliegen tomnen, ooch ungern taucben, fo fudben fie lie= ber, wenn ez moglid ifit, Daburd zu entflieben, daj fie aufz

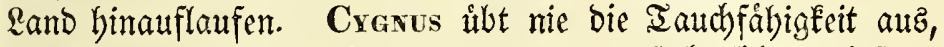

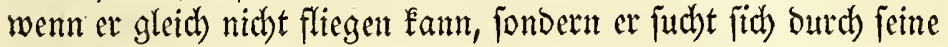
autzoezeichnete Sdywimmfábigkeit zu retten, weldhes mit einer

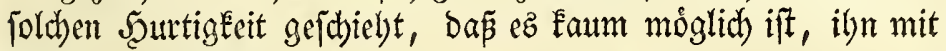
Bovten einzulyolen.

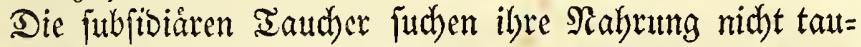
dyend, wie bie angrenzenden 2arten von Platypus, fundern entweder auf Dem Irodéenen, ober auf Der SBafferfládbe jelbit,

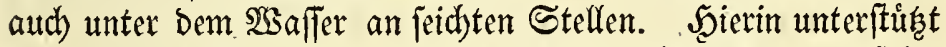

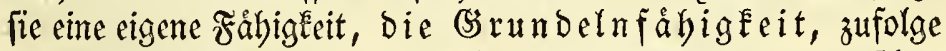
Deren fie im Stande jind, Durd die Mitwinkung einer rafden

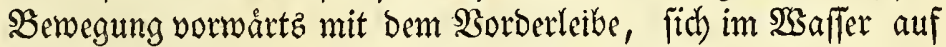
Den אopf zut ftellen, und, mit den Fữen gegen bie Sallerfláche arbeitend, bie $\Re$ abrung zu jutchen, weldbe auf dem (Srumbe bes feid)ten 23 affers Fónte ge funden werben. SGenn fie einmal in bie fenfred te Steflung getommen find, find fie im Stande, fith, obne fonderlich die Fuspe zu gebrauden, in ber Balance zu erbalten.

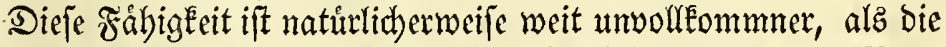

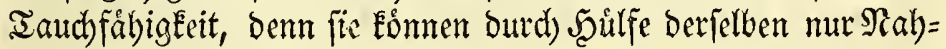
rung im $\mathfrak{B a}$ alfer erbalten, beffen Tiefe bis auf den (sirund nicht

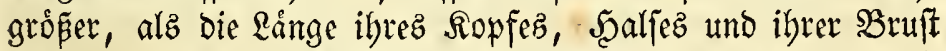
ift; Dody mird biefe Fertigfeit eben fo oft und beynab eben fo

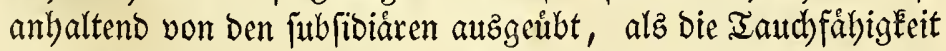

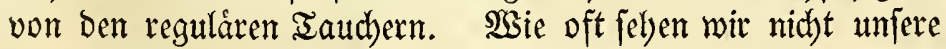
zahmen Enten uno Şânfe in den Dorfweibern fo auf bem Sopfe fteben! Diefe (Srundelnfåhigkeit ift eigentlich ein Heberbleibjel

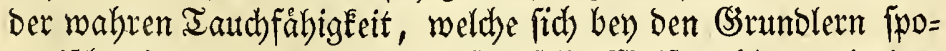
rabifh zeigt, benn fie miro auf biefelbe Şeife getbt, wie bas verticale Tauchen von ben $\widetilde{F}$ stauthern, indem fie mit ange=

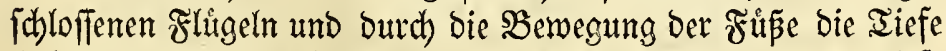

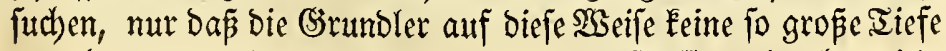

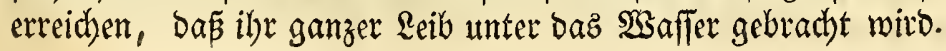


Wsenn bie (Enten tautchen, find fie Fligeltaucher; als (s)runbler aber gebrauden fie bie Flurgel nicht, fondern bemegen mur bie

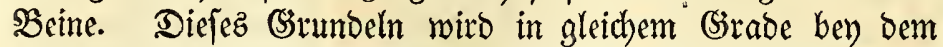
Sdywane autsgebildet angetroffen; er wenbet es aber feltener an,

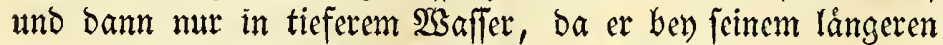
Şalje, in jeichtem $\mathfrak{W}$ âfer ben (Sinund unter bemjelben zu unter: fuchen vermag, obne, wie bie Enten oder Gänje, fich auf ben Sopf zu ftellen. So wie ber Schman, unterfud)en bie Enten

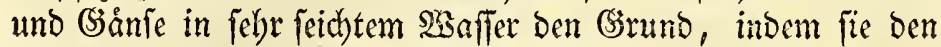
Sopf und Scals unter bas Şaffer ftecken, obne fidh auf ben Sopf zu ftellen. Man bemerte blops bas Schnattern unjerer zab)= men Enten in ben Ieid)en u. f. wo.

Die febr zarten Sungen von Anas und Arsen babe ich nie bas (Girumbeln anwenden fellen; auch wurbe es innen ibres kur= zen Saalfes wegen mu wenig Nuken fdeffen. (5z ift cine Frage, ob biefe nicht baher in Dem fritheften 2ater, ba fie von

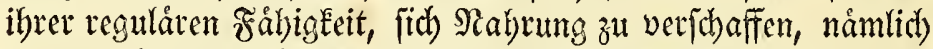

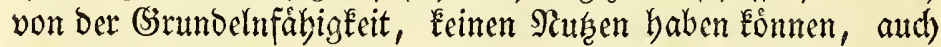
ganz untertauchen, um bieje zu fudben, fo wie jie in (siefalyr zu taudben vermógen. *)

So wie die Tautbfáligheit zuweilen von ben (sirunblern extraorbinår angewandt wirb, fo wirb die (Sirundelnfábigfeit auth von einigen Sdymimmtaudbern angewandt, z. SB. von ben Pratypus-2irten, yon weldyen idh mollissima fidh auf ben Sopf ftellen jah), um ben (Situno zu unterjuchen.

Einen 3weig ber Grundelnfáhigkeit bemert man fpora= Difh bey einigen Sumpfoỏgelm, z. B. bey Haematopus ostralegus, Recunvinostra avocetta, Aadea cinerea, Lmosa melanura, Totanos calidris uno Tringa alpina, mit meldre= $\mathfrak{r e n}$, weld be bis an bie Sniee ins $\mathfrak{3}$ affer waten, und ben Sibna= bel und Sopf unter baffelbe fteclen, um auf bem (sumbe Siab)= rung zu fuchen.

\section{§. 50.}

Die regulåren Iautcher baben eine grópere ober geringere Frertigkeit im Tauchen, fo wie fie ez in mebreren ober wenigern

*) Sachdem diefer $\oint$ gefdrieben war, habe idj die halberwadh fenen

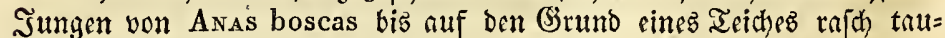
den, und wenn fie auf bie Sberfláde gefommen, bann fduntternd et= was verzehren jehen. 


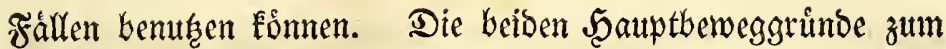

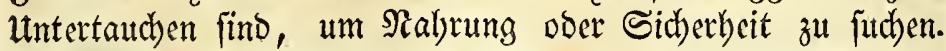

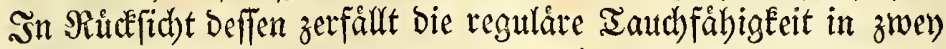
Iheite, in bie unbebingte, welche forobl um Nabiung

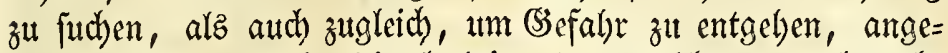
wandt wird, und in bie bebingte,- tweldese nur gebrautht wirb, um siabrung zu juthen.

Der unbesingt regutåren Tautder, von melchen Şrliger

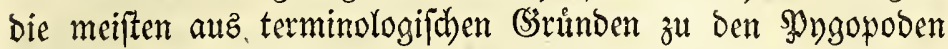
záalte, find bie meiften an ber 3ahl, námlich) alle reguláan Taudjer, auper Mergus und Piatypus. Diefe tauden fo= wobl nach :aabrung, als in (sefaht. Sie find baher mehr anz

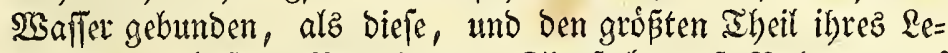
bens binourd) feime Bewolner. Sie fuchen oft $\Re$ abrung auf bem Grtunde, und tauthen, wenn fie verfolgt werden, fo anbal=

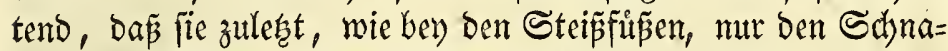
bel berworftecten, um zu athmen. Stur bann fonnen fie zum Fluge berwegt werben, wenn fie von allen Seiten eingefdloffen,

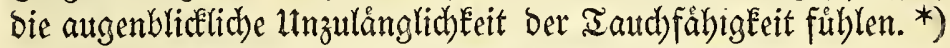
Einige biejer (Şattungen find jebod) leid)ter zum Fłluge zu bringen, alz andere, am fojwerften Colymbus, Poniceps umb Carbo, fo auth fojner Uria, Cephus, Mergulus, Alca, Mormos, weldye body, bejonders in ber Sruitzeit, zumeilen ftatt zut taud)en, fliegen, wenn fie beunrubigt werben, am håtu= figften Puffinus, welder, wenn er eridgedect miro, eben fo oft fliegt, als tautd)t. SSGenn biefe $\mathfrak{B o g} g e($ frank ober tóbtlid) angejdorlten find, vermógen fie gleidhwohl zu tauthen. Sd babe bey Mnyatn einen Podiceps arcticus aufgenommen, wel= dher mit einem Sdbrote burd' ben Sopf unter bả 23 affer tautdete:

*) Dak Die 2(nzahl ber Sndiviouen ber 2(rEen, Utrien, Rarventaut= (her, u. F. w., bie ber Enten u. F. w. Liberfteigt, obglrich biefe lesten

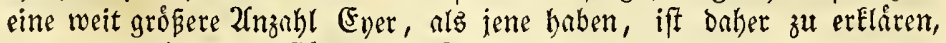
Daß fie fich beynah beftandig im Meere nufbalten, uno tauchen, wenn fie verfolgt werden, fict, alfo in einem Medium verbergen, in welchem

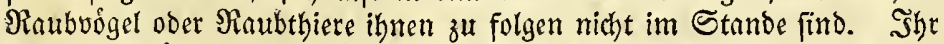

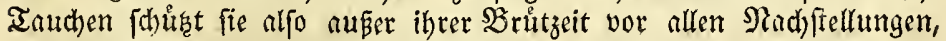
ausggenommen vor einzelnen Maubfifthen. Doch trigt auth bie (Gefel=

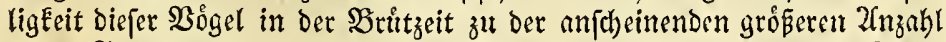

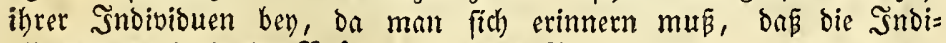
vibuen, welthe in ber Scrutzeit an einem \$uncte gefunden werben, aus einem Diftricte bon megreren Meilen im UmEreife fith verfammeln, wel= ber aljo zu ber 3eit von Den Snoiviouen ber 2irt entblópt ift. 
und etne Conymos rufogularis taudhte biz fie tobt auf Dem Salfer fdrwamm. Wrenn fie achtjam find, taudben fie beym Sdhimmer bez Bünopulberz, ebe fie ber Sdbrot erreichen Fann; kein norbifacer Såger bezmeifelt biefes, uno id babe es felbft oft bey Colrmbus glacialis, Ponsceps arcticus und mebreten erfabren. Es ift fo fdymer, im Seetbfte in ben izlänoifden

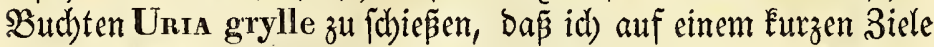
8 bis 10 Siduiffe nach eitrem und demjelben Sogel getlan habe, ebe idh inn uiberrafden fonnte. Dep̧yalb fteflen einige Sdit=

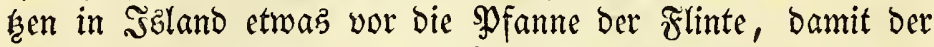
Schimmer bez 3undpulwers nicht gefehen werde. Die Steißs= fúpe (id) bemerkte ez bey Podiceps arcticus in Şzland uno $\mathbf{P}$. cristatus in Dånemark) nebmen ifre zarten Sungen unter bie Flugel, im fie zu befducten, wenn fie taukben.

şenn bie Taudber tóbtlich verwundet ba unterfidiesen, wo fie nur einige Nlaftern bis auf Den Grumb haben, verliert man fie oft, weil fie fich im Iodezkrampfe in bem am (strunde wadjenden Meergraje feftbeipen, und nicht mebr zum Borfdsein fommen; mur wenn fie in fefr tiefem $\mathfrak{G a}$ affer vermundet wer= ben, baben fie bas \$ermógen nicht, fid) bis an ben (sitund zu arbeiten, und fommen bann tobt berauf. 2Guf biefe $\mathfrak{S e i f e}$ verliert

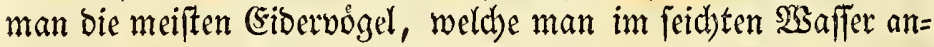
jobiest, uno id) bin felbit Beuge gemejen, wie cin Mergus serrator mit einer Stange beratsgezogen wurbe, weldyer am (5iunde Des Meeres auf Dem Ropfe im Meergraje cingebiffen ftand und todt war.

Die regulåren Tauther, weld)e in bas bichtere Mebium, bas $\mathfrak{B S a f t e r , ~ c i n b r i n g e n , ~ e n t w e d e r ~ u m ~ N a b r u n g ~ z u ~ j u c h e n , ~ o b e r ~}$ um zu entflieben, baben einige 2 2 nalogie mit Den (siåbern unter ben Såugthieren, weldhe jich gleid) falle mit einem bidteren Me= bium, mit ber Eroe, umgeben, entweder um Nabrung zu juchen, wie bie Maulwurfe, bie (Erorafen, ober um fich in Sichert)eit zu miffen, wie die F̌̉̆bje uno Spirmåufe.

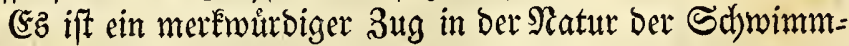
vogel, und giebt einen intereffanten Bentrag zu ibrer \$pbyfio=

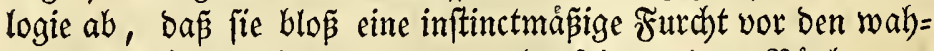

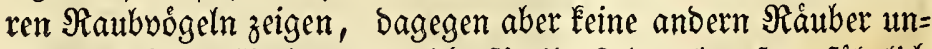

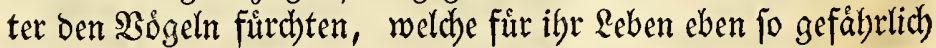

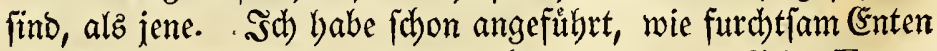
und Såger bev Mevvatn untertaudbten, wenn der Kleine Fauco caesius nach innen ftieś; Dabey Durften fie nidht einmal ifr re= 


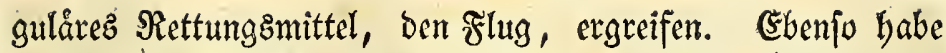
ici) gefehèn, wie Unia grylle immerfort untertaut)te, wegen einez über fie fidwebenden Fauco albicilla, welcher fie burd) Tauchen žu ermatten fudbte. $\quad 23 e n n$ bagegen andere $\Re$ Răuber

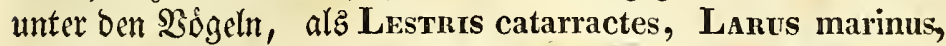

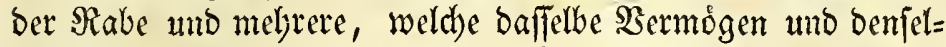

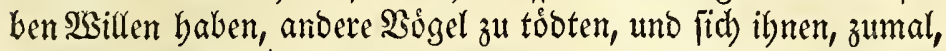
wenn bieje etwas krank fino, nábern, um ilynen ben Iobesfto zu geben, habe id bie fabuimmenden Ura troile und Alca torda, ftatt tautheno zut entilieben, fie beipen, und fid gegen bieje Freinbe vertheibigen fallen, bis fie von ifnen úbermunden und getóbtet muttoen.

Die beoingten regutåten Tauther, nåmlich Mengus uno

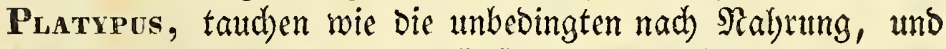
oft cben fo gut, als fie; in (Gefabr aber entflieben fie in Der Siegel nicht tauchend, fonbern fliegent, mut wenn fie fo plós=

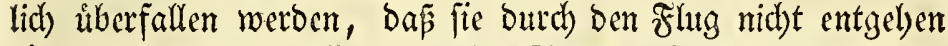
fónnen, ober zum Fliegen auper Stand gejeģt werben, ent=

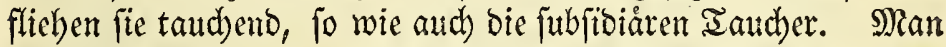
hat oft (Selegenheit, biefez bey ben norbifthen Enten von ber

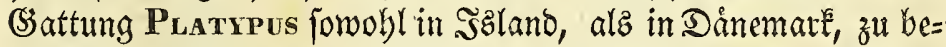
merken, nåmlich yon mollissima, glacialis, marila, histrionica, nigra, fusca, clangula $\mathfrak{u}$. . w. fammt Mergus serrator, weldhe, metm fie audh in nod) fo gropen Scaufen auf bem Wsaffer liegen, relle auffliegen, wenn fie erjobrectet werben, in= Deffen bie nebenan jajwimmenten Unia grylle ober Arca torda

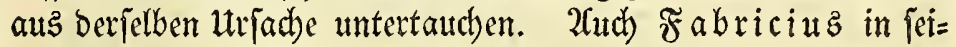
ner Monographie von Aras spectabilis bemertft a. a. S., báp biefe Ente, weldhe iobrigens ein gutter Iaudher ift, wern ifs bange wirb, in ber $\Re$ egel auffliege, aber mur tauthe, wenn fie plóstidid

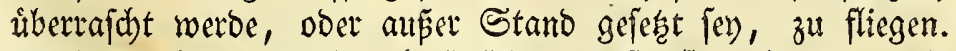
Diefe Tautcher jind aljo nidjt fo febr ans waller gebunden, alz jene.

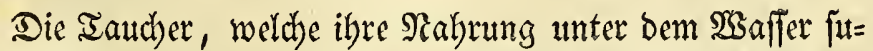
d)en, find im Stande, nad) und nad) mebrere (Segenftánde zu ergreifen und mit bem Schnabel feft zu balten, z. $\mathfrak{B}$. Monuov

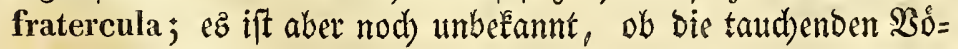

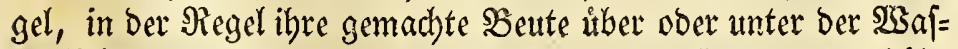

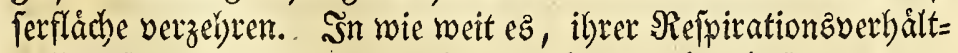

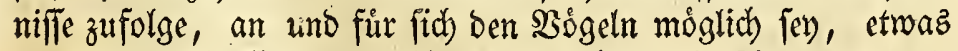

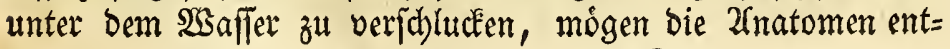




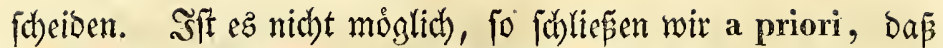

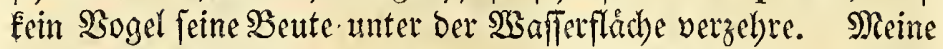

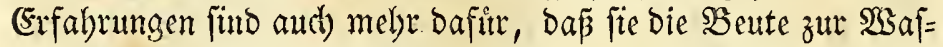
ferfläche bringen, und fie ba verzebren, alz baj biefer 2 ct un=

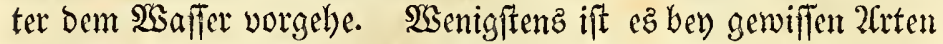
immer ber Fall. Wienn die Carso-2irten auf dem Ģrunde ei= nen Cotrus gefunden baben, bringen fie ifn beftånbig berauf, und find oft eine ganze SBiertelftunbe bejchaftigt, ebe fie biefen breiten Fif auf einmal veridyluden Eonnen. Sie nelymen ben Fifd), wie alle fifdfferfenden Soget, beym Ropfe, und ver= fhlingen ibn von vorn, bamit die Flopfedern ober die Sdhup= pen beum $\mathfrak{B e r f b l i n g e n ~ n i d y t ~ b i n d e r n ~ j o l l e n . ~ S o ~ b a b e ~ i d ~ a n d e r e ~}$

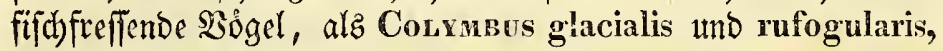
Monmon fratercula, Unia grylle und Alca torda, ibre Beute über ber $\mathfrak{B}$ aflerflád)e verzel)ren feben. (Sileid) fallz fommt ber Eibervogel oft vom (Sintube berauf, indem ot Etwaz im

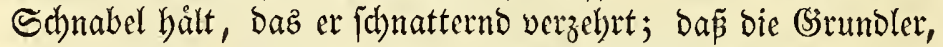
in ber ?iegel, ez allezeit thun, baben wir (selegenbeit, bey den zalymen Enten, (Sänjen und Sd)wånen zu bemerten; Dod babe id) wieber andere (Entenarten gejd)offen, nadboem id fie oft batte tauthen feben; fie batten Den Sropf woll Schaaltbiere, ob ich

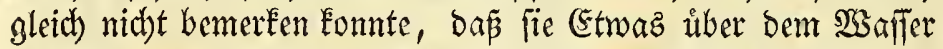
beridblangen. Unter ben Stoptauthern verfidlingt Sterna die gemachte Beute allezeit itber Dem Şafler; bagegen babe id nie. Sura alba ober Lanus tridactylus nach jebem Stoptauden

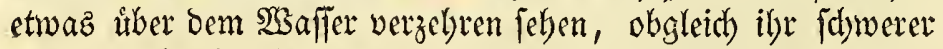
Flug zut (S)enitge berwiez, dap̃ fie nicht immer fehlgeftopen bat= ten, fondern wobl belaben waren. *) Sch bin biefen $30 \dot{g e l n}$ biz auf einige Slaftern nabe gemefen, uno kann mich Daber wohl nicht leidht ben meiner Seobadhtung getảufht baben. Sollten

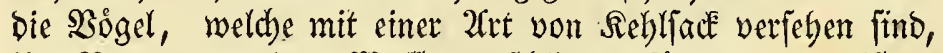
ibre Beute unter Dem Safler verichlingen fonnen, ober ift $\mathfrak{s}$ mur Skabrung von leblofen oder wenig berwegliden Dingen, z. $\mathfrak{B}$.

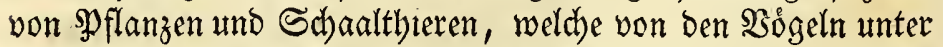

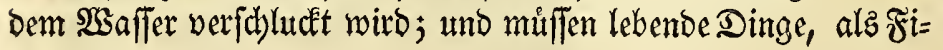

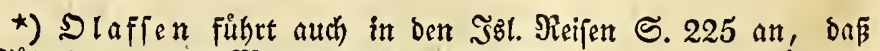
bie నo boch irter in ber Meinung, daß fie ein pan Minuten unten zu blei= ben vermỏgen. 


\section{5}

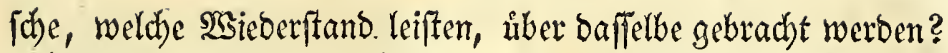
Fid) laffe Diefe Fragen unbeantwortet, uno babe nur meine ein= zelnen (Evfahrungen angefiuthrt. Sey Der Bergleichung meiner angefúthrten Senfpiele wirb man finden, Daß bie Bogelarten,

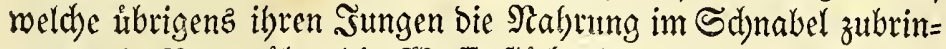
gen, bie Beute ůber bie Şafferflád)e berauflyolen, wenn fie diefe jelbfit verzebren wollen, z. B. Uria und Stersa, und

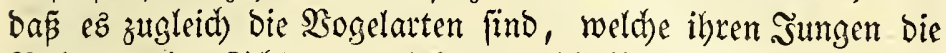
Nahrung im Cdylunbe zubringen, bie ibre eigene unter bem

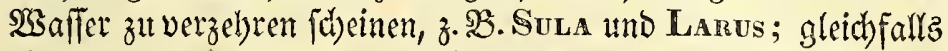
fübren viele ber 2 reten, welche bie Sungen gar nicht futtern,

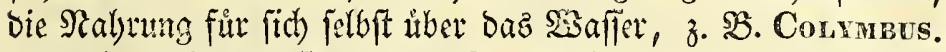

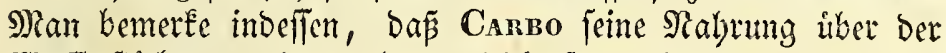

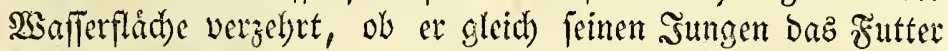
im Edblunde zuttrágt. Die tauthenten Sångthiere, bie See=

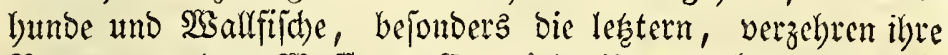

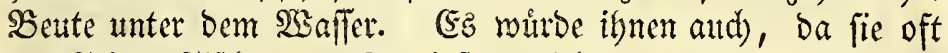
von Fleinen Fif jebesmal die Sberfläche dez Meerez zu futhen, wenn fie ityre Beute verfeblingen wollen. Die Seehund = 2reten fiebt man

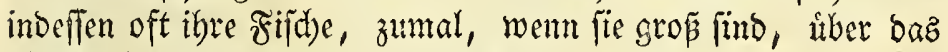
Şaffer bringen, um fie in ber $\mathfrak{L} u f t$ zu verzebren.

\section{§. 51.}

Die unbebingt regulåren Taudber ủben bie Tanduffáhig=

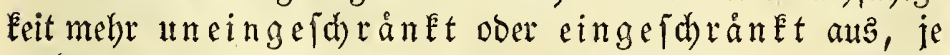
nadboem fie biefe in allen 2urtern, ober nur als erwachjen ober im Feberfleibe antwenden. Die erften find bie 2rten von Cosm-

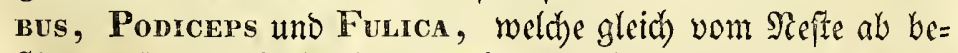
fitimmt find, fich felbft zut ernåbren; fie gehen baher in ben

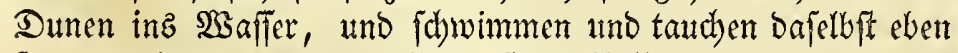
fo gut, als bie 20lten; Dafferlbe ift Der Fall mit ben besingt $x=$

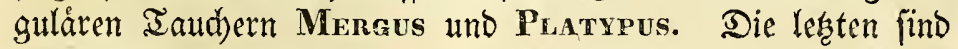
bie 2 rten von Uria, Cephus, Mergulus, Alca, Mormon, Сarbo, Puffinus, meld be, fo lange fie bie Dunen tra= gen, im Nefte liegen bleiben, und balder nidyt beftimmt find zit tauthen, biz jie bie Feoern erlyalten baben. Sommen fie als Flaumjunge burch einen Bufall inz $\mathfrak{B a f f e r}$, fo find fie, wie bie Fraumjungen Der Seebunbe, nidbt im Stanbe, unterzutaudden, fo gute Tautder fie auch nadbyer merben. 
Der Scauptgrund bez Iaatchenz bey ben Schimimmbógeln

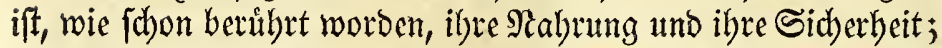
bod) feken wir aud einige ?frten auz andern Motiven tauthen.

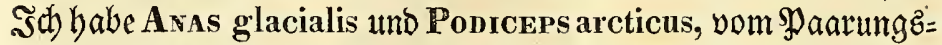

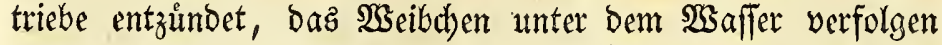
fehen; und, gleidhfalls tauthen einige Bógel zuweilen nady ein= ander, um zu fpielen. So feben wir oft fogar unfere zahmen Enten und (Şåñe mit vieler Frertigkeit nach einander untertau=' dhen, und id babe ben lyerrlicten Ianther Colymbus glacialis beobadbtet, wenn er im Sherbfte mit feiner Framilie in bie Budten von šbland Eommt, wie biefe ganze Stunden einer nad) Dem andern untertauldeten, und einander fo bidst unter ber

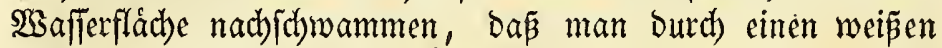

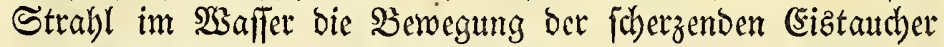
jeben Fonnte.

Iñ $\mathfrak{Z}$ nfebung ber Iauduverbáltniffe madben Cranus un= ter ben fubjïbiåren a a autchern, und Procellania unter ben Stoptautchern, Den $\mathfrak{U}$ ebergang zut ber einzetnen Sdymimmfálbig= Eeit. Puffinus bildet daz $\mathfrak{t}$ ebergangzglied zur Stoftautd $=$ =, und Mergus z̧u ber unbebingt reguláren Tauthfáhbigkeit.

Somobl bie Ia audbfảbigkeit, alz bie Schmimmfåbigkeit, breitet fidch fporabifd auth auf andere Sromungen, auf bie ber

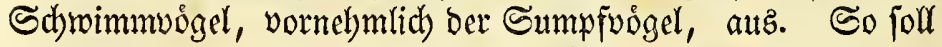
Rallus aquaticus ein recht guter Iaatdher fenn; gleidffallz babe id) bie jungen Наematopus ostralegus, da fie erfd)recett wutr= Den, fertig mit ausgebreiteten Flugeln tauthen fehen; ein ange= jobofiener Charadrius hiaticula und 'Tringa alpina, welde mz $\mathfrak{B}$ affer fieten, thaten baffelbe. I I eil mann bemert auth diefez yon Totanus hypoleucos, a. a. $\mathfrak{D}$. S. 125 . Dak Iautchen biejer Sumpfoógel iff fubjitiaiar, da ez, wie ben Avas Bhm. und Arser nutr gejoiebt, wenn fie in (Sefabe find, und zu einer Beit, wenn fie nid)t fliegen Eornnen. Dagegen ift ber

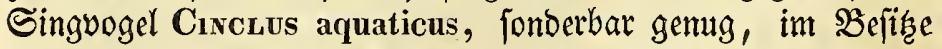

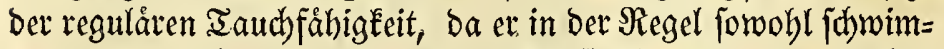
men, als tautdhen, und unter Dem 23 affer feine $\Re$ ahbrung jutchen fann.

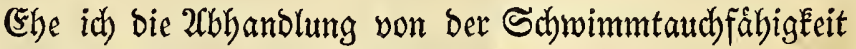

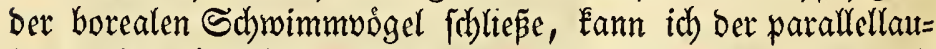

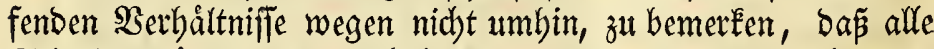
Sdymimmbógel ber eingejdyraำt unbedingten und zugleidh regu= láren Iauthfoáhigkeit von ber zujammengefésten Monogamie fino, 


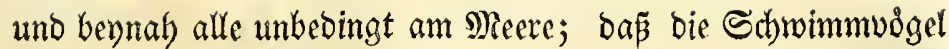

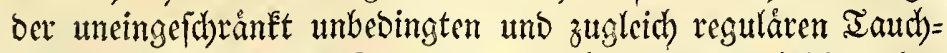
fäbigkeit zur mittlern Monogamie geljoren, uno unbeding ben

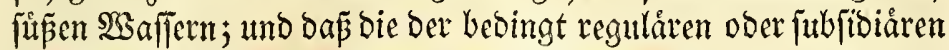
Iaudffåhigkeit von ber cinzelnen Monogamie find, und autd

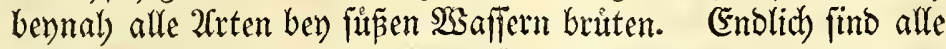
Stoptauther von der zufammengefersten Monogamie; von ibnen

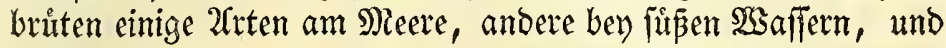

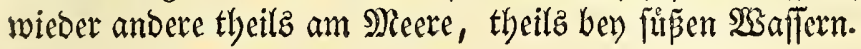

\section{§. 52.}

Die zmente Şauptgruppe ber mit ber zufammengelegten Schmimmfábigkeit verielyenen 2 ögel jind bie, weldye bie

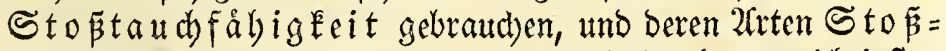
tauder genannt werben. Sm 47 §. babe idh ben widhtigften

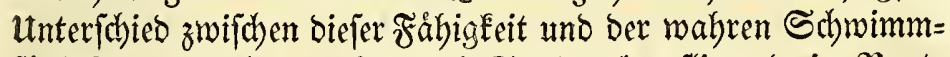
fäbigkeit angegeben. SYsenn bie Stoptautcher fliegend eine Beute

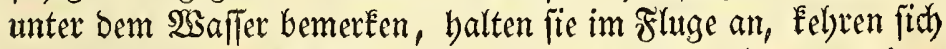

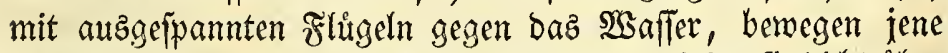
cinigemal, um bem ralle Siraft zu geben, britken fie bidbt úber bem 2 saffer zujammen, uno zwingen fich fo etwas unter baf=

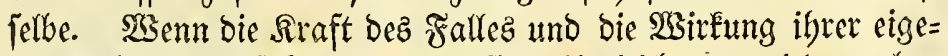

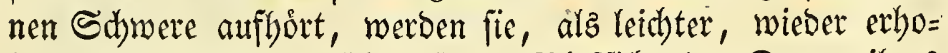

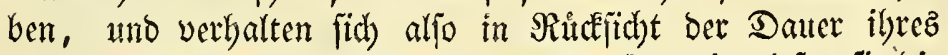
ZCufentbaltes unter bem ssaffer ganz paffin; ie tiefer fie bie

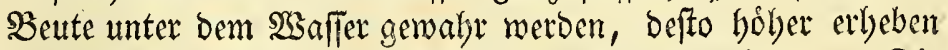
fie fich in bie \&uft, um bie Saraft bez Stoptautcher wiffen fegr gut bie Stoble in ber \&uft zu berect)=

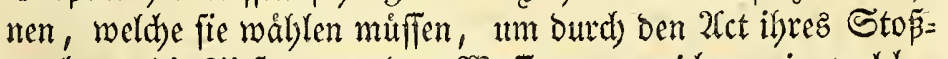

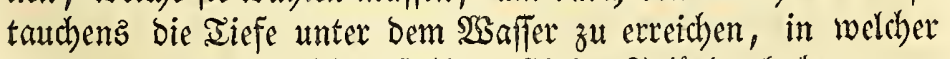
ibre erfebene Beute fich auffält. Einige Saländer haben gegen mich bie Meinung geáupert; bap̃ ber weipse Tólpel fich eben po bod) íber bas $\mathfrak{B a f f e r}^{2}$ erbebe, als er bey Dem Stoptauthen unter bafletbe bimunterfallen molle. Diefe Meinumg ift natiullich er=

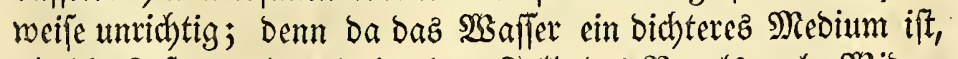

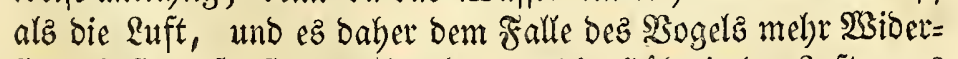

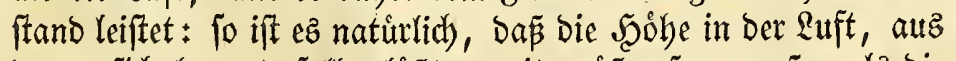

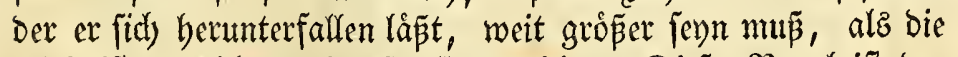

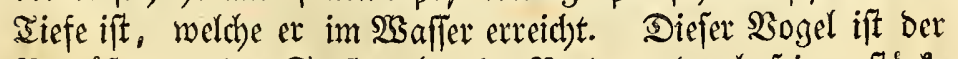

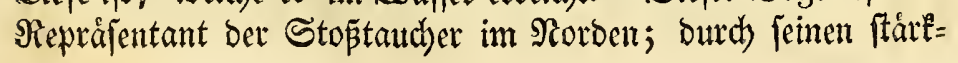




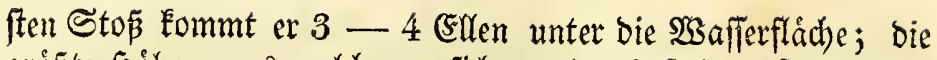
gróste Şoble, auz welchor er fidd aus der Ruff berabfallen lápt,

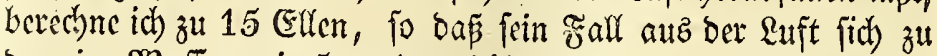

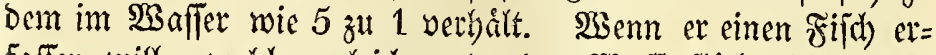

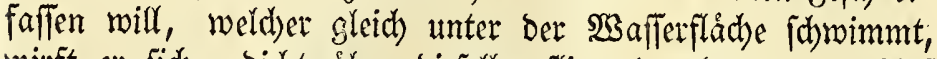
wirft er fich, bicht itber biefelbe fliegeno, berunter. 2fuf

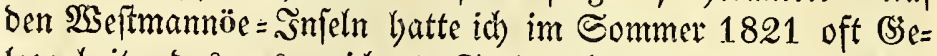

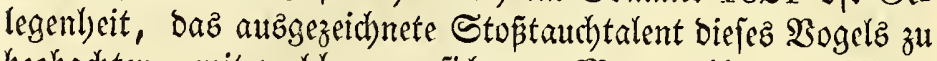
beobachten, mit weldhem er fith vom Morgen bis zum 2rbento bejobaftigte. Daber war id) oft 2fugenzenge, wie er, wenn

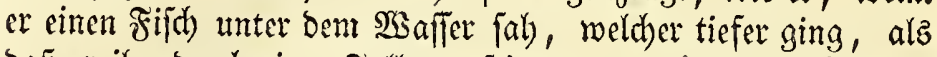

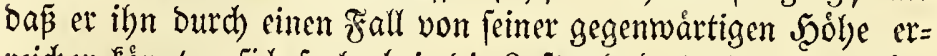

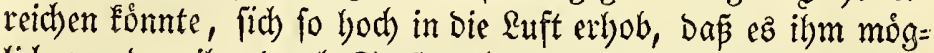
lid) wurbe, ibn burch Stoptauchen zu erreiden; er verfeblte audd wobl am feltenften unter allen ভtoptautchern feine Bente. Die andern, roeldye in biêer Fábigkeit meniger volffommen

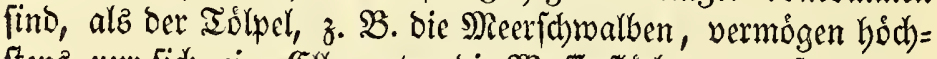

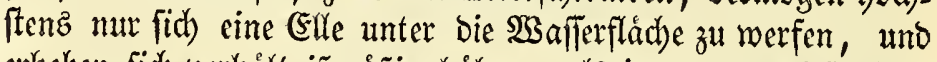

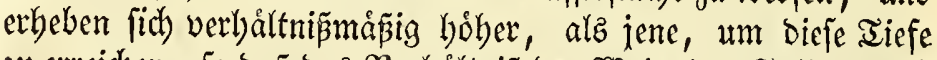

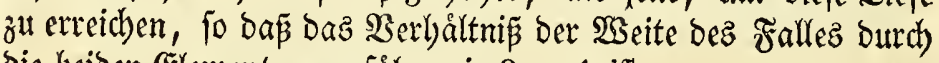
die beiben Elemente ungefåbr wie 8 zu 1 ift.

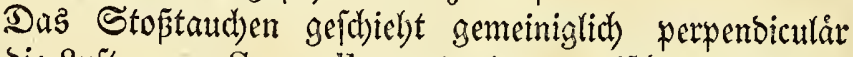
ourdh bie $\mathfrak{R} u f t$; nur Suba alba unter ben norbifdsen Stoptau= dhern vermag nidst allein bie fenfted te zu gebraudhen, fondern

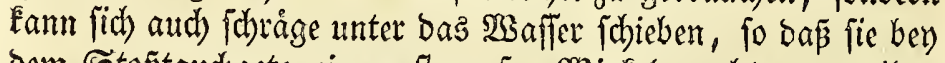
bem Stoptauchacte einen ftumpien şinkel madt; zumeilen, wenn fie bidbt íber bie $\mathfrak{B}$ afferflådbe fliegt, Eann fie, wie ein

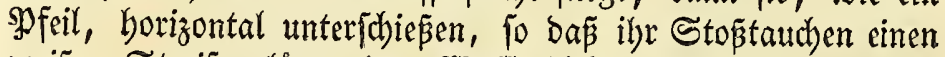
weî̉en Streifen lüngs ber Ssafferfláche berworbringt. Die ůbrigen Stoßtauther ůben nut bas perpenbiculåre Stoß̧taud)en aus, und fommen ungefåbr in berfétben sinie mieber zum 200 fidyein, in weldher fie beruntergefallen find. Niddtz defto meniger

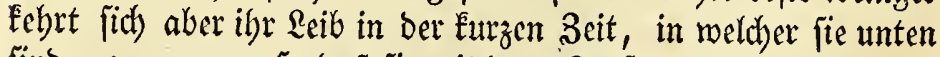
find, ganz um, fo baj fie mit bem Sopfe, mit weldhem fie

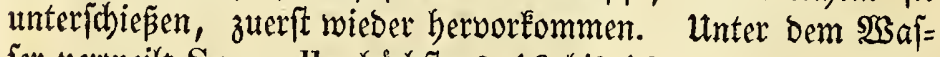
fer verweilt Sula alba bojdfftenz 10 bis 12, und bie andern 2frten 3 biz 4 Gecumben.

Die Stop̧taudher fifchen am liebften im ftillen Ssafifer;

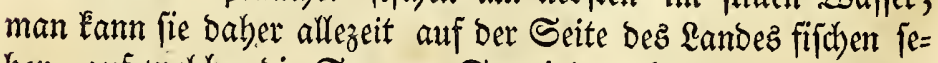
hen, auf welcher bie See vom Seeminbe nidbt beunrubigt wirb.

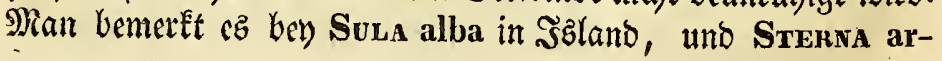




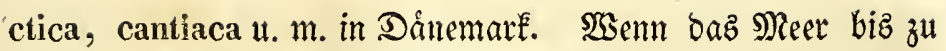

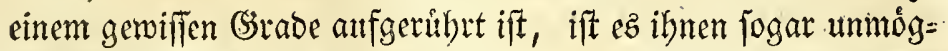

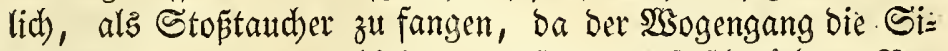
d)erbeit bez Stopez verbindert und feine Jiaft fchwåd)t. Naur Sula alba habe id) fidj fogar in 3 ranoungen -werfen fehen.

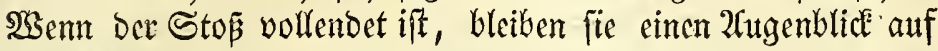
Dem Sasaffer fir beben fich barauf wieber, um ihre Fif heren zu wieberbolen, welches zumeilen umunterbrod)en mebrere Stunden bauert. . Nur

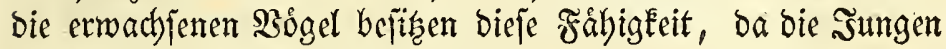
im Flaum nod) nidbt fliegen E⿺辶nnen.

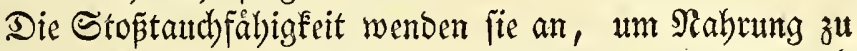
erbalten, nidjt um zu entflieben. Sie ift ilbrer Siatur nady

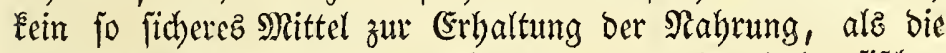
Iaudbfábigkeit; und wenn idh Stenns arctica habe fiffhen fehen, hat fie offter feblgeftopen, als etwas erbalten. Sie balten fich baher am liebften ba auf, wo bie Fijde ber Scaufen find, wo bie Menge berfelben $e \mathfrak{z}$ ihnen leidfter madht, recht zut greifen, und baun an joldhen Stellen, wo bie Zifiche an. ber Sberfláche Des WSafferz fohmimmen. Saber geben bie uiber=

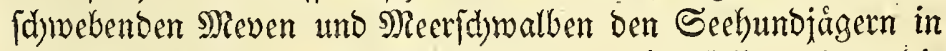

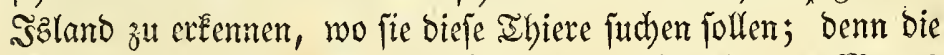
Seehunde jagen bie Eleinen Şáringe vom Şrunde dez Meeres gegen bie Sberflect)e auf, wo fie baun von ben ftoptautdenden

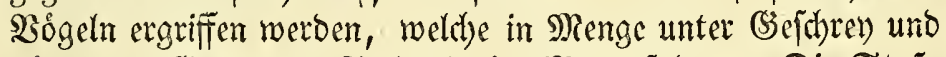
Rårm bem Sange ber Seelyumbe im Meere folgen. Die Stón=taudher find bey biejem Suchen nady Mabrung lieber in (Befelle=

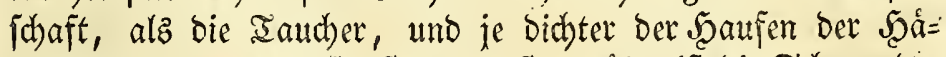

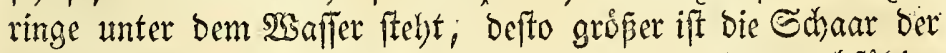

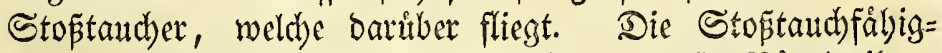
feit ift gemeiniglid) nicht allein zutreichend, biefen $\mathfrak{B o g} g$ eln ilyen Rebenzunterhalt zu veridhaffen; mut bey Sura alba ift bie ráhig=

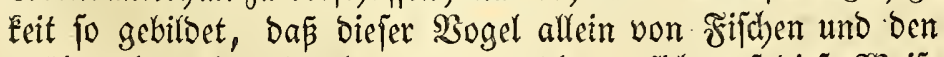

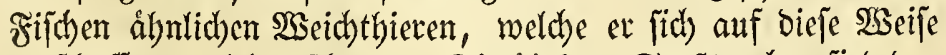
veridhartt, zul leben icheint. Die uibrigen Stoptautcher find ba=

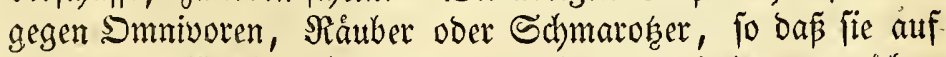

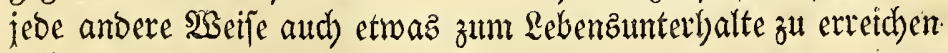
juthen.

Råchjt der Sula ift Sterna der befte Stoptautder, uno

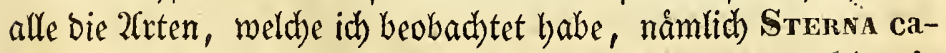
spica, arctica, hirundo, cantiaca, anglica, nigra unb mi- 
nuta, baben fid) auf dieje Şeife verproviantirt. Šn der Stops= taud fäbigkeit gleiden ilynen unter den Meven Larus leucopterus uno tridactylus. Dagegen nimmt fie ab, und veridhwindet bey einigen norbifichen uno zugleidy dánifden Meven, als LAsus marinus, glaucus, argentatus, canus, ridibundus, von welchen bie zwey eriten 2irten nur felten, und bann am meiften $\mathfrak{a m}$ Crcloptenus lumpus z̆t erbalten, bie ủbrigen aber, nadh

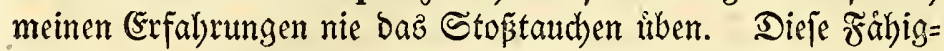

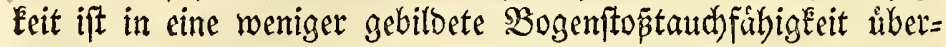
gegangen, zufolge welcher jie fliegend einen Bogen gegen bie Şaflerfláche felbjt machen, um bie fdomimmende Sabrung zu ergreifen, mie Proceldaria glacialis; fie ftopen fich) aber nicht unter. Sie find baber jebr begierig nach 2 noerer Soute. (5i= nige, als Lanus marinus uno glaucus rauben Ever uno Sum= ge; andere, alz Larus argentatus, gehen fogar aufz Irodine

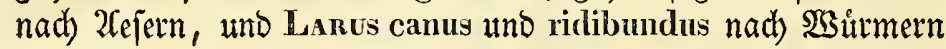
uno Sinfecten auf ben $\mathcal{X}$ eckern, ja alle die genannten, auß̈genommen bie lesten 2 rten, nebmen jogar mit Meergraz, mo= mit ich ibren Magen angefüllt gefunden habe, vorlieb.

Bey den Raubmeven ilt die walbre Stoptaud fábigleit gleid)fallz verid)wunden: idh Eann wenigftens nidht mit (Gemi $\beta=$ beit bebaupten, jemals gefeben zu lyaben, dap̃ fie diejelbe aub= geibt haben; fie ift aber bey ben Eleinern 2 rten, als Lestris parasitica, pomarina und Buffoni, zu einer $\_\mathfrak{u} f$ fffo $\left.\tilde{\beta} t \mathfrak{a} \mathfrak{d} d\right)=$ fábigke it veråndert, burch weld)e, wenn fie fliegende $\mathfrak{B e r}=$ wanbten, als bie Meerfowalben u. a., gezwungen haben, ihre Beute fabren zu laffen, fie fidh bann fentredt gegen bie Erbe ober baz $\mathfrak{B}$ affer mit aubgebreiteten frligeln gegen bas Berlor= ne werfen, und es nod in ber auft ergreifen, worauf fie fich

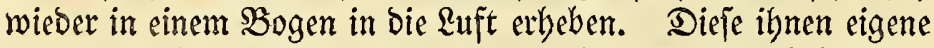
Fåkigkeit ift ein wahrer 3weig Der rechten Stoptaud fåhigkeit,

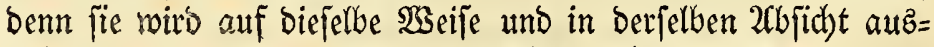
geubt, wie biefe, mur dap die \&uftftoptaudher ibre Beute in ber

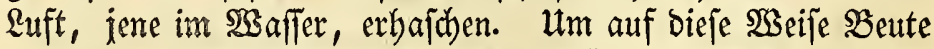

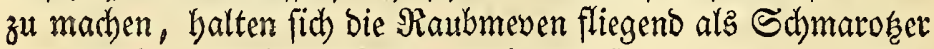

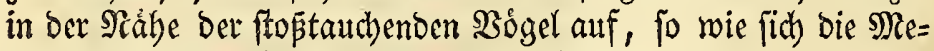
ven bey Den Iaudbern fdwimmend aufbalten, um an ibrem er= morbenen Raube theilzunebmen. Ser Bwed ift Derfelbe, nut

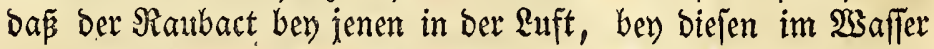
vorgebt. Lestris catarractes hat dieje Făhigkeit jeiner Gat= tungsverwandten ganz verloren; fie áupert fid) bey ibm fpora= 


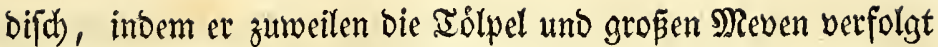

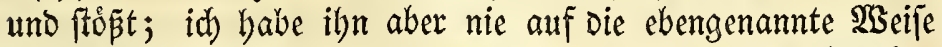
feine Beute erbajchen feben; Dagegen ift er ber gemaltigite $\Re_{R}$ åt= ber unter ben Sduwimmvo̊geln im Norden, uno verproviantirt fid táglid) in Den Bogelbergen mit jungen $\mathfrak{B o g} g e l n$. Die \&uft= ftopitaudb fáhigkeit ift nod) weniger, als bas wabre Stoptaud)er, im Stande, ibre Befiţer allein zu ernábren; fie werden baber oft auf bem Felbe gejeben, no fie SSirmer fuden, und find die årgften Feinde Der Eyer ber Eitoervỏgel und anderer Enten.

Endlich hat die Stoptaudfábigkeit ibren urfprunglichen (Sharakter bey Den Sturmbo̊geln und ben eben genannten Me= ven am meiften verloren, bey weldyen fie nur als ein fidwaches Ueberbleibfel in ber (sigenjebaft gefunden wirb, fid) fliegeno aufs Bzaffer jelbft herunterzuwerfen, um bie barauf jedwimmende Nabrung zu ergreifen. Sie thun biejes gern in einem Bogen,

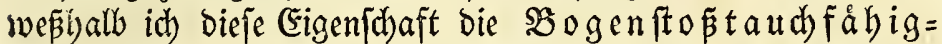

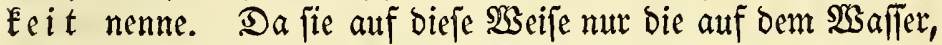

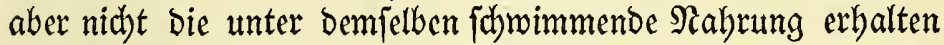
fonnen, fo find fie unter allen 2 sogeln am wenigften lecker in ber $\mathfrak{S}$ abl ilyrer Nabrung, uno nelymen fogar nit Medujen und Eodylearen vorlieb. WBir finden aljo auch bey ben Stoptau= chern baz grabweife Steigen in ber Billung ber Fáabigkeiten

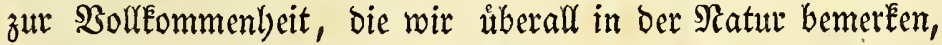

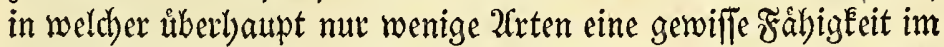
bochiten (srabe ber 2utbilloung bejten, Dagegen bie itbri= gen Befifer berjelben fie mebr ober minder volftommen $b a=$

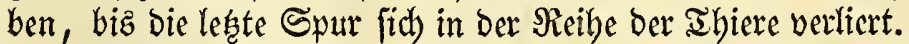

Die Stoptaucher bilben aus vielen parallellaufenden ge=

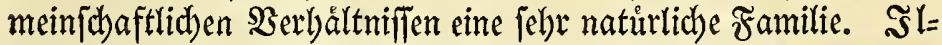
liger bat einen Theil berjelben zu Der Familie longipennes ge: redhnet; er hat aber Sura uno Canso in die Famillie Steganopodes und Proceluaria uno Puffinus in bie Familie Tubimares unridftig gejeft, oa Sula uno Proceldaria in ifren natưlidben Berbáltniffen ganz zur Familie Longipennes, $b a=$ gegen aber Canbo und Pufrivus zu ben wahren Tauthern ge= boren. Sie find alle langfligelig und aubigezeidhnete Flieger. Sie find meiftens Sdymarofer, Siatboogel ober Smniboren unter ben Sdymimmern. Sie baben alle bie (Eigenifhaft, dap fie fid) fammeln, und um (šegenftånbe berumfliegen, weldbe ihre 2utwmerkfamkeit erregen; fie leben in ber zufammengejesten

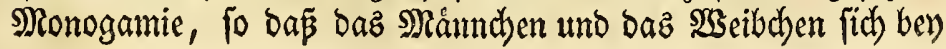




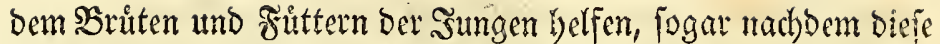
flugge geworden find. Sie bringen iben sungen baz zuttter in ber Speiferóbre, und wirgen es fir fie auf, ausgenommen bie Stenva, weldbe ez im Sdnabel bringt. Das Mannd)en tund 23 eibchen find einamber in ber Farbe vollemmen gleich, auth bifferiren fie nidbt viel in Der Grofópe. Die meiften borealen $2 \mathfrak{t}=$ ten find zum Theil Standwógel in Den norbifchen Meeren. But diefer Framilie geboren gewifíp unter ben tropifd)en (Şattungen: Rhynclops, Diomedea, Fregata umo Phaeton.

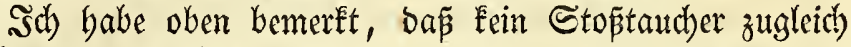

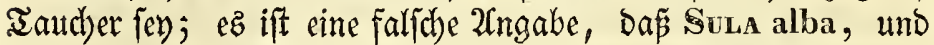

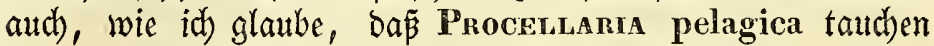
Eonnen; aud babe id biefes ben feiner 2ret ber Meerfebualben, Meven, Raubmeven ober Gturmbógel gefehen; fie vermod)ten nicht einmal, wenn fie angefdoffen auf bem SGaffer fidwammen, zut taudben, und fich baburd) zut retten; fie wurben baber leid)t auf ber Şafferflád)e ergriffen. Namentlid babe ib unter ben vielen Taujenden von Procellaria glacialis, weldbe ich fidnimmen fab, nie einen taudben feben. Utm fo auffallender

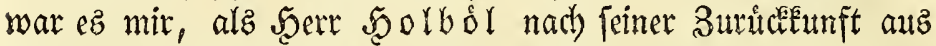

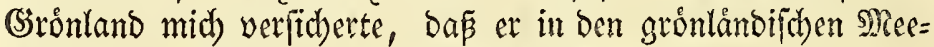

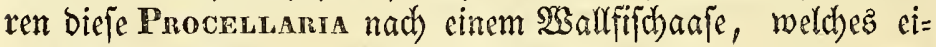
nige Fũ unter Dem $\mathfrak{B S a f f e r}$ lag, babe untertauchen feben. So wiberfpred)end biefe (Erfal)rung aud ber meinigen beym eriten

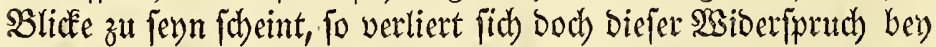
nåberer Unterjuchung. Denn biefer 2uct bey Proceldara gla-

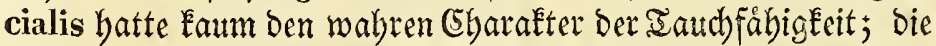
wabren Taucher fuchen erft nad) Siabrung, wenn fie unterge= taudbt baben, und tauchen wobl felten ober nie nad ciner Beute,

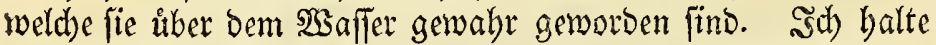
diefez Untertauden bey Procellaria glacialis mebr für ein extraordinåres Befteben, eine fo merthe Naburung zu erlangen, weldhe in biejem Falle unter ber Walferfläche lag, alz fir cine Folge einer reguláren Tauchfábigkeit. So jeben wir ja audb zumeilen Lanus marinus, im $\mathfrak{B S}_{\text {affer }}$ ftebeno, bennab mit ben ganzen Reibe untertauchen, am einen entbeciten Crcloptenus lumpus im Gande zu erbalten, und ilyn anz $\mathfrak{R}$ and zieben, obne

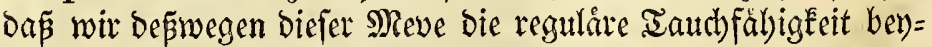
legen. So witblen Convus frugilegus und Tundus merula

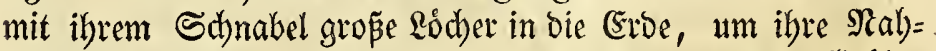

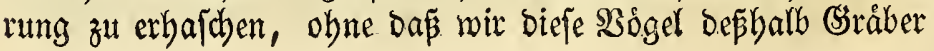




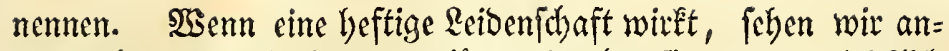

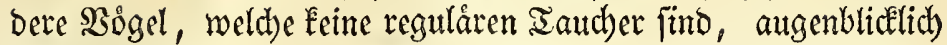
untertaudben, wie ich es fdon von ben angejdyolienen Sumpf= vogeln berid)tet lyabe, weld)e taudben, wenn fie ins : $3 a$ aller fal=

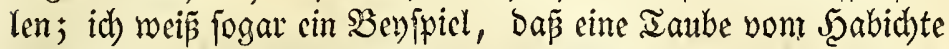
verfolgt, fich unter bas $\mathfrak{W}$ affer gemorfen bat, um fich zut ret= ten, und baburd) ibren 3wede erreid)te, ohne baj ez Ginem bar=

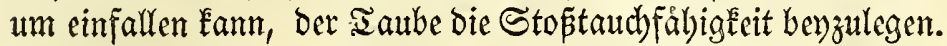

Bey andern $\mathfrak{B g}$ geloronungen finden wir Spuren ber Stoptaudbfåbigkeit und von ben 2 bånderumgen berjelben. Die wahre hat z. $\mathfrak{B}$. Falco albicilla und haliaëtos, fo wie Alcedo

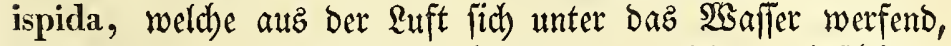
ibre. Beute zu ergreifen vermógen, und wieber unbejdjåbigt

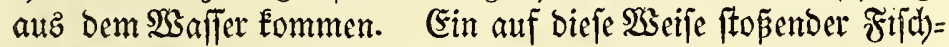
abler wurbe im Serbfte 1819 in einem $\mathbb{R} a d$ sgane in Mnvatn 3

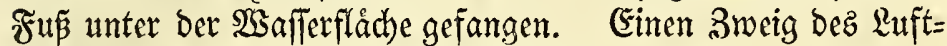
fto

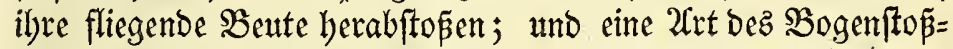
taudhens ủben die Schwalben auz, wenn fie, ủber Stróme ober Ieid)e fliegend, jid) aut bem Fluge gegen bie Şafferflidbe wer= fen, um bie auf Dem $\mathfrak{s a f f e r}$ (d)wimmenden sinjecten zut ergreifen. 
IV.

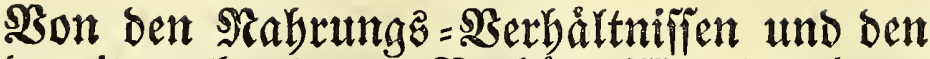 Damit verbundenen Berbáltnifien Der bore= alen $\mathfrak{B o g} g \mathfrak{l}_{+}$}

\section{§. 53.}

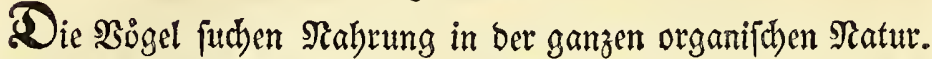

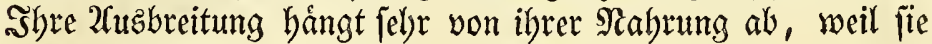

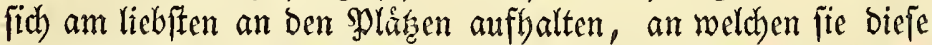
reichlid) finoen, fo wie fidjon im 21 §. gezeigt worden ift. Esz

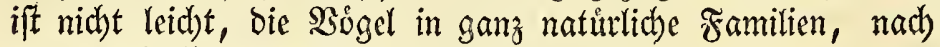

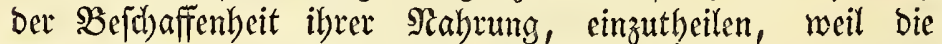

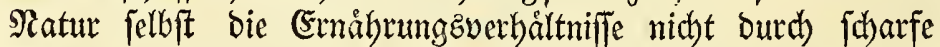
(Sirenzen beftimmt hat, jo baj biefelbe Sogelart oft $\mathfrak{N a l}=$

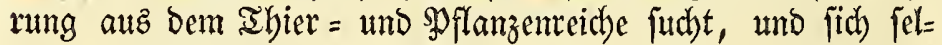
ten an eine Elafie, noch feltener an eine $\mathfrak{I}$ hier = oder $\mathfrak{P f l a n =}$ zengattung oder 2 trt allein hålt. Sie haben zwar cine 2 frt ber Nabrumg, welde fie allen andern vorzieben; wenn aber bieje nicht zu erbalten ift, futhen fie autd biefelbe in andern Besegen= ftánden. Die Unia - und Platypus-2Crten zieben refpectio Fifiche und Sdbaalthiere allem 2(ndern vor; wenn aber biefe nidbt zut erfalten fino, fo nimmt bie erfte mit den Carcer - uno

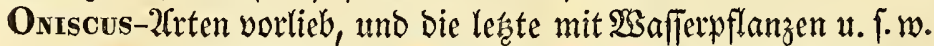

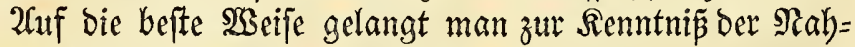

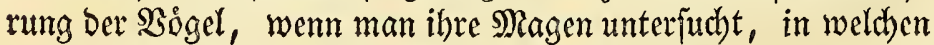
man biejelbe oft unverbaut findet. 2huf bieje $2 \mathfrak{r t}$ bin ich auf verfbiebene intereffante Refultate getonmen. $2(m$ fobmierig=

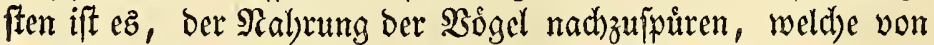
weidhen Imfecten und 2 sirmern leben, weil man in ilyrem $\mathfrak{M a}=$

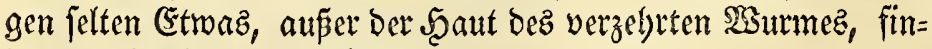
bet, z. B. Wey ben Sdinepfen.

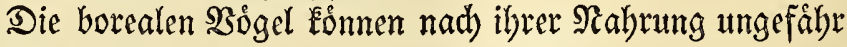
eingetheilt werben in:

1) blo Thiere freffende $\mathfrak{B o g} g e l$, (Aves mere carnivorae,)

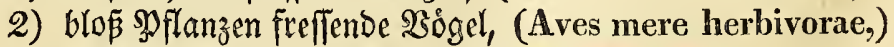

3) Bielerley freflende Bogel, (Aves multivorae,) uno

4) 2alertey freffende $\mathfrak{B o g g e l}$ (Aves omnivorae.) 
Ez ift befannt, daß manche Snjecten von Der Ratur an gewiffe İlere ober $\mathfrak{P f l a n z e n}$ gewiefen find, von welchen fie al= lein leben, und baj fite fterben, wenn fie nicht bieje Nabrung erhalten; aber fo wie eb ůberfyaupt felten ober nie ber Fall un=

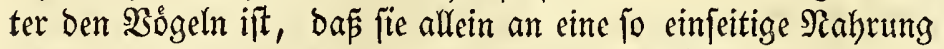
gebunden (aves univorae) find: jo balten fidh aud bie fijd er felten ober nie zu einer uno berjelben Fijchart ober (s)attung. Die beften Iaudber, weldhe alfo bas frebejte Sermógen baben, unter mebreren 2Crten bie zu wáblen, welche fie am liebften fref= fen, haben zwar zuweilen einen Fif $\mathfrak{c}^{2}$, welchen fie vorzinglich ju= d)en; wenn biejer aber nid)t zut erbalten ift, nefmen fie mit an= bern 2irten vorlieb. So juchen bie 2arten Carso am liebften Cottus scorpius, verproviantiren fich aber boch auth, wenn fie bey füpen $\mathfrak{B a f f e r n}$ bruten, mit ben Crprasus-20tten; Cephus grylle futht am liebften Buevrius gunellus, uno Monnow fratercula Amionvtes tobianus; idh labe fie aber and) Cucpea sprattus verfochlingen jehen. Die Colvmbus-2frten geben Samo den Korzug; idf fab aber aud Conymus glacialis, Cottus uno Pleunonectes, und Colymeus rufogularis die Clupea - 2trten fifhen; Mergus sercator zieht Gasterosteus aculeatus vor; ich fand aber audh andere Eleine Fijche in feinem Schlunde; Sula alba fript am liebften Şáringe; be= gmigt fich aber aud mit Dintfifichen; Andea cinerea zieht den

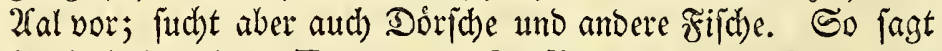

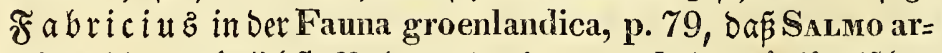

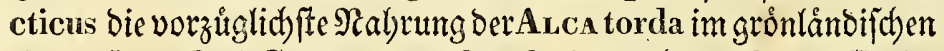
Reere fey. Dã Colymbus rufogularis, nach dem Beugniffe bie= fes (Selebrten, (5ruftaceen frefle, babe ich eben fo wenig er= fahren, als dap Aras boscas Fijhe fuche. Die wahren Fifher nebmen eben fo wenig, alz bie wal)wen Raubuogel, unter Den Segetabilien ihre Naburung, und fibeinen bieje nicht ver= bauten zu konnen. Es ift baber jebr jelten, daś bie So̊gel,

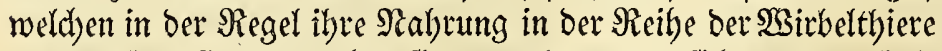
angemiejen ift, zugleich spflanzennabrung zu fich nebmen foll= ten; Dagegen finden wir oft, baß bie 2 sogelarten, weldbe fich

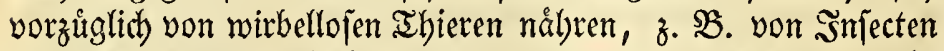
und $\mathfrak{W u i r m e r n}$, zugleid) ibre Slabrung auts Dem Sflanzemeidbe nelymen, z. B. bie 2fiten Tordis, Strunus. (5z giebt zmar einige Injecten freffende 2(rten, weldhe fich allein an bieje hal= ten uno Eeine SPflanzennabrung fucben, $\mathfrak{z}$. $\mathfrak{B}$. Avthus, Faum

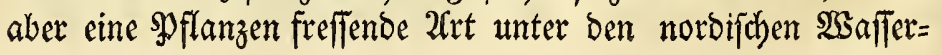




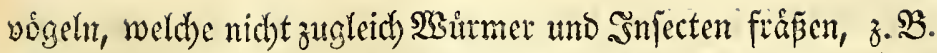
dic 2 treten von Poncerps, Crgines, Anas, Limosa u. f. w. Das Sthmeelubn ift alfein \$flanzen frefiend.

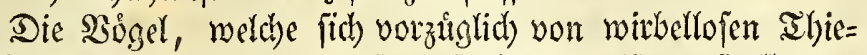

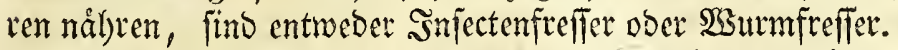

Dieblo śsnfecten freffenden $B$ ógel gehoren al= lein zu ben Singuogeln, uno von ben norbijt)en $\mathfrak{B o g}$ geln zü Den (3aftungen Motacillia, Saxicola troglorlytes, Antrus und

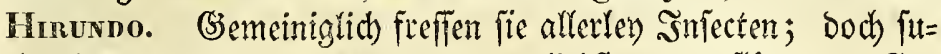
dhen Motacilia und Hrnundo am liebiten zmenfliggelige, Ca-

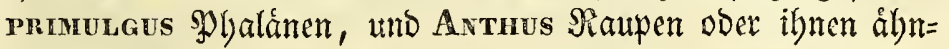
lid)e Şinmer.

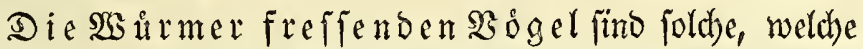

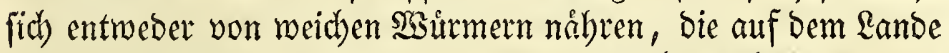
ober an fumpfigen Sertern, oder von Sedaalmürmern ober bartfdhaaligen Eruftaceen, bie bejonders im Mcere gefumben werben. Su benen, weld e weidhe Şatrmer futhen, ge= borten viele Sumpfudgel, z. $\mathfrak{B}$. Haenatopus ostralegus, bev (iid) vorzliglid) vom Stranbregenwurme nåhrt, und nicht, wie fein siame 2Cufternfifd)er unnid)tig bezeidnet, 2uftern ober andere Sdjaalthiete mit bem Sdynabel offnet. Sie haben bieje SBildung ibres Schnabets, um mit Demielben im Sambe nad'

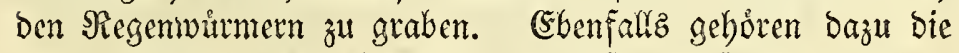
2irten von Calinhis, Charabrius, befonder' hiaticula, Totanus, Vaneluus, Scolopax, Phalanopus, weldye lefetere audi) zuweilen Mideken uno andere Smecten freffen. -

Bu ben Berfdingern ber Sda althiere und anderer bartfialiger meerinfecten geboren mu wenige Sumpfoógel, namentlid) Trivga maritima, weldye alleir

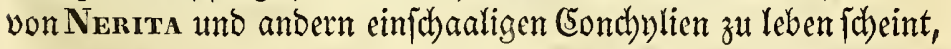
bie fie auf Den Sdheeren findet; aber viele Sdhwimmwoigel, $\mathfrak{n} \mathfrak{a}=$ mentlid) Merauuss, welche meiftens von (Enuftaceen lebt; bie 2frten von Platy pus, weldhe vorzitiglid im Meere Fleine Schaal= thjere von Mrunus, Venus, Nerita, audd yon Oniscus und

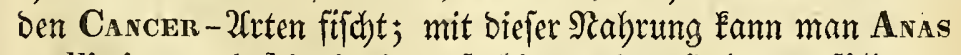
mollissima und histrionica oft bis an ben Şals angefiulllt an= treffen; mur in Der Srützeit bey Den füpen 2 Baffern begnitgen

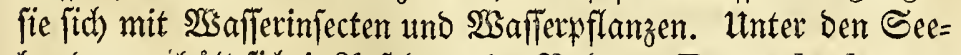

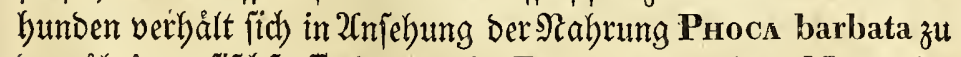
den ůbrigen fifchfreilenden, wie Platypus zut den Mergus2rten; benn biefer Seebunt befapt fich nie mit Fifichen, fon= 
Dern ich fand in feinem Magen mur Eruftaceen, Oriscus psora, Cancer homaroides u. m. Einige Sumpfodgel nebmen ilyre Sabrung fowohl unter ben hartfdyaaligen, als weid)en ŞSürmern, z. B. Die 2irten von Numenius und die meiften'Tringae, Strepsmas, ja, fie fuchen fogar sjoflanzennabrung, als Charadrius pluvialis, welder fith im Seerbfte mit den $\mathfrak{B e e}=$ ren von Vaccinium uno Empetrum nigrum auf den izlándi= id)en Sceiben nåbrt. Sm Magen der Lryosa melanura fand id')

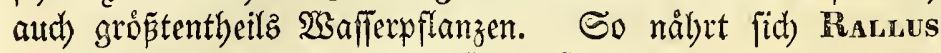
aquaticus aud zumeilen mit \$oftanzenfutter.

Die Bogel in verjdjedene (Şuppen einzutlyeilen, je nad)= Dem fie Nabrung im füpen $23 a f f e r$ oder im Meeve furden, ift barum nicht móglidy, weil ez keinen Sd)wimmuogel giebt, wel=

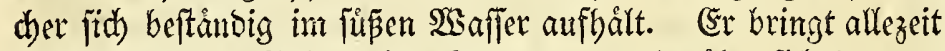

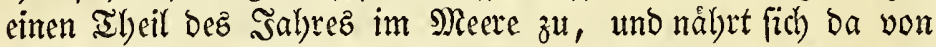
ben \$roducten befielben. So futchen bie Podrceps-2fiten in

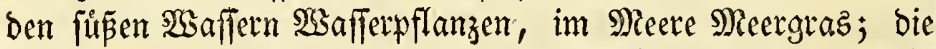

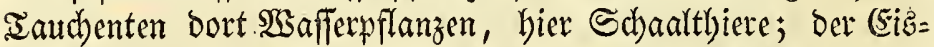

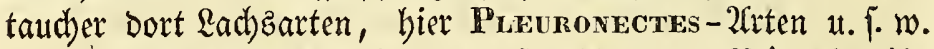

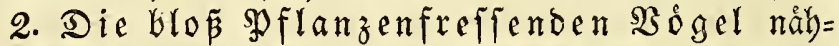
ren fict) entweder allein mit ber Frrucht ber \$ুllanzen, z. B. bie jaamenferefenden 2frten von Loxia, Enbertza, Frivgidua,

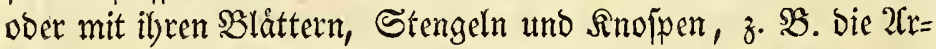
ten yon Lagopus, Podiceps, Fulica, Aras, Avser und

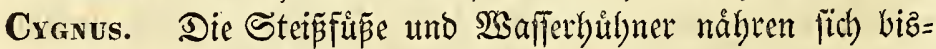
weilen nid)t von Fifichen, wie man gemeiniglid) glaubte; idh fand biefe nie in ibrem Magen, fondern bloz $\mathfrak{z}$ afferpflanzen, be=

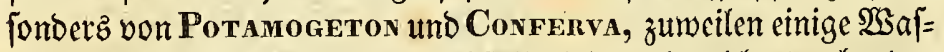
ferinjecten uno Wsiurmer; gleidhfallz leben bie nicht tauthenden

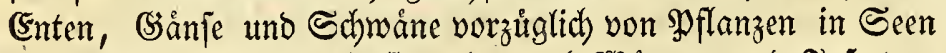

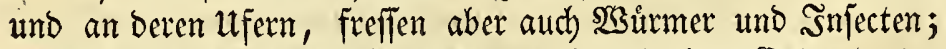
bagegen fand ich nie Fifthe im Magen irgend einer Ente.

3. $\mathfrak{B i e l e r l e y ~ f r e f f e n d e ~} \mathfrak{B} \dot{o g e l}$ nenne idj diejeni= gen, weldhe zmar eine beftimmte Nabrung baben, wie bie vor= bergebenden 20btheilungen, mit weldber fie abwedbieln; bie aber

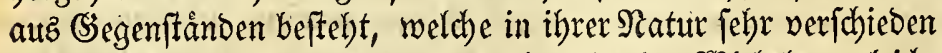

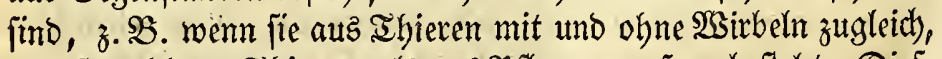

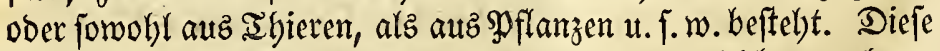
2rten fino nod' nicht Omnivorae; Denn ob fie gleid) ganz bete= rogene Dinge freffen, fo find biefe bods nodb beffimmter 2 (rt,

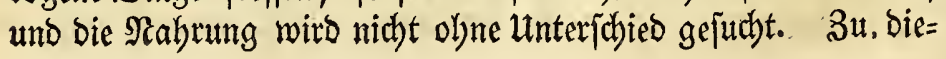




\section{$-289$}

fer 2Cbtheilung záble ith eben fowohl bie Sögel, welde fith von hobkeren und nieorigeren Ibieren zugleich, wie von abieren uno sp flanzen, uno alfo von veridbiebenen Raturreidjen ernåbren; Denn Bevípiele von biejem fonmen weit háufiger vor, als von jenem. Sab habe jhon oben einige Aves multivorae genannt, und biefe werben háufig im Norben gefunden. Die 2liten'Tun-

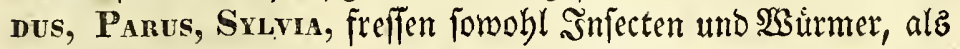
Saamen uno Beeren, Charadruus pluvialis $\mathfrak{B u i r m e r ~ u n d ~}$ Beeren, Raulus aquaticus, die 2frten yon Poniceps und Fu-

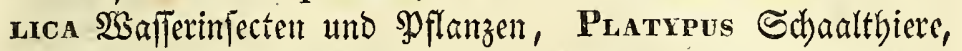
Eruftaccen und 2 gafferpflanzen, Axas, Axsen und. CygNus 2Safierpflanzen, Bsetraide, Snlecten uno WSirmer; bie Sterna arctica friēt fijifhe, als Clupea sprattus, Gasterosteus aculeatus, Syngmathus acus; bod) babe id)

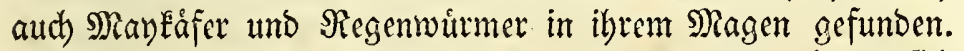
Unia troile, Lanus tridactylus uno leucopterus nádben fid vorzuiglid) von Fifden, begnigen fid) aber auth mit (Eruftaceen,

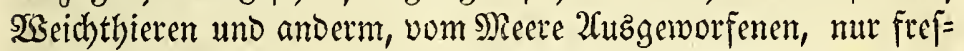
fen fie Feine. Mebufen, weldye Kein Bogel, meinez Ssifjenz, aut=

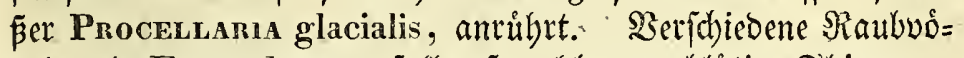
gel, alz Falco buteo, falfen fowobl warmblútige Illiere an,

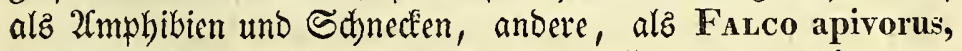

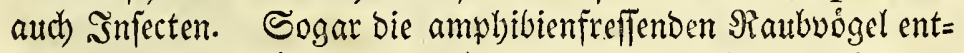
balten fich. Der Rrỏte; zwar tóbteten und verzelyrten meine ge: zăbmten FaLCo albicilla und buteo biefellben, wenn fie hung. rig waren, fie fpieen aber bie Stitce gleid) wicber aub.

4. Arterley freffende $\mathfrak{B}$ ógel ober Smmivoren nente

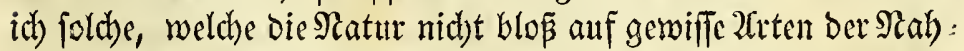

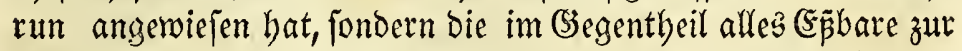
Beute machen, wenn ez mut verbaut werben Kann. Sie find ge:

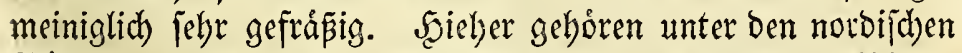
Bógeln Convus corax, weldher lebendigen uno tobten I Ifieren nadbftellt ; Enar, Fifiche, Schaalthiere aller 2(rten fript, bie er in

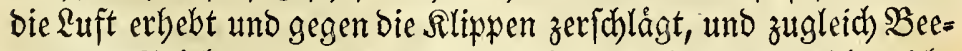
ren uno Fruidhte verzebrt; ferner Diejenigen Meven, weldbe nidbt eigentliche Stoptaudber fino, alz Lanus marinus, glaucus, argentatus, canus, ridibundus, won welthen bie beiben erf́ten franke

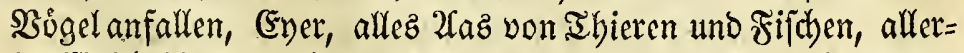
Ley $\mathfrak{B s e i d b t h i e r e , ~ w e l d h e ~ a m ~ S t r a n d e ~ t r e i b e n , ~ v e r z e h r e n , ~ j a , ~ w e n n ~}$ Eeine anbere Mabrung zu erbalten ift, fogar ibren Magen mit Meer= gras anfiuflen. Die britte 20rt babe idy in Dảnemart fogar auf 
2refern von Sauztyieren angetroffen, und fie gebt mit ben beiben

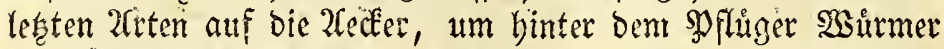
tmo S̃nfecten zu fammelin. Son ben Lestris-20rten ift catar-

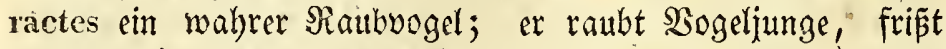
todte Fijche und andere 25 cichthiere, parasitica und pomarina jagen anderen Sjogeln ibre Fild abe fitllen ben. Eyern ber Enten nach, uno fuchen sinfecten und Şümer auf ben Felbern, Procellanda glacialis verichlingt allerley fette Spei=

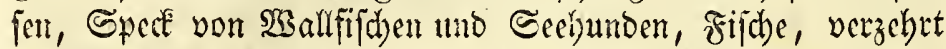
Cruftaceen und Medufen, uno in ben Mogelbergen fogar Roffel= fraut. 2rub jener thranigen Speife entfifebt in fanem Sorma= gen eine Fluffigfeit, weld)e er Ellentucit gegen feine Serfolger ausipeyt.

Diejenigen $280 g d$, weiche von eincr cinzigen (3attung ber Sabrung leben, baben such eine autsgezsid)nete Fåabigét erbal=

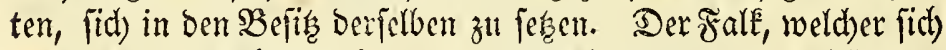

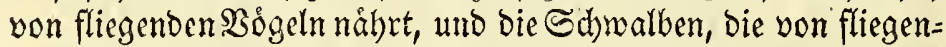
Den Snfecten leben, fino gute Flieger. Die Scharben uno Saucher, welche fich bon tieffdwimmenden Fifden ernålyren, find gute Taudber. Einige Srnitgologen bebaupten audb, baß unter ben Stoptruchern gemiffe 2rten eine beftimmte fifdhnalyrung ba= ben, oaj̃ namentlich Sterna aretica fich allein von Gasterostwus aculeatus nábre. Sath habe jeood) meine Erfabrungen gegen dicie Mcilumg Dargeftellt, und, ba bie meiften Stop̈tau= d)er melyr ober weniger Smnivoren find, fo konnen wir aud) a priori willen, bap̃ bie Satur dieje nicht anf eine einzige 2(rt ber গabrung beichrånkte. Soll bie Satur namlich nicht mit fich felbit im $\mathfrak{S i b e r i p r u c h e ~ f t e b e n , ~ f o ~ m u s ~ e i n e ~ a u z g e z e i c h n e t e ~} \mathfrak{F} \hat{a}=$ bigkeit zut Erlangung Der Nabrung im birecten Berbåltniffe zu einer gewiffen 2frt berfelben fteben, welche fidwer zat erwerben ift, benn fonft wurbe eine siegel in ber Natur fejtgefeft fenn;

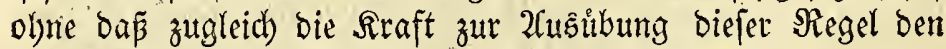
sndivibuen mitgetbeilt wàre. Die Bogelarten, beren $\mathfrak{L}_{e}=$ ben allein von einer gerwiffen 2(rt ber Sabyung abhinge, und

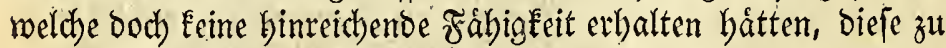
erwerben, mifften verbungern, und die 2 rten auf biefe Siseife burd) einen phylifden Mangel untergeben. (Eine foldhe unre=

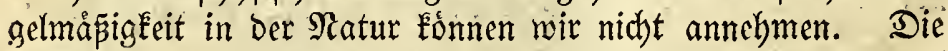
Ihjere fino von ihr mit Sorgfalt, und nidht befpotifh bebandelf worben. SBenden wir biejen allgemeinen Sas auf biefen einzelnen Fall an, fo baben bie Stoptaud)er mur eine jow wache Fábigfeit, 
unter Dem 2 affer Beute zut machen, und biefes Element ift Daz, in weld)em fid bie Fijale in ber Regel aufbalten. Da fich nun

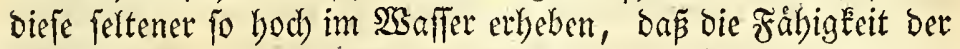
Stoptaucher zurcicheno ift, fie dafelbit zu crreichen, fo berubt es ganz uno gav auf einem Sufall, wenn ein fitostaudbender Bogel einen fisich erreichen forl, und cs tann melyere Tage, ja viel= leid)t $2 \mathfrak{s o d}$ en, bauern (aubgenommen bey Sura alba), bejoni Ders, wenn bicie Fijebrabrung abfolut in einer gewifien $2 \mathfrak{r t}$ be= fteben follte. Woblte man Daher ammebmen, dapip die Stoptaut= cher lith allein von Fifden follten nábien Eommen, fo ljiepe bies, ibie Exiftenz und ilyr Reben vom Bufalle abbangig machen. Sben baber find afle Stoptaudber, wie oben gefagt, Smmivo= ren, und zwar fo viel melsr, je weniger fie im Etande find, zu ftoptauchen, fo wie umgekelyrt bie @durwimmoogel, weld)e bie be= fien Iaucher find, fich meiftens an eine 2art von Fijchen balten.

Im Norben wetden mel)r. Baffer = und Sumpfoogel, als eigentlidse Ranbuogel gefunden; Denn jene nebmen ilyre vol=

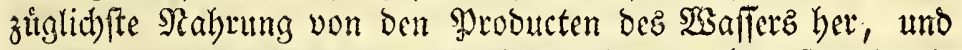

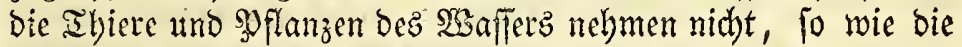

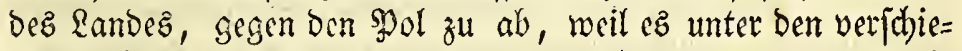
Denen Graben ber Breite cine weit gleidere Semperatur, alz Die $\mathfrak{a}$ ft, lat, und barum ein paffender $2 \mathfrak{d}$ fenthaltsort für Thiere unb Mflanzen fenn Eann. Daber find bie Bogelarten am băufigften im Morben, weldhe sifiche uno andere Meertbiere freflen.

Da Sslumb eine ziemlic) inpiige Begetation bat, fo bejift biefe sniel aud mebrete Trten, welde allein ober zum Ihbeil von

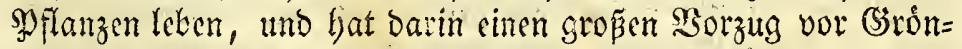
land; bie wenigfren find bie ?tren, welche alfein von Lambin= fecten leben, namentlid) verfchiebene Singwógel, ba bie Menge ber Snjecten gegen den şol fely abnimmt. Diefe bobe Breite

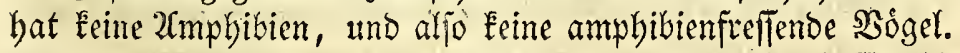

Nirgends findet man in šland die snfecten freflenden ober zum Ibeil Snjecten freflemben siogelarten biefer Snjel håu= figer in Snbividuen, als̈ bey Miyvatn, weil biejer Lanbjee eine fo auperoroentliche खenge zwerifligeliger snjecten bat, baj er von ibrer Rnwefenteit dafelbit feinen Namen erbielt. Die Mú= den bedecten bie 11 fer bes Sees und oft feine Sberfläbe. Nad einem Sturme Eann man in Den 2 ejern Der Nheken biz ait bie Ferjen waten; ihre Śbroárme bebecten augenblictich bie Rlei= Der vom Ropfe bis zu Den 3eben, uno inre Menge bat midh zil= weilen im atthmen gebindert; fo bas id, um atbem zu fdodpfen, 
mein (Gejicht mit einem Flore bebedéen, ober mich auf bie Frbe nieberwerfen mustte. Bon Mueken verfolgt, laufen zumeilen die

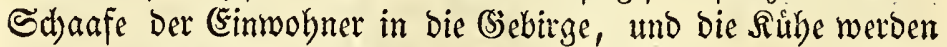
mager, indeflen bie wilben Bógel, weld)e bajelbft in Renge find, bon ifnen fett werben. Motaciula alba, Saxicola oenanthe, Anthus pratensis, die fleinen Phalaropus, fammeln diefe Nahrung von ber $\mathfrak{B a f f e r f l a ̊ c h e ~ a u f , ~ b i e ~ E n t e n ~ f a u g e n ~ f i e ~}$ butch den Sd)nabel ein, und jelbit Şaufen von Numenius phaeopus und Lestres parasitica fudben fie auf ben Freldern.

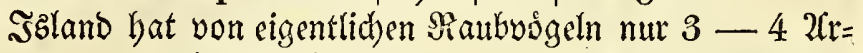
ten, von eigentlidhen Fifd fieflern 16, von Sdaalenveridhlu= dern, weldbe von bartichaaligen 2 burmern uno von Gruftaceen

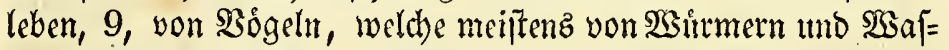
ferinjecten leben, 16, von Bogeln, weldbe blop Ranbinjecten ju:d)en, 5 , von benen, weld)e gróptentbeils ober allein von \$flan= zen leben, 19, uno von Denen, weld)e Die meiften epbaren Sub= ftanzen freflen, 10 2rten.

Die Bogel fuchen am liebften ibr Futter bey Tage, uno find aljo im 2algemeinen Iagoógel; einige Rautboigel madben am liebften Beute in Den Morgenftunden; die meiften andern fuchen ben ganzen Tag hiber nad, Salurung, Denn ich habe bey ben Ílpeln, Meeridwalben, Neven, Rummen, Sdbarben, Iaudbenten $\mathfrak{u}$. m., Eeine gewiffe Tagezzeit bazu bejonders be= ftimmt gefumben. Die Sturmoogel, fomofgl Proceldaria glacialis, als pelagica, find auth volftommene Tagoigel. Da= gegen find die Sturmtaudher (Pufrinus) am meiften $\Re a d$ t $=$ vógel; ob fie fich gleid) audh bes నagez nad Nahrung um= felben, fo find fie bod, wie einige Enten = und Biegenmelter, am meiften in ber Dámmerung in Berwegung.

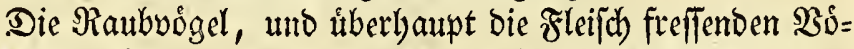
gel, funnen långer bungern, alz die \$Jlanzen frellenden; aber auch grópere Portionen, als biefe auf einmal verzebren. Sc)

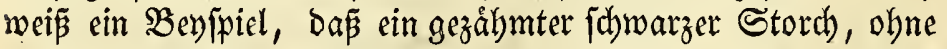
bavon angefodten zu werben, $10-12$ Iage hungerte, weil er nichts 2(noeres, alz Fif d)e genief̃en wollte. Nein gezálymter STrix nyctea worlte zulest nichtz, alz lebende Boggel freflen, uno ba idh inm bicje nidht veridhaffen fonnte, hungerte er 24 Iage, obne bas Mindefte gefreffen zu baben, ebe cr ftarb.

Die $\mathfrak{B o g}$ gl freflen überbaupt viel und oft, wenn Nabrung zu haben ift; bies ift eine Folge ifres gefdminderen 2 themzu= gez, ihrer ftarken Slutcirculation uno ber bamit in Berbin= 
bung ftelyenden gefdrminderen Berbanung. Der Stieglife und

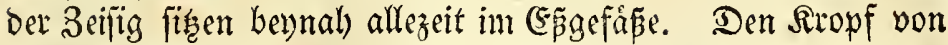
Tetrao Islandorum fand ich) mit אnoppen uno Bláttern ange= fullit; die Sylvien uno Meifen bịpfen beynaly ben ganzen Tag

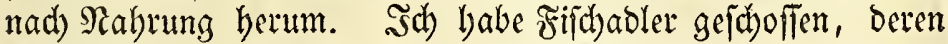

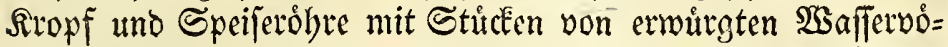
geln angefüllt waten. Die Eiberboggel und andere Saudhenten

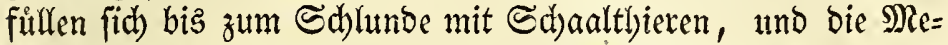
ven, Gdarben uno Iaudber verjolingen fo grope Fijade, daß ber Schwanz berjelben in ber Speiferobre ftedft, bis ifhe vor= bern Sheile im Magen berbaut werben, fo wie die Seehumbé vor Phoca vitulina, annellata und groenlandica, weld de fid bis an ben Sd)lund mit Cuupea sprattus anfiullen. Suna alba uno Stersa arctica fiebt man ben ganzen Tag ftoptautben. Die Magen von Podreps uno Fulica fino beynal) immer von Şafferpflanzen ausgedelynt.

Diele $\mathfrak{B}$ ogel trinken nad) bem Freflen offter ober feltener; bie Fleifh freffenden weniger, alz die \$flanzen freffenden. Die,

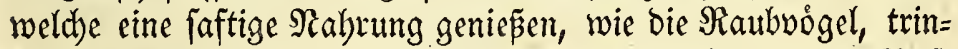

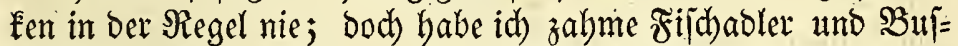
farbe gehabt, weldbe in ber (Gefangenflhaft gern tranken. Die Sdyimmoógel bringen oft fdrwimmeno ben Sdhabel ge= gen bie $\mathfrak{W a f f e r f l a ́ c h e ; ~ d i e f e s ~ i f t ~ a b e r ~ n u t ~ c i n e ~ ( S e b a r b e , ~ u n o ~ f i e ~}$ trinken bey weitem nicht jebesmal, wenn fie biefes. thun. Sal= zigez 2 Bafler befommt ihnen eben fo gut, alz fitzes. ZClle Sdynimmoỏgel trinten, indem fie $\mathfrak{S a f f e r ~ i n ~ b e n ~ S d h a b e l ~ n e l ) = ~}$ men, uno ben Sopf etwas zuruedeugen. (Einige 2rten, wie bie Tauben, pumpen bas $\mathfrak{B}$ affer hinein. Id erinnere mich nicht, jemals irgeno eine 2art Sumpfoogel trinken gejeben zul haben; vielleidbt pumpen fie bas $\mathfrak{S a}$ afper in fied, wie die Tauben, in= bem fie mit ihrem langen Sdhnabel die Moráfte doer das utfer unterfutchen.

\section{§. 54.}

Die Bo̊gel faften ibre Sabrung gewoobnlich mit dem

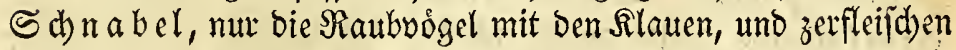
fie mit bem Schnabel. Dáp Cuculus canorus jomohl zumei= len auf SBogel nieberjhlage, als aud alsoann feine Beute mit ben Slauen eigreife, fo wie bie Raubvogel, ift eine vollig fi= d)ere Erfahrung, weldhe im 2luguit 1825 in ber (Segend von

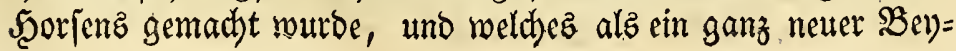


trag zur Dekonomie biejes jonberbaren Bogelz, eben jo intex= effant ift, als es bie allgemeine Sage bez gemeinen Mannes in

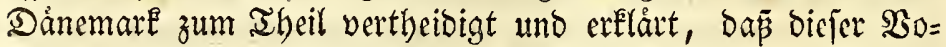
gel im Scerbfte in einen Sperber verwandelt werbe. Dem ein

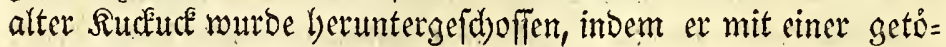
Deten Emberiza citrinella in ben ßlauen flog, und auf feinen

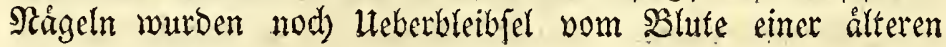
Beute gefunden.

Sie gebrauden ihren Sd, nabel zum Ergreifen und $3 \mathfrak{e r}=$ backen, nidht aber zum Sauten, und bie Niahrung wiro entwe=

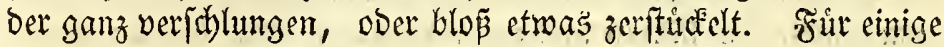

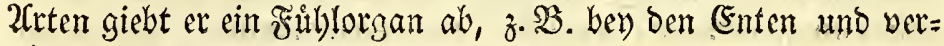
fobiederen Sumpfodgeln, als Recurvinostra avocetta, HaEmatopus, Totanus, 'Tringa u. m.., weldhe dutrdh) Seitlfe def=

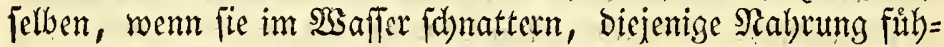

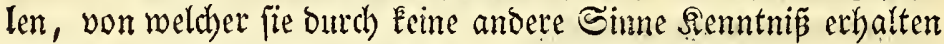

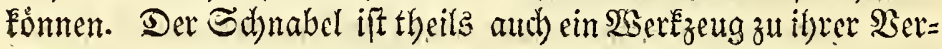

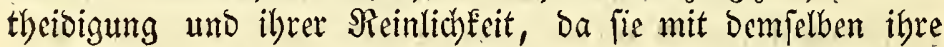
Febern zuredtetlegen, weldhe beum Baben in 1 tnorbming gefom= men fint, und von ibrer Fettorúfe bie Fettigkeit holen, mit weldher fie ihre Federn Durdyziclen, bie den Sdjwimmboigein

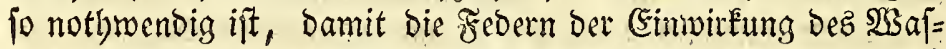
fers wiberfteben. Durth Sallfe bez S(d)nabets bringen aud gewifife 2feten, z. \$B. von Unua, Alca, Mormon, und alle Singuigel, ilyren sungen Futtêt.

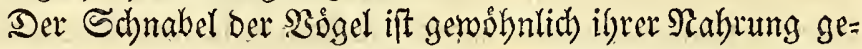
mås gebilbet. Die, Deren Sd)nabel am (Enbe mit einem $\mathfrak{5} \mathfrak{a}=$ fen verfeben ift, nábren fid) gern von lebendigen (Segenfitån= Den, weldhe unter bem Ergreifen Miderifand leiften. Der $5 \mathfrak{a} a=$ ken am Sdanabel von Pufrinus, Carbo, Lanus, Lestris,

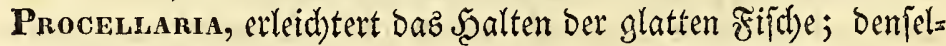

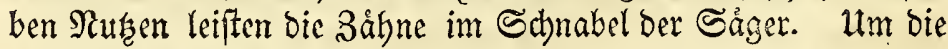
Siraft bes Sd)nabelz zu verftårḱten, und eime grope $\mathfrak{B}$ entte zu

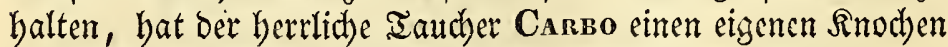

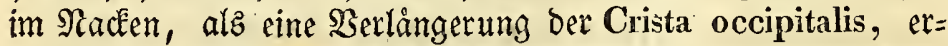

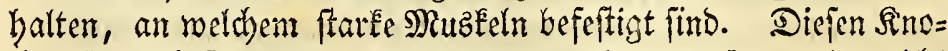
d)en fand id jowohl bey cormoranus, als graculus, aber nid)t

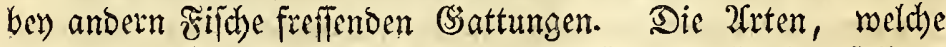
mebrere Fif che anf einmal fangen, uno jie alle fefficalten jollten,

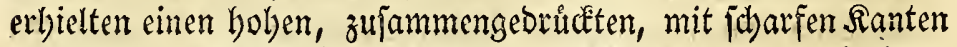
verjésenen Schnabel, als Alca, Monuon. Diejenigen, 


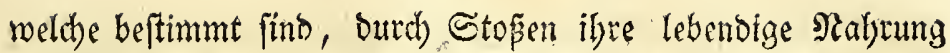
zu ergreifen, haben einen langen, barten und pisigen Sdynabel, wie bie 2 Irten von Crcona, Aroea, Hammatopus, Sula und STerva; autd haben die Taudder und Qunmen einen ålan=

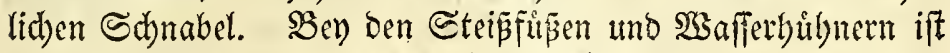

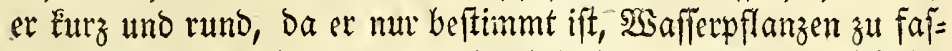
fen. 2fuz ber Billoung bez Edynabels bey ben Enten, Şånjen

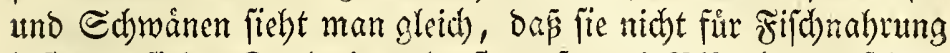
befitimmt find. Der breite, abgefitumpfte, mit Blättchen veriehene

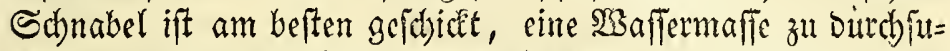
dhen, uno mit ben Blättchen bie Schaaltbiere uno SBsirmer auf= zufangen, welche Darin gefunden werben Eonnen. Sin etwas analoges Fangwertzeug zut einer ábnlichen Nahrung Gat ber ei=

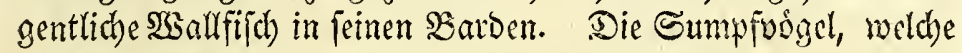
weiche und tiefe Steften nach \$surmern unterfuthen follen, $\mathfrak{b} a=$ ben einen langen und weid)en S(b) nabel, wie Linosa, Totanus, Tringa, Scolopax uno Phalaropus; $\mathfrak{y}$ arter ift er bey Numenius, weldher attd) Sibaalthiere friêt; einen kurrzeren Gat Charadrius vanellus uno Strepsilas, welder leagterer mit jeinem harten uno etwas in bie Scoblye gebogenen Sănnabel Steine umbendet, um $\mathfrak{R a b u m g}$ zu fublen. Die Snjecten fref= fenden Singuogel haben einen fpiten, Dưnen Schnabel, als Saxicola, Motacilia, Sylvia, Avthus, und zugleich cinen weiten $\Re$ adben und fteife Mundhaare, ween bie Infecten im Fluge follen gefangen werden, wie ber Caprinulatus und Hinundo. Die Saamen oder Pflanzen freffenden gaógel ha= ben einen futzen, dicten uno ftarken Sdhnabel, wie 'Tetrao, Loxia, Emberiza, Fringilla; etwag långer und fpi fer ift ex bey Denen, weldbe von Salfecten und SGeeren zugleid) leben, als bey Sturnus, Tundus, Ampelis, Parus; der

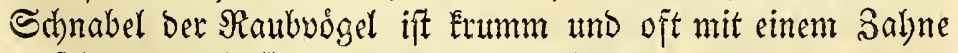
verfechen, um befier bie Seute zu zerreipen.

Dic 3 unge ift bey ben norbiidjen Mógeln meiftenz lang oder mittelmǟig; eine furze lyaben die \$flanzen freeffenden, bie

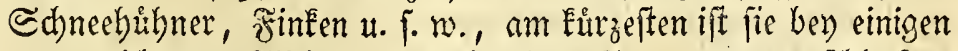

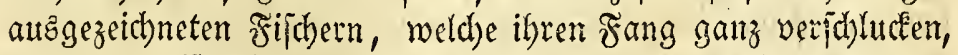

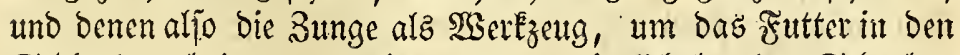
Schluno zu bringen, unnotthig war, námlid bey Den Sabarben

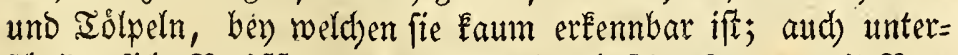
idheidet fidh Briffon s Pufrinus durd feine kurze; mit Bor= ffen bejegete Bunge yon Procellaria, mit weld)em die neueren 
Srnithologen inn wieber vercinigen wollen; benn bie 3unge ber \$rocellarien ift, wie ber ben Meven, lang uno etrwaz fleifdoig.

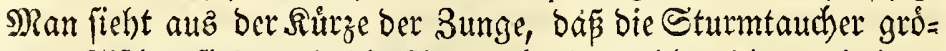
Fere Frifter find, als bie Sturmuógel, weldhe nidbt, wie jene, madh biefer $\Re$ iabrung tauchen fỏnnen. Die $\Re a$ aubvóget uno $\Re a=$ ben Gaben eine mittelmápig lange 3unge, fo aud bie norbifach snjecten frefifenden Singuogel; fie ift lang bey ben meiffen Sumpfoógeln, uno ridhtet fich nad) der Rånge ifres Sdynabels; Dod) ift fie bey Numenius futrz im Berbåltniffe zu biefem. Bey

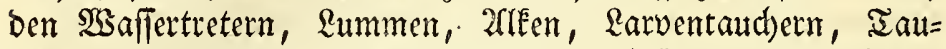

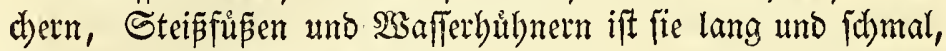
bey Den Sågern, Meeridbwalben, Meven, Raubmeven unt Sttrmbỏgeln lang trno etwaz fleifhig, am Enoe bornartig, bey ben Iauchenten, Enten, Şånjen uno Sdjwánen breit, flei= fdjig und ftumpf, gegen bas Endoe mit einer Fleinen şlatte verjehen.

Bon allen norbifhen Sdywimmoógeln haben oie Salar=

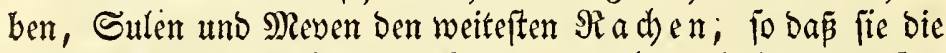

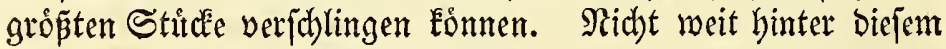

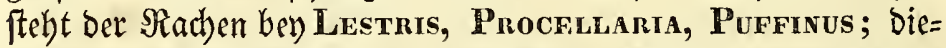
fem folgt der bey Stenna, Colymbus, Mergus, Pratypus, Avas, Anser, Cygnus; Fleiner ifít er bey Uria, Mergulus, Alca, Monnon, am Eleinften bey Poniceps, Fulica und Phalaropus.

Dic $\mathfrak{S a f f e r b o ́ g e l ~ b a b e n ~ E e i n e n ~ \Re r o p f , ~ a b e r ~ e i n e ~ e r w e i t e r t e ~}$ Speiferơhre, uno eimen gropen Bormagen. Şhr Magen ift mel)r ober weniger muakuto̊z, und die inwendige Magenbaut fehr runzelig. 2(lz eime Sonderbarkeit bemerke idh, baß̃ bie Magenhaut aller ber Mergulus alle, bie id im Sommer 1820 auf Ģrimioe unterfudbte, rein grasgrữn war; im Şerbft aber ift fie bey berferthen 9 Sogelart graugetb. Findet bie grime Farbe nur allein in ifrer SBrutzeit Statt, ober entipringt jie aus einer ei= genen 2(rt ber Mabrung? Die Magenbaut Eonnte nid)t auts= gerwajchen werden, und fdjien von ber gruinen Farbe: gainz

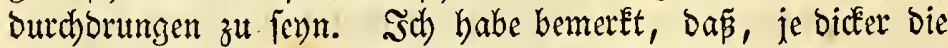
Muželn jino, welche ben Magen umgeben, befto Eleiner ber

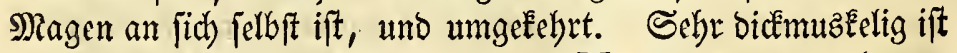
er bey Den 2frten yon Unia, Alca, Monnov, uno megreren

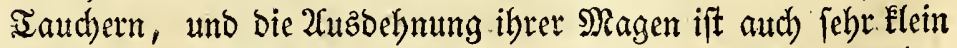
in 2 ergleid)ung mit ber gróseren ber minber bidémuseefigen bey Den Meven uno Meeridswalben. 
(53 ift eine allgemeine Erfabrumg, Da⿱艹 man im Magen Der meiften $\mathfrak{B o g} g$ el sine Sammlung von Fleinen Steinen uno Sand findet, fogar auth, wenn er ribrigens leer ift. Dieje find

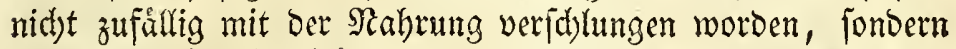
vom $\mathfrak{B o g e l}$ verfdyludt, damit fie zur 3ermalmung ber $\mathfrak{R}$ abrung bentragen; fie treten aljo in bie Function Der Bålne bev ben Såtrgthieren. Șm Magen aller Sumpfógel findet man biefe fleinen Steine; idh fand fie bey veridbiedenen 2 frten von Haematopus, Charaprius, Totanus, Streepsilas, Trivga, Numenus, Scolopax und Phalanopus, allezect im Magen Der Meven, Meerjhbalben, Såger, Ěnten, Şånje, baăufig bey Den bihynerartigen und Singuogeln, feltener aber bely Den 2irten yon Uria, Alca, Monmon, Colymbus, Carbo

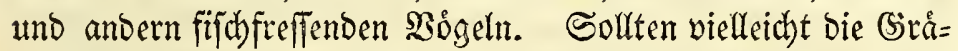

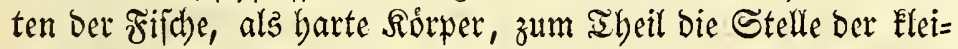
nen Steine vertreten, und bie weicheren Iheile zermalmen? Denn Gståten findet man im Magen biejer $\mathfrak{B} \delta$ gel, nachbem bas

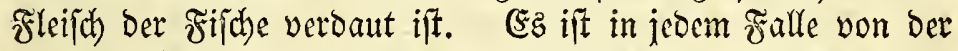
Ratur befitimmt, dap bie 2(rten, weldhe fich bon Sdhaalthieren u. \{. w. nåbren, z. B. bie Taudbenten, Truxga maritima u. m., wenigere Steine verfblingen, weil daz fteinharte Şauz diefer Sd)aalthiere, weldhes mit bem Il biere ferbft verifhlungen wird, Den Dienft Der Eleinen Eteine verridtet. Man findert theils les= bige Schneckenháuler im Magen biejer $\mathfrak{B o g}$ get, auz weldhen bie Thiere Durch bie Serdaunng verzehrt fino, theils bieje burch bie

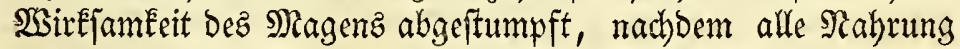
aus ifmen weg ift. Ein eigenes Mittel zur. Berbauturg ber Nahrung, weldhes einigermap̃en biejelben: Diemfte, wie bie

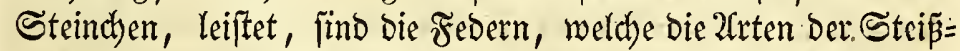

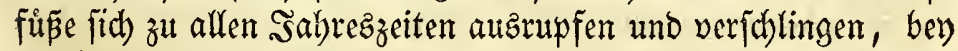
welden man fie im Magen unter Den verzebrten Segetabilien fin=

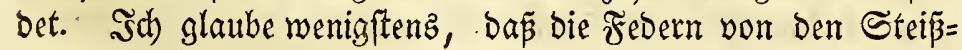
firzen verichlungen werben, um bie $\mathfrak{B}$ erbauung zu erleidtern, fo wie cinige Srnitbologen anmehmen, ba gel frane werben, wenn fie nicht.zumeilen $\mathfrak{R a b}$ rung erbalten, welche mit Şaaren ober Federn bebefft ift. Sob biefe rebern auz Dem Magen Der Stei bey Den Raubboigeln, oder ob fie zerrieben, uno burdh. Die Cloaca ausgeleert werben, wie bie verichludeten Steine un= ter ben (Excrementen ber andern Bogel, ift nod) nidht ausge= 
madht; id babe nie ein fold)es (Frbredhen bey diefen Sdbrimm= vógeln beobaditet.

\section{§. 55.}

Die Sinne ber Bo̊gel ftehen in einiget $\mathfrak{B}$ eziebung zu it)= rer Nalurung. Daz (S) eficht ift ber Sinn, weld er uberbaut am meiften ben ifnen ausgebildet ift. (Es iff $\mathfrak{a m}$ jdariffiten ben benen, weldbe in einem 2aftande inre Beute feben jollen; da= her am beften bey den Rauboogeln, und bey Den Stoptauchern

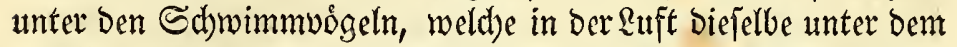
Waffer ausipåken. Der bodffliegende 2Coler und ber Milan bemer= Een die Serbegung Eleiner Thiere auf der Erbe; ber weipe Tol= pel fielst cimen Eleinen Fijh won einer anjebnlichen Şobe, und die Meven, Seeridwalben, Raubmeven und Sturmbógel fom= men von allen Srten berbengeflogen, wenn etwas auf bem

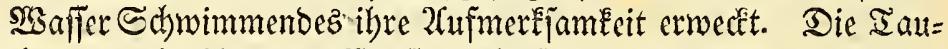
d)er, welche iber dem Sisaffer nicht fo gut fehen, als die Stop̃ taud)er, felsen unter biejem weit beffer, alz bieje, wo fie eigent= lich auch beftimmt find, ibre $\Re$ abrung zut jutben. Sb jie, um

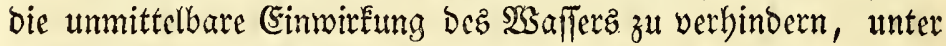
bem Iaudben bie Nickbaut vor das 2luge zieben, wie menn fie ge= gen bie Sonne fehen, ift nod nidht ausgemadht. Dod) lyat man aud einzelne Beyfpiele eines auszezeidheten (Sefid)tz ber

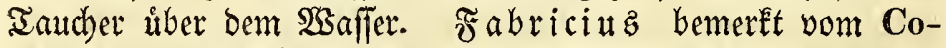

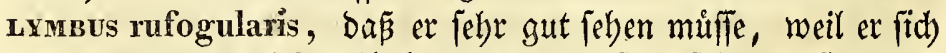

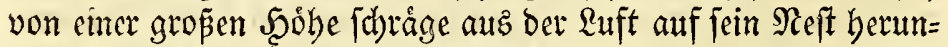
ter werfen fann. Daffelbe bemerkte idh bey Coumbus glacialis in Szland, und wie notbwendig ift nicht uberhaupt Das

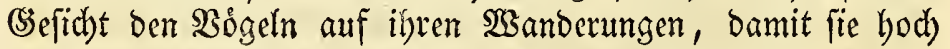

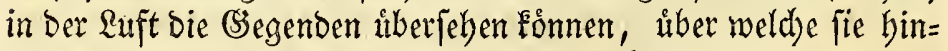
wandern, befonders ba fie auth dez Sachts reifen, wenn ez nicht gar zu Dunfel ift. Eine fidh nábernde (Siefabr felyen bie So̊gel, ebe fie biefelbe horen. Sch habe mich Davon liberzettgt, ba id) offer ben fifenden 2 saffervógeln, ob ich gleich ftart im $\mathfrak{S}$ affer ruberte, febr nabe Eommen Fonnte, fo lange bas Boot von ihnen nidit gejeben wutbe; fobald jie aber feinet an= fidtig murben, entfloben fie fogleid). Die Scausvodgel feben

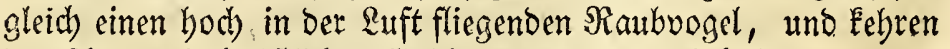

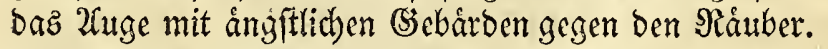

Der 2 utgenftern if bey ben verferiebenen Sogelarten in Der Farbe verfdieden; et variint zuweilen nach bent 2alter und 
Dem (Sefhledte. So ifter bey den jungen Meven braun, bén den alten gelb oder mei

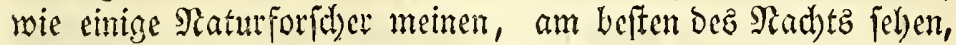
beftåtigen einige (Entenarten, obgleid) einige andere 2 trten berfelben (Satung ilyr wiberfweechen; Denm STrix nyctea und nisoria fehen befier, und St. passerina Auct. eben fo gut am Iage,

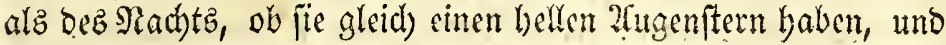

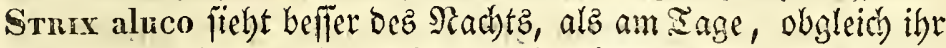

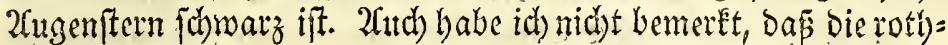

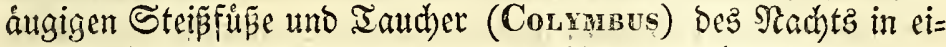

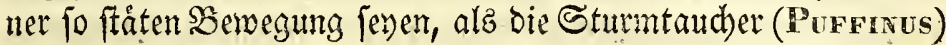

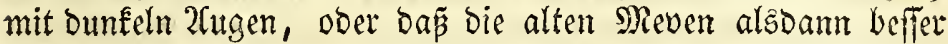

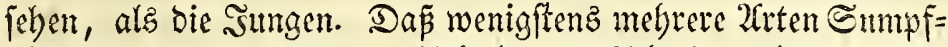

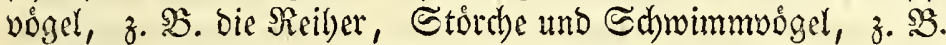

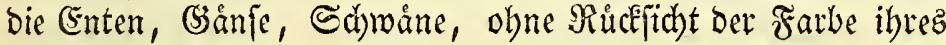

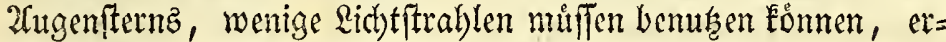

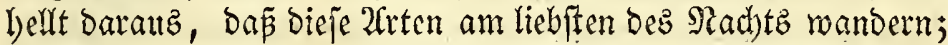
die Enten find in Den monbbellen Iiádbten, wie bie Euten, in fråter Berwegung, ba fie unablåfifig yon bent Mieere nadb Den

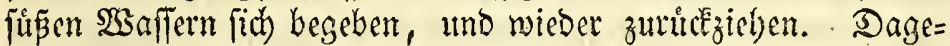
gen babe ich im 2a(rgemeinen genonmen ben ben Singuogetn be=

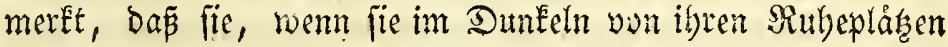
aufgejagt werben, mit unficheretm Fhtuge berumflattern, als wem fie, aus Mangel ber Ridetifteablen, ibre Sidutung, in Der fie fliegen wollten, nidht beftimmen fonnten. Die Singuoget wanbern aud fibwerlid bes Pachts, fondern früh Morgens. Die meiften Singuógel baben freilid) auth einen bunḱth $2 \mathfrak{U}=$ gemitern.

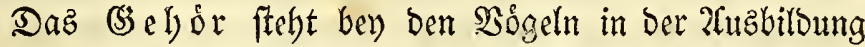

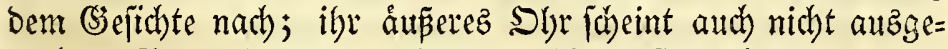
zeichnet fưr biejen Sinn gebildet. Zfm beften hoiren wolgl bie Urten, weldhe eine, mit ber Shrenmuldhel ber Sáugtliere ana = loge Berooppelung ber åupern Şaut bahen, z. S3. Die Euten.

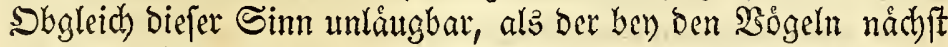
Dem Gefichte am meiften ausgebitbete, ben zwenten $\Re$ ang be= bauptet, fo habe id) bod) ben ben borealen SBögrin Eein auffal=

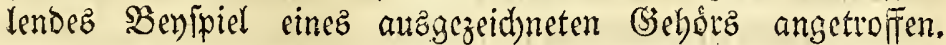
Diejer Sinn juseint am meiften bey ben Singuogegen zu Sauje zut geboven, weldhe felbit cine melobijde Stimme baben, uno ganze Melodien aubwenbig lernen Eónnen. Die hordhenoe $\mathfrak{B} e=$ wegung mit bem Sopfe, weldhe bie Såugthiere, ż. $\mathfrak{B}$. Die My ferbe, 
Şaajen, bie ein frines (3̧ebỏr baben, madyen, babe id bey den

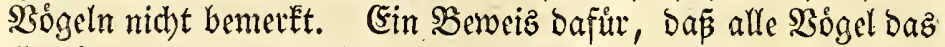
Gebor anwenden, giebt ibre Rodeftimme, weldhes ber Raut ift, burd) weldben fie einander thre gegenfeitige Slåbe zut erkennen geben, uno weld)r in ber Regel Eeinem Bogel mangelt, we= nigftens nid)t in einer gemiffen 3eit bez Sabrez.

Da bie Najenlober in Dem harten Sdhnabel liegen, jo

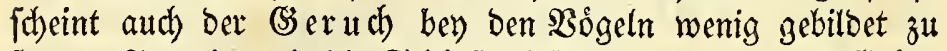

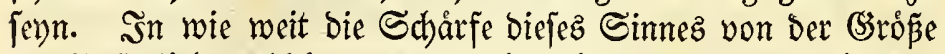
ber গajenlod)er abbånge, fann id) nid)t beftimmen; bod babe id) Eeinen vorzüglich forarjen (Seruch bey benjenigen Sumpfod:= geln ober Gdhimmógeln gefunden, weldhe grop̃e গajenlod der baben, z. B. bey Den Meven. SBey Den Scharben und Tol= peln find die Najenlócher fo flein, baß̃ fie ganz ibre Bebeutung für ben Sinn bez (Seruchs verloren baben. Den feimften (Ge $=$ ruch haben die autj[uchenden $\mathfrak{B o g} g e l$, z. SB. Die Raben, uno ez

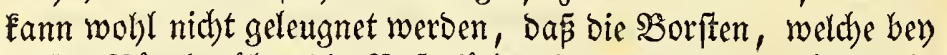
diefen $\mathfrak{B}$ ogeln ủber bie Nafenlódher berausliegen, nicht allein bazu bienen, bie Lmeinigkeiten von benjelben abzubalten, fonbern audh, um bie riechenden Sartifeln aufzufangen. Sod) babe in

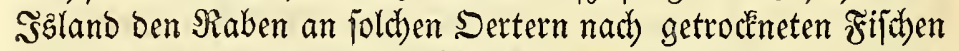
fuchen (eb)en, wo er nut burch Den (S)erud in (Erfabutung bringen

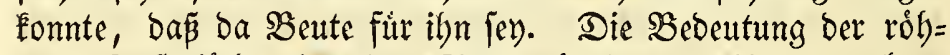
rigen Sajenlócber bey ben Sturmbo̊geln uno Sturmtauchern Eann ich nicht mit Beftimmtbeit angeben. 3war lebt ProcelLARIa glacialis gróptentbeilz won $\mathcal{U}$ ejern, wep̧wegen ein fei=

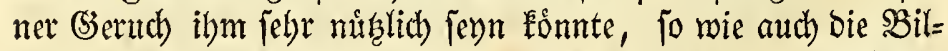

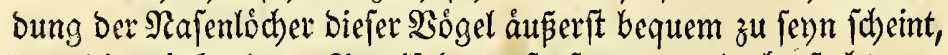
um bie ried)enden Sartieleln auffufangen; boch fucht ex, meinen Erfabrungen von Der Rebensart dieles ßogelz gemåă, feine Beute mebr burd) Şilffe bez (Siefichtz, alz Dez (Sienuchz auf. Dap er feinen Thran burdh bie Najenlócher ausjprife, ift nid)t ber Fall, obgleich cinige Srnitbologen biefer Meinung [ind; benn biefes gefdiebt Durd) den Radben.

Die wabren Sdymimmtaudber haben entweder febr fleine Rajenlódher, z. SB. bie Scharben, ober foldbe, weldbe mit einer weichen Şaut verfeben finb, z. S. Die Taudhenten; eS ift nidjt

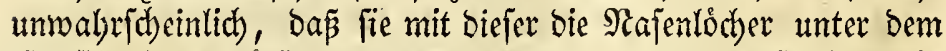

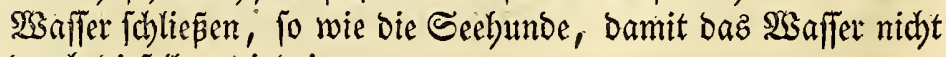
burd) biefelben eindringe. 


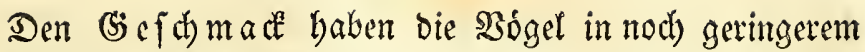
(Sirade, als ben (Sertuth; ihre 3unge ift felten fleifd)ig, oft born=

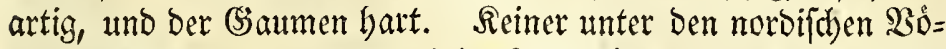
getn, ausgenonmen etwa einige Rautboógel, wie bie Fif

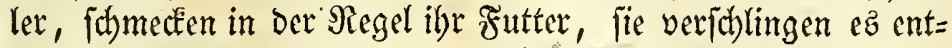
weber ganz ober etroaz Elein gemadt. Bey ben Enten, Ģån= fen uno Schwảnen if bie 3unge fleifdhig; fie netymen unter ib= rem Suthen nach Rabrung einen Theil im Schnabel auf ein= mal, fannattern alsoann, utmo lafien barauf das unbrautchbare wieber auz den Seiten bes Sdhnabets herausfallen, verfduluten aber baz Utebrige. Diefen Sỏgetn fornnen wir baher wohl ben (Bejchmade nidbt ganz abjprechen. Mebrigenz ift bie Reinumg

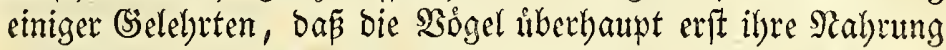

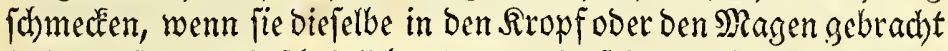

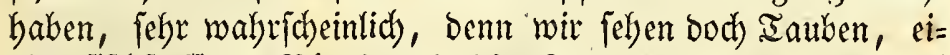

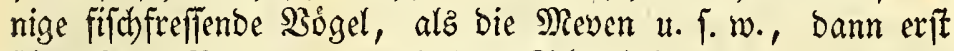
fahmedende Bewegungen mit Dem Sd)nabel mad)en, wenn die Nabrung fohon verfchlungen ift.

Die Sỏgel find zwar fehr irritabel; jogar bie Temperatur

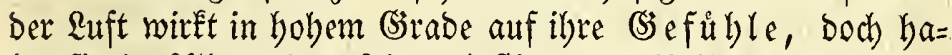
ben fie im Zatgemeinen feinen beftimmten Iyeil bes Leibes, in

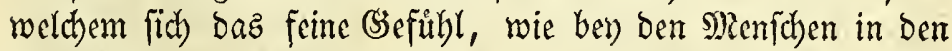

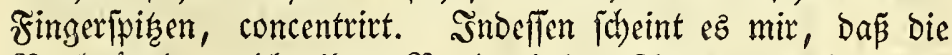

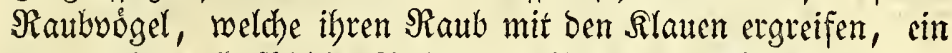

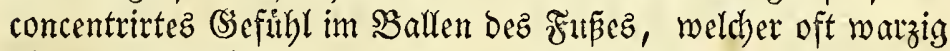
ift, haben mixflen, ba bie 2irten, weldhe ithre Beute an fold)en

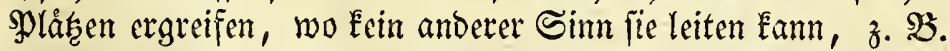
FaLco albicilla und haliaëtos, unter Dem $2 \mathfrak{s a f f e r}$ fonft nicht

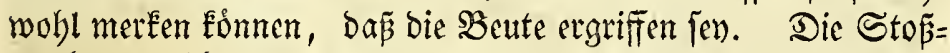

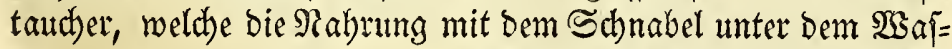
fer ergreifen, fo wie auth bie wirkflidhen Ianther, beburrfen Eei= nes vorzunglichen (3efiriblez im Sdynabel, ba fie unter bem $23 a$ af = fer fehen. Dagegen giebt ez einige unter ben Sump $=$ und Echwimmbógeln, bie in ber weichen Scaut, welche bie șurzel Dez Sd)nabelz umgiebt, ein verfeinertez Şefühl baben, nåm=

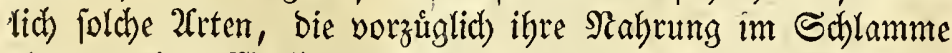
ober umreinen 2 saffer auffudben, wo ibnen kein anderer Sinn

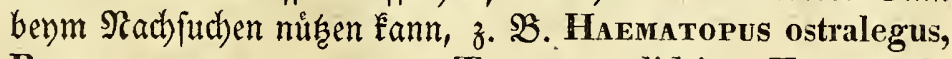
Recurvirostra avocetta, Totanus calidris, Tringa alpina, die 2irten yon Aras, Anser uno Crgnus. 


\section{§. 56.}

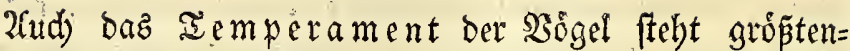
theilz mit ihrer Rebensat in Berbindung. Die Raubvoigel, weld)e nad) warmblutigen afieren ftopen, find do olerifdh, felfr zum 3orn geneigt, und graufam. Sie leben einfam, weil fie Eeinen um fich leiben fónnen, weldher ibnen bie Seerrfohaft

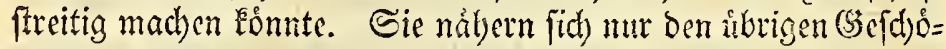
pfen, um Secroulftung zu verbreiten; ibre Sefftigkeit nimmt zu uno ab, je nadjoem fie fid) melyr ooer weniger von biejer 2art

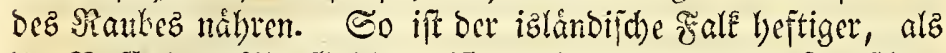

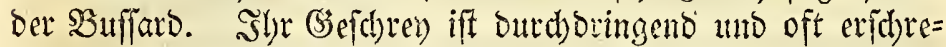
déeno. (Sin álunlichez a emperament lyat Lestris catarractes

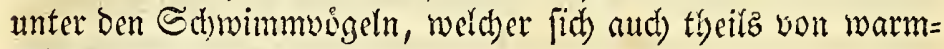
blütigen Şìbelthieren nábrt.

Dic Singuoigel fins fanguinifh, rege, munter, hutr= tig, firblen mit Syeftigkeit, vergeffen es aber geid)wind; in ei=

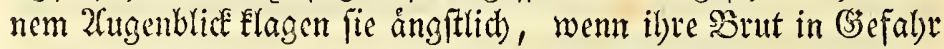

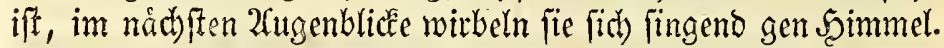
Sie werben leid)t zum 3orne gereizt, fahließ̄en aber bald zrieDen mit ihrem (Segner, und jind alsobann beiter tno janft in ib= ren Manieren. Sie find ferys gefellf

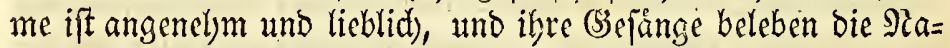
tur. Sie nåbren fich von Srrfecten oder Segetabilien.

Die meiften Sumpfoogel find melandolifd. Sie find zwar ofter in Berwegung; diefe ift aber entweder langlam, wie bey den Stórchen und Reigern, oder Gürtig, Dann aber

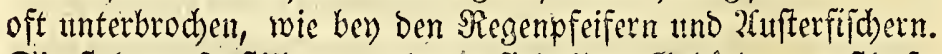
Eie fteben oft fitill, und bann find ihre Giebairben ernfthaft,

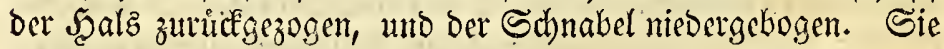
baben ein tiefez (Se jeirhl fưr ihre S3rut, uno igre Sorgfalt fúr

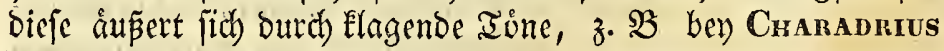
hiaticula, Hafmatopus ostralegus, Recurvinostra avocetta, Numenius phaeopus, Totanus calidris, Vanellus

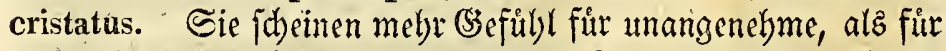
angenebme Einoridée zul baben. Sie fommen felten in Streit, áupern aber nie ben feutigen 2 fubbruch ber Freube, wie bie Singuógel. Sinen 2 (nftrid) von \$hlegma haben bie Stôrche und Seiger, bie Iringen und Sdhnepfen. WSirmer find mei= ftens ilyre Siabrung, jeltener Fif be ober Mflanzen. Die raben= artigen Bỏgel fino gleidjfalls melandyolif ch, aber mit éinem dolerifhen 2tnftridje, fo wie viele andere Smmizoren. 
Die Schnimmooiget find iberbautpt ply legmatif h.

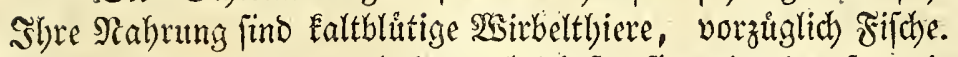
$\mathfrak{U}$ m biefe Rabrung zu erhalten, bedirrfen fie reder Der jangui=

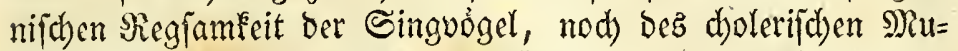

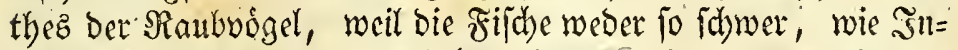
fecten und 23 ismer; aufzufuchen fino, nod) fo vielen $23 i b e r=$ ftand leiffen, als bie Săugthiere uno Boggel. Sie baben kein tiefes (sefiulyl, weber fin angenebme, nodh unangenelyme (sin=

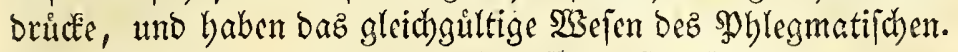

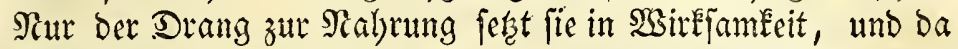

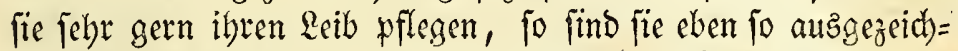
net fett, wie es oft bel Fall bey phlegmatifchen Renj(d)en ift.

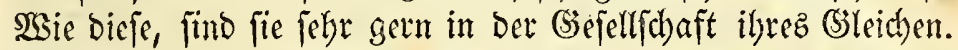

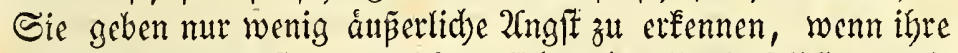
Brut in (Befahr ift, und buten fid) nidst allezeit felbft vor ci=

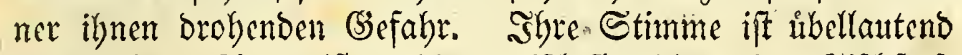

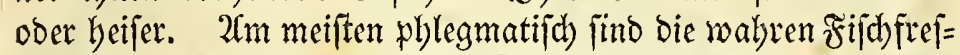
jer, weldhe nidjt einmal merklid) in Berwegung gejeşt werben, wenn ilfere Brut beunnubigt miro, z. B. Dic 2 trten yon Uria, Alca, Mormon, Carbo, Puffinus, Mergus, Sula, und Procellaria. Die phlegmatiface Uria troile und Alca tordá wat= icheln bin, um ibren ßameraben zu betrad)ten, weldhen man ib= nen zut Seite erfadyoffen hat, uno gehen bann ganz ruthig wicber

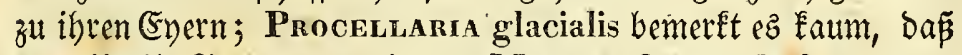
man ihr ithr Sungez wegnimmt; Monxos fratercula kann ganze

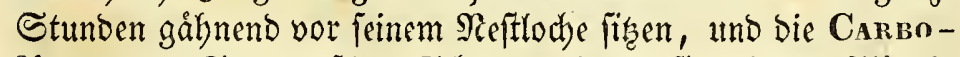
Zfrten ganze Tage auf Den Sdheeten, indem fie mit ben Fluhgeln

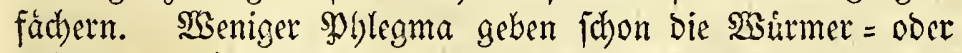
Dflamzen frefienden 2iften yon Platypus, Anas uind Anser zit erkennen, weldbe reger werben, wenn ilbre Brut in Şefalyr ift,

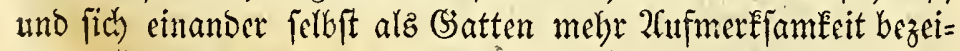

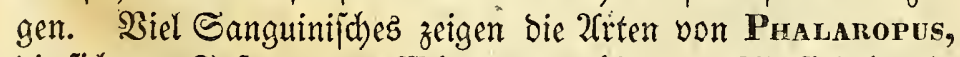
bie fid) von Infecten uno 2 surmetn ernåbren. Sie finb hurtig in ifren Bewegungen, ichlagen fich oft, find aber fibrigenz un=

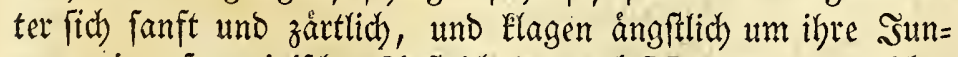
gen; einen fanguinifhen 2(nftrid) hat aud) Mergulus, weldher allein von Eruftaceen lebt. \$ollegma mit Melandholie vet=

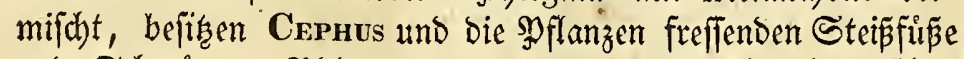
und Schmåne. \$glegma mit einem fanguinif d = dolerifhen Iemperamente zeigen bie 2frten von Stersa, und mit melan= doolijeb = bolerijach Larus uno Lestris, befonderz bervor= 


\section{$30 t$}

ftecheno Lestris catarractes; biefe 2frten nábren fid aud nut

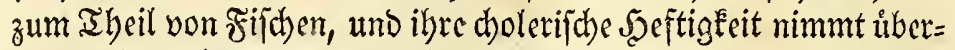

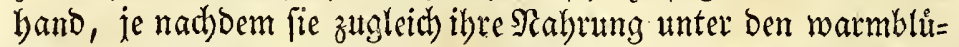
tigen $\mathfrak{S}_{3}$ rrbelthieren judben. . Die Meven z. $\mathfrak{B}$. ferfien gern bie. 2lejer ber Såugthiere, ja fallen jogar franke Bögel an; fie find auch) cholerifcher, als bie. Meerichwalben, und gleichen im $\mathfrak{I} e m=$

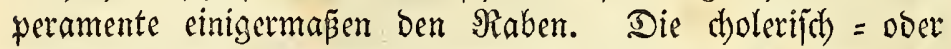
fanguinifoch = phlegmatif(h) Sdhwimmoógel fino ftáter in Bewegung, als bie rein = phlegntatifhen, und vertheibigen audh ifte sungen muthig; bod) find fie alle barin von

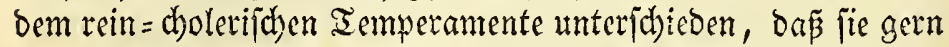
in (S) ejellichaft find. Die 2itten Colmubus find die einzigen bo=

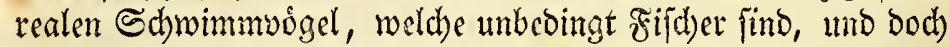
kein rein = phlegmatifches a Iemperament haben; benn ez hat bey ihnen einen ftarten melandbolifd = cholerifchen 2 inftrich. Sie le=

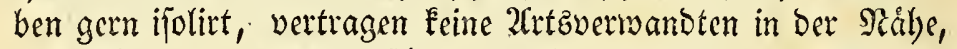

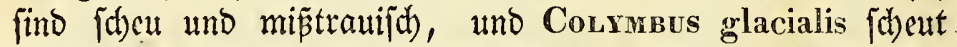
(iid) nicht, Den anzufallen, ber ihre Brut beuntuljigen will. 2fuz

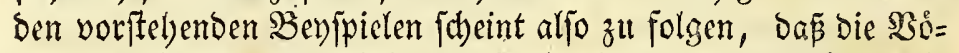
gel, weld)e von warmblitigen SSirbelthieren leben, dyolerijch, bie von Ealtblütigen 23 irbelthteren, phlegmatifh, von snjecten;

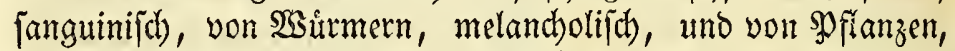

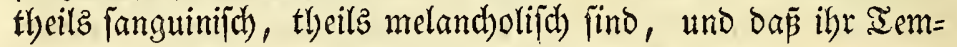
perament mel)r ober weniger aus biefen vier Şaupttemperamen= ten befrebe; je nachbem ihre $\mathfrak{R a b u n n g ~ m e h r ~ o b e r ~ m i n d e r ~ a u z ~}$ Den genannten verjdbiedenen Raturgegenftänden zufammenge= 作然 ift.

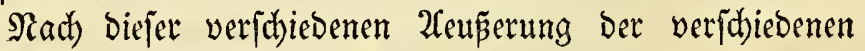
Iemperamente finben wil aud, , fo zul jagen, ben Ion ganz verfdhieben, weldyer an ben Sertern herrfdht, an weldhen bie eine ober bie andere biejer.Sogelorbmungen bie herridhende ift. Sn umfern ftimmt, wenn er an einem fojonen Sommertage die angenely= men Melodien Der Singuógel hơrt, uno bie MunterEeit walys= nimmt, mit welcher bieje Fleinen Ssejchoppfe auf ben 3weigen herumbưpfen, ober fitch in bie \&uft binaufmirbetn; mur ein ein=

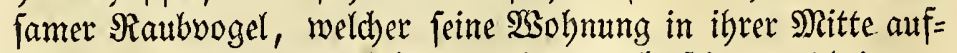
geid)lagen bat, verurfacht zuweilen burd) feinen tobbringen= Den 2 nffall eine traurige Sataftrophe.

Sn ben norbiifhen Bogelbergen, wo bie Sajwimmuoigel verjammelt jino, berrjht wohl Emjigkeit uno Reben; lebterez 
ift aber mebr lårmend, und hat nicht den erhabenen Eharafter,

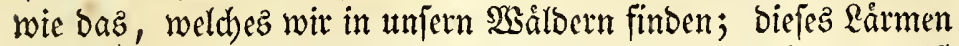

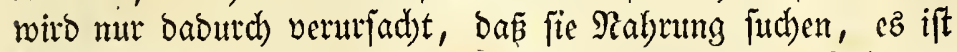

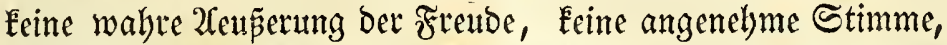

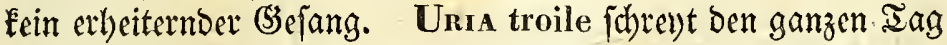
ůber ihr monotonez err, 'ein ewigez (Seplander ohne Sebeutung.

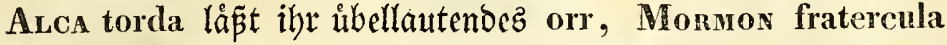
feine gåbnende, uno Proceluaria glacialis feime gackernde Stimme hơren, indefifen bie Edyarben und Tolpel beynal im=

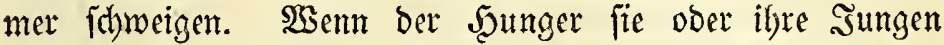
nicht plagt, firsen fie ganze Stunden rubig an bem jelben \$la Die Scene erlyălt einen nod) weit buifterern $2 \mathfrak{n}$ (t)trid) burch bas

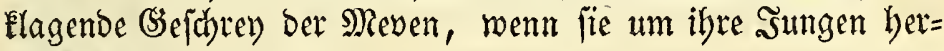
umfliegen.

Beffteigt man cin einjam liegendez, mit (G̋raz bewad)jeneż, wafferreid)es Sajeldten, fo ift man an bem Srte, an welchem

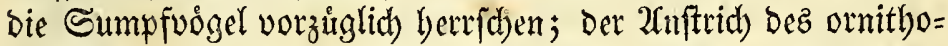

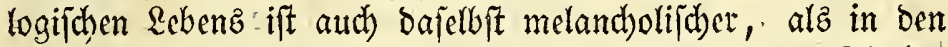
Wsálbern, und jentimentaler, als in den Bogelbergen. Die be $=$

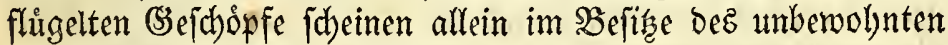

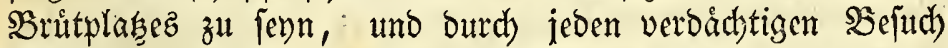

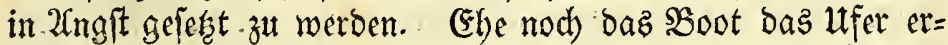
reid)t bat, Eommen ilym fohon bie Stutmmeven und arktijoten

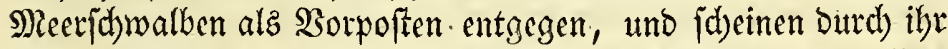

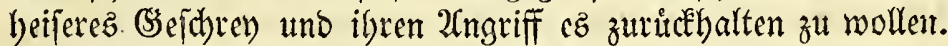

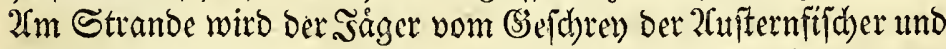

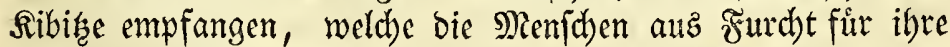
Jungen umfliegen. Silagend flótet ber rothfüpige SSaffertåufer,

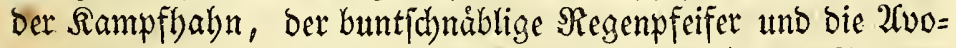

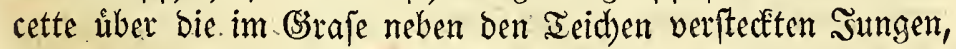

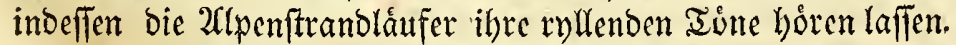
Shaufen von (Şolbregenpfeifern uno Bradjuoggeln fliegen unter ibren flotenden Io̊nen auf, utno entflieben wilb bem kommen= ben Såger. 


\section{V. \\ Bon ber Qebensmetaniorphoje ber Gorealen Ziỏgel.}

\section{§. $5 \%$}

Der grabmcifen Entwicfelung ber $\mathfrak{B o g} g e l$, vom Eye an bis zur Seriobe il)rer Britfälyigkeit, fino wir bizl)er gefolgt, uno baben gefeben, Daj bie Beit ibrer Sindbeit und Sutgend, ober ihre un=

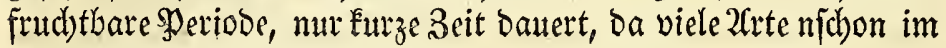

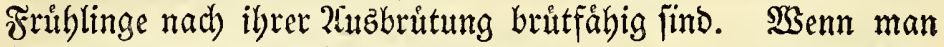
ưberbaupt bey Den Sångthieren annimmt, Das̄ ifre Lebenzzeit

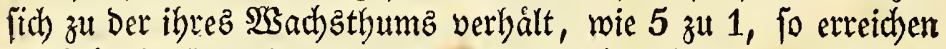
die Bogel, fo viel man meip; im Berbáltniffe ein febr ho bes alter. Das bódhfte 2flter, weldhes die repectiven $2 \mathfrak{r}=$ ten erreichen fónnen, mit (şemiß̄beit anzugeben, ift unmóglid), und id) will nicht einmal verjutchen, es burdh 2Rpproximation fiut bie norbifhen $B$ sogel autfindig zu machen; benn jedez der gefin= Denen Rejultate wirbe zut unjtcher fenn, um zut intereffiren. Der Grund, warum diefes alter jo jhyer genau zu beftimmen ift, liegt theil(z in Der Schwierigkeit, einen $B o g e l$ von feiner (S)burt biz zu feinem Tode zu beobachten (weld)es fidh jedod) mur bey zal)men Boogeln thun lápt, uno aud bieje leben boch nicht jo lange in ber (5iefangenfdaft, als fie im freben 3uftande wuirden gelebt baben), theils in bem Utmitande, das bas bohe 2ulter ber.

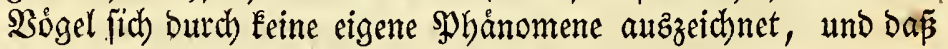
mobl bic Mleiften eine Beute ihrer Nachjteller werben, ebe fie abgclebt find.

Soviel man meips, leben bie grópern $20 \circ g e l$ långer, als bie Elemern; bod) ftebt wohl bey ifnen allen bie 3eit ihrer un=

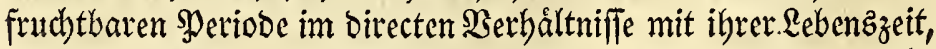
fo bap bic 2frt am lángften lebt, meldye bie långfte 3eit burd)= gebt, ebe fie britfåbig ift. Dafin foheinen einige politive (5r= fabrungen zu fwreden. Der 20 ler ift feinez 2 ltters wegen be= Eannt, und foll ez bis zu 100 Sabren bringen; er burdblebt

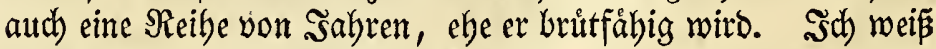
ein $\mathfrak{B e v j p i e l ~ v o n ~ e i n e m ~ g e z a ̊ b m t e n ~ F i f ~ h a b l e r , ~ w e l c h e r ~ i m ~ S a h r e ~}$ 1816 aub bem seft genommen wurbe, und in feinem 10ten 


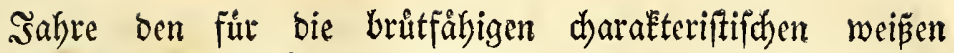
Sdjwanz nod nidbt ganz erhalten hat. \$lafien erwảhnt ein\$aar (Eibervógel, weld)e 20 salyre lang nad) benfelben $\mathfrak{B r u t}=$

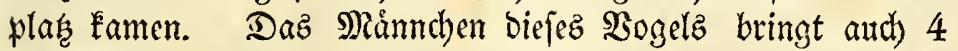
bis 5 sabre in feiner unfrud)tbaren sugend zu. Die 2arten,

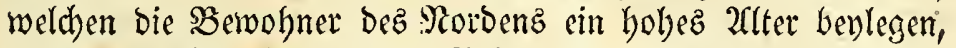

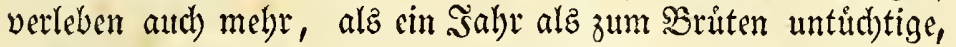
3. \$. aureer Den genanten, Der (siztaudber, Der Singid)wan,

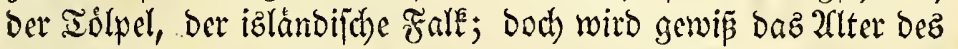
Singichwanez uno bez Saben zu hod) angejeşt, wenn man ez auf 100 sagre beftimmt. Siad) ben ủbrigenz jd)wer zu bervei= jenben socen, weldbe ich von Dem 2 Itter ber veridsiebenen bo=

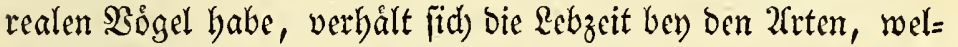
d)e mebrere Salyre alz unfrudbtbar verleben, zu Der Beit ibrer

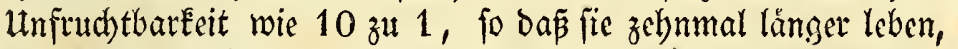

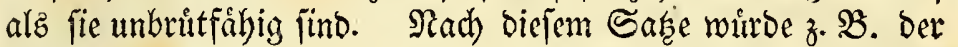

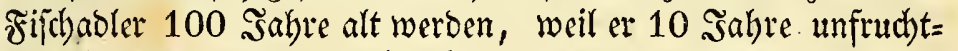
bar ift; baz (Eibervogetmainnd)en 40 Sahre, da es 4 Sabre im Sugendfletioe ift; Larus glaucus, marinus, leucopterus, tridactylus, Suna alba und Cephus grylle 30 Sabre; Die Lestris - 2 trten, Avas clangula, glacialis, histrionica 20 Sabre, u. f. w. Wfuth bev Den Eleinern yon Den 2(rten, weldhe mur cin Sabre unfrudtbar zubringen, namentlich bey ben meiften Sing=

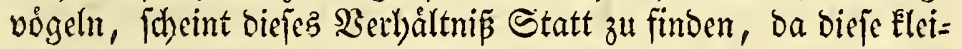

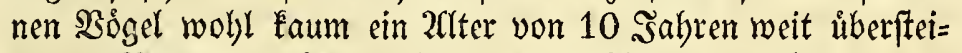
gen. Sen Den grósern aber yon ben 2(rten, weldhe nur ein Sabr zut ibrer Mambarkeit brauthen, z. B. Den meiften Sumpf=

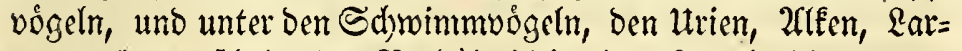
ventauchern, icheint bas Derbáltni范 in einer Mittelzabl 20 zu 1

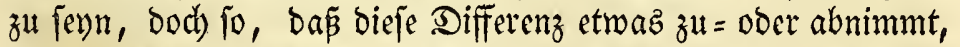
je nadboem die 3 sogel gróper ober fleiner jint. Dap die

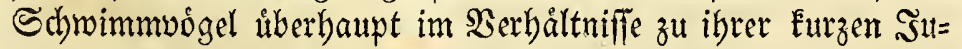
geno lange leben müffen, erhellt aus ber ungeheuern indivibuel=

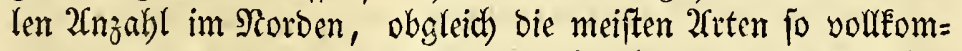

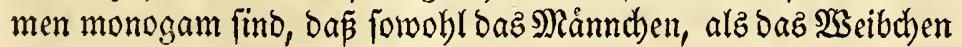
mit Derfelben Brut bejdhaftigt ift, wenn fie auth ben ganzen Commer úber nur Eine $\mathfrak{B} r$ ut baben, uno bie Babl ihrer Eyer jo gering ift, baj oft 2 sndivibuen eimen ganzen Briftter= min hindurd bamit bejohiftiget fino, bie 2 trt mut mit cinem einzigen snoivio zu vermebren, ba noch Dazu mehr alz bie

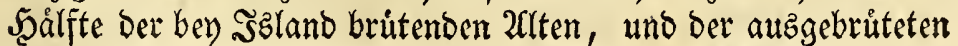


jungen Bogel jåhrlid) yon ben (Sinwobnern weggefangen wirb.

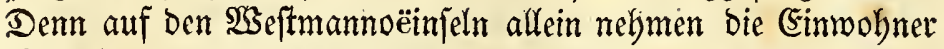
jåbrlic) $20-30000$ sumge von Proceldaria glacialis weg, aljo bie Sint von 40 - 60000 alten Bógeln, obne dáp fid bie $2(n z a d) l$ ber bruitenden Bógel bafelbjt merflid) verringert; und obgleid) die meiften sungen von Monmos fratercula $b \mathfrak{a}=$

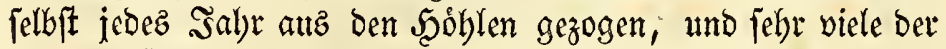
2Clten gefangen werben, jo bebecten bod) biefe $\mathfrak{B o g} g e l$ in bet

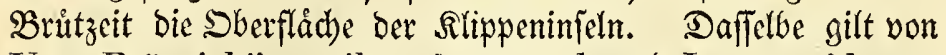
Uria Brünnichii, troile, Alca torda undo Larus tridacty-

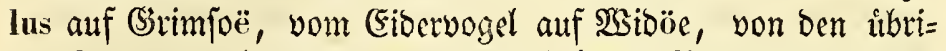
gen Entenarten bey Mryvatn, Deren briutende Sndividuen an bic=

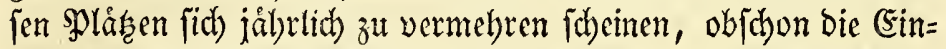

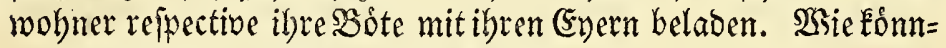
ten biefe 2(rten bie Menge ibret Indivibuen bier aufredbt erbalten,

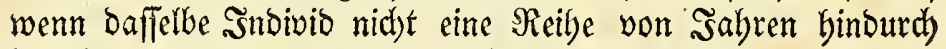
fortfúbre, Die 2(rt zu vermel)ren?

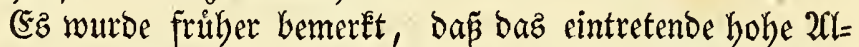

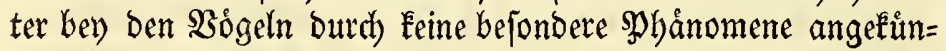
bigt werbe. Daz Scaar wirb bey dem Greije weí, bey ver= fichiedenen Såugthieren, z. B. bey ben \$yferden, werben fie eben= fallz weís, oder fallen ganz $\mathfrak{a u z}$, wie id) ez bey einer alten Pнoca barbata u. m. gejeben habe; die 3áfhe werden ftumpf,

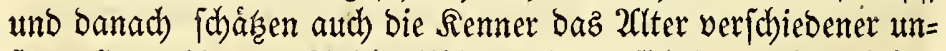

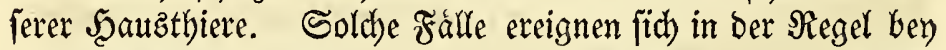

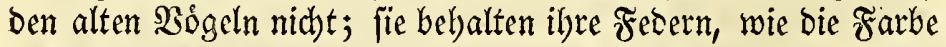
ihrer. Mannbarkeit bis jie fterben; antd ifhr Sabnabel und ibre Filauen werben nid)t merflid) ftumpf. (Einige Sonithologen be=

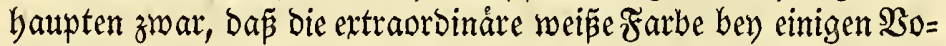

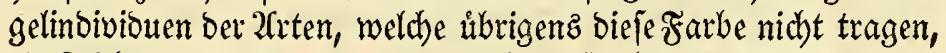
ein Beidhen, bez hoben und vielleidht unfruthtbaren Z(lterz, biejer Bógel fen; bod kann ich biejer Meinumg nicht bentreten, fondern

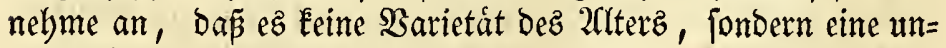

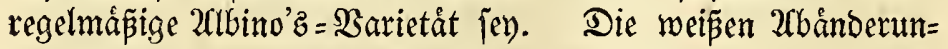
gen ber Måufeburfarde, Sdhwalben und Sperlinge findet man

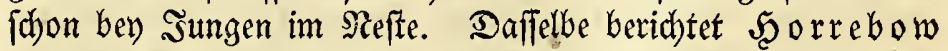

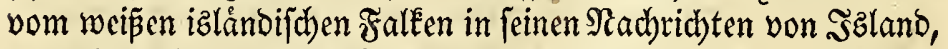

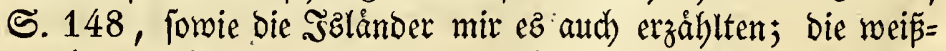

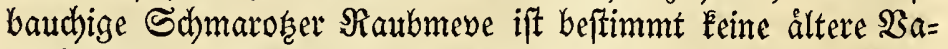
rietåt ber braunbauddigen, fondern biejer $\mathfrak{B o g e l}$ theilt fird. vom Neffteleibe in bieje beiden rarbenverảnderungen. "Dafferbe ift 


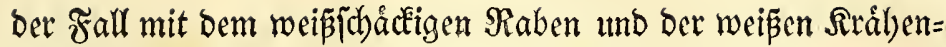
(d)arbe auf ben Farröeinjeln, uno ģewi Unia alle, Cephus grylle uno Aras histrionica yon Grón= lano. 2(ber fo wie fie in eimem febr hoben 2 tter bie Farbe nidht ganz verándern, fo nimmt bagegen ber (S3lanz il)rer Febern zu, je mebr fie in ibrem mánnlichen âter fortjdyreiten, und befon= bers verlangern jid) ibre Feberziertatben mit bem 2(lter, wenn fie bieje baben. Se alter ber brütfábige Reiger ift, befto langer ift fein Feberbujch. Diejes findet aud bey. Dem אibis

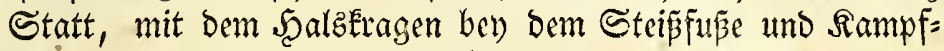
babne, uno mit ben langen Sibwanzfedern bev Lestris parasitica, Aras glacialis und acuta. (5z ift baher immer unfitiber, die Långe biejer. Theile zu Sennzeiden verichiebener 2 rrten zu wảblen, Da, wo bie şseibd)en die Bierratyen ber Mánndhen

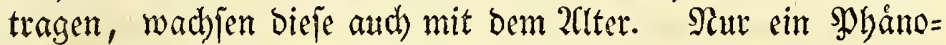
men, woran ein bobes 2Clter erkannt wirb, trift man bey Den 2 seibchen einiger Sogelarten, beren (5efd)led)ter von ver= fdiedener Farbe find, z. B. bey einigen bubnerartigen $\mathfrak{B} \delta$ geln, ba fie, wenn fie aufbòren, (5yer zulegen, eine neue Sleidung er= balten, welde fich ber fdỏnern bez Månnd, ens nábert, und fo in ihrer lesten Rebensperiode die Feberfarbe des månndbens befom= men, fo wie bie jungen sabunden in ber erften periobe inres

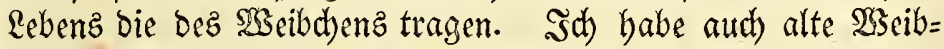
den von Mergus merganser and serrator, von Aras glacialis, histrionica uno crecca gefehen, weldbe Etwas von ber Fe= Derpradht ibres s)iannd ben batten.

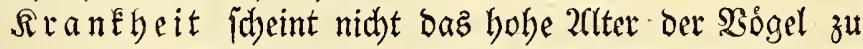
d)arafterifiren. Sie werben im wilden 3uftande felten von Iranlbeiten geplagt, uno bcjonders von feimer regelmápig ein= tretenden Schwadbheit. Sur wenn fie maujern, fino fie unpås $=$

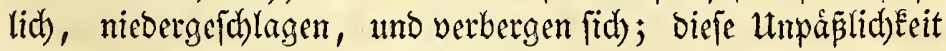
aber ift bey Sógeln im wilden 3 uftande. felten tóbtlich. Swar fand id) bie jungen (sibervogel oft abgezelut burd) cin (Siewaids in ber SBauchlyoble von Der (sirópe cines (Śánjeeves; aud treiben Ura troile und Brïmichii oft im 2 Sinter tóbtlid) Erant, von ciner mir unbetannten Schwachbeit ermattet, an Den Strand. İn gewifien Sabren mirb Sula alba von einer anfectenden

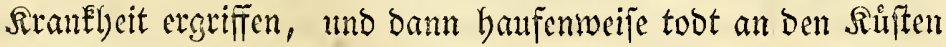
von Şland aubgeworfen. Ulebrigens werben bie borealen.Bogel

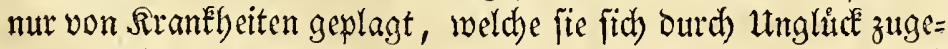
zogen baben, z. B. wenn ibre Beine ber. Froft verlest, voer biefe 


\section{$-310$}

am Eije feftfrieren, weld)es in Eisjabren mit Alca torda, Urra

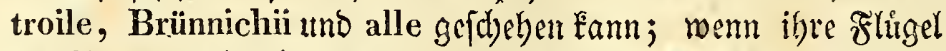
im Sturme gebrod)en werben, wovon idh ein Shevipirl bey Procellarra glacialis gefelyen babe, uno wenn bie Saungersnoth

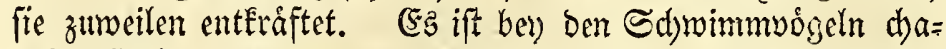

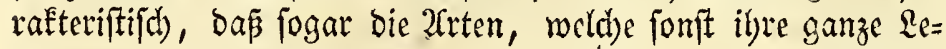
benzzeit auf bem Meere zubringen, uno Fegr ungern baz $\mathfrak{B S a f f e r}$

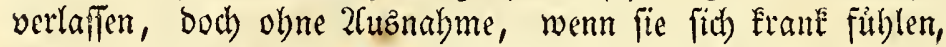

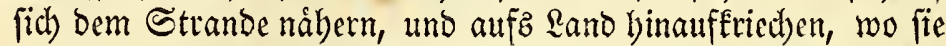
ihr \&eben enden, und baber in ber Regel auf Demferben MRe= bium fterben, auf weld)em fie ausgebritet find, ob fie fid gleid) in ber ganzen 3wifichenzeit, auper in Der Brủtzeit, babin

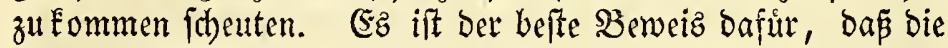
Qummen, Iautcher, Eiberenten frank find, wenn fie fortfahren, fid) an Dem $\mathfrak{u}$ fer Dez Strandez zu balten, und ob fie gleid) nie=

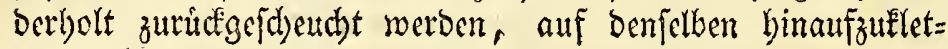
tern futchen.

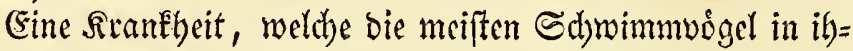
rem Šnnern tragen, ift eine umzáblige Minge (Eingeweiberwir: mer; fie fdheinen aber eben fo wenig bavon beláftigt zu werben, wie ber Seełund, namentlich PHoca barbata, befien ganze in=

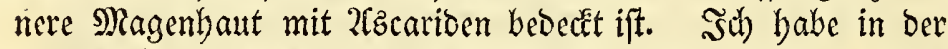
Magenlyỏble ben Mormos fratercula einen fleinen $\mathfrak{B a f l e n}$ zu= fammengerollter, blaugeftreifter K(zcariben gefumben, obne ba baz 3 Sogetintivio aussgemergelt war, uno ç wirt folten eine Uria, Cephus oder Alca aufgeifhnitten, obne daj man $\mathfrak{B a n}=$

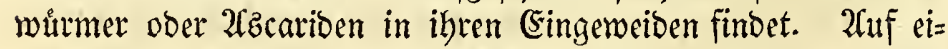

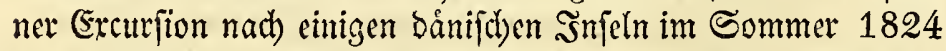
uno 1825 fano id) ben Darmeanal von Podrcsps subcristatus mit taenia angefiưllt, won weldyen der gróste 12 3oll lang war; und bodh war ber Bogel gefund und fett. Nefhe fdeinen bie borealen Bögel von ben aušwendigen Sthmarokern zu lei= ben, weldbe fie auf ibrem Reibe tragen, námlich von ber Menge

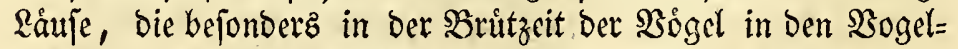
bergen unb in ihren Reffern wimmeln. Sebe Sogelart hat

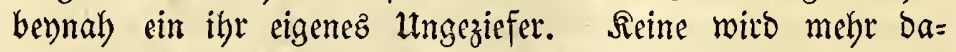
von geplagt, alz Uria troile uno Monnos fratercula, Deren ungeziefer breit, flach und bläulid) ift, fïd ber Schaflaus an

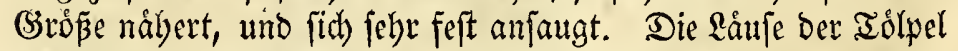
uno Scharben find länglidy, foumal uno im Berbáltniffe Hein; etwas kleiner, als bie, weldàe unreinlidbe Menjdyen plagen; 
bery andern 2irten, wie bey ben Meven und Maben, find fie nod) Eleiner, uno jeben autz wie Milben.

Die Bógel geben burch) Schláfrigkeit, auffecounjene $\mathscr{J} e=$ Dern, Bertuft bez 2fppetitz, Nagerkeit, unb. wenn fie gern Dent

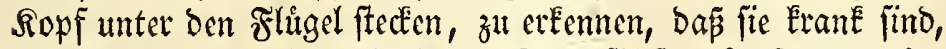

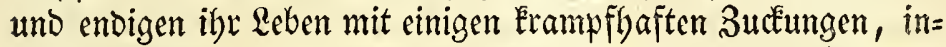

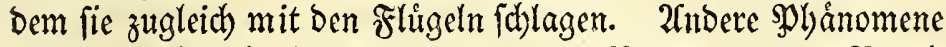
ereignen fich nid)t bey ifrem $\mathfrak{I}$ o be. Saur von einem 20 get,

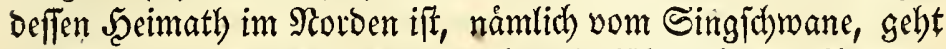

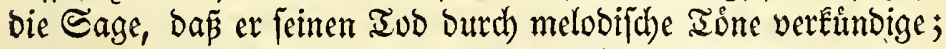
uno bieje Sterbetóne hat man ben Sthwanengejang genannt.

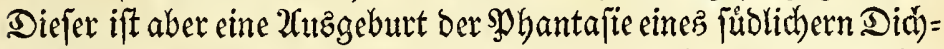
terz, und wåhrend et in Den Sdhriften Der (Şelehrten bie (̧e=

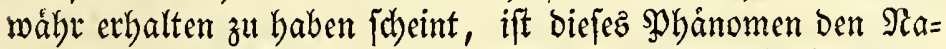

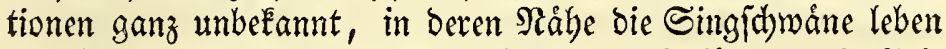
und fterben. Siamentlich babe ich ben Den Salåndern bie Mei= mung nie åußetn bơren, baß̄ er burd) eigene Iỏne feinen Iod ankúnbigen follte. Die Sage hat ihren $\mathfrak{u}$ triprumg von ben wobllautenden \$ojautnento̊nen, welche er autz feiner Eünftlichge=

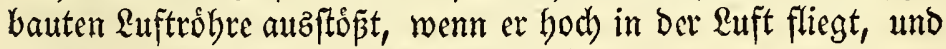
wowon er zugleid) feimen naturbiftorifden Samen erhalten bat.

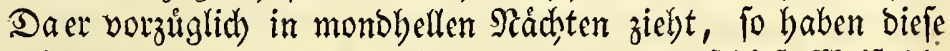
Ione mehr auf bie \$olyantafie gewiret, und auf biefe Şseife bie eben erwáhnte Sage veranlapt, fo wie bie bes Miadhtz in Dev

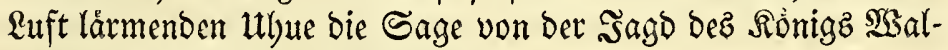
bemar, ober vom wilden Sảger.

Die meiften Bogel fterben bey weitem nidht vor 2flter oder

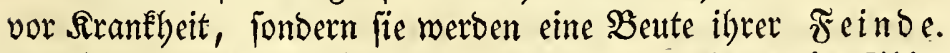

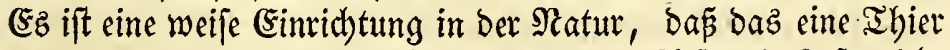

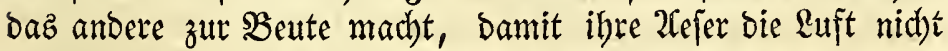
verpeften, ober ihre Bermehrumg mit ber Mroduction der, ciner

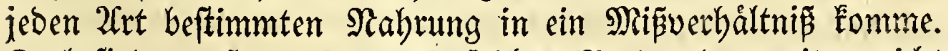
Dod findet auf dem Rande ein foldbes Morden bey weitem nicht Statt, wie gegenfeitig unter den Bewolynern dez Meerez. Die

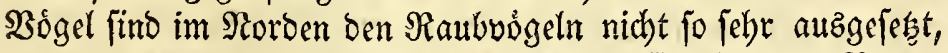
alz in ben temperitten Råndern; in ŞGland find ifnen z. $\mathfrak{B}$. mut

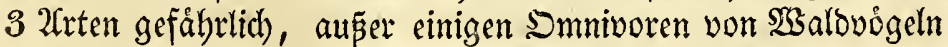

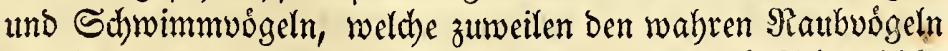

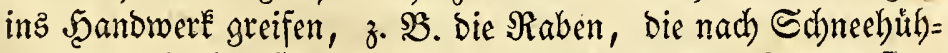
nern uno Iauben ftoß̈en, Larus marinus, ber kranke, utno Le-

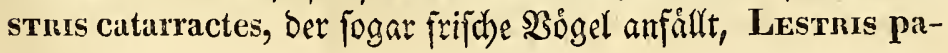


rasitica, weldhe înen (Eyern nachftellt u. f. w. Unter Den Såugthieren ift ber Polarfuchs ibr eifrigfter Sachfteller, uno cine einzelne taud)ende Rumme ober 2 ake $\mathfrak{k}$ ann aud auf Dem (Sirunde bez Meeres von einem gefräigigen (sishai wegge=

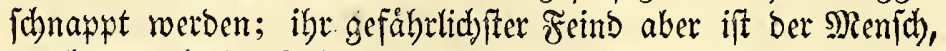
weldber burd) ibre 3abmbeit uno (Sefelligkeit in Der Brutzeit be= gůnftigt, fich jålyrlica meit mebrerer Sndivibuen bemåchtigt, als alle ůbrigen ilbnen nachftellenden Raubthiere fufammenge= nommen.

SBenn fich bie SBogel Der (Sefalyr berwapt werben, in wel= d)er fie fidweben, fo fưlllen fie $2 \mathfrak{n}$ gft, und da fie bas mora= lifhe Utebergemidht, weld)es bie \$ermunft giebt, nidbt Eennen, fo ergreifen fie gemeiniglich auch alzbann bie flucht, wenn es fur ihre Sidherbeit nid)t nothnendig ift. Sie geben zugleidy

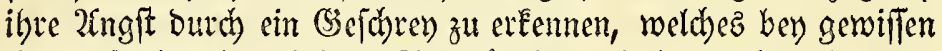
Sausvógeln, bev cinigen Singuogeln, wie bey Sdymalben uno SReifen, biefem (Sefuible eigen ift; mur wenige atten feren fo

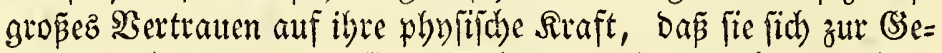
genwebr fteflen, wern fie wirlich daz llebergenicht des (Seg=

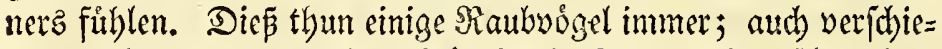
Dene Sibnimm = und Sumpfüget, als Meven, Meeridymalben, Sibise, wenn fie Sunge baben. Daber find die Raubvogel ủber= baupt aud) Den Nenfdhen nidbt fo gefábrlich, alz die Maubthiere,

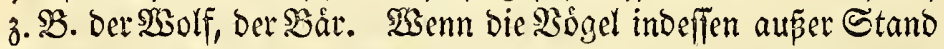
find, zut entfiteben, fo vertheibigen fidh fogat bie fanftmuthig= ften 2(rten, fo wie aud ber feigite Menfich jich webrt, wenn inm bie Flud abgeidnitten ift. So beipen bie fleinen Sing= vógel bie Menjt)en in bie Finger, wenn fie fie ergriffen baben, und bie in bie Fylugel gejchoffenen Meven und Enten verfuchen es, fich vom šåger lozzubeišen; mur die mit einem langen uno weichen Sidnabel verjelbenen Sumpfoógel, z. :B. bie Schne= pfen, feren fich, wern jie ergriffen weroen, nie zur (şegen=

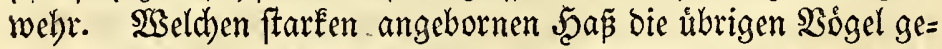
gen bie wirflichen Rauboigel hegen, erfieht man aus ber mere=

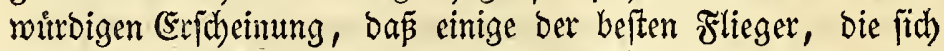
leid)ter buten Eonnen, won ibmen ergriffen zu werben, ihre 2ngft vor ibnen ưberminden, und fie weit mit (sejechen uno Redereven berfolgen. So jeben wir bie Sdymalben, Raben,

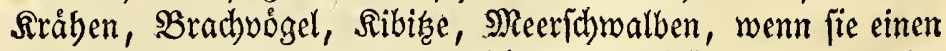
Rauboogel erblicken, biejem gejdbind nachfliegen, und ibn \{chreyend in Der Ruft verfolgen. 


\section{- 313}

Bon ber $\Re$ uhe unb bem Shlafe ber borealen $\mathfrak{B} \delta=$ gel babe idh fdon mebrmals gelegentlid gefwrod)en. Die meiften ichlafen im Dunfeln, und nur wenige norbifate $\mathfrak{B o g} g e t$ find, wie einige (Eulen und bie Sturmtauther, wabre Radht= vógel. In Der $2 \mathfrak{B}$ anderungzzeit benutsen inderfen auth einige

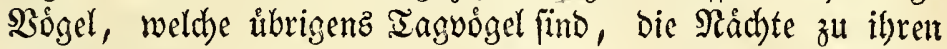

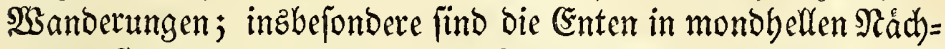
ten in ftarker Bewegung. Die Robrobmmel, Lniosa melanura, Gallinula crex und bie Nacthtigal, lajien in ber Dåmmerung am liebiften ihre Stimme bơren; audb fobrenen bie

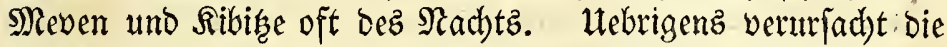
Dunkelbeit Stille in ber ornitbologifhen $\mathfrak{S}_{\text {selt. }}$ Sefonderz in ben norbifhen Råndern ift baher bie Dauer ibres Schlafes nach

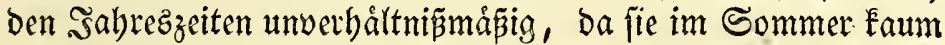
einige Stunden follafen, in ben langen, bunfeln $\mathfrak{B i n t e r n a ́ d}$ ten aber 16 - 18 Stumben. Der långere હd)laf im SBinter und bie baher rúlyrende geringere $\mathfrak{B} e$ wegung, wie der geringere

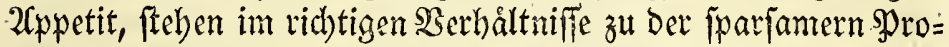

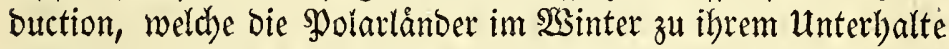

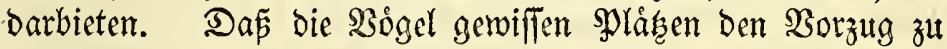

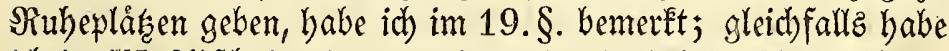
id) im III. 2(bjd)nitte bavon gebandelt, bas einige 2frten idswer fdhlafen, als Sula alba, andere leidjt, wie bie (Enten; einige

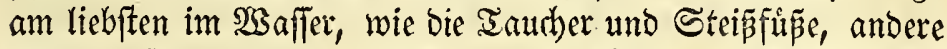

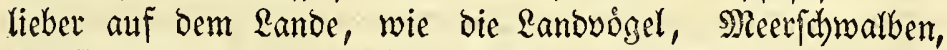
2Salfertreter; einige meiftens fteheno, als einige Sumpfoigel,

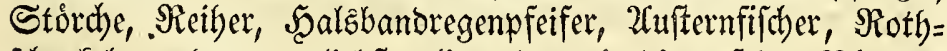
foheneet; andere am liebften liegend, wie bie auf ben Baăumen foblafenden 2frten; wieder andere theils ftehend, theilz lie= geno, wie bie Ënten, Şåmie, Schnåne; cinige $2 \mathfrak{r t e n}$ beugen

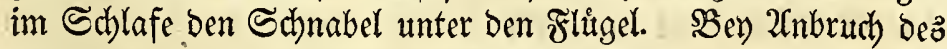

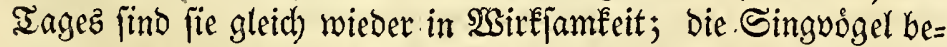

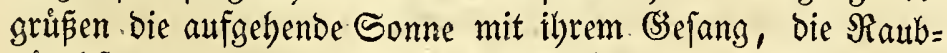
vógel fangen an zu jagen, bie Sumpfoỏgel taufent umber, uno bie auf bem Lanbe rubenden Sdywimmvỏgel begeben fich inz Meer. 


\section{$-314$ \\ $\mathfrak{U} \mathfrak{n} \mathfrak{h} \mathfrak{a} \mathfrak{n} \mathfrak{g} \quad \mathbf{I}$.}

Bon Den borealen $\mathfrak{B}$ geln in $\Re$ udefidt toe De

Fonomie und Iedhologie ber Berobner dez Rordenz.

\section{§. 58.}

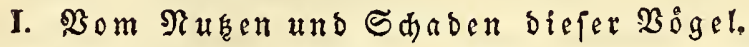

Der mitterbare $\mathfrak{A n t}$ en, weldhen bie borealen $B o g e l$

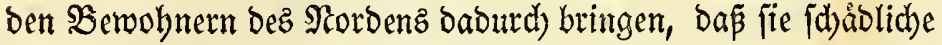
Ihiere und pllanzen autzrotten, ift nur gering; benn fo bock

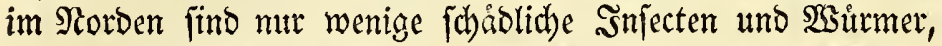
nod) weniger giffige $\mathfrak{B}$ flanzen, und Keine 2(mplibien; Motacrusa alba und Saxicola oenanthe fangen zumeilen die den getroctetneten Fif nebft Astrus pratensis, mefreren Sumpf = und Sdhwimm= vógetn, alz Tringa alpina, Phalaropus, und den Aras-

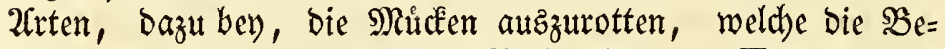
wobner bey Mnyatn uno ihr Sieh plagen. Turdus ilia-

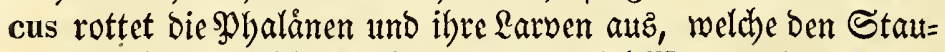

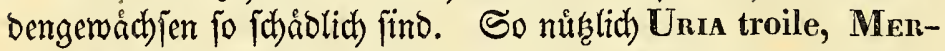
gulus alle, und die meiften 2iften von Platypus bey iferer Rebenzart in Dånemark fenn mưrben, um bie Menge von ONIscus pulex auzzurotten, weldye bas (şarn Der Fiffher zernagen;

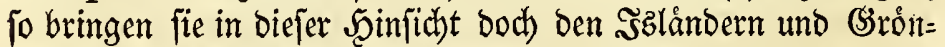
ländern wenig Bortheil, Da diefe felten mit Ģarn firfhen. Die Fif habler erwifchen zumeilen bie jungen Blaufüdhle, und bie

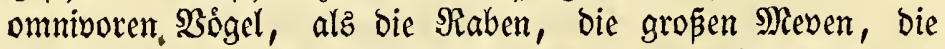
Raubmeven, ber Eiz = Sturmvogel, verzehren einen IIleil ber auf Den Strand getriebenen $\mathfrak{H}_{e j e r}$, weldhe jebodh in biejem

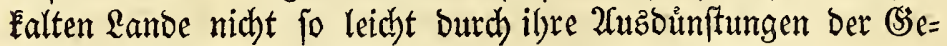

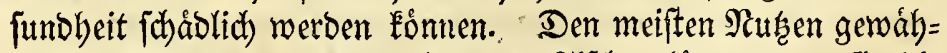

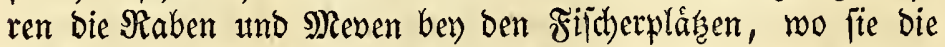
ftinkenden (Fingeroside ber Fif fhe verzebren, weldhe bie Fifdher

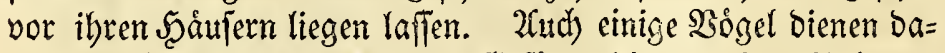

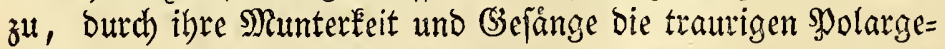
genden za beleben, z. $\mathfrak{B}$. Emberiza nivalis und calcarata, Anthus pratensis, Sruvia suecica, Turdus iliacus $\mathfrak{u} . \mathfrak{m}$.

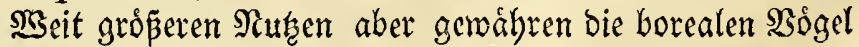
unmittelbar butch ibre 2fnwendung in Der Sefonomie ber 


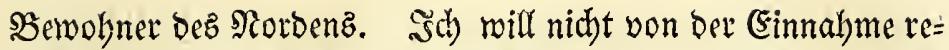
Den, welche die şalånder auz bem Fange und bem ßerkaufe dez isłândijchen Falken zut 3eit ber Falkenjago zogen, weldhe jåhr $=$

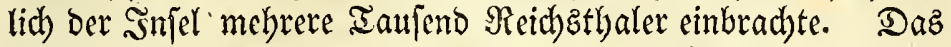
Fleifd) ber in ben Bogelbergen brutenden $\mathfrak{B g}$ gel wirb fowohl frifd, als gerofitet, fel)r gern gejpeift, und einige 2(rten, wie bie jungen Sula alba, Proceluaria glacialis und Mormon fratercula, werben fuit ben $\mathfrak{Z}$ inter eingejalzen. 2uflez, waz fett ift, ift den Sewol)nern bez Slordens angenebm; baber fpeifen bie

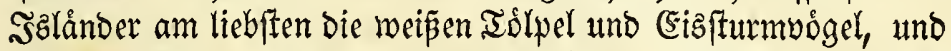
licber Utien, 2(reen und Larbentaud)er, als Neven. Das Fleifh von Den Scharben, Taudhern und Raubmeven finden fie nicht wohlichmedeno, vielleidht theils barum, weil fie biejelben fủr Raubvógel halten. Die wirklichen Raubvógel uno Raben jpeijen fie cbenfallz nicht. Sbbleich daz Saneebubn bem Fremben eine angenelyme Speife iff, befonders, wenn er fich alz Seifender in Den Şolarlåndern aufyált, und im Şinter fo wenig (Gelegenlyeit bat, frijd)ez Fleifh zu erbalten, fo machen

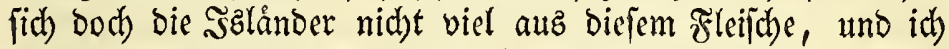
faufte auf bem Rorblande, wo fie im Winter in Menge gefan=

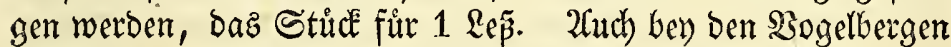
ipeifte ich oft getoftete \&ummen und 2ufen; boch fdienen mir

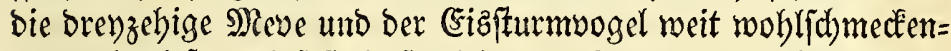
Der, alz dieje. Tuf Gsrimpö̈ leben bie (simmohner gróptentheilz im Sommer von ihrem Bogelberge, und fie wưrben ber Seun= gerznoth ausgefegt feun, wenn bieje Nalyrungzquelle verfiegte. Auf den $\mathfrak{W e f t m a n n o e ̈ ~ = ~ S i n f e l n ~ w e r b e n ~ j e b e n ~ S o m m e r ~ v i e l e ~ T a u = ~}$

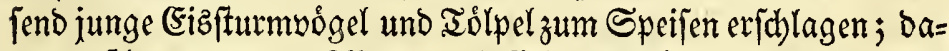
gegen idfont man bie 2aten, uno jieht ce nicht gern, wenn man fie tobtet, weil fie jebes salyr fichere Qieferanten find. 2ưf biejen Injeln, auf welchen zugleich eine gute Fifcheren ift, be= fummert man fich nicht viel um $\mathfrak{a}_{\text {ammen, }}$ alken, uno brevzehige

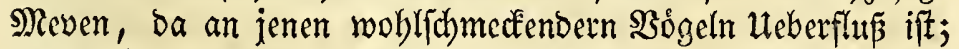
bie meiften alten Larbentaucher, weldhe bie Einwohner fangen; bången fie, nacboem fie ihnen bie Shaut abgezogen baben, um fie in Der $Q$ ufft trodênen zu laffen, auf, uno brennen fie im $23 i n=$ ter mit Fleijd) und Snodhen fatt Der Freuerung; man Denke jidh, weluben (Seruth und Dampf Diejez Surrogat Der Freuerung ver=

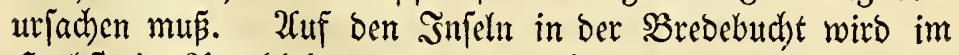

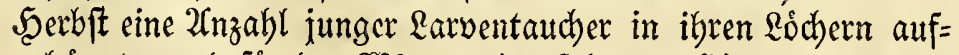
gebångt, und fưr ben $\mathfrak{S i n t e r ~ e i n g e f a l z e n . ~ S ̧ i e ~ u n d ~ d a ~ w e r = ~}$ 


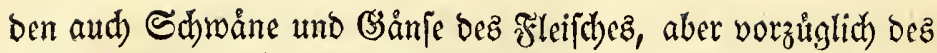
Balgez und ber Febern wegen geidholfen. Die 23 ruft von $\mathrm{Cx}-$ Grus musicus habe idh wohliddmedent gefunden. Die bel) Den

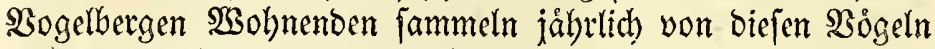
eine Menge rebern, von weld)en fie Den Raufleuten Den grỏs ten Iheil verkaufen, weil fie fie ofiter nid)t felbft in ibrem Scauje

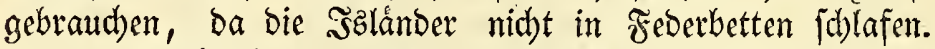

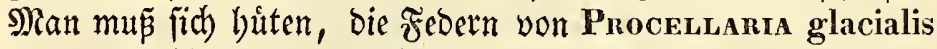
unter bie úbrigen zu mifden, weil fie ibnen einen fdhled)ten (3ierud) geben. Die Febern ber Meven find vorzitglich gut, meid) und elaftifd. $\quad 2$ n ben Bruitpláen ber Enten, nament= (ich) bey Miyvatn, bemutht man fith nidt um bie Febern biejer So̊gcl; bod ficht man es ungern, wenn man fie fojiest; denn

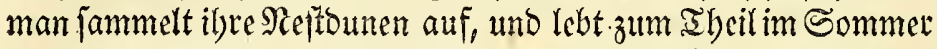
von ihren Eyern. 2 n ben Sertern, an melden ber (Fiderbo= gel brutet, befonders auf Wiooë, bev ber Minoung bes Rachs=

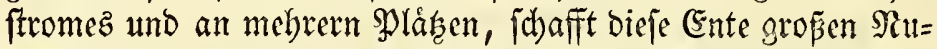
Gen, uno obne 3weifel ben gropten unter allen 280 geln in SBland. Da fie fid ftets an einzelnen Sruitplágen aufbalten, fo find je= bod) nut wenige (Einwohner, weldbe Nuken von ibnen zieben. Shre Eyer werden gegeffen; aber vorzuglich fino es ibre foftba= ren Dunen, weldbe unter bem Namen ber Siberdunen einen cou= ranten Şandelsartiłel abgeben. Dieje Dunen fammelt man cin paar Mal jeben Sommer aus ibren Neftern. Die Şzlan=

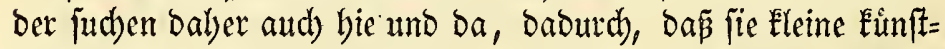
liche Sanjeldben in ibren Ieichen anlegen, biejen $\mathrm{Bogel}$ anzulo=

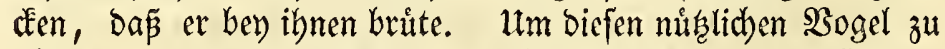

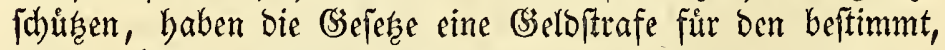
ber ifn tóbtet. Dicies Gejefs wirb aber nid)t immer mit ber ge= bơrigen Strenge befolgt, uno Daber find mebreve shläce, an weld)en ber Eiberoogel fonft britete, jest yon ifm verlafien. Namentlich beflagte fich ber Baucr auf Raramuri, baj feine (Eibervogelbrut merelich abnål)me, foit Dem man am nabliegen-

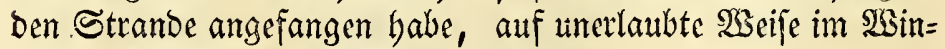
ter bie Gibervoogel mit (Sarn zu fangen.

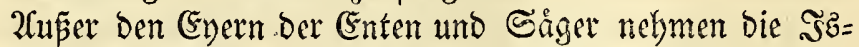

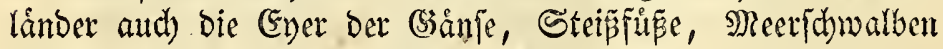
uno Meven, weldhe fehr woblichmedend find, zum Speijen weg; fie jpeijen bey den 30 gelbergen meiftens die (Eyer von \&ummen uno ateen; feltener bie ber Sdymáne, und weder die ber Sdyar= ben, Iaudber, \&arventaucher, Tolpel, nod) ber Sturmuógel; 


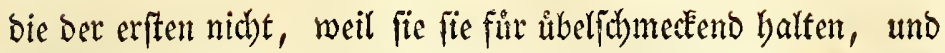
bebaupten, Das fie beym Rod)en nicht bart werben; eben

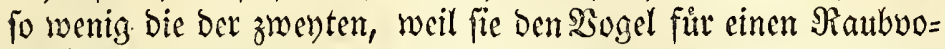
gel Galten, nod) bie ber brey leesten, weil fie fie lieber auzbriten laffen, woourd fie ein gropes und fettez sutinges crbalten. 2futd) fpeifen fie gern bie Eyer yon Numenus phaeopus, CanaraDrus pluvialis und Totanus calidris, neflmen aber keine

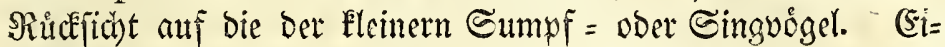

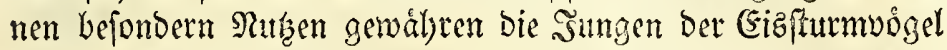
Den Şrimipöern, bic, wenn fie, um biejen Bogel zu fangen, in Dem Bogelberge berabgelaffen werben, fleine bollzerne Siefä́pe mit= bringen, in weldher biefe ibre Ifyranfeuthtigheit ausfpeyen, weldhe man im $23 i n t e r$ in ber $\mathbb{L} a m p e$ brennt. Daz Fett Des 2folers wiro

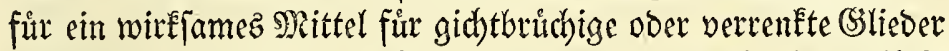

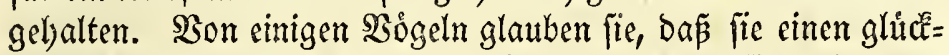

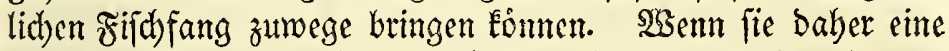
todte Ardea cinerea finden, ichnetben fie ifhr bie Beine ab, und verwabren fie als 2 mulette. 2fus berjelben $\mathfrak{H}$ trjache juthten bie Salånoer auf ber fübmeftlid)en Seite ebenfalls einen ausgeftopf=

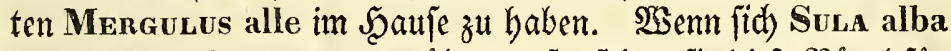
ober Lanus leucopterus nảbert, to fehen fie bieje Bógel für Borboten einer nalbe bevorftebenden Fifcherey an.

Der unmitterbare Sdaben, weldent bie morbi= ichen 20 gel ben Menjchen zufigen, ift unbebeutend. Bwar er=

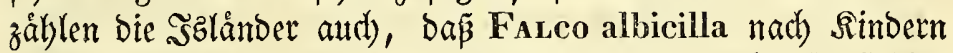

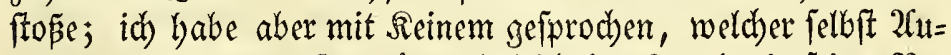
genzenge bavon gewejen wåre, obgleid) Sar. $\mathfrak{L} a$ not in feiner $\mathfrak{B} e=$

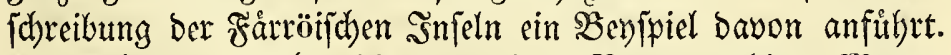
Der Sdhaden, weldhen bie wegen ihrer SBrut unrubigen Meben,

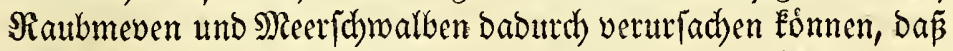

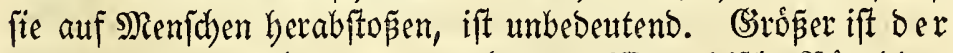
mittelbare $S_{d}$ a den, welden gewiffe norbijthe Bogel ben

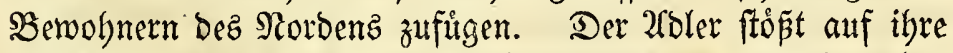

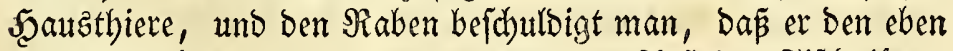

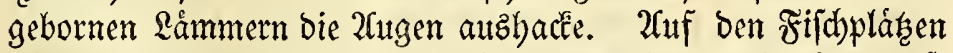

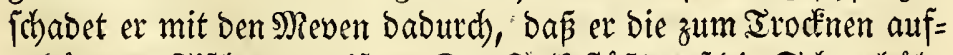

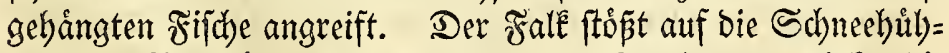
ner, ihre Berguogel, und bie Meven und $\Re$ autumeven trinten bie Eyer ber Berguogel, Eidoerbógel und Enten aus. Utnter allen Fifhtrefiern haffen fie bie Iatdher, weldhe abgefagte Feinde

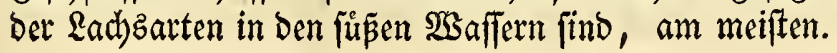




\section{§. 59.}

II. Bon ber Sigd und bem Fange biefer $\mathfrak{B} g$ gel.

Die Şzländer ftellen keine eigene Bogeliagoen an, wie die Sironlånder, vergl. Fabricii Fauna grönlandica, unt jeine 2(b)andung vom zrange dez (Eitervogels. Sie verffel)en nicht, bie Pfeile ber (Sroonlånoer zu gebraud)en, und Spulver und Sdhrot anzufhaffen, um bamit Migel zu johiesen, ift für fie zu

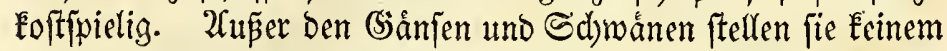
anbern Sogel gewolynlich mit ber finte nach, auper baß̄ bie

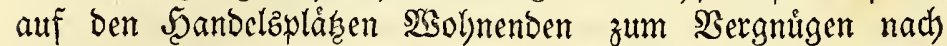
Sdneebilbnern uno Enten jagen. Die Raben gehen in Rube

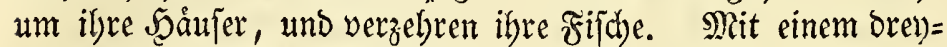
zmeigigen eifernen Inftrumente, weldhez eigentlid gebraud)t wirb, um ben Scebajen zu fted en, verfteben (Finige idwimmenoe

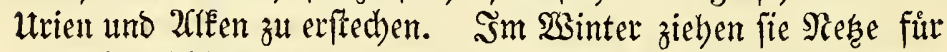
bie Sd)neebihner, unb fangen wobl aud) bin und wieber bie tall= dhenden Eibervógel barin. Die Raubmeven werben zumeilen mit Sdhlingen itber ben Eyern ber (Enten ober (Fibervógel, weld)e fie austrinken wollen, gefangen. 2luf Grimfoë fing man auth Mormos fratercula in Sdhlingen, weldbe auf ben $\mathfrak{s l a ́ c e n ~ b e z ~}$ Berges gelegt murben, auf weldien fich biefer 2 ogel bez

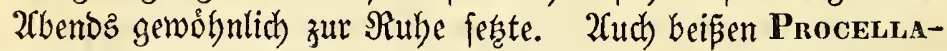
RIA glacialis und Lestris catarractes an einen Şamen, wel= c)er mit Resung aufz Meer fonimment ausgeworfen wirb. Daffelbe erzáblt $\mathfrak{R}$ eem S. 287. von ben Meven in Rappland. SBey Dem $\mathfrak{B}$ ogelberge Drangöe wendet man ein bejonberez Mit= tel an, bie \&ummen, 2uken und \&arventaucher zu fangen, in= Dem fdurimmende Breter mit Schlingen ins Meer gelegt wer= Den, auf weld)e bieje Boogel Elettern, und fo gefangen werben. Bergl. Slaffenz Befchreibung bes Bogelfangez auf Dran=

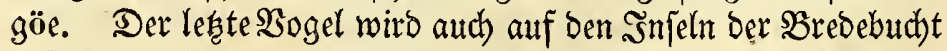
gefangen, inoem er mit Stangen aus feimen \&óchern herworge= zogen wirb, ober in Norwegen burch abgerichtete Scunde. In క̧sland werben die Sdumåne und (3̋åme burd) Sunde zu ber 3eit verfolgt, wenn fie nicht fliegen fómen. Die Courmbus 2trten fängt man zuweilen auf ibren (Eyern mit Sdblingen, um

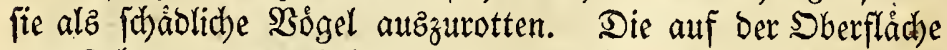
Der Sdberen ausgebruteten jungen Tolpel uno Eisfturmvo:= gel werben auf Den $\mathfrak{B e f f m a n n o e ̈ = ~ \Im n j e l n ~ i m ~ S e r b / t ~ m i t ~ I ̂ n i t = ~}$ 
teln elfdhlagen thi inz Meer geworfen, wo fie von ber Mann= fidaft ber unten liegenden Bote aufsejammelt werben.

(sin eigenez Mittel, beffen fid) bic Farröer und Finn= marfer bebienen, um bie in ben freilen Felfenjeiten brutenden 20 gel zu erbalten, ift die $\$$ mit einor Sablinge, am andern mit einem Qdffel verjeken ift.

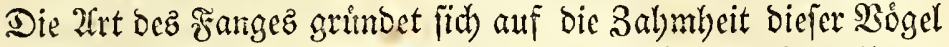
in Der Brutzeit. Die Einwobner, weldhe am Bogelberge Iheil baben, veriammeln jich atf ber Spiţe; fie bringen Tatte

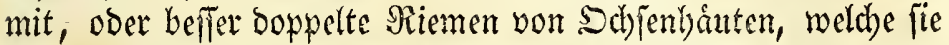
an cinem farken und weiden (3)iutel $\mathrm{tm}$ bie Mitte bes $\mathfrak{B o g e l}=$ fângerz befeftigen. Diejen nennen fie Sigemand, weil er im

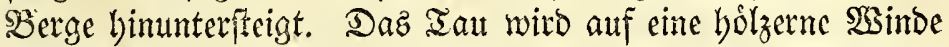
gelegt, Damit ez fidh nidht verid)leife. Selyn biz zmolf Menjoben ergreifen Daz זau, und halten ben Bogelfänger, weld)er fich

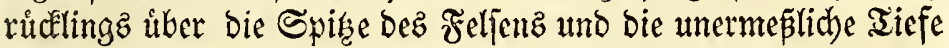

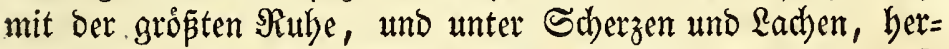
unterlapst. Er nimmt eine foldbe Stellung, dap er, fo weit alz moghlich, die Frî̉e gegen bie Seiten bez Felfenz an= fesen fann. Wenn er in bie Begend gefommen ift, wo er bie meiften $\mathfrak{B o g e l}$ gewabr wird, fo giebt ex einem oben ftebenden Beobachter ein 3eidhen, dap fie mit Dem Nieberlaffen innebal= ten follen. (Er wirft bebende die Sdhlinge um Den Salz ber fidern $\mathfrak{B o g g e l , ~ z i e b t ~ f i e ~ a n ~ f i c h , ~ b r e b t ~ i f n e n ~ b e n ~ S c a l a ~ u m , ~ u n o ~}$ befeftigt fie an feinem (situtel. Mit Det umgefelrten $\mathfrak{B o g e l}=$

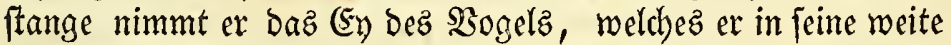
sacke fteckt. Še bebender er ift, defto melyr fann er fangen, und diefez beftimmt feinen $\mathfrak{S}$ serth alz $\mathfrak{B o g e l f a ̈ n g e r . ~ W B e n n ~} \mathfrak{e r}$ belaftet ift, giebt er ein Beiden zum langiamen Seraujzieben. Sommt in Der Seite Dez Felfenz ein Boriprung, unter welchem er Bögel gemabr wirb, fo bringt er fich Durd Schwentung bez Tauez Dahin. Derfdlbe Sogelfänger witb 3 biz 4 mal bez Tagez beruntergelaflen. 2luf bieje $\mathfrak{B e i j e}$ erbalten fie eine an= febnliche Menge Urua troile, Brünnichii, Alca torda, Monmos fratercula, Larus tridactylus, uno ibre Eyer, fammt jungen $\mathfrak{B g} g e l n$ von Sula und Procellaria. Sa, wie be= kannt, die Şungen von Urra uno Alca nux febr Elein fino, menn fie ben Sogelberg verlaffen, fo läpt man fith nicbt nad) ibnen nieber. Die 2uabcute mirb gleich auf bem $\mathfrak{B}$ ogel= berge getbeilt, und der Bogelfänger nimmt daz Doppelte gegen

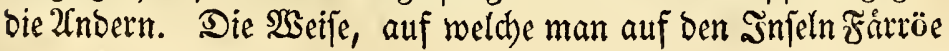


verfåhrt, um bie Sogelberge von untenber zut befteigen, unb burdh gegenjeitige Shitlfe fich in bie Şobhe zu bringen, wiro in

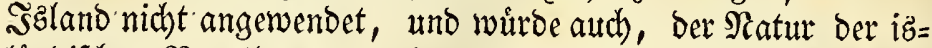

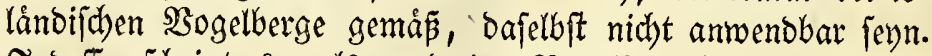

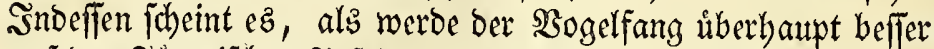

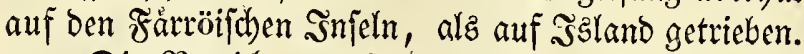

Die Berrid)tung eines foldhen Bogelfangers ift an und

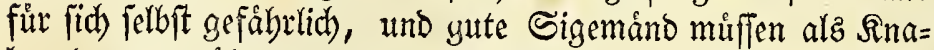
ben bazu gewóbnt werden. Sie fheinen den Schwindel nicht zul Fennen, und idb babe fie, obne fidd an (Etwas zu balten, auf

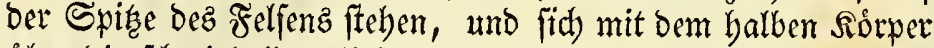
$\mathfrak{u} b e r$ die fdymindelige Tiiefe herausbeugen feben, um bie beften

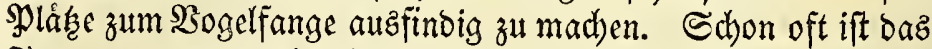
Iau, wenn es nicht ftark genug gewejen, geriffen, und ber Mann zwif́chen bie Cteine ober inz Mcer binuntergefallen.

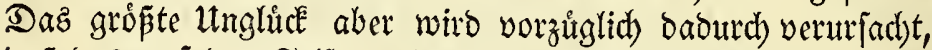

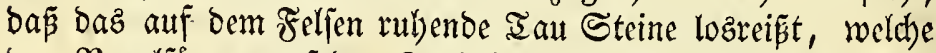

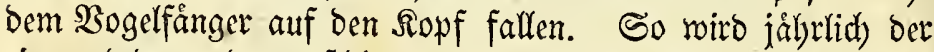

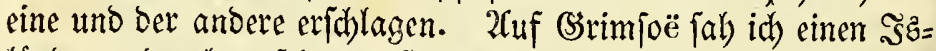
länder, ber bey feiner erften \$robe als Sigemano auf biefe $\mathfrak{B} 3$ eife fo ganz verftůmmelt, an 2frmen und Beinen zutm Siruppel gerovoden war, uno tiefe Rodfer im Ropfe hatte, io Dáp bie Șirnjchaale an einigen Stellen verloren gegangen zu fern fobien; ebenjo mutroe ein junger șlander, als ich mich auf

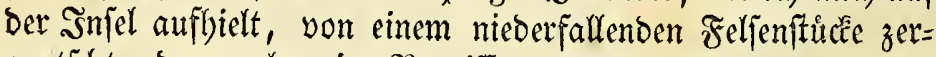
queticht, ba er eben im. Begriff war, -unter bem $\mathfrak{B}$ ogetberge einer niebrig brutenden brenzebigen Meve auf itgren (Eyern bie Schlinge um den Şals zu werfen.

Mebrerez uiber ben Bogelfang in ben norbifathen 20 getber=

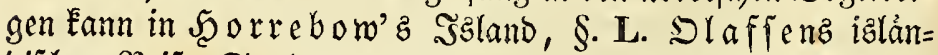

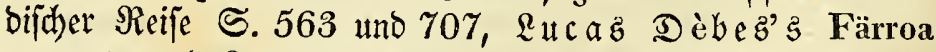

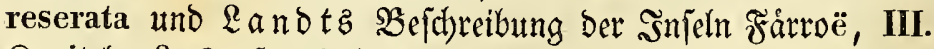

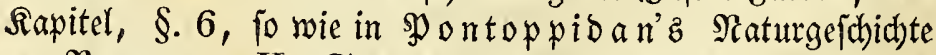

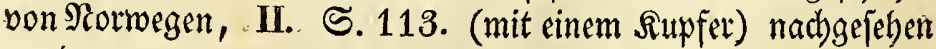
werben. 


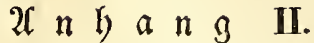

Bon ber Romenclatur ber Bewohner bez $\mathfrak{R o r}=$ benz in $\Re$ ilefifid toer borealen $\mathfrak{B}$ begl.

\section{§. 60.}

Die Bemolnner bez Rorbenz kennen gemeiniglid) bie fie

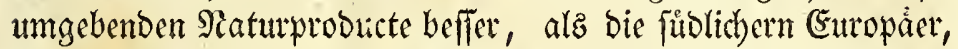

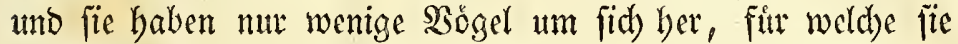

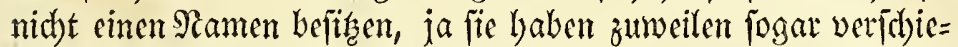
Dene Benennungen zu Derfelben $2 \mathfrak{r t}$ nad) ben verjd)iedenen $\mathfrak{R}=$

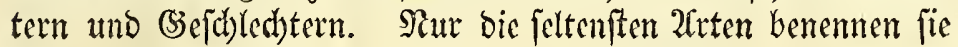
nicht. Fiu bieje baben fie einen generifhen গamen, mit wel:-

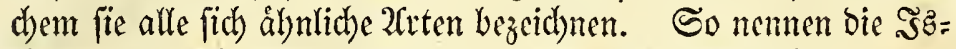

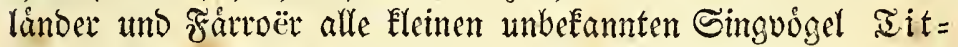

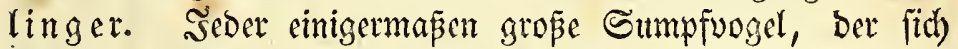
felten nad) Şland verint, 子. B. Vanelues cristatus, TrinGa pugnax, wiro von ben słlånbern $\Re$ éloujuin genannt, von weldbem $\mathfrak{B o g e l}$ bie (Singebornen fidc) viele Fabeln erzáblen.

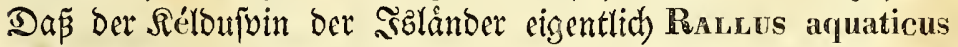
fer), Gabe id) in meinem shrobromuz der izl. Snnithol. S. 31. bemertet.

Da ez nidst unwidhtig ift, bie Bencmnungen zu Eemnen,

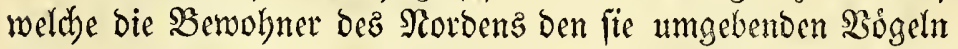
geben, bejonderz fiut den Sornithologen, weld)er Rutf lyat, biefe Sobgel in ilyrer wahren Sceinath) aufzufuthen: fo babe id) auf

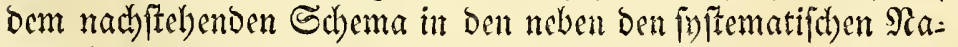

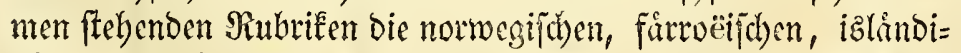

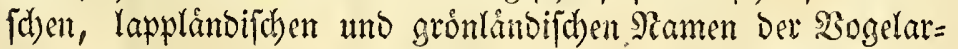
ten angefíbrt, weldye gewodgnlith in zwey ober melyreren biefer nơrolidhen Ränber vortommen. Esz find folgende: 


\section{D) $\mathfrak{x} \mathfrak{u} \mathfrak{d} \mathfrak{f} \mathfrak{e} \mathfrak{h} \mathfrak{l} \mathfrak{e} \mathfrak{r}$}

5. 2. 3. 6 v. o. ft. finnifden l. odnifden. - 5. 2. 3. 7. v. o. 估. F. gronland. l. F. groenland. - 5 . 2. 3. 16. v. o. fehlt bas punct binter

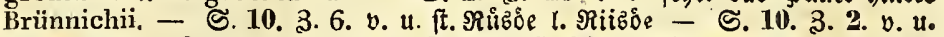
ft. nefas l. rufus. - S 13. 3. 8. v. u. ft. $70^{\circ}$ l. $76^{\circ}-$ S. 14. 3. 20. v. u. ft $90^{3}$ l. $59^{\circ}$ - S. 15. 3. 1. v. u. S. 30. 3. 12. v. u., S. 81. 3. 3.

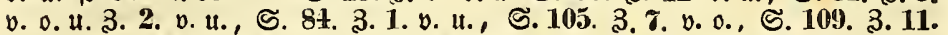

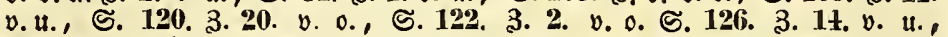
ङ. 142. 3. 5. v. o. it Marmon $\mathfrak{l}$. Mormon - ․ 17. 3. 16. v. o. 任.

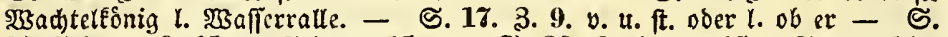
23. Februar 6. 15. l. Februar 15. - S. 26. 3. 4. Der 1ften Spalte feblt vor Sruv, cin.: 6. - - 33. 3. 17. v. o. ft. (Sefdled)te l. Sattungen. ङ. 37. 3. 2 und 8. v. u. ft. $\mathfrak{B r a d j o o g e l}$ 1. Soldregenpfeifer. - 5.39 .3$. 3. v. o. ft. Scollftein t. Scoliftein. - S. 46. 3. 14. v. o. uno fállt weg. S. 49. 3. 1. v. o. ft. Eabe 1. Eod)e. - S. 56. 3. 5. v. u. l. ft. Reiber Reiten von, 3. 18. v. u. ft. fditeit l. fhrwebt. - S. 67. 3. \%. v. o. ft.

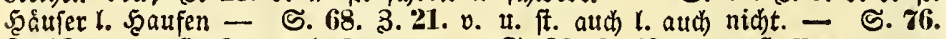
3. 18. v. จ. ft. Dunen I. Dauer. - ․ 86. 3. 17. v. u. ft. Faun. suec. 1. SEandinabifde F̧auna. - S. 88. 3. 16. v. o. ft. Sd)wimm=1. Sd)mung.

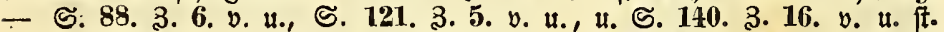
Phal. platyrhincus $\mathfrak{l}$. Phal. platyrhinchus. - $\mathfrak{S} 9 \pm$. 3. 3. v. o. ft. und babe f. aud babe id. - - 98 . 3. 17. v. o. ft. ringuca 1 . hringvia. -

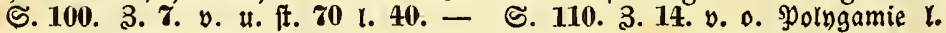
פolygynie. - S. 123. 3. 13. v. u. ft. Stróc l. Soróe. - S. 132. 3.. 17. v. u. ft. aud l. bod. - S. 142. Us ner Iabelle gebort bie 2te unter= abth.: Eben fo viele Eise u. f. w., nidbt unter Phalaropus cinereus

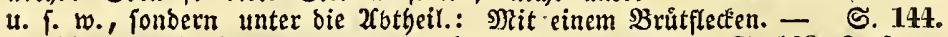
3. 16. v. o. ft. Oumme \&umme l. Dummer \&ummr. - S. 148. 3. 4. b. o. ft. fie erft $\mathfrak{l}$. die erfte. ธ. 152. 3. 14. ft. SBeugung 1. Bau. 
321. 8.

\begin{tabular}{|c|c|c|c|c|c|c|c|c|c|c|c|}
\hline Exfano & Nontregifde 9tamen. & 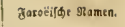 & 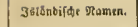 & Rapws norifte Pramen. & 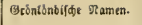 & Eyftematidde Maraen. & Rozibegifde Ramen. & Fazoëifde Rament. & zoldenbifole Mamin. & Capplándiffe Tanaen. & 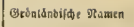 \\
\hline 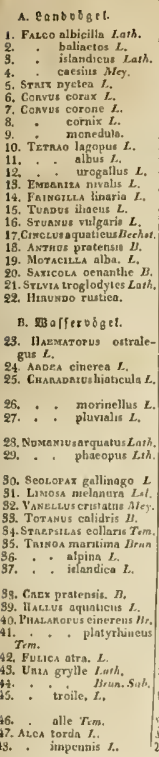 & 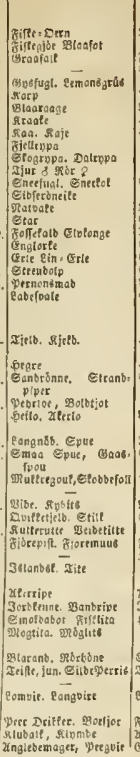 & 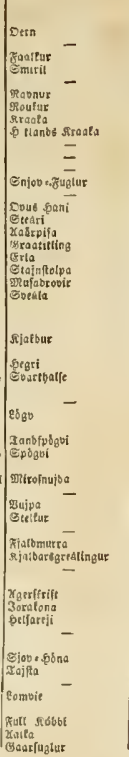 & 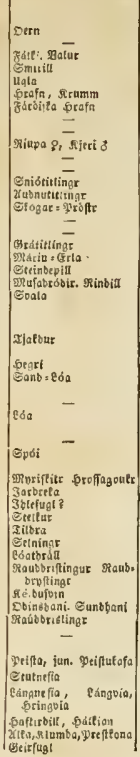 & 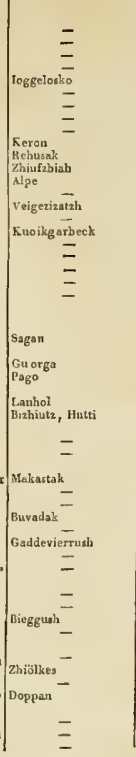 & 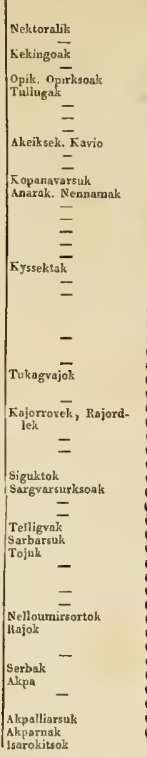 & 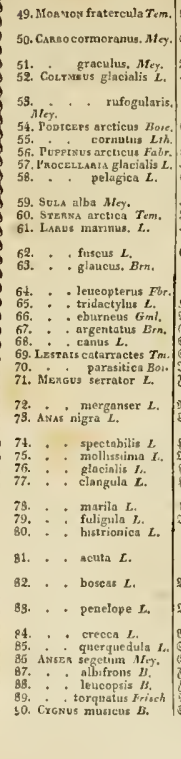 & 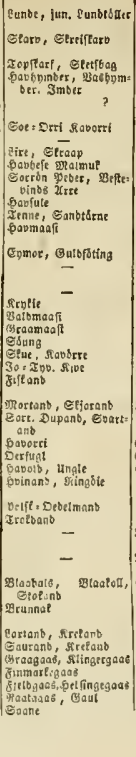 & 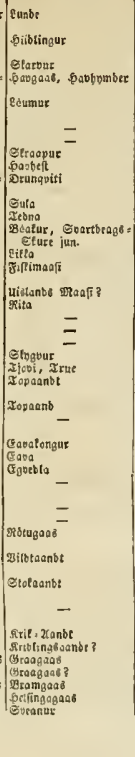 & 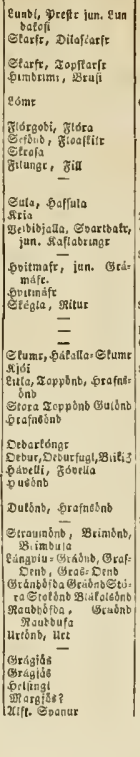 & 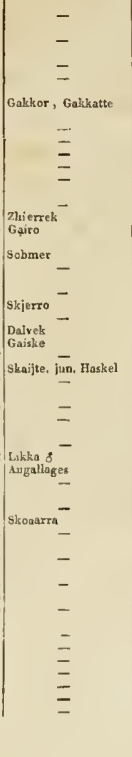 & 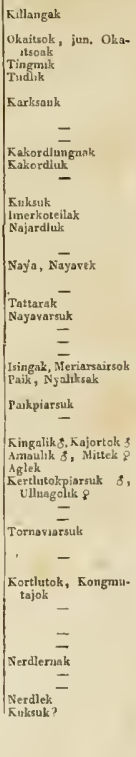 \\
\hline
\end{tabular}



Sm Berlage von Ernft $\mathfrak{F l e i f d e r ~ i n ~ R e i p z i g ~ i f t ~}$

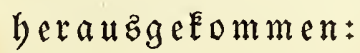

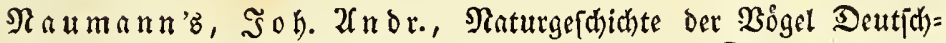
lands, nach eigenen Erfohiungen entworfer. Durdiats umge= arbeitet, fyftematifh georonet, fehr vermehrt, vervollftindigt, uno mit getreu nach ber Natur eigenbåndig gezeichneten und ge=

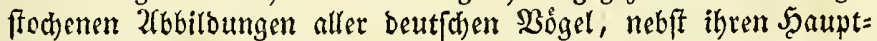
verichiedentbeiten, aufa Reue berauzgegeben von beffen Sobne

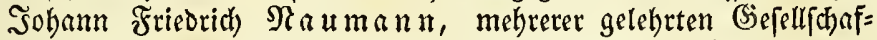
ten Mitgliede. Mit vielen colorirten Rupfern. Lepiconoctav.

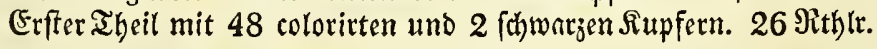

Deffelben Werkez zweiter Theil mit 30 colorirten uno 1 fhwar= zen Nupfer. $16 \Re \mathfrak{l t h}$ lr.

Deffelben WerEez britter Wheil mit 15 colorirten und 1 fhwarzen תupfer.

$11 \Re \mathfrak{n t h} \mathfrak{l}$.

Deffelben 2 Berkez vierter Iheil mit 23 colorirten und 1 fhwarzen Supfer.

$13 \Re$ thlt.

Deffelben $\mathfrak{W e r k e z ~ f u ̈ n f t e r ~ T h e i l . ~}$

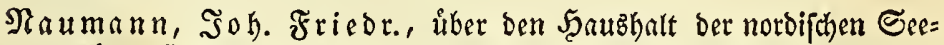

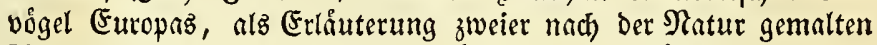
Znfichten von einem Theil ber Dinen auf Der notblidffiten Spize

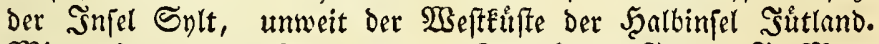
Mit zwei colorirten Supfertafeln. Flein Suet = Folio. In Map= pen $=$ Futteral.

4 Rthlr. 16 Şr.

Sroofez'b, Sam., 2foleitung zu bem Studium ber Condyylien= lehre. Zủ Dem Englifthen uberferet, unb mit 9 colorirten uno 2 ichwarzen englifchen SriginalEupfern erlåutert. SBevorwortet und mit einer $\mathfrak{I} a f e l$ úber bie ZInatomie der FluFmufchel ver=

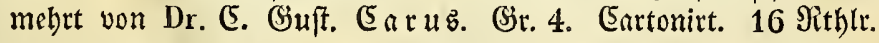

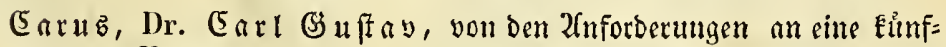

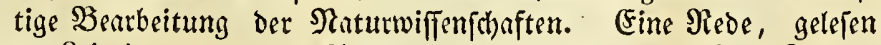
zu Leipzig am 19ten September 1822 in ber erften 3u[am=

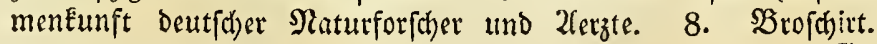


Eazpari, Dr. Earl, ber Stein in genetifher, chemifher, bingno=

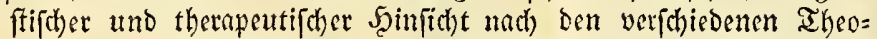
rien álterer und neuerer 2 erzte betradetet, nebft einer volyftándi= gen Befchreibung aller alten und neuen bahin gehórigen Spe=

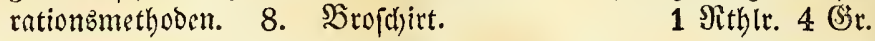

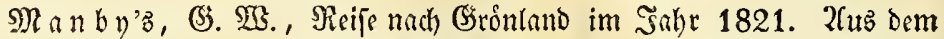

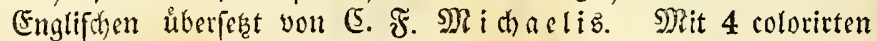

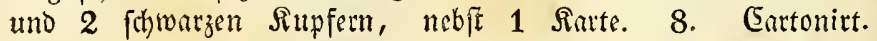
2 গthlr. 4 Grr.

Spotorno, Şiambatt., Shriftoph Solombo und Feine Entode Eungen. Teutich) benrbeitet won 2loolf $\mathfrak{B}$ agner. Sit Colom=

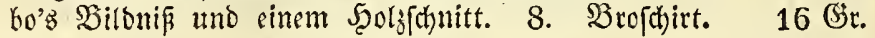




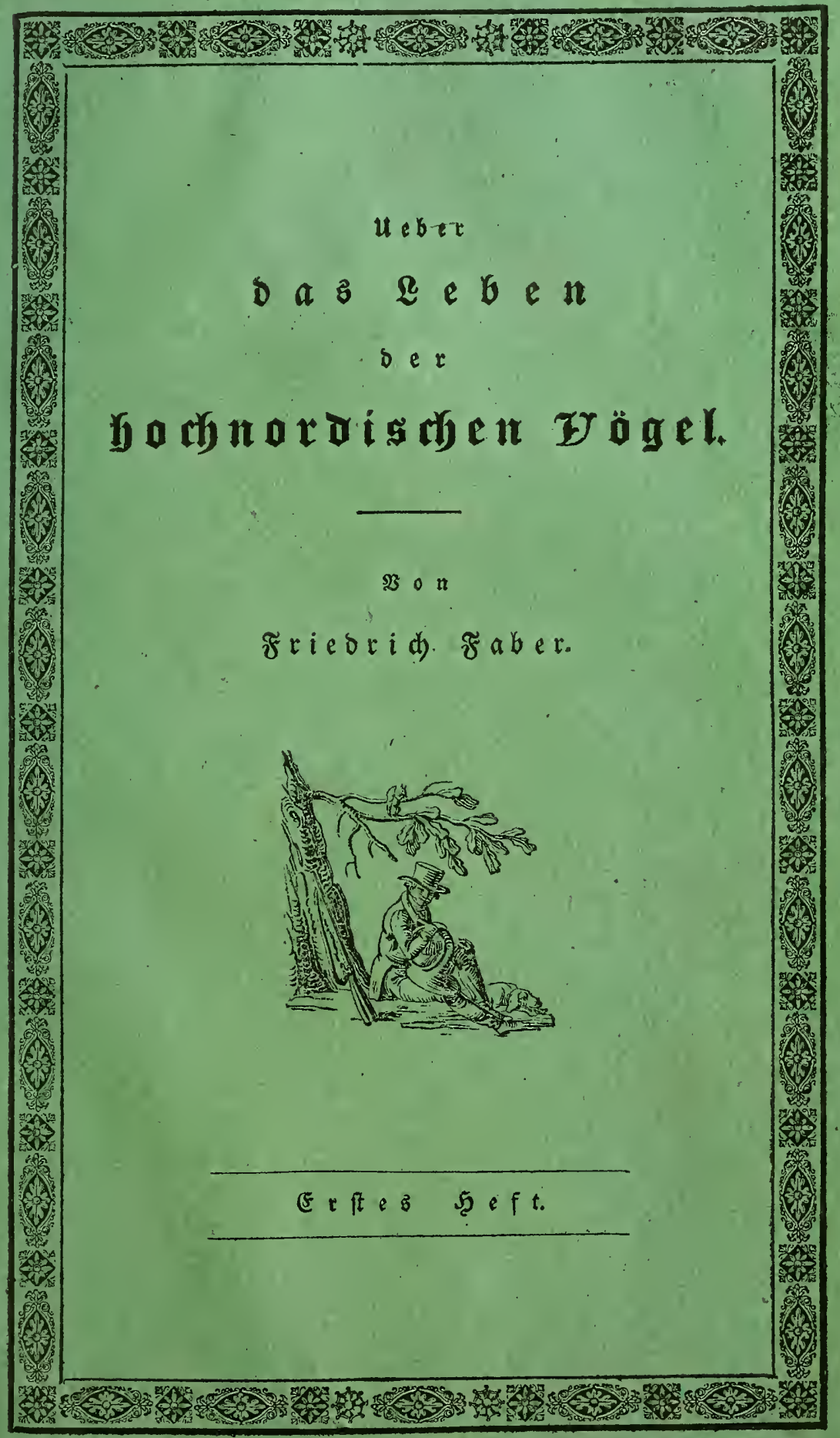




$$
\frac{1}{7}+\frac{1}{1}+2
$$

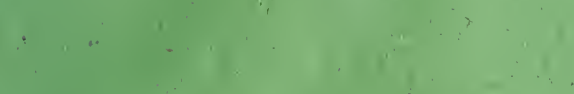

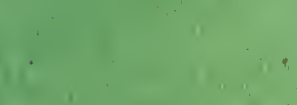

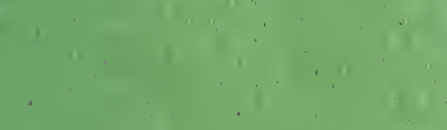
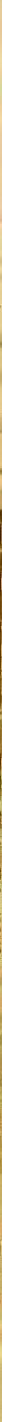


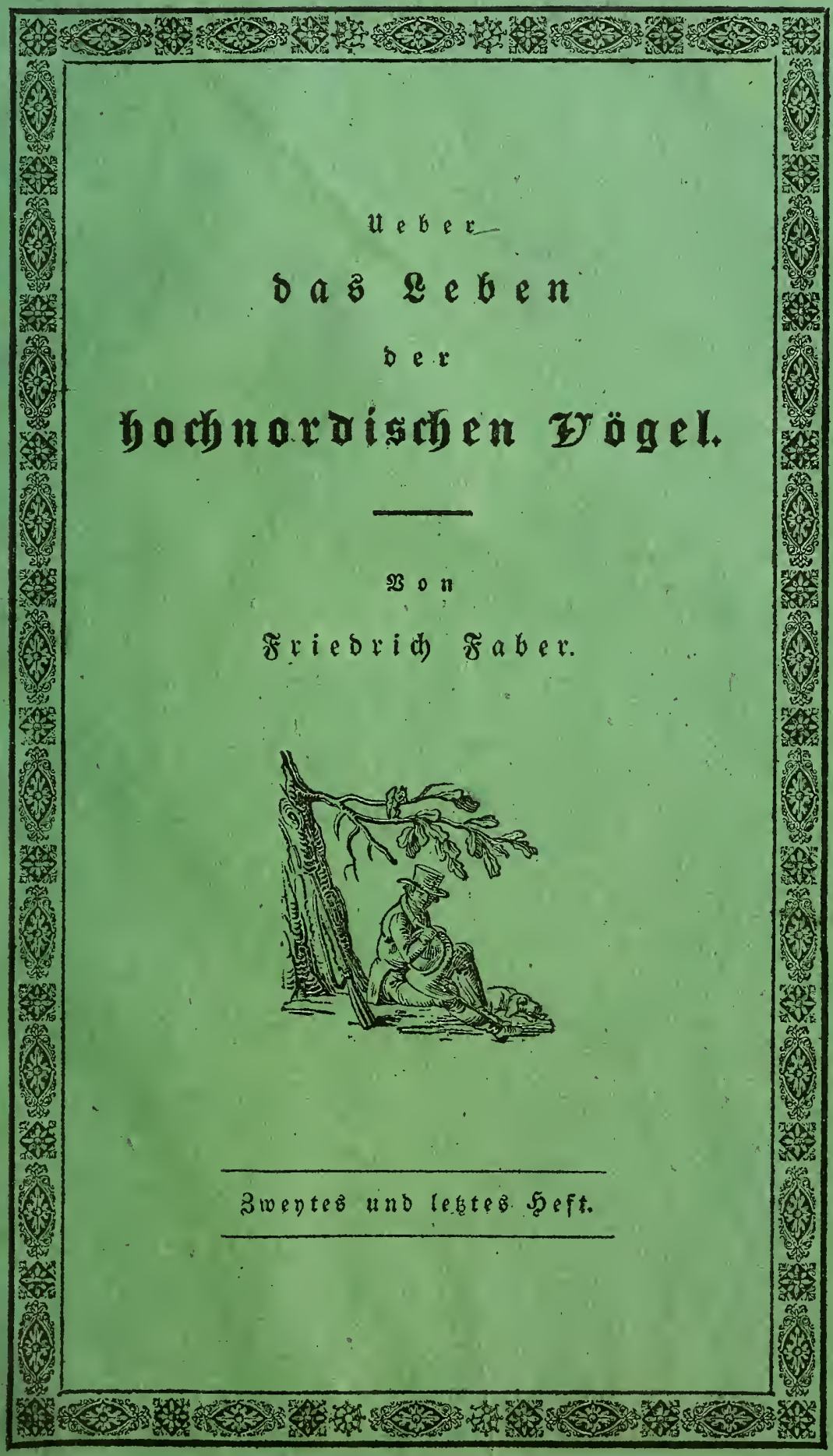





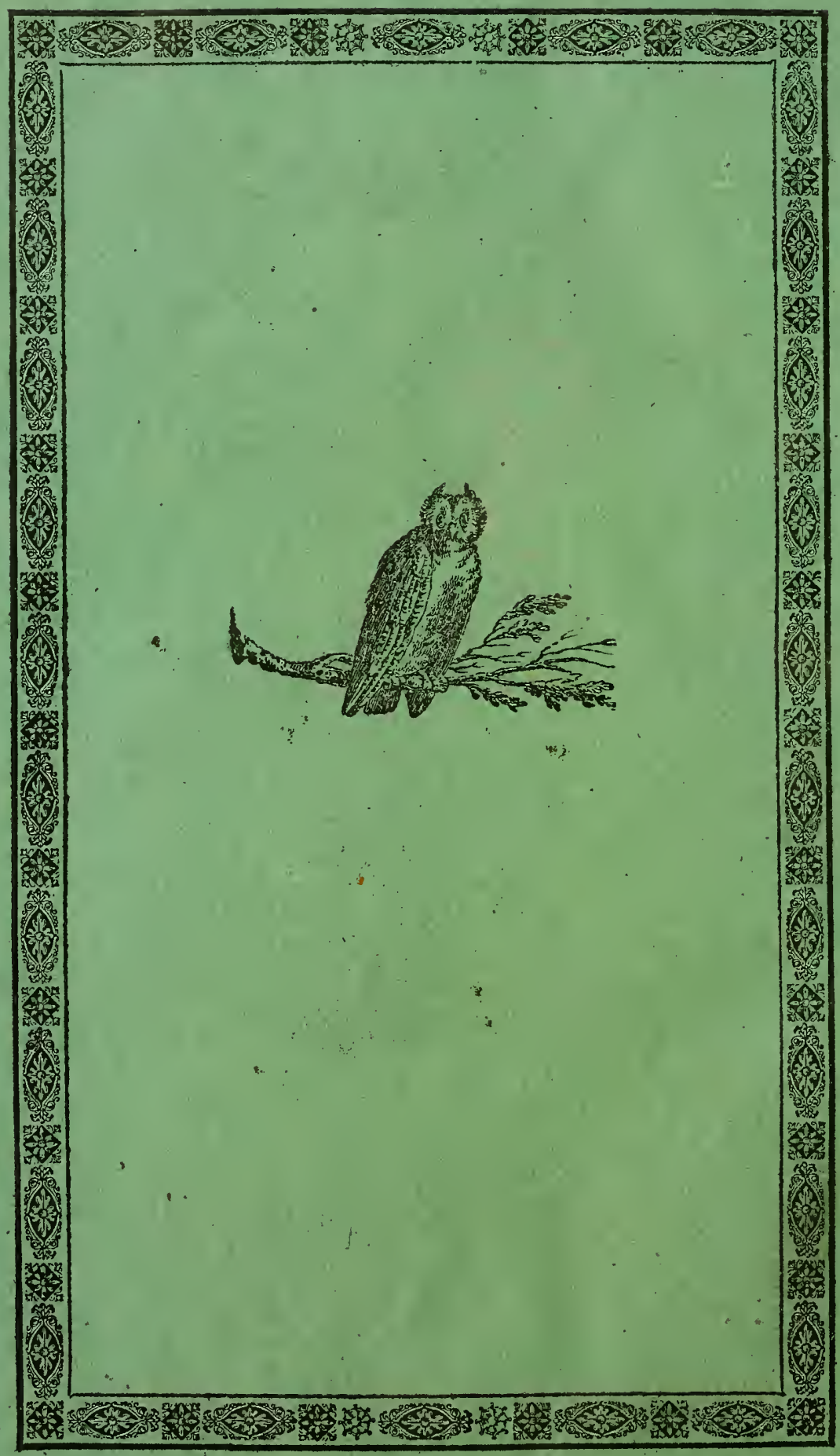





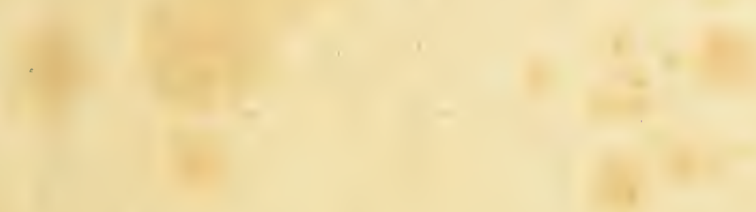

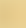

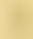
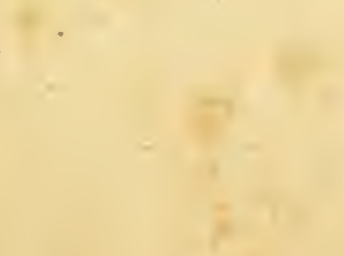
